\title{
Revisión sistemática, análisis cladístico y biogeográfico del género Ophryosporus Meyen (Asteraceae, Eupatorieae, Critonitinae)
}
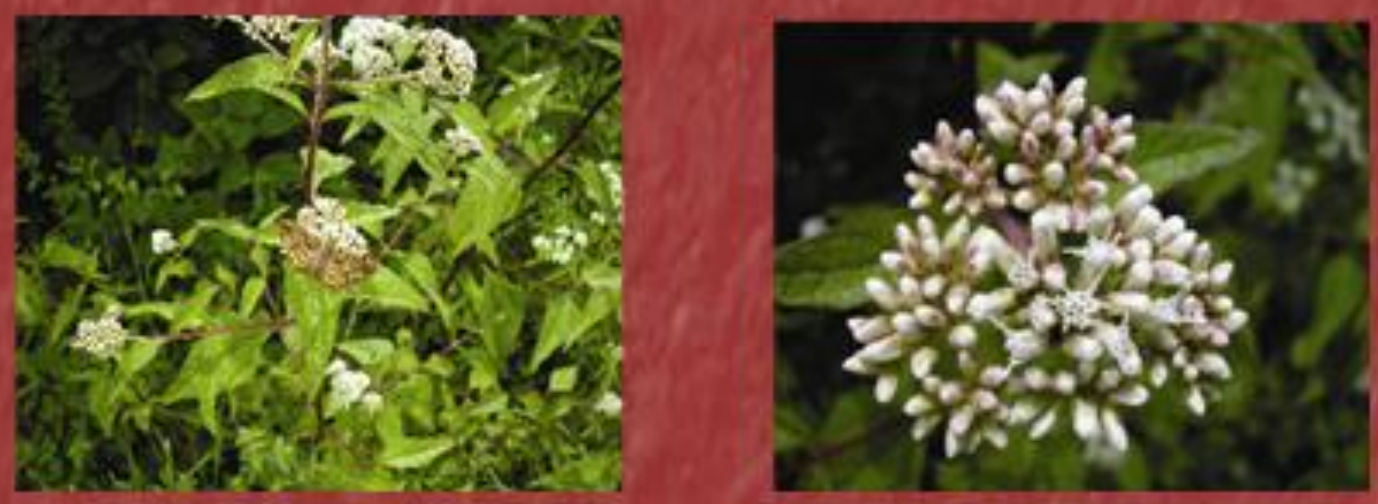

\section{Anabela Plos}

Directora: Dra. Gisela Sancho

Codirector: Dr. Jorge V. Crisci

Tesis presentada para optar por el grado académico de

Doctor en Ciencias Naturales

Facultad de Ciencias Naturales y Museo

Universidad Nacional de La Plata

ARGENTINA

2012 


\section{AGRADECIMIENTOS}

A mi familia, por apoyar todas mis decisiones, aunque no estuvieran siempre totalmente de acuerdo: Mimí, Gardo, Gaby, Carolina.

A mi viejo por inculcarme desde muy chica el ansia de saber y de aprender....

A mis dos abuelas, Carolina y Angélica, mis primeras maestras de botánica!

A Gastón, por estar siempre ahi, aguantarte campañas, congresos, cursos.... y darme su apoyo y cariño todos los días.

A la Dra. Gisela Sancho, por sugerir el tema de tesis, dirigir y apoyarme en mi trabajo y por estimularme en mi formación académica.

Al Dr. Jorge V. Crisci por codirigir la tesis, brindarme un lugar para desarrollarla y el apoyo necesario para llevar a cabo este estudio.

A los Jurados, por su buena predisposición para la lectura crítica de la presente tesis.

A los integrantes de la División Plantas Vasculares: Liliana Katinas, Gisela Sancho, Laura Iharlegui, Diego Gutierrez, Mariana Grossi, Gustavo Delucchi, Marisa Prada, Hugo Calvetti, por recibirme y hacerme formar parte de un grupo hermoso.

A mis amigos y compañeros de la División Plantas Vasculares: Laura, Favio, Pablo, Mariana, Diego, Marisa, Cristina, Gustavo, Jéssica, María Jose, Maira, por haber acompañado el desarrollo de la tesis. También a los chicos de base de datos: Elián, Valeria, Lucero, Mariana, Egly, gracias!

A mis amigos del Museo-Facultad: Gaby, Marian, Maricel, Malena, Elena, Eliana, Georgina, Josefina, ....a los amigos que surgieron de los congresos y cursos: Elsi, Inés, Mapy, Ana....a los "chicos" (y chicas) del TFALP, por ayudarme a descargar tensiones y compartir asados interminables!!. A los amigos de siempre, Fede, Pancho, Daniela, Melisa, Vanesa, Marcela, Julio...gracias a todos!

A Jorge A. González....por tomarse un pequeño retiro de sus dinosaurios y dibujar los aspectos generales de las especies.

A Marina Aguirre por la lectura crítica del capítulo de análisis biogeográfico.

A Gastón A. Laborde por la confección de mapas y la compilación de las láminas. 
A los curadores de los herbarios, por contestar mis interminables consultas y suministrar materiales y fotos, gracias!

A Daniel Giuliano por estar ahí siempre.... Gracias por las ayudas nomenclaturales!

A Mariela Theiller de CINDECA, gracias por la paciencia y horas frente al MEB!

A Pablo Simon, Lázaro Novara, Marcela Hernández, Ana Lopéz, Gregory Plunkett y Antoine Nicolas por los viajes de campaña y toda la ayuda recibida.

Al Consejo Nacional de Investigaciones Científicas y Técnicas (CONICET) y a la Agencia Nacional de Promoción Científica y Tecnológica.

Gracias 
La ciencia es más que un simple conjunto de ideas, es una manera de pensar.

Carl Sagan 


\section{Revisión sistemática, análisis cladístico y biogeográfico del género Ophryosporus Meyen (Asteraceae, Eupatorieae, Critoniinae)}

Por Anabela Plos

\section{RESUMEN}

\section{$\underline{\text { Revisión Sistemática }}$}

El género Ophryosporus Meyen pertenece a la subtribu Critoniinae R. M. King \& H. Rob., tribu Eupatorieae Cass., e incluye 41 especies sudamericanas distribuidas en Argentina, Brasil, Bolivia, Chile, Ecuador y Perú.

Ophryosporus fue descripto en el año 1834 por Meyen, quien incluyó sólo la especie, $O$. triangularis Meyen, basada en materiales chilenos. Si bien posteriormente se describieron más especies originalmente como Ophryosporus, una gran parte de las que actualmente están incluidas en este género fueron descriptas inicialmente como Eupatorium L. En 1906, B. L. Robinson realizó la primera revisión del género e incluyó 17 especies y una variedad. Este mismo autor identificó dos secciones: Euophryosporus y Ophryochaeta. En 1972, King \& Robinson, ampliaron el concepto del género al incluir una sección del género Piqueria Cav. y un género monoespecífico (Trychinolepis B. L. Rob.).

Como resultado de la presente revisión sistemática, todas las especies de Ophryosporus fueron descriptas e ilustradas, en muchos casos por primera vez aportándose también mapas de distribución, datos ecológicos y fenológicos, información sobre usos medicinales y compuestos químicos asociados, así también como una clave para la identificación de las especies dentro del género que hasta el momento no se había realizado. Además, se seleccionaron 12 lectotipos y se resolvieron complejos problemas nomenclaturales. 


\section{Análisis Cladístico}

Para corroborar la monofilia de Ophryosporus y establecer las relaciones entre sus especies y con las especies pertenecientes al grupo externo, se realizó un análisis cladístico considerando las 41 especies del género. Se obtuvieron 61 caracteres cualitativos, de los cuales 24 fueron vegetativos y 37 reproductivos. Para la conformación del grupo externo, se eligieron especies pertenecientes a los géneros Critonia P. Browne, Cronquistianthus R. M. King \& H. Rob., Koanophyllon Arruda, (los tres pertenecientes a la subtribu Critoniinae) y Fleischmannia Sch. Bip. (subtribu Fleischmanniinae).

Se comprobó que el género Ophryosporus es monofilético y el clado se encuentra definido por la presencia de involucros de hasta 8 filarios, dispuesto en 1 o 2 series de filarios, hasta 8 flores por capítulo, apéndices conectivales de las anteras nulos o muy rudimentarios, ramas del estilo clavadas y por células del carpopodio heteromorfas. Se comprobó la inaplicabilidad de las secciones propuestas por B. L. Robinson al actual concepto de Ophryosporus. Si bien se obtuvieron dos clados claramente definidos, los mismos no están debidamente sustentados. Este hecho, sumado a que muchos caracteres surgen en paralelo en ambos clados, imposibilita la creación de secciones en Ophryosporus.

\section{Análisis Biogeográfico}

Se realizó un análisis biogeográfico utilizando el análisis de dispersión y vicarianza, DIVA, que incluyó tanto a las especies de Ophryosporus como a las del grupo externo. Nueve áreas de endemismos fueron consideradas para el análisis biogeográfico.

De acuerdo a los resultados, se postula el origen del género Ophryosporus en los Andes Húmedos Centrales-Norte de Sudamérica. Posteriormente, se habrían producido dispersiones hacia las áreas Andes Secos Centrales-Sur y Chaco. Los eventos vicariantes principales se habrían producido en el área ancestral Desierto peruano-chileno / Pacífico Ecuatorial Seco y en el área ancestral Andes Húmedos Centrales-Norte / Andes Secos Centro-Sur. 
De acuerdo al registro fósil de tribus cercanas a Eupatorieae, conjuntamente con los datos bibliográficos aportados por el análisis de las tasas evolutivas del gen $n d h F$ podría sugerirse que el origen de Ophryosporus habría tenido lugar entre los 7,4 y 14,8 Ma. 


\section{ABSTRACT}

\section{Systematic Revision}

Ophryosporus Meyen belongs to the subtribe Critoniinae R. M. King \& H. Rob, tribe Eupatorieae Cass., and includes 41 South American species, distributed in Argentina, Bolivia, Brazil, Chile, Ecuador and Peru.

Ophryosporus was first described in 1834 by Meyen. In 1906, B. L. Robinson carried out the first revision of the genus, with the inclusion of 17 species and one variety. Also, the autor defined two sections: Euophryosporus and Ophryochaeta. In 1972, King \& Robinson expanded the genus concept by the inclusion of a section of the genus Piqueria Cav. and a monospecific genus (Trychinolepis B. L. Rob.).

As a result of the present systematic revision, all the species of Ophryosporus were described in detail and illustrated, in many cases for the first time. Distribution maps, ecological and phenological data, information about medicinal uses and chemistry compounds associated is also provided. A key for the identification of the species of the genus is presented for the first time. Moreover, twelve lectotypes were selected and complex nomenclatural problems were resolved.

\section{Cladistic Analysis}

To corroborate the monophyly of Ophryosporus and to establish the relationships among its species, a cladistic analysis was made, considering all the 41 species of the genus. For the analysis, 61 qualitative characters, 24 vegetative and 37 reproductive characters were used. For the conformation of the outgroup, species belonging to the genus Critonia P. Browne, Cronquistianthus R. M. King \& H. Rob., Koanophyllon Arruda (the three from Critoniinae) and Fleischmannia Sch. Bip. (subtribe Fleischmanniinae) were chosen.

Ophryosporus was found monophyletic, defined by the presence of up to 8 phyllaries, arranged in one or two series, up to 8 florets by capitula, anthers without 
conectival appendices or, if present, very rudimentary, style branches clavate and by heteromorphical carpopodial cells.

The infrageneric sections proposed by B. L. Robison are inapplicable to the actual concept of Ophryosporus. Even with the results with two clades, these clades lack of appropiate support.

\section{Biogeographical Analysis}

A biogeographical analysis was performed using DIVA, with all the species of Ophryosporus and outgroups. Nine endemism areas were considered for the biogeographical analysis.

Ophryosporus would have originated in the Humid Central-North Andes of South America, with subsequent dispersions to the Dry Central-South Andes and Chaco. The main vicariant events would have occured on the ancestral area of the Peruvian Chile Desert and Ecuatorial Dry Pacific, and in other event, on the area of Humid Central-North Andes and Dry Central-South Andes.

According with the fossil record of of other subtribes of Eupatorieae, based on bibliographic data of the evolutionary rate of the gen $n d h F$ the origin of Ophryosporus could be suggested between 7,4 to $14,8 \mathrm{Ma}$. 


\section{INDICE DE CONTENIDOS}

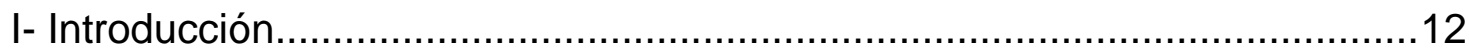

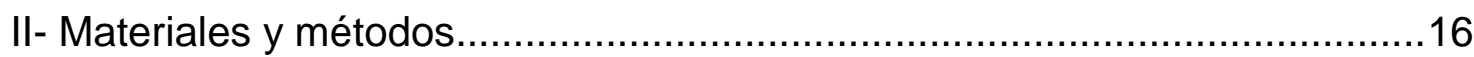

III- Historia taxonómica y relaciones genéricas............................................22

IV- Aspectos morfológicos y anatómicos

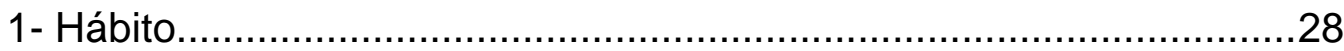

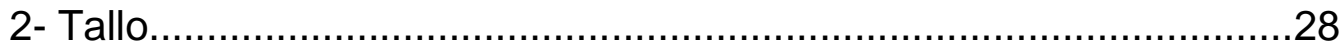

a- Pubescencia

b- Anatomía

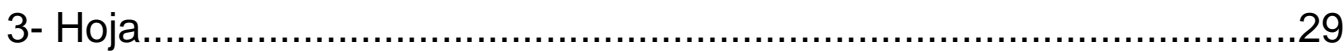

a- Morfología externa

b- Pubescencia

c- Nerviación

d- Anatomía

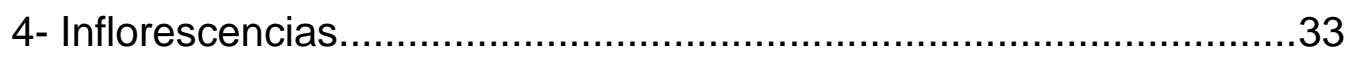

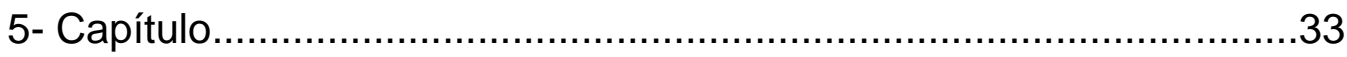

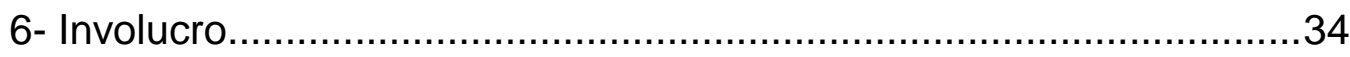

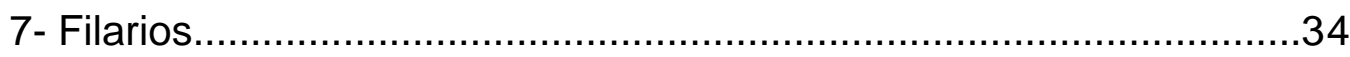

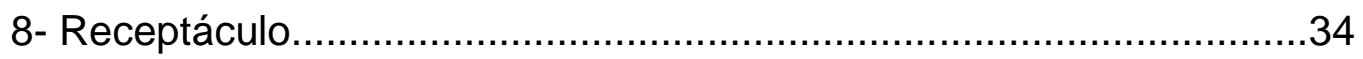

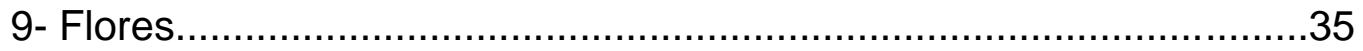

a. Corola

b. Androceo

c. Estilo

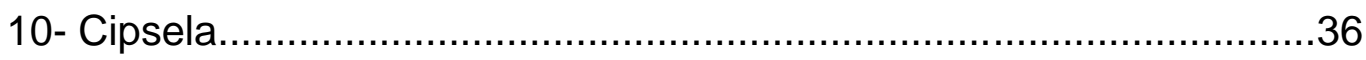

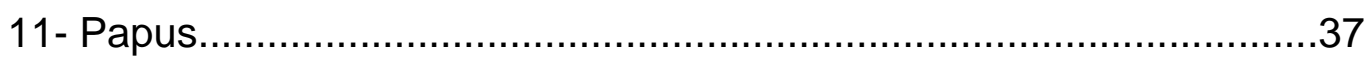

V- Tejidos secretores y compuestos químicos............................................46

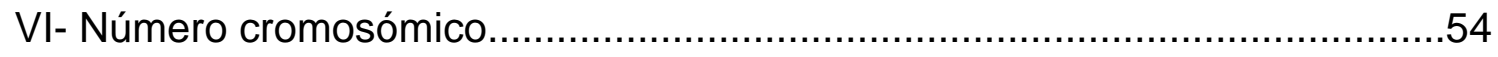

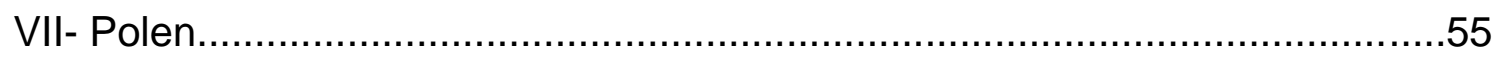

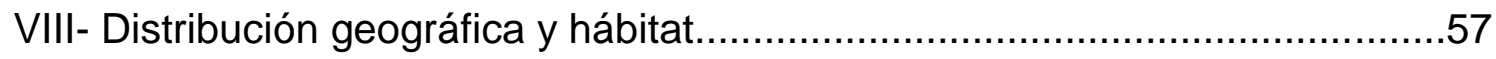

IX- Tratamiento taxonómico

1- Descripción de Ophryosporus........................................................ 


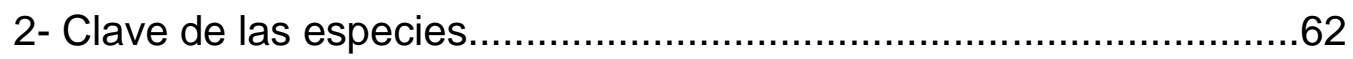

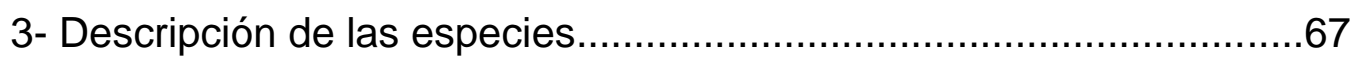

4- Especies y variedades excluidas.....................................................

X- Análisis cladístico

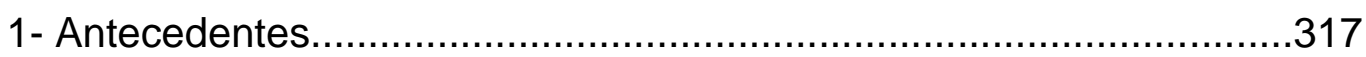

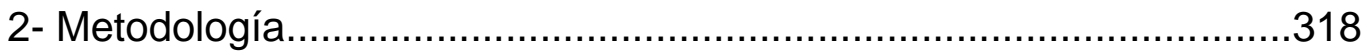

a- Elección del grupo externo

b- Grupo interno

c- Codificación y análisis

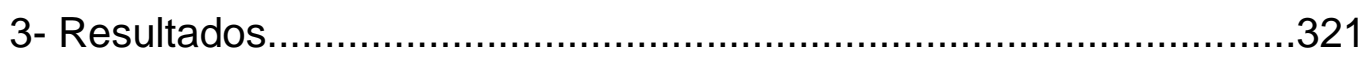

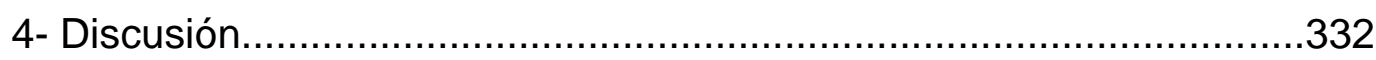

a- Relaciones intergenéricas de Ophryosporus

b- Monofilia y taxonomía infragenérica de Ophryosporus

c- Análisis de la evolución de los caracteres

XI- Análisis Biogeográfico

1- Introducción. 341

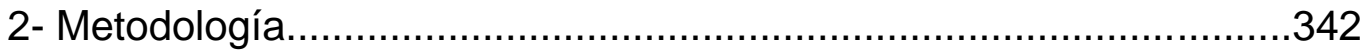

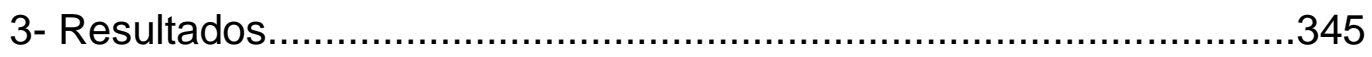

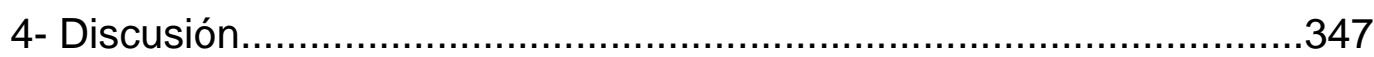

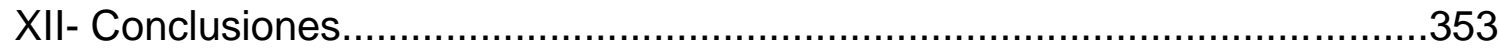

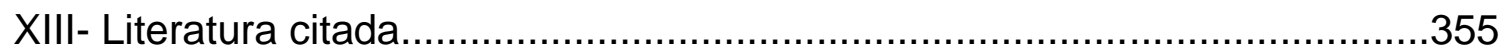

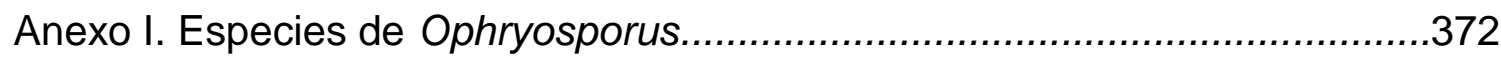

Anexo II. Materiales utilizados en el análisis cladístico...................................374

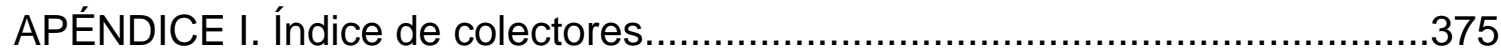

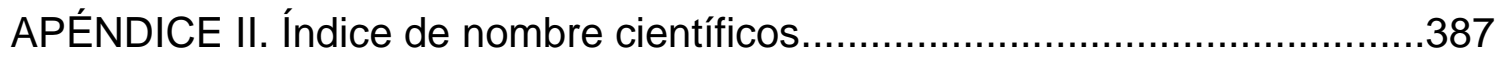




\section{I- INTRODUCCIÓN}

El género Ophryosporus Meyen pertenece a la subtribu Critoniinae R. M. King \& H. Rob., tribu Eupatorieae Cass., e incluye 41 especies sudamericanas (Anexo 1) distribuidas en Argentina, Bolivia, Brasil, Chile, Ecuador y Perú (King \& Robinson, 1987; Bremer, 1994; Hind \& Robinson, 2007).

Ophryosporus se caracteriza por su hábito arbustivo erecto o más raramente apoyante, hojas usualmente opuestas o alternas en fascículos, inflorescencias cimoideas o tirsoideas, capítulos con pocas flores, (3)-4-10-(12), involucros acampanados o cilíndricos con hasta 8 filarios "eximbricados", corolas blancas, ramas del estilo lisas, extremos clavados, aquenios 5-costados y papus formado por cerdas, escamas o ausente, aunque su carácter distintivo son las anteras con apéndices conectivales rudimentarios o nulos (King \& Robinson, 1987; Bremer, 1994; Hind \& Robinson, 2007).

El género Ophryosporus fue descripto en el año 1834 por F. J. F. Meyen, quien incluyó sólo la especie $O$. triangularis Meyen, basada en materiales chilenos. Si bien posteriormente se describieron más especies originalmente como Ophryosporus, una gran parte de las especies actualmente incluidas en este género fueron descriptas inicialmente como Eupatorium L. En 1906, B. L. Robinson realizó la primera revisión del género e incluyó 17 especies y una variedad. Este mismo autor identificó dos secciones: Euophryosporus y Ophryochaeta. En 1972, King \& Robinson, ampliaron el concepto del género e incluyeron una sección del género Piqueria Cav. y un género monoespecífico (Trychinolepis B. L. Rob.). Históricamente la diferenciación entre especies en la tribu Eupatorieae se basó principalmente en macrocaracteres. Sin embargo, King \& Robinson (1987) describieron cerca de 100 géneros nuevos, derivados de Eupatorium s. I., en base a microcaracteres anatómicos y morfológicos. Cabe destacar que Meyen fue uno de los primeros autores e utilizar microcaracteres para la identificación de especies de Eupatorieae antecediendo 150 años a la obra de King \& Robinson (1987). 
Actualmente, Ophryosporus se encuentra incluido en la subtribu Critoniinae. Sin embargo, originalmente, este género fue considerado por Meyen (1834) como miembro de la tribu Eupatorieae, cercano al género Kuhnia L., sin indicar pertenencia a subtribu alguna. B. L. Robinson (1913) consideró a Ophryosporus como miembro de la subtribu Piqueriinae Benth. \& Hook., la cual incluía taxones con apéndices conectivales nulos o rudimentarios, con extremos romos y cipselas seríceas. Inicialmente, este mismo criterio fue seguido por King (1967) quien ubicó el género Ophryosporus en la subtribu Piqueriinae, en base a apéndices conectivales nulos. En 1980, King \& Robinson, crearon la subtribu Critoniinae y reasignaron géneros a diferentes subtribus. Posteriormente (1987) dichos autores, en su obra "The Genera of the Eupatorieae", ubicaron al género Ophryosporus en Critoniinae. Dicho criterio fue posterioremente mantenido por Robinson et al. (2009).

Hasta el momento, no existe un estudio global de Ophryosporus que incluya a todas las especies de este género. Por otro lado, tampoco existen descripciones detalladas, ilustraciones, ni claves que consideren a todas sus especies. Si bien Ophryosporus parece ser homogéneo en cuanto a caracteres de involucro (ej. "eximbricado"), anteras (ej. apéndice conectivales rudimentarios o nulos) y ramas del estilo (ej. clavadas), el papus es extremadamente variable como resultado de la inclusión en el mismo de especies de diferentes géneros. Por ello, un profundo estudio morfológico es necesario para evaluar las discontinuidades encontradas en Ophryosporus. Por otro lado, las divisiones subgenéricas de Ophryosporus no han sido estudiadas desde la revisión de B. L. Robinson (1906), a pesar de que numerosas especies fueron adicionadas posteriormente. En este sentido, un estudio filogenético permitirá confirmar o modificar las entidades subgenéricas de Ophryosporus así como establecer las relaciones filogenéticas entre sus especies.

Dos géneros, Koanophyllon Arruda y Cronquistianthus R. M. King \& H. Rob., han sido señalados como posiblemente cercanos a Ophryosporus (King \& Robinson, 1987). Sin embargo, hasta el momento, esta hipótesis no ha sido contrastada con estudios filogenéticos que incluyan estos géneros. 
Ophryosporus contiene un alto número de especies endémicas (ca. 31 de un total de 41) en los diferentes países en los que se halla distribuido (Ecuador con dos especies endémicas, Perú con 11 especies endémicas, Bolivia con cinco, Argentina con cinco, Chile y Brasil con cuatro). Incluso, las especies peruanas de Ophryosporus y una de Ecuador se encuentran en la lista roja de la IUCN (International Union for the Conservation of Nature and Natural Resources, o UICN en español) como "potencialmente amenazadas" (Beltrán et al., 2006; Anónimo, 2012). El conocimiento biogeográfico, al incluir la ubicación de los componentes de la biodiversidad, permite identificar áreas únicas en su composición biótica (Humphries et al. 1995, Crisci et al. 2000). En ese sentido, la biogeografía histórica aporta no sólo la información necesaria para la conservación, sino que algunos de sus métodos pueden ser aplicados para la determinación de áreas prioritarias para conservación (Crisci et al. 2000, 2003). Los estudios de biogeografía histórica de Ophryosporus contribuirán a establecer las relaciones entre biotas de diferentes áreas de América del Sur y permitirán realizar una estimación indirecta de áreas de gran valor para la conservación de las especies del género.

Ciertas especies de Ophryosporus presentan múltiples usos medicinales, como analgésico, antisifilítico (De Lampasona et al. 1997, Barboza et al. 2006), actividad antiinflamatoria (Favier et al. 1998), actividad antiprotozoica, expectorante, alivio de migrañas (Fournet et al. 1994), alivio de golpes, antiséptico y actividades antimicrobianas (Rojas et al. 2003), entre otras. Por lo tanto, el esclarecimiento de la sistemática del grupo a partir de las relaciones filogenéticas permitirá aportar a otras disciplinas tales como farmacéutica y medicina.

El presente trabajo de tesis tiene como objetivos:

1. Delimitar el género Ophryosporus y sus especies, ampliar las descripciones, resolver problemas nomenclaturales, proporcionar mapas de distribución y claves de determinación de las especies del género. Ampliar el conocimiento actual sobre aspectos anatómicos y morfológicos del género. 
2. Realizar un análisis cladístico con el fin de comprobar si el género Ophryosporus es monofilético y establecer las relaciones filogenéticas de sus especies integrantes.

3. Realizar un estudio de biogeografía histórica del género Ophryosporus. 


\section{II- MATERIALES Y MÉTODOS}

\section{Herbarios consultados.}

Se han analizado especímenes $\mathrm{y} / \mathrm{o}$ fotos provenientes de los siguientes herbarios. Las abreviaturas corresponden a las siglas del "Index Herbariorum" (Holmgren et al. 1990). A continuación, se indican con (F) los herbarios de los que sólo se tuvo acceso a fotos; con (E-F) cuando se dispuso de especímenes y fotos y $(E)$ cuando se dispuso únicamente de especímenes para su estudio.

AAU: Herbarium, Science and Technology Museums Aarhus University. Aarhus, Dinamarca. (E).

B: Herbarium, Botanischer Garten und Botanisches Museum Berlin-Dahlem, Zentraleinrichtung der Freien Universität Berlin. Berlín, Alemania. (F).

BM: Herbarium, Department of Botany. The Natural History Museum. Londres, Inglaterra, Reino Unido. (F).

CONC: Herbario, Departamento de Botánica. Universidad de Concepción. Concepción, Chile. (E-F).

CORD: Herbario, Facultad de Ciencias Exactas, Físicas y Naturales. Universidad Nacional de Córdoba. Córdoba, Argentina. (E-F).

E: Herbarium Royal Botanic Garden. Edimburgo, Escocia, Reino Unido. (F).

F: Herbarium, Botany Department, Field Museum of Natural History. Chicago, Estados Unidos. (E-F).

G: Herbarium, Conservatoire et Jardin Botaniques de la Ville de Genève. Ginebra, Suiza. (E-F). 
GH: Harvard University Herbaria. Cambridge, Massachusetts, Estados Unidos. (EF).

GOET: Herbarium, Department of Systematic Botany Albrecht von Haller Institute of Plant Sciences Universität. Göttingen, Alemania. (F).

JUA: Herbario, Facultad de Ciencias Agrarias. Universidad Nacional de Jujuy. San Salvador de Jujuy, Jujuy, Argentina. (E).

K: Herbarium Royal Botanic Gardens. Kew, Inglaterra, Reino Unido. (E-F).

LD: Herbarium, Botanical Museum. Lund, Suecia. (F).

LIL: Herbario Fundación Miguel Lillo. San Miguel de Tucumán, Argentina. (E).

LP: Herbario División Plantas Vasculares, Museo de La Plata. La Plata, Buenos Aires, Argentina. (E).

LPB: Herbario Nacional de Bolivia, Universidad Mayor de San Andrés. La Paz, Bolivia. (E).

M: Herbarium Botanische Staatssammlung. München, Alemania. (F).

MCNS: Herbario Facultad de Ciencias Naturales. Museo de Ciencias Naturales. Universidad Nacional de Salta. Salta, Salta, Argentina. (E).

MERL: Herbario Ruiz Leal. Unidad Botánica y Fitosociología. Instituto Argentino de Investigaciones de las Zonas Áridas (IADIZA, CRICYTME). Mendoza, Mendoza, Argentina. (E).

MO: Herbarium, Missouri Botanical Garden. Saint Louis, Missouri, Estados Unidos. $(\mathrm{E}-\mathrm{F})$.

MOL: Herbario, Departamento Académico de Biología. Universidad Nacional Agraria La Molina. Lima, Perú. (E).

NY: New York Botanical Garden. Bronx, New York, Estados Unidos. (E-F). 
P: Herbier National de Paris, Département de Systématique et Evolution Phanérogamie, Muséum National d'Histoire Naturelle. París, Francia. (F).

QCNE: Herbario Nacional del Ecuador, Sección Botánica. Museo Ecuatoriano de Ciencias Naturales. Quito, Ecuador. (E).

S: Herbarium Swedish Museum of Natural History. Estocolmo, Suecia. (F).

SGO: Herbario Sección Botánica, Museo Nacional de Historia Natural. Santiago, Chile. (E-F).

SI: Herbario Instituto de Botánica Darwinion. San Isidro, Buenos Aires, Argentina. $(\mathrm{E})$.

U: National Herbarium of the Netherlands, Herbarium Utrecht. Leiden, Holanda. $(\mathrm{F})$.

US: United States National Herbarium, Department of Botany, Smithsonian Institution. Washington D. C., Estados Unidos. (E-F).

W: Herbarium Department of Botany Naturhistorisches Museum Wien. Viena, Austria. (F).

Z: Herbarium Institut für Systematische Botanik Universität. Zürich, Suiza. (F).

Los macrocaracteres morfológicos de los ejemplares fueron analizados a simple vista o mediante una lupa binocular. Cuando fue necesario para realizar las mediciones, se recuperó el material hidratándolo en agua: glicerina (1:1), posteriormente se enjuagó con agua destilada y se almacenó en FAA (formol, agua destilada, ácido acético y alcohol etílico; 100:350:50:500 V/V/V/V). Las mediciones de caracteres macroscópicos fueron realizadas con un escalímetro.

Para realizar la observación de microcaracteres morfológicos se recuperó el material tanto vegetativo como reproductivo colocándolo en agua con detergente o 
agua: glicerina (1:1) durante 24 horas, posteriormente se enjuagó con agua destilada y se almacenó en FAA.

Los gráficos de los aspectos generales fueron realizados por Jorge González (excepto O. macrodon que fue realizado por la autora), mientras que los detalles fueron realizados en su totalidad por la autora. De las 41 especies, fueron graficadas por primera vez 31 especies.

En los casos en que fue necesario diafanizar, una vez hidratado el material, se lo colocó en soluciones de $\mathrm{NaOH}$ al $5 \%$ o $20 \%$, se enjuagó y se lo aclaró en hipoclorito de $\mathrm{Na}$ al $50 \%$ o 70\%. Luego, se lo tiñó con safranina, cristal violeta y/o fast-green. El material fue montado en gelatina-glicerina. En ciertos casos, donde la naturaleza del material así lo requería, se procedió al hervido del órgano en una solución de $\mathrm{NaOH}$ al $20 \%$, enjuagues con agua destilada y se lo aclaró con hipoclorito de sodio al $50 \%$. Posteriormente, se sometió al material a una serie creciente de alcoholes ( $50^{\circ}$ con safranina, $70^{\circ}, 90^{\circ}$ y $100^{\circ}$ ) para luego ser colocado en xilol. Posteriormente fueron montados en bálsamo de Canadá sintético.

Los cortes anatómicos fueron realizados tanto a mano alzada, como con micrótomo rotatorio tipo Minot marca Microm HM 315. Los cortes a mano alzada se decoloraron con hipoclorito de $\mathrm{Na}$ al $30 \%$ o 50\% y posteriormente se tiñeron con colorantes (Azul Nilo, Sudán III), para determinar la naturaleza química de los contenidos de estructuras secretoras. Posteriormente se montaron en gelatinaglicerina. Para obtener los cortes mediante micrótomo, se incluyeron los órganos en parafina, se tiñeron y se montaron en bálsamo de Canadá (Johansen, 1940). Las fotografías tomadas tanto de los corte anatómicos como de los microcaracteres fueron tomadas con una cámara digital incorporada a un microscopio marca Nikon Eclipse ER 200.

Para las observaciones al microscopio electrónico de barrido (MEB), se procedió a recuperar el material en gelatina: glicerina (1:1), se enjuago con agua destilada y se depositó en FAA para fijar las estructuras durante 3 semanas. Posteriormente, se sometió el material a una serie creciente de alcoholes (50으, 
$70^{\circ}, 80^{\circ}, 90^{\circ}, 96^{\circ}$ y $\left.100^{\circ}\right)$. Dichos materiales fueron estabilizados mediante la técnica de Punto Crítico llevada a cabo en un equipo EMITECH, Modelo K850 y metalizados con Au, mediante "sputtering" en un metalizador Balzers. Se observaron en un microscopio marca Philips SEM 505, con un programa para la obtención de imágenes digitales (Digitalizador de Imagen Soft Imaging Sistem ADDA II (SIS)), perteneciente al Servicio a Terceros de CINDECA (Centro de Investigación y Desarrollo en Ciencias Aplicadas), Universidad Nacional de La Plata (UNLP).

Para el análisis de la morfología general, se utilizaron diferentes textos, de acuerdo al órgano/estructura en cuestión: hojas (Hickey, 1973; Leaf Architecture Working Group, 1999), inflorescencias (Font Quer, 1993; Rua, 1999), capítulos, flores, androceo y gineceo (King \& Robinson, 1987; Bremer, 1994; Hind \& Robinson, 2007). Las áreas foliares se estimaron utilizando la clasificación de Raunkier (1934), Webb (1959) y las plantillas generadas por el Leaf Architecture Group (1999). Se agruparon las categorías en tres grupos: áreas foliares inferiores a $25 \mathrm{~mm}^{2}$ hasta $225 \mathrm{~mm}^{2}$ (leptofilo y nanofilo), mayores a $225 \mathrm{~mm}^{2}$ pero inferiores a $4500 \mathrm{~mm}^{2}$ (microfilos y notofilo) y áreas foliares mayores a $4500 \mathrm{~mm}^{2}$ (mesofilo).

Para la descripción de los tricomas se siguió la nomenclatura propuesta por Ramayya (1962a, 1962b), excepto para los pelos gemelos, que donde se utilizaron los textos de Hess (1938), Freire \& Katinas (1995) y Sancho \& Katinas (2002).

En cuanto a la anatomía, se utilizó la terminología propuesta por Metcalfe \& Chalk (1979), Curtis \& Lersten (1986), King \& Robinson (1987), Fahn (1988), Lersten \& Curtis (1988) y Ragonese (1988).

Los datos de color de flor, hábitat, fenología y usos se obtuvieron de las etiquetas de herbario, de publicaciones varias (publicaciones científicas, floras, recuentos florísticos, etc.) y datos obtenidos en el campo.

Solamente se transcribieron las etiquetas del material tipo; la información correspondiente al material adicional examinado se encuentra ordenada por país y 
subdivisión política en orden alfabético; se cita ubicación geográfica, fecha, colector, número e institución en que se encuentra depositado el material.

La identificación de los holotipos se realizó a partir de los datos de colector y localidad citados por los autores en las descripciones originales. En los casos en que fue necesario, se procedió a la designación de lectotipos.

Cuando no fue posible determinar la ubicación del material tipo se ha seguido la obra Taxonomic Literature (Stafleu \& Cowan, 1976-1988) y sus suplementos (Stafleu \& Mennega, 1992-2000) para identificar la institución donde el autor de la especie haya trabajado. Para aquellos taxa en que no se menciona en el protólogo la institución donde la colección original está depositada, se presume que el holotipo o sintipo es un ejemplar que se encuentra donde el autor ha trabajado al momento de describir la especie, de acuerdo a la recomendación 9A.4 del Código Internacional de Nomenclatura Botánica (McNeill et al., 2006). 


\section{III- HISTORIA TAXONÓMICA Y RELACIONES GENÉRICAS}

\section{Historia taxonómica.}

La tribu Eupatorieae presenta serias dificultades en la separación de muchos de sus géneros sobre la base de macrocaracteres.

La mayoría de las especies de la tribu Eupatorieae alguna vez fueron clasificadas en el amplio género Eupatorium s.l., pero en la actualidad se encuentran reasignadas a otros géneros, tales como Ophryosporus. Entre los años 1966 y 1986 R. M. King y H. Robinson publicaron alrededor de 235 de trabajos sobre la clasificación de la tribu. Dicha información fue compilada en su obra, "The Genera of the Eupatorieae" (King \& Robinson, 1987). En esta monografía de las eupatoreas, King y Robinson describieron cerca de 100 géneros nuevos, principalmente sobre la base de microcaracteres. La reorganización de Eupatorium s.l. en numerosos géneros pequeños o bien la asignación de muchas de sus especies a géneros ya descriptos como Ophryosporus, no ha sido aceptada por todos los especialistas en la familia y sus esquemas de clasificación han sido mirados con cierto escepticismo. De esta manera, si el polifiletico Eupatorium s.l. es reclasificado en géneros monofiléticos con menor número de especies, el esquema propuesto por estos autores provee un marco de referencia útil para futuras investigaciones y mejora la clasificación genérica de la tribu antes que un vasto e incomprensible Eupatorium s.l. (Bremer, 1994).

A continuación se describen cronológicamente los eventos que llevaron a la conformación actual de Ophryosporus.

1834. F. J. F. Meyen, en su obra Reise um die erde, describe por primera vez al género Ophryosporus basado en material chileno e incluye una sola especie, $O$. triangularis. 
1838. A. P. De Candolle, en su Prodromus, cita a Ophryosporus triangularis como única especie perteneciente al género. Por otro lado, describe a Piqueria floribunda, Piqueria galioides, Eupatorium foliolosum, Eupatorium piquerioides y Nothites ovatifolia. Dichos nombres, en los años subsiguientes serán sinonimizados bajo el género Ophryosporus por diversos autores.

1873. G. Bentham \& J. D. Hooker, en su obra Genera Plantarum, incluyen siete especies de Ophryosporus e indican un rango de distribución del género desde Sudamérica a México. Como Ophryosporus sólo incluyen a $O$. triangularis, especie a la cual le asignan varios nombres como sinónimos. Dichos autores, a su vez incluyen en Ophryosporus otras especies de otros géneros, aunque sin hacer explícitamente las nuevas combinaciones.

1874. A. H. R. Grisebach, en Plantae Lorentzianae, describe a Eupatorium clavulatum, el cual, en su obra Symbolae ad Floram argentinam (1879) es transferido al género Ophryosporus. En esta última obra, Grisebach establece las relaciones de Ophryosporus clavulatus con las especies brasileñas 0 . piquerioides Benth. y $O$. regnelli Baker. A su vez describe a Eupatorium axilliflorum y a Mikania charua, las cuales serán transferidas posteriormente a Ophryosporus.

1876. J. G. Baker, en la Flora Brasiliensis de C. F. P. Martius, cita siete u ocho especies de Ophyosporus. En esta obra el autor describe cinco nuevas especies: Ophryosporus burchelli, O. pachychaeta, O. freyreissii, O. regnelli y O. laxiflorus.

1881-1882. W. B. Hemsley, en Biologia Centrali-Americana, cita a Ophryosporus con siete especies, con un rango de distribución desde México a Chile y Brasil.

1895. J. D. Hooker \& B. D. Jackson, en el Index Kewensis, son los primeros en listar las doce especies del género conocidas hasta ese momento, además de incluir varios sinónimos. 
1897. G. H. E. W. Hieronymus, en Botanische Jahrbücher für Systematik, Pflanzengeschichte und Pflanzengeographie, cita ocho especies de Ophryosporus y describe dos especies (Ophryosporus kuntzei y O. lorentzii) y una variedad nueva (O. origanoides var. microcephala).

1901. G. H. E. W. Hieronymus, en Botanische Jahrbücher für Systematik, Pflanzengeschichte und Pflanzengeographie describe una nueva especie (Ophryosporus sodiroi) e incluye una nueva variedad [O. solidaginoides var. bonplandiana (Schultz-Bip) Hieron.].

1901. K. F. Reiche transfiere Eupatorium foliolosum DC. a Ophryosporus.

1905. B. L. Robinson transfiere Eupatorium venosissimum Rusby a Ophryosporus y relaciona a dicha especie con $O$. cumingii Benth.

1906. B. L. Robinson (1906b) publica la primer revisión del género Ophryosporus, donde incluye 17 especies (O. axilliflorus, O. charua, O. clavulatus., $O$. cumingii, O. freyreissi, O. kuntzei, O. laxiflorus, O. Iorentzii, O. macrodon, $O$. origanoides, $O$. pachychaeta, $O$. paradoxus, $O$. piquerioides, $O$. regnellii, $O$. sodiroi, $O$. triangularis y $O$. venossisimus) y una variedad ( $O$. piquerioides var. microcephala), y excluye cinco especies y una variedad. Además, establece dos secciones en el género: Euophryosporus y Ophryochaeta.

1919-1930. B. L. Robinson adiciona a Ophryosporus nueve especies nuevas y realiza cinco nuevas combinaciones. De esta manera, en esos años, 26 especies y una variedad constituyen al género Ophryosporus.

1957. Á. L. Cabrera, a partir de material colectado en Brasil, describe una nueva especie, Ophryosporus organensis.

1969. R. M. King \& H. Robinson excluyen tres especies mexicanas de Ophryosporus en su monografía de Decachaeta DC. Limitan, de esta manera, la dispersión del género a Sudamérica. 
1972. R. M. King \& H. Robinson amplían el concepto genérico de Ophryosporus al considerar una variación mayor en las formas adoptadas por el papus. Sobre esta base, trasfieren a Ophryosporus al género monotípico Trychinolepis B. L. Rob. y a toda la sección Artemisioides perteneciente a Piqueria. En total, con otras transferencias realizadas, incluyen 38 especies en el género Ophryosporus.

1973. Á. L. Cabrera, a partir de material de Argentina, describe a Ophryosporus burkartii, siendo esta especie la de distribución más reducida en nuestro país. Además, indica su afinidad con $O$. lorentzii Hieron.

1998. $\mathrm{H}$. Robinson describe tres especies nuevas (O. carchiensis, $O$. ferreyrii y $O$. sagasteguii) a partir de material de Ecuador y Perú.

2008. A. Sagástegui Alva y E. F. Rodríguez Rodríguez, a partir de material peruano, describen una nueva especie, Ophryosporus marchii e indican alrededor de 48 especies para el género.

\section{$\underline{\text { Relaciones intergenéricas. }}$}

La tribu Eupatorieae (Asteraceae) está compuesta actualmente, de acuerdo a Robinson et al., 2009, por 19 subtribus (Adenostemmatinae B. L. Rob., Ageratinae Less., Alomiinae Less., Ayapaninae R. M. King \& H. Rob., Critoniinae R. M. King \& H. Rob., Disynaphiinae R. M. King \& H. Rob., Eupatoriinae Dumort., Fleischmanniinae R. M. King \& H. Rob., Gyptidinae R. M. King \& H. Rob., Hebecliniinae R. M. King \& $H$. Rob., Hofmeisteriinae R. M. King \& H. Rob., Liatrinae R. M. King \& H. Rob., Mikaniinae R. M. King \& H. Rob., Neomirandeinae R. M. King \& H. Rob., Oaxacaniinae R. M. King \& H. Rob., Oxylobinae R. M. King \& H. Rob., Piqueriinae Benth. \& Hook., Praxelinae R. M. King \& H. Rob.y Trichocoroninae R. M. King \& H. Rob), que reúnen 180 géneros y aproximadamente 2200 especies, constituyendo aproximadamente el $10 \%$ de la familia Asteraceae (King \& Robinson, 1987). Esta organización de la tribu, difiere en la delimitación de algunos grupos con la propuesta por autores anteriores (King \& Robinson, 1987; Bremer, 1994; Hind \& Robinson, 2007). Eupatorieae es la tribu 
menos estudiada dentro de la familia Asteraceae (King \& Robinson, 1987). Si bien la condición monofilética de la tribu no es cuestionada, las relaciones entre sus subtribus y la condición monofilética de las mismas no están resueltas. Esto se debe al escaso número de análisis filogenéticos desarrollados en Eupatorieae (Bremer, 1994; Ito et al., 2000a; Robinson et al. 2009), como así también a la limitada representatividad de géneros en los mismos (Robinson et al., 2009).

La subtribu Critoniinae comprende 40 géneros con un total de 332 especies (King \& Robinson, 1987). Sus miembros se caracterizan por los involucros persistentes y algunas veces eximbricados, engrosamientos anulares en las células de los collares anterales y apéndice conectival bien desarrollado o a veces rudimentario (e.g. Koanophyllon Arruda, Ophryosporus, Mexianthus B. L. Rob.), raramente nulo (e.g. Ophryosporus) en los estambres y por ramas del estilo fuertemente clavadas.

Critoniinae está compuesta de subgrupos importantes. Dichos subgrupos presentan especializaciones extremas, que potencialmente podrían representar nuevas subtribus (King \& Robinson, 1987). Sin embargo, la presencia de formas intermedias impide la escisión de la subtribu Critoniinae. Dentro de Critoniinae, Ophryosporus está incluido en el subgrupo Koanophyllum (King \& Robinson, 1987), que contiene 11 géneros: Koanophyllum (de distribución americana, desde México hasta Argentina); Bishovia R. M. King \& H. Rob.; Lorentzianthus R. M. King \& H. Rob, Idiothamnus R. M. King \& H. Rob y Chacoa R. M. King \& H. Rob de regiones templadas sudamericanas; Nothobaccharis R. M. King \& H. Rob de Perú; Ophryosporus de distribución sudamericana mayormente andina; Sphaereupatorium (O. Hoffm.) B. L. Rob. y Santosia R. M. King \& H. Rob de Brasil; Grisebachianthus R. M. King \& H. Rob de Cuba y Eupatoriastrum Greenm. de México y América Central. El subgrupo Koanophyllon incluye a aquellos miembros de la subtribu que presentan involucros débilmente subimbricados 0 eximbricados y apéndices conectivales rudimentarios o nulos (King \& Robinson, 1987). 
Los estudios filogenéticos que incluyen a Critoniinae son escasos (Bremer, 1994; Ito et al., 2000a; Robinson et al., 2009) y sólo consideran a miembros del género Critonia P. Browne y Aristiguietia R. M. King \& H. Rob. como representantes de los 40 géneros que componen dicha subtribu.

Dos géneros, Koanophyllon y Cronquistianthus R. M. King \& H. Rob. (que si bien pertenece a Critoniinae, no está incluído en el grupo Koanophyllon) han sido señalados como posiblemente cercanos a Ophryosporus Meyen. Muchas especies pertenecientes a Koanophyllon presentan apéndices conectivales rudimentarios y ramas estigmáticas largas, incluso otras presentan involucros eximbricados, caracteres similares a Ophryosporus. Sin embargo, la extrema reducción de los apéndices conectivales de Ophryosporus diferencia a este género de Koanophyllon. En cambio, la similaridad en la cipsela lo acerca a Cronquistianthus: ambos presentan algunas especies con cipselas con carpopodio excéntrico. Sin embargo, Cronquistianthus difiere de Ophryosporus por sus apéndices conectivales bien desarrollados e involucros fuertemente imbricados. Hasta el momento, no se han realizado estudios filogenéticos que incluyan a Koanophyllon y Cronquistianthus (King \& Robinson, 1987) y que permitan confirmar las relaciones de Ophryosporus con los mismos. 


\section{IV- ASPECTOS MORFOLÓGICOS Y ANATÓMICOS}

\section{Hábito.}

La totalidad de las especies de Ophryosporus tienen un hábito arbustivo, siendo la gran mayoría arbustos erectos (Fig $1 \mathrm{~A}, \mathrm{H}$ ). Algunas especies (ej. $O$. apricus, $O$. carchiensis, $O$. cumingii), son arbustos apoyantes. Su altura varía entre $0,5 \mathrm{~m}(0$. galioides) hasta $3 \mathrm{~m}$ (O. macrodon).

La distancia de los entrenudos es variable, con un promedio de $0,1-1 \mathrm{~cm}$ (ej. $O$. hoppii) o con promedio de 6,5-11 cm (ej. O. angustifolius).

\section{Tallo.}

Los tallos de las especies de Ophryosporus tanto erectos como apoyantes son cilíndricos y pueden ser estriados o no. En la mayoría de las especies, presentan colores permanentes que varían entre el rojizo y el púrpura.

\section{a. Pubescencia.}

La mayoría de los tallos son glabros a pubescentes. El grado de pubescencia suele ser mayor en ejes jóvenes. Los tricomas pueden ser tanto eglandulares uniseriados multicelulares, del tipo simple cónico, como por tricomas glandulares vesiculares biseriados subtipo $\alpha$.

- Tricoma eglandular simple cónico: pie simple. Cuerpo uniseriado, entero, con 2 a muchas células, cónico, con célula terminal frecuentemente aguzada. Las paredes laterales entre las células se encuentran constreñidas. Las células inferiores presentan mayor longitud, siendo la basal más ancha que larga. Las paredes externas pueden ser delgadas 0 gruesas; pudiendo adelgazarse hacia el extremo distal. La superficie es lisa o rugosa (estrías).

- Tricoma glandular vesicular biseriado, subtipo a: pie compuesto. Cuerpo biseriado, diferenciado en pie y cabeza. El pie presenta de 2 a 5 
células en cada fila, uniforme en ancho o a veces estrechándose hace el extremo apical. Las células de las filas son alternas o subopuestas, de longitud variada. Contenido translúcido. Las paredes internas son delgadas. Las paredes externas son derechas o ligeramente convexas, gruesas y lisas. La cabeza tiene de 4 a 8 células en cada fila, fuertemente diferenciadas del pie. Las células de las filas a lo largo del tricoma son opuestas o subopuestas, variando su longitud, siendo las superiores relativamente largas. Contenido denso, persistente. Las paredes internas son delgadas. Las paredes externas son rectas o ligeramente convexas, delgadas a ligeramente gruesas, lisas. La vesícula cuticular rodea de 1 a 3 niveles de células o se encuentra restringida al ápice de la célula terminal, pudiendo colapsar tempranamente o ser persistente. (Fig 5 C-F)

\section{b. Anatomía.}

Los tallos son de sección transversal circular. Presentan una peridermis con una cutícula, en algunos casos prominente, paquetes de fibras esclerénquimáticas en el anillo vascular, las cuales pueden ser más o menos frecuentes (dependiendo de la especie y de la madurez del eje) y en algunos casos, varias capas de parénquima cortical subepidérmico, donde pueden observarse canales secretores de tamaño y abundancia variable. El cilindro vascular presenta crecimiento secundario y una médula con células parenquimáticas de paredes engrosadas. (Fig 3 A-B)

\section{Hoja.}

\section{a. Morfología externa.}

Las hojas se disponen tanto de manera opuesta (Fig. 1 A-B; 2 A1) como alterna (Fig. $1 \mathrm{H}, \mathrm{I} ; 2 \mathrm{~A} 2$ ) en fascículos (ej. O. triangularis).

Las hojas son pecioladas, con pecíolos bien desarrollados, hasta $2 \mathrm{~cm}$ (ej. $O$. macrodon) o casi subsésiles, 0,5 cm (ej. O. hoppii) (Fig 2 B-C). 
El margen de la lámina es entero, aunque en $O$. bipinnatifidus es profundamente lobado. Su forma varía entre lanceolada (ej. O. peruvianus), ovado-lanceolada (ej. O. charua) u ovada (ej. O. apricus). La base puede ser cuneada (ej. O. galioides), decurrente (ej. O. freyreisii), redondeada (ej. $O$. organensis) y hasta truncada (ej. O. burkartii). Los ápices varían entre agudos (ej. O. piquerioides) a cortamente acuminados (ej. O. apricus), pudiendo en O. hoppii llegar a ser obtusos. El tamaño de la lámina es muy variable, siendo el menor en O. triangularis $(0,1-0,35 \times 0,3-0,6 \mathrm{~cm})$ y el mayor en 0 . macrodon $(5-8 \times 10-18$ cm) (Fig. 2 C1-6).

Los márgenes varían entre enteros (ej. O. hartwegii), denticulados (ej. $O$. heptanthus), aserrados (ej. O. macrodon) y profundamente lobados ( $O$. bipinnatifidus). Los márgenes aserrados, pueden presentar dientes de primer orden (ej. O. hoppii) como de segundo orden (ej. O. macrodon) (Fig. 2 C1-6).

Además, el margen puede ser revoluto (Fig. 11, 2 D2) en unas pocas especies (ej. O. triangularis) o plano, como en el resto de las especies (Fig. 2 D1).

\section{b. Pubescencia.}

Las hojas de la totalidad de las especies de Ophryosporus presentan algún tipo de pubescencia, ya sea en ambas caras, como en la cara adaxial o abaxial. Además, su disposición puede ser preferencialmente sobre las venas, las láminas o en ambas. En el último caso, se encuentra una diferencia de densidad entre la pilosidad de las venas y de las láminas, ya sea mayor en la lámina o en las venas.

Los tricomas pueden ser tanto eglandulares (Fig. 5 G) como glandulares (Fig. 5 A-F). Los tricomas eglandulares son simples cónicos.

En cuanto a los tricomas glandulares, se presentan de dos tipos, glandular biseriado tipo $\alpha$ y tipo $\beta$, siendo el tipo $\beta$ mucho más delicado y difícil de observar debido a su escasa conservación en materiales herborizados. Dichos tricomas contienen aceites esenciales. 
- Tricoma glandular vesicular biseriado, subtipo $\beta$ : pie compuesto. Cuerpo biseriado, entero, no diferenciado en cabeza y pie, con 4 a 10 células en cada fila, de forma oblonga. Las células de las filas son subopuestas usualmente, con varias longitudes, pudiendo ser más largas las inferiores o todas de longitud similar excepto aquellas del nivel superior que pueden ser más largas. Contenido denso, en general persistente. Paredes interiores delgadas. Paredes externas ligeramente convexas, delgadas, lisas. La vesícula cuticular rodea de 1 a 4 niveles de células, pudiendo colapsar tempranamente o ser persistente (Fig. 5 A-B).

\section{c. Nerviación.}

La mayor parte de las especies de Ophryosporus poseen hojas trinervadas, desde cerca de la base de la lámina, a veces con otras venas laterales basales de segundo orden. El patrón de venación de las venas de tercer orden de la hoja suele formar un retículo, más o menos prominente según las especies. Las venas laterales principales pueden ser paralelas al margen foliar o no. De acuerdo a la clasificación de Hickey (1973), la nerviación de las hojas de Ophryosporus corresponde al tipo acródroma imperfecta suprabasal (Fig. B 1-3).

\section{d. Anatomía.}

La cutícula de las hojas es usualmente delgada, aunque en O. heptanthus puede ser de mayor grosor y lisa, pero en algunos casos presenta estrías, las cuales pueden ser incipientes, (ej. O. angustifolius) o muy notorias (ej. $O$. peruvianus) (Fig. 3 C-G).

La epidermis es uniestratificada, con células tanto isodiamétricas como rectangulares. Las células epidérmicas presentan variaciones en sus paredes tangenciales longitudinales, pudiendo éstas ser rectas (ej. O. pinifolius), onduladas (ej. O. peruvianus) o profundamente digitadas (ej. O. freyreisii).

Las láminas son anfiestomáticas (ej. O. peruvianus), o con estomas solamente en la cara abaxial (ej. O.piquerioides) o raramente adaxial (ej. O cumingii). Los 
estomas son del tipo anomocítico, pudiendo estar parcialmente recubiertos con rebordes de la cutícula (ej. O. freyreissi) (Fig. $3 \mathrm{E}$ ).

En algunas especies (ej. O. regnelli Baker, O. macrodon) se detectaron estomas atrofiados, los cuales forman parte de órganos secretores denominados hidatodos. Los hidatodos tienen conexión con el xilema, mediante un tejido denominado epitema, el cual expulsa agua a través de los estomas atrofiados (también denominados acuíferos, Font Quer, 1993). Estas estructuras se presentan en los extremos de los dientes de las láminas en algunas especies (ej. O. macrodon).

Los haces vasculares primarios son colaterales y frecuentemente presentan casquetes de colénquima tanto en la parte superior como inferior; los haces vasculares secundarios se encuentran dispuestos en una línea, aproximadamente en el centro del mesófilo. No se han observado haces esclerenquimáticos asociados a los haces vasculares de las hojas.

El mesófilo está conformado por clorénquima que suele estar pobremente desarrollado, en correlación con la naturaleza herbácea y delicada de las láminas (Metcalfe \& Chalk, 1979). En general es dorsiventral, donde se definen parénquima en empalizada y esponjoso (ej. O. apricus), aunque se han registrado casos (ej. O. laxiflorus) de mesófilo isolateral donde todo el tejido parenquimático es esponjoso. En $O$. triangularis, se ha identificado un mesófilo con gran cantidad de espacios intercelulares, similares a tejidos acumuladores de agua (Metcalfe \& Chalk, 1979) coincidentemente con la textura carnosa de las láminas de las hojas.

Casi la totalidad de las especies de Ophryosporus presentan reservorios secretores. Se utiliza el término reservorio ya que, a diferencia de canal, cavidad o bolsillo, no hace referencia a la forma exacta del mismo.

Mediante las vistas paradermales y los cortes seriados, se observó que los reservorios secretores de Ophryosporus son ductos simples (sin conexión entre ellos) y cavidades, ambos de dimensiones variables. Sin embargo, la 
diferenciación entre estas dos categorías no siempre es clara. Los ductos son elongados (ej. O. peruvianus). Las cavidades son redondeadas (ej. O. steinbachii) o más comúnmente elípticas (ej. O. axilliflorus). El diámetro relativo, en corte transversal, de las estructuras secretoras varía de 4-50 X 6-100 $\mu \mathrm{m}$. A pesar de las diferencias en posición y forma, la estructura anatómica es similar: poseen un epitelio unicelular delimitando el lumen. Las células epiteliales varían en número desde 4 a 7 , con citoplasmas vacuolados aunque en algunos casos se observó citoplasmas más densamente coloreados. El lumen se encuentra generalmente ocupado por aceites, de color amarillo a marrón oscuro y formando gotas esféricas (Fig. 4 A-I).

\section{4 - Inflorescencia.}

Las inflorescencias en Ophryosporus son principalmente de dos tipos: tirsoideas (ej. O. triangularis) y cimoideas, (ej. O. macrodon). Las inflorescencias cimoideas, a su vez, pueden estar conformadas de corimbos laxos (O. apricus) o densos $(O$. chilca) o de glomérulos ( $O$. axilliflorus). Las tirsoideas están conformadas por corimbos, los cuales se pueden disponer de manera laxa (ej. $O$. hartwegii) o densa (ej. O. triangularis) (Fig. 1 A-J; 2 E-F).

En ambos casos, presentan hojas persistentes formando parte de las inflorescencias. Dichas hojas pueden ser de tamaño similar a las hojas superiores del tallo (ej. O. angustifolius) o bien ser de menos de $1 / 4$ parte de las hojas del eje (ej. O. apricus).

\section{5 - Capítulos.}

Los capítulos son numerosos, desde unos 30 a 50 (ej. O. bipinnatifidus), hasta más de 300 (ej. O. macrodon). Respecto al pedúnculo son subsésiles a pedunculados $(0,1-3 \mathrm{~mm})$, pubescentes. La cantidad de flores es reducida, variando de (3)-4 en O. peruvianus hasta 10-(12) en O. macrodon. Los capítulos son discoideos, homógamos, con todas las flores hermafroditas. 


\section{6 - Involucro.}

El involucro en Ophryosporus es acampanado (ej. O. angustifolius) aunque también presenta involucros cilíndricos (ej. O. apricus) (Fig. 2 G 1-2). El número de filarios varía entre 4 y 8 .

\section{7 - Filarios.}

Los filarios son generalmente herbáceos, aunque pueden presentar una consistencia subcoriácea. Se disponen de manera eximbricada (ej. O. triangularis) a levemente subimbricada (ej. O. hartwegii), en una o dos series. Los filarios en dos series pueden ser isomórficos o dimórficos. Si son dimórficos, los externos son ovados, con ápices agudos a obtusos y los internos son ovado-lanceolados, con ápices generalmente agudos. Los ápices de los filarios suelen ser fuertemente fimbriados (ej. O. macrodon), aunque también se presentan casi enteros (ej. $O$. bipinnatifidus). En ciertas ocasiones, presentan algunas bandas de naturaleza esclerenquimática entre las venas (esteroma) (Fig. 2 H 1-2).

En general, son pardos o verdes, pero en algunos casos pueden tener tintes violáceos en su base, cuando inmaduros (O. heptanthus y $O$. triangularis).

Los filarios pueden ser glabros (ej. O. hartwegii), pubescentes o glandulosos. Los tricomas observados pueden ser tanto eglandulares como glandulares. Los tricomas glandulares pueden disponerse por todo el cuerpo del filario (ej. $O$. pinifolius) o sólo en los bordes (ej. O galioides). En cambio los tricomas eglandulares, varían la densidad de su disposición, ya sea laxa (ej. O. burkartii) o densa (ej. O. triangularis) (Fig. $5 \mathrm{H}$-L). Los tricomas se presentan en la cara externa.

\section{8 - Receptáculo.}

El receptáculo en Ophryosporus es siempre desnudo, liso, glabro y macizo. Pudiendo variar su forma desde plano a ligeramente convexo. 


\section{9 - Flores.}

Las flores presentes en Ophryosporus son hermafroditas.

\section{a. Corola}

Las corolas son infundibuliformes, con paso gradual entre tubo y limbo (ej. $O$. angustifolius) o con paso abrupto entre limbo y tubo (ej. O. axilliflorus) o tubulares, (ej. O. heptanthus) (Fig. 2 I1-3). Son pentalobadas, con lóbulos de forma triangular $(0,3-0,5 \times 0,2-1,5 \mathrm{~mm})$. Suelen presentar papilas cortas tanto en la cara externa como en la interna de los lóbulos (Fig. 6 D-F).

Las corolas son blancas, blanquecinas, verdosas o amarillentas.

Las corolas puede ser pubescentes y/o glandulosas. Los tricomas de la corola son comúnmente glandulares, Fig. 6 A-C (ej. O. heptanthus), o más raramente eglandular (ej. O. charua) o presentar ambos tipos (ej. O. Iorentzii). Los tricomas se observaron en los lóbulos de la corola (ej. O. floribundus), en toda la extensión de la corola (ej. O. sodiroi) o hacia la base del tubo (ej. O. regnellii).

\section{b. Androceo}

Los estambres son siempre cinco. Las anteras son lineares, de base generalmente redondeada u obtusa, Fig. $2 \mathrm{~K} 2$ y 4 (ej. 0 . macrodon), a veces ligeramente auriculada, Fig. 2K 1 y 3; $6 \mathrm{G}$ (ej. O. pinifolius). El apéndice conectival generalmente es nulo, Fig. $2 \mathrm{~J} 1 ; 6 \mathrm{H}-\mathrm{I}$ (ej. O. pinifolius), a veces rudimentario, conformado por unas pocas células y con un surco medial, Fig. $2 \mathrm{~J} 2,6 \mathrm{~J}-\mathrm{K}$ (ej. $O$. heptanthus) o bien sin surco medial Fig $2 \mathrm{~J} 3$ (ej. O. bipinnatifidus). El collar anteral se encuentra bien desarrollado, es generalmente cilíndrico, Fig. $2 \mathrm{~K} 1$ y 2 (ej. $O$. angustifolius), aunque puede estar levemente ensanchado en su base (ej. O.bipinnatifidus) y a menudo posee engrosamientos en las paredes tangenciales de sus células (Fig $2 \mathrm{~K} 3$ y $4,6 \mathrm{G}$ )). 


\section{c. Estilo}

El estilo es bífido, las ramas estigmáticas son largamente exertas (al menos $1 / 3$ del largo total de la corola), clavadas en el ápice (Fig. 2 L; 7 A-B). Los ápices presentan, en algunos casos, una coloración más intensa que el resto de la rama estigmática. La superficie externa de las ramas estigmáticas es papilosa, excepto en la zona receptiva donde es casi glabra. La superficie interna de las ramas estigmáticas es también papilosa, excepto a la altura de la zona receptiva donde las papilas se modifican y forman dos bandas paralelas; la zona interna comprendida entre estas bandas es glabra y lisa. Las especies de Ophryosporus no presentan engrosamientos notables ni tricomas en la base del estilo.

El estilopodio se encuentra representado por un nectario anular.

\section{0 - Cipsela.}

Las cipselas son negras, por la presencia de fitomelanina, piriformes, rectas 0 ligeramente falcadas, 5-costadas, con costillas muy notables. Pueden llegar a ser estipitadas (ej. O. angustifolius).

Presentan un carpopodio conspicuo, más o menos simétrico, de forma anular (ej. O. axilliflorus) o cilíndrica (ej. O. bipinnatifidus). Las células del carpopodio generalmente son subcuadradas y levemente engrosadas, pudiendo ser las mismas iso o heteromorfas. El carpopodio puede ser central respecto de la cipsela (ej. O. charua) o levemente excéntrico (ej. O. angustifolius). La ubicación excéntrica del carpopodio, respecto del eje mayor de la cipsela, se debe a la presencia de un giro, denominado "twist" por King \& Robinson (1987) (Fig 2 M-N).

Las cipselas son seríceas y/o glandulosas, ya sea en la base cerca del carpopodio (ej. O. heptanthus), en las costillas (ej. O. burkartii), cerca de la inserción del papus, (O. hoppii) o en toda su superficie, (ej. O. cumingii); en algunos casos, son totalmente glabras (ej. O. galioides). Los tricomas pueden ser pelos gemelos o glandulares vesiculares biseriados tipo $\alpha$. Las cipselas pueden tener ambos tipos (ej. O. johnstonii) o eglandulares (ej. O. hoppii) o solamente 
glandulares (ej. O. heptanthus) Fig $7 \mathrm{C}$-E. Además, las cipselas pueden presentar esculturas mamelonadas en su pared Fig. $8 \mathrm{~K}$ (ej. O. angustifolius) o más raramente ser lisa (O. apricus).

- Pelo gemelo típico, Zwillingshaare (Hess, 1938): Está formado por 4 células, dos basales y dos células del pelo. Éstas últimas son más o menos cilíndricas, de extremos agudos y con paredes gruesas. Pueden presentar variaciones en relación a la longitud de las células del pelo (simétricamente iguales o una de las células notablemente más larga que la otra) y en relación a la unión celular (totalmente concrescentes, separarse en los extremos o divergir desde la base). Fig. 8 F-J.

\section{Papus.}

El papus en Ophryosporus es tanto presente como ausente Fig $2 \mathrm{O} 1$ (ej. O. galioides). Cuando presente (Fig 202 y 3), se dispone en una sola serie, siempre connada en la base (Fig. 7 F-G). Está conformado por cerdas (ej. O. triangularis) 0 por escamas (ej. O. hoppii.). Las cerdas están en número de 4 a 40 , blanquecinas a amarillentas, capilares o subplumosas, con longitudes entre 0,75 a 3,2 $\mathrm{mm}$ y con células apicales agudas (Fig $2 \mathrm{P}$ ).

En el caso de $O$. sagasteguii si bien está conformado por cerdas, estas se presentan en número de 3-5-(14), llegando en algunos casos, a estar ausente.

Las escamas están en número de 3 a 6, pardas, laciniadas (Fig. 7 G).

La variación del papus de las especies de Ophryosporus es muy particular, ya sea por el papus ausente o por la variación de los elementos que lo conforman. 

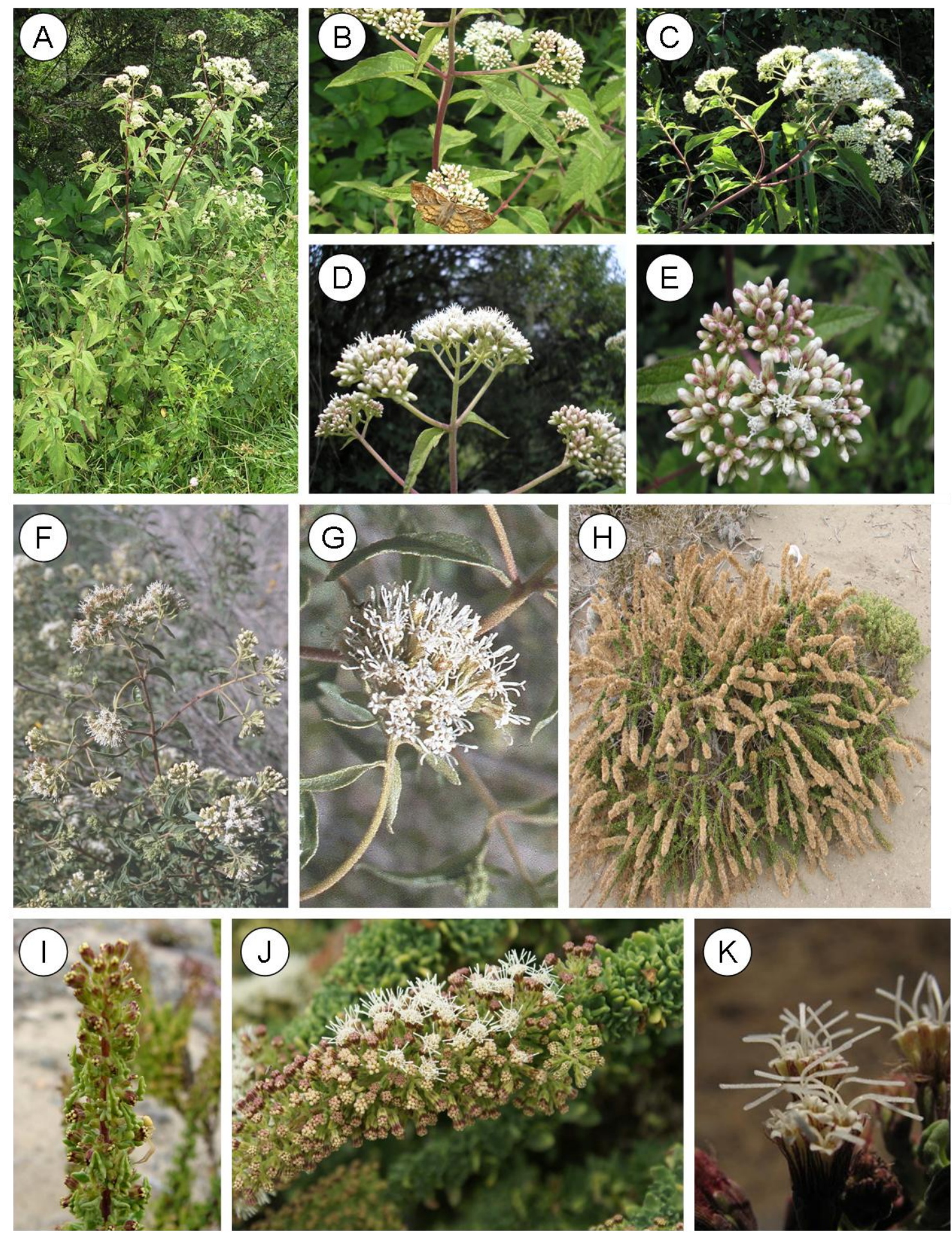

Figura 1. A-E: O. macrodon. F-G: O. heptanthus. H-K: O. triangularis. A, F, H. aspecto general. B-E, G, detalle de inflorescencias cimoideas. I-J, detalle de inflorescencias tirsoideas. $K$, detalle de capítulos, con ramas del estilo largamente exertas. (Las fotos A-E fueron tomadas por la autora, las fotos F-K fueron obtenidas de internet) 

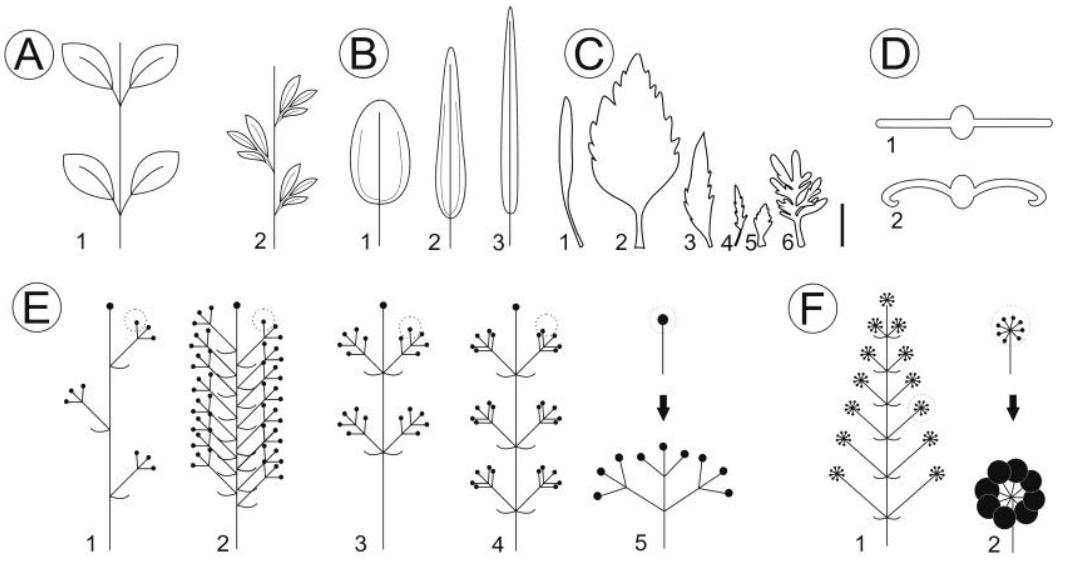

(G)

\section{(H)}
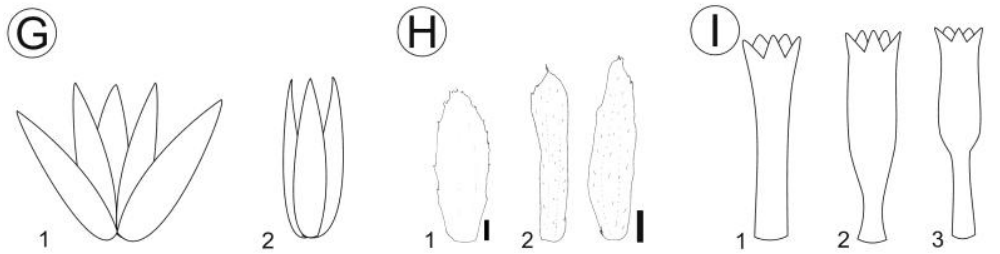

(J)

K
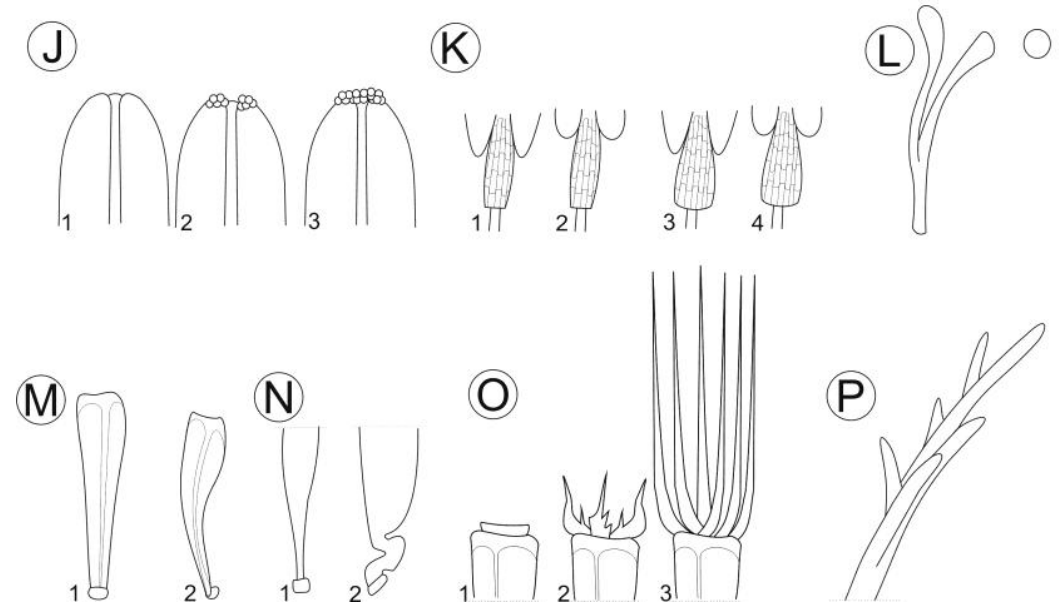

Figura 2. Generalidades de Ophryosporus. A. Filotaxis, 1 hojas opuestas, 2 hojas alternas fasciculadas. B. Forma de la lámina, 1 ovada, 2 ovada-lanceolar, 3 linear. C. Hojas, formas de márgenes y tamaños de pecíolos (escala: $1 \mathrm{~cm}$ ). D. Margen de las hojas, 1 plano, 2 revoluto. E. Inflorescencias, 1 tirsoidea laxa, 2 tirsoidea densa, 3 cimoide laxa, 4 cimoide densa, 5 detalle de inflorescencia parcial. F. Inflorescencia cimoidea formada de glomérulos, 1 aspecto, 2 detalle de inflorescencia parcial. G. Involucro, 1 acampanado, 2 cilíndrico. H. Filarios, 1 ovados, 2 lanceolados. I. Corolas, 1 tubulosa, 2 infundibuliforme con paso gradual entre tubo y limbo, 3 infundibuliforme con paso abrupto entre tubo y limbo. J. Apéndices anterales, 1 ausente, 2 rudimentario con surco medial, 3 rudimentario entero. $\mathbf{K}$. Base de las anteras, 1 base de las tecas auriculadas y collar anteral cilíndrico, 2 base de las tecas obtusas y collar anteral cilíndrico, 3 base de las tecas auriculadas y collar anteral cilíndrico ensanchado hacia la base, 4 base de las tecas auriculadas y collar anteral cilíndrico ensanchado hacia la base. L. Estilo con ramas clavadas. M. Cipsela, 1 piriforme recta, 2 piriforme falcada. N. Modificaciones en la base de la cipsela, 1 estipitada, 2 con carpopodio excéntrico (twist). O. Papus, 1 ausente, 2 presente, de escamas, 3 presente de cerdas. P. Detalle de células apicales de las cerdas del papus. 

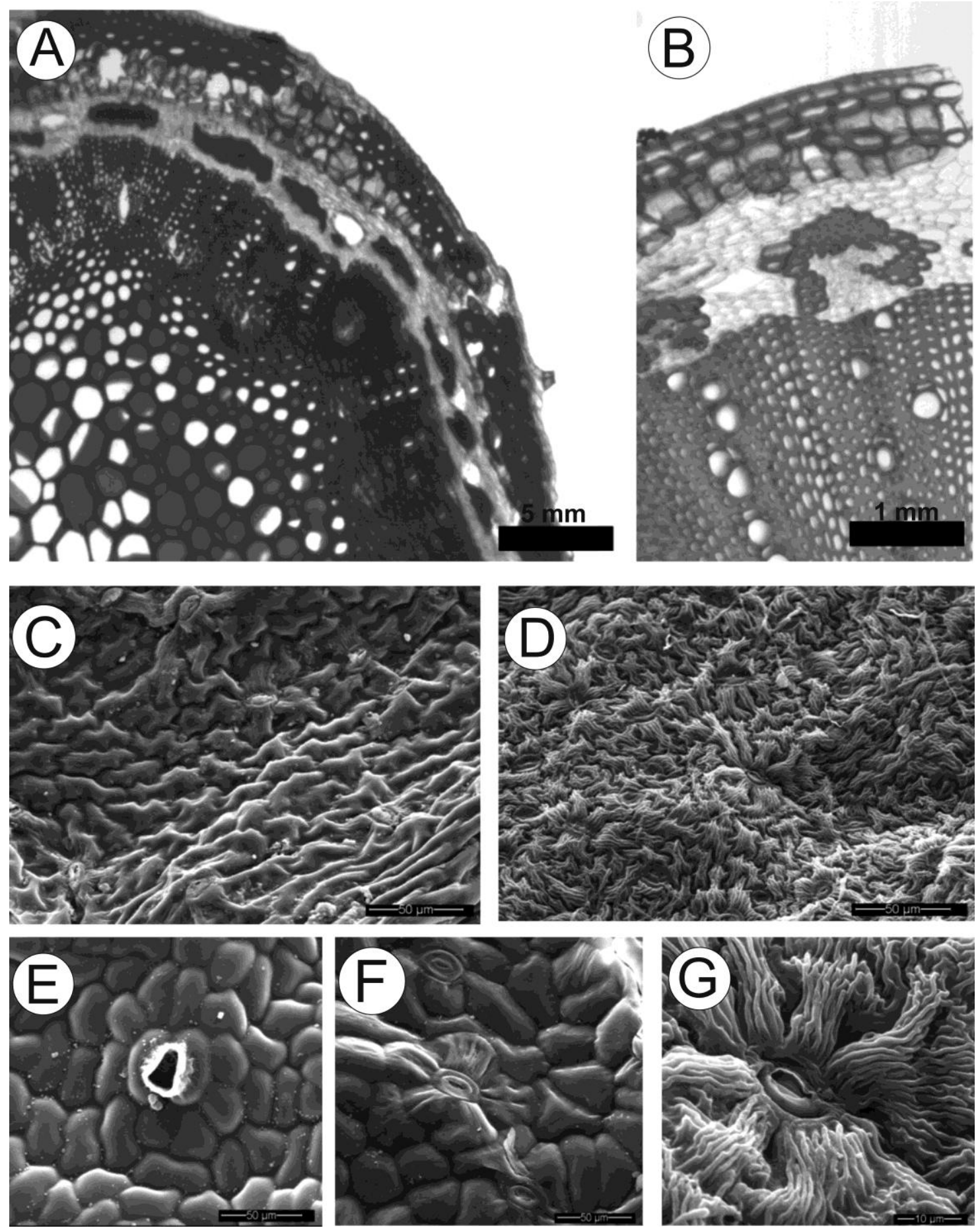

Figura 3. A-B Tallo, CT (O. piquerioides). C-D Vistas de epidermis. C epidermis lisa ( $O$. hartwegii), D epidermis con estrías (O. peruvianus) E-G Estomas. E. estoma con reborde (O. freyreissi), $\mathrm{F}$ estoma con pocas estrías ( $O$. hoppii), G estoma con abundantes estrías (O. peruvianus). 

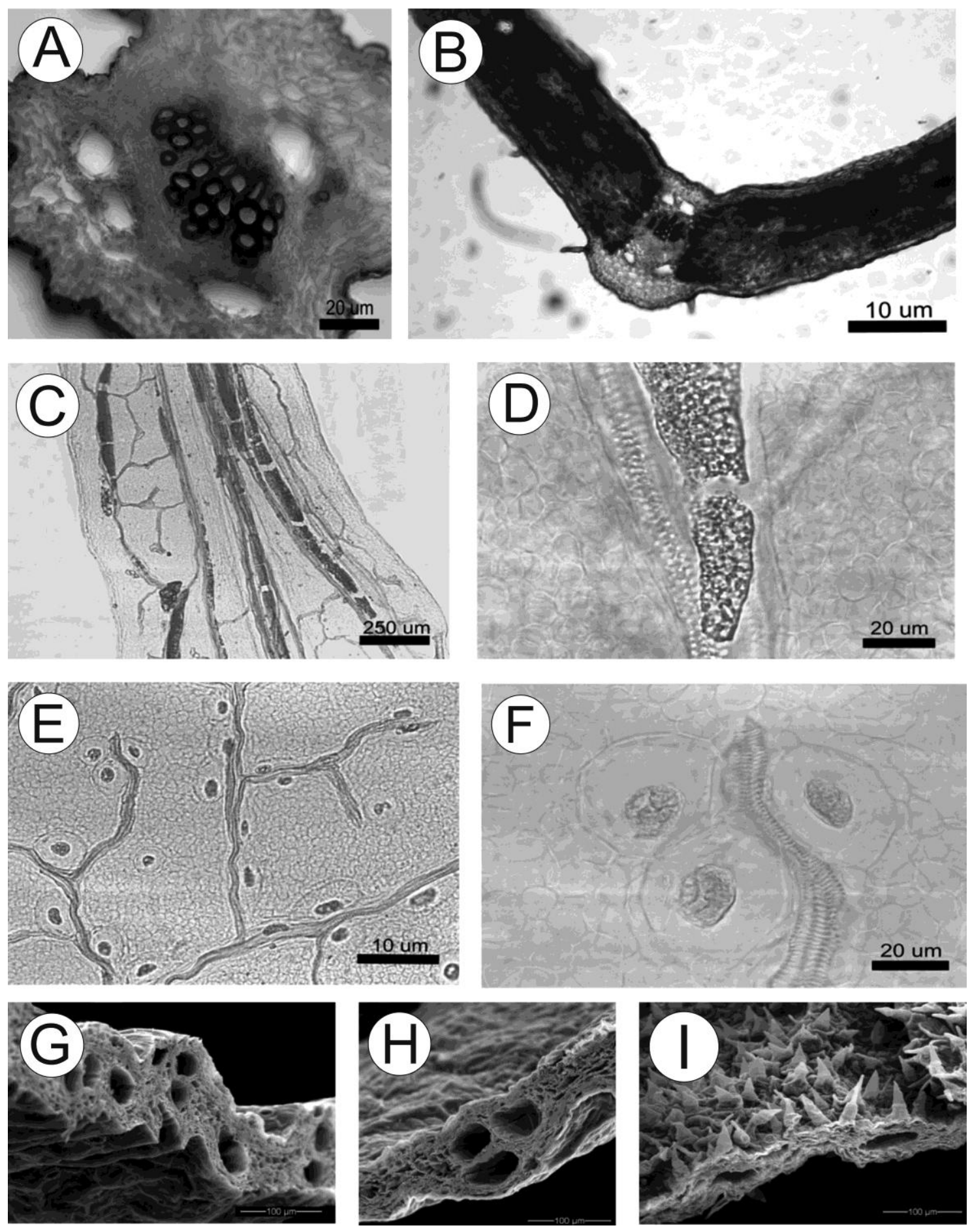

Figura 4. A-B Hojas, CT (O. cumingii), A detalle de vena media, B, canales apareados. CF Vistas paradermales, C-D ductos (O. peruvianus), E-F cavidades ( $O$. steinbachii). G-I Hojas, CT, G-H canales agrupados (O. angustifolius), I, canales aislados ( $O$. triangularis). 

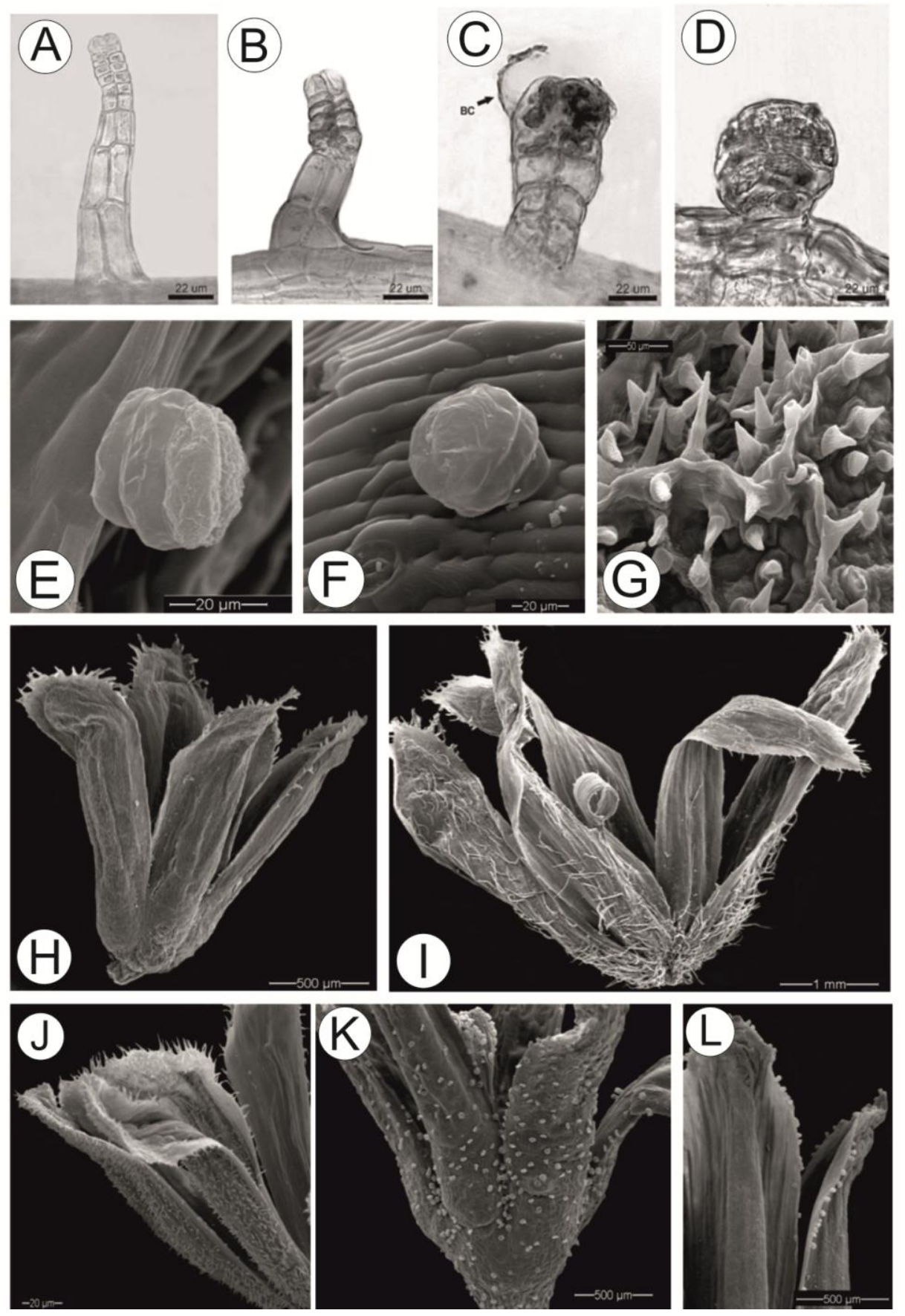

Figura 5. A-G Tricomas, A-B tricomas glandulares tipo $\beta$ (A. O. venosissimus, B. 0 . steinbachii) C-F tricomas glandulares tipo a (C. O. apricus, D-E O. pinifolius, F. $O$. galiodes) $\mathrm{G}$ tricoma eglandular simple cónico ( $O$. triangularis). $\mathbf{H}-\mathbf{L}$ Involucros, $\mathrm{H}$ glabro (O. hartwegii), I pubescente, tricomas eglandulares laxos ( $O$. burkartii), J pubescente, tricomas eglandulares densos ( $O$. triangularis), $\mathrm{K}$ glanduloso, tricomas glandulares en todo el cuerpo ( $O$. pinifolius), L glanduloso, tricomas glandulares en los bordes $(O$. galioides). 

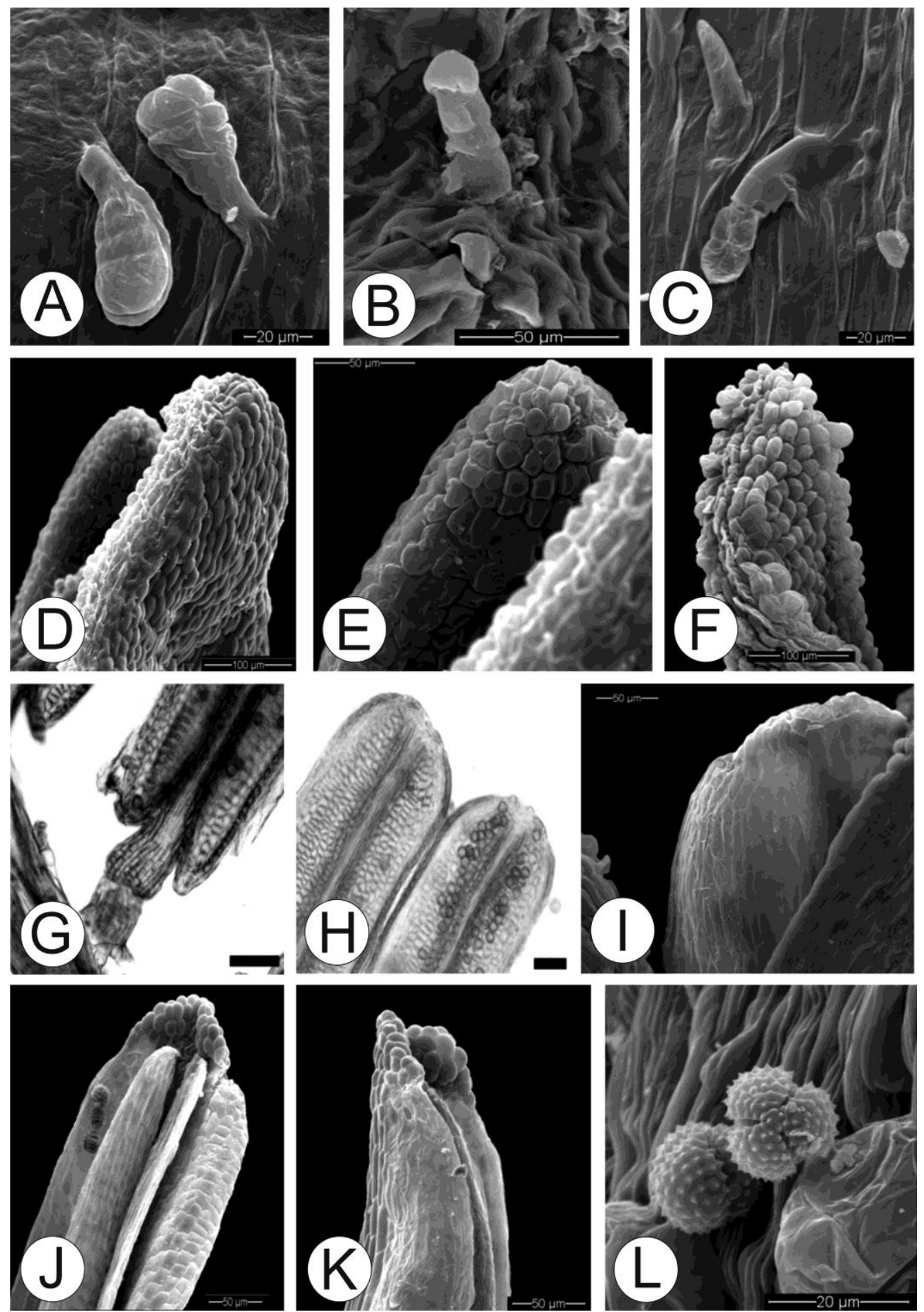

Figura 6. A-C Tricomas glandulares de corolas, A tipo $\beta$ (O. heptanthus), B-C tipo a (O. carchiensis). D-F Lóbulos de la corola (D-E O. chilca, F O. johnstonii). G-K Anteras, G detalle de base de las tecas auriculadas y collar anteral cilíndrico ensanchado hacia la base ( $O$. bipinnatifidus), $\mathrm{H}-\mathrm{I}$ detalle apéndice anteral nulo $(\mathrm{H}$ O. bipinnatifidus, $O$. pinifolius), J-K detalle apéndice anteral rudimentario con surco medial ( $O$. heptanthus). $\mathbf{L}$ Polen, vista polar y ecuatorial (O. chilca). 

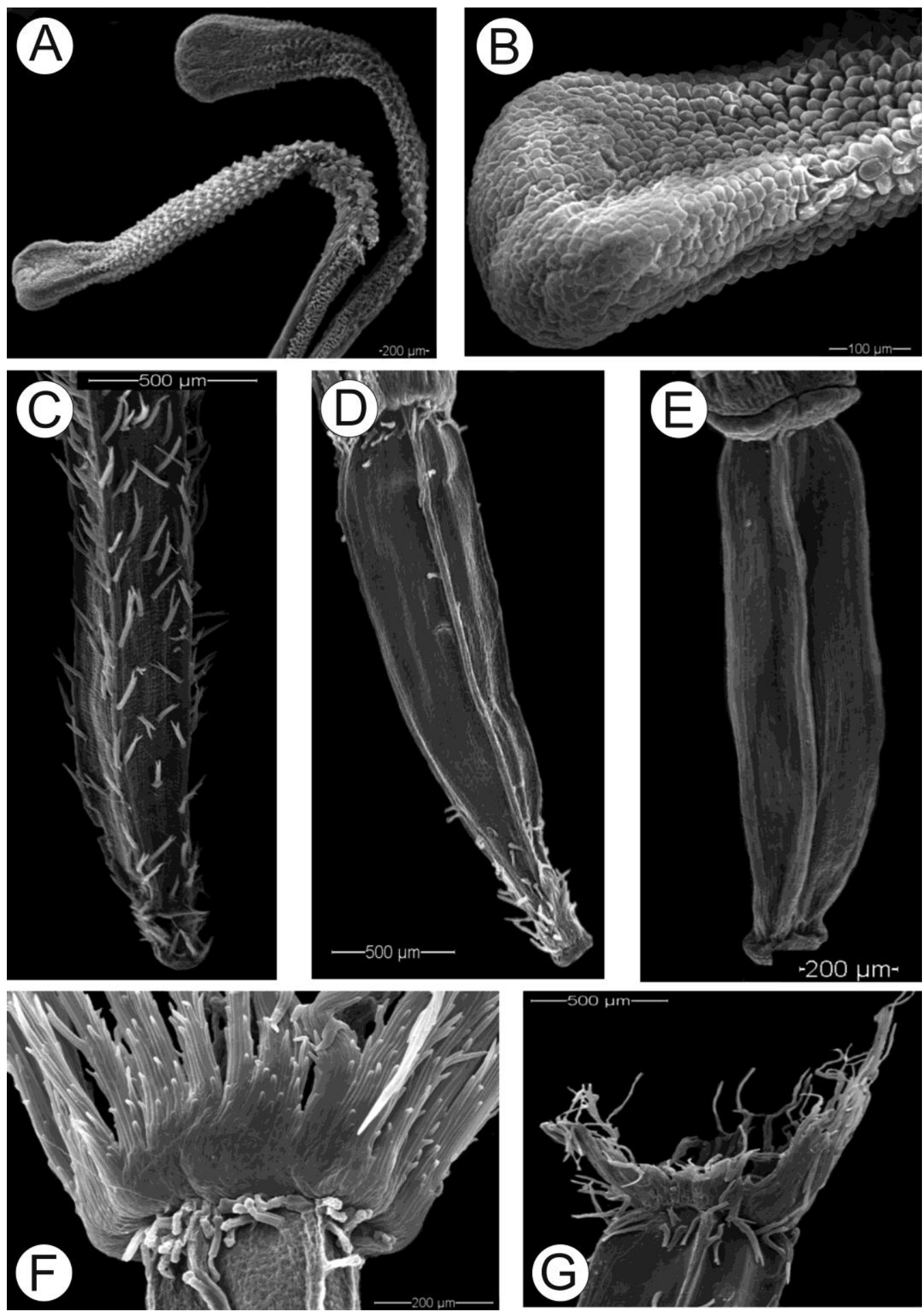

Figura 7. A-B Estilo, A aspecto general del estilo (O. hoppii), B detalle del ápice clavado de la rama del estilo. C-E Cipselas, $C$ serícea $(O$. angustifolius), D serícea y glandulosa (O. apricus), E glabra (O. galioides). F-G Papus, $\mathrm{F}$ detalle de cerdas connadas ( $O$. apricus), $\mathrm{G}$ detalle de escamas connadas ( $O$. hoppii). 

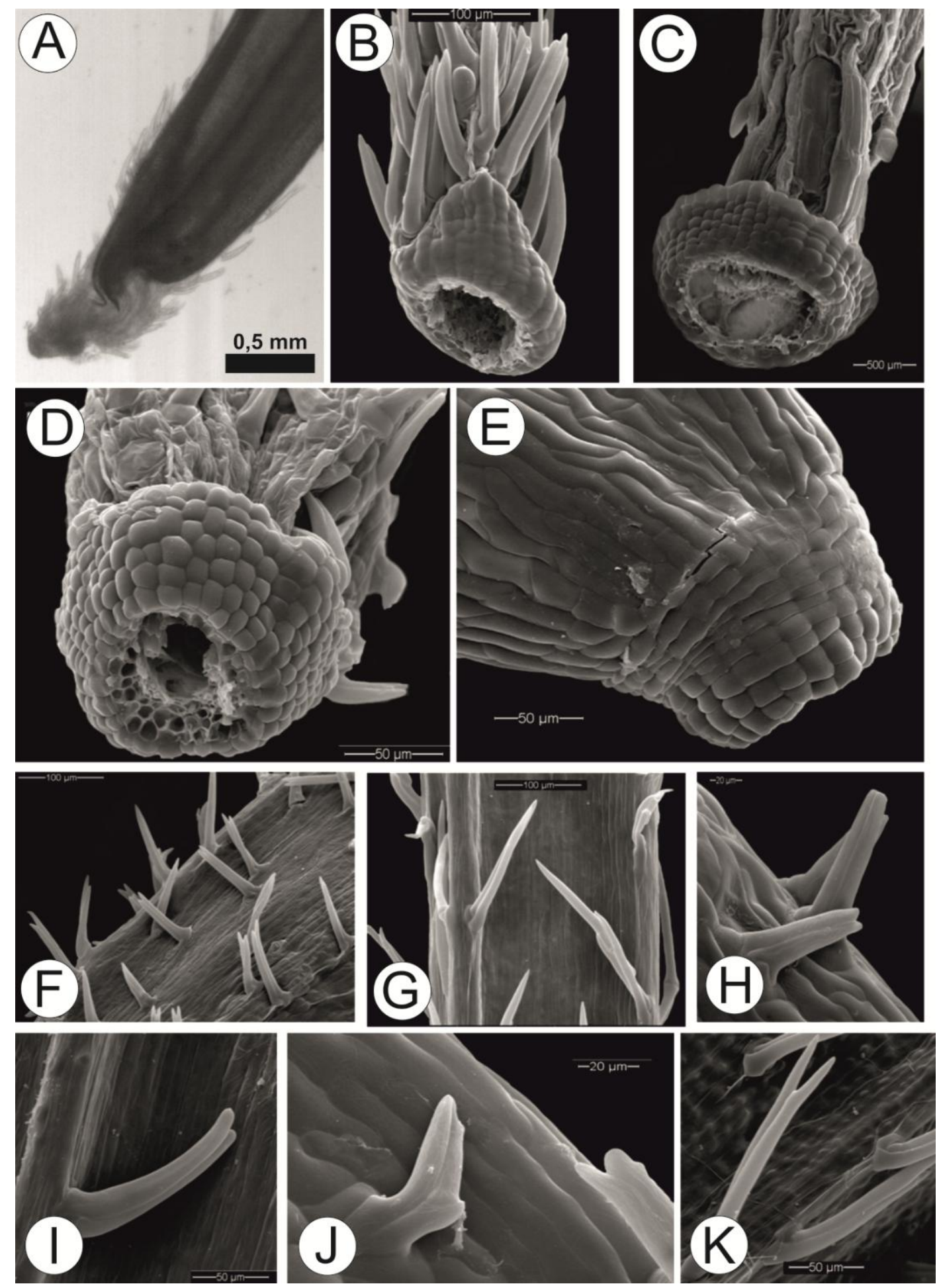

Figura 8. A-E Carpopodios, A detalle de carpopodio excéntrico ( $O$. angustifolius), B-C carpopodio anular (B O. chilca, C O. floribundus), D-E vista frontal y lateral del carpopodio (O. bipinnatifidus). F-I Pelos gemelos (F O. bipinnatidus, G O. chilca, $\mathrm{H}$ y J O. pinifolius, I O. hoppii). K Detalle de la pared de la cipsela (O. angustifolius). 


\section{V- TEJIDOS SECRETORES Y COMPUESTOS QUÍMICOS}

La mayoría de los compuestos químicos naturales más importantes han sido utilizados por el hombre a través de los tiempos y son generados por los tejidos secretores de las plantas vasculares. Estos tejidos difieren en estructura, posición topográfica y material secretado. La secreción es usualmente eliminada de las células secretoras hacia el exterior de la planta o dentro de espacios intercelulares especializados. Los tejidos secretores pueden estar conformados por una única célula o por grupos de células, sean éstas, grandes o pequeñas. Los tejidos que secretan sustancias lipofílicas pueden presentarse en la superficie exterior de la planta, mayormente en la forma de tricomas glandulares, como en su interior. En el último caso, se encuentran representados por una única célula o por una línea de células especializadas o por estructuras compuestas de un epitelio que tapiza un espacio intercelular. $\mathrm{Si}$ esta última estructura es aproximadamente isodiamétrica, se la denomina "cavidad secretora"; en cambio, si es elongada, se la considera "ducto secretor" (Fahn, 1988).

En Asteraceae, las estructuras secretoras generalmente se presentan en raíces, rizomas y partes aéreas (Thouvenin, 1884; Col, 1903; Tetley, 1925; Metcalfe \& Chalk, 1950; Curtis \& Lersten, 1986; Jeffrey, 2007; Göpfert et al., 2009). En efecto, las estructuras secretoras descriptas para Asteraceae son cavidades, ductos y tricomas glandulares (Col, 1903; Tetley, 1925; Metcalfe \& Chalk, 1950; Ramayya, 1962; Fahn, 1988; Lersten \& Curtis, 1988; Simon et al., 2002; Milan et al., 2006; Andreucci et al., 2008).

En la tribu Eupatorieae, como en el resto de las tribus pertenecientes a la familia Asteraceae, los compuestos químicos son principalmente secretados por los tricomas glandulares ubicados en las hojas (Taleb-Contini et al. 2007) y por cavidades y ductos secretores ubicados en el mesófilo. Estas estructuras de algunas eupatoreas como Bahianthus R. M. King \& H. Rob. fueron descriptas como "bolsillos resiníferos" (King et al. 1979), "puntos pelúcidos" en Critonia (King \& Robinson 1971), "cavidades secretoras" en Liatris L. (Metcalfe \& Chalk 1950), y "cavidades bicelulares" y "cavidades tubulares" en Eupatorium (Curtis \& Lersten 
1986, Lersten \& Curtis 1986). Muchas de estas cavidades presentan un origen esquizógeno típico y se encuentran recubiertas por un epitelio (Curtis \& Lersten 1986, Lersten \& Curtis 1986, Ragonese 1988, Simon et al. 2002, Milan et al. 2006).

En Ophryosporus fueron halladas dos tipos de estructuras secretoras: tricomas glandulares, subtipo $\alpha$ y $\beta$ (Fig. 5 A-F) y reservorios secretores del tipo ducto y cavidad (Fig. 4). Los tricomas hallados son frecuentes en Asteraceae (Ramayya, 1962; Lersten \& Curtis 1988; Andreucci et al., 2008) y han sido indicados como sitios de producción primaria de muchos metabolitos secundarios bioactivos (Duke, 1994; Rossi Monteiro et al., 2001; Göpfert et al., 2009). Los reservorios hallados en Ophryosporus son similares en forma, posición y anatomía a otros hallados en Asteraceae (Metcalfe \& Chalk, 1950; Fahn, 1988), aunque las cavidades esferoidales presentes en $O$. steinbachii son poco comunes para la familia (Curtis \& Lersten, 1986).

Los tricomas glandulares han sido indicados como sitios de producción primaria de muchos metabolitos secundarios bioactivos (Duke, 1994; Rossi Monteiro et al., 2001; Göpfert et al., 2009). Sólo la mitad de las especies estudiadas de Ophryosporus tienen tricomas glandulares, aunque todas tienen reservorios secretores. Algunas especies que carecen de tricomas glandulares tienen un gran desarrollo de los reservorios secretores (ej. O. axilliflorus, O. freyreissi, 0. regnellii).

Ha sido postulado que los tricomas glandulares y reservorios tienen diferentes roles ecológicos, como protección frente a insectos y otros patógenos, atracción de polinizadores, efectos alelopáticos y protección frente a condiciones ambientales extremas (Langenheim, 1994). En algunas Asteraceae, los tricomas glandulares han sido indicados como contenedores de poderosas fitotoxinas, las cuales se alojan en el espacio subcuticular del tricoma, para evitar la autotoxicidad (Göpfert et al., 2009). De esta manera, los tricomas glandulares representan un repositorio de sustancias insecticidas y antimicrobianas (Duke, 1994). Las lactonas sesquiterpénicas, como las halladas en Ophryosporus, usualmente se acumulan 
en los tricomas glandulares de las hojas y están relacionadas con la defensa contra hervíboros (Wagner, 1991; Duke, 1994; Werker, 2000). En Ophryosporus, los tricomas glandulares se presentan mayormente en las venas, en este caso, los reservorios secretores son las estructuras encargadas de la defensa contra herbívoros (Dussourd \& Denno, 1991).

La actividad medicinal es atribuida a los metabolitos secundarios (Combrick et al., 2007). En once especies de Ophryopsorus se han aislado una serie de compuestos (Fig. 9), con actividad medicinal, asociados a lactonas sesquiterpénicas como mono y sesquiterpenos (Zdero et al. 1990, Sigstad et al. 1996), diterpenos (Bohlman et al. 1984, Ferracini et al. 1989, Zdero et al. 1990, Favier et al. 1997), benzofuranos y dihidrobenzofuranos (Bolhman \& Zdero 1979, Ferracini et al. 1989, Zdero et al. 1990, Sigstad et al. 1992, Sigstad et al. 1993, Sigstad et al. 1996, De Lampasona et al. 1997, Favier et al. 1998), cumarinas, cromenos y compuestos aromáticos (Bohlman \& Zdero 1979, Bohlman et al. 1984, Ferracini et al. 1989, Zdero et al. 1990, Sigstad et al. 1992, Sigstad et al. 1993, Sigstad et al. 1996, De Lampasona et al. 1997, Favier et al. 1998) y flavonas, flavononas y sus glicósidos (Ferracini et al. 1989, Zdero et al. 1990, Favier et al. 1997). Las variedades de terpenos citados anteriormente, cuando se hallan en conjunto reciben la denominación de "aceites esenciales" (Langenheim 1994) y pueden ser secretados por una gran variedad de estructuras anatómicas especializadas (células epidérmicas, tricomas, ductos, etc.).

Ciertas especies de Ophryosporus presentan múltiples usos medicinales, como analgésico, antisifilítico (De Lampasona et al. 1997, Barboza et al. 2006), actividad antiinflamatoria (Favier et al. 1998), actividad antiprotozoica, expectorante, alivio de migrañas (Fournet et al. 1994), alivio de golpes, antiséptico y actividades antimicrobianas (Rojas et al. 2003), entre otras.

La fuente primaria de metabolitos secundarios potencialmente medicinales en Ophryosporus serían los reservorios secretores presentes en las hojas. Como se observa en la tabla 1, la cantidad y desarrollo de los reservorios es variable. La variación en el desarrollo puede ser atribuída a presiones de stress como 
condiciones ambientales extremas (Harborne, 1994) o herviboría (Dussourd \& Denno, 1991). Las especies con un buen desarrollo del sistema de reservorios secretores, como $O$. freyreissi, $O$. laxiflorus, $O$. organensis, $O$. regnellii, $O$. steinbachii y $O$. venosissimus pueden representar una potencial fuente de metabolitos secundarios con aplicación medicinal. 


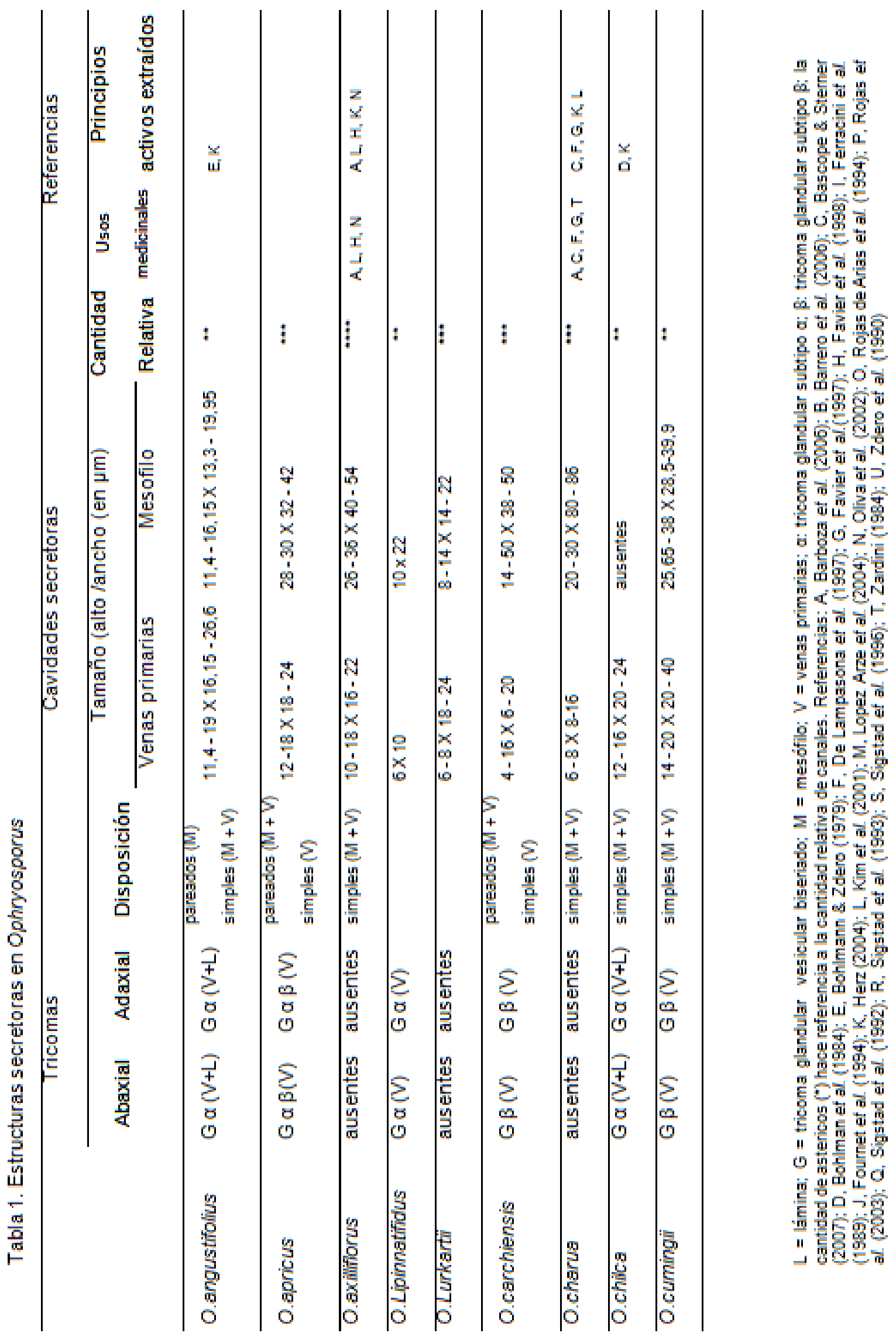




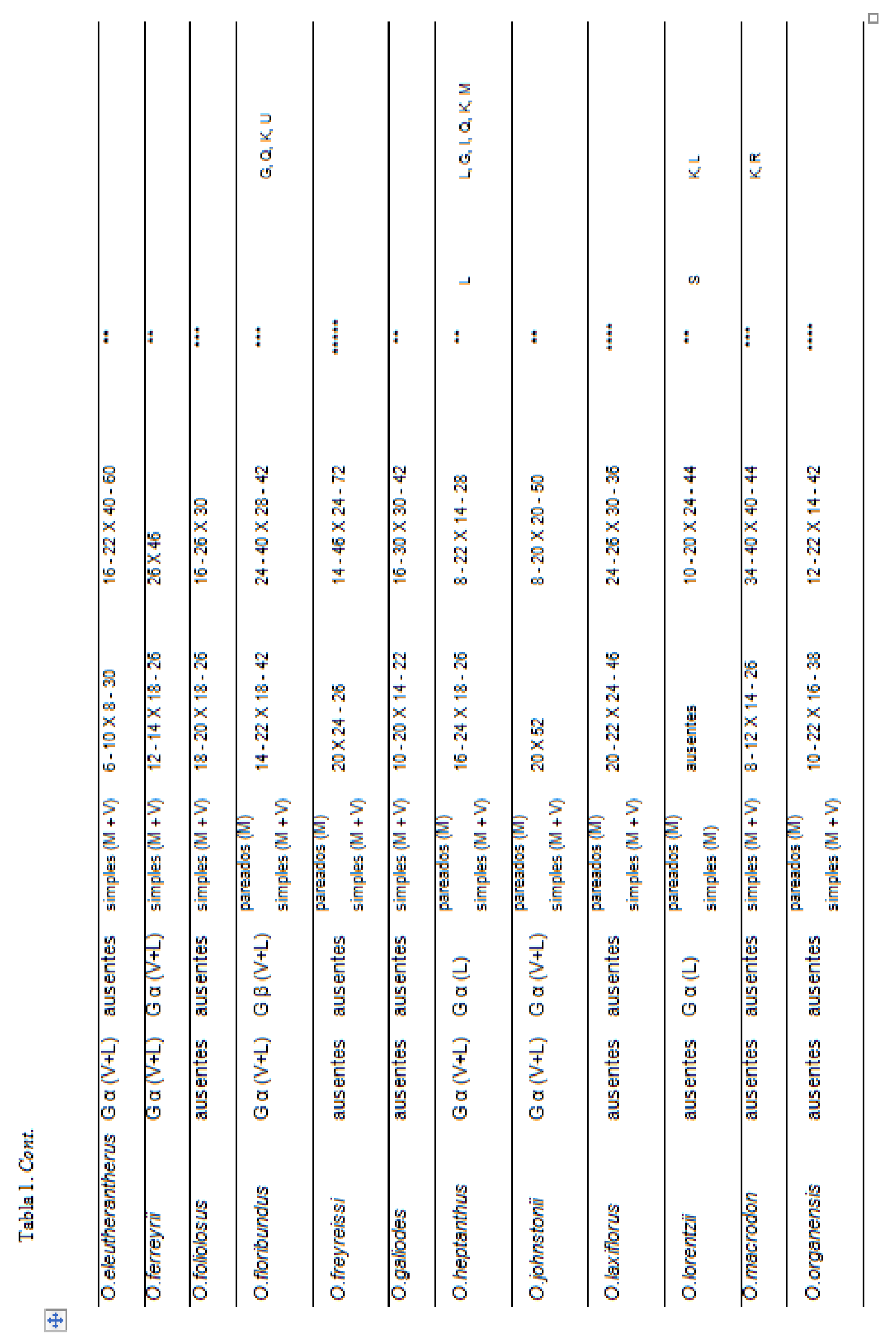




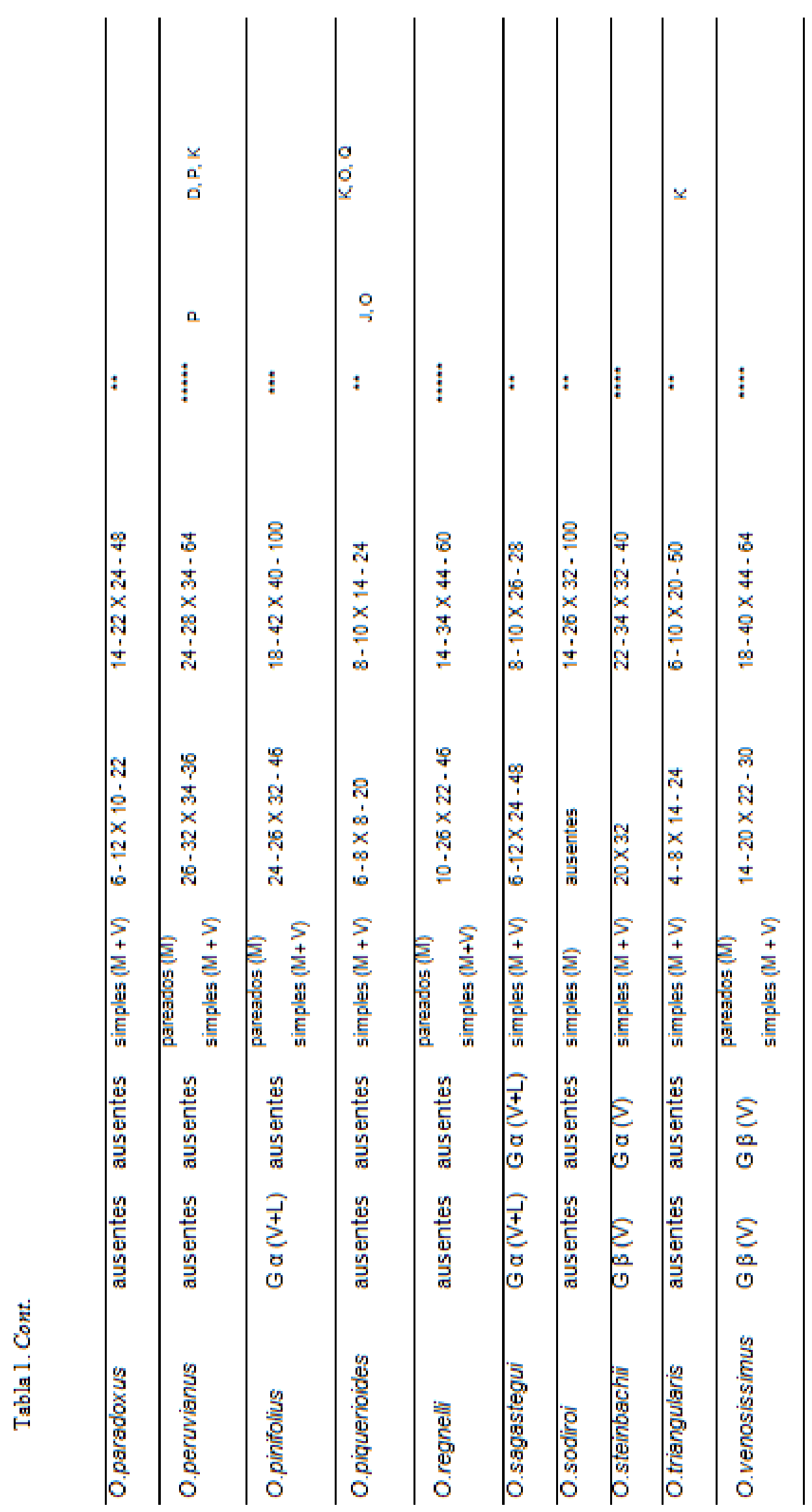




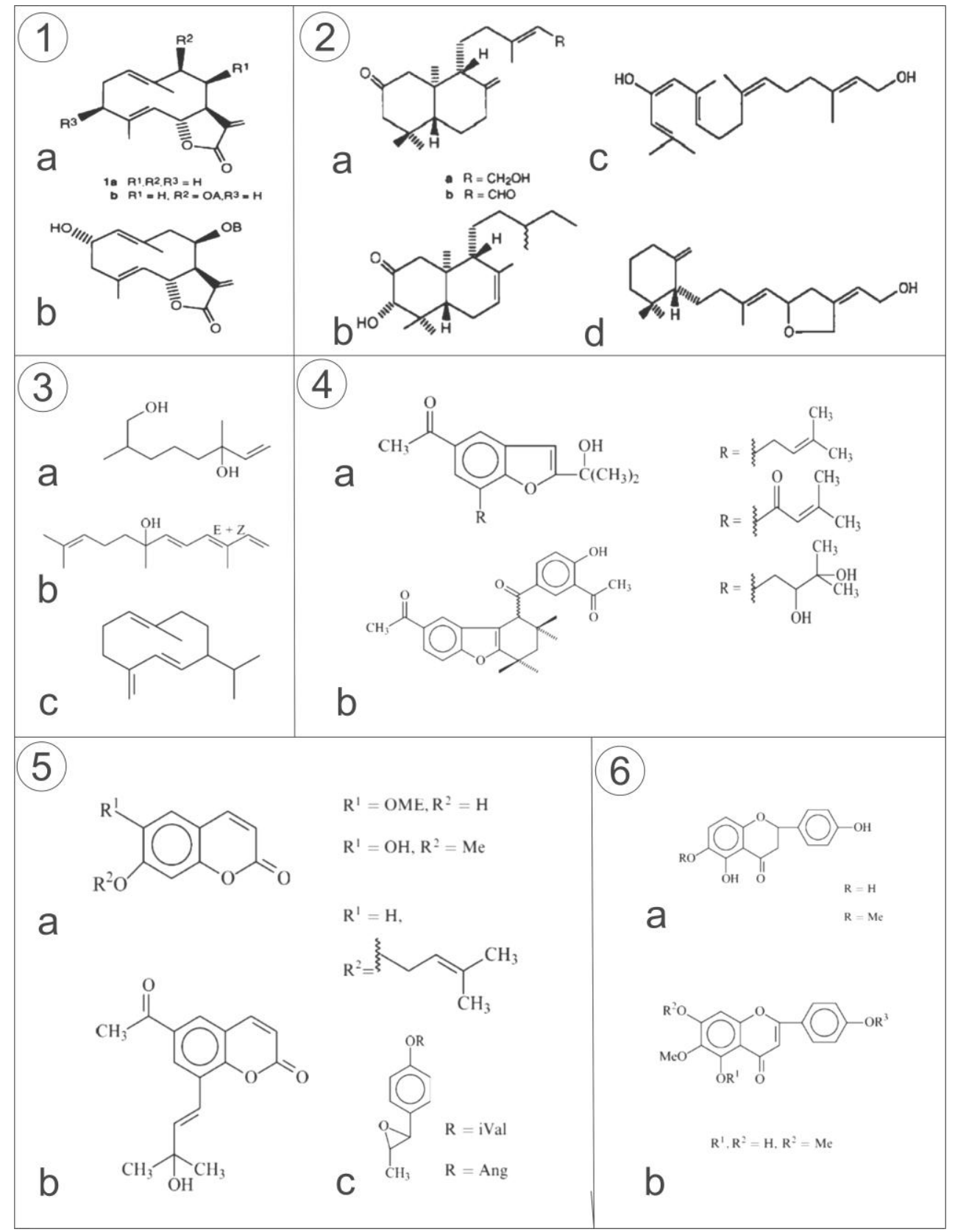

Figura 9. Algunos compuestos químicos hallados en Ophryosporus (tomados de Herz, 2004). 1. Lactonas sesquiterpénicas. 1a. O. floribundus, 1b. $O$. lorentzii. 2. Mono y sesquiterpenos. 2a. Nerodiol, O. floribundus y O. lorentzii. 2b. Germacreno D, O. floribundus. 3. Diterpenos. 3a. O. heptanthus. 3b. $O$. chilca y 0 . floribundus. 3c. O. charua. 3d. O. floribundus. 4. Benzofuranos y dihidrobenzofuranos. 4a. O. macrodon. 4b. O. charua. 5. Cumarinas, cromenos y compuestos aromáticos. 5a. 0 . angustifolius, 0 . lorentzii y 0 . piquerioides. $\mathbf{5 b}$. O. Iorentzii. 5c. O chilca. 6. Flavonas, flavonoles y flavononas. 6 a. 0. triangularis. 6b. O. charua. 


\section{VI- NÚMERO CROMOSÓMICO}

La tribu Eupatorieae presenta un amplio rango en números cromosómicos, incluyendo $n=4,8,10,11,12,15,17,18,20,25$ y sus múltiplos (King et al., 1976); aunque se reconoce como número básico predominante a $n=10$ y $n=17$ (King et al., 1976; Watanabe et al. 1995; Ito et al., 2000b).

El número cromosómico determinado para la subtribu Critoniinae es $n=10$ (King, et al., 1976; King \& Robinson, 1987; Watanabe et al., 1995; Robinson et al., 2009).

De las 41 especies pertenecientes al género Ophryosporus, se han registrado conteos de números cromosómicos para $O$. lorentzii $(n=9)$, siendo éste el primer registro para el género (Turner et al., 1979). En 1981, fue determinado $O$. heptanthus ( $n=10) \quad$ (Fernández Casas \& Fernández Piquerias, 1981). Posteriormente, fueron determinados los números de $O$. angustifolius $(n=10), O$. chilca $(n=10)$ y $O$. heptanthus $(n=20)$ (Robinson et al., 1989). Finalmente, en 1996, fue determinado el número cromosómico de O. macrodon. ( $n=10$ II) (Wullf et al. 1996). Al ampliarse el concepto de Ophryosporus por la inclusión de una sección perteneciente a Piqueria (Artemisioides), no hubo cambios a nivel cromosómico, ya que las especies sudamericanas pertenecientes a dicha sección presentan $n=10$ (a diferencia de otros miembros del género Piqueria que poseen $n=12,24$ y 25, King et al., 1976). El número $n=10$ parece ser el dominante en Ophryosporus, tal como ocurre en otras Critoniinae.

Los números cromosómicos altos son considerados basales dentro de la tribu Eupatorieae, con una posterior reducción del número cromosómico básico a 5, 90 10 en los grupos más derivados (Bremer, 1994; Watanabe et al., 1995; Schilling et al., 1999; Ito et al., 2000b).

El alto número $(n=20)$ encontrado en $O$. heptanthus podría deberse tanto a eventos de diploidía como de hibridización. 


\section{VII- POLEN}

Los granos de polen en la tribu Eupatorieae han sido estudiados en menor medida, en relación a otras tribus de Asteraceae (Skvarla et al., 1977; Abreu et al., 2009). Los primeros estudios palinológicos de la tribu Eupatorieae fueron realizados por Stix (1960), quien analizó bajo microscopio óptico los granos de polen de 12 especies de la tribu Eupatorieae, a los cuales caracterizó como oblato esferoidales, 3-colporados, con colpos tenuimarginados y con extremos redondeados, endoaberturas lalongadas, exina espinosa, con 14 espinas en el plano ecuatorial, cavada, tectum con perforaciones en la base de la espina (Stix, 1960). Los granos de polen de las eupatoreas presentan un patrón tipoEupatorium, el cual se caracteriza por la presencia de un gran cavidad por debajo de las base de las espinas que conforman la capa más externa de la ectexina. Skvarla et al. (1977) analizaron los granos de polen de otras siete especies de Eupatorieae y concluyeron que pertenecían al patrón Helianthoide, el cual consiste en la presencia de una exina caveada con forámenes internos y que surge de la redefinición del patrón tipo-Eupatorium.

Los granos de polen hallados en Ophryosporus son de tamaño pequeño a medio $(17 \times 18 \mu \mathrm{m})$, isopolares, 3-colporados, prolatos, prolato-esferoidales a subprolatos, con áreas polares pequeñas y sexina espinosa. Consistentemente con los resultados obtenidos por Stix (1960) y Skvarla et al. (1977), los granos de polen de Ophryosporus, tienen espinas y una exina caveada (Fig. $6 \mathrm{~L}$ )

Hasta el momento no existen estudios palinológicos que abarquen todas las especies del género Ophryosporus, solo para algunas especies de Brasil: $O$. freyreisii, O. laxiflorus, O. organensis y O. regnelli (Abreu et al., 2009) y una presente en Perú, O. peruvianus (Taugourdeau, 2006). Si bien dichas especies son muy similares entre sí, aunque se encontraron diferencias en el tamaño, forma, índice de área polar y dimensiones de las espinas. (Abreu et al., 2009).

Se ha detectado la presencia de polen de Ophryosporus peruvianus en mieles del distrito de Chotabamba perteneciente al Valle de Oxapampa, Perú, aunque 
solamente se encuentra representado en el $0.05 \%$ del total del polen presente en las mieles (Sayas Rivera \& Huamán Mesía, 2009). Por otro lado, en el nevado Coropuna (Arequipa), también fue hallado el polen de $O$. peruvianus (Taugourdeau, 2006). Si bien la distribución de O. peruvianus es amplia, sus poblaciones no representan un recurso de importancia para la apicultura local, como lo refleja el bajo porcentaje de la presencia de polen en mieles. 


\section{VIII- DISTRIBUCIÓN GEOGRÁFICA Y HÁBITAT}

La subtribu Critoniinae a la cual pertenece Ophryosporus se encuentra ampliamente distribuida en la región Neotropical, aunque se encuentra concentrada en las áreas más húmedas, excluyendo a la cuenca Amazónica. Los miembros de la subtribu conforman un elemento predominante de las Eupatorieae en América Central, islas del Caribe y los Andes sudamericanos (King \& Robinson, 1987).

Las 41 especies de Ophryosporus son sudamericanas y se hallan distribuidas en Argentina, Brasil, Bolivia, Chile, Ecuador y Perú (Fig. 10).

Las especies se encuentran a lo largo de la cordillera de los Andes, desde Ecuador hasta Argentina y Chile, donde se encuentra el límite sur de distribución de Ophryosporus. Además, habita en las sierras pampeanas en Argentina (Córdoba, San Luis) y unas especies en Brasil, en los estados de Espírito Santo, Minas Gerais, Paraná, Río de Janeiro y Saõ Paulo. En lo referente a la altura, Ophryosporus exhibe un amplio rango, desde el nivel del mar, en la costa del Pacífico (ej. O. hoppii, O. triangularis) hasta $4000 \mathrm{msnm}$ en la cordillera de los Andes (ej. O. angustifolius, O. heptanthus).

Las especies de Ophryosporus presentan afinidad por una variedad de hábitats, ya sean disturbados y con alta insolación (bordes de caminos, claros de selva, laderas de montañas, pastizales abiertos) tanto con altas como bajas humedades relativas; como así también ambientes selváticos, con altos doseles y baja insolación y ambientes xéricos.

En lo referente a ambientes selváticos, habitan en las formaciones denominadas Yungas o selvas nubladas a lo largo de los Andes sudamericanos (ej. O. macrodon). El clima es cálido y húmedo, con lluvias principalmente estivales y heladas durante el invierno. La precipitación pluvial alcanza los 2.500 $\mathrm{mm}$ anuales y son acrecentadas por las neblinas que cubren casi continuamente las montañas. El relieve está conformado por montañas escarpadas, quebradas, valles y llanuras onduladas (Cabrera \& Willink, 1973; Josse et al., 2003). 
Otro ambiente selvático donde se encuentra Ophryosporus, es la Mata Atlántica que incluye las montañas costeras que recorren $4.000 \mathrm{~km}$ a lo largo del margen este de Brasil (ej. O. laxiflorus). Las precipitaciones varían entre 1500 a $2000 \mathrm{~mm}$ anuales, con una estación seca en invierno y abundantes lluvias estivales.Es un terreno montañoso, con alturas que varían entre los 1000 y 3000 msnm. Ya más hacia el norte, Ophryosporus se encuentra en las laderas occidentales bajas de los Andes ecuatorianos y colombianos, incluyendo a los valles interandinos, conocidos como las selvas de Chocó (ej. O. carchiensis). Se trata de una de las regiones más húmedas del planeta, con puntos donde la precipitación anual llega a los 10.000 mm anuales (Josse et al., 2003).

En cuanto a los ambientes más secos, Ophryosporus se encuentra en la formación denominada Chaco, con llanuras con ligeras depresiones o con cauces de ríos, con algunas serranías de poca elevación (ej. O axilliflorus). Las precipitaciones son variables. También se ubica en las regiones secas de los Andes, desde sur de Perú hasta Argentina, con su máximo desarrollo en Bolivia (ej. O. charua). Incluye a las altas montañas de la cordillera de los Andes y se encuentra por encima de los $2500 \mathrm{msnm}$. Las precipitaciones son sólo estivales y decrecen a medida que aumenta la altitud (Cabrera \& Willink, 1973).

El ambiente más extremo donde habita Ophryosporus corresponde al desierto peruano-chileno, el cual forma un cinturón continuo a lo largo de la costa oeste de Sudamérica, extendiéndose $3500 \mathrm{~km}$ desde el norte de Perú hasta el norte-centro de Chile, cercano a La Serena (ej. O. anomalus). La zona desértica puede llegar a extenderse desde 20 a $100 \mathrm{~km}$ hacia el continente. Las precipitaciones son muy escasas a lo largo de la costa, el principal aporte de humedad es mediante las neblinas provenientes del océano Pacífico. En la costa se encuentran desarrollados parches de vegetación denominados "lomas" (Veblen et al., 2007). Además habita en áreas secas lindantes: hacia el norte abarca el extremo costero norte de Perú y hacia el sur ocupa una banda angosta a lo largo del margen oeste de Sudamérica, desde los 30 a $36^{\circ} \mathrm{S}$ en Chile central (ej. O. triangularis) y también el extremo sur costero de Ecuador (ej. O. densiflorus). Al igual que en el 
desierto peruano-chileno, las precipitaciones son escasas y básicamente están representadas por neblinas. Las precipitaciones anuales son escasas variando entre 200 a 700 mm al año (Cabrera \& Willink, 1973; Josse et al., 2003; Veblen et al., 2007). 


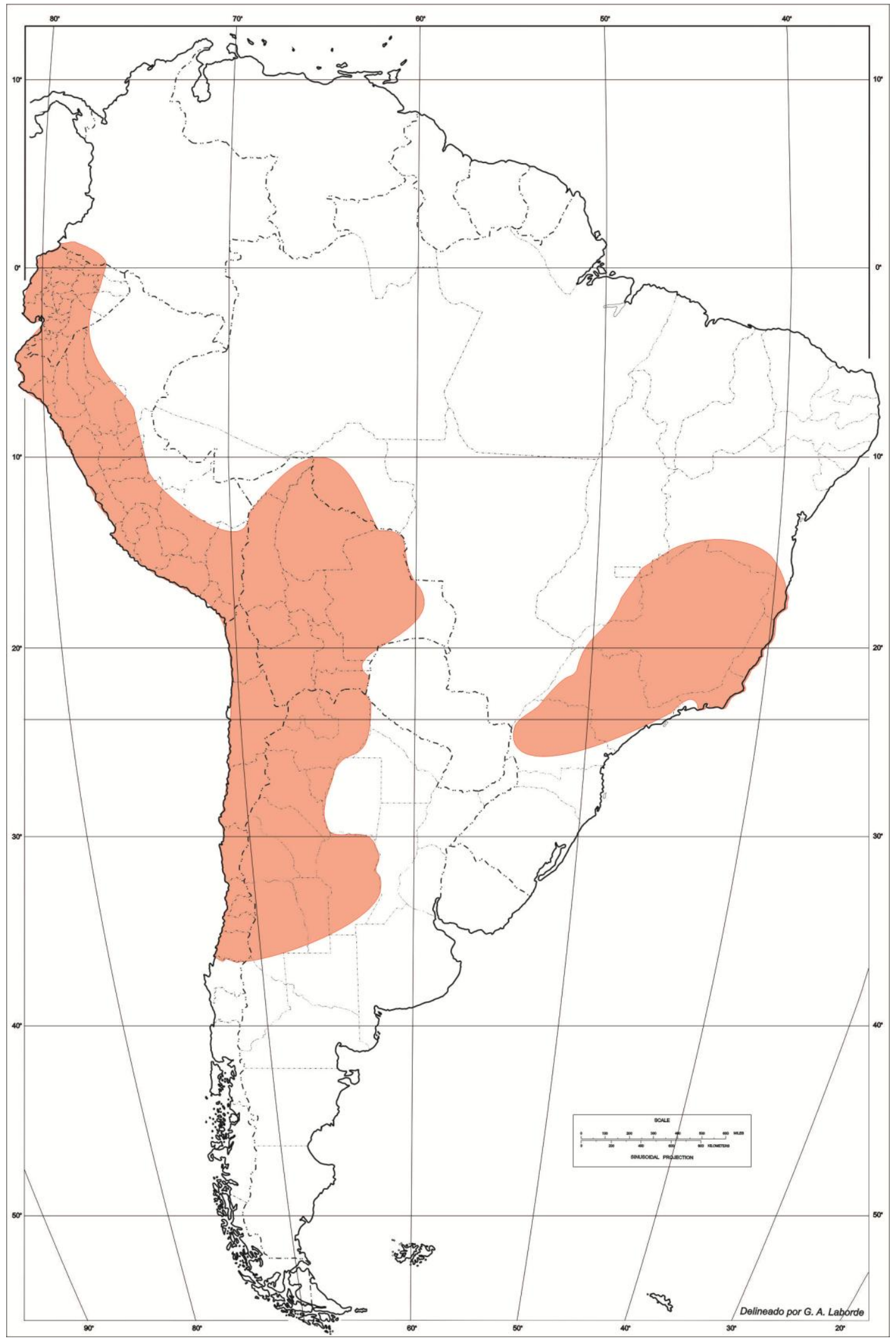

Figura 10. Distribución del género Ophryosporus. 


\section{IX-TRATAMIENTO TAXONÓMICO}

\section{1- Descripción del género Ophryosporus}

Ophryosporus Meyen, Reise um die Erde 1: 402. 1834. Tipo: Ophryosporus triangularis Meyen.

Piqueria sección Artemisioides DC., Prodromus 5: 105. 1836. Tipo: Piqueria artemisioides Kunth en H. B. K.

Trychinolepis B. L. Rob., Contributions to the Gray Herbarium n.s. 80: 6. 1928. Tipo: Trychinolepis hoppii B. L. Rob.

Arbustos erectos, con tallos leñosos o sus bases, menos comunmente arbustos apoyantes o escandentes; leve a densamente ramosos, frecuentemente con ramas en fascículos axilares. Tallos cilíndricos, estriados o no, glabros 0 pubescentes. Hojas usualmente opuestas solitarias o raramente alternas en fascículos; pecíolos cortos a moderadamente largos; láminas de tamaño ampliamente variable, generalmente lanceoladas, lanceolado-ovadas u ovadas, menos comúnmente lineares; base simétrica o raramente asimétrica, cuneada a truncada; márgenes enteros, denticulados a profundamente incisos; margen recto o raramente revoluto; ápice agudo a cortamente acuminado; venación leve a fuertemente trinervada; glabras o tomentosas, en algunos casos con tricomas glandulares. Inflorescencia secundaria cimoidea o tirsoidea, terminales y axilares, con inflorescencias terciarias corimbosas o glomerulosas. Capítulos isomorfos, homógamos. Involucro acampanado o cilíndrico. Filarios 4-8, eximbricados o levemente subimbricados, en 1 o 2 series subiguales, ovado-lanceolados a oblongos, persistentes; glabros, pubescentes o glandulosos, tricomas eglandulares y glandulares. Receptáculo plano, epaleáceo, glabro. Flores (3)-410-(12) por capítulo; corolas blanquecinas, amarillentas o verdosas, raro levemente violáceas cuando cerradas; actinomorfas, angostamente tubulosas 0 infundibuliformes, ya sea con paso gradual o abrupto entre tubo y limbo; lóbulos triangulares, 1-2 veces mas largos que anchos; collar anteral cilíndrico a 
levemente más ancho hacia la base; apéndice conectival nulo o rudimentario, entero o con un surco medial que delimita dos diminutos lóbulos; base del estilo de igual diámetro que la porción apical, glabra; ramas del estilo clavadas en el ápice, dorsalmente papilosas, exertas al menos $1 / 3$ del largo total de la corola; estilopodio presente (nectario). Cipselas prismáticas, piriformes o levemente falcadas, pentacostadas; a veces cortamente estipitadas, seríceas, con tricomas eglandulares (gemelos) o glandulares; carpopodio anular o cilíndrico, ensanchado hacia la base, central o excéntrico. Papus formado por cerdas escábridas, escamoso-laciniado o ausente, persistente. Granos de polen isopolares, 3colporados, prolatos, prolato esferoidales a subprolatos, sexina espinosa, con espinas y cavus, de 17-22 $\mu \mathrm{m}$ de diámetro. Número cromosómico $n=10$. (Fig. 1 8).

\section{2 - Clave de especies}

1. Arbustos apoyantes o escandentes, no erectos

2. Papus ausente. O. densiflorus

2'. Papus formado por cerdas. 3

3. Inflorescencia cimoidea, formada por glomérulos densos 4

4. Hojas de la inflorescencia iguales a las eje

O. cumingii

4'. Hojas de la inflorescencia diferentes a las del eje. O. charua

3'. Inflorescencia cimoidea, formada por corimbos. .5

5. Inflorescencias parciales laxas

6

6. Hojas lanceoladas

O. freyreyssii

6'. Hojas ovadas. .7

7. Anteras con apéndice conectival nulo O. carchiensis 7'. Anteras con apéndice conectival rudimentario O. apricus 


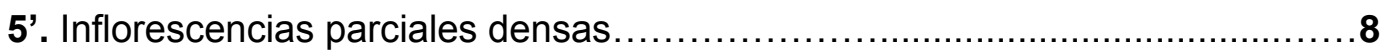

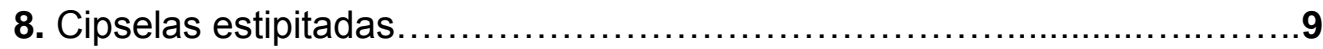

9. Cipsela con carpopodio excéntrico........................... O. ferreyrii

9'. Cipsela con carpopodio central.......................... sodiroi

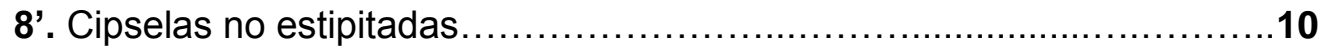

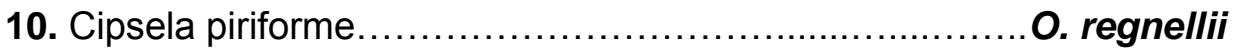

10'. Cipsela falcada..................................... organensis

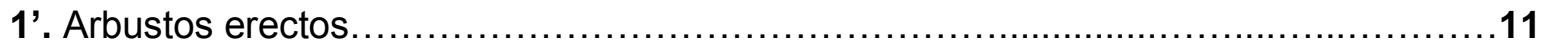

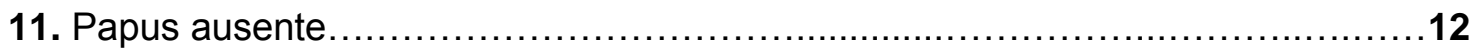

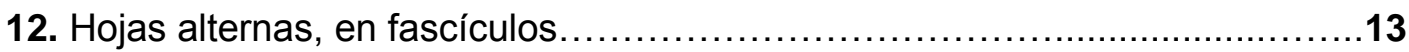

13. Inflorescencia cimoidea de corimbos laxos.......................... galioides

13'. Inflorescencia tirsoidea..............................................14

14. Inflorescencia laxa............................................... . hartwegii

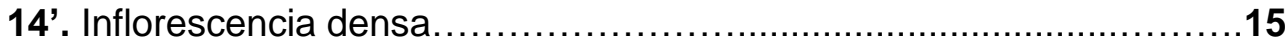

15. Más de 200 capítulos por inflorescencia.

O. peruvianus

15'. Menos de 100 capítulos por inflorescencia............... O. anomalus

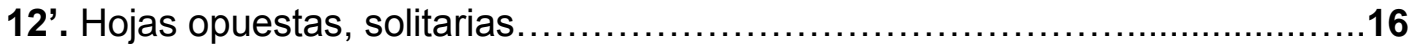

16. Inflorescencia cimoidea de corimbos densos.

O. pubescens

16'. Inflorescencia cimoidea de corimbos laxos

.17

17. Hojas con base asimétrica.

O. marchii

17'. Hojas con base simétrica

18

18. Filarios de márgenes fimbriados.

O. mathewsii

18'. Filarios de márgenes enteros.

O. floribundus 
11'. Papus presente.

19. Papus formado por escamas.

20

20. Hojas lineares

O. pinifolius

20'. Hojas ovadas.

O. hoppii

19'. Papus formado por cerdas.

21

21. Hojas alternas, en fascículos.

22

22. Inflorescencias tirsoideas laxas.

O. paradoxus

22'. Inflorescencias tirsoideas densas.

.23

23. Láminas foliares con margen profundamente inciso

O. bipinnatifidus

23'. Láminas foliares con margen entero

.24

24. Láminas foliares ovadas

O. triangularis

24'. Láminas foliares lineares

O. johnstonii

21'. Hojas opuestas, solitarias

.25

25. Láminas foliares lanceoladas

O. angustifolius

25’. Láminas foliares ovadas

.26

26. Inflorescencias cimoideas de glomérulos

O. axilliflorus

26'. Inflorescencias cimoideas de corimbos.

27

27. Inflorescencias parciales laxas

28

28. Hojas aserradas, con dientes de primer orden

29. Filarios glandulosos

O. sagasteguii 
29'. Filarios eglandulosos.

30. Cipsela con carpopodio excéntrico

O. laxiflorus

30'. Cipsela con carpopodio central

O. macbridei

28'. Hojas aserradas, con dientes de segundo orden O. burkartii

27'. Inflorescencias parciales

densas. 31

31. Inflorescencias de posición terminal.

32. Corolas infundibuliformes con paso abrupto entre tubo y limbo

33. Cipselas con carpopodio excéntrico O. eleutherantherus

33'. Cipselas con carpopodio central

O. serratifolius

32'. Corolas infundibuliformes con paso gradual entre tubo y limbo

O. ovatus

31'. Inflorescencias terminales y axilares

34. Cipselas con carpopodio excéntrico O. steinbachii

34'. Cipselas con carpopodio central. 35

35. Filarios glandulosos 36

36. Tricoma glandular tipo $\alpha$ O. macrodon 
36'. Tricoma glandular tipo $\beta$

37. Involucro de 2- 4 filarios

O. Iorentzii

37'. Involucro de 7 u 8 filarios

O. heptanthus

35'. Filarios eglandulosos

38. Apéndice conectival nulo

O. venosissimus

38'. Apéndice conectival

rudimentario

39. Apéndice conectival entero

O. kuntzei

39'. Apéndice conectival con surco medial

O. piquerioides 


\section{3 - DESCRIPCIÓN DE LAS ESPECIES}

\section{Ophryosporus angustifolius B. L. Rob.}

Contributions from the Gray Herbarium of Harvard University 90: 3. 1930.

Tipo: Bolivia: "Cerro La Negra, Dept. Santa Cruz. Meereshöre 1800 m. 9 Okt. 1928. José Steinbach 8187'. Holotipo GH! 00010772, isotipos E 00413769 foto! (http://plants.jstor.org/specimen/e00413769), GH! 00010770 y GH! 00010771, PH 00019844 foto! (http://plants.jstor.org/specimen/ph00019844), K 000486683 foto! (http://plants.jstor.org/specimen/k000486683), NY 01104694 foto!, U 0259367 foto! (http://plants.jstor.org/specimen/u0259367), US 00146329!, S no visto (Anderberg et al. 1996). Fig. 11.

Arbusto erecto $(1-1,6 \mathrm{~m})$. Tallo con entrenudos entre 6,5 y $11 \mathrm{~cm}$, ramificaciones secundarias opuestas, ramas glabras, marrón oscuro a púrpura, con estriaciones. Hojas opuestas, pecioladas, pecíolo 0,1-1 cm, láminas ovadolanceoladas a lanceoladas, a veces, levemente falcadas, 0,3-1 $\times 2-6 \mathrm{~cm}$ base atenuada, ápice agudo, margen aserrado, plano; consistencia herbácea, venación acródroma imperfecta suprabasal; tomentulosa, tricomas eglandular simple cónico y glandulares (tipo $\alpha$ ). Inflorescencia cimoidea, compuesta de corimbos laxos; terminal y axilar, con hojas persistentes bien desarrolladas. Capítulos ca. 130320 , pedunculados (1,5-2 mm), 2,5 x 3,5 mm. Involucro acampanado, $2 \times 3 \mathrm{~mm}$; filarios 4, eximbricados, en dos series, los externos ovados, 2,1-2,3 x 0,8-1 mm, los internos ovado-lanceolados, 2-2,3 x 0,7-0,9 mm; ápice levemente fimbriado, margen entero, consistencia herbácea, tomentuloso, tricomas eglandulares. Flores 4 , hermafroditas, corola blanca a verdosa-amarillenta, infundibuliforme, con paso gradual entre tubo y limbo, tubo 0,8-0,5 x 12-15 mm, limbo $0,5 \times 0,3 \mathrm{~mm}$, 5dentada, lóbulo 0,5 × 0,3 mm; glandulosa en toda la corola, más denso en el tubo, tricomas glandulares (tipo $\alpha$ ). Estambres 5, anteras 1,2-1,4 x 0,6-0,8 mm, collar anteral cilíndrico, base de la teca obtusa; apéndice conectival nulo. Estilo 2-2,5 $\mathrm{mm}$, cortamente exerto, ramas del estilo fuertemente clavadas en el ápice, ápices más oscuros que el resto de las ramas, las ramas 1,25-1,5 mm. Cipsela negra 
ligeramente estipitada, piriforme a levemente falcada, 1,2-5 mm, marcadamente 5costada; serícea, con pelos gemelos en costillas y carpopodio; carpopodio anular, central. Papus formado por 20-24 cerdas amarillo-blanquecinas, connadas en la base, 0,75 - 2 mm. $n=10$ (Robinson et al., 2009). Fig. 12.

Fenología: Florece de noviembre a febrero.

Distribución: Bolivia (departamentos de Santa Cruz y Chuquisaca), y Perú (departamentos de Ancash y Cajamarca) entre 1250-4500 msnm. Habita en bosques secos montanos con ambientes rocosos. Frecuente como vegetación secundaria en bordes de caminos o luego de incendios. Fig. 13.

Nombres comunes: "Sheklla" (Olivera González et al. 2011).

\section{Notas:}

1. El isotipo Steinbach 8187 (GH00010770), depositado en GH, está fechado el 10 de octubre de 1928 y no el 9 de octubre de 1928 como el resto de los materiales tipo.

2. Algunos isotipos habían sido determinados originalmente como Baccharis $L$.

3. De acuerdo a Robinson (1930), esta especie es fácilmente distinguible de sus congéneres por sus pequeños capítulos y las hojas extremadamente estrechas.

4. Prefiere suelos con $\mathrm{pH}$ muy ácidos a ligeramente alcalinos, con textura entre arena franca y franco arenosa (Olivera González et al. 2011).

5. Muy fragante.

Etimología: Deriva del latín angustus, estrecho y folius, hoja indicando la forma angosta de la lámina de las hojas (Font Quer 1993, Gledhill 2008).

Estado de Conservación: En Bolivia se ha coleccionado material en el Parque Nacional de Amboró. Las principales ecorregiones abarcadas por el área protegida son el bosque húmedo montañoso de yungas, chaco, bosques secos montanos y los bosques nublados. Sin embargo, es muy frecuente en bordes de caminos y áreas disturbadas. 
Compuestos químicos de interés: De acuerdo a Herz (2004) presenta benzofuranos, dihidrobenzofuranos, cumarinas y cromenos. Bohlmann \& Zdero (1979) indican la presencia de derivados de anol y fenilpropanoides.

Usos: Se emplea como leña, reforzar las barreras y las hojas se utilizan para contrarrestar dolores causados por el frío (Olivera Gonzáles et al. 2011).

Especímenes adicionales estudiados: BOLIVIA. Chuquisaca: Tomina, Río Yotala (El Villar), 31/05/1981, R. E. (ERTS) 315 (US). Santa Cruz: Manuel Maria Caballero, $2 \mathrm{~km}$ from Comarapa, on road to Cochabamba, 05/02/1978, R. M. King \& L. E. Bishop 7638 (MO, US). Florida, Tres Cruces, above Bermejo, north of Rio Bermejo, 35 km E of Samaipata, 18 09' S 63 34' W, 09/09/1947, F. R. Fosberg 28607 (NY, MO); $5 \mathrm{~km}$ (by road) and $3 \mathrm{~km}$ (by air) NE of Bermejo, Cerro Herradura, along old horse road to Santa Cruz and petroleum pipeline, $18^{\circ} 07^{\prime} \mathrm{S}$ 63 37' W, 25/09/1990, M. Nee 38918 (MO, NY). Ichilo, Cerro Amboró, 24/09/1990, M. Lewis 37778 (NY, MO). PERÚ. Cajamarca: Cajamarca, Caserío Otuzco, 16/06/1975, A. Sagástegui A., J. Cabanillas S. \& O. Dios C. 8039 (NY). Contumazá, Lledén, 28/06/1983, A. Sagástegui A., E. Alvitez \& J. Mostacero 10840 (NY). Otuzco, Salpo-Chanchacap, 24/05/1984, A. Sagástegui A., M. Diestra \& S. Leiva $11651(\mathrm{NY})$. 


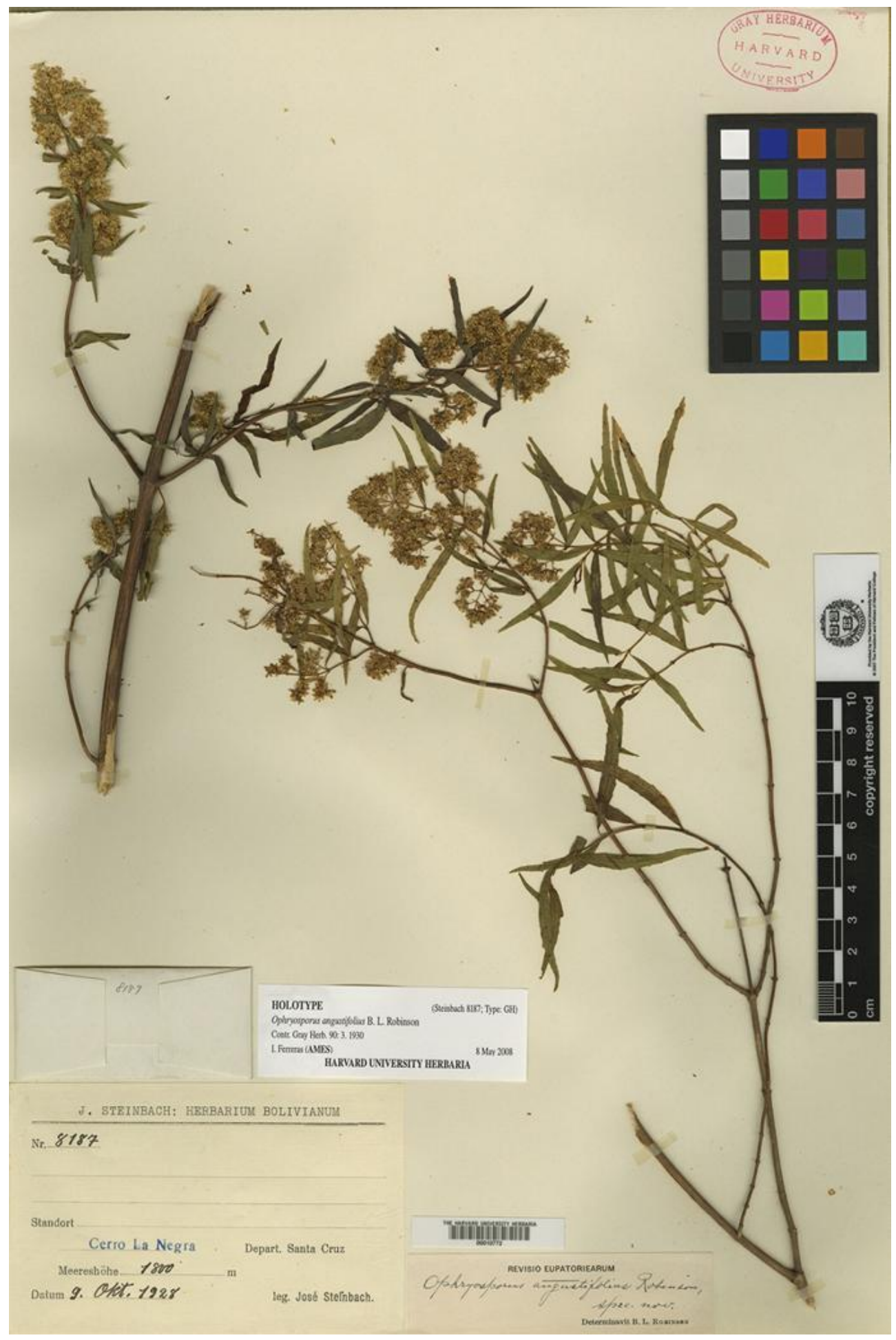

Figura 11. O. angustifolius, material tipo. J. Steinbach $8187(\mathrm{GH})$. 


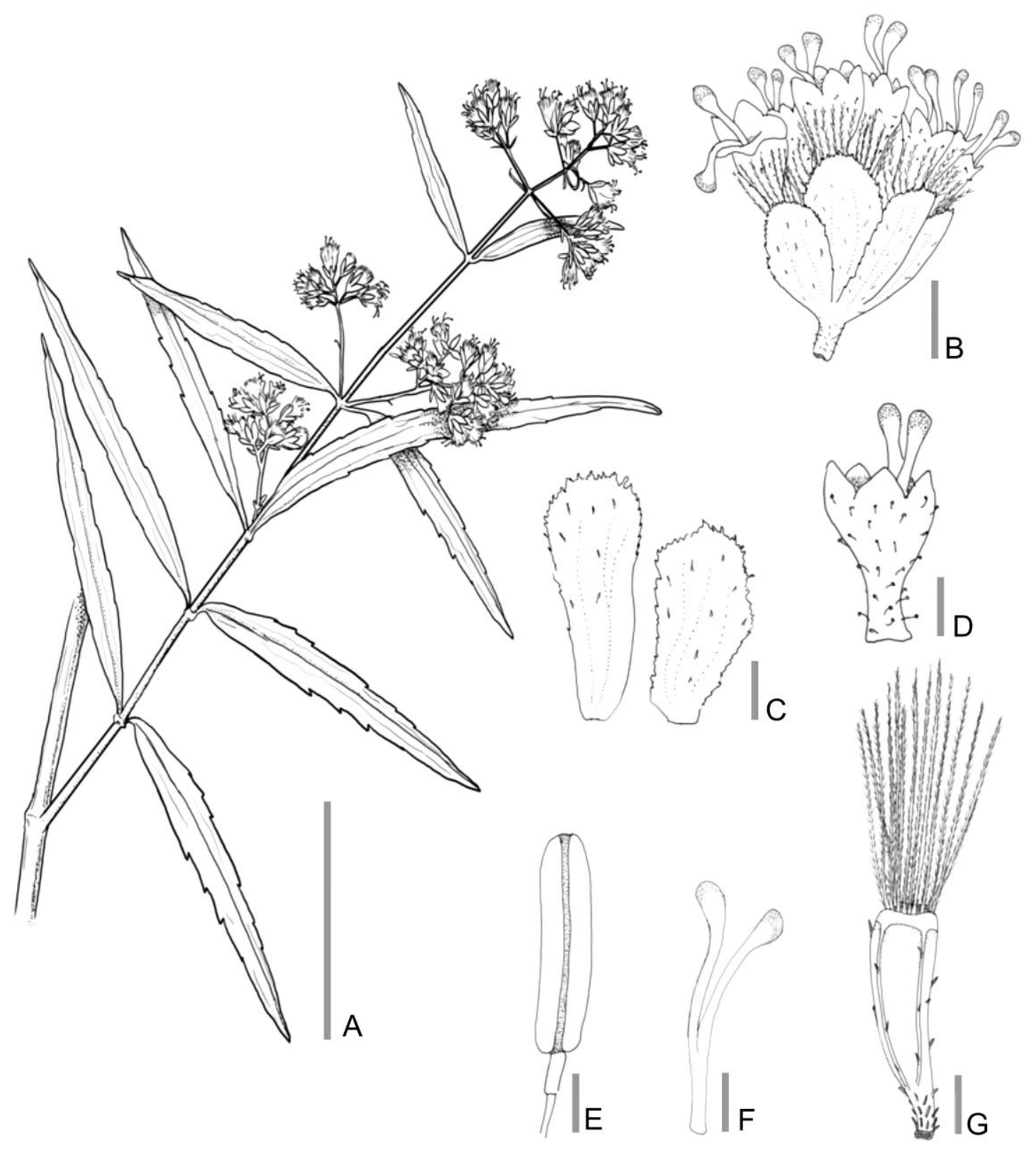

Figura 12. O. angustifolius. A. Rama florífera. B. Capítulo. C. Flor sin papus ni cipsela. D. Filarios. E. Antera. F. Estigma. G. Cipsela. Escalas: A: 2,5 cm; B-C: 1 cm; D-E: 0,5 cm; F-G: $200 \mu \mathrm{m}$. (A-G basados en J. Steinbach 8187, GH). 


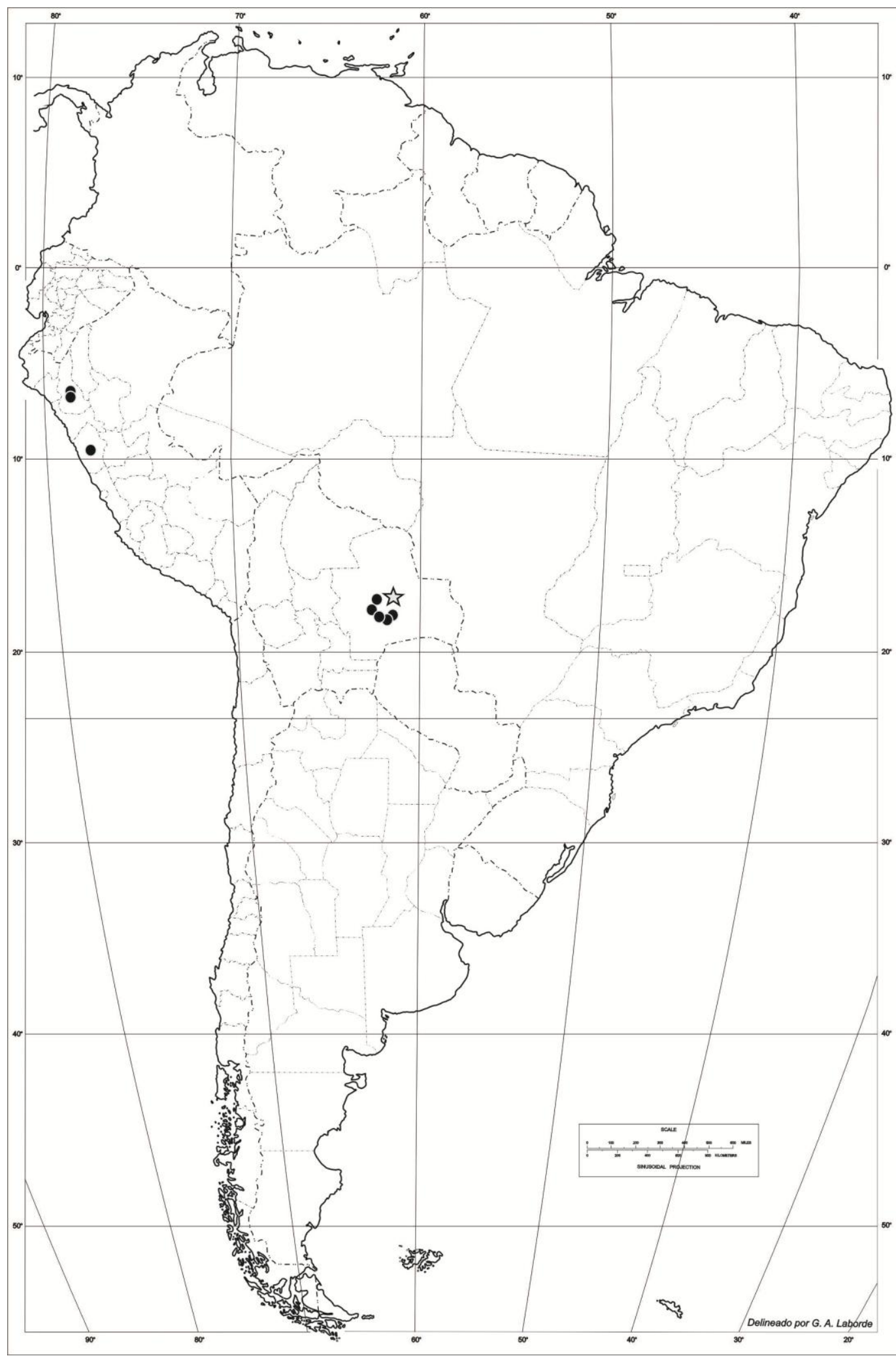

Figura 13. O. angustifolius. Distribución geográfica, la estrella indica la localidad tipo. 
Ophryosporus anomalus R. M. King \& H. Rob.

Phytologia 25: 66. 1972.

ミ Piqueria cumingii B. L. Rob.

Proceedings of the American Academy of Arts and Sciences. 62 (1). Contributions from the Gray Herbarium of Harvard University. New Series 32: 11. 1906.

Lectotipo: Chile: "Peruviæ meridionalis, Cobija, lquiqui et Arica. 1831. H. Cuming 953'. K 000486684 foto! (http://plants.jstor.org/specimen/k000486684), isolectotipos: E 00322766 foto! (http://plants.jstor.org/specimen/e00322766), $\begin{array}{llll}\text { fragmento } & \mathrm{GH} & 00010778\end{array}$ (http://asaweb.huh.harvard.edu:8080/databases/specimen_index.html), $\quad \mathrm{K}$ 000486685 foto! (http://plants.jstor.org/specimen/k000486685), W 0014073 no visto.(Plos \& Sancho, 2012). Fig. 14.

= Ophryosporus cumingii (Sch.Bip.) Benth. \& Hook. f. Genera Plantarum 2: 239. 1876.

ミ Mikania cumingii Sch. Bip. Linnaea 34: 535. 1865. Bolivia. Cuming $102 \mathrm{P}$ 00742213 foto!

Arbusto erecto, ramoso. Tallos con entrenudos entre 6 y $8 \mathrm{~cm}$, ramificaciones secundarias subopuestas a alternas, ramas subglabras, marrón claro. Hojas en fascículos alternos, pecioladas, pecíolo 0,6-1 cm, láminas lanceoladas, 1-2,5 × 3$11 \mathrm{~cm}$, base decurrente, ápice agudo, margen aserrado, plano; consistencia herbácea, venación acródroma imperfecta suprabasal; pubescente, tricomas eglandulares. Inflorescencia tirsoidea densa, a veces levemente cimoidea, compuesta de corimbos. Capítulos ca. 50 , pedunculados, $3 \times 5 \mathrm{~mm}$, discoides, homógamos. Involucro cilíndrico, $3 \times 4,5 \mathrm{~mm}$; filarios 4-5, eximbricados a levemente subimbricados; formado por una serie de filarios ovado-lanceolados, $2 \mathrm{x}$ $4 \mathrm{~mm}$; margen entero, consistencia herbácea con resinas superficiales. Flores 5 , hermafroditas, corola blanca a amarillenta, tubulosa, $3 \mathrm{~mm}$; glandulosa, tricomas 
glandulares. Estambres 5. Estilo cortamente exerto, ramas del estilo clavadas. Cipsela negra, piriforme, $3 \mathrm{~mm}$, marcadamente 5-costada. Papus nulo. Fig.15

Observación: como únicamente se dispuso con un material de herbario estéril, la descripción se completó con datos de la descripción original e imágenes de alta definición del material tipo.

Fenología: Florece en octubre.

Distribución: Chile (regiones de Antofagasta y Tarapacá) y Perú (provincia de Arequipa) entre 0-200 msnm, habita en zonas de desierto costero (Luebert et al. 2007). Fig. 16

\section{Notas:}

1. Se designo como lectotipo al material depositado en $\mathrm{K}$, ya que si bien la recomendación 9A del Código de Viena (MacNeill et al., 2006), indica que se debería designar el material tipo depositado en el herbario donde se alojo el investigador (B. L. Robinson en este caso), como el material depositado en $\mathrm{GH}$ es un fragmento de uno de los materiales depositados en K, se procedió a elegir dicho material como lectotipo (Plos \& Sancho, 2012).

2. De acuerdo con Luebert et al. (2007), es necesario aclarar que King \& Robinson (1972) y Brako \& Zarucchi (1993) lo señalan para la flora de Perú, probablemente debido a que el material tipo de la especie (Piqueria cumingii B.L.Rob.) fue recolectado por Cuming en 1828 (Cuming 953, K, $\mathrm{GH}$ !) en "Cobija, Iquiqi et Arica, Peruvia meridionalis"; las restantes colecciones corresponden a materiales recolectados por Jaffuel en Tocopilla y por Gaudichaud en Cobija; dado que Cuming efectivamente recolectó en casi todos los puertos importantes al norte de Valparaíso durante su viaje por la costa Pacífica, consideran que la especie es endémica del área de Tocopilla-Cobija.

3. El isosintipo de $\mathrm{GH}$ presenta un labelo donde se lo sinonimiza con Ophryosporus cumingii (Sch. Bip) Benth., dicho dato es erróneo, ya que corresponde al material tipo de $O$. anomalus. 
4. Se debería proceder con cuidado, ya que la numeración correspondiente a Cuming 953, también se repite para Acacia philippinarum Benth. colectado en Filipinas (depositado en BM). Algo similar ocurre con Cuming 102, también se repite para Nephrodium diversilobum C. Presl colectado en Filipinas (depositados en BM, GOET, MICH y RB).

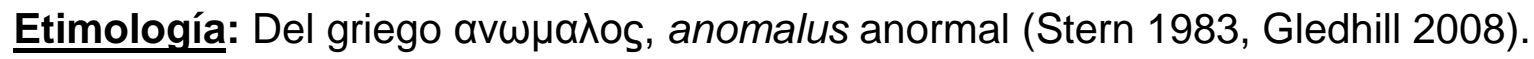

Estado de Conservación: Si bien, esta especie fue citada como frecuente al sur de Cobija, en las colecciones de W. Biese en 1949 depositadas en el Herbario SGO (Schultz et al., 2011), no ha sido hallada desde entonces. Esta ausencia, sumada a otras especies, indica un gran cambio en la composición florística.

Especímenes adicionales estudiados: CHILE. Antofagasta (II Región): Tocopilla, Tocopilla, 27/10/1930, F. Jaffuel 1026 (CONC). 


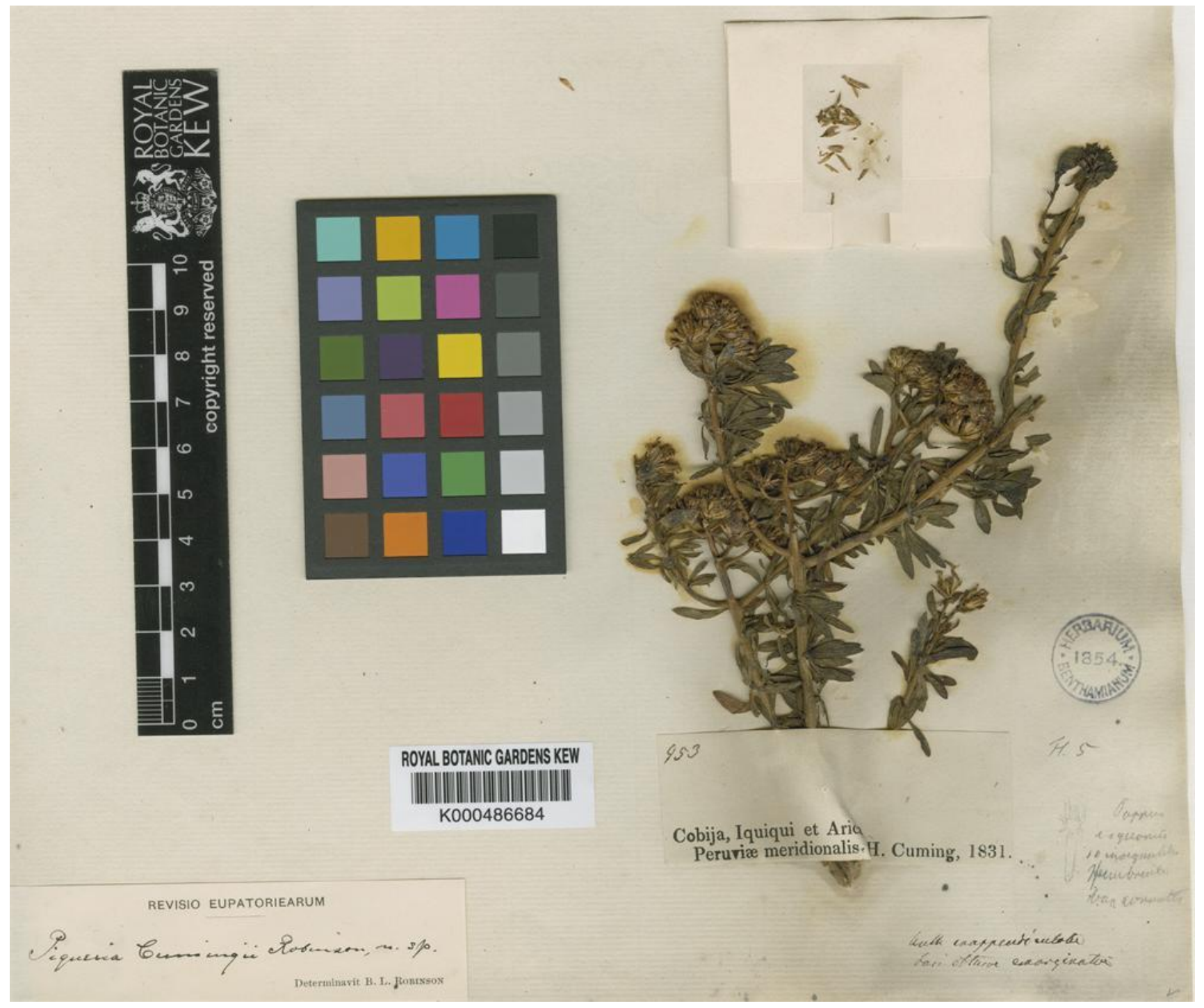

Figura 14. O. anomalus, lectotipo. H. Cuming 953 (K). 


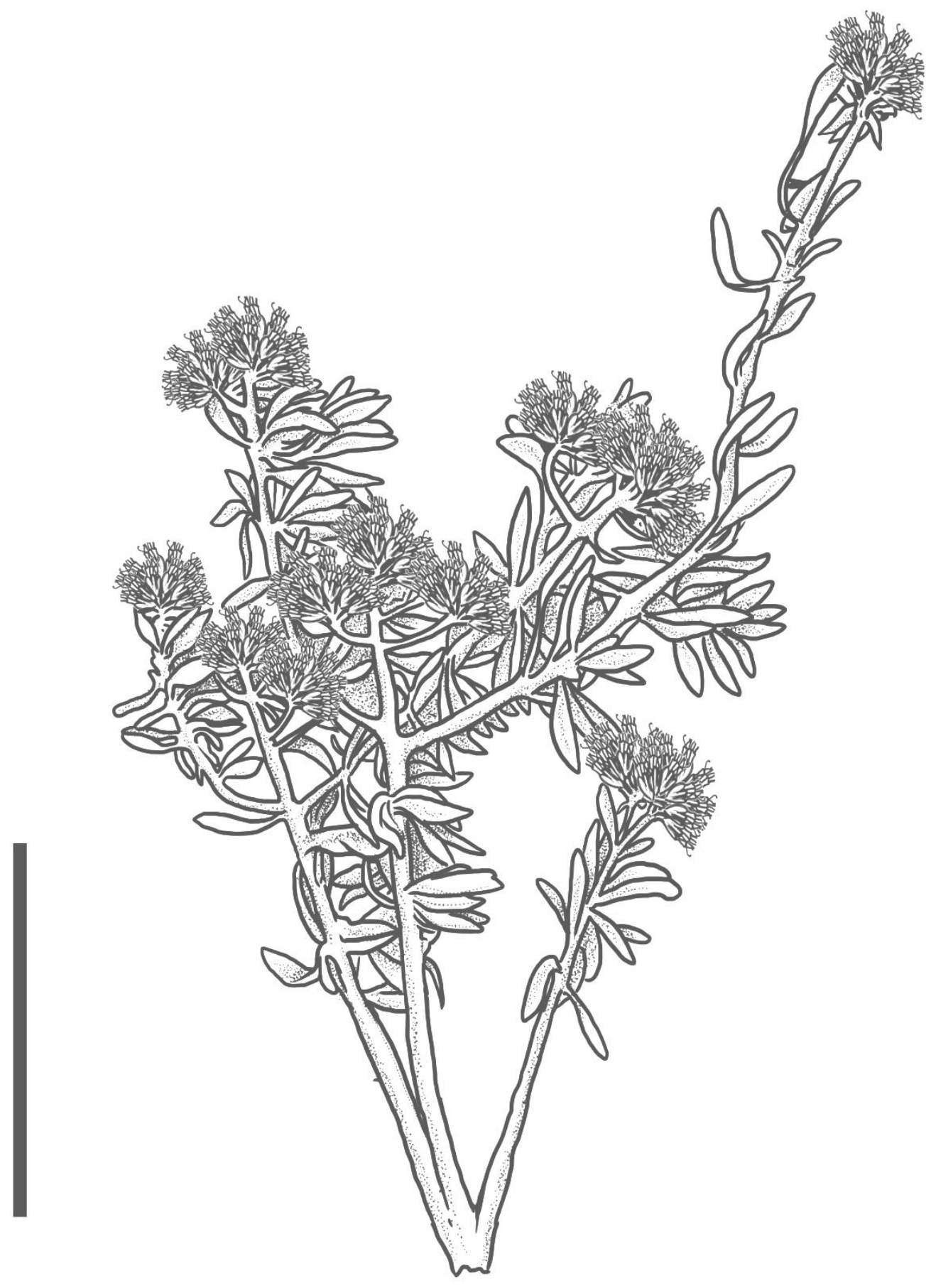

Figura 15. O. anomalus. Rama florífera. Escala: $5 \mathrm{~cm}$ (A basado en foto de $H$. Cuming 953, K). 


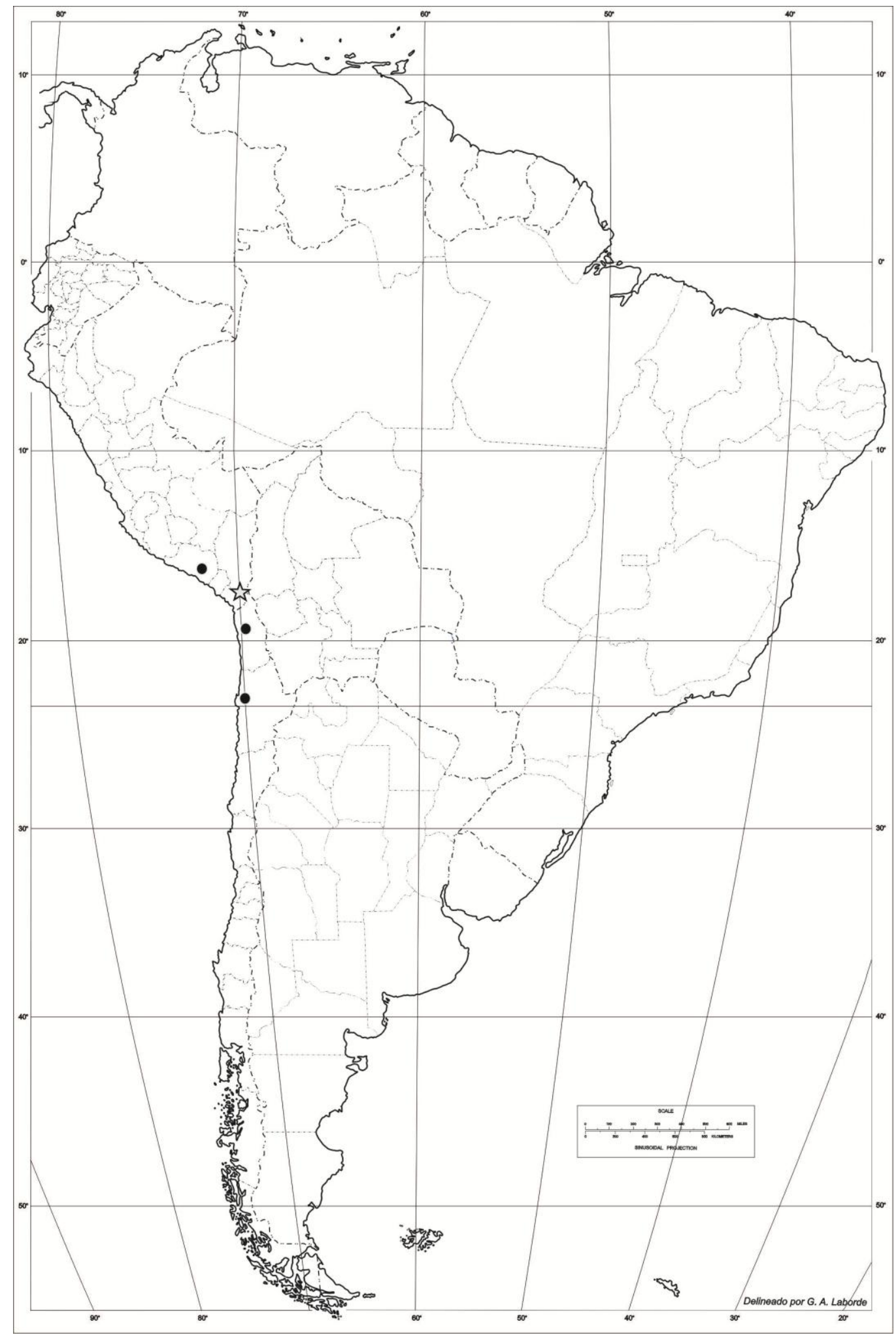

Figura 16. O. anomalus. Distribución geográfica, la estrella indica la localidad tipo. 


\section{Ophryosporus apricus B. L. Rob.}

Contributions from the Gray Herbarium of Harvard University. New Series 73: 3-4. 1924.

Tipo: Perú: Cuzco "Vilcabamba, Hacienda on Rio Chinchao, about $6000 \mathrm{ft}$. elev., July 17-26, 1923. J. F. Macbride no. 5204". Holotipo F!, isotipos GH!, US!. Fig. 17.

Arbusto apoyante. Tallo con entrenudos entre 6 y $12 \mathrm{~cm}$, ramificaciones secundarias opuestas, ramas subglabras, marrón claro a rojizo. Hojas opuestas, pecioladas, pecíolo 0,8 cm, láminas ovadas, $2-4 \times 3-4,5 \mathrm{~cm}$, base redondeada, ápice acuminado, margen aserrado, plano, consistencia delicadamente herbácea a herbácea; venación acródroma imperfecta suprabasal; pubescente y glandulosa, tricomas eglandulares simples cónicos y glandulares (tipo $\alpha$ y $\beta$ ). Inflorescencia tipo cimoidea, compuesta de corimbos laxos; terminal y axilar, con hojas persistentes poco desarrolladas. Capítulos ca. 100-120, pedunculados (2 mm), 3 x 3,5 mm. Involucro cilíndrico, 2 × 2,5 mm, filarios 7, eximbricados, en dos series de filarios, los externos ovados, 0,5 $\times 2 \mathrm{~mm}$, los internos ovado-lanceolados, $1 \times 3$ $\mathrm{mm}$; ápice levemente fimbriado, enteros, consistencia herbácea; glandulosos, tricomas glandulares (tipo a). Flores 6-7, hermafroditas, corola blanca, infundibuliforme, con paso gradual entre tubo y limbo, tubo $2,5 \times 0,5 \mathrm{~mm}$, limbo 1,2 x 0,4 mm, lóbulo 0,4 x 0,3 mm, 5-dentada; glandulosa, tricomas glandulares (tipo a). Estambres 5, anteras 0,8 $\times 0,4 \mathrm{~mm}$, collar anteral cilíndrico; base de la teca obtusa; apéndice conectival rudimentario, con surco medial. Estilo cortamente exerto, 4,2 $\mathrm{mm}$, ramas del estilo fuertemente clavadas en el ápice, 1,7 mm. Cipsela negra ligeramente estipitada, piriforme, 1-3 mm, marcadamente 5costada; seríceas y glandulosas, pelos gemelos en las costillas y glandulares (tipo a) en toda la cipsela; carpopodio cilíndrico, central. Papus formado por 25 cerdas amarillo-blanquecinas, connadas en la base, 2,5-2,8 mm. Fig. 18.

Fenología: Florece de septiembre a marzo.

Distribución: Perú (departamentos de Amazonas, Cajamarca, Cuzco, Junín y Lima), entre 1500-2500 msnm, habita en bosques muy húmedos montanos, por 
debajo de los bosques pluviales montanos en la vertiente oriental (León et al. 2006 [2007]). Fig. 19.

\section{Notas:}

1. De acuerdo a la colección tipo, prefiere zonas soleadas.

2. De acuerdo con Robinson (1924), esta especie es cercana a O. sodiroi Hieron. De ella difiere por los dientes de las hojas (hojas con dientes más marcadas y profundos), filarios angostos y oblongos (contra obovados) y estigmas más pequeños.

Etimología: Del latín apricus, amante del sol, hace referencia a su preferencia por sitios soleados y expuestos (Gledhill, 2008).

Especímenes adicionales estudiados: PERU. Cajamarca: Contumazá, La Pampa debajo de Guzmango, 24/07/1977, A. Sagástegui A \& J. Mostacero 9058 (US). Junín: Huancayo, Agua de las Vírgenes, cerca a Huancayo, 01/04/1951, $O$. Tovar 348 (LP). La Libertad: Otuzco, alrededores de Otuzco, 19/06/1959, N. Angulo 902 (LP). Lima: Canta, camino de Canta a Huaros, 27/08/1963, I. Meza R. 212 (LP). 


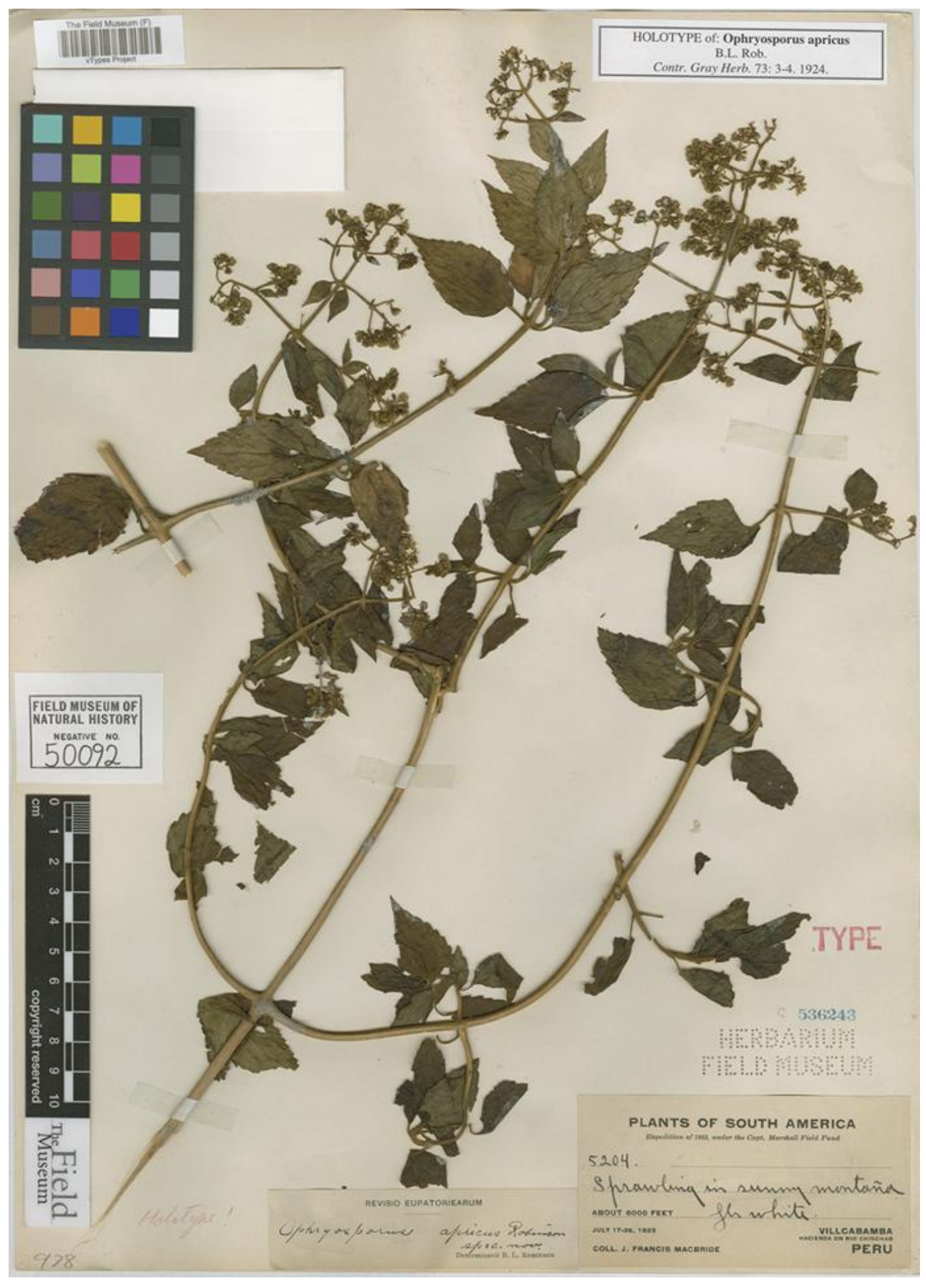

Figura 17. O. apricus, holotipo. J. Francis Macbridei 5204 (F). 


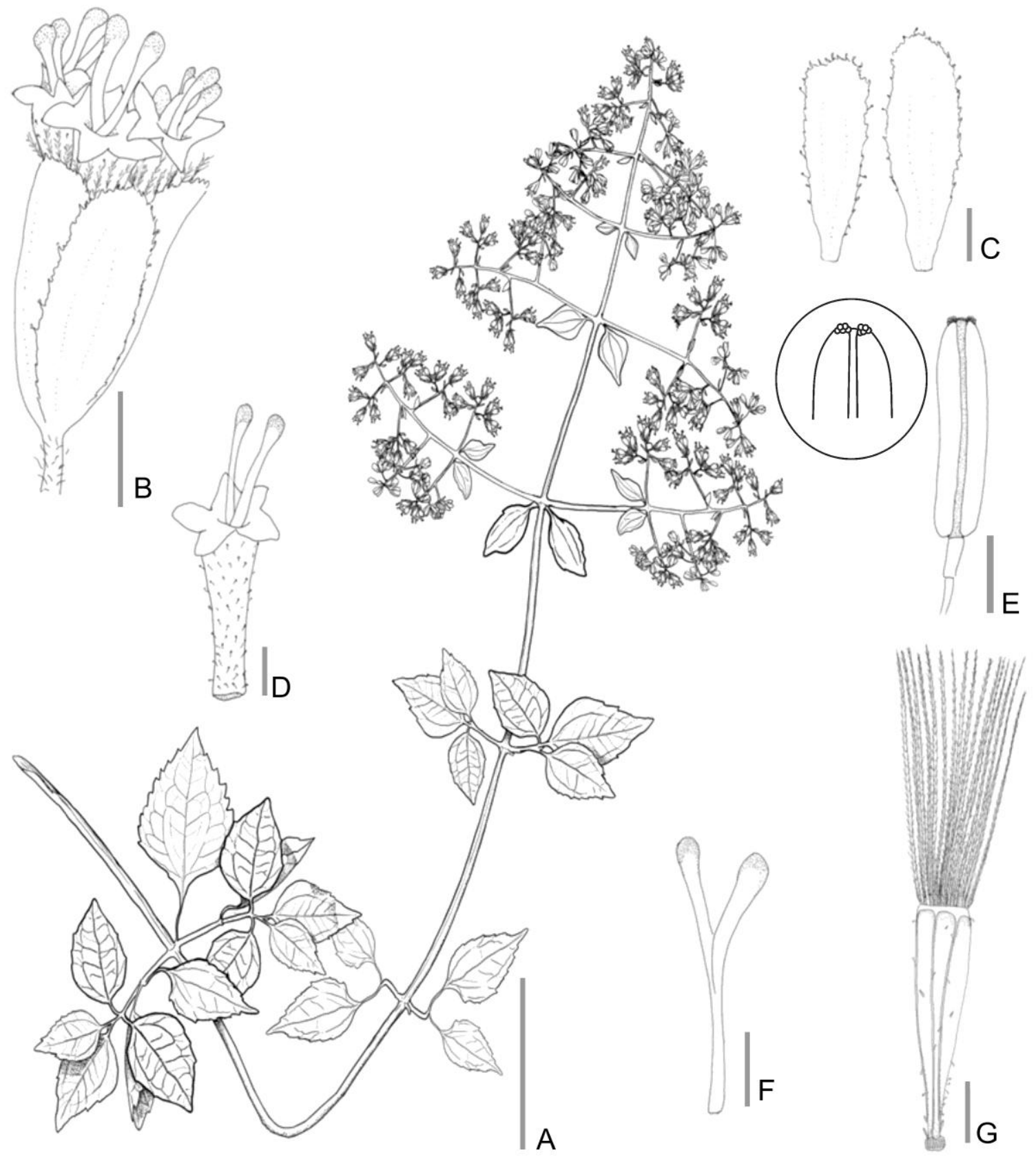

Figura 18. O. apricus. A. Rama florífera. B. Capítulo. C. Flor sin papus ni cipsela. D. Filarios. E. Antera. F. Estigma. G. Cipsela. Escalas: A: $5 \mathrm{~cm}$; B: $1 \mathrm{~cm}$; C-D: 0,5

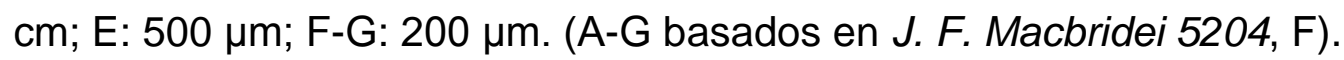




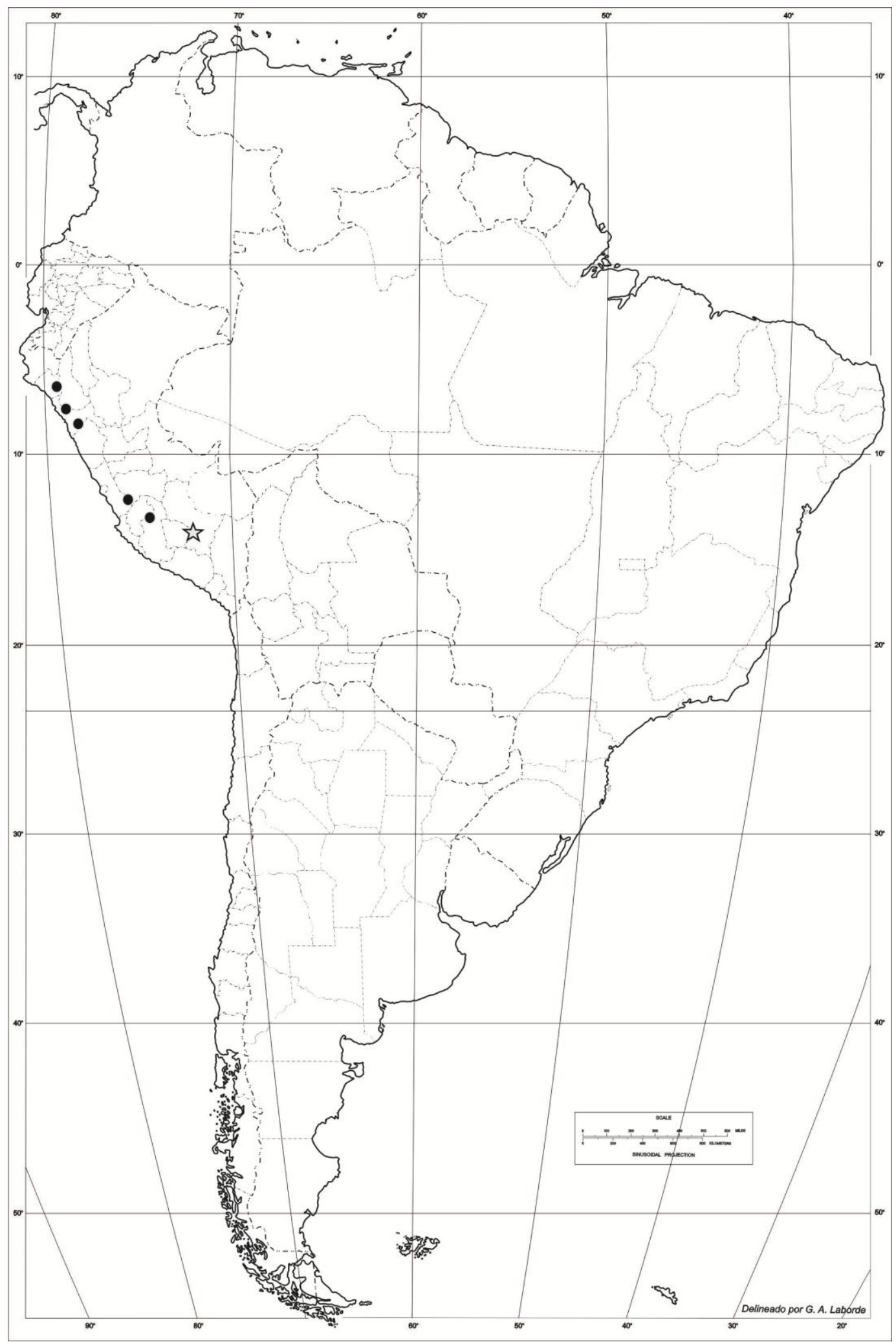

Figura 19. O. apricus. Distribución geográfica, la estrella indica la localidad tipo. 


\section{Ophryosporus axilliflorus (Griseb.) Hieron.}

Botanische Jahrbücher für Systematik, Pflanzengeschichte und Pflanzengeographie 22: 706. 1897.

\section{E Eupatorium axilliflorum Griseb.}

Abhandlungen der Königlichen Gesellschaft der Wissenschaften zu Göttingen 19: 169. 1874.

Plantae Lorentzianae. Bearbeitung der ersten und zweiten Sammlung argentinischer Pflanzen der Professor Lorentz zu Cordoba: 121. 1874.

Tipo: Argentina, "Cordoba, bei Ascochinga, 04/1871. P. G. Lorentz 195". Holotipo GOET foto! (http://plants.jstor.org/specimen/goet001855), isotipos B foto! (posiblemente destruido), CORD CORD00006272! y CORD00006273!, GH foto! (http://plants.jstor.org/specimen/gh00010774) Fig. 20.

Arbusto erecto $(1,5-2 \mathrm{~m})$. Tallo profusamente ramificado desde la base, entrenudos entre 5 y $7,5 \mathrm{~cm}$, ramificaciones secundarias opuestas, ramas glabras, púrpura, con estriaciones. Hojas opuestas, pecioladas, pecíolo 0,7-1 cm, láminas ovadas, 1-3 x 3-6 cm, base cuneada, ápice agudo, margen dentado, plano, consistencia herbácea, venación acródroma imperfecta suprabasal; tricomas eglandulares. Inflorescencia tipo cimoidea, compuesta de glomérulos densos; terminal y axilar, con hojas persistentes poco desarrolladas. Capítulos ca. 220, pedunculados (1,5-3 mm), 2,8 x 5,5 mm. Involucro acampanado, filarios 5-6, eximbricados, 2,8 $83 \mathrm{~mm}$, en una serie de filarios; ápice fimbriado, margen entero, consistencia herbácea; ovados, $1 \times 3 \mathrm{~mm}$; glanduloso, tricomas glandulares (tipo a). Flores 5, hermafroditas, corola blanca a verdosa, infundibuliforme, sin paso gradual entre tubo y limbo, tubo proximal $1 \times 0,4 \mathrm{~mm}$, tubo distal $1,5 \times 0,6 \mathrm{~mm}$, limbo $0,8 \times 0,3 \mathrm{~mm}$, lóbulo $0,4 \times 0,3 \mathrm{~mm}, 5$-dentada, superficie del limbo lisa; glandulosa, tricomas glandulares (tipo a). Estambres 5, anteras 1,1 $\times 0,3 \mathrm{~mm}$, collar anteral cilíndrico, base de la teca levemente auriculada; apéndice conectival nulo. Estilo 4,6 mm, largamente exerto, ramas del estilo clavadas en el ápice, 
ápices más oscuros que el resto de las ramas, 2,5-2,75 mm. Cipsela negra ligeramente estipitada, falcada, 2,2 $\mathrm{mm}$, marcadamente 5 -costada; serícea, pelos gemelos en costillas; carpopodio anular, excéntrico. Papus formado por 24 cerdas amarillentas, connadas en la base, 2,8 mm. Fig. 21.

Fenología: Florece de octubre a marzo.

Distribución: Argentina (provincias de Catamarca, Córdoba, Jujuy, La Rioja, Salta, San Luis y Tucumán) y Bolivia (departamentos de La Paz, Tarija y Santa Cruz), entre 1000-2000 msnm, habita en selva y matorrales serranos de las provincias fitogeográficas yungas, altoandina y chaqueña. Fig. 22.

Nombres comunes: “Charrúa” (Barboza et al., 2006).

\section{Notas:}

1. A veces presenta ramas verdes y rojizas en la misma planta (Ariza Espinar, 1994).

Etimología: Del latín axilla, axila y florus, florecer, refiere a la disposición axilar de las inflorescencias (Stern 1983, Gledhill 2008).

Estado de Conservación: De acuerdo a Delucchi \& Plos (2011), le corresponde la categoría LC de la UICN, de menor interés, debido a su amplia distribución geográfica.

Compuestos químicos de interés: De acuerdo con Favier et al. (1998), presenta en sus rizomas y hojas cromonas y derivados de acetofenonas. Herz (2004) cita la presencia de benzofuranos, dihidrobenzofuranos, cumarinas y cromenos. Oliva et al. (2002), al realizar un estudio de los aceites esenciales, observaron que los constituyentes principales fueron limoneno, gama muroleno y biciclogermacreno.

Usos: Las hojas se utilizan como antisifilítico, astringente, dermopático (Nuñez \& Cantero 2000). Favier et al. 1998 han reportado actividad analgésica y antiinflamatoria. Se ha determinado actividad antimicrobiana en diversas bacterias (Streptococcus, Klebsiella, Proteus, Pseudomonas entre otras) (Oliva et al. 2002). 
Especímenes adicionales estudiados: ARGENTINA. Catamarca: Andalgalá, Cuesta del Clavillo, 20/09/1946, A. T. Hunziker 6807 (LP); Capital, Quebrada del Tala, La Brea, 04/1910, L. Castillón 1884 (LIL); Tinogasta, Nacimientos, 05/1910, L. Castillón 1438 (LIL). Córdoba: Colón, Ascochinga, 12/06/1938, E. G. Nicora 1933 (LP); Unquillo, 04/05/1947, A. T. Hunziker 7428 (LP). Ischilín, Ongamira, 25/10/1936, M. L. Giardelli 584 (LP); ib. 31/03/1947, A. P. Rodrigo 3571 (LP). Punilla, Cosquín, Pan de Azúcar, 01/07/1973, A. L. Cabrera \& E. M. Zardini 23905 (LP); Cerro Blanco, más allá de El Durazno, en el camino de Tanti a Los Gigantes, 22/05/1949, A. T. Hunziker 7617 (LP, NY); ib. 07/04/1950, A. T. Hunziker 8348 (LP); San Roque, 20/03/1878, C. Galander s.n. (NY); Sierra Chica, Los Cocos, 03/1940, A. L. Cabrera 6399 (LP, NY); Villa Carlos Paz, 16/04/1977, E. D. Gautier 8567 (LP). San Javier, Quebrada del Tigre, 09/05/1948, Ruiz Leal 12462 (MERL); ib. 09/05/1949, Ruiz Leal 12542 (LP). Santa María, Alta Gracia, barranca arroyo B. García, 06/12/1945, A. T. Hunziker 1258 (LP). Región no especificada: Córdoba, 12/1891, O. Kuntze s.n. (NY); ib. 25/04/1899, C. Spegazzini 13677 (LP); ib. 06/1916, Lloveras \& López s.n. (LP). Jujuy: Dr. Manuel Belgrano, Quebrada de las Varas, 10/04/2000, A. Carranza 705 (JUA), ib. 26/04/2000, A. Carranza 735 (JUA); camino a las Lagunas de Yala, 23/03/2000, A. Carranza 679 (JUA); Yala, 09/06/1948, J. B. Sotelo 10056 (LP). Ledesma, serranía de Calilegua, 17/10/1963, H. A. Fabris 4473 (LP). Tumbaya, Volcán, 06/03/1955, A. L. Cabrera 12167 (LP); ib. 09/05/1962, A. L. Cabrera et al. 14335 (LP), ib. Chilcayo, 4-6/03/1965, A. L. Cabrera et al. 17018 (GH, LP). Salta: Anta entre Anta y Piquete, 17/05/1959, J. Morello \& A. R. Cuezzo 1116 (LIL); PN El Rey, camino a Santa Elena, 12/07/1979, Brown 889 (MCNS). Cachi, Cuesta del Obispo, cerca de Valle Encantado, 04/10/1981, E. M. Zardini \& M. L. Pochettino 1406 (MO); La Paya, 18/09/1977, L. J. Novara 469 (LP). Capital, San Lorenzo, 28/05/1933, A. L. Cabrera 3027 (LP). Chicoana, San Fernando a cumbre de la Cuesta del Obispo, 03/05/1947, T. Meyer 12486 (LIL). Guachipas, Pampa Grande, 27/04/1942, A. T. Hunziker 1711 (LP). Rosario de Lerma, Campo Quijano, Dique Las Lomitas, 21/09/1980, L. J. Novara 1310 (LP). Santa Victoria, Santa Victoria, 10/02/1974, R. Kiesling et al. 705 (LP); alrededores de Santa Victoria, 18/04/1974, A. L. Cabrera \& R. Kiesling 25129 (LP); 
Parque Nac. Baritú, faldeos al SE de Sa. del Porongal, 21-22/09/1990, L. J. Novara 10020 (MCNS). Tucumán: Lules, Lules prope Tucumán, 01/1895, C. Spegazzini 13680 (LP). BOLIVIA. La Paz: Inquisivi, Rio Ckanchu Vado, 16 57' S $67^{\circ} 11^{\prime}$ W, 17/05/1988, M. Lewis 88638 (MO, NY). Tarija: Arce, $39.9 \mathrm{~km} \mathrm{~S} \mathrm{of} \mathrm{jct.} \mathrm{of}$

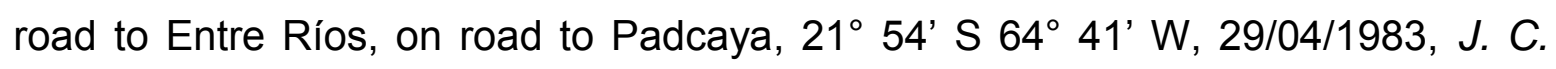
Solomon 10237 (NY); Cercado, Rincón de la Victoria, 17 Km W de Tarija, 18/05/1971, A. Krapovickas, L. A. Mroginski \& A. Fernández 18883 (LP). Santa Cruz: Caballero, along highway from Comarapa to Cochabamba, $7.3 \mathrm{~km}$ (by road) and $22 \mathrm{~km}$ (by road) NW of bridge at Comarapa, 17 49.5' S 64 39.1' W, 06/08/2003, M. Nee \& M. Mendoza 52529 (NY). 

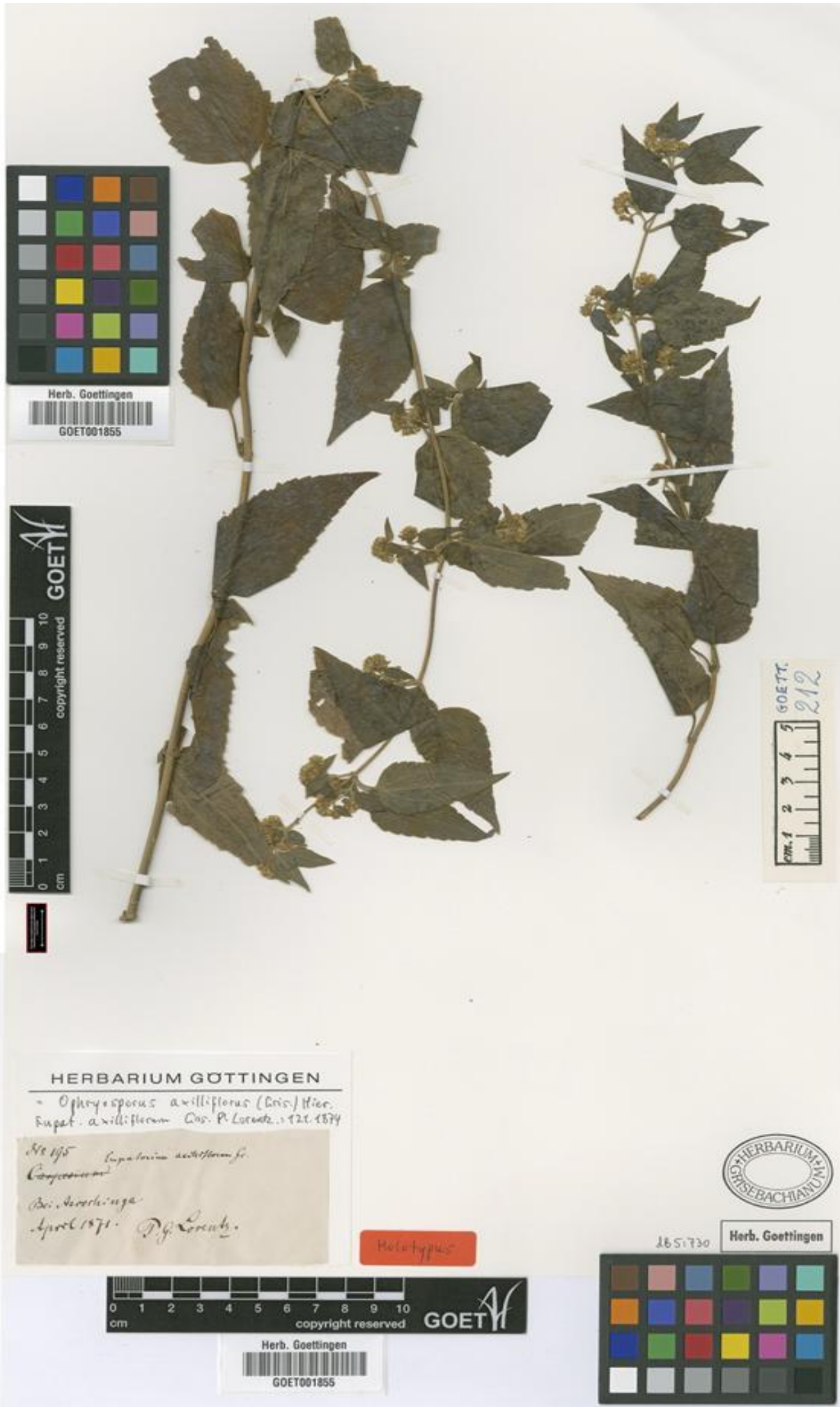

Figura 20. O. axilliflorus, holotipo. P. G. Lorentz 195 (GOET). 


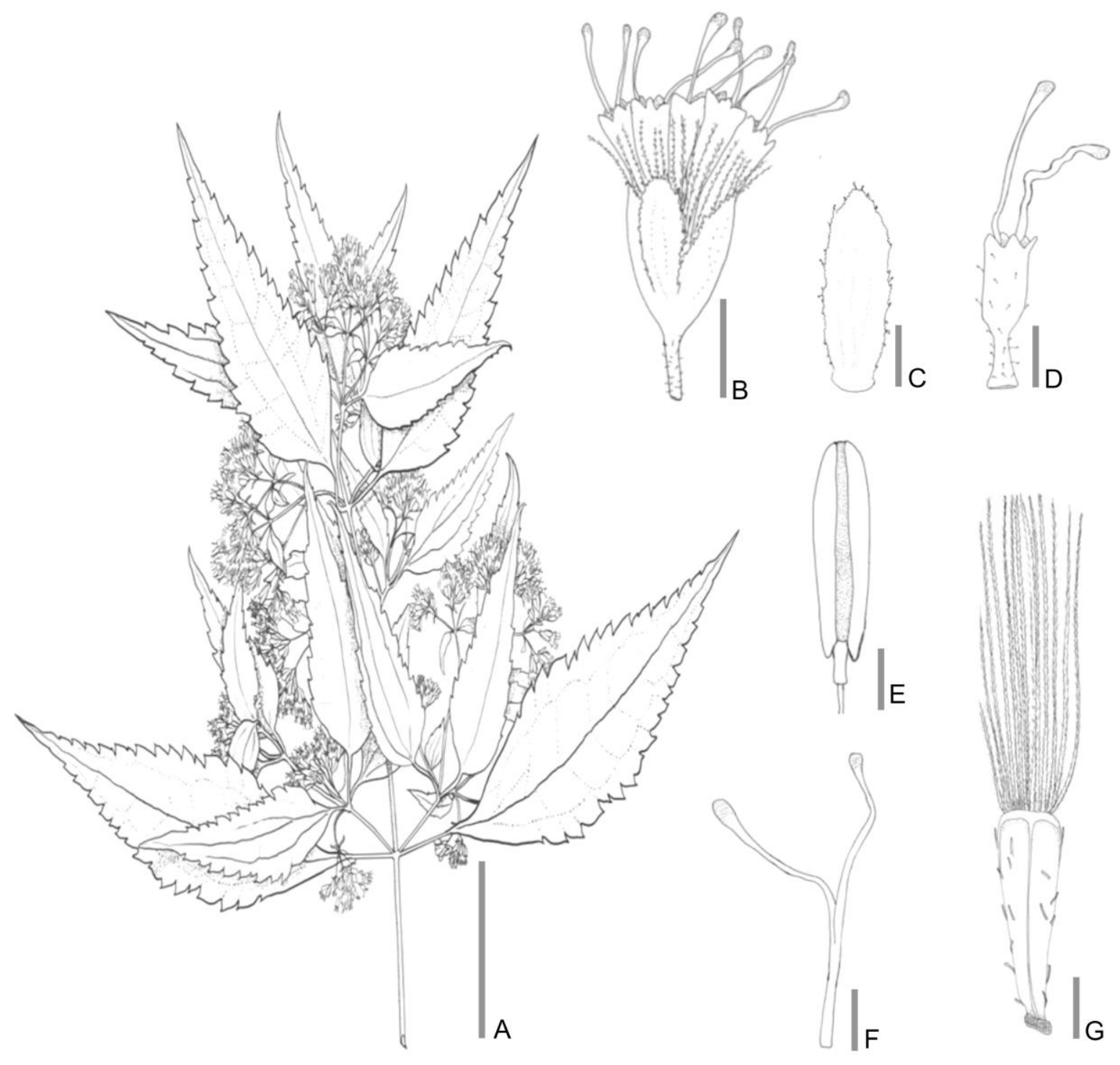

Figura 21. O. axilliflorus. A. Rama florífera. B. Capítulo. C. Flor sin papus ni cipsela. D. Filario. E. Antera. F. Estigma. G. Cipsela. Escalas: A: 2,5 cm; B: $2 \mathrm{~cm}$; C-D: $1 \mathrm{~cm}$; E-G: 200 m. (A-G basados en E. D. Gauthier 8567, LP). 


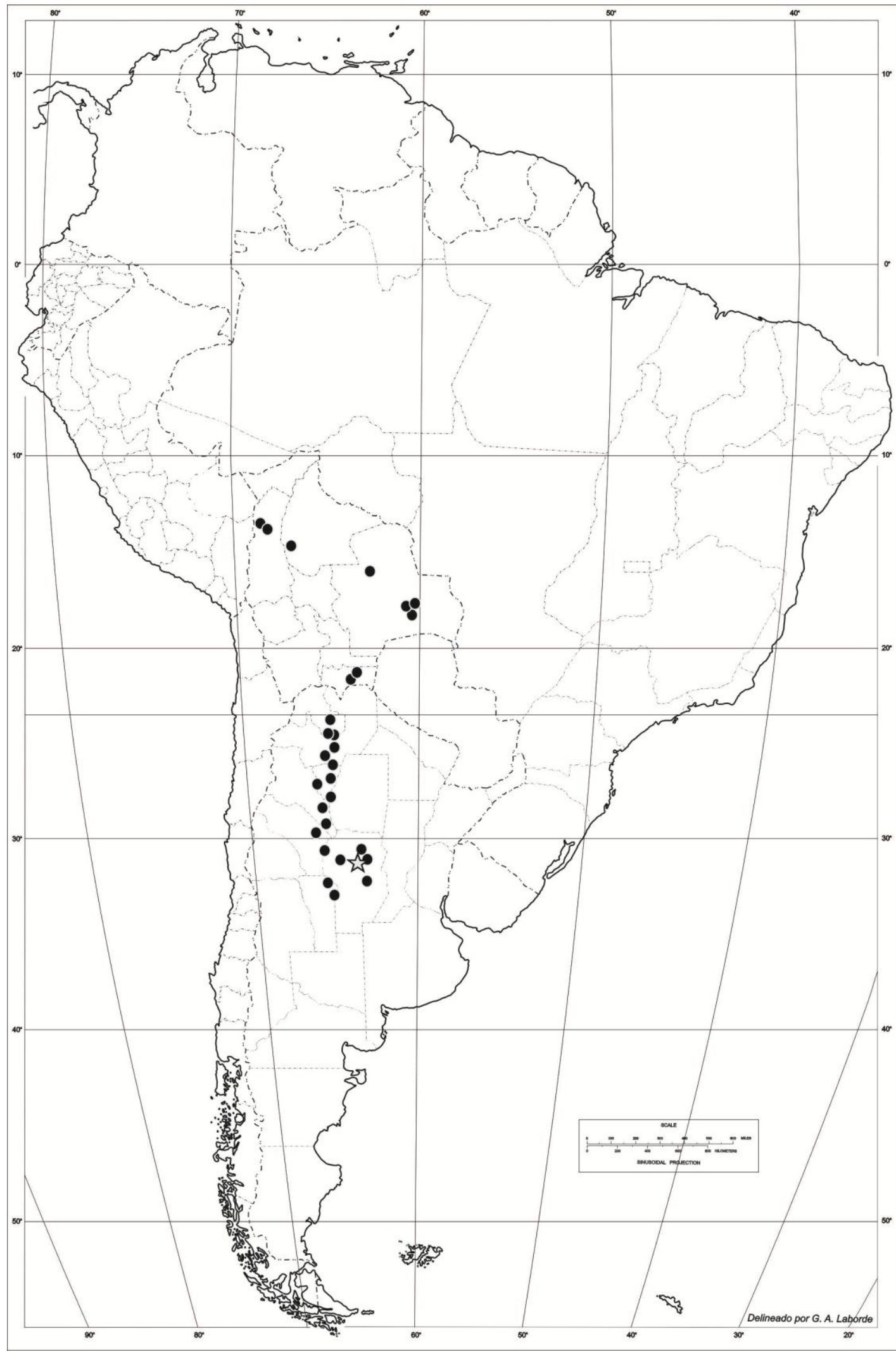

Figura 22. O. axilliflorus. Distribución geográfica, la estrella indica la localidad tipo. 


\section{Ophryosporus bipinnatifidus B. L. Rob.}

Contributions from the Gray Herbarium of Harvard University. New Series 60 . Proceedings of the American Academy of Arts and Sciences 55: 5. 1919.

Tipo: Peru, "vicinity of Posco, August 6, 1914. Mr. and Mrs. J. N. Rose 18805". Holotipo US!, isotipos NY!, GH!. Fig. 23.

Arbusto erecto. Tallos con entrenudos entre 0,3 y $3 \mathrm{~cm}$, ramas subglabras, marrón claro, con estriaciones. Hojas alternas, fasciculadas, pecioladas, pecíolo 0,2-1,2 cm, láminas ovada muy incisa, base decurrente, $1-2 \times 2-6,7 \mathrm{~cm}$, ápice agudo, margen profundamente inciso a lobulado, plano, consistencia herbácea, venación acródroma imperfecta suprabasal; pubescente y glandulosa, tricomas eglandulares simples cónicos y gladulares (tipo $\alpha$ ). Inflorescencia tirsoidea densa compuestas de corimbos; axilar, hojas persistentes bien desarrolladas. Capítulos ca. 50-60, pedunculados (0,1-0,2 mm), 4 × 4,5 mm. Involucro acampanado, 2 × 3 $\mathrm{mm}$, filarios 4-5, eximbricados, en una serie de filarios; márgen entero, consistencia herbácea; ovados, 0,8 × 3,2 mm; pubescente y glanduloso, tricomas eglandulares simples cónicos y glandulares (tipo a). Flores 4, hermafroditas, corola blanca a crema, infundibuliforme con paso gradual entre tubo y limbo, tubo $1,5 \times 0,5 \mathrm{~mm}$, limbo $6 \times 1,5 \mathrm{~mm}$, lóbulo $0,5 \times 1,5 \mathrm{~mm}$; 5-dentada; glandulosa, tricomas glandulares (tipo a). Estambres 5, anteras 1,3 x 0,4 mm, collar anteral levemente ensanchado hacia la base, base de la teca levemente auriculada; apéndice conectival rudimentario, entero. Estilo $5 \mathrm{~mm}$, largamente exerto, ramas del estilo fuertemente clavadas en el ápice, 2,3 $\mathrm{mm}$. Cipsela negra no estipitada, piriforme, marcadamente 5-costada; serícea y glandulosa, pelos gemelos y glandulares en toda la cipsela; carpopodio cilíndrico, central. Papus formado por 18-20 cerdas amarillo-blanquecinas, connadas en la base, 2 mm. Fig. 24.

Fenología: Florece de marzo a agosto.

Distribución: Perú (departamentos de Arequipa y Moquegua), entre 600-1200 msnm. Habita en el desierto semicálido tropical, localizado a la largo de la franja costera y bordes de ríos, al sur del valle del Chicama. Fig. 25. 
Notas: El material tipo fue determinado originalmente como Eupatorium.

Etimología: Del latín bipinnatifidus, hace referencia al patrón presente en la lámina de la hoja, aproximadamente bipinnado (Gledhill 2008).

Estado de Conservación: De acuerdo con Beltrán et al. (2006) su categoría en la UICN es CR B1 ab (iii), en peligro crítico. Habita las lomas y podría estar amenazada por la destrucción de su hábitat por expansión urbana y actividades agrícolas. Si bien, la localidad del material tipo, no está bajo la presión del cultivo o la expansión urbana, la Quebrada de Posco es una zona con alta actividad sísmica (7 en la escala Richter).

Especímenes adicionales estudiados: PERU. Arequipa: Islay, Lomas de Mejía, Quebrada Challascapa, 06/03/1998, FLSP 1539 (NY, US). Moquegua: Moquegua, Valle de Moquegua, 09/04/1959, C. Vargas C. 12630 (LP). 


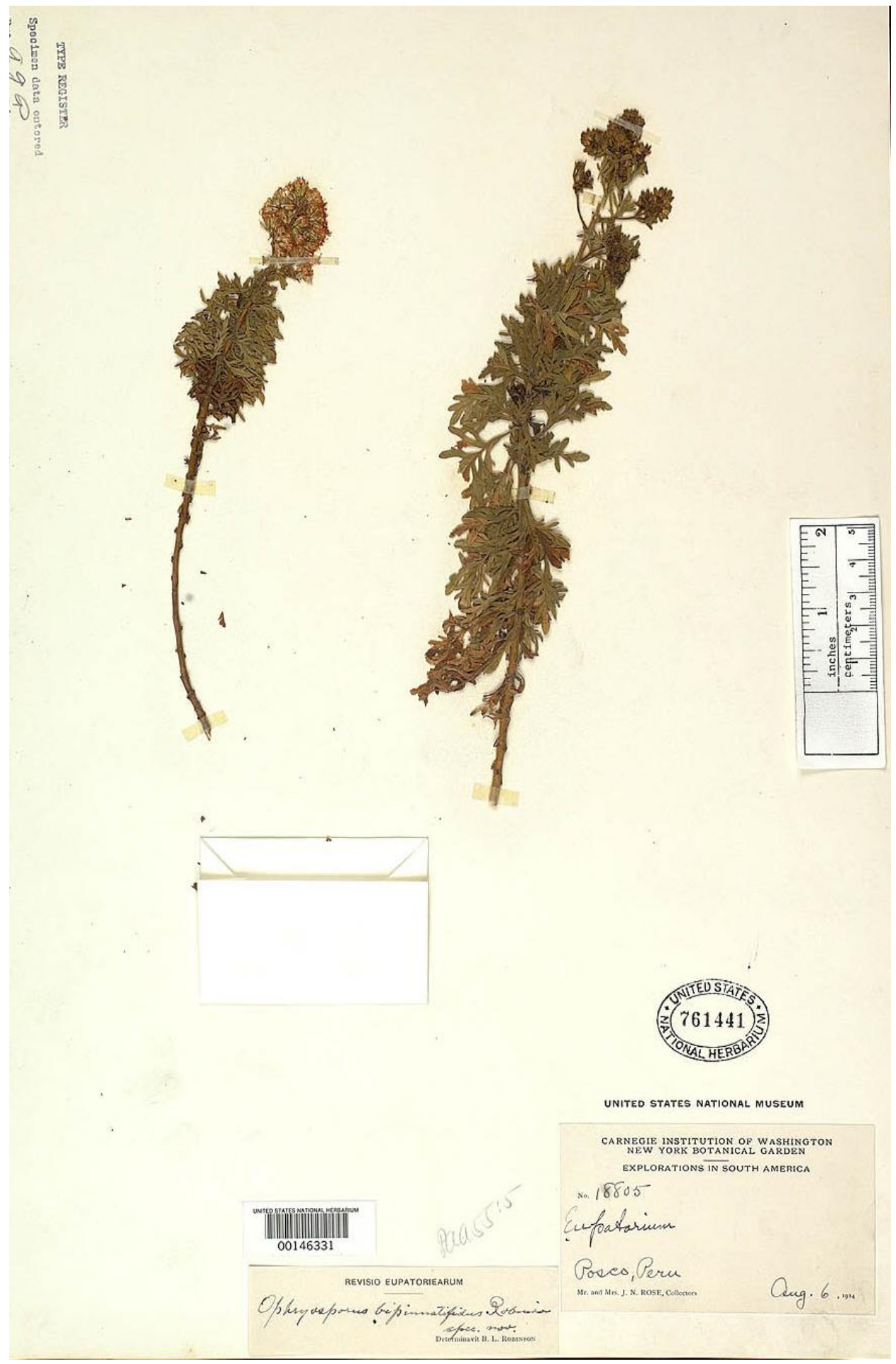

Figura 23. O. bipinnatifidus, holotipo. Mr. and Mrs. J. N. Rose 18805 (US). 


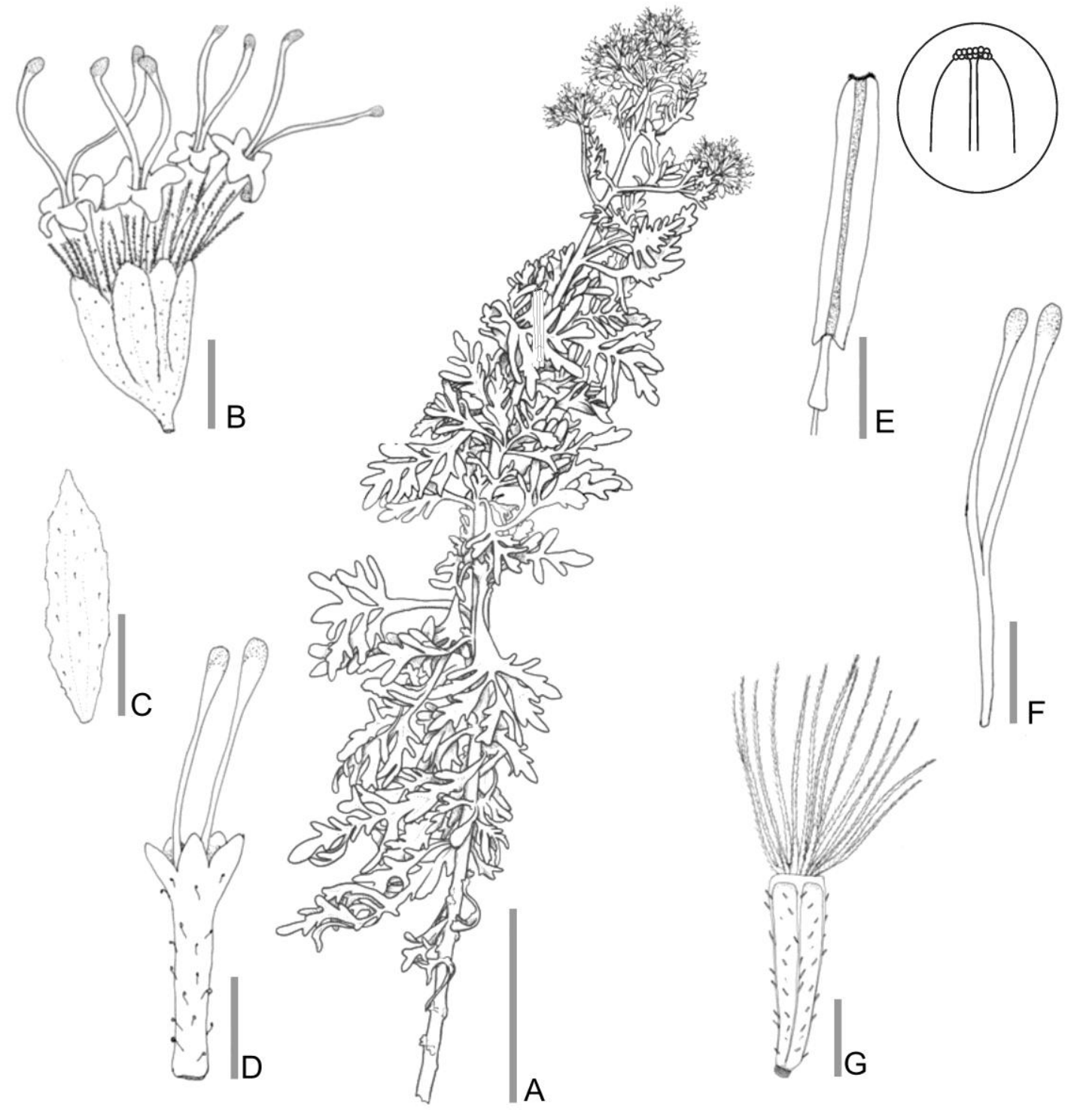

Figura 24. O. bipinnatifidus. A. Rama florífera. B. Capítulo. C. Flor sin papus ni cipsela. D. Filario. E. Antera. F. Estigma. G. Cipsela.Escalas: A: $5 \mathrm{~cm}$; B: 0,25 cm; C: $750 \mu \mathrm{m}$; D: 1 mm; E: $750 \mu \mathrm{m}$; F: $300 \mu \mathrm{m}$; G: $100 \mu \mathrm{m}$. (A-G basados en Mr. and Mrs J. N. Rose 18805, US). 


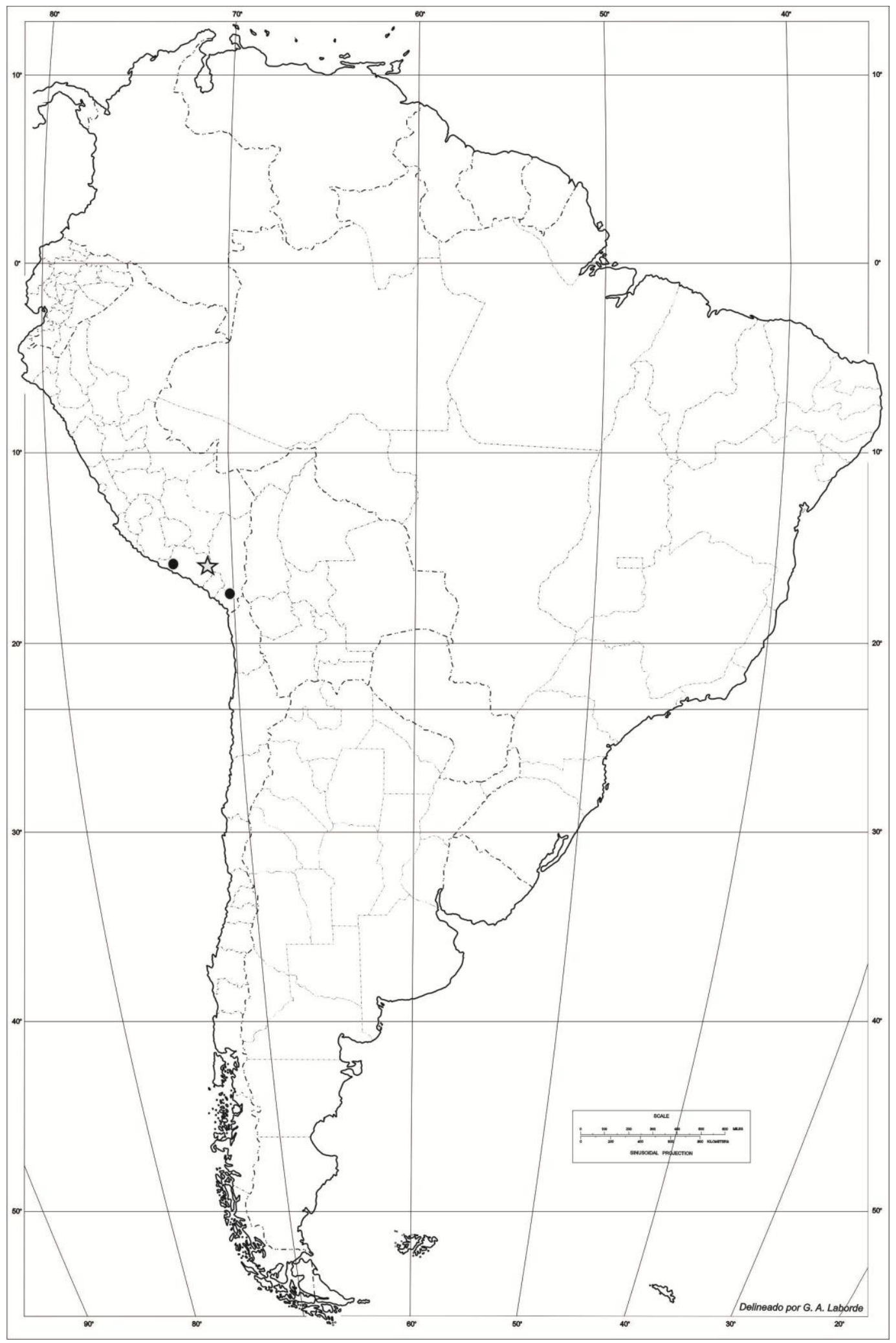

Figura 24. O. bipinnatifidus. Distribución geográfica, la estrella indica la localidad tipo. 


\section{Ophryosporus burkartii Cabrera.}

Boletín de la Sociedad Argentina de Botánica 15: 114-116. 1973.

Tipo: Argentina: "Prov. de Jujuy, Dep. Valle Grande, Caspalá a 3200 msn, subarbusto, flor blanca. 01/03/1940, Arturo Burkart \& Nélida S. Troncoso 11736". Holotipo: LP!, isotipos SI000920! y SI000921! Fig. 26.

Arbusto erecto $(1,5 \mathrm{~m})$. Tallo profusamente ramificado, entrenudos entre $4 \mathrm{y}$ $8,2 \mathrm{~cm}$, ramificaciones secundarias opuestas, ramas subglabras, púrpura, con estriaciones. Hojas opuestas, pecioladas, pecíolo 1-1,5 cm, láminas ovada a ligeramente ovado-lanceolada, $1,8-3 \times 3,5-6,5 \mathrm{~cm}$, base truncada, ápice acuminado, margen dentado, plano, con dientes de primer y segundo orden, consistencia delicadamente herbácea, venación acródroma imperfecta suprabasal;pubescente, tricomas eglandulares simples cónicos. Inflorescencia cimoidea, compuesta de corimbos laxos; terminal y axilar, con hojas persistentes poco desarrolladas. Capítulos ca. 130-250, pedunculados (0,3-0,5 mm), 3,2 × 5 $\mathrm{mm}$. Involucro acampanado, 2,5 × $4 \mathrm{~mm}$, filarios 5, eximbricados, en una serie de filarios; ápice fimbriado, margen entero, consistencia herbácea; lanceolados, 1-1,2 $x$ 4,5 mm. Flores 5, hermafroditas, corola blanca, infundibuliforme, con paso gradual entre tubo y limbo, tubo $1,5 \times 0,4 \mathrm{~mm}$, limbo $1 \times 0,4 \mathrm{~mm}$, lóbulo $0,3 \times 0,4$ $\mathrm{mm}$; 5-dentada, glandulosa, tricomas glandulares (tipo $\alpha$ ). Estambres 5, anteras $0,9 \times 0,3 \mathrm{~mm}$, collar anteral cilíndrico, base de la teca levemente auriculada; apéndice conectival nulo. Estilo $5,2 \mathrm{~mm}$, largamente exerto, ramas del estilo clavadas en el ápice, 2,7 mm. Cipsela negra no estipitada piriforme, 2,5 mm, marcadamente 5-costada; serícea, pelos gemelos en las costillas; carpopodio anular, excéntrico. Papus formado por 20 cerdas blanco-amarillentas, conadas en la base, 3-4,2 mm. Fig. 27.

Fenología: Florece de enero a marzo.

Distribución: Argentina (provincia de Jujuy) a 3000-3200 msnm, hábitat prepuneño. Fig. 28. 


\section{Notas:}

1. Especie conocida únicamente en la localidad tipo.

2. Especie afín de O. Iorentzii, pero con hojas menores, involucro pubescente y aquenios velludos en los ángulos (Cabrera, 1978).

Etimología: Hace referencia al colector del material tipo, el botánico argentino Arturo Burkart (1906-1975).

Estado de Conservación: De acuerdo a Delucchi \& Plos (2011), le corresponde la categoría CR de la UICN, en riesgo crítico, debido a su escasa distribución geográfica (es conocida sólo en la localidad tipo). El proyecto PlanEAr (2012), le adjudica la categoría $\mathbf{5}$, plantas de distribución restringida con poblaciones escasas o sobre las que se presume que puedan actuar uno o más factores de amenaza (destrucción de hábitat, sobreexplotación, invasiones biológicas, etc.).

Especímenes adicionales estudiados: ARGENTINA. Jujuy: Valle Grande, Caspalá, 18/01/1974, R. Kiesling et al. 455 (LP, SI); ib. 12/03/1967, H. A. Fabris \& J. V. Crisci 6914 (LP, SI). 


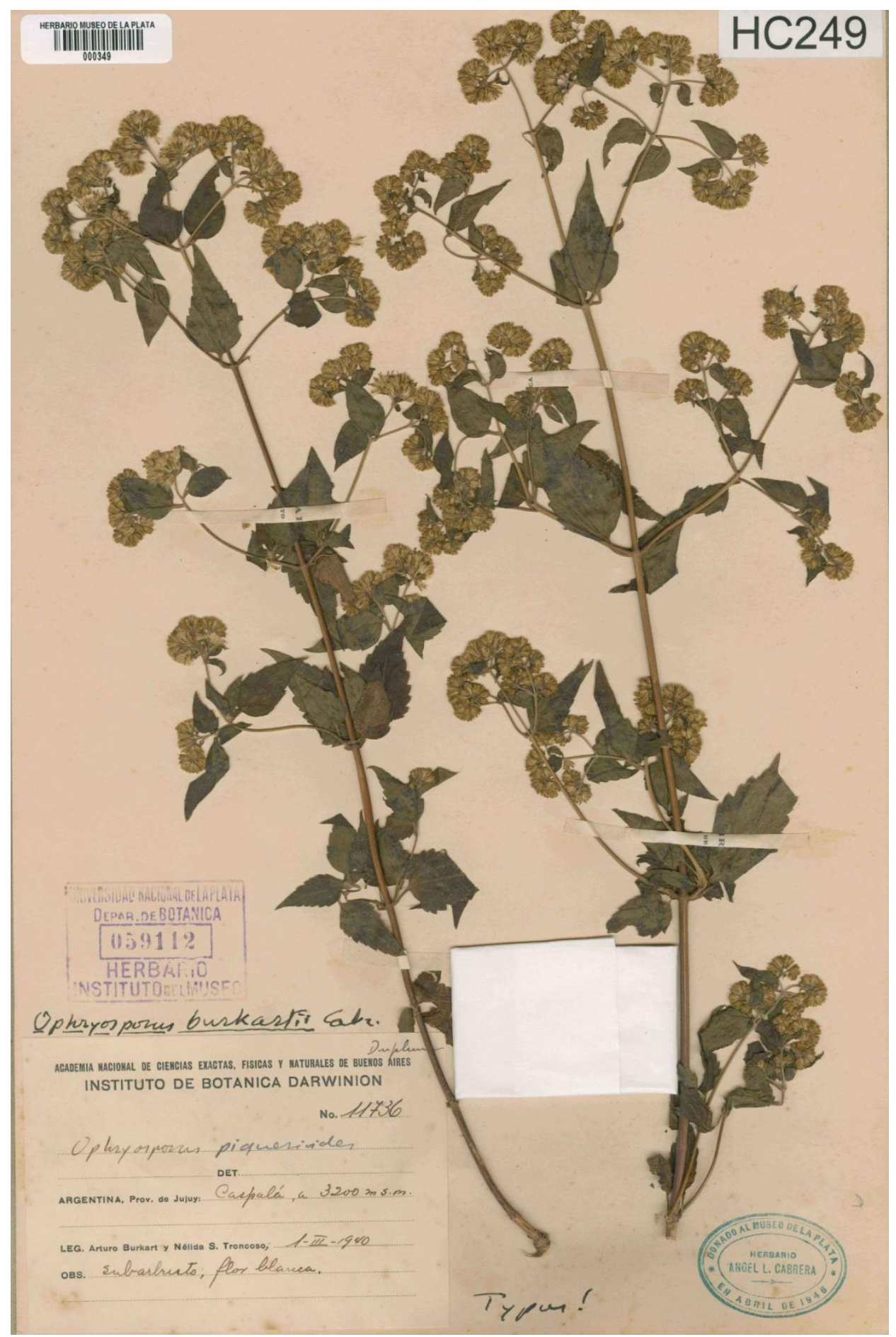

Figura 26. O. burkartii, holotipo. A. Burkat \& N. S. Troncoso 11736 (LP). 

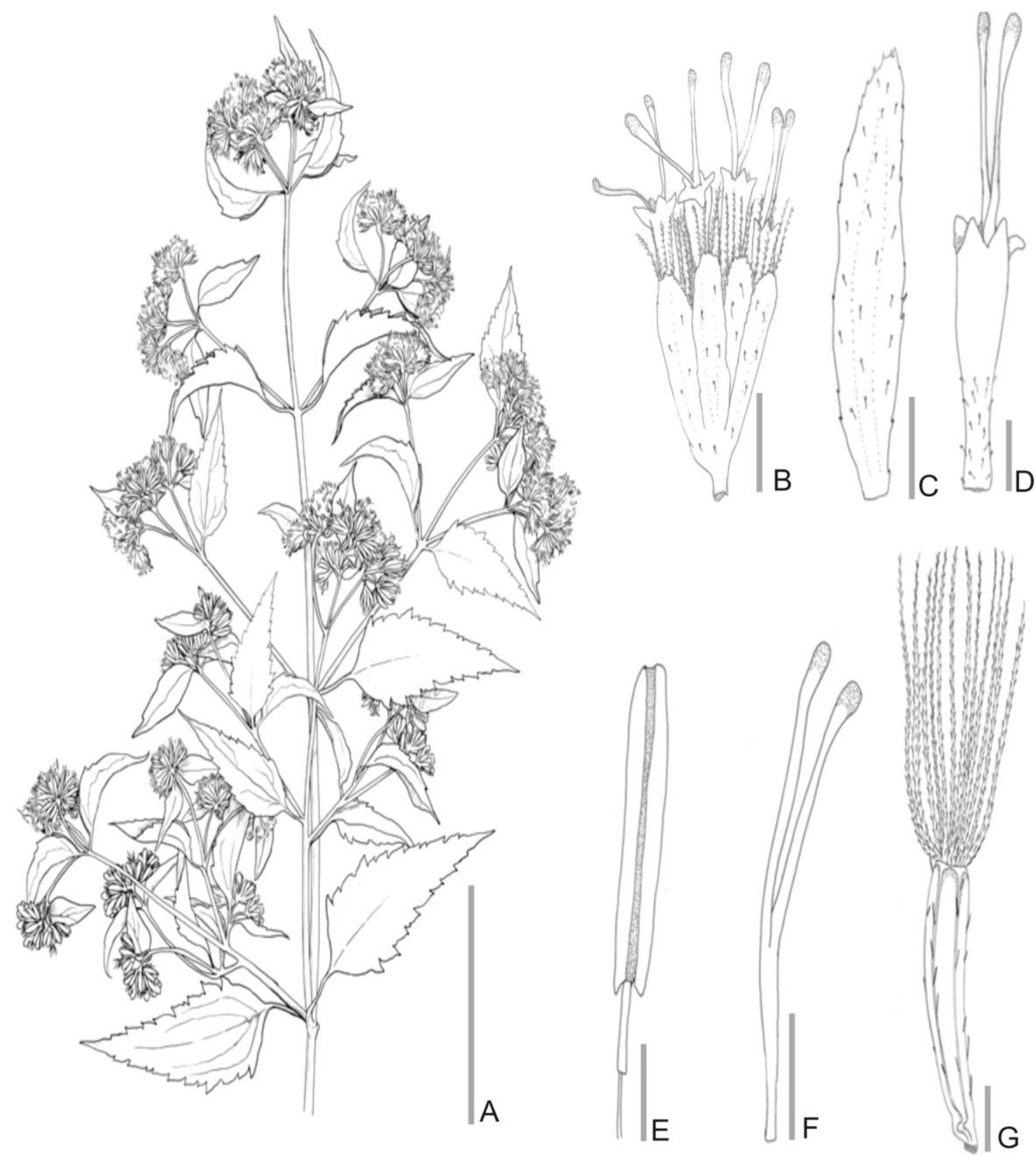

Figura 27. O. burkartii. A. Rama florífera. B. Capítulo. C. Flor sin papus ni cipsela. D. Filario. E. Antera. F. Estigma. G. Cipsela. Escalas: A: 5 cm; B: 2 mm; C-E: 500

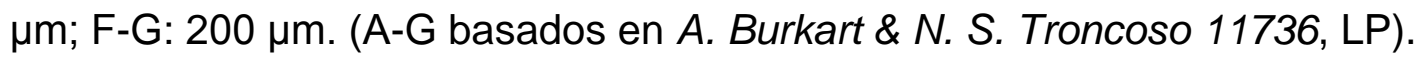




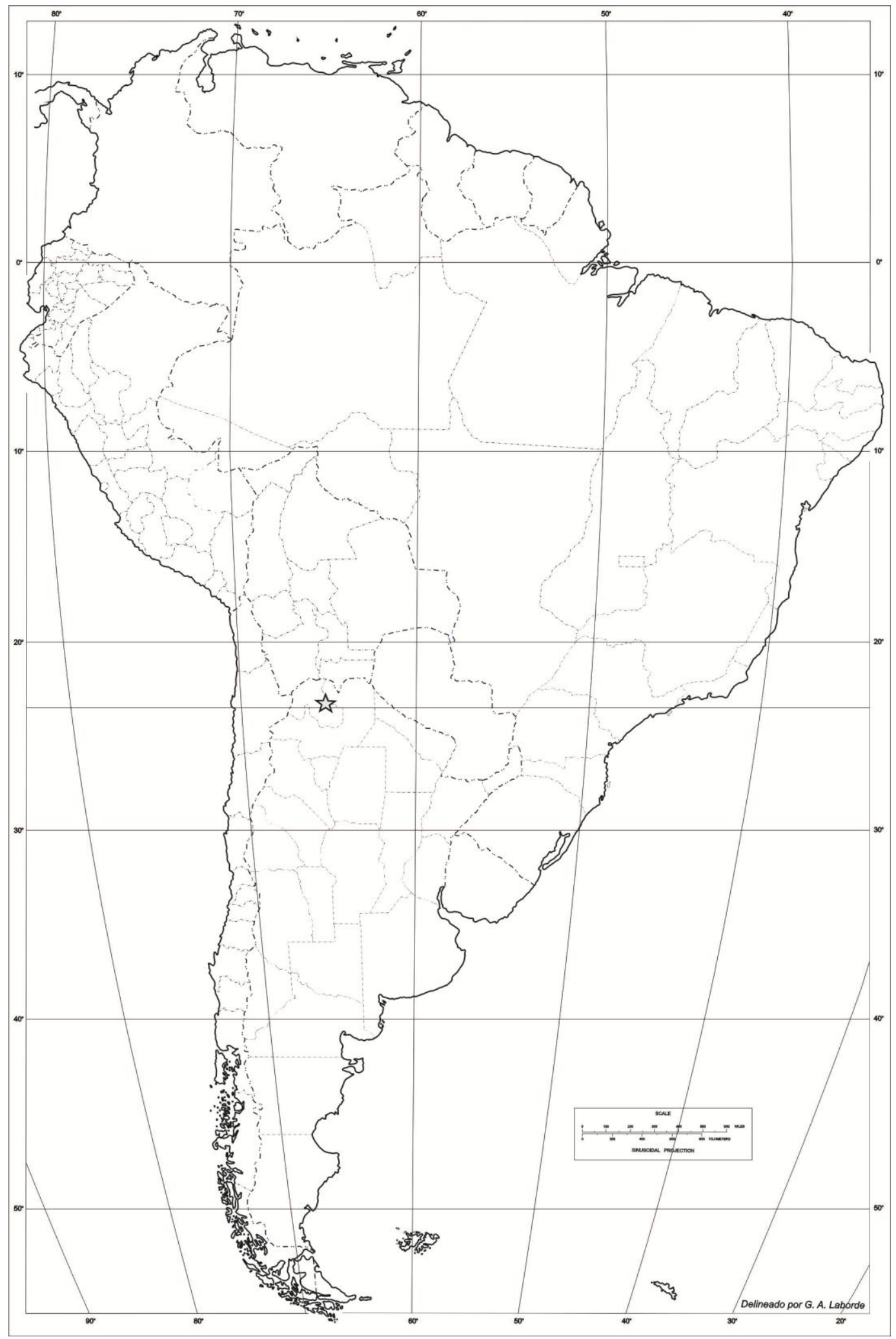

Figura 28. O. burkartii. Distribución geográfica, la estrella indica la localidad tipo. 


\section{Ophryosporus carchiensis H. Rob.}

Phytologia 84 (5): 350-351. 1998.

Tipo: Ecuador: "Carchi: Montufar Canton, Loma El Corazón (Bretaña) al SE de Mariscal Sucre, Río Minas. Bosque muy húmedo. Montano. $00^{\circ} 35^{\prime} \mathrm{N} 77^{\circ} 42^{\prime} \mathrm{W}$. 3150 m. Liana sobre sotobosque. Capítulos verdes. Lígulas crema. 22-23/12/1992. Walter Palacios \& G. Tipaz 10524". Holotipo: US!, isotipo: MO no visto. Fig. 29.

Arbusto apoyante, profusamente ramificado. Tallo con entrenudos entre 5,8 y $8,5 \mathrm{~cm}$, ramificaciones secundarias opuestas, ramas tomentosas, marrón claro a rojizo, con estriaciones. Hojas opuestas, pecioladas, pecíolo 3-8 cm, láminas ovadas, $1-1,8 \times 1,8-2,8 \mathrm{~cm}$, base redondeada, ápice acuminado, margen dentado, plano; consistencia herbácea, venación acródroma imperfecta suprabasal; pubescente y glandulosa, tricomas eglandulares simples cónicos y glandulares (tipo $\beta$ ). Inflorescencia cimoidea, compuesta de corimbos laxos; terminal y axilar, con hojas persistentes poco desarrolladas. Capítulos ca. 50-80, pedunculados (1-2 mm), $3 \times 4,5 \mathrm{~mm}$. Involucro acampanado, $2 \times 3,6 \mathrm{~mm}$; filarios 5-6, eximbricados; en dos series de filarios, los externos ovados, $1 \times 3 \mathrm{~mm}$, los internos ovado-lanceolados, $1,2 \times 3,5 \mathrm{~mm}$; ápice fimbriado, margen entero, consistencia herbácea, a veces con porciones esclerificadas en el centro; glabros. Flores 6-7, hermafroditas, corola blanca, infundibuliforme, con paso gradual entre tubo y limbo, tubo $1 \times$ 0,6 mm, limbo 1,3 x 0,4 mm, 5-dentada, lóbulo 0,7 × 0,4 mm; glandulosa sólo en la base del tubo, tricomas glandulares (tipo a). Estambres 5, anteras $0,75 \times 0,25 \mathrm{~mm}$, collar anteral cilíndrico, base de la teca obtusa; apéndice conectival nulo. Estilo 4,8 mm, largamente exerto, ramas del estilo fuertemente clavadas en el ápice, ápices más oscuros que el resto de las ramas, las ramas 1,8 $\mathrm{mm}$. Cipsela negra ligeramente estipitada, piriforme, 1,2 mm, marcadamente 5costada; serícea, pelos gemelos escasos en las costillas; carpopodio anular, central. Papus formado por 20-23 cerdas amarillo-blanquecinas, connadas en la base, 2-2,3 mm. Fig. 30.

Fenología: Florece en diciembre. 
Distribución: Ecuador (provincia de Carchi) a 3150 msnm. Hábitat bosque muy húmedo, montano. Fig. 31.

\section{Notas:}

1. Esta especie es conocida únicamente por la colección tipo (la cual consta de 3 especímenes). El material tipo supuestamente depositado en QCNE, nunca fue enviado a dicho herbario.

2. Constituye al representante del género con la distribución norteña extrema.

Etimología: Hace referencia a la provincia ecuatoriana en la cual fue hallado el material tipo, Carchi. 


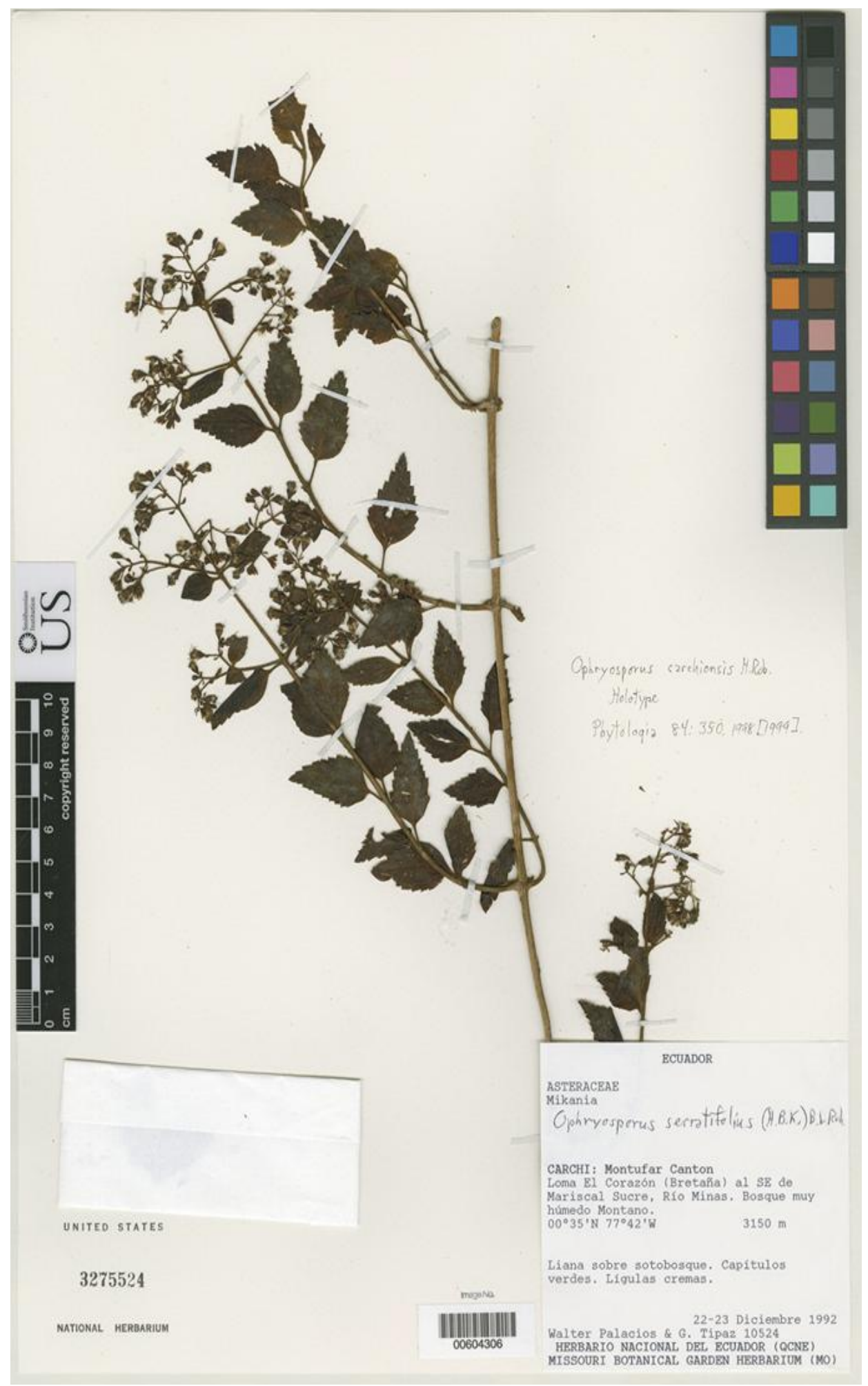

Figura 29. O. carchiensis, holotipo. W. Palacio \& G. Tipaz 10524 (US). 


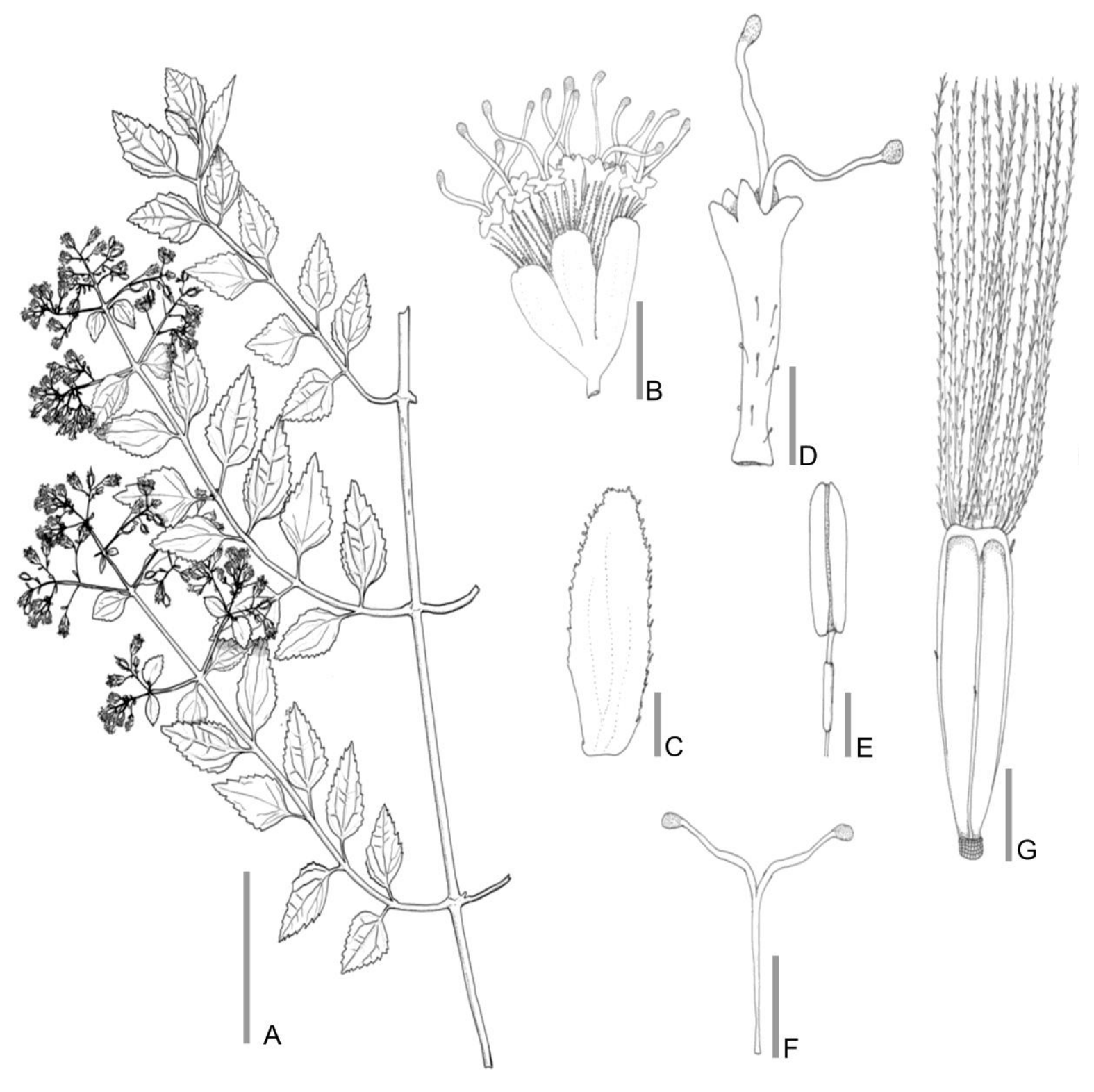

Figura 30. O. carchiensis. A. Rama florífera. B. Capítulo. C. Flor sin papus ni cipsela. D. Filario. E. Antera. F. Estigma. G. Cipsela. Escalas: A: $5 \mathrm{~cm}$; B: $2 \mathrm{~mm}$; C-E: $500 \mu \mathrm{m}$; F: $200 \mu \mathrm{m}$; G: $750 \mu \mathrm{m}$. (A-G basados en W. Palacio \& G. Tipaz 10524, US). 


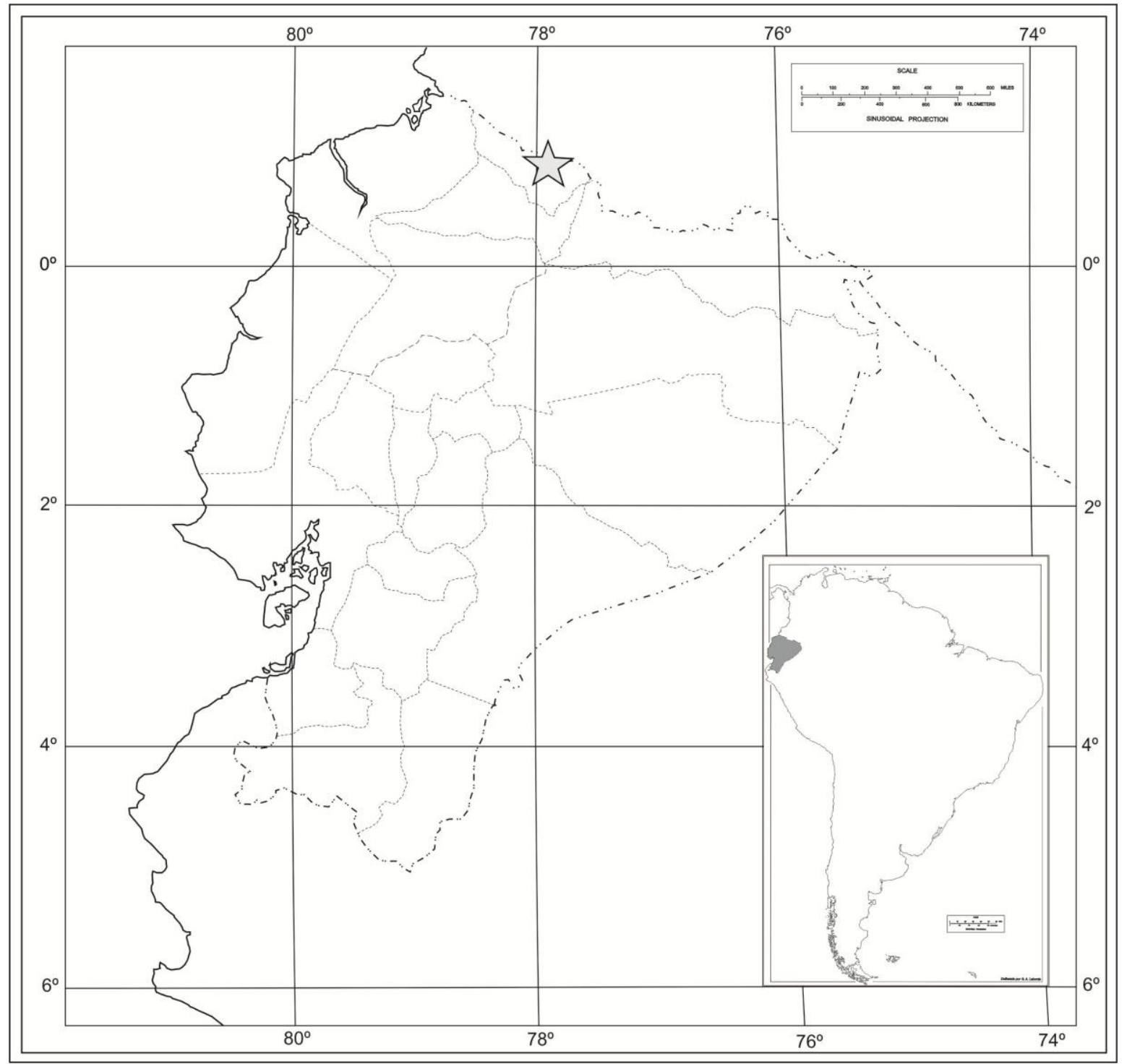

Figura 31. O. carchiensis. Distribución geográfica, la estrella indica la localidad tipo. 


\section{Ophryosporus charua (Griseb.) Hieron.}

Botanische Jahrbücher für Systematik, Pflanzengeschichte und Pflanzengeographie 22: 705-706. 1897.

\section{三 Mikania charua Griseb.}

Abhandlungen der Königlichen Gesellschaft der Wissenschaften zu Göttingen 24: 174. 1879.

Symbolae ad Floram Argentinam. Zweite Bearbeitung argentinischer Pflanzen, mach den durch die Regierung zu Buenos Ayres veranstalteten Sammlungen der Professoren Lorentz und Hieronymus, so wie den im Museum zu Göttingen aufbewahrten Herbarien anderer Naturforscher: 174. 1879.

Tipo: Argentina: "Catamarca, Yacutula (por Yacu-Tula), 10/1872, F. Schickendantz 3". Holotipo: GOET (http://plants.jstor.org/specimen/goet001856); isotipo CORD!. Fig. 32.

= Willoughbya charua (Griseb.) Kuntze. Revisio Generum Plantarum 1(1): 372. 1891.

Arbusto erecto $(0,7-2 \mathrm{~m})$. Tallo con entrenudos entre 8 y $13 \mathrm{~cm}$, ramificaciones secundarias opuestas, ramas glabras, marrón claro a púrpura, con estriaciones. Hojas opuestas, pecioladas, pecíolo 0,5-1,2 cm, láminas ovadas a ovado-lanceoladas, 1-1,5 x 3-6 cm, base cuneada, ápice agudo, margen dentado, plano; consistencia herbácea, venación acródroma imperfecta suprabasal; pubescente, tricomas eglandulares simples cónicos. Inflorescencia cimoidea, compuesta de glomérulos densos; terminal y axilar, con hojas persistentes poco desarrolladas. Capítulos ca. 300, pedunculados $(1-2,8 \mathrm{~mm}), 2,7 \times 4,5 \mathrm{~mm}$. Involucro acampanado, 1,5 x 3,5 mm; filarios 4, eximbricados; en una serie de filarios, lanceolado-ovados, 1 X $3,5 \mathrm{~mm}$; ápice fimbriado, margen entero, consistencia herbácea; pubescente, tricomas eglandulares simples cónicos. Flores 4, hermafroditas, corola blanca, infundibuliforme, sin paso gradual entre tubo y limbo, tubo $0,3 \times 0,6 \mathrm{~mm}$, limbo $0,5 \times, 1 \mathrm{~mm}$, 5-dentada, lóbulo 0,4 x 0,5 
mm; pubescente sólo en la base del tubo, tricomas eglandulares simples cónicos. Estambres 5, anteras $0,2 \times 1,2 \mathrm{~mm}$, collar anteral cilíndrico, base de la teca auriculada; apéndice conectival rudimentario, con surco medial. Estilo $4 \mathrm{~mm}$, largamente exerto, ramas del estilo fuertemente clavadas en el ápice, ápices más oscuros que el resto de las ramas, las ramas $1,5 \mathrm{~mm}$. Cipsela negra ligeramente estipitada, piriforme, levemente falcada, $5 \mathrm{~mm}$, marcadamente 5-costada; glabra; carpopodio cilíndrico, excéntrico. Papus formado por 20-25 cerdas blanquecinas, connadas en la base, 2,5-2,7 mm. Fig. 33.

Fenología: Florece de enero a diciembre.

Distribución: Argentina (provincias de Catamarca, Córdoba, Jujuy, La Rioja, Tucumán, San Juan, San Luis y Salta), entre 500-3500 msnm, hábitat serrano y en pastizales de altura, cerros graminosos y terrenos áridos y duros. Provincias fitogeográficas de yungas, chaqueña y del monte. Fig. 34 .

Nombres comunes: "Chacua" (Grisebach, 1879), "charrua" (Robinson, 1906), "charruga" (Hieronymus 1882; Zardini 1984).

\section{Notas:}

1. La localidad tipo Yacu-Tula, es uno de los oasis que se encuentran en el valle de Belén, en Catamarca.

2. Existe material determinado como $O$. charus, en vez de O. charua debido a un error de tipeo. Lo mismo ocurre en varias citas y materiales determinados como $O$. charrua.

3. Hieronymus (1897) hace referencia a la variación en la longitud del involucro en las especies que habitan en Catamarca, Córdoba y La Rioja, reduciendo su tamaño.

4. Intensamente fragantes (Hunziker et al. $23727 \mathrm{NY}$ ).

Etimología: Hace referencia al nombre común dado a la especie "charrúa".

Estado de Conservación: De acuerdo a Delucchi \& Plos (2011), le corresponde la categoría LC de la UICN, de interés menor, debido a su amplia distribución 
geográfica. En cuanto a la clasificación de PlanEAr (2012), se le otorgó la categoría 3, plantas comunes, aunque no abundantes en una o más de las unidades fitogeográficas del país.

Compuestos químicos de interés: De acuerdo con Hanson (1999), presenta diterpernoides bicíclicos (clerodanes). Hertz (2004) lista la presencia de benzofuranos, dihidrobenzofuranos, cumarinas, cromenos, diterpenos y glicósidos (flavonas, flavonoles y flavononas).

Usos: Se utilizan las hojas como antisifilítico y astringente. Los tallos y hojas sirven como dermopático (De Lampazona et al. 1997, Barboza et al. 2006). Según Zardini (1984), la decocción de la planta se emplea en el tratamiento de enfermedades cutáneas de carácter sifilítico (Hieronymus 1882). Ya Grisebach (1879) hacía referencia a la utilización de la decocción de esta planta para baños.

Especímenes adicionales estudiados: ARGENTINA. Catamarca: Andalgalá, Cuesta del Clavillo, 20/11/1946, A. T. Hunziker 6807 (LP); Cuesta de Capillitas, entre campo de los Pozuelos y el Bolsón de Pipanaco, 15-30/11/2004, $R$. Argarañaz \& M. Azarevich 1957 (MCNS); Las Capillitas, 28/11/1946, E. Wall s.n. (NY); entre Campo del Arenal y Capillitas, 19/09/1946, A. T. Hunziker 6837 (LP); Quebrada del río Pisavil, 26/11/1948, R. Filipovich Urquiza 125 (LIL). Capital, Sierra de Ambato, Quebrada del Tala (ruta prov. 4), cerca de La Calera, a unos 18 km al NO de Catamarca, 10/10/1964, A. T. Hunziker \& A. E. Cocucci 17630 (NY). Paclín, Cuesta de Singuil, 15/10/1966, Fabris 6564 (LP); Pomán, 1939, C. Spegazzini 13673 (LP). Córdoba: Copina, 31/12/1935, A. Burkart 7520 (LP); ib. Sierra Achala, 17/10/1946, A. T. Hunziker 6993 (LP). Ischilín, Ongamira, 25/10/1936, Troncoso, Giardelli \& Nicora 1120 (LP). Jujuy: Región no especificada: Jujuy, 10/1892, O. Kuntze s.n. (NY); Gay s.n. (NY); 1828-1824, Gay 384 (NY). La Rioja: Sanagasta, Sierra de Velazco, 11/1945, J. Morello 5064 (LP); ib. J. Morello 5232 (LP); ib. J. Morello 5337 (LP). San Juan: Angaco, Sierra de Pie de Palo, subiendo por el camino al Mogote Los Corralitos, en la Quebrada del Molle, 28/11/1980, A. T. Hunziker, R. Subils \& A. J. Toledo 23727 (NY). Jáchal, Río de Los Piojos, 9-10/12/1957, Ruiz Leal \& F. Roig 18885 (LP, MERL). San 
Luis: Carolina, Paso del Rey, 01/11/1958, Ruiz Leal 19797 (LP, MERL). Coronel Pringles, Cerros Largos, 12/10/1958, Ruiz Leal 20128 (LP, MERL); El Trapiche, 10/1966, G. Dawson 3486 (LP). Merlo, Peñón Colorado, 18/12/1929, Castellanos 29/480 (LP). Pedernera, Cerro El Morro, Estancia La Morena, 12/10/1958, Ruiz Leal 19704 (LP, MERL). Región no especificada: San Luis FCP, 04/10/1927, D. O. King 310 (LP). Salta: Capital, Quebrada de San Lorenzo, 23/08/1936, A. L. Cabrera 3804 (LP); La Quesera, 18/09/1991, A. Del Castillo s.n. (MCNS). Cafayate, río Colorados, 3-5 al W de Cafayate detrás del camping El Divisadero, 25/09/1999, L. J. Novara \& S. Bruno 11348 (MCNS). Cachi, Pie de la Cuesta del Obispo, 02/11/1971, D. Abbiatti et al. 3225 (LIL); La Paya, $5 \mathrm{~km}$ al O del río Calchaquí, 18/09/1979, L. J. Novara 469 (MCNS). Chicoana y Cachi, Valle Encantado, 15/10/1978, C. Suárez 45 (MCNS); ib. 24/10/1980, C. Suárez 1383 (MCNS); ib. 23/08/1980, L. J. Novara 1270 (MCNS); ib. L. J. Novara 1273 (MCNS); ib. 02/10/1980, Varela, Colina \& Hoy 45 (MCNS); ib. ladera Co del Candado, 31/10/1980, L. J. Novara \& G. Hoy 1413 (MCNS). Guachipas, Quebrada de Guachipas, 12/1896, C. Spegazzini 13605 (LP); El Cebillar, 15-20 km al SE de Guachipas, 22/08/1983, F. Juarez \& A. Del Castillo 215 (MCNS). La Caldera, río Potrero, 2-6 km al sur del Potrero de Castillo, 15/10/1984, L. J. Novara 4300 (MCNS). La Viña, Coronel Moldes, La Hoyada, 14/11/1942, A. Burkart 13290 (LP). Rosario de Lerma, Campo Quijano, al pie del paredón del Dique Las Lomitas, 03/08/1986, L. J. Novara 5475 (MCNS); ib. márgenes del Dique Las Lomitas, 21/09/1980, L. J. Novara 1310 (MCNS); $10 \mathrm{~km}$ al W de la Sillela, Fca. El Manantial, 31/08/1983, A. Del Castillo 71 (MCNS). Tucumán: Chicligasta, Cuesta del Clavillo, 10/1966, Fabris 6571 (LP). Tafí del Valle, camino de Villa Nogués a San Javier, 29/08/1963, Lognamo \& Cuezzo 4149 (LIL); La Cienaguita, 03/01/1913, D. Rodriguez 1326 (LP); entre Abra del Infiernillo y Amaicha, 19/10/1948, Ruiz Leal 12303 (LP, MERL); Ruta Provincial 307, Amaicha del Valle, 08/11/1978, S. A. Renvoize, M. Wilmot-Dear \& R. Kiesling 3395 (NY); Siambón, 02/10/1944, R. Díaz s.n. (NY); Sierras de San Javier, 28/09/1923, S. Venturi 2602 (MO); ib. ladera occidental, 07/12/1938, A. P. Rodrigo 2035 (NY); ib. faldeos al W, El Portezuelo, 20/08/1962, F. Vervoorst 7266 (LIL); Tafí Viejo, Saladillo, 
20/10/1907, Lillo 7137 (MO); Taficillo, 03/09/1950, H. Sleumer 749 (LIL); ib., 21/10/1955, De la Sota 365 (LIL). Trancas, Sierra de la Candelaria, 25/08/1924, S. Venturi 3490 (LIL); Tapia, 10/10/1920, S. Venturi 964 (LP). Yerba Buena, Parque Aconquija, Cerro San Javier, 12/10/1948, Ruiz Leal 12158 (LP, MERL). 


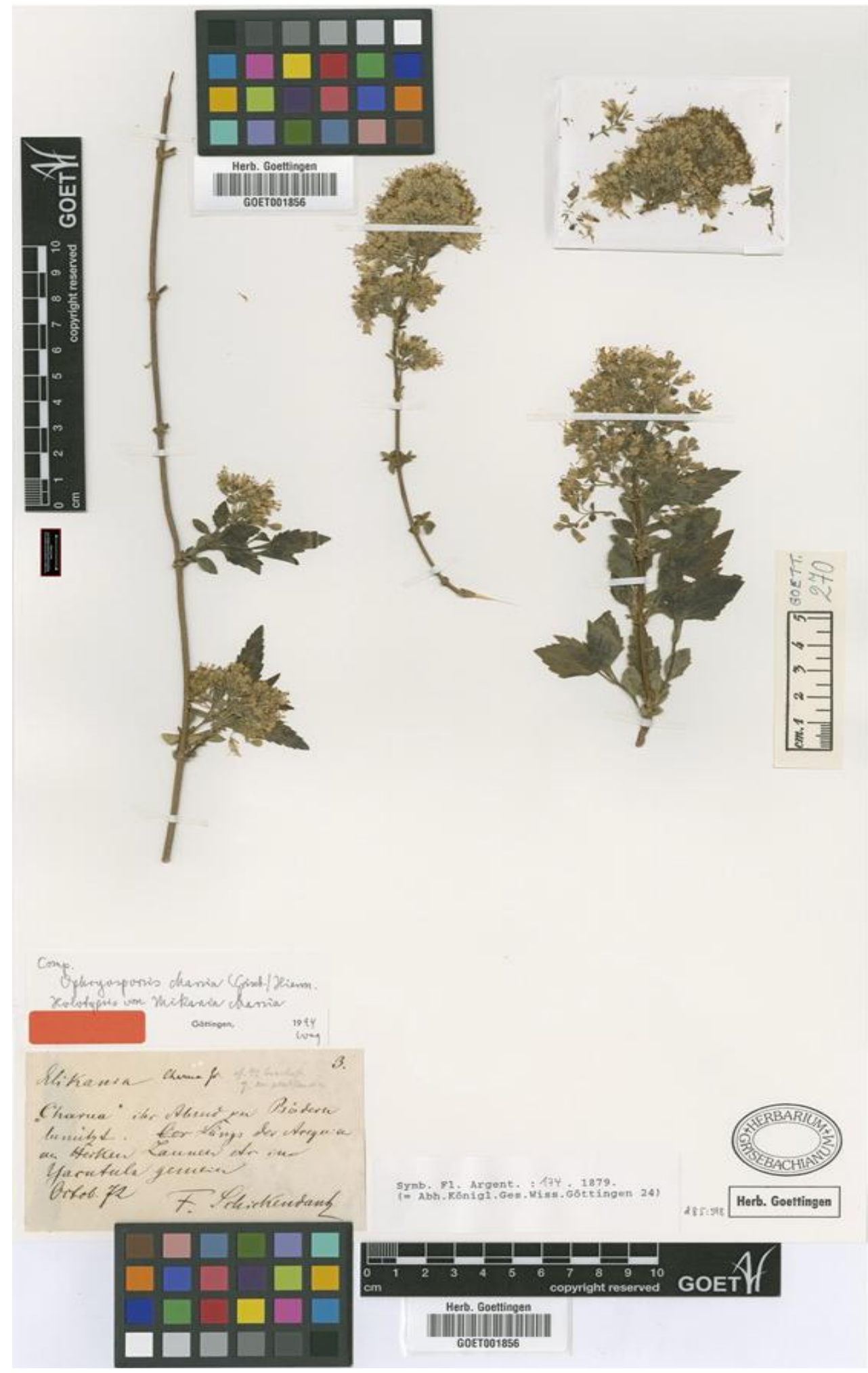

Figura 32. O. charua, holotipo. F. Schickendantz 3 (GOET). 

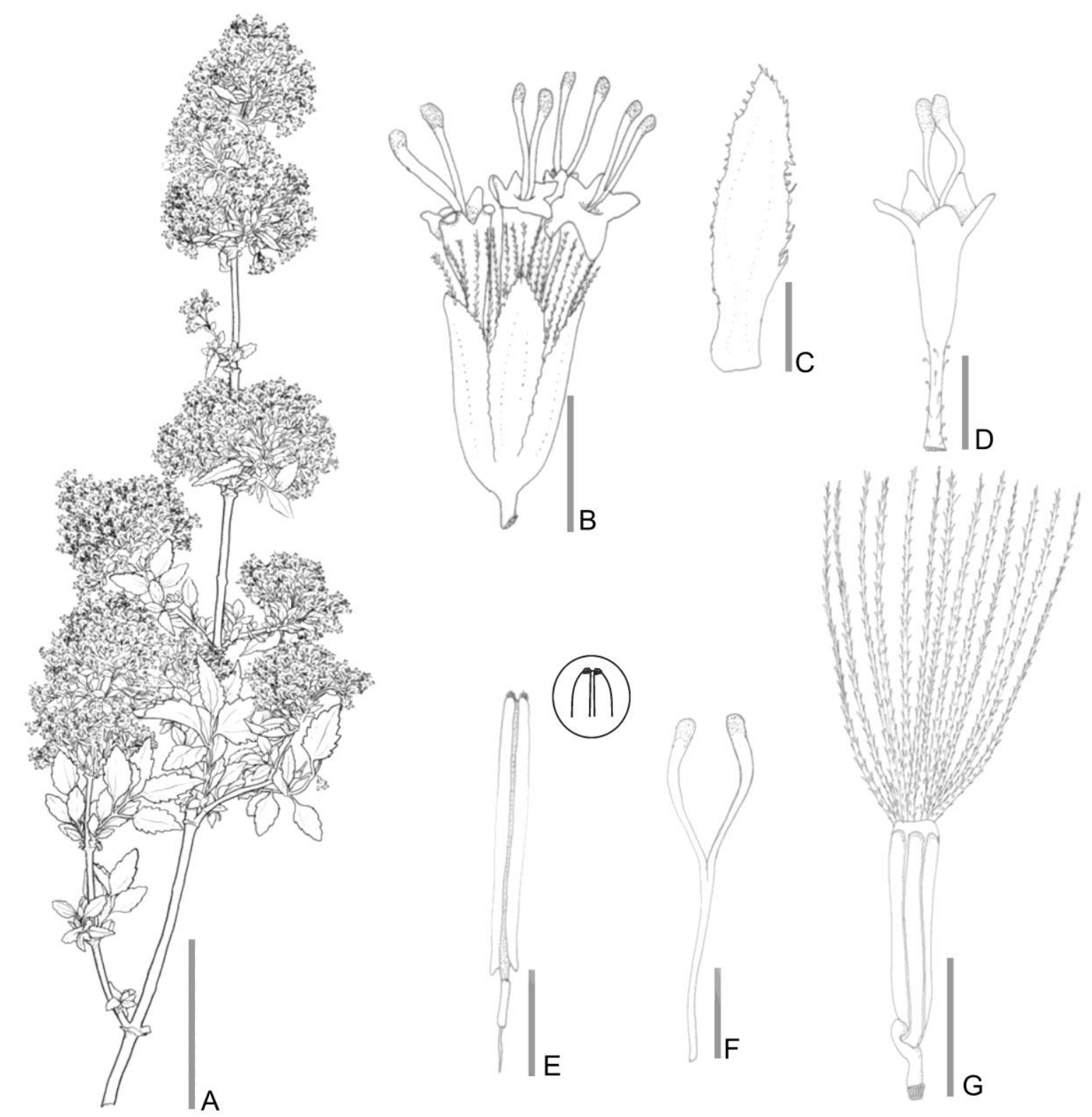

Figura 33. O. charua. A. Rama florífera. B. Capítulo. C. Flor sin papus ni cipsela. D. Filario. E. Antera. F. Estigma. G. Cipsela. Escalas: A: 5 cm; B: 2 mm; C-E: 500 $\mu \mathrm{m} ; \mathrm{F}: 200 \mu \mathrm{m}$; G: $300 \mu \mathrm{m}$. (A basado en E. Wall s.n., NY, B-E basados en Fabris 6564, LP). 


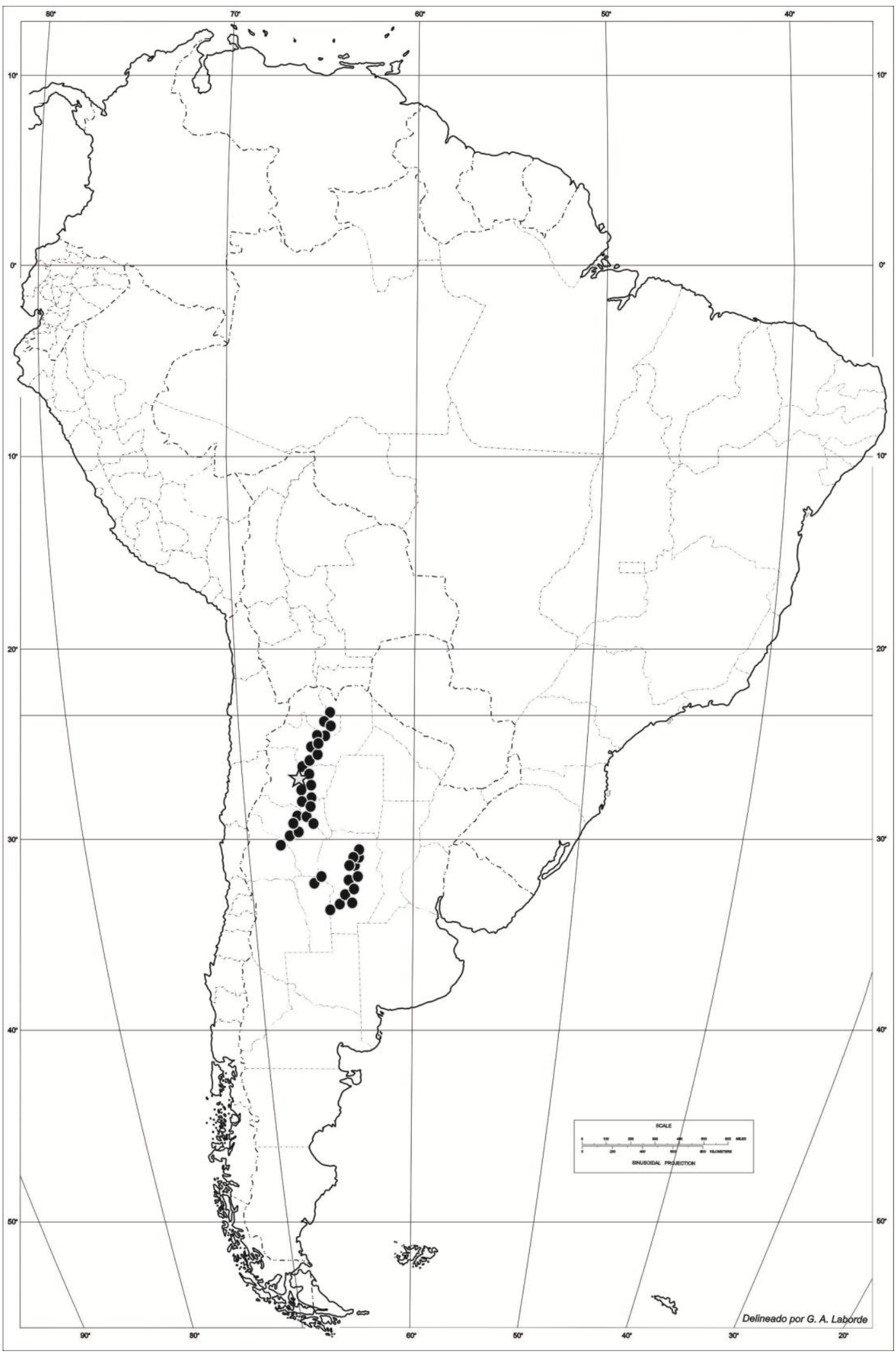

Figura 34. O. charua. Distribución geográfica, la estrella indica la localidad tipo. 


\section{Ophryosporus chilca (Kunth) Hieron.}

Botanische Jahrbücher für Systematik, Pflanzengeschichte und Pflanzengeographie 22: 705-706. 1897.

\section{E Eupatorium chilca Kunth en H. B. K.}

Nova Genera et Species Plantarum (folio ed.) 4: 98. 1820 [1818]. También en quarto ed. 4: 125-126 (1820).

Tipo: Perú: "Crescit in radicibus montis Santæ Poloniæ juxta urbem Caxamarca Peruvianorum, atl. 1480 hex. $\hbar$.Floret Augusto" Humboldt \& Bonpland 3682. Holotipo: P no visto; isotipos: fragmento P 00742277 foto!, GH foto!. Fig. 35.

= Eupatorium affine Kunth. in H. B. K. Nova Genera et Species Plantarum (folio ed.) 4: 98-99. 1820 [1818]. También en quarto ed. 4: 125-126 (1820). "Crescit cum præcedente".

Arbusto erecto $(2 \mathrm{~m})$, profusamente ramificado. Tallo con entrenudos entre 6 y $12 \mathrm{~cm}$, ramificaciones secundarias opuestas, ramas glabras, púrpura. Hojas opuestas, pecioladas, pecíolo 0,2-0,6 cm, láminas ovadas a ovado-lanceoladas, 0,5-1,2 x 2-4 cm, base cuneada, ápice agudo, margen denticulado, plano; consistencia delicadamente herbácea, venación acródroma imperfecta suprabasal; glandulosa, tricomas glandulares (tipo a). Inflorescencia cimoidea, compuesta de corimbos densos; terminal y axilar, con hojas persistentes bien desarrolladas. Capítulos 300, pedunculados (1-3 mm), 2,6 x $4 \mathrm{~mm}$, discoides, homógamos. Involucro acampanado, $2 \times 3,2 \mathrm{~mm}$; filarios 4-6, eximbricados; en una serie de filarios, ovado-lanceolados, $0,8 \times 3,2 \mathrm{~mm}$; ápices fimbriados, margen entero, consistencia herbácea, a veces con porciones esclerificadas en el centro; glandulosos, tricomas glandulares (tipo a). Flores 4-5, hermafroditas, corola blanquecina a verdoso amarillenta, infundibuliforme, sin paso gradual entre tubo y limbo, tubo 0,3 × $2 \mathrm{~mm}$, limbo 0,7 × 1,5 mm, 5-dentada, lóbulo 0,3 × 0,7 mm; glandulosa en toda la corola, más denso en el tubo, tricomas glandulares (tipo $\alpha$ ). Estambres 5, anteras $1 \times 0,2 \mathrm{~mm}$, collar anteral cilíndrico, base de la teca 
auriculada; apéndice conectival nulo. Estilo 4,2 mm, largamente exerto, ramas del estilo fuertemente clavadas en el ápice, ápices más oscuros que el resto de las ramas, las ramas $0,7 \mathrm{~mm}$. Cipsela negra ligeramente estipitada, piriforme, 2,4 $\mathrm{mm}$, marcadamente 5-costada; seríceas, pelos gemelos en costillas; carpopodio cilíndrico, excéntrico. Papus formado por 18-20 cerdas blanquecinas, connadas en la base, 2-2,2 mm. $n=10$ (Robinson et al., 1989). Fig. 36.

Fenología: Florece de mayo a octubre.

Distribución: Ecuador (provincias de Cañar y Loja) y Perú (departamentos de Ancash, Cajamarca y La Libertad), entre 2400-3800 msnm. Habita en pastizales secos de altura. Fig. 37.

Nombres comunes: "Sheklla" (Smith $10574 \mathrm{MO})$.

\section{Notas:}

1. En el fragmento de material presente en $\mathrm{GH}$, hay un error en la numeración, ya que se indica Humboldt \& Bonpland 3082 (numeración correspondiente a Amaranthus quitensis Kunth) en vez de Humboldt \& Bonpland 3682.

2. En la revisión Robinson (1906), queda como especie excluída, ya que posee (según el autor) apéndices anterales y debe ser restituido como Eupatorium chilca Kunth. Posteriormente, en 1920, lo reconoce como Ophryosporus chilca (Kunth) Hieron.

3. Eupatorium affine Kunth corresponde a una forma de hojas más largas de E. chilca (Robinson, 1920).

4. Resinoso (López \& Sagástegui 8220 MO).

Etimología: Hace referencia al nombre común utilizado para muchas eupatoreas, "chilca".

Estado de Conservación: Es frecuente en zonas disturbadas, con actividad agrícola y bordes de caminos. 
Compuestos químicos de interés: Bohlmann et al. (1984), cita la presencia de éster cinamilico 2 y 2 oxo-labda-8(17),13dien-15-ol. Herz (2004) cita la presencia cumarinas, cromenos y diterpenos.

Usos: Las hojas maceradas se utilizan como emplasto en caso de dislocaciones (Smith $10574 \mathrm{MO}$ ).

Especímenes adicionales estudiados: PERU. Ancash: Carhuaz, Huascarán National Park, Quebrada Honda, valley bottom, 09 19' S $77^{\circ} 28^{\prime}$ W, 04/10/1985, D. N. Smith, M. Buddensiek \& R. Valencia 11690 (MO); ib. Quebrada Ulta, north side of valley, $09^{\circ} 07^{\prime} \mathrm{S} 77^{\circ} 32^{\prime} \mathrm{W}, 29 / 07 / 1985$, D. N. Smith 11415 (MO). Chiquian, (15 Km SE), 10 10' S 77²02' W, 11/06/1981, K. Young \& M. Eisenberg 901 (MO, NY). Huaylas, Huascarán National Park, Parón Valley, 09 01' S $77^{\circ} 43^{\prime} \mathrm{W}$, 08/05/1985, D. N. Smith 10574 (MO); ib. 29/10/1985, D. N. Smith 11547 (MO). Huaraz, Cerro San Cristóbal, 08/07/1977, M. Evangelista s.n. (MO). Yungay, entre Yungay y Llanganuco, 09/08/1986, J. Mostacero L. et al. 1376 (NY). Cajamarca: Cajamarca, Cajamarca-Caledón road, between Cajamarca and Pampa de la Culebra, 31/05/1984, D. N. Smith 7370 (MO); Cajamarca-Celedin road, between

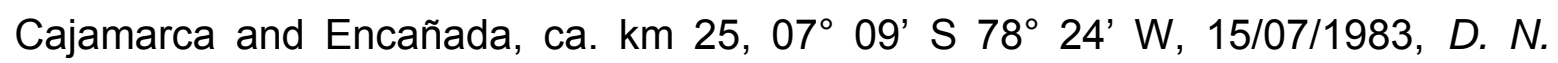
Smith \& I. Sánchez V. 4242 (MO); Cajamarca, Caserío Otuzco, 16/06/1975, A. Sagástegui A., J. Cabanillas S. \& O. Dios C. 8039 (MO); Cajamarca, Pullucana (Arriba de Baños del Inca), 17/08/1984, A. Sagástegui A., J. Mostacero \& S. Leiva 12002 (MO). Contumazá, alrededores Contumazá, 25/05/1981, A. Sagástegui A., S. López \& J. Mostacero 9840 (MO); margen río Contumazá, 06/08/1995, E. Rodríguez R. et al. 405 (MO); Lledén, 28/06/1983, A. Sagástegui A., J. Mostacero L. \& E. Alvitez I. 10840 (NY). La Encañada, 17/08/1973, A. Sagástegui A. 7770 (MO). La Libertad: Otuzco, Salpo-Chanchacap, 29/05/1984, A. Sagástegui A., M. Diestra \& S. Leyva 11651 (MO, NY). Pataz, Huancaspata-Puente Mamahuaje, 26/06/1974, A. López M. \& A. Sagástegui A. 8220 (MO). Santiago de Chuce, alrededores de Santiago de Chuce, 13/06/1984, A. Sagástegui A., J. Mostacero L. \& M. Diestra Q. $11719(\mathrm{MO})$. 


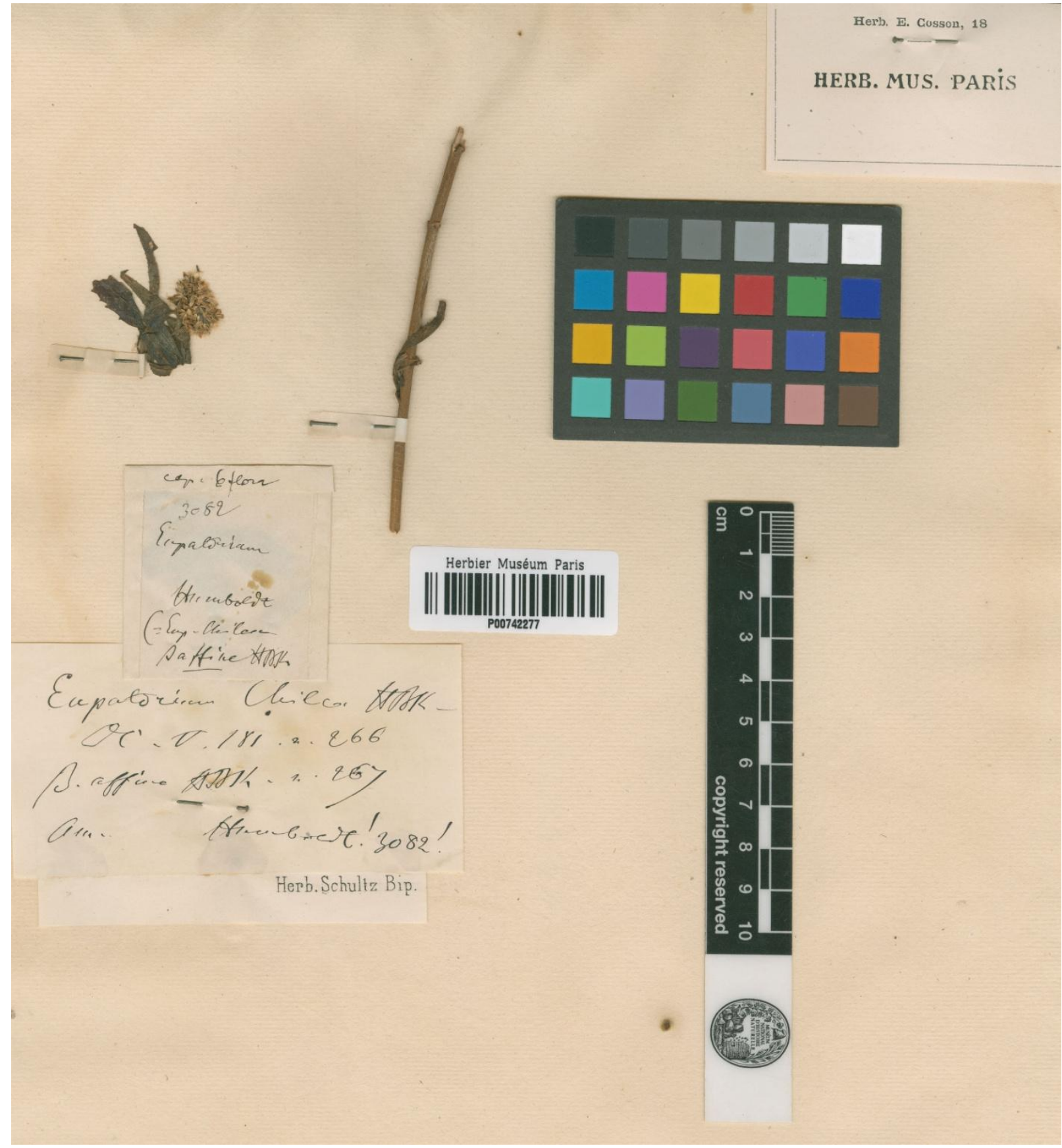

Figura 35. O. chilca, fragmento del holotipo. Humboldt \& Bonpland $3682(\mathrm{P})$. 

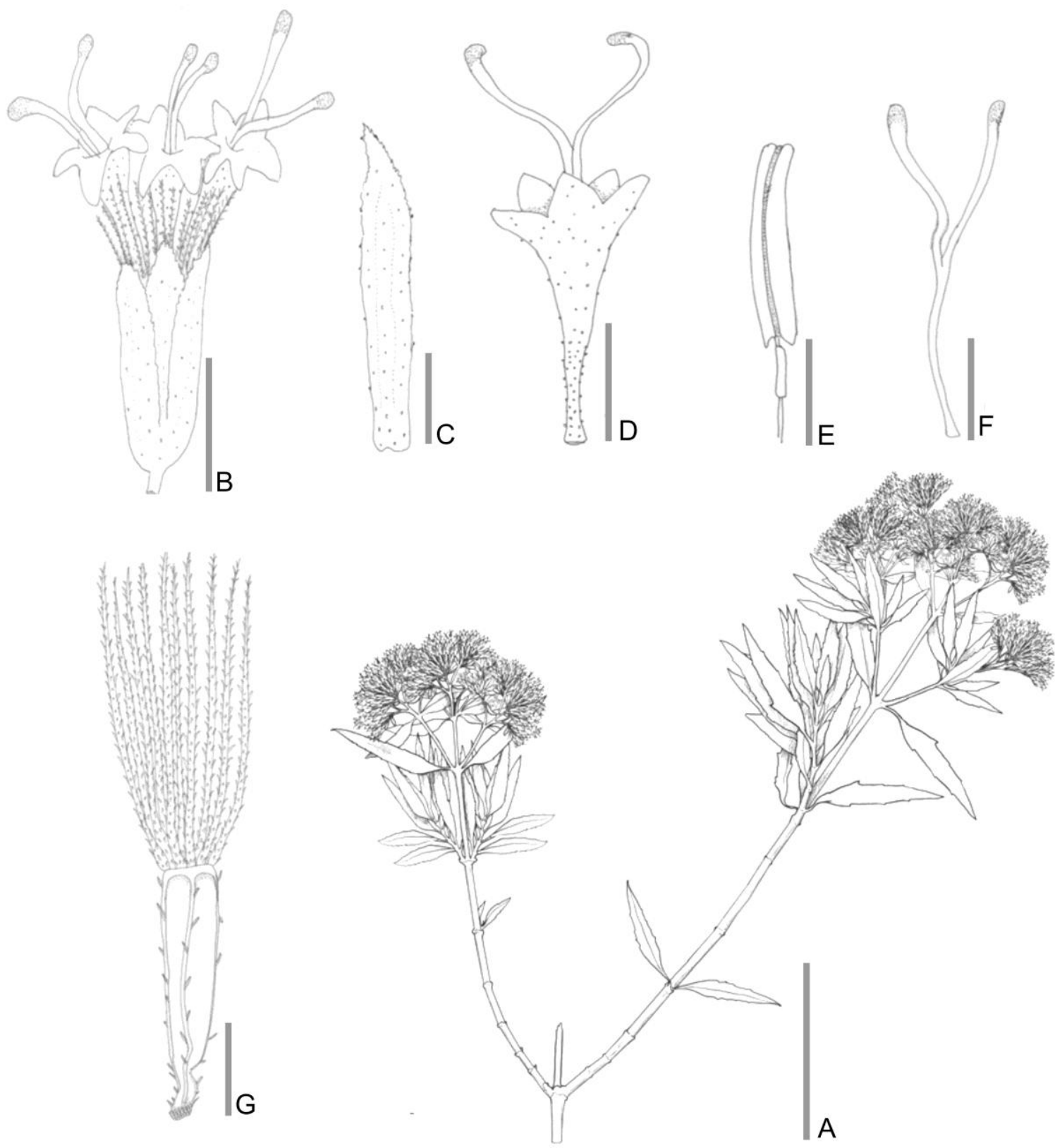

Figura 36. O. chilca. A. Rama florífera. B. Capítulo. C. Flor sin papus ni cipsela. D.

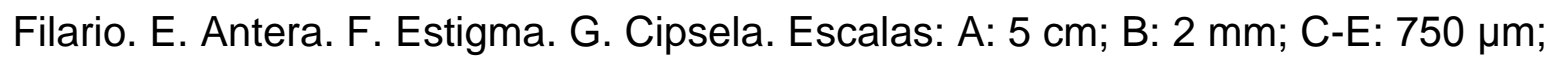
F: $300 \mu \mathrm{m}$; G: $750 \mu \mathrm{m}$ (A-G basados en Smith 11415, MO). 


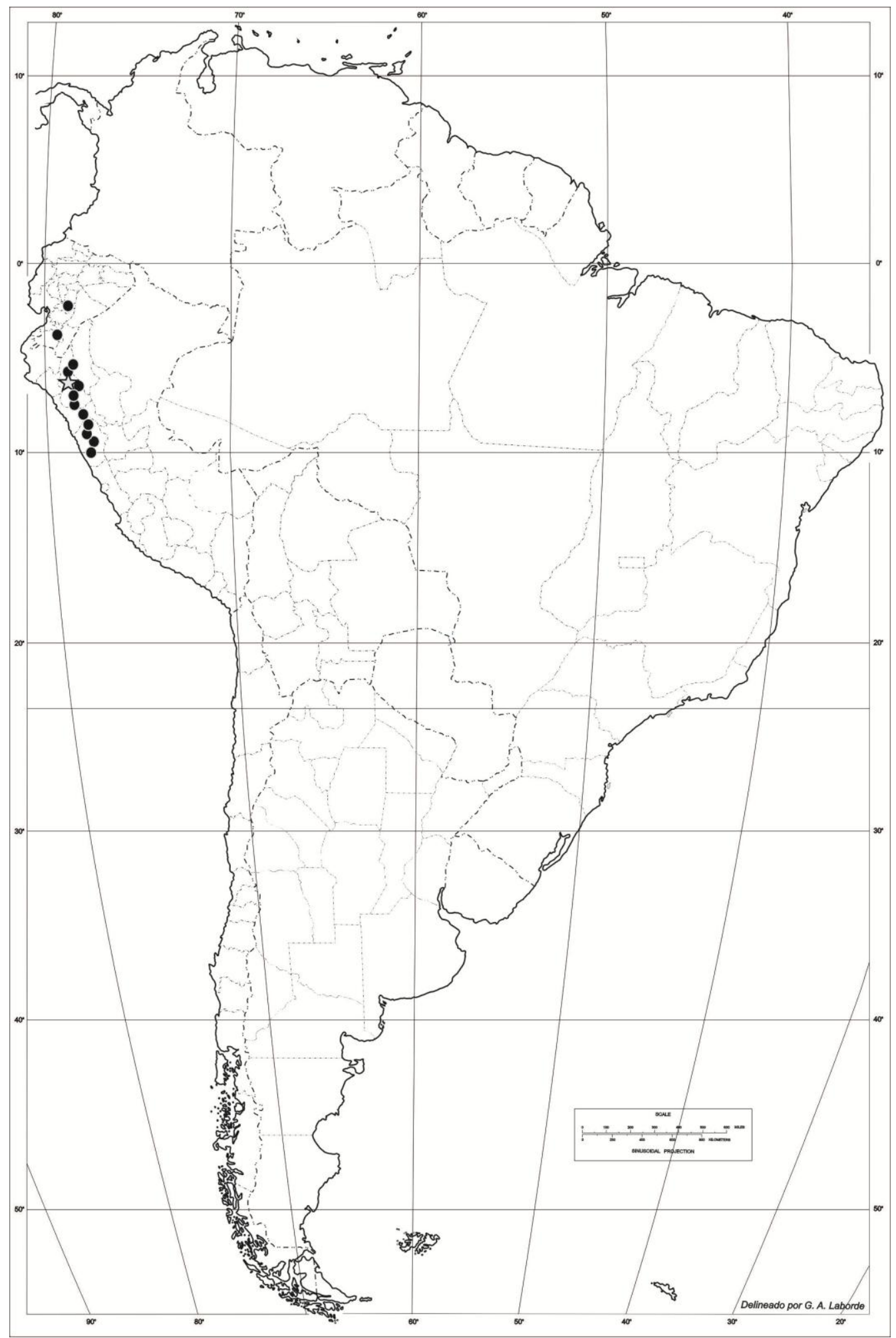

Figura 37. O. chilca. Distribución geográfica, la estrella indica la localidad tipo. 


\section{Ophryosporus cumingii Benth. ex Baker}

Flora Brasiliensis 6(2): 188. 1876.

= Ophryosporus cumingii (Sch. Bip.) Benth. \& Hook. f.

Genera Plantarum 2: 239. 1876. Nomem illeg. por ser su basónimo un nomen nudum.

\section{三 Mikania cumingii Sch. Bip.}

Bull. Soc. Bot. France 12: 82. 1865; Linnaea 34(5): 535. 1866. Nomen nudum (basado en Mandon 264 y Cuming 102).

Tipo: Bolivia. "Hab. Prov. Larecaja, viciniis Sorata; inter Ladrilloni et Condurpata, in nemoribus regiones températe 2700-2900 m alt. Jun.-Aug 1858. G. Mandon 264'. Holotipo: K foto! (http://plants.jstor.org/specimen/k000542516), isotipo MO no visto, NY! Fig. 38.

Arbusto apoyante, profusamente ramificado. Tallo con entrenudos entre 6 y $12 \mathrm{~cm}$, ramificaciones secundarias opuestas, ramas glabras, púrpura, con estriaciones. Hojas opuestas, pecioladas, pecíolo 0,6-1 cm, láminas ovadas a ovado-lanceoladas, $1-2,2 \times 5-7,2 \mathrm{~cm}$, base decurrente, ápice agudo, margen dentado, plano; consistencia herbácea, venación acródroma imperfecta suprabasal; pubescente y glandulosa, tricomas eglandulares simples cónicos y glandulares (tipo $\beta$ ). Inflorescencia cimoidea, compuesta de glomérulos densos; terminal y axilar, con hojas persistentes bien desarrolladas. Capítulos ca. 120230, pedunculados ( $2-5 \mathrm{~mm}), 2 \times 4,7 \mathrm{~mm}$. Involucro acampanado, $2 \times 3 \mathrm{~mm}$; filarios 4, eximbricados; en una serie de filarios, ovados, $1,2 \times 3 \mathrm{~mm}$; ápice fimbriado, margen entero, consistencia herbácea; glabros. Flores 3-4, hermafroditas, corola blanquecina, infundibuliforme, sin paso gradual entre tubo y limbo, tubo 0,3 × $2 \mathrm{~mm}$, limbo $1 \times 4 \mathrm{~mm}$, 5-dentada, lóbulo 1,2 $\times 1 \mathrm{~mm}$; glandulosa sólo en la base del tubo, tricomas glandulares (tipo $\alpha$ ). Estambres 5 , anteras $1,1 \mathrm{x}$ $0,2 \mathrm{~mm}$, collar anteral cilíndrico, levemente ensanchado hacia la base, base de la teca auriculada; apéndice conectival rudimentario, con surco medial. Estilo 3,8 
$\mathrm{mm}$, largamente exerto, ramas del estilo fuertemente clavadas en el ápice, ápices más oscuros que el resto de las ramas, las ramas $1,8 \mathrm{~mm}$. Cipsela negra no estipitada, piriforme, 1,4 mm, marcadamente 5-costada; seríceas, pelos gemelos escasos en toda la cipsela; carpopodio anular, central. Papus formado por 15-20 cerdas blanquecinas, connadas en la base, 2,3-2,5 mm. Fig. 39.

Fenología: Florece de junio a septiembre.

Distribución: Bolivia (departamentos de Cochabamba, La Paz, Potosí, Santa Cruz y Tarija), entre 2400-3400 msnm. Habita en bosque montano, tucumanoboliviano, con Weinmannia L. y Hesperomeles Lindl. Zona con alta influencia de neblinas (Serrano et al. $6146 \mathrm{MO}$ ). También en zonas con abundante cultivo, con árboles ralos de Polylepis Ruiz \& Pav. y Alnus acuminata Kunth. Fig. 40.

Nombres comunes: "Kinpaya" (Lewis 39958 MO).

\section{Notas:}

1. Con olor fuertemente dulce. Incluso ha sido citado como fragancia a vainilla (Nee \& Mendoza 52527 NY).

2. Hay variaciones entre las plantas que crecen al sol y a la sombra: hojas más laxas, de consistencia más delicada, entrenudos más largos, inflorescencias más laxas y con menor número de capítulos. (Lewis 39135 MO-sun form- y Lewis 39132 MO-shadow form-).

Etimología: Hace referencia al naturalista inglés, Hugh Cuming (1791-1865).

Estado de Conservación: Con naturaleza malezoide. Suele formar pequeñas poblaciones al margen de campos cultivados.

Especímenes adicionales estudiados: BOLIVIA. Cochabamba: Chapare, Yanta-Aduana, 10/06/1929, J. Steinbach 9811 (MO, NY). Tunari, 29/95/1929, J. Steinbach 9767 (NY). Ucuchi, Valle de Cochabamba, 21/08/1967, H. Adolfo M. $104 \mathrm{c} /$ (LP). La Paz: Inquisivi, boca río Amutara, in the deep canyon of the río Amutara near its junction with the río Aguas Calientes, $7 \mathrm{~km}$ SE of Choquetanga, 
$16^{\circ} 53^{\prime}$ S $67^{\circ} 15^{\prime}$ W, 25/06/1991, M. Lewis 39132 (MO); Kinpaya, at the mouth of the río Jancha Kaihua where the Aquilani-Choquetanga trail crosses the río Ocsalla, $10 \mathrm{~km} \mathrm{~N}$ of Choquetanga, 16 $45^{\prime} \mathrm{S} 67^{\circ} 17^{\prime} \mathrm{W}, 07 / 09 / 1991$, M. Lewis 39958 (MO); Pongo de Quime, 17/07/1921, O. E. White 153 (NY); Planicie de Ramada, $1 \mathrm{~km}$ W of Bella Vista which as marked on the map is actually Sopacari on the ground $6.5 \mathrm{~km}$ SE of Choquetanga, $16^{\circ} 53^{\prime} \mathrm{S} 67^{\circ} 15^{\prime} \mathrm{W}, 26 / 06 / 1991, M$. Lewis 39135 (MO); Tambo Pata, walk on slopes W of río Glorieta and along the river between the mouthes of the río Aballahuanta and the río Cayani $7 \mathrm{~km} \mathrm{~S}$ of Choquetanga, 16 $54^{\circ}$ 'S 67 17' W, 19/06/1991, M. Lewis 38964 (MO). Larecaja, Sorata, 07-08/1818, G. Mandon 264 (NY). Murillo, Valle del río Zongo, $28.5 \mathrm{~km}$ al norte de la cumbre (cerca de la Escuela Cambaya), $16^{\circ} 08^{\prime} S 68^{\circ} 06^{\prime} \mathrm{W}$, 29/07/1988, J. C. Solomon 18707 (MO). Noryungas, road from Cotapata to Chairo, 09/08/1994, P. Acevedo-Rdgz \& A. Siaca 6719 (NY). Potosí: Incacorral, 06/1911, T. Herzog 2219 (LP). Santa Cruz: Manuel María Caballero, along highway from Comarapa to Cochabamba, $7.3 \mathrm{~km}$ (by road) NW of Torrecillas and $22 \mathrm{Im}$ (by road) NW of the bridge at Comarapa, $17^{\circ} 49.5^{\prime} \mathrm{S} 64^{\circ} 39.1^{\prime} \mathrm{W}, 06 / 08 / 2003$, M. Nee \& M. Mendoza 52527 (NY); Carrasco de Cochabamba, Siberia, 20/05/1966, R. F. Steinbach 207 (MO, NY); ib. alrededores de la escuela y tramo de $2 \mathrm{~km}$ al S bajando por el camino a Oconi, $17^{\circ} 50^{\prime} \mathrm{S} 64^{\circ} 45^{\prime} \mathrm{W}, 25 / 07 / 1996$, I. G. Vargas C. 5001 (NY). Tarija: Arce, Padcaya, Reserva Natural de Flora y Fauna Tariquía, bajando de la cima del Cerro Lorayoj al Abra del Lorayoj, $21^{\circ} 54^{\prime} 18^{\prime \prime} \mathrm{S} 64^{\circ} 54^{\prime}$ 14.1" W, 03/08/2005, M. Serrano, J. Villalobos \& A. Lliully 6146 (MO). 


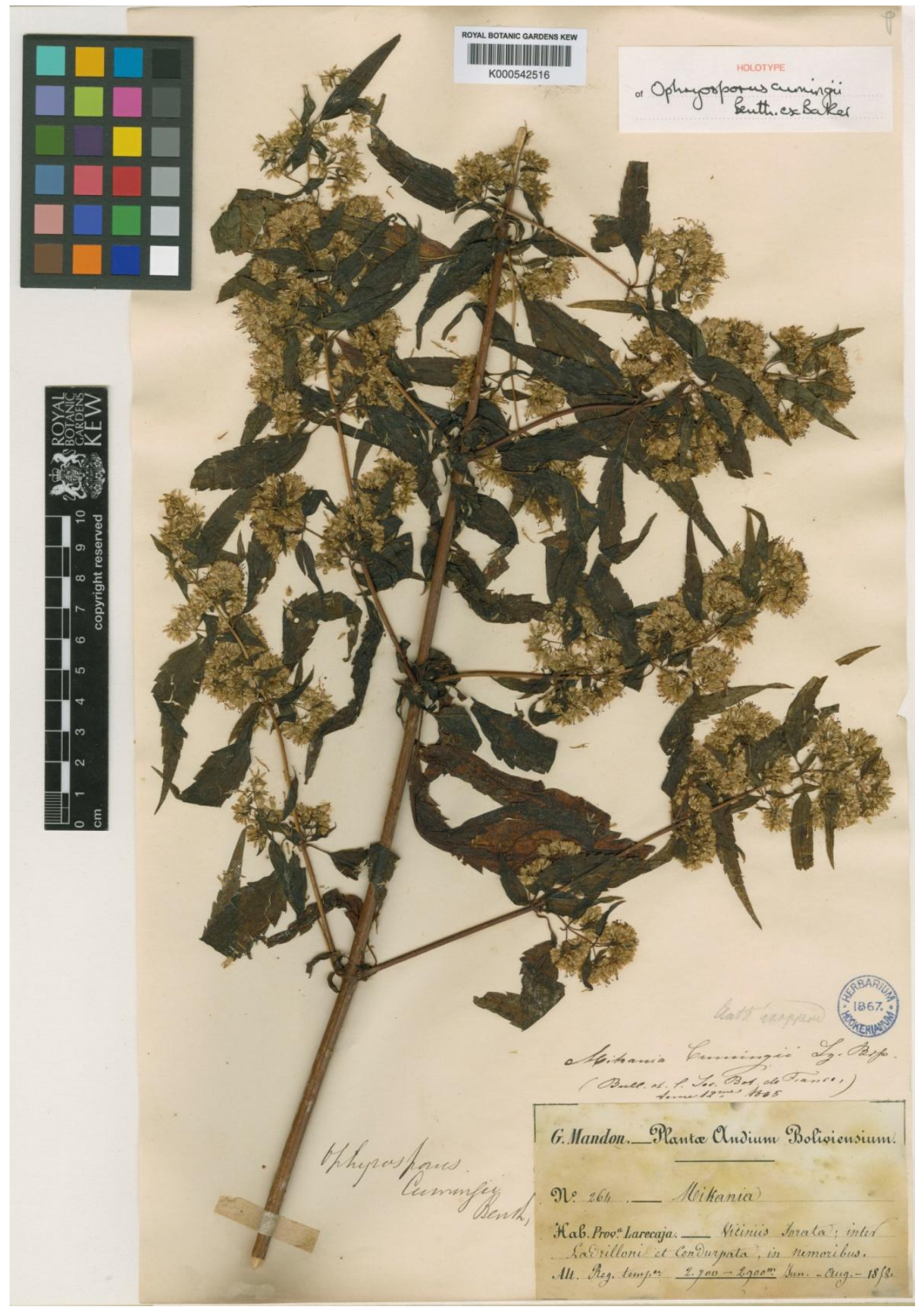

Figura 38. O. cumingii, holotipo. G. Mandon 264 (K). 


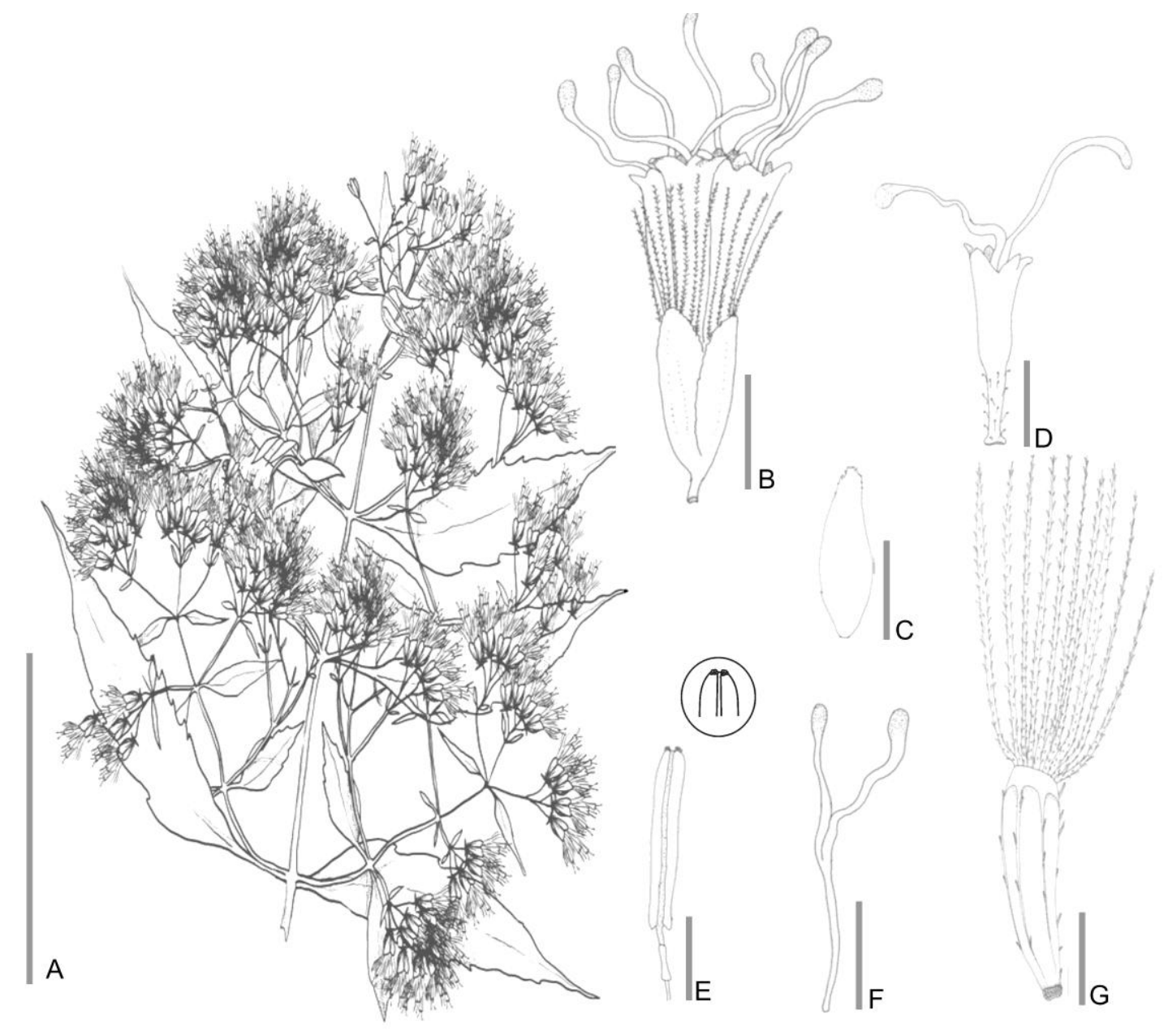

Figura 39. O. cumingii. A. Rama florífera. B. Capítulo. C. Flor sin papus ni cipsela. D. Filarios. E. Antera. F. Estigma. G. Cipsela. Escalas: A: $5 \mathrm{~cm}$; B: $1 \mathrm{~cm}$; C-D: 0,5 mm; F-G: 200 um. (A-G basados en M. Lewis 39958, MO). 


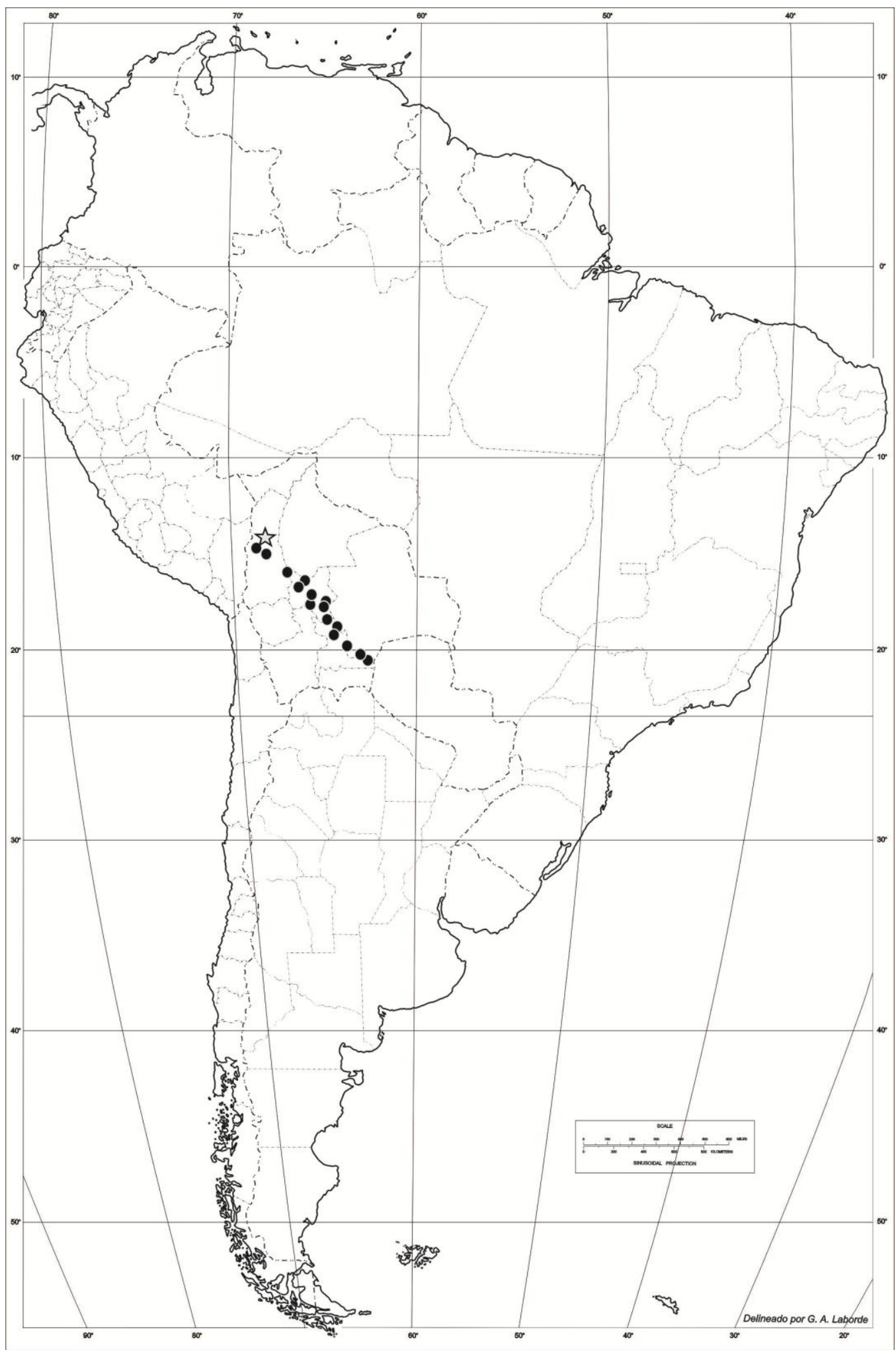

Figura 40. O. cumingii. Distribución geográfica, la estrella indica la localidad tipo. 
Ophryosporus densiflorus (Benth.) R. M. King \& H. Rob.

Phytologia 25: 66. 1972.

\section{三 Piqueria densiflora Benth.}

The Botany of the Voyage of the H. M. S. Sulphur: 110. 1845.

Tipo: Ecuador, "Guayaquil, Puná, 1841. Hinds s.n.". Holotipo: BM no visto, isotipo K foto! (http://plants.jstor.org/specimen/k000486682) Fig. 41.

Arbusto apoyante, profusamente ramificado. Tallo con entrenudos entre 5,8 y $8,5 \mathrm{~cm}$, ramificaciones secundarias opuestas, ramas glabras, marrón claro. Hojas opuestas, pecioladas, pecíolo $1 \mathrm{~cm}$, láminas ovadas a ovado-lanceoladas, 1-3 x 4-6 cm, base cuneada, ápice acuminado, margen dentado, plano; consistencia delicadamente herbácea, venación acródroma imperfecta suprabasal; glabras. Inflorescencia cimoidea, compuesta de corimbos laxos; terminal y axilar, con hojas persistentes poco desarrolladas. Capítulos ca. 50-80, pedunculados (1-2 $\mathrm{mm}$ ), 1 × $4 \mathrm{~mm}$. Involucro cilíndrico, 1 × 2,8 mm; filarios 4-5; subimbricados; en una serie de filarios, ovados, 1,2 × 2,8 mm; margen entero, consistencia herbácea, a veces con porciones esclerificadas en el centro; glabros. Flores 4-5, hermafroditas, corola blanca, infundibuliforme, sin paso gradual entre tubo y limbo, tubo 0,8 x 0,3 mm, limbo $1 \times 0,5 \mathrm{~mm}, 5$-dentada, lóbulo $0,4 \times 0,3 \mathrm{~mm}$; glandulosa sólo en la base del tubo, tricomas glandulares (tipo $\alpha$ ). Estambres 5 , anteras 0,75 x $0,25 \mathrm{~mm}$, collar anteral cilíndrico, base de la teca auriculada; apéndice conectival rudimentario, con surco medial. Estilo $4,8 \mathrm{~mm}$, largamente exerto, ramas del estilo fuertemente clavadas en el ápice, ápices más oscuros que el resto de las ramas, las ramas $2,8 \mathrm{~mm}$. Cipsela negra ligeramente estipitada, piriforme, $2 \mathrm{~mm}$, marcadamente 5-costada; glabra; carpopodio anular, excéntrico. Papus nulo. Fig. 42.

Distribución: Ecuador (provincia de Guayas), entre 0-500 msnm, hábitat costero en selvas deciduas y semi-deciduas. Fig. 43. 


\section{Notas:}

1. En ciertas referencias, como el Catálogo de Plantas Vasculares de Ecuador, se incluyó en la distribución de esta especie a las islas Galápagos, pero dicha cita sólo se debe a un error en la colocación de las etiquetas en los materiales de herbario.

Etimología: Del latín densus, denso y florus, florecer, que florece profusamente (Gledhill 2008).

Estado de Conservación: De acuerdo con Montúfar \& Pitman (2003), le corresponde la categoría NT, casi amenazado, ya que sólo es conocido por 3 colecciones en Puná Vieja, isla de Puná. Dicha área, corresponde a un área protegida.

Especímenes adicionales estudiados: ECUADOR. Guayas: Isla Puná. El Tabor (vicinity of Puná Nueva), $79^{\circ} 56^{\prime} \mathrm{W} 02^{\circ} 44^{\prime} \mathrm{S}, 08 / 08 / 1987$, J. E. Madsen 63858 (AAU); from Puná Vieja to Poza de Lechusa, 80 09' W 02 56' S, 04/09/1987, J. E. Madsen 63902 (AAU). 


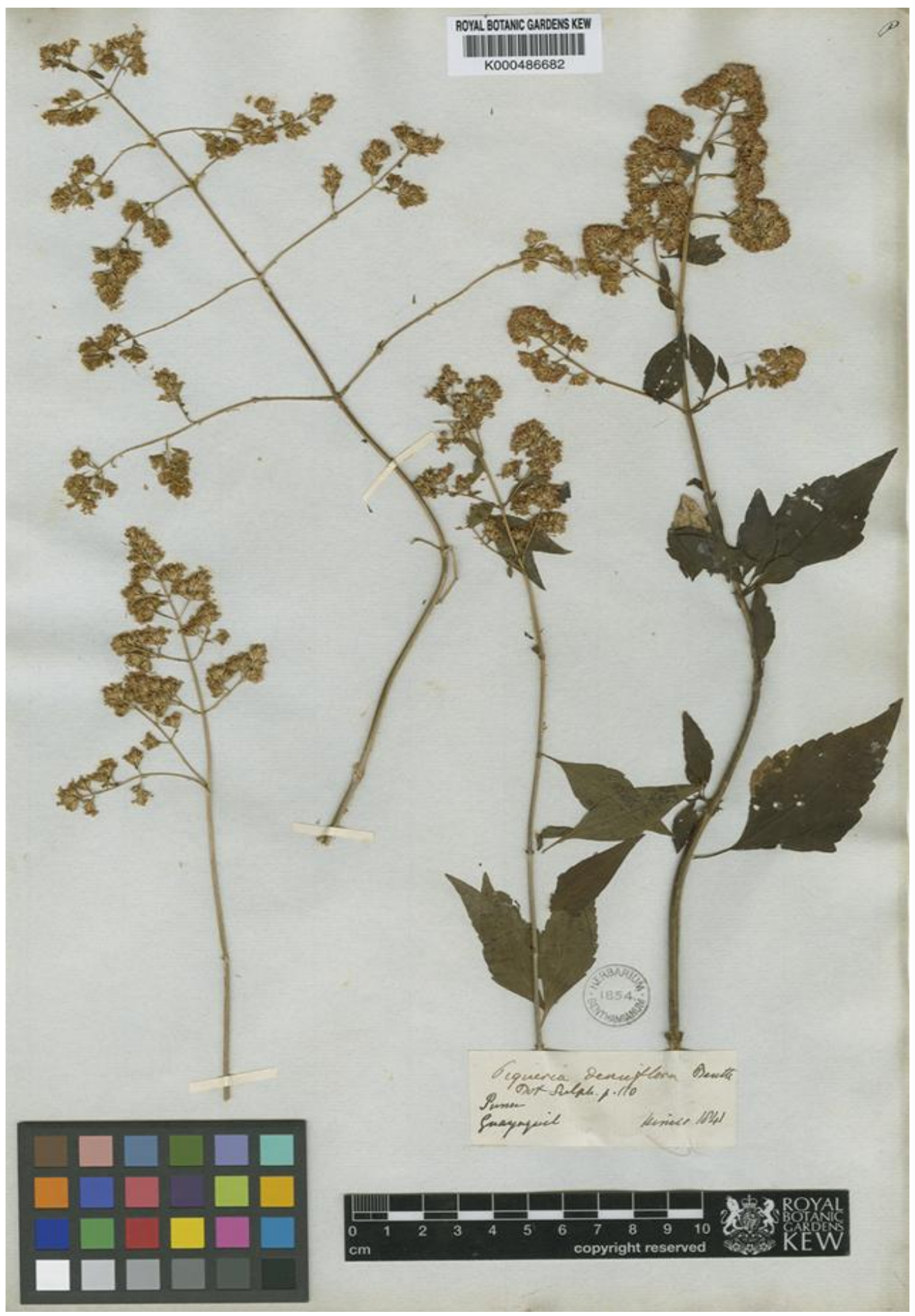

Figura 41. O. densiflorus, isotipo. Hinds s.n. (K). 


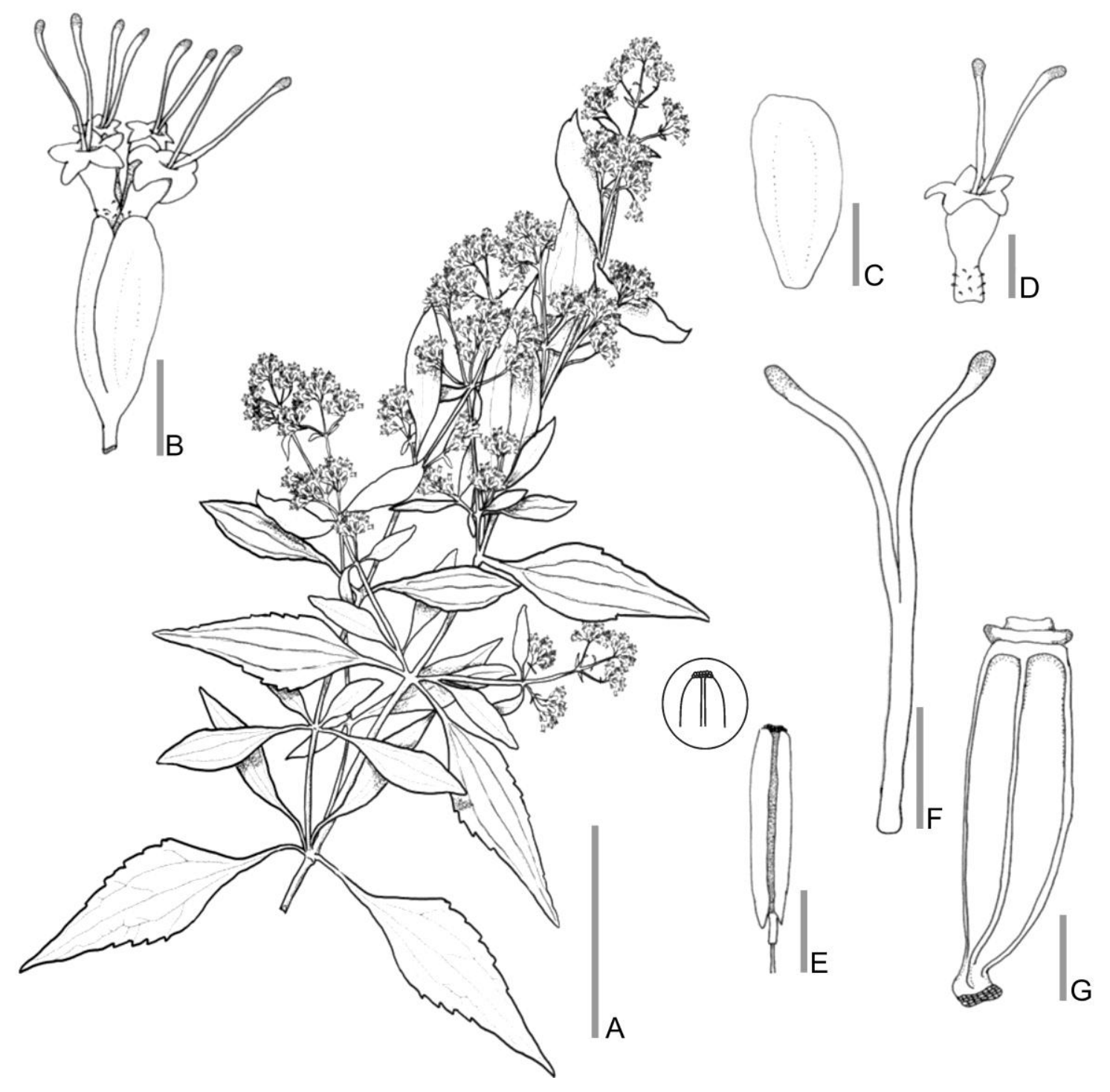

Figura 42. O. densiflorus. A. Rama florífera. B. Capítulo. C. Flor sin papus ni cipsela. D. Filario. E. Antera. F. Estigma. G. Cipsela. Escalas: A: $5 \mathrm{~cm}$; B: $3 \mathrm{~mm}$; C: 2 mm; E: 1 mm; F-G: 200 m. (A-G basados en E. Madsen 63902, AAU). 


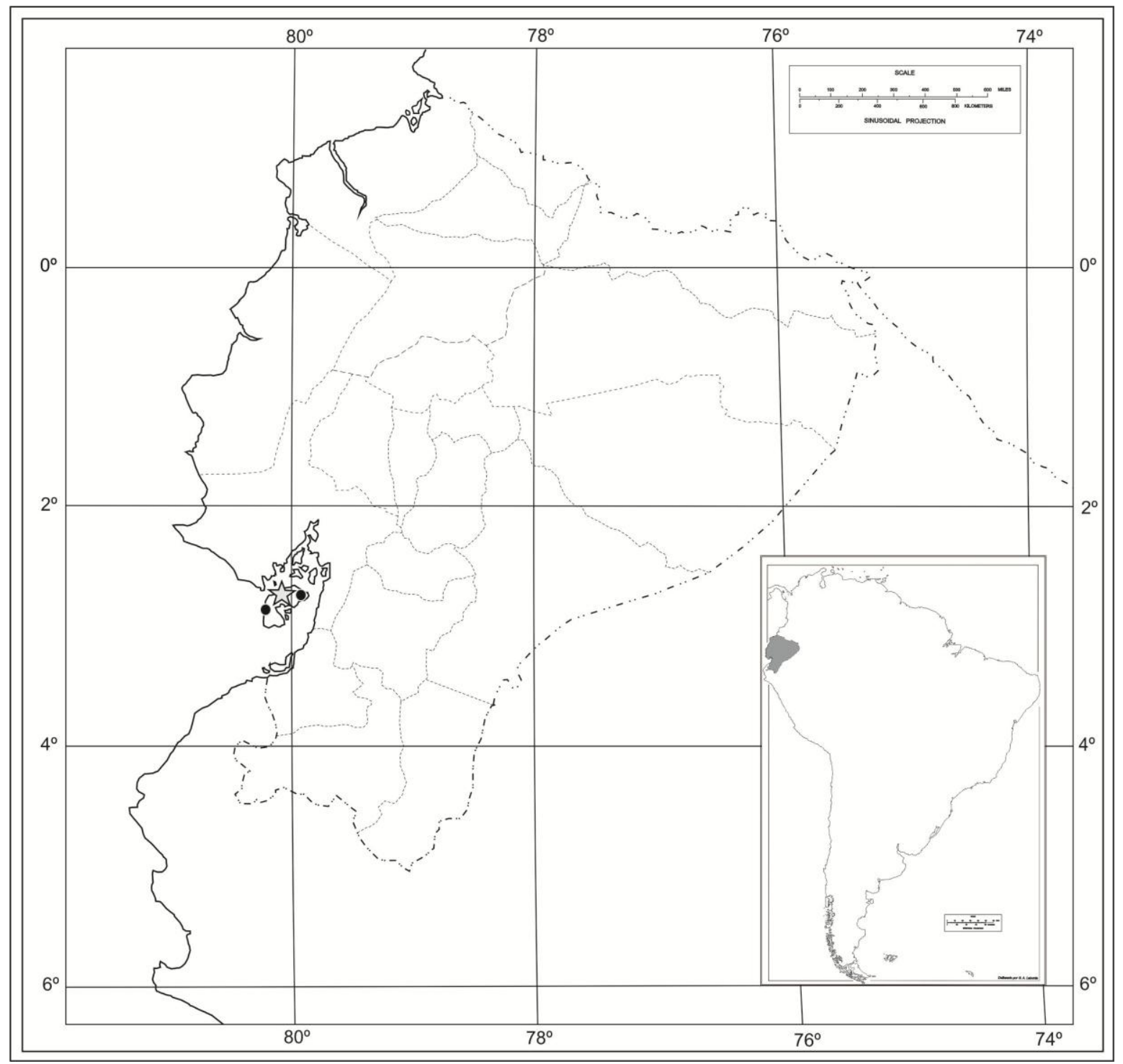

Figura 43. O. densiflorus. Distribución geográfica, la estrella indica la localidad tipo. 


\section{Ophryosporus eleutherantherus (Rusby) B. L. Robinson}

Contributions from the Gray Herbarium of Harvard University. New Series 61: 27. 1920.

E Eupatorium eleutherantherum Rusby, Memoirs of the Torrey Botanical Club 3(3): 53. 1893.

Lectotipo: Bolivia, "Vic. La Paz, 10.000 ft. 1889”, M. Bang 27 (NY 00169004!); isolectotipos: $\mathrm{E}$ foto! 00413767, $\mathrm{K}$ foto! 000486681, MO foto! 714392, NY! sin número. Sintipos: Bolivia, "Vic. La Paz, 10.000 ft. 1890”, M. Bang 193 E foto! 00413768, K foto! 000541517, MO foto! 714393, NY 00169003! y NY! sin número (Plos \& Sancho, 2012) Fig. 44.

= Willoughbya officinalis (Mart.) Kuntze. Revisio Genera Plantarum (Revis. Gen. PI.) 1: 372. 1891.

三 Mikania officinalis Mart. Reise in Brasilien (Reise Bras.) 1: 283. 1823. "Brasil", sin fecha, Anónimo (Mart. Hb. Fl. Bras.) 780. B (foto F!), posiblemente destruido.

= Eupatorium officinale (Mart.) Baill. Traité de Botanique Médicale Phanérogamique (Traité Bot. Me. Phan.) 2: 1127. 1884.

= Willoughbya cordifolia (L. f.) Kuntze. Revisio Generum Plantarum (Revis. Gen. PI.) 1: 372. 1891.

玉 Cacalia cordifolia L. f. Supplementum Plantarum (Suppl. PI.) 351-352. 1781 [1782]. Sintipo: Mutis s.n. LINN foto!

= Mikania cordifolia Willd. Species Plantarum. Editio quarta (Sp. PI.) 3(3): 1746. 1803

Arbusto erecto. Tallo con entrenudos entre 3 y $6 \mathrm{~cm}$, ramificaciones secundarias opuestas, ramas tomentosas, rojizo, con estriaciones. Hojas opuestas, pecioladas, pecíolo 0,3-1 cm, láminas ovadas, 1-1,5 x 2,4 cm, base 
cuneada, ápice agudo, margen dentado, plano; consistencia herbácea, venación acródroma imperfecta suprabasal; pubescente y glandulosa, tricomas eglandulares simples cónicos y glandulares (tipo a). Inflorescencia cimoidea, compuesta de corimbos densos; terminal, con hojas persistentes poco desarrolladas. Capítulos ca. 150-200, pedunculados $(3-5 \mathrm{~mm}), 3 \times 6 \mathrm{~mm}$. Involucro acampanado, $3 \times 4 \mathrm{~mm}$; filarios 8; en dos series de filarios, los externos ovados, $1 \times 5 \mathrm{~mm}$, los internos ovado-lanceolados, 0,8 x 4,5 mm; ápice levemente fimbriado, margen entero, consistencia herbácea, pubescente y glanduloso, tricomas eglandulares simples cónicos y glandulares (tipo $\alpha$ ). Flores 8, hermafroditas, corola blanca, infundibuliforme, sin paso gradual entre tubo y limbo, tubo $2 \times 0,6 \mathrm{~mm}$, limbo $2 \times 0,5 \mathrm{~mm}, 5$-dentada, lóbulo $0,5 \times 0,5 \mathrm{~mm}$; glandulosa sólo en la base del tubo, tricomas glandulares (tipo $\alpha$ ). Estambres 5, anteras 1,8 $\mathrm{x}$ 0,3 mm, collar anteral cilíndrico, base de la teca auriculada; apéndice conectival nulo. Estilo 7,2 mm, largamente exerto, ramas del estilo fuertemente clavadas en el ápice, ápices más oscuros que el resto de las ramas, las ramas 3,8 mm. Cipsela negra no estipitada, piriforme, $2,5 \mathrm{~mm}$, marcadamente 5-costada; serícea y glandulosa, pelos gemelos y gladulares (tipo $\alpha$ ) en toda la cipsela; carpopodio anular, excéntrico. Papus formado por 20-24 cerdas amarillo-blanquecinas, connadas en la base, 3,8-4,2 mm. Fig. 45.

Fenología: Florece en febrero.

Distribución: Bolivia (departamento de La Paz), a 3300-3450 msnm, habita en yungas. Fig. 46.

\section{Notas:}

1. Rusby (1893), menciona dos sintipos en el protólogo de Eupatorium eleutherantherum "1889 (M. Bang) 27” y "1890 (M. Bang) 193", encontrándose los duplicados de este último en E (00413768 foto!), K (000542517 foto!), MO (714393 foto!) y NY (00169003! y NY sin número!). 
2. El material tipo fue determinado como Eupatorium (?), dicha duda es debido a diferencias de dicho material con los de Eupatorium más típicos: olor denso y anteras diferentes (Rusby 1893).

3. Si bien la descripción original no se encuentra en latín, es válida de acuerdo al Código de Nomenclatura Botánica.

4. El sintipo Bang 27 (NY) 00169003 fue determinado originalmente como Stevia Cav.

Etimología: Del griego $\varepsilon \lambda \varepsilon \cup \theta \varepsilon \rho \circ \varsigma$, con estambres no unidos (Gledhill 2008).

Estado de Conservación: Hasta el momento desconocido.

Usos: De acuerdo con Spix y Martius (1823) se la utilizaba contra la fiebre y los dolores abdominales.

Especímenes adicionales estudiados: BOLIVIA. La Paz, 22/02/1919, $O$. Buchtien 541 (NY).

Especímenes tipo adicionales estudiados: BOLIVIA. La Paz, 1890, M. Bang 27 (E, K, MO, NY); ib. M. Bang 193 (E, K, MO, NY). 


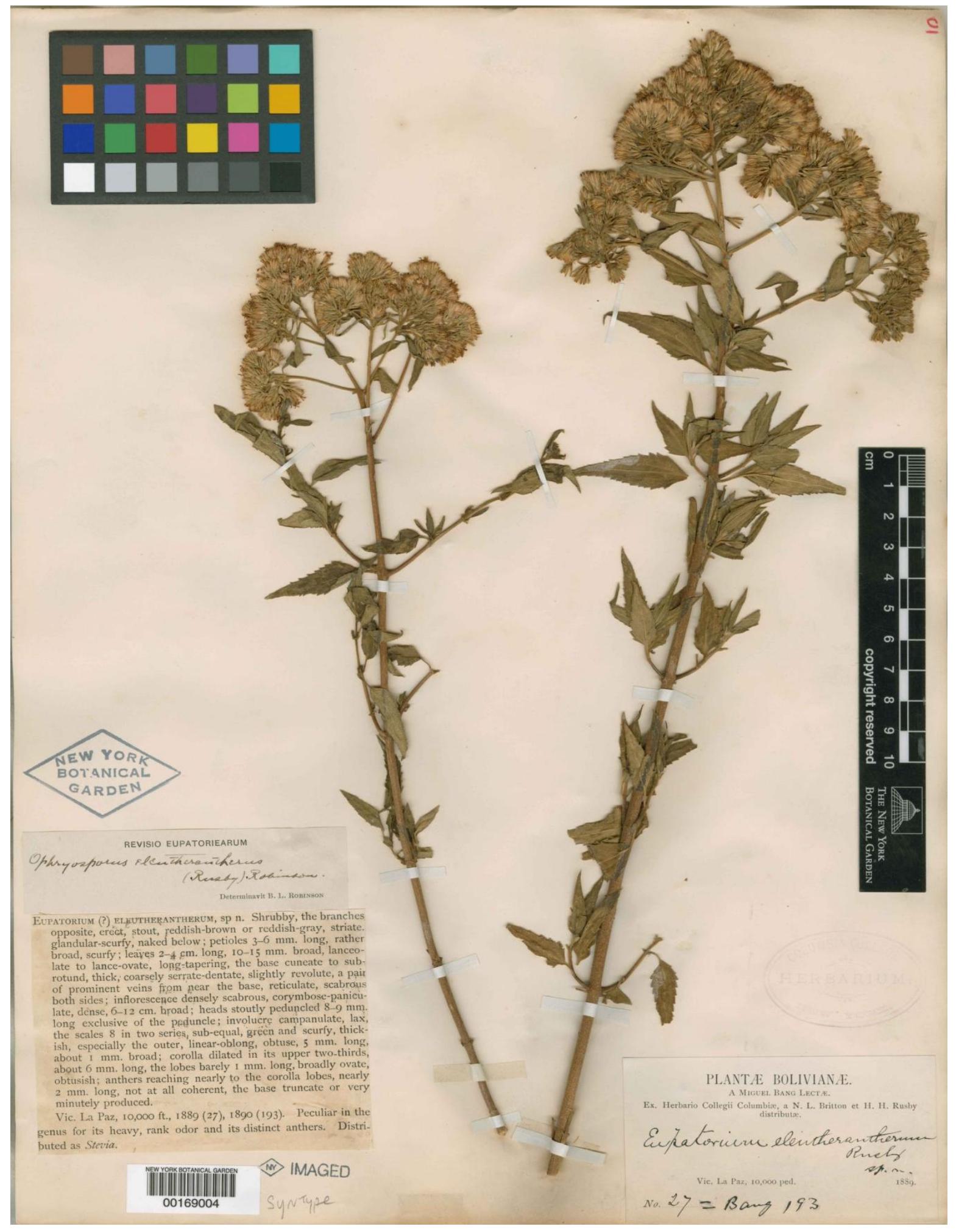

Figura 44. O. eleutherantherus, lectotipo. M. Bang 27 (NY). 


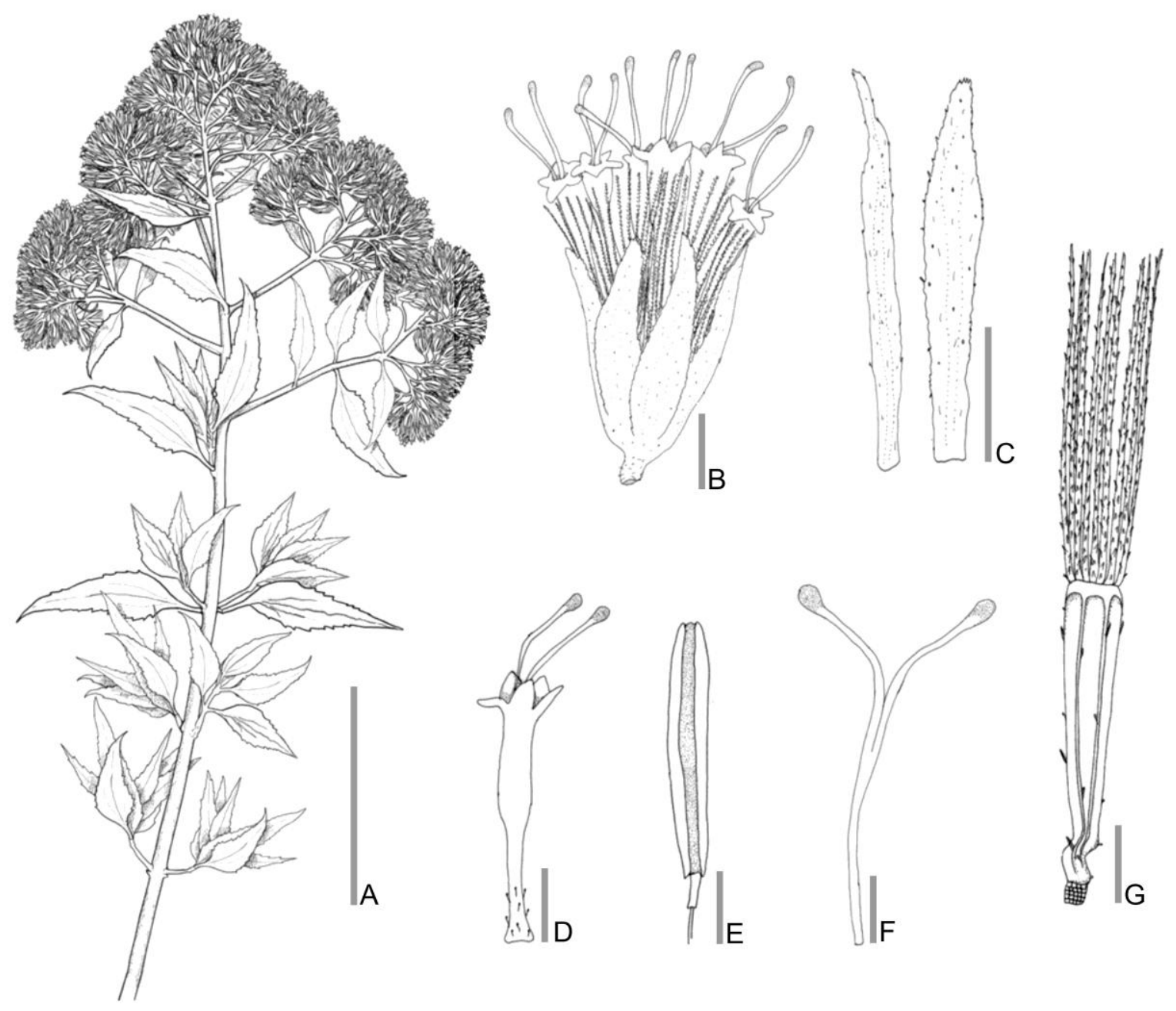

Figura 45. O. eleutherantherus. A. Rama florífera. B. Capítulo. C. Flor sin papus ni cipsela. D. Filarios. E. Antera. F. Estigma. G. Cipsela. Escalas: A: $5 \mathrm{~cm}$; B: 2 mm;

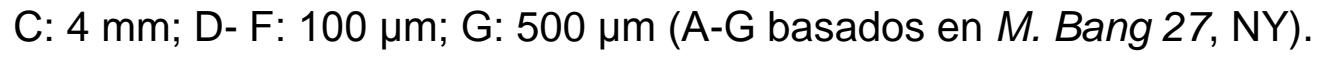




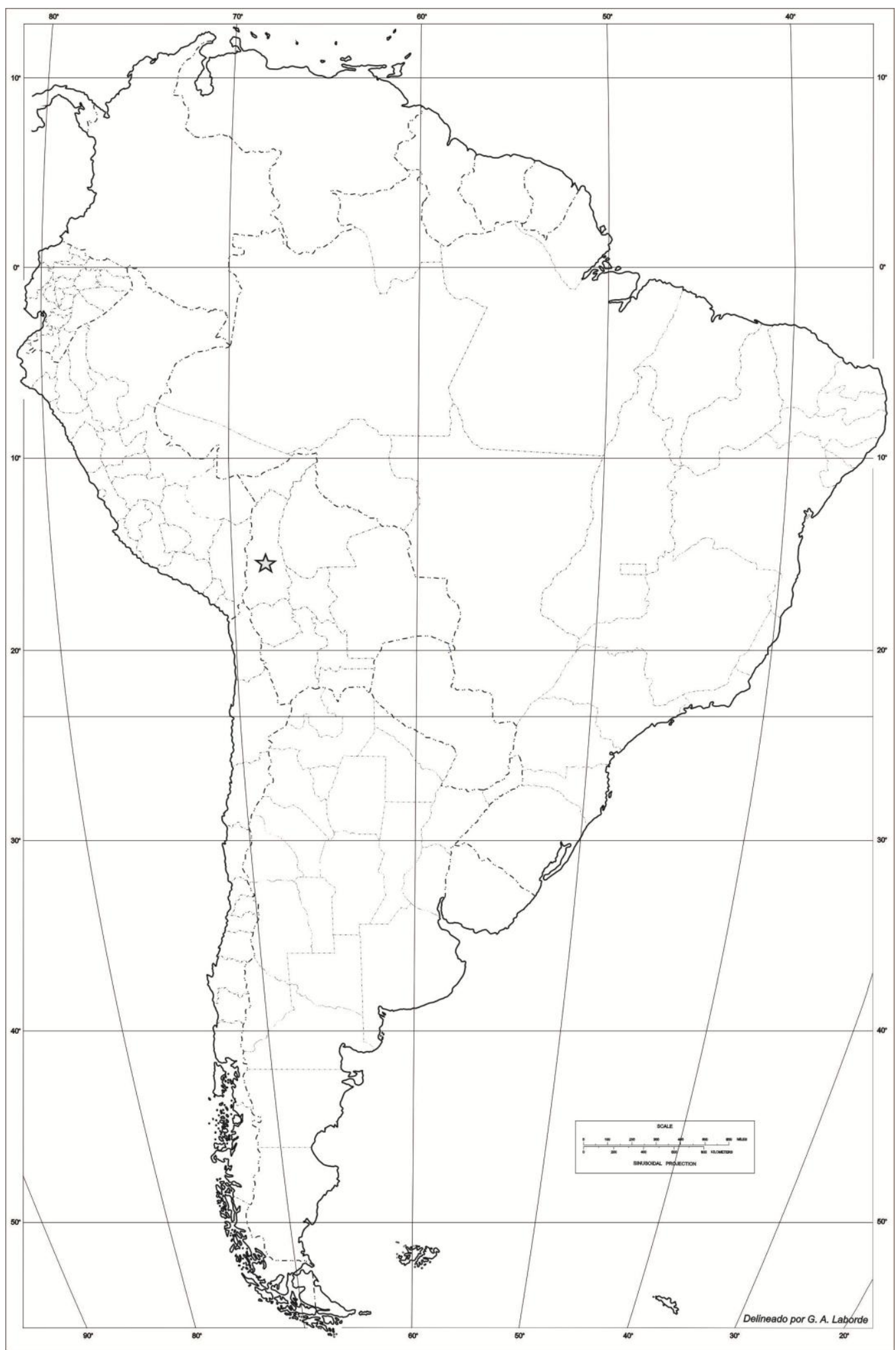

Figura 46. O. eleutherantherus. Distribución geográfica, la estrella indica la localidad tipo. 


\section{Ophryosporus ferreyrii H. Rob.}

Phytologia 84(5): 351-352. 1998.

Tipo: Perú. "Lima: Huarochiri Province, Carretera Central, Infiernillo. High montane, semi-arid shrublands. $3200 \mathrm{~m}$. Clambering shrub, flowers white, sweet odor. 10 May 1984. D. N. Smith, R. Ferreyra \& O. Tovar 7002." Holotipo: US!, isotipos: MO! Fig. 47.

Arbusto apoyante, profusamente ramificado. Tallo con entrenudos entre 2,5 y $7,2 \mathrm{~cm}$, ramificaciones secundarias opuestas, ramas tomentosas, rojizo, con estriaciones. Hojas opuestas, pecioladas, pecíolo 0,8-1,1 cm, láminas ovadas, 11,2 x 3-6 cm, base truncada, ápice agudo, margen dentado, plano, con dientes de segundo orden; consistencia herbácea, venación acródroma imperfecta suprabasal; pubescente y glandulosa, tricomas eglandulares simples cónicos y glandulares (tipo a). Inflorescencia cimoidea, compuesta de corimbos densos; terminal y axilar, con hojas persistentes poco desarrolladas. Capítulos ca. 50-70, pedunculados (1-2 $\mathrm{mm}$ ), $5 \times 8 \mathrm{~mm}$. Involucro acampanado, $2 \times 4 \mathrm{~mm}$; filarios 6-8, eximbricados; en una serie de filarios, ovado-lanceolados, 1,2 x 5,3 mm; ápice fimbriado, margen entero, consistencia herbácea, a veces con porciones esclerificadas en el centro; glanduloso, tricomas glandulares (tipo $\alpha$ ). Flores 6-9, hermafroditas, corola blanca, infundibuliforme, sin paso gradual entre tubo y limbo, tubo 2,8 × 0,3 mm, limbo $2 \times 0,5 \mathrm{~mm}, 5$-dentada, lóbulo 0,25 ×0,5 mm; glandulosa sólo en la base del tubo, tricomas glandulares (tipo $\alpha$ ). Estambres 5 , anteras $2 \times$ 0,3 mm, collar anteral cilíndrico, levemente ensanchados hacia la base, base de la teca auriculada; apéndice conectival nulo. Estilo 8,2 mm, largamente exerto, ramas del estilo fuertemente clavadas en el ápice, ápices más oscuros que el resto de las ramas, las ramas $2,8 \mathrm{~mm}$. Cipsela negra ligeramente estipitada, piriforme a levemente falcadas, $3,5 \mathrm{~mm}$, marcadamente 5-costada; serícea y glandulosa, pelos gemelos escasos y glandulares (tipo $\alpha$ ) en las costillas; carpopodio cilíndrico, excéntrico. Papus formado por 30 cerdas amarillentas, connadas en la base, 4-5 mm. Fig. 48. 
Fenología: Florece de septiembre a mayo.

Distribución: Perú (departamento de Lima) a 3200-3900 msnm, habitat mesoandino y puna húmeda y seca (León et al. 2006 [2007]). Fig. 49.

\section{Notas:}

1. De acuerdo con Robinson (1998), es una especie cercana a O. heptanthus (Sch.-Bip. ex Wedd.) R. M. King \& H. Rob., incluyendo O. origanoides (Meyen \& Walp.) Hieron. Se diferencia de ella por las ramas ascendentes y las laminas de las hojas más angostas, con una base más redonda y margenes levemente aserrados. Ambas especies presentan la base de la cipsela delgada, extendida, pero dicha base en 0 . heptanthus presenta paredes más gruesas.

2. Perfume muy agradable (Ribeiro $30 \mathrm{LP}$ ).

Etimología: En honor al el botánico peruano Ramón Ferreyra (1910-2005).

Estado de Conservación: De acuerdo con Beltrán et al. (2006) su categoría en la UICN es VU, B1ab(iii), plantas vulnerables.

Especímenes adicionales estudiados: PERU. Lima: Canta, Lachaqui, sobre la población, 29/06/1992, A. Granda P. 597 (US).

Especímenes tipo adicionales estudiados: PERU. Lima. Central highway $7 \mathrm{~km}$ NE of San Mateo on road to La Oroya, 22/06/1966, G. Edwin \& J. Schunke V. 3796 (US). Infiernillo, between San Mateo and río Blanco, 08/08/1949, R. Ferreyra 6247 (US). San Mateo, arriba de San Mateo, falda del cerro, 07/05/1966, F. Riocio \& F. La Rosa 554 (US). 


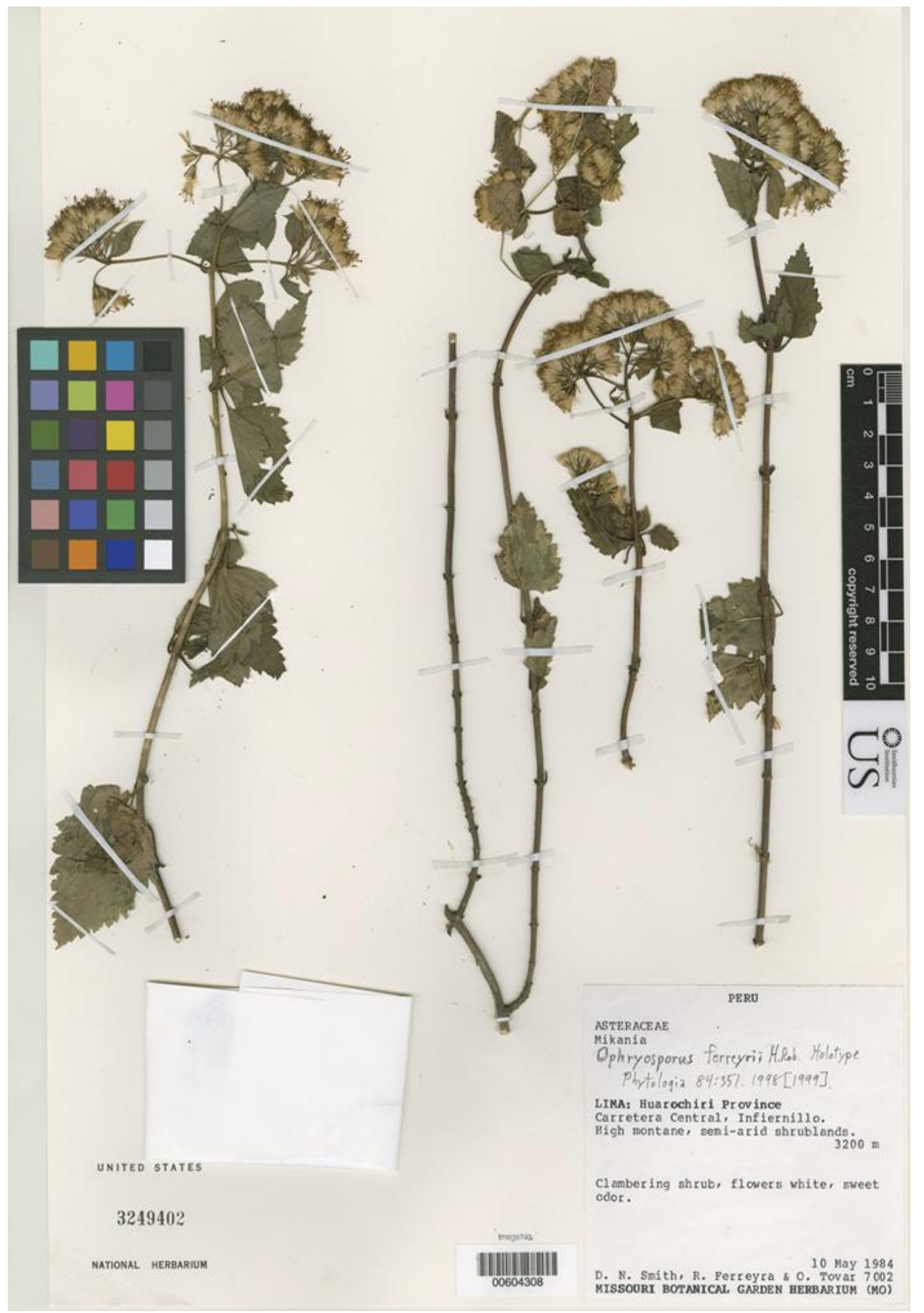

Figura 47. O. ferreyrii, holotipo. D. N. Smith, R. Ferreyra \& O. Tovar 7002 (US). 

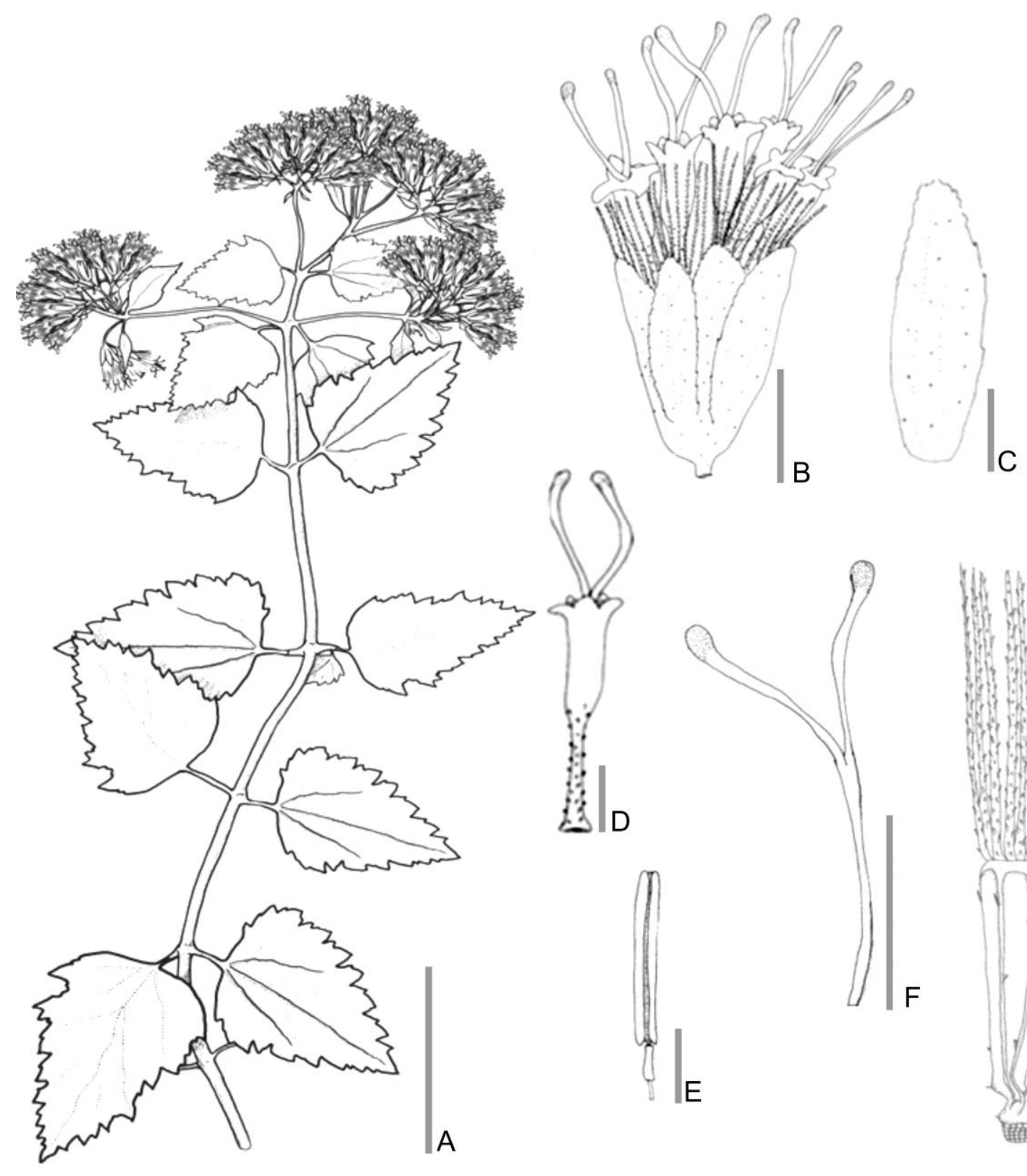


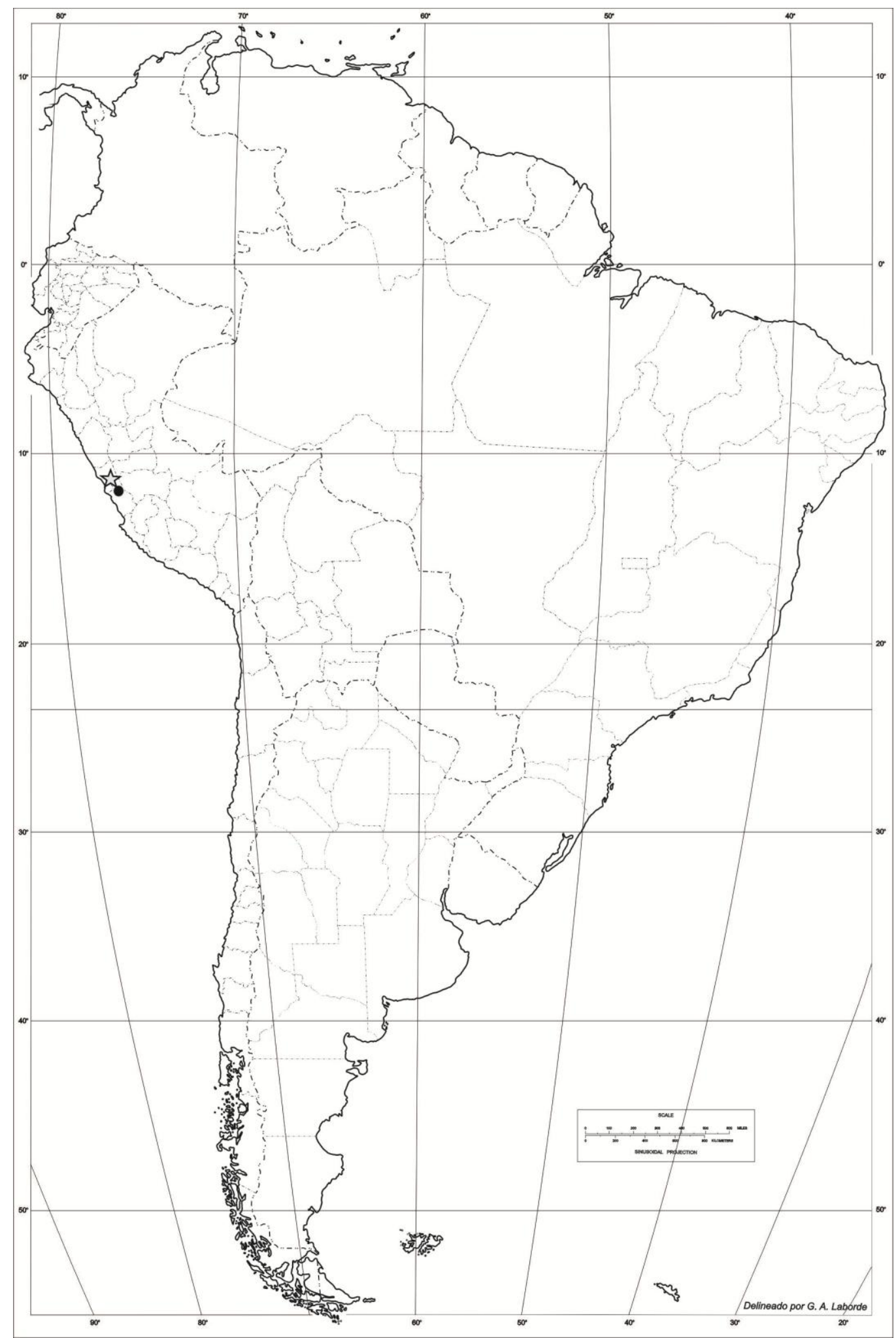

Figura 49. O. ferreyrii. Distribución geográfica, la estrella indica la localidad tipo. 
Ophryosporus floribundus (DC.) R. M. King \& H. Rob.

Phytologia 25: 66. 1972

巨Piqueria floribunda DC.

Prodromus Systematis Naturalis Regni Vegetabilis 5: 105. 1836

Tipo: Perú, “Perou Cordillera, 1834. Haenke s.n.”. Holotipo G-DC!. Fig. 50.

Arbusto erecto, profusamente ramificado. Tallo con entrenudos entre 0,8 y 3 $\mathrm{cm}$, ramificaciones secundarias opuestas, ramas glabras, marrón claro, con estriaciones. Hojas opuestas, pecioladas, pecíolo 0,6-1 cm, láminas ovadas, 0,5$1,2 \times 2,5-4 \mathrm{~cm}$, base cuneada, ápice agudo, margen dentado, plano; consistencia herbácea, venación acródroma imperfecta suprabasal; pubescente, tricomas eglandulares simples cónicos. Inflorescencia cimoidea, compuesta de corimbos laxos; terminal y axilar, con hojas persistentes poco desarrolladas. Capítulos ca. 30-50, pedunculados $(0,5-1 \mathrm{~mm}), 1,6 \times 6 \mathrm{~mm}$. Involucro cilíndrico, 1,5 x 4,5 mm; filarios 5, levemente subimbricados; en una serie de filarios, lanceolados, 0,8 × 3,5 $\mathrm{mm}$; margen entero, consistencia herbácea, a veces con porciones esclerificadas en el centro; glanduloso, con tricomas glandulares (tipo a). Flores 4-5, hermafroditas, corola blanca verdosa, infundibuliforme, con paso gradual entre tubo y limbo, tubo $1 \times 0,5 \mathrm{~mm}$, limbo 1,3 $\times$ 0,5 mm, 5-dentada, lóbulo 0,3 × 0,5 mm; glandulosa sólo en la base del tubo, tricomas glandulares (tipo a). Estambres 5, anteras 1,5 x 0,2 mm, collar anteral cilíndrico, base de la teca obtusa; apéndice conectival rudimentario, entero. Estilo 4,2 $\mathrm{mm}$, largamente exerto, ramas del estilo fuertemente clavadas en el ápice, ápices más oscuros que el resto de las ramas, las ramas $2 \mathrm{~mm}$. Cipsela negra no estipitada, piriforme, $2 \mathrm{~mm}$, marcadamente 5costada; seríceas, pelos gemelos en las costillas; carpopodio cilíndrico, central. Papus nulo. Fig. 51.

Fenología: Florece de diciembre a mayo.

Distribución: Chile (regiones de Antofagasta y Tarapacá) y Perú (departamento de Lima) a 800-2900 msnm, en secas pendientes pronunciadas. Fig. 52. 


\section{Notas:}

1. Si bien De Candolle (1836) tiene sus dudas respecto de si esta especie está presente en Chile y le adjudica el dato dudoso a un cambio de etiquetas, con posterioridad se han obtenidos colectas pertenecientes a territorios chilenos.

2. De acuerdo con Robinson (1906), es posible que la nota en la descripción original que hace referencia a "montanis Orocensibus" corresponda a "montanis Huanoccesibus"

3. Matorral verde oscuro brillante, oloroso (Pinto s.n. SGO 14948)

Etimología: Del latín flos, flores y bundus, profusamente hace referencia a la abundante presencia de flores (Stern 1983, Gledhill 2008).

Compuestos químicos de interés: De acuerdo con Herz (2004) y Zdero et al. (1990) se ha detectado la presencia de benzofuranos, dihidrobenzofuranos, cumarinas, cromenos, mono y sesquiterpenos (nerodiol y germacreno D), diterpenos y glicósidos (flavonas, flavonoles, flavononas).

Especímenes adicionales estudiados: CHILE. Tarapacá (I Región): Alto Punta Gruesa, 20²2' S 70 09' W, 14/12/1997, R. Pinto s.n. (SGO 14948). Alto Punta Lobos $21^{\circ} 02^{\prime} \mathrm{S} 70^{\circ} 09^{\prime} \mathrm{W}, 14 / 01 / 1998$, R. Pinto s.n. (SGO 142950). Alto Punta Patache, $1^{\circ}$ Faldeo W, $20^{\circ} 49^{\prime} \mathrm{S} 70^{\circ}$ 09' W, R. Pinto s.n. (SGO 142949). Iquique, entre Guatacondo e Igua, $20^{\circ} 56^{\prime}$ S 68 $58^{\circ}$ ' W, 11/02/1969, M. Ricardi \& O. Parra 31 (G). PERU. Lima: Huarochirí, Matucana, 25/05/1940, E. Asplund 11072 (G); San Miguel de Viso, 5-14/05/1922, Macbride \& Featherstone 767 (G). 


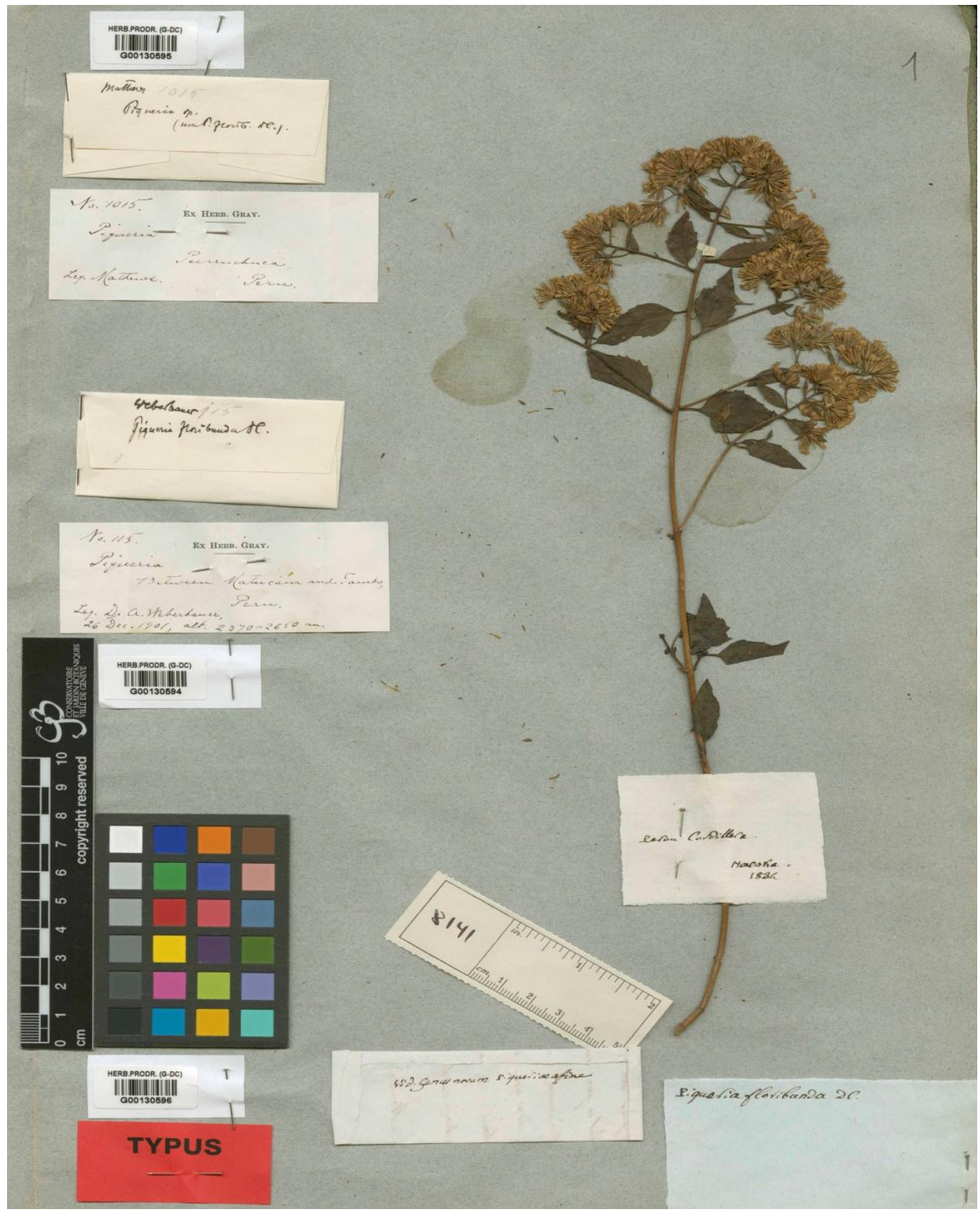

Figura 50. O. floribundus, holotipo. Haenke s.n. (G-DC). 


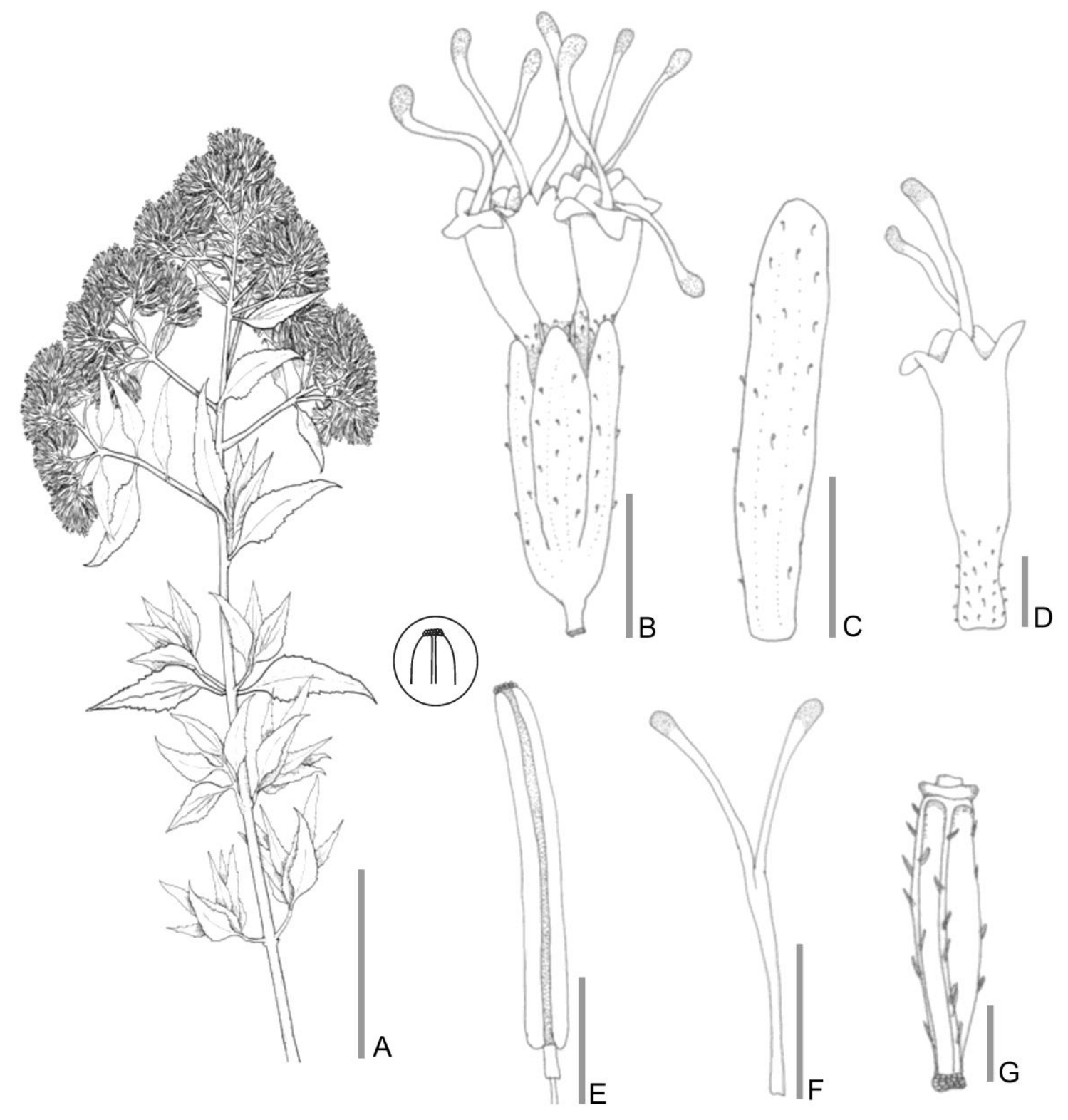

Figura 51. O. floribundus. A. Rama florífera. B. Capítulo. C. Flor sin papus ni cipsela. D. Filario. E. Antera. F. Estigma. G. Cipsela. Escalas: A: $5 \mathrm{~cm}$; B: $2 \mathrm{~mm}$; C-E: $500 \mu \mathrm{m}$; F-G: $200 \mu \mathrm{m}$. (A basado en Haenke s.n., G-DC; B-G basados en $R$. Pinto s.n. (SGO 14948). 


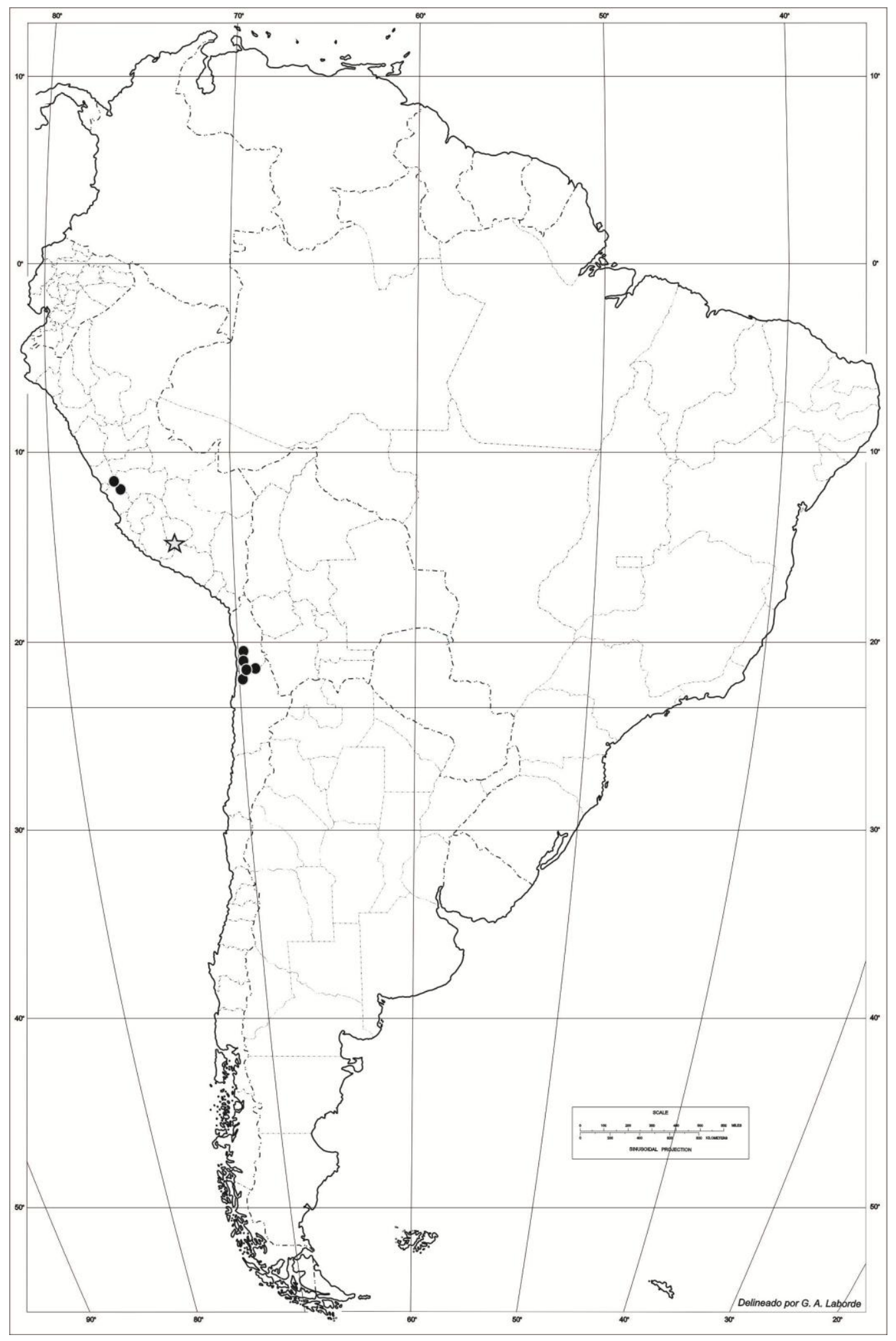

Figura 52. O. floribundus. Distribución geográfica, la estrella indica la localidad tipo. 


\section{Ophryosporus freyreissii (Thunb.) Baker}

Flora Brasiliensis 6(2): 188. 1876.

\section{E Eupatorium freyreysi Thunb.}

Plantarum Brasiliensium 2: 25. 1818.

= Mikania clavellata DC. Prodr. 5: 192. 1836.

= Eupatorium freyreissi DC. Prod. 5: 169. 1836. Bajo E. laeve DC.

= Eupatorium riedelianum Gardn. in Hook. Lond. Journ. Bot. 5: 478. 1846. Lectotipo: Brasil "Serro do frio. Diamont Dist.", 08/1840. Gardner 4851 BM foto! 000795971, isolectotipos GH foto! 00007602. K foto! 000542514, K foto! 000541515 , NY foto! 00801362 y US foto! 00130514 (Plos \& Sancho, 2012).

Tipo: "Brasilia. Minas Geraes". Holotipo: Freyreiss s.n. UPS foto! Fig. 53.

Arbusto apoyante, profusamente ramificado. Tallo con entrenudos entre 4 y $12 \mathrm{~cm}$, ramificaciones secundarias opuestas, ramas glabras, púrpura, con estriaciones. Hojas opuestas, pecioladas, pecíolo 0,3-1 cm, láminas lanceoladas, 0,8-1,2 x 5-7 cm, base decurrente, ápice agudo, margen dentado, plano; consistencia herbácea, venación acródroma imperfecta suprabasal; pubescente, tricomas eglandulares simples cónicos. Inflorescencia cimoidea, compuesta de corimbos laxos; terminal y axilar, con hojas persistentes poco desarrolladas. Capítulos ca. 200-250, pedunculados (1-3 mm), 3 x 4,5 mm. Involucro acampanado, $3 \times 2,5 \mathrm{~mm}$; filarios 5-7, eximbricados; en una serie de filarios, ovados, 1 x $2 \mathrm{~mm}$; ápice fimbriado, margen entero, consistencia herbácea; glabros. Flores 3-6, hermafroditas, corola blanca, infundibuliforme, con paso gradual entre tubo y limbo, tubo $1,7 \times 0,3 \mathrm{~mm}$, limbo 1 × 0,5 mm, 5-dentada, lóbulo $0,25 \times 0,5 \mathrm{~mm}$; glanduloso en toda la corola, más denso en la base del tubo, tricomas glandulares (tipo $\alpha$ ). Estambres 5 , anteras $0,7 \times 0,3 \mathrm{~mm}$, collar anteral cilíndrico, base de la teca obtusa; apéndice conectival nulo. Estilo $3,2 \mathrm{~mm}$, 
largamente exerto, ramas del estilo fuertemente clavadas en el ápice, ápices más oscuros que el resto de las ramas, las ramas 1,2 mm. Cipsela negra no estipitada, piriforme a levemente falcada, $1,5 \mathrm{~mm}$, marcadamente 5-costada; serícea y glandulosa, pelos gemelos y glandulares (tipo $\alpha$ ) en las costillas; carpopodio cilíndrico, excéntrico. Papus formado por 20 cerdas blanquecinas, connadas en la base, 2,2-2,5 mm. Fig. 54 .

Fenología: Florece de octubre a agosto.

Distribución: Brasil (estados de Bahía, Minas Gerais, Espírito Santo, São Pablo y Rio de Janeiro), a 1420 msnm, habita en mata atlántica (Campostrini Forzza et al. 2010). Fig. 55.

\section{Notas:}

1. El tallo en la parte inferior está desnudo o con hojas secas.

2. Si bien Robinson (1906) cita al nombre como O. freyreysii (Dallm.) Bak., el basónimo corresponde a Eupatorium freyreissii Thunb.

3. George Gardner (1846), al describir E. riedelianum cita como material de referencia al número 4851 de su colección (pág. 478). Ese mismo número (4851), aunque de un espécimen totalmente diferente, es citado en la misma obra para describir a Trichogonia multiflora Gardner (pág. 460). Como los dos ejemplares son totalmente diferentes, no cabe duda de que se trata de un error al asignar números a los especímenes colectados por Gardner. Este tipo de errores en la numeración de los ejemplares de referencia de nuevas especies de Gardner (1846) parecería ser más usual de lo esperado ( $\mathrm{N}$. Hind, comunicación personal). De los materiales estudiados depositados en $\mathrm{K}$ como Gardner 4851, dos corresponden a $E$. riedelianum ( $\mathrm{K} 000542514$ y $\mathrm{K} 000541515$ ) y dos a $T$. multiflora ( $\mathrm{K}$ 000542512 y K 000542513). Se designó como lectotipo de Eupatorium riedelianum al ejemplar Gardner 4851 depositado en BM, dejando constancia del error de número de colecta que coincide con el ejemplar de 
referencia de T. multiflora. El ejemplar, además, indica en su labelo "Serro do Frio", coincidiendo perfectamente con la localidad indicada en el protólogo de E. riedelianum (Fig. $56 \mathrm{~A}$, a).

4. Gardner (1846) cita como material de referencia para E. compressum al ejemplar de su colección número 4852, cuyo holotipo se encuentra depositado en BM (BM 000554171; duplicados US y G) bajo la numeración 4851/2. Tanto en $\mathrm{GH}$ (GH 00007602 que incluye una foto de $\mathrm{B}$ ) como en $\mathrm{K}$ (K 000541515) se encuentran ejemplares con el número Gardner 4852 que no corresponden a $E$. compressum sino a E. riedelianum. El ejemplar de $\mathrm{K}$ lleva una nota de puño y letra de Baker que dice "probably should be 4851 in Hb. Hook." (Fig. 56 B, b). Lo indicado por Baker, ha sido confirmado aquí mediante la identificación de los respectivos materiales de $\mathrm{GH}$ y $\mathrm{K}$.

Etimología: Hace referencia al colector del material tipo, el naturalista alemán Georg Wilhelm Freyreiss (1789 - 1825).

Especímenes adicionales estudiados: BRASIL. Bahía: Rio de Contas, Pico das Almas, vertente leste, Fazenda Silvina, $19 \mathrm{~km}$ ao NO da cidade, $13^{\circ} 32^{\prime} \mathrm{S} 41^{\circ} 58^{\prime}$ W, 23/10/1988, R. M. Harley et al. 25330 (NY). Minas Gerais: Lima Duarte, Conceição da Ibitipoca, Biquinha, 18/09/1940, Mendes Magalhães 406 (LP). Rio de Janeiro: Petrópolis, Correias, Serra dos Orgãos, camino para a Gruta de Presidente, 22/08/1970, J. P. P. Carauta et al. 1119 (NY). Región no especificada: Brasil, 24/08/1824, L. Riedel 356 (NY). Brasilia, sin fecha, C. H. Schultz 138 (NY); ib. sin fecha, Pohl 3015 (NY). 

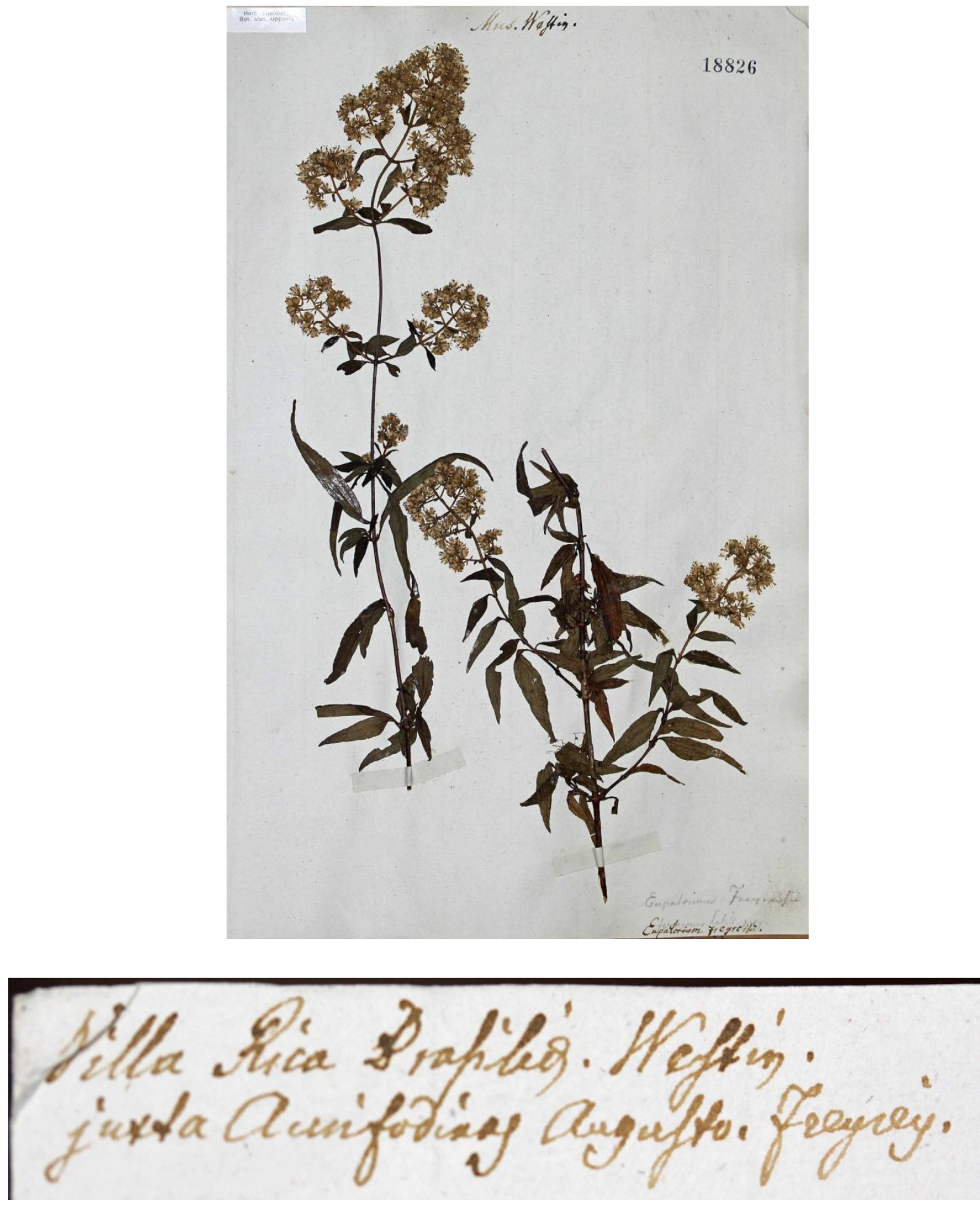

Figura 53. O. freyreissii, holotipo. Freyreiss s.n. (UPS). 


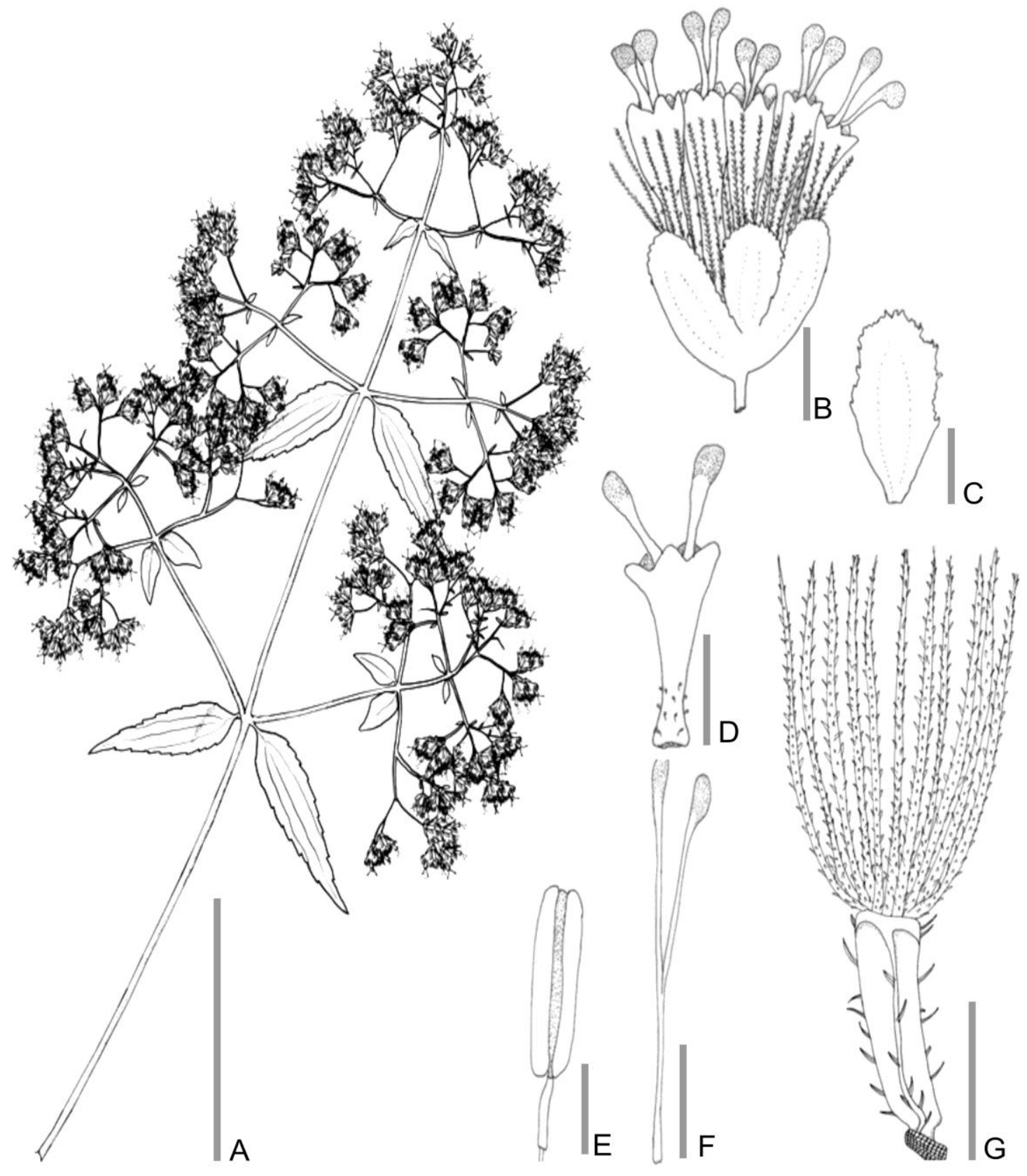

Figura 54. O. freyreissii. A. Rama florífera. B. Capítulo. C. Flor sin papus ni cipsela. D. Filario. E. Antera. F. Estigma. G. Cipsela. Escalas: A: $5 \mathrm{~cm}$; B-D: $1 \mathrm{~mm}$; E-G: $300 \mu \mathrm{m}$. (A-G basados en Gardner 4851, NY) 


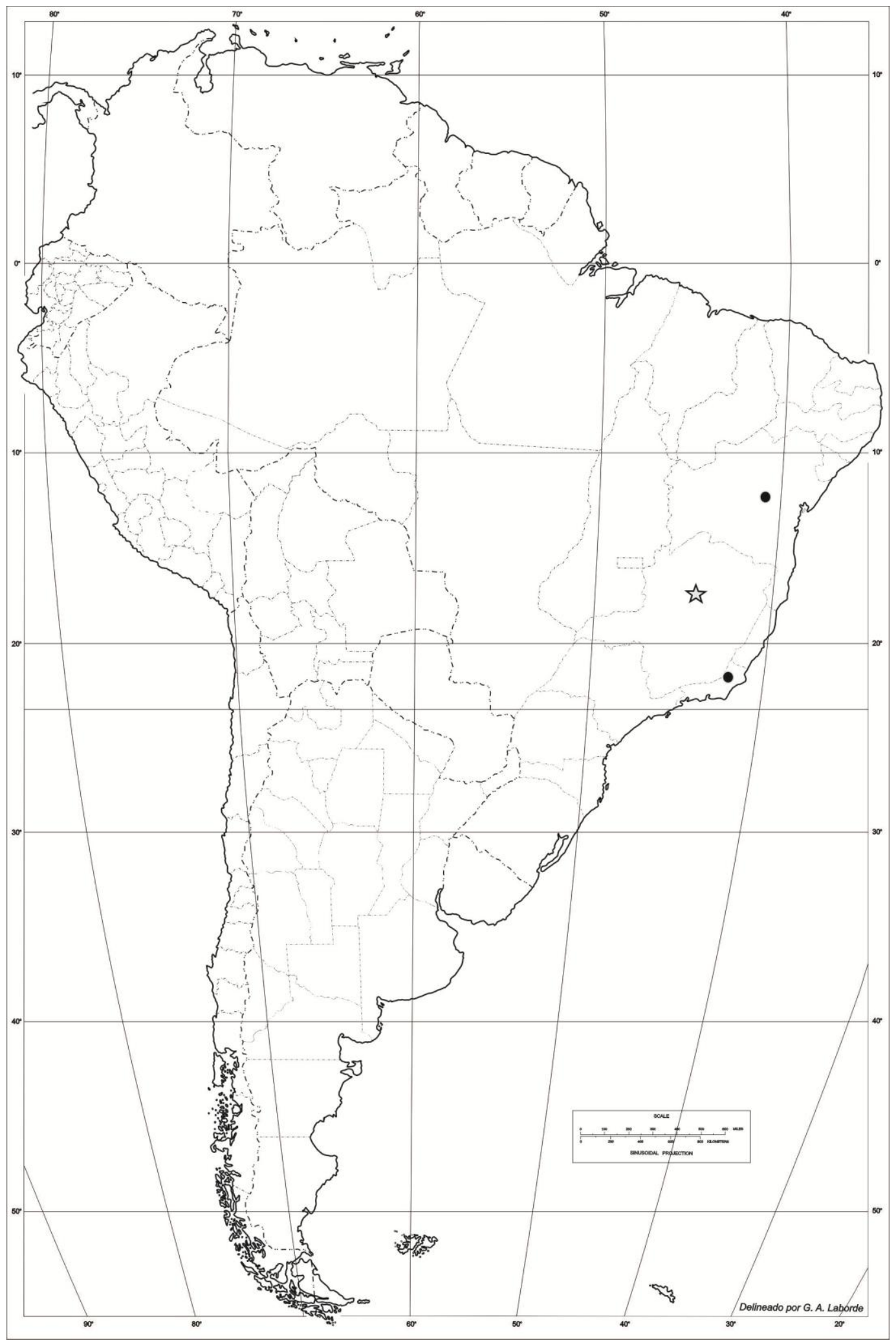

Figura 55. O. freyreisii. Distribución geográfica, la estrella indica la localidad tipo. 

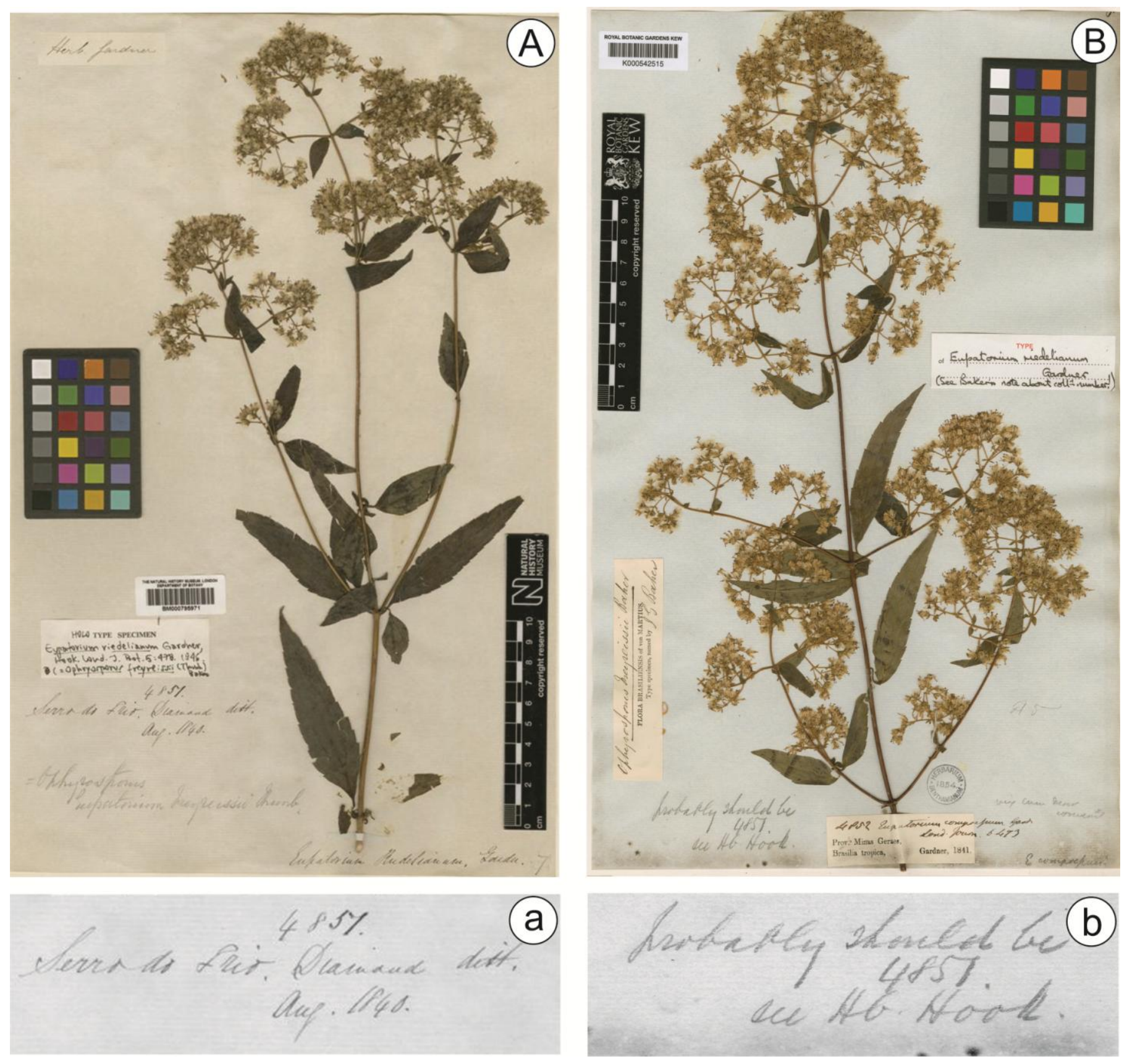

Figura 56. Materiales de E. riedelianum Gardner. A: Lectotipo, Gardner 4851 (BM). a: Detalle correspondiente a la localidad de colecta (imagen obtenida de http://plants.jstor.org/specimen/bm000795971) B: Sintipo, Gardner 4851/2 (K). b: Detalle correspondiente a la anotación de Baker (imagen obtenida de http://plants.jstor.org/specimen/k000542515). 
Ophryosporus galiodes (DC.) R. M. King \& H. Rob.

Phytologia 25(2): 66. 1972.

\section{三 Piqueria galioides DC.}

Prodromus Systematis Naturalis Regni Vegetabilis 5: 105. 1836.

Tipo: “Perou cordillera. 1834" Holotipo: Haenke s.n. G-DC! Fig. 57.

Arbusto erecto $(0,5 \mathrm{~m})$, profusamente ramificado. Tallo con entrenudos entre 0,3 y $1,2 \mathrm{~cm}$, ramificaciones secundarias opuestas, ramas glabras, marrón claro. Hojas alternas, en fascículos, pecioladas, pecíolo 0,5-1,5 cm, láminas lineares, 0,2-0,4 x 1,5-4 cm, base cuneada, ápice agudo, margen entero a denticulado, revoluto; consistencia herbácea, venación acródroma imperfecta suprabasal; pubescente, tricomas eglandulares simples cónicos. Inflorescencia cimoidea, compuesta de corimbos laxos; terminal y axilar, con hojas persistentes bien desarrolladas. Capítulos ca. 80-100, pedunculados (0,5-1 mm), 1,5 x $4 \mathrm{~mm}$. Involucro cilíndrico, 1,5 x 3,5 mm; filarios 4, subimbricados; en una serie de filarios, ovado-lanceolados, $0,7 \times 3,3 \mathrm{~mm}$; ápice fimbriado, margen entero, consistencia herbácea, a veces con porciones esclerificadas en el centro; glanduloso, con tricomas glandulares (tipo $\alpha$ ). Flores 3-4, hermafroditas, corola blanca, tubular, 2,8 x 0,7 mm, 5-dentada, lóbulo 0,3 × 0,4 mm; glanduloso sólo en la base del tubo, tricomas glandulares (tipo $\alpha$ ). Estambres 5, anteras 0,75 $\times 0,25$ $\mathrm{mm}$, collar anteral cilíndrico, base de la teca auriculada; apéndice conectival nulo. Estilo $3,8 \mathrm{~mm}$, largamente exerto, ramas del estilo fuertemente clavadas en el ápice, ápices más oscuros que el resto de las ramas, las ramas 1,8 $\mathrm{mm}$. Cipsela negra no estipitada, piriforme, $1,5 \mathrm{~mm}$, marcadamente 5-costada; glabra, carpopodio cilíndrico, central. Papus nulo. Fig. 58.

Fenología: Florece de octubre a julio.

Distribución: Perú (departamentos de Cajamarca, Huancavelica, La Libertad, Lima y San Martín) a 150-2000 msnm, habita tanto en desierto semicálido tropical (localizado a la largo de la franja costera, al sur del valle del Chicama), matorral 
desierto (en las laderas de la vertiente del Pacífico) y áreas mesoandina (incluye las vertientes occidentales, las laderas de valles interandinos y el altiplano) (León et al. 2006 [2007]). Común en laderas pedregosas, con estrato arbóreo y hierbas anuales perennes: Loxopterygium Hook. f., Cordia L., Cercidium Tul., Neoraimondia Britton \& Rose, Melocactus Link \& Otto, Aristida adscensionis L., Boutelona disticha (Kunth.) Benth. Fig. 59

Etimología: Que recuerda al género Galium L. (Gledhill 2008).

Estado de Conservación: Citada en las exsicattas como frecuente.

Especímenes adicionales estudiados: PERU. Cajamarca: Contumazá, AscopeAlgarrobal, 29/12/1983, A. Sagástegui A. \& J. Mostacero L. 11334 (MO); El Balconcito, Algarrobal-San Benito, 02/02/1985, A. Sagástegui A. et al. $12457(\mathrm{~F})$; Huertas (Chilete-Contumazá), 24/05/1981, A. Sagástegui et al. 9790 (F, MO); Southwest of El Portachuela, 02/04/1987, David Keil et al. 199962 (MO). Huancavelica: Castrovirreina, Pámpano, 05/1910, A. Weberbauer 5379 (F). La Libertad: Trujillo, Cerro Campana, 25/10/1983, A. Sagástegui 10940 (MO); Lomas de Virú, 05/09/1984, J. Mostacero L. \& L. Ramírez V. 672 (MO); Lambayeque: Chiclayo, Cerro Reque, 17/06/1979, Santos Llatas Q. 478 (MO). Lima: along Rio Chillón, near Viscas, 10-15/06/1925, Francis W. Pennell 14475 (F); Cajatambo, Pampa Libre entre Sayán y Churín, 30/05/1948, Ramón Ferreyra 3554 (F); Huarochiri, San Bartolomé, 29/05/1940, Erik Asplund 11201 (G); Quive, 09/07/1925, Francis W. Pennell 14308 (F). San Martín: al oeste de la localidad de Quinden, sobre la carretera a Chepen, 08/07/1983, I. Sánchez V. et al. 3025 (F); Frente a Gallito-Ciego, 05/05/1984, I. Sánchez Vega 3412 (MO). 


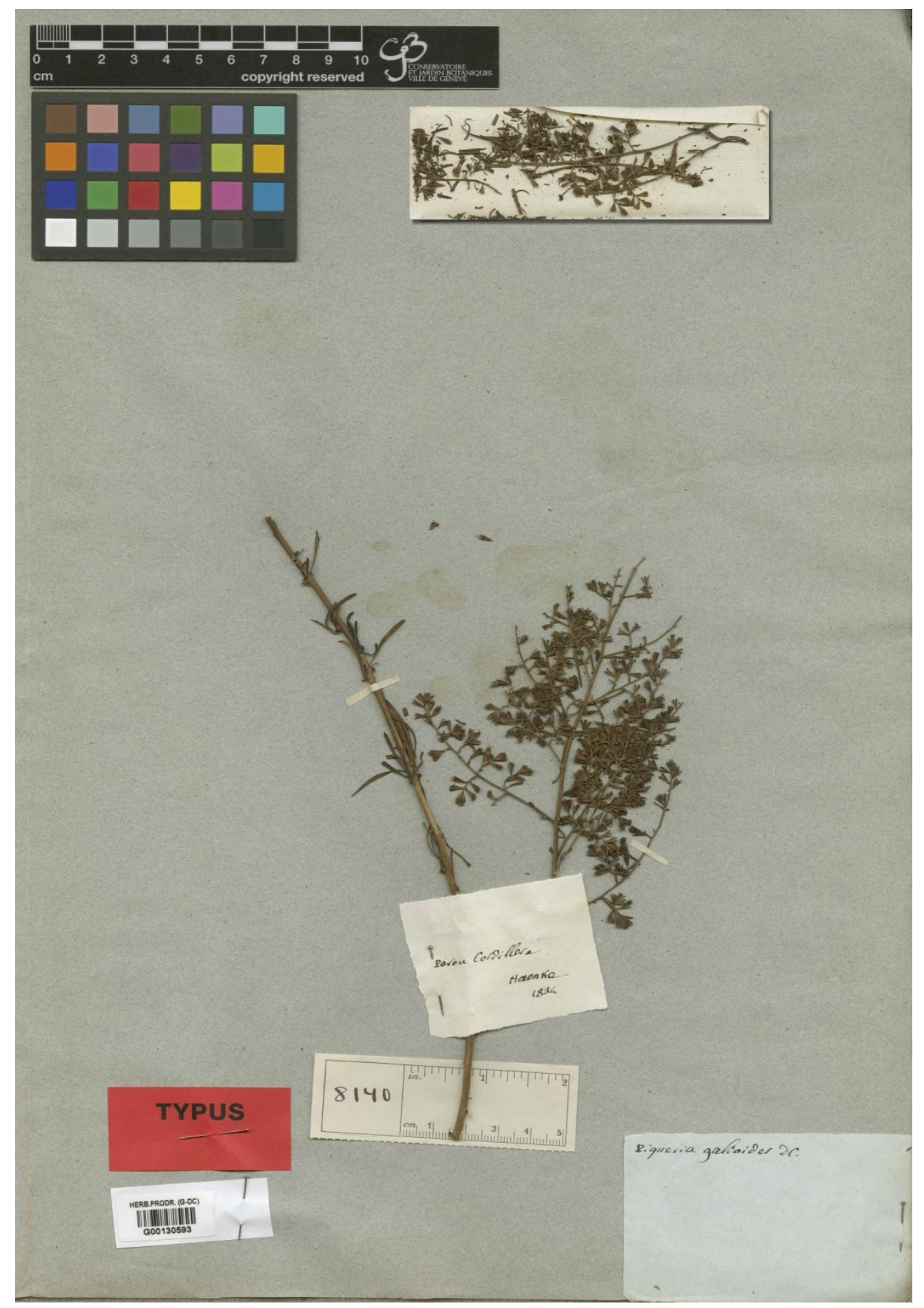

Figura 57. O. galioides, holotipo. Haenke s.n. (G-DC). 

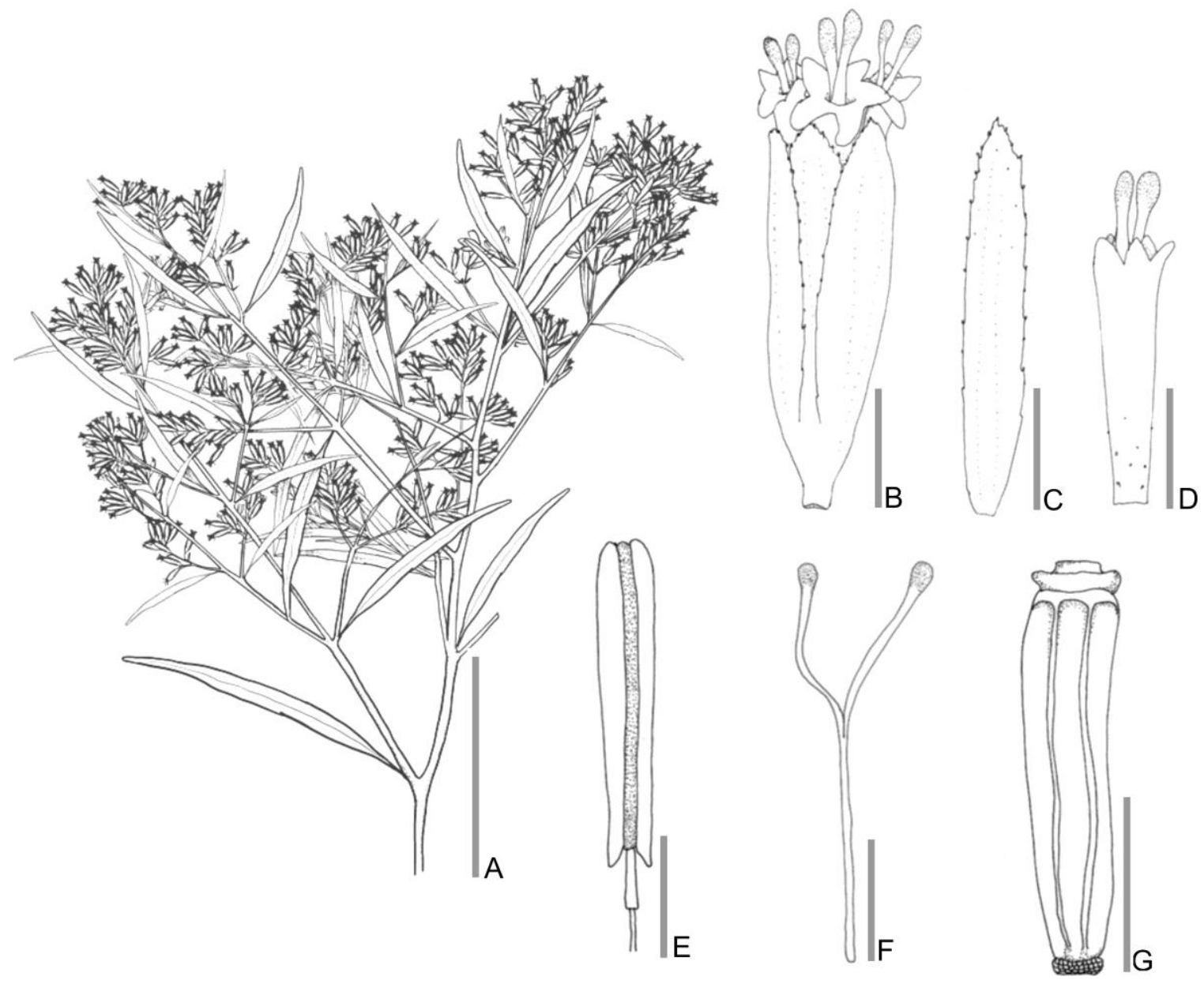

Figura 58. O. galioides. A. Rama florífera. B. Capítulo. C. Flor sin papus ni cipsela. D. Filario. E. Antera. F. Estigma. G. Cipsela. Escalas: A: $5 \mathrm{~cm}$; B-D: $1 \mathrm{~mm}$; E: 250

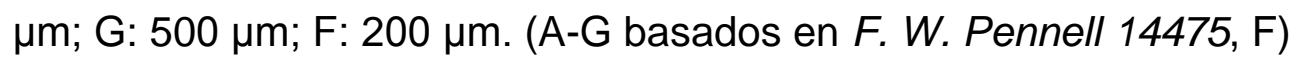




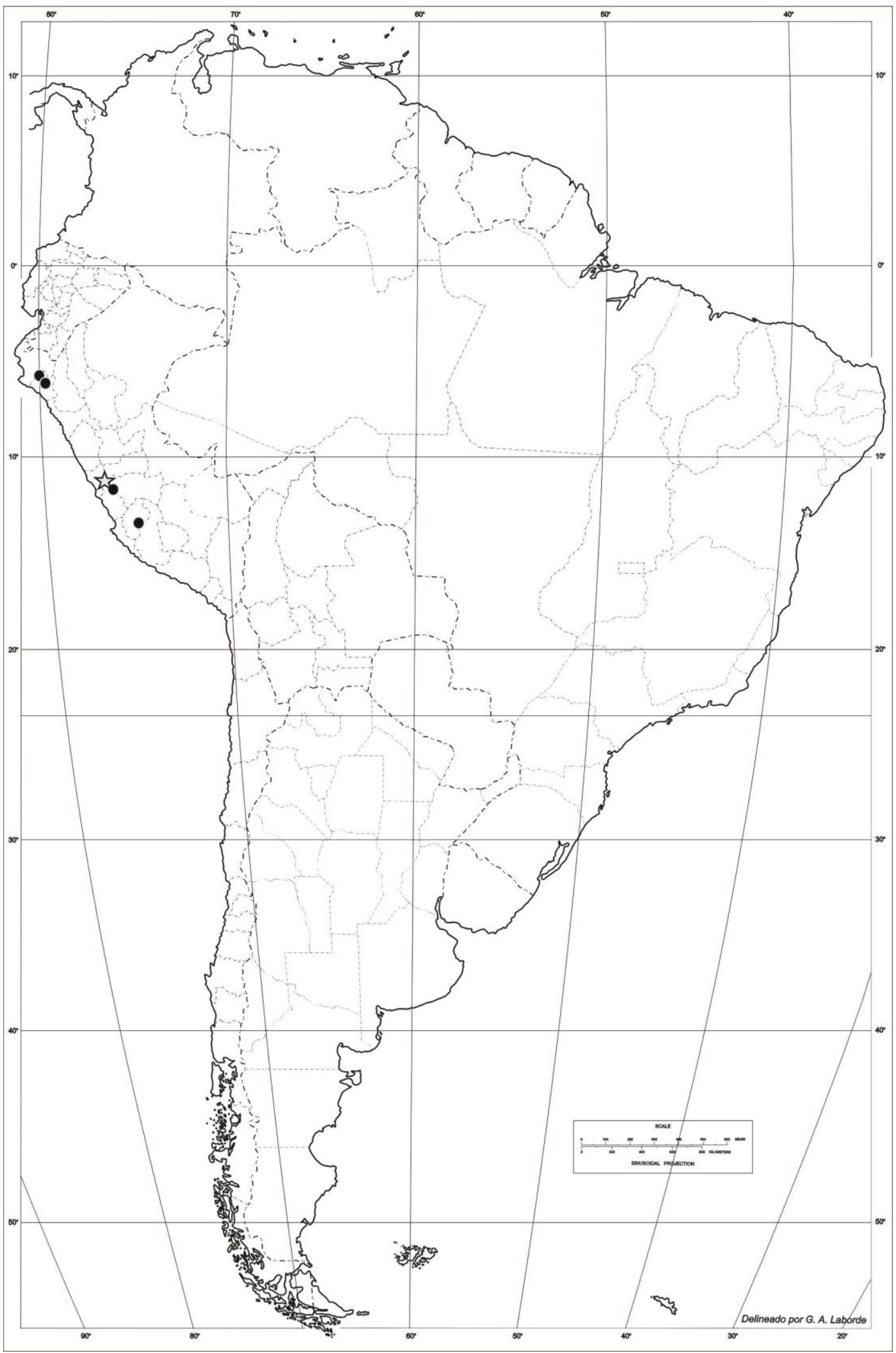

Figura 58. O. galioides. Distribución geográfica, la estrella indica la localidad tipo. 
Ophryosporus hartwegii (B. L. Rob.) R. M. King \& H. Rob.

Phytologia 25(2): 66. 1972.

三 Piqueria hartwegi B. L. Rob.

Proceedings of the American Academy of Arts and Sciences 42: 14. 1906

Lectotipo: "Perú. El Catamayo. 1841", T. Hartweg 762 K foto! 000486679 , isolectotipos fragmento $F$ foto! 878479 , fragmento $F$ foto! 1012365 , fragmento $\mathrm{GH}$ foto! $00010780, \mathrm{~K}$ foto! 000486680, LD foto! 1215187, $\mathrm{P}$ foto! $00742193, \mathrm{P}$ foto! 00742194, P foto! 00742195 (Plos \& Sancho, 2012) Fig. 60:

$=P$. artemisioides HBK. Nova Genera et Species Plantarum (folio ed.) 4: 120. $1820[1818]$.

Arbusto erecto $(0,90-1 \mathrm{~m})$. Tallo con entrenudos entre 0,3 y $0,5 \mathrm{~cm}$, ramificaciones secundarias opuestas, ramas glabras, marrón claro. Hojas alternas, en fascículos, pecioladas, pecíolo 0,3-0,5 cm, láminas lineares, 0,1-0,2 x 1,5-3,5 cm, base cuneada, ápice agudo, margen entero, revoluto; consistencia herbácea carnosa, venación acródroma imperfecta suprabasal; glandulosa, tricomas glandulares (tipo $\alpha$ ). Inflorescencia tirsoidea laxa, compuesta de corimbos; terminal y axilar, con hojas persistentes bien desarrolladas. Capítulos ca. 200-225, pedunculados (0,5-1 mm), 1,2 x 3,5 mm. Involucro cilíndrico, 1,2 × 3 $\mathrm{mm}$; filarios 4 , subimbricados; en una serie de filarios, ovado-lanceolados, $0,5 \times$ 2,8 mm; margen entero, consistencia herbácea, a veces con porciones esclerificadas en el centro; glanduloso, tricomas glandulares (tipo a). Flores 4-5, hermafroditas, corola verdosa, infundibuliforme, sin paso gradual entre tubo y limbo, tubo $0,4 \times 0,25 \mathrm{~mm}$, limbo $1 \times 0,6 \mathrm{~mm}$, 5-dentada, lóbulo 0,3 x 0,6 mm; glanduloso sólo en la base del tubo, tricomas glandulares (tipo a). Estambres 5, anteras 0,8 x 0,2 mm, collar anteral cilíndrico, base de la teca auriculada; apéndice conectival rudimentario, entero. Estilo $2 \mathrm{~mm}$, cortamente exerto, ramas del estilo fuertemente clavadas en el ápice, ápices más oscuros que el resto de las ramas, las ramas $0,8 \mathrm{~mm}$. Cipsela negra no estipitada, piriforme a levemente falcada, 1,7 
mm, marcadamente 5-costada; glabra; carpopodio cilíndrico, excéntrico. Papus nulo. Fig. 61.

Fenología: Florece de junio.

Distribución: Perú (departamentos de Cajamarca y La Libertad) a 2900 msnm. Fig. 62.

\section{Notas:}

1. En la descripción original, Robinson (1906) hace referencia a la colección Hartweg 762 con duplicados depositados en diferentes herbarios. Si bien, el Código de Viena (McNeill et al. 2006) en su recomendación 9 A1, indica que para lectotipificar se deberían priorizar los materiales depositados en los herbarios donde el investigador desarrolló sus actividades, en este caso, como el material depositado en $\mathrm{GH}$ es un fragmento acompañado de una foto correspondiente a un material depositado en $\mathrm{K}$, se procede a designar al espécimen depositado en $\mathrm{K}$ como lectotipo. Dicho material se encuentra completo, en excelente condiciones de conservación y permite la correcta identificación de la especie.

Etimología: Hace referencia al colector del tipo, el botánico alemán Karl Theodor Hartweg (1812-1871).

Estado de Conservación: De acuerdo con Brako \& Zarucchi (1993) es considerado un endemismo.

Especímenes adicionales estudiados: PERU. Lima: Matucana, 24/06/1951, $O$. V. Núñez 3100 (LP). 


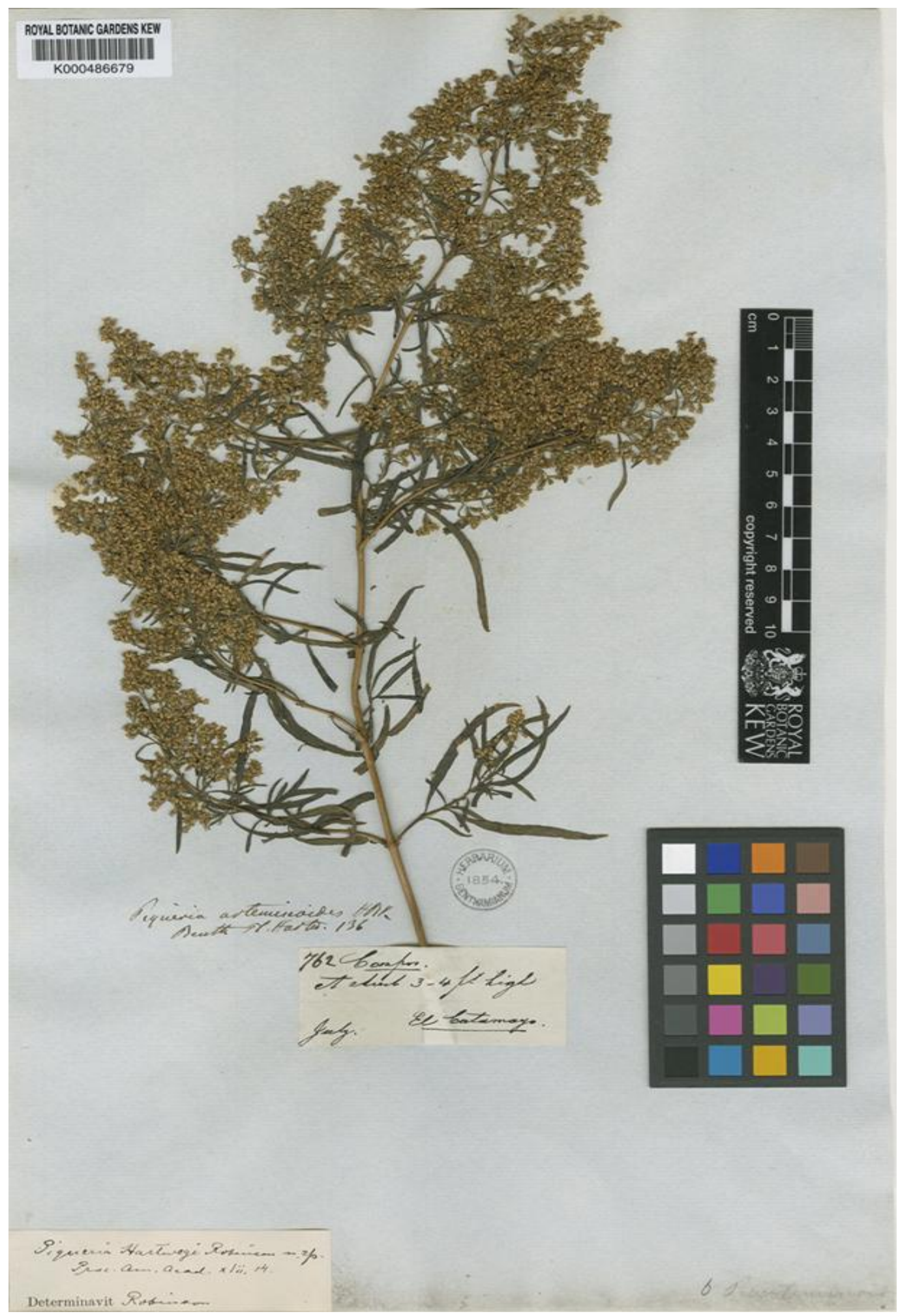

Figura 60. O. hartwegii, holotipo. Hartweg $762(\mathrm{~K})$. 

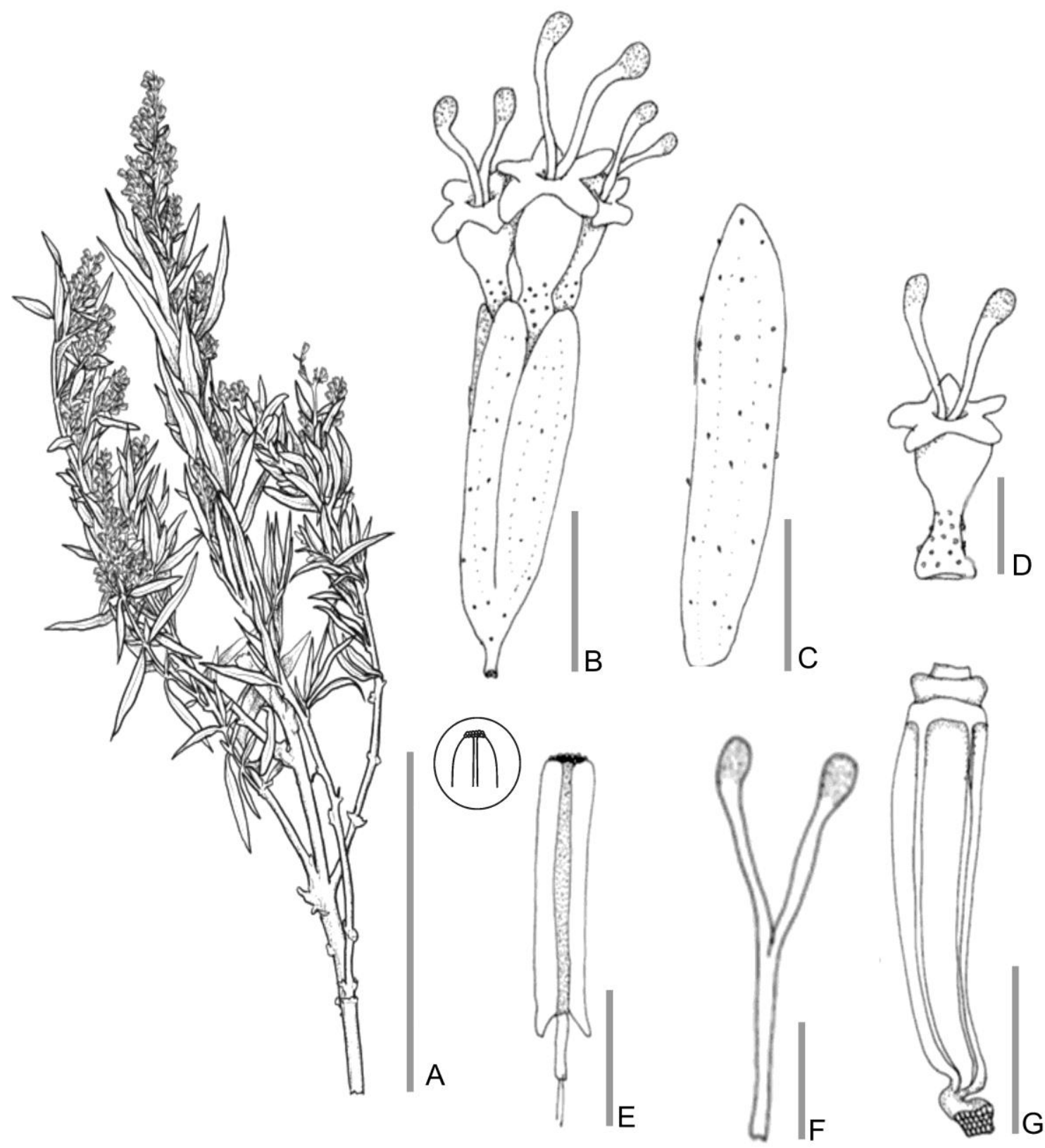

Figura 61. O. hartwegii. A. Rama florífera. B. Capítulo. C. Flor sin papus ni cipsela. D. Filario. E. Antera. F. Estigma. G. Cipsela. Escalas: A: $5 \mathrm{~cm}$; B-C: $1 \mathrm{~mm}$; D-E:

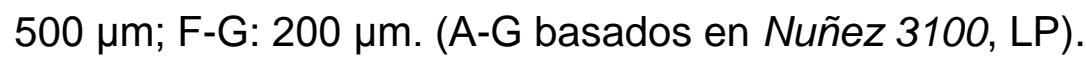




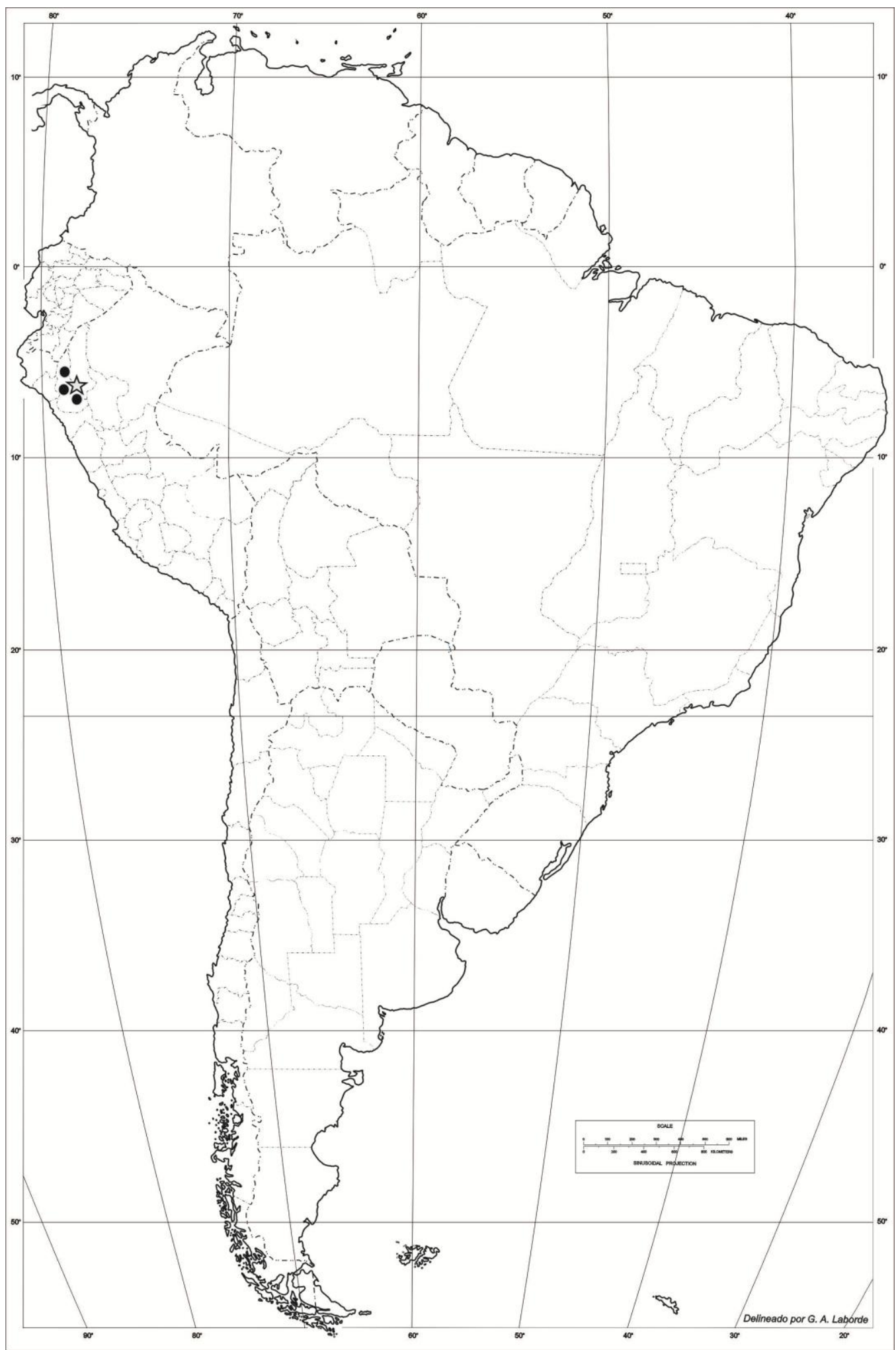

Figura 62. O. hartwegii. Distribución geográfica, la estrella indica la localidad tipo. 
Ophryosporus heptanthus (Sch. Bip.) R. M. King \& H. Rob.

Phytologia 58: 528. 1985.

ミ Eupatorium heptanthum Sch. Bip.

Bonplandia 4: 50 y 54.1856.

Lectotipo: "Pérou, sur les montagnes, aux environs de la ville de d'Azangaro. 1854", Lechler 1751 P 00742426 foto!, isolectotipos: GOET foto! 001506, K foto! 000542525 (montado junto con Pentland s.n., K 000542524), NY sin número!, P foto! 00742425, P foto! 00742428, W foto! 0018472 (Plos \& Sancho, 2012) Fig. 63.

= Ageratina sterbergiana (DC.) R. M. King \& H. Rob. Phytologia 19: 217. 1970.

= Eupatorium origanoides Meyen \& Walp. Nov. Actorum Acad. Caes.-Carol. Nat. Cur. 19, Suppl 1: 257. 1843, nom. illegit. non Kunth (1818).

= Eupatorium heptanthum Sch. Bip. ex Wedd. Chloris Andina. 1855 [1857], nom. nud. Lechler 1751 y Weddell 615.

= Ophryosporus origanoides Hieron., Bot. Jahrb. Syst. 22(45): 707. 1897

= Ophryosporus origanoides. var. microcephala Hieron., Bot. Jahrb. Syst. 22(45): 708. 1897. Lectotipo: "Bolivien bei Cochabamba, $3000 \mathrm{~m}$. 26/03/1892" Kuntze s.n. (NY 00230826!). Isolectotipos: B (probablemente destruido), fragmento GH 00010786 foto! (Plos \& Sancho, 2012).

Arbusto erecto $(1 \mathrm{~m})$. Tallo con entrenudos entre 1,2 y $5 \mathrm{~cm}$, ramificaciones secundarias opuestas, ramas tomentulosas, rojizo, con estriaciones. Hojas opuestas, pecioladas, pecíolo $0,3-0,5 \mathrm{~cm}$, láminas ovadas a ovado-lanceoladas, 0,3-0,8 x 2-4 cm, base redondeada, ápice agudo, margen dentado, plano; consistencia herbácea, venación acródroma imperfecta suprabasal; pubescente y glandulosa, tricomas eglandulares simples cónicos y glandulares (tipo $\alpha$ ). Inflorescencia cimoidea, compuesta de corimbos densos; terminal y axilar, con hojas persistentes poco desarrolladas. Capítulos ca. 50-80, pedunculados (1-2 
$\mathrm{mm}$ ), $4 \times 5 \mathrm{~mm}$. Involucro acampanado, $4 \times 2,3 \mathrm{~mm}$; filarios 7-8, eximbricados; en dos series de filarios, los externos ovados, $1,3 \times 3,5$, los interno ovadolanceolados, 1-1,2 × $3 \mathrm{~mm}$; ápice fimbriado, margen entero, consistencia herbácea, a veces con porciones esclerificadas en el centro; glanduloso, tricomas glandulares (tipo $\alpha$ ). Flores 7-8, hermafroditas, corola blanca, tubular, $5 \times 1 \mathrm{~mm}, 5$ dentada, lóbulo 0,3 × 0,6 mm; glandulosa sólo en la base del tubo, tricomas glandulares (tipo $\alpha$ ). Estambres 5 , anteras $3 \times 0,3 \mathrm{~mm}$, collar anteral cilíndrico, base de la teca auriculada; apéndice conectival nulo. Estilo $6 \mathrm{~mm}$, largamente exerto, ramas del estilo fuertemente clavadas en el ápice, ápices más oscuros que el resto de las ramas, las ramas $3,2 \mathrm{~mm}$. Cipsela negra ligeramente estipitada, piriforme a levemente falcada, 3,5 $\mathrm{mm}$, marcadamente 5-costada; serícea y glandulosa, pelos gemelos escasos y glandulares (tipo $\alpha$ ) en las costillas; carpopodio anular, excéntrico. Papus formado por 20-22 cerdas amarillentas, connadas en la base, 3,5-3,8 mm. $n=10$ (Fernández Casas \& Fernández Piquerias, 1981), $n=20$ (Robinson et al., 1989) Fig. 64 .

Fenología: Florece de enero a julio.

Distribución: Bolivia (departamento de Cochabamba, La Paz, Oruro). Chile (región de Tarapaca). Perú (Arequipa, Ayacucho, Cuzco, Huancavelica, Junín y Puno) a 3000-4000 msnm, habita en monte bajo pluviifolio, con Baccharis L., Buddleja L., Cassia L., Schinus L. y Minthostachys (Benth.) Spach. Fig. 65.

Nombres comunes: "Chilca" (Arteta Beltrán, 2008), "huairasacha" (Tovar 1251 LP).

\section{Notas:}

1. Suele citarse el papus de color púrpura, pero en realidad esa tonalidad es dada por las ramas del estilo, siendo el papus de color pálido.

2. Hojas con la cara adaxial mate y la abaxial nítida (Camp 4009 NY).

3. E. heptanthum ha sido considerado usualmente un nomen nudum de Schulz Bipontinus que fue posteriormente validado por $\mathrm{H}$. A. Weddell (1855). En el texto precedente a la lista de especies y ejemplares 
colectados por Lechler ("Lechleri plantae peruvianae ed. R. F. Hohenacker", Bonplandia 4: 50-55, 1856) publicado por Schultz Bipontinus se hace referencia a ciertos caracteres florales de E. heptanthum (pág. 50, "Die beiden neuen Eupatorien gehören zur Ser. III. Eximbricata, E. heptanthum hat 7, das $E$. azangaroense 40-50 Blüten im Köpfchen" = De los dos nuevos eupatorios que pertenecen a la sección III, eximbricata, E. heptanthum cuenta con siete flores en capítulos pequeños y $E$. azangaroense cuenta con 40-50 flores). En este texto, Schultz Bipontinus brinda datos florales y de pertenencia de la nueva especie E. heptantum a una sección del género Eupatorium, lo cual, junto con el ejemplar citado en la pág. 54 completa las deficiencias de la descripción y permite su clara identificación. Por lo tanto, consideramos que debería respetarse la autoría de Schultz Bipontinus y tratarse ese nombre como válidamente publicado (Plos \& Sancho, 2012).

Etimología: Del griego हmта, siete y av९os, flores (Gledhill 2008).

Estado de Conservación: Se cita como ruderal, presente en áreas con malezas.

Compuestos químicos de interés: Herz (2004) cita la presencia de benzofuranos, dihidrobenzofuranos, diterpenos y glicósidos (flavonas, flavonoles, flavononas). A su vez, Ferracini et al. (1989) indica la presencia de diterpenoides de ent-labdano, derivados de tremetona y cromenos y flavonoides. En estudios realizados sobre aceites esenciales, se ha detectado la presencia de santolinatrieno (Barrero et al. 2006), precoceno, monoterpenos, p-cimeno, sesquiterpenos, mono y sesquiterpenos oxigenados (Lopez Arze et al. 2004).

Usos: Se detectó actividad antioxidante en extractos (Rosas-Romero \& Saavedra 2005).

Especímenes adicionales estudiados: BOLIVIA. Cochabamba: Tapacari, 19/03/1892, O. Kuntze s.n. (NY). $26 \mathrm{~km}$ from Tolata, on road to Santa Cruz from Cochabamba, 04/02/1978, R. M. King \& L. E. Bishop 7593 (MO). Ica: Pisco, valley rio Pisco, 10/03/1951, colector ilegible 384 (NY). La Paz: M. Kapac, Kasani, 07/07/1998, M. Nee \& D. Atha 49979 (NY). Murillo, Cerro Kantunani, lower slopes 
of Cerro Kantunani between Villa La Florida and the municipal tree farm, ca. $8 \mathrm{~km}$ SE of Plaza San Francisco, 16 ${ }^{\circ} 33^{\prime}$ S 68 $8^{\circ} 06^{\prime} \mathrm{W}$, 02/05/1988, M. Lewis 88372 (NY); Lago Titicaca, 03/1910, O. Buchtien 3022 (LP); ib. Isla del Sol, 03/1900, O. Buchtien 3022 (NY); ib. O. Buchtien 3023 (NY); Lake Titicaca, Capachica Peninsula, hills to N of Camjata Hacienda, 28/04/1937, T. G. Tutin 1090 (NY); Ovejuyo, ca. 1 km NW of Ovejuyo, $16^{\circ} 32^{\prime} \mathrm{S} 68^{\circ} 03^{\prime} \mathrm{W}, 02 / 04 / 1982$, J. C. Solomon 7453 (NY, MO); Pacajes, 02/1921, R. S. Shepard 247 (NY); 2 km al sur de Palca por el camino a Comunidad Lacayani, $16^{\circ} 34^{\prime} \mathrm{S} 67^{\circ} 57^{\prime} \mathrm{W}, 15 / 03 / 1987$, J. C. Solomon 16325 (MO); $4 \mathrm{~km}$ up the río Achumani from Calacoto, $16^{\circ} 30^{\prime} \mathrm{S} 68^{\circ} 02^{\prime}$ W, 11/04/1986, J. C. Solomon 15271 (NY). Loayza, Canyon de Yaco, in the narrow red sandstone canyon ca. $1.5 \mathrm{~km}$ down the río Yaco from Yaco, ca. $8 \mathrm{~km}$ SW of Caxata, $17^{\circ} 10^{\prime} \mathrm{S} 67^{\circ} 25^{\prime} \mathrm{W}, 04 / 12 / 1987$, M. Lewis 871214 (MO). Oruro: Cercado, Oruro, 25/04/1957, J. Cañigueral S. J. 485 (LP). Puno: Puno-Juliaca road, 24/04/1977, J. D. Boeke 1565 (NY); Lago Titicaca, south peninsula, 04/06/1954, Monheim 17 (NY); ib. 13/07/1954, Monheim 64 (NY). Región no especificada: Bolivia, 01-04/1859, G. Mandon 260 (NY). Cochabamba, 08/03/1920, E. R. D. Halway s.n. (NY). CHILE. Tarapacá (I Región): lquique, Chusmiza, 10/01/1969, $O$. Zöllner 2997 (LP). PERU. Arequipa: Arequipa, 26-28/03/1925, F. W. Pennell 14277 (NY). Ayacucho: Huanta, 19-21/05/1929, E. P. Killip \& A. C. Smith 23319 (NY). Cuzco: Coraupampa, between Cusco and Pisac, 30/04/1925, F. W. Pennell 13711 (NY); Cusipata, 22/04/1925, F. W. Pennell 13538 (NY); Cuzco, 19/05/1958, P. R. Reitz 5993 (LP); Cuzco, alrededores, 19/05/1958, A. L. Cabrera \& H. A. Fabris 13536 (LP); Cuzco, near ruins at Sacsayhuaman above the city of Cuzco, $13^{\circ} 30^{\prime}$ S $72^{\circ}$ 03' W, 11/05/1981, G. Sullivan, D. Soejarto \& J. K. Sullivan 899 (MO). Huancavelica: Huancavelica, Huando, 05/04/1953, O. Tovar 1251 (LP); ib. Pararpuquio, abajo de Conaica, 17/03/1952, O. Tovar 753 (LP); Chorillos entre Izcuchaca y Mariscal Cáceres, 15/04/1953, O. Tovar 1384 (LP). Junín: Tarma, hills above Tarma, ca. $11^{\circ} 25^{\prime} \mathrm{S} 75^{\circ} 45^{\prime} \mathrm{W}, 19 / 05 / 1982$, L. R. Landrum 4637 (NY); ib. open hillside, 20-22/04/1929, E. P. Killip \& A. C. Smith 21820 (NY); ib. 2022/04/1929, E. P. Killip \& A. C. Smith 21829 (NY); ib. along shaded stream bank, 20-22/04/1929, E. P. Killip \& A. C. Smith 21861 (NY). 


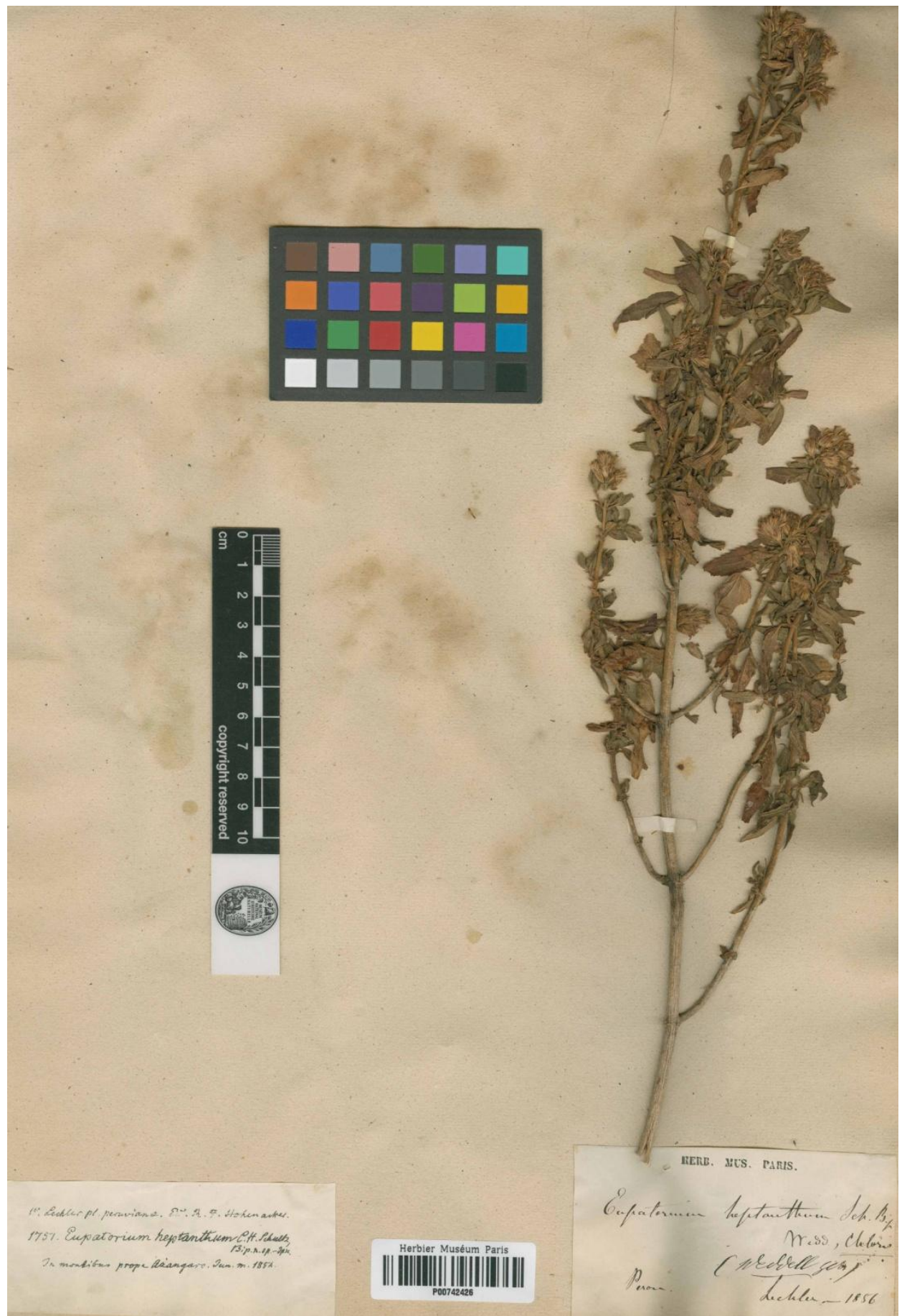

Figura 63. O. heptanthus, lectotipo. Lechler 1751 (P). 


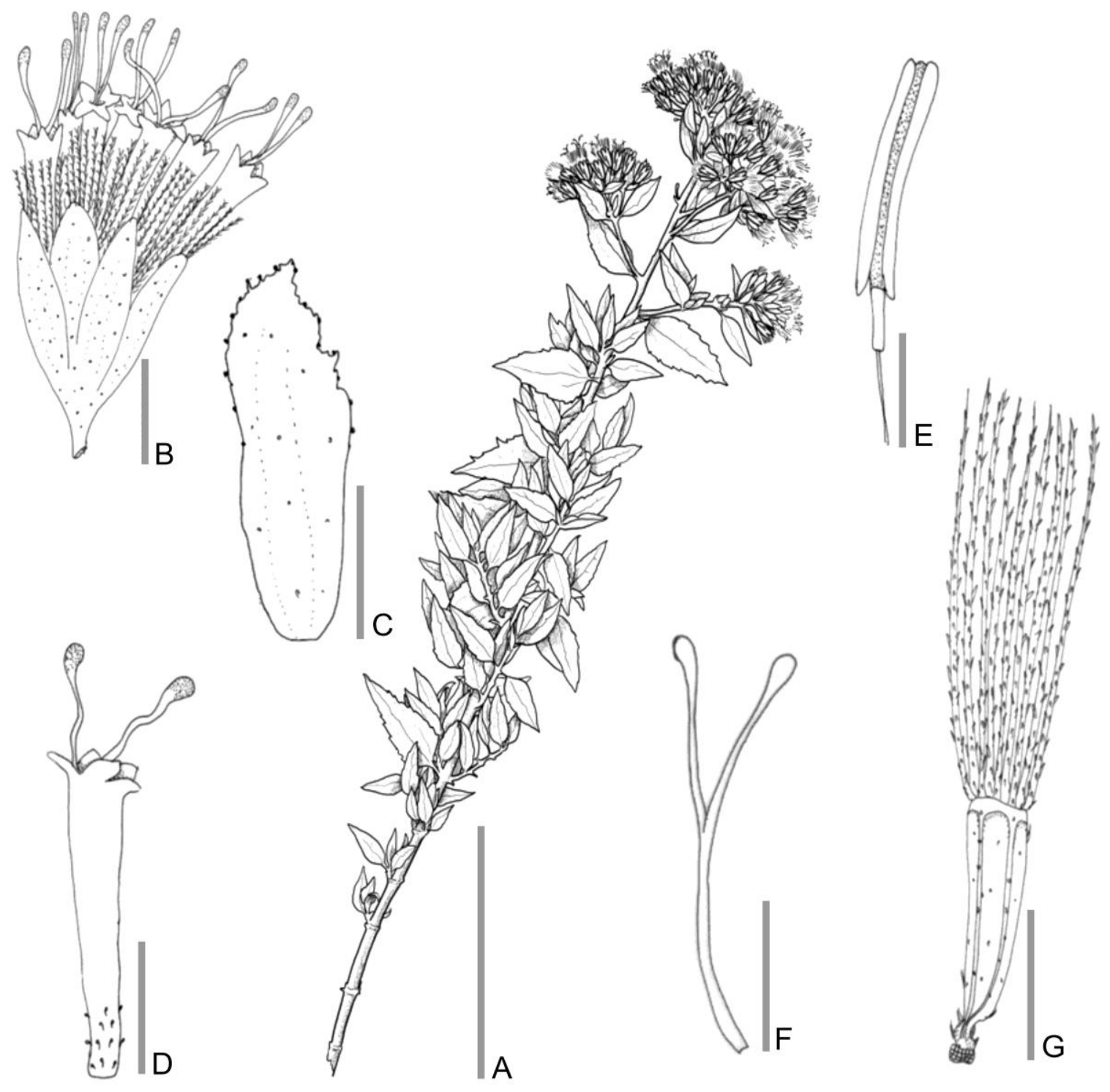

Figura 64. O. heptanthus. A. Rama florífera. B. Capítulo. C. Flor sin papus ni cipsela. D. Filario. E. Antera. F. Estigma. G. Cipsela. Escalas: A: $5 \mathrm{~cm}$; B: $2 \mathrm{~mm}$; C-D: 2 mm; E: 0,1 cm; F: $200 \mu \mathrm{m}$; G: $500 \mu \mathrm{m}$ (A-G basados en L. R. Landrum 4637, NY). 


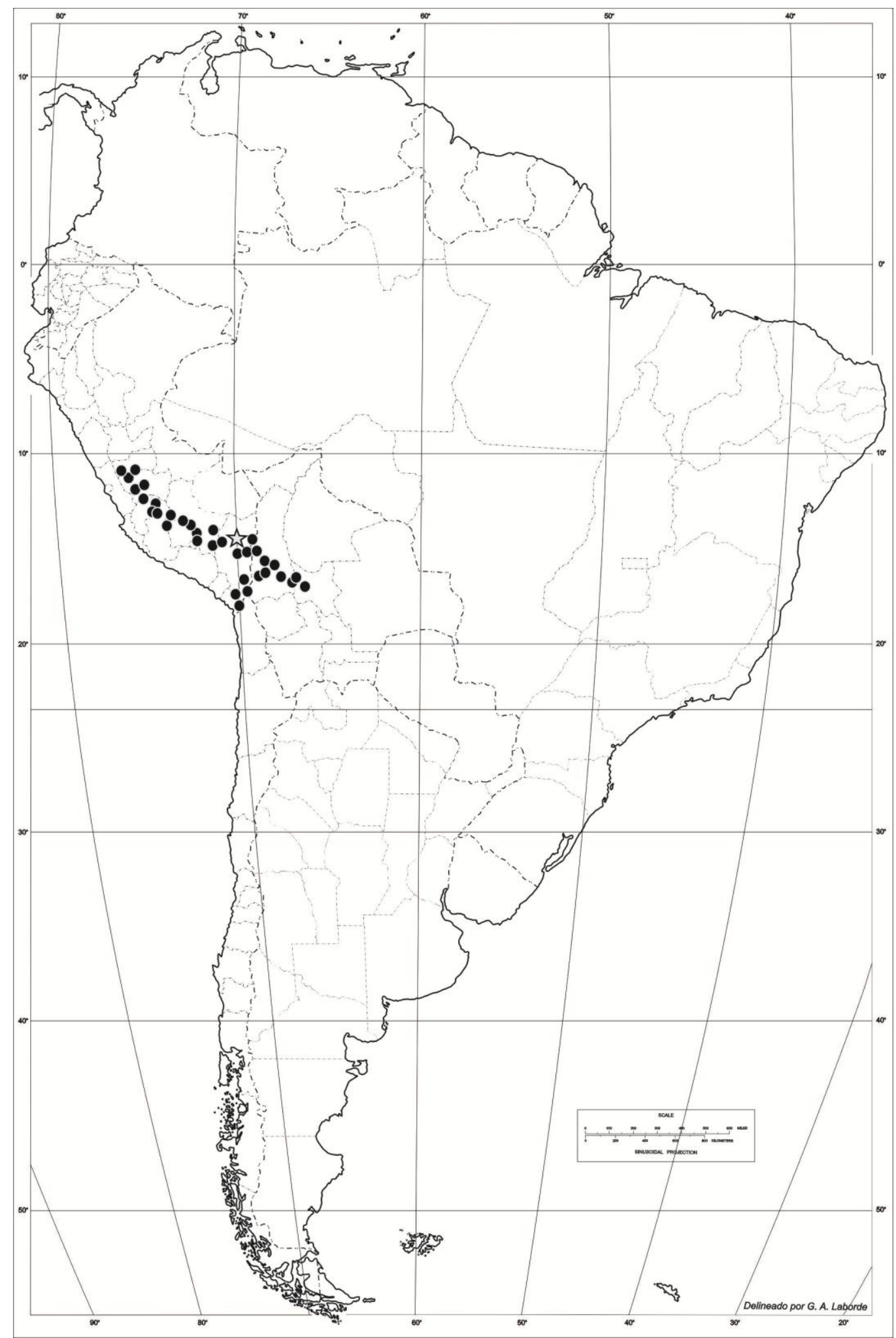

Figura 65. O. heptanthus. Distribución geográfica, la estrella indica la localidad tipo. 
Ophryosporus hoppii (B. L. Rob.) R. M. King \& H. Rob.

Phytologia 23: 399. 1972.

\section{三 Trychinolepis hoppii B. L. Rob.}

Contributions from the Gray Herbarium of Harvard University 80: 6. 1928.

Tipo: Perú, "Arequipa, on rocks and sand, alt. 2500 - 2800 m., July 1925". Werner Hopp, no. 28. Holotipo: B foto!, isotipo $\mathrm{GH}$ foto! (http://plants.jstor.org/search?searchText=trychinolepis\%20hoppii) Fig. 66.

Arbusto erecto. Tallo con entrenudos entre 0,1 y $1 \mathrm{~cm}$, ramificaciones secundarias opuestas, ramas tomentulosas, marrón claro, con estriaciones. Hojas opuestas, pecioladas, pecíolo 0,3-0,5 cm, láminas ovadas, 0,5-1 x 0,8-2 cm, base decurrente, ápice obtuso, margen dentado, revoluto; consistencia herbácea, venación acródroma imperfecta suprabasal; glandulosa, tricomas glandulares (tipo a). Inflorescencia tirsoidea densa, compuesta de corimbos; terminal y axilar, con hojas persistentes bien desarrolladas. Capítulos ca. 48-60, pedunculados (0,5-1 $\mathrm{mm}$ ), $5 \times 5,8 \mathrm{~mm}$. Involucro cilíndrico, $5 \times 4,3 \mathrm{~mm}$; filarios 4-6, subimbricados; en una serie de filarios, ovado-lanceolados, 1,2 $\times 4 \mathrm{~mm}$; margen entero, consistencia herbácea a levemente coriácea, a veces con porciones esclerificadas en el centro; glanduloso, tricomas glandulares (tipo $\alpha$ ). Flores 4-5, hermafroditas, corola blanquecinas, infundibuliforme, con paso gradual entre tubo y limbo, tubo 0,9 x 0,3 $\mathrm{mm}$, limbo 1,2 × $1 \mathrm{~mm}$, 5-dentada, lóbulo 0,5 × 0,6 mm; glandulosa más densamente en la base del tubo, tricomas glandulares (tipo a). Estambres 5, anteras $1 \times 0,2 \mathrm{~mm}$, collar anteral cilíndrico, base de la teca auriculada; apéndice conectival rudimentario, con surco medial. Estilo $4,8 \mathrm{~mm}$, largamente exerto, ramas del estilo fuertemente clavadas en el ápice, ápices más oscuros que el resto de las ramas, las ramas $3 \mathrm{~mm}$. Cipsela negra no estipitada, piriforme a levemente falcadas, $1,9 \mathrm{~mm}$, marcadamente 5-costada; glabra; carpopodio cilíndrico, excéntrico. Papus formado por 4-6 escamas laciniadas pardas, connadas en la base, 0,8-1 mm. Fig. 67. 
Fenología: Florece en enero a mayo.

Distribución: Chile (regiones de Arica y Parinacota, Antofagasta y Tarapacá) y Perú (departamento de Arequipa) a 300 - 3200 msnm, hábitat mesoandino, incluye las vertientes occidentales, las laderas de valles interandinos y el altiplano (León et al. 2006 [2007]) Fig. 68.

\section{Notas:}

1. Originalmente, este taxón se encontraba bajo el género monotípico Trychinolepis, porque sin bien presenta anteras con apéndice anteral nulo, el papus escamoso no pertenecía a la definición del género Ophryosporus. King \& Robinson (1972), al ampliar la definición del género incluyendo otras variantes en su papus, trasladan este taxón al género Ophryosporus

Etimología: Dedicado al colector del material tipo, el naturalista alemán Werner Hopp.

Especímenes adicionales estudiados: CHILE. Arica y Parinacota (XV Región): Parinacota, Putre, Quebrada de Socoroma, en las faldas frente al pueblo, 05/05/1972, Ricardi, Wedlt \& Quezada 150 (CONC). Antofagasta (Il Región): Tocopilla, al norte de Tocopilla, Quebrada de Mamilla, $21^{\circ} 58^{\prime} \mathrm{S} 70^{\circ} 09^{\prime} \mathrm{W}$, 21/10/1964, Ricardi, Manticorena \& Matthei 1067 (CONC). Tarapacá (I Región): Iquique, Chusmiza, 01/1969, O. Zöllner 2997 (CONC); Alto Patache, 2048' S 70 09' W, 16/01/1998, H. Larraín 98200 (CONC). 


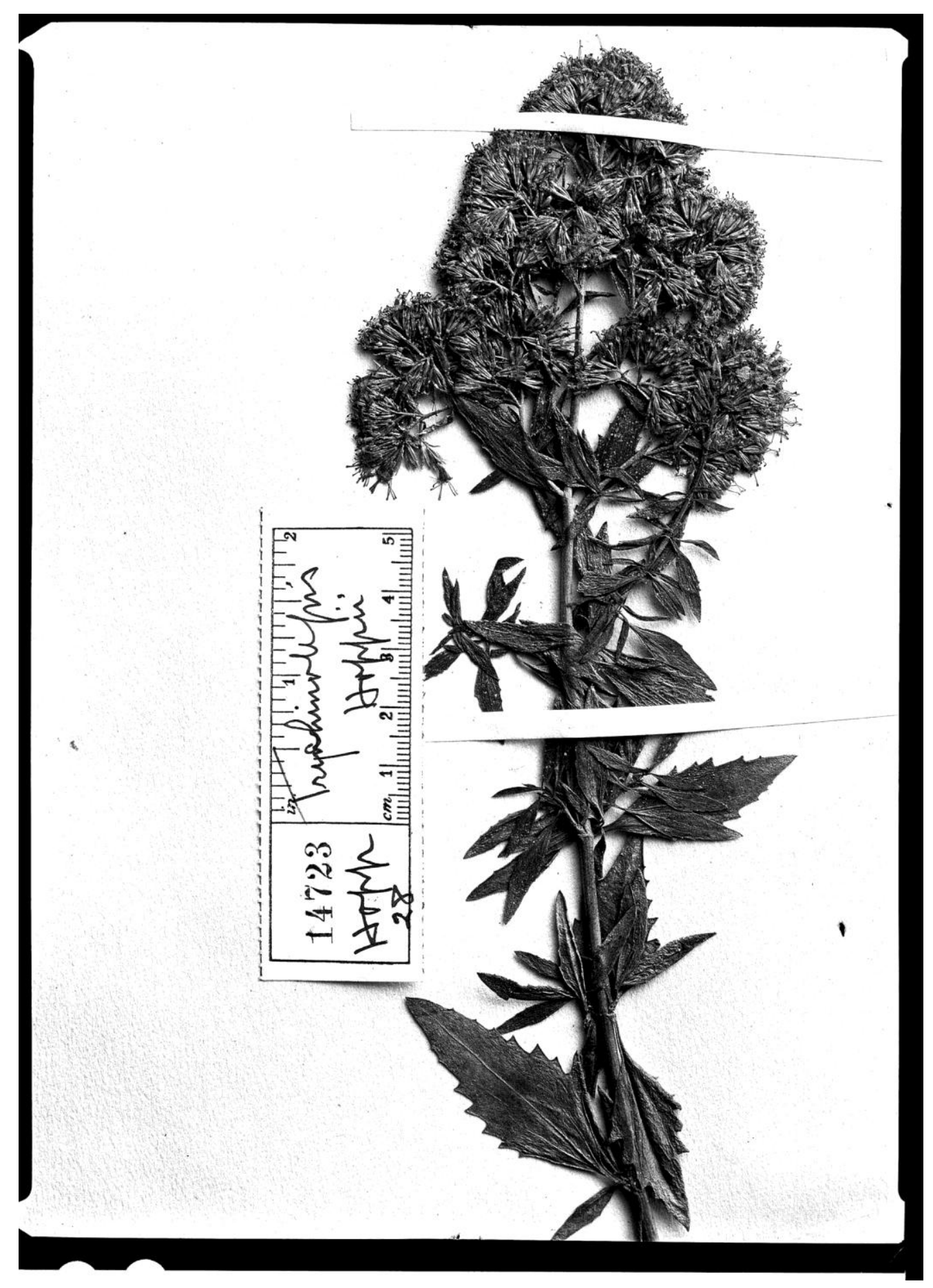

Figura 66. O. hoppii, holotipo. W. Hopp 28 (B). 


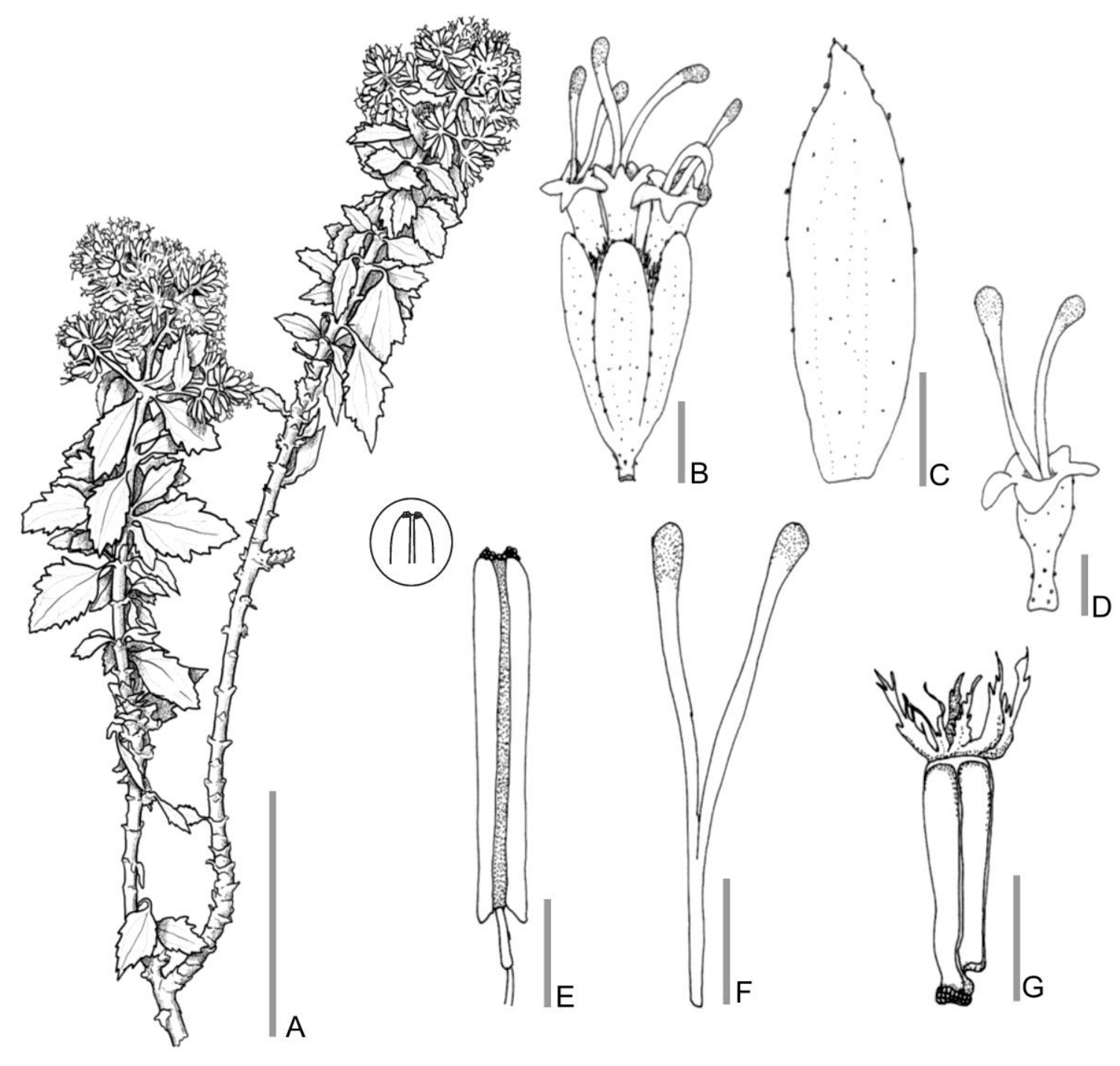

Figura 67. O. hoppii. A. Rama florífera. B. Capítulo. C. Flor sin papus ni cipsela. D. Filarios. E. Antera. F. Estigma. G. Cipsela. Escalas: A: $5 \mathrm{~cm}$; B: $1 \mathrm{~mm}$; C: 1,2 mm;

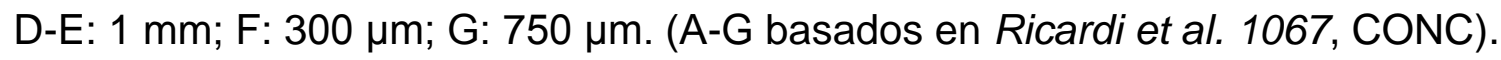




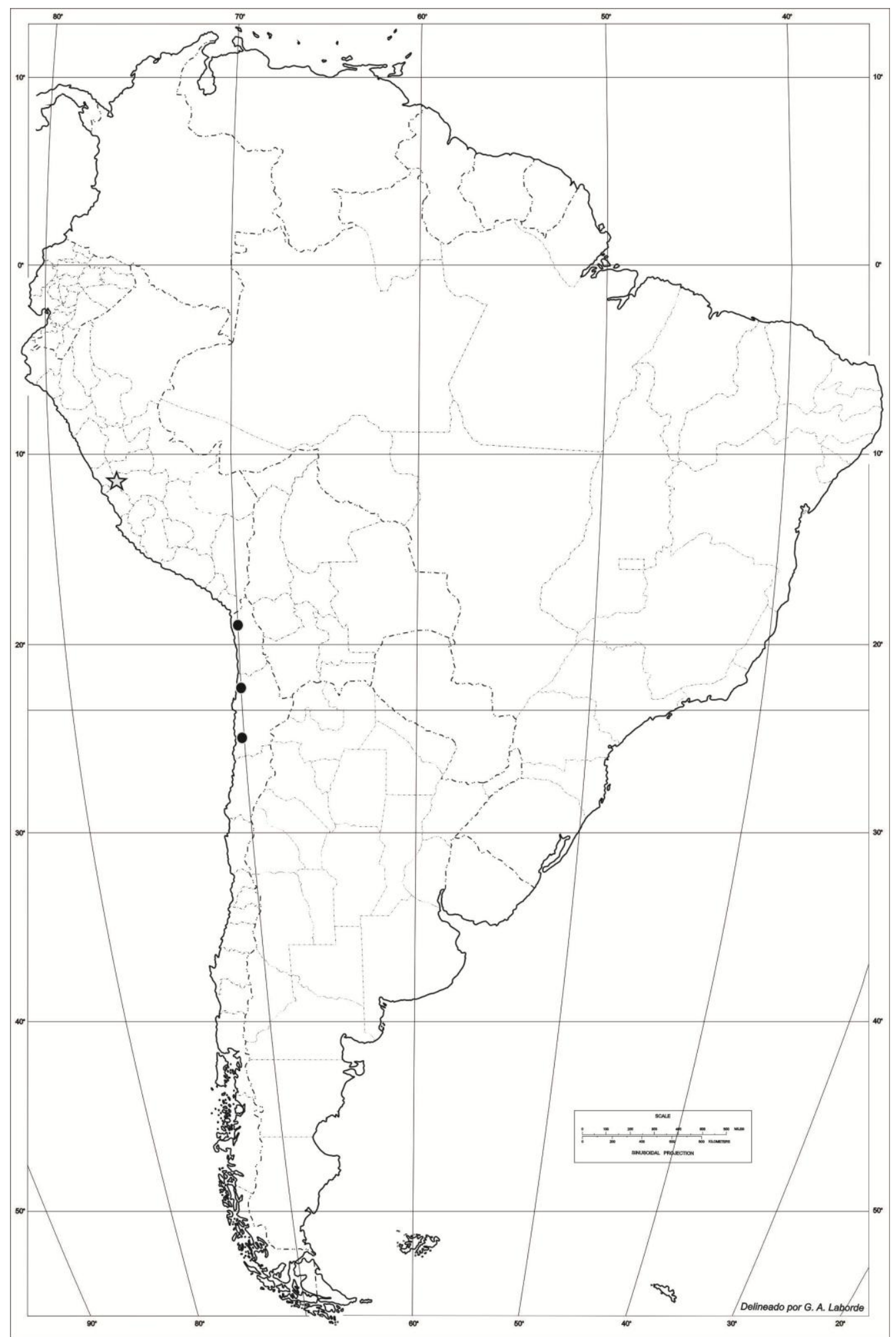

Figura 68. O. hoppii. Distribución geográfica, la estrella indica la localidad tipo. 


\section{Ophryosporus johnstonii B. L. Rob.}

Contributions from the Gray Herbarium of Harvard University. 77: 4-5. 1926.

Tipo: Chile, Prov. Antofagasta, Dept. Taltal, Aguada del Panul, Dec. 4 1925, "rounded compact intricately branched bush ca. $1 \mathrm{~m}$. tall. In gravelly stream channels below water hole", I. M. Johnston 5424. Holotipo GH!, isotipo US!, S no visto (Anderberg et al., 1996) Fig. 69.

Arbusto erecto $(1 \mathrm{~m})$. Tallo con entrenudos entre 0,7 y $1,1 \mathrm{~cm}$, ramificaciones secundarias opuestas, ramas glabras, marrón claro. Hojas alternas, en fascículos, pecioladas, pecíolo 0,1-0,3 cm, láminas linear-ovadas, 0,1-0,2 x 0,5-1,2 cm, base cuneada, ápice agudo, margen dentado, revoluto; consistencia carnosa, venación acródroma imperfecta suprabasal; pubescente y glandulosa, tricomas eglandulares simples cónicos y glandulares (tipo a). Inflorescencia tirsoidea, compuesta de corimbos, densa; terminal, con hojas persistentes bien desarrolladas, aunque escasas. Capítulos ca. 50-80, pedunculados $(0,3-0,5 \mathrm{~mm})$, 2,5 x 4,5 mm. Involucro acampanado, 2,5 × 2,3 mm; filarios 6 , eximbricados; en dos series de filarios, los externos ovados, 1 × 2,9 mm, los internos ovadolanceolados, 0,8 × 3,2 mm; ápice fimbriado, margen entero, consistencia herbácea a papirácea, a veces con porciones esclerificadas en el centro; pubescentes, tricomas eglandulares simples cónicos. Flores 3-5, hermafroditas, corola blanca, tubular, 1 × 0,15 cm, 5-dentada, lóbulo 0,5 × 1,2 mm; glandulosa sólo en la base del tubo, tricomas glandulares (tipo a). Estambres 5 , anteras $5 \times 0,1 \mathrm{~mm}$, collar anteral cilíndrico, levemente ensanchados hacia la base, base de la teca auriculada; apéndice conectival nulo. Estilo $8 \mathrm{~mm}$, largamente exerto, ramas del estilo fuertemente clavadas en el ápice, ápices más oscuros que el resto de las ramas, las ramas $3 \mathrm{~mm}$. Cipsela negra no estipitada, piriforme a levemente falcadas, 3-5 mm, marcadamente 5-costada; serícea y glandular, pelos gemelos escasos y glandulares (tipo $\alpha$ ) en el tercio superior de la cipsela; carpopodio anular, central. Papus formado por 30 cerdas amarillentas, connadas en la base, 4-5 mm. Fig. 70. 
Fenología: Florece de noviembre a diciembre.

Distribución: Chile (regiones de Atacama y Antofagasta) a 1200-1300 msnm, habita en quebradas rocosas. Fig. 71.

Notas: Posibles híbridos con O. triangularis (Johnston 5297 US y Johnston 5299 US)

Etimología: Dedicada al colector de los materiales tipo, el botánico norteamericano, Iván M. Johnston (1898-1960).

Especímenes adicionales estudiados: CHILE. Atacama (III Región): San Félix, 09/11/1956, M. Ricardi 3849 (LP). Antofagasta (II Región): Taltal, vacinity of Aguada de Cardon, ca. $24^{\circ}$ 45' S, 30/11/1925, Ivan M. Johnston 5259 (GH); ib. Ivan M. Johnston 5297 (GH, US); vicinity of Aguada de Miguel Diaz, 1-4/12/1925, Ivan M. Johnston $5310(\mathrm{GH})$. 


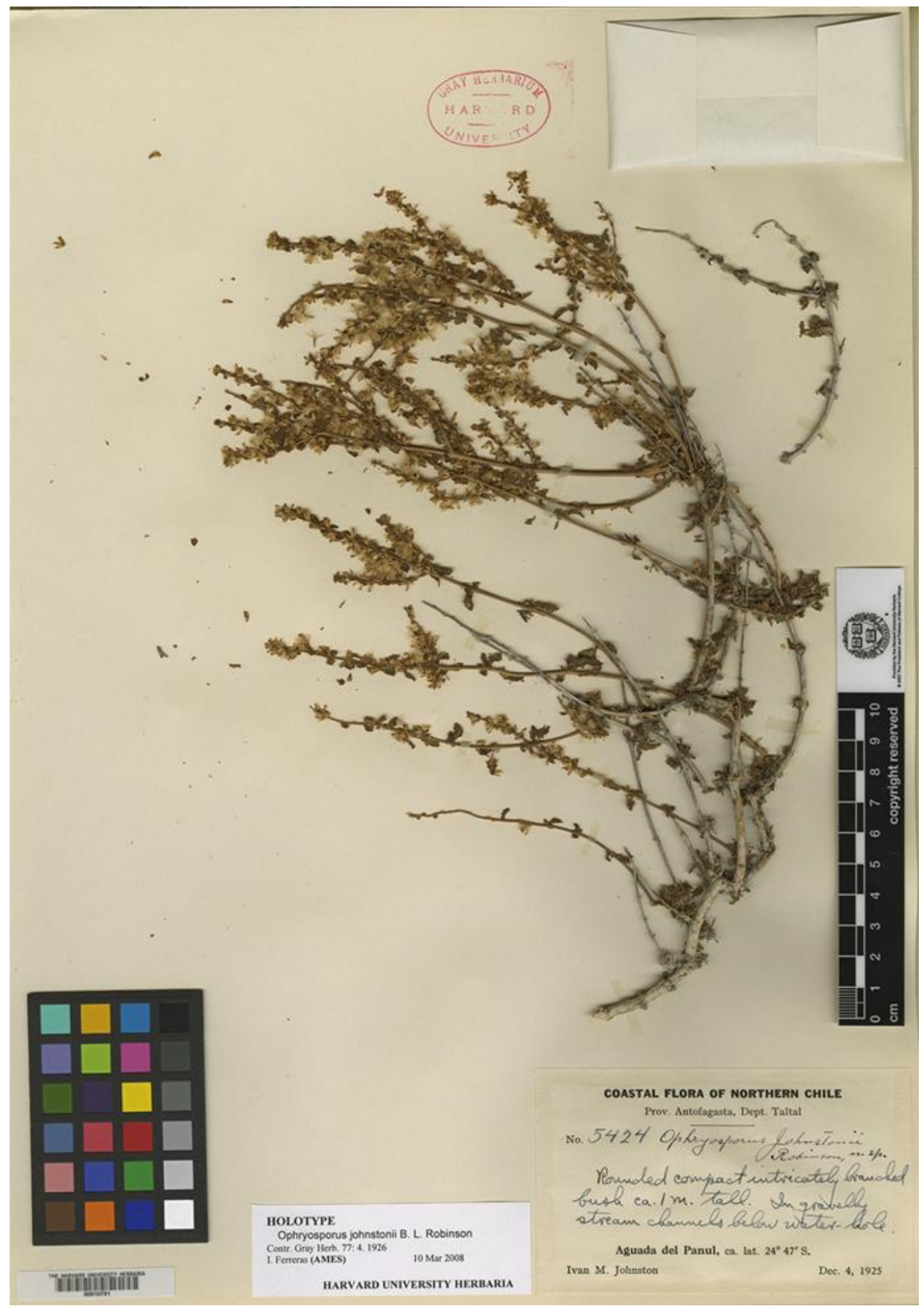

Figura 69. O. johnstonii, holotipo. I. M. Johnstonn 5424 (GH). 

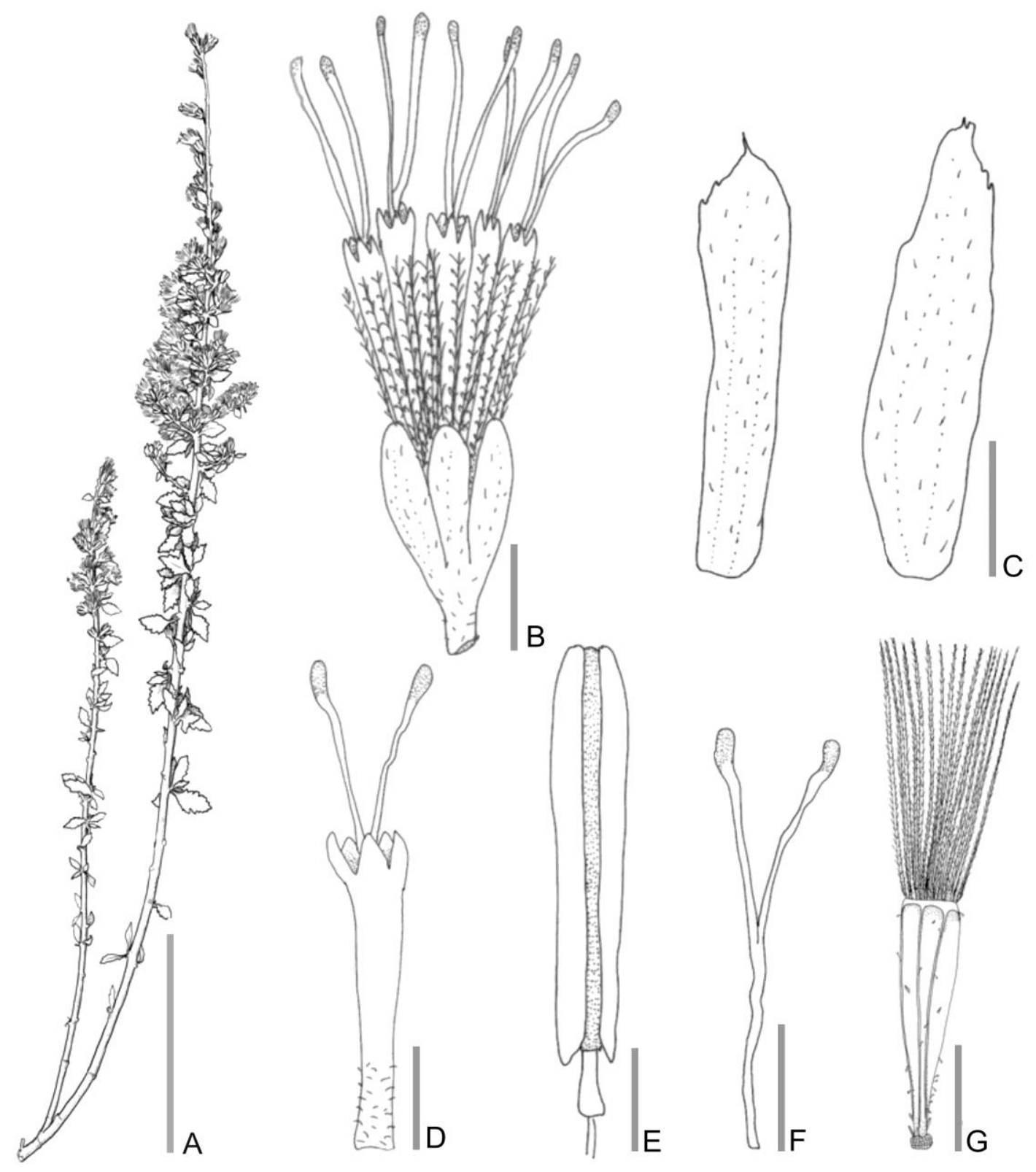

Figura 70. O. johnstonii. A. Rama florífera. B. Capítulo. C. Flor sin papus ni cipsela. D. Filarios. E. Antera. F. Estigma. G. Cipsela. Escalas: A: $5 \mathrm{~cm}$; B: 2 mm;

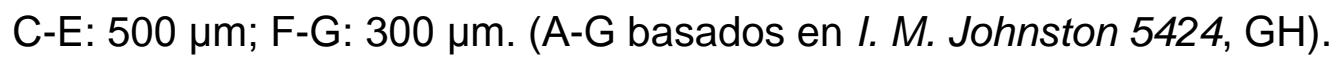




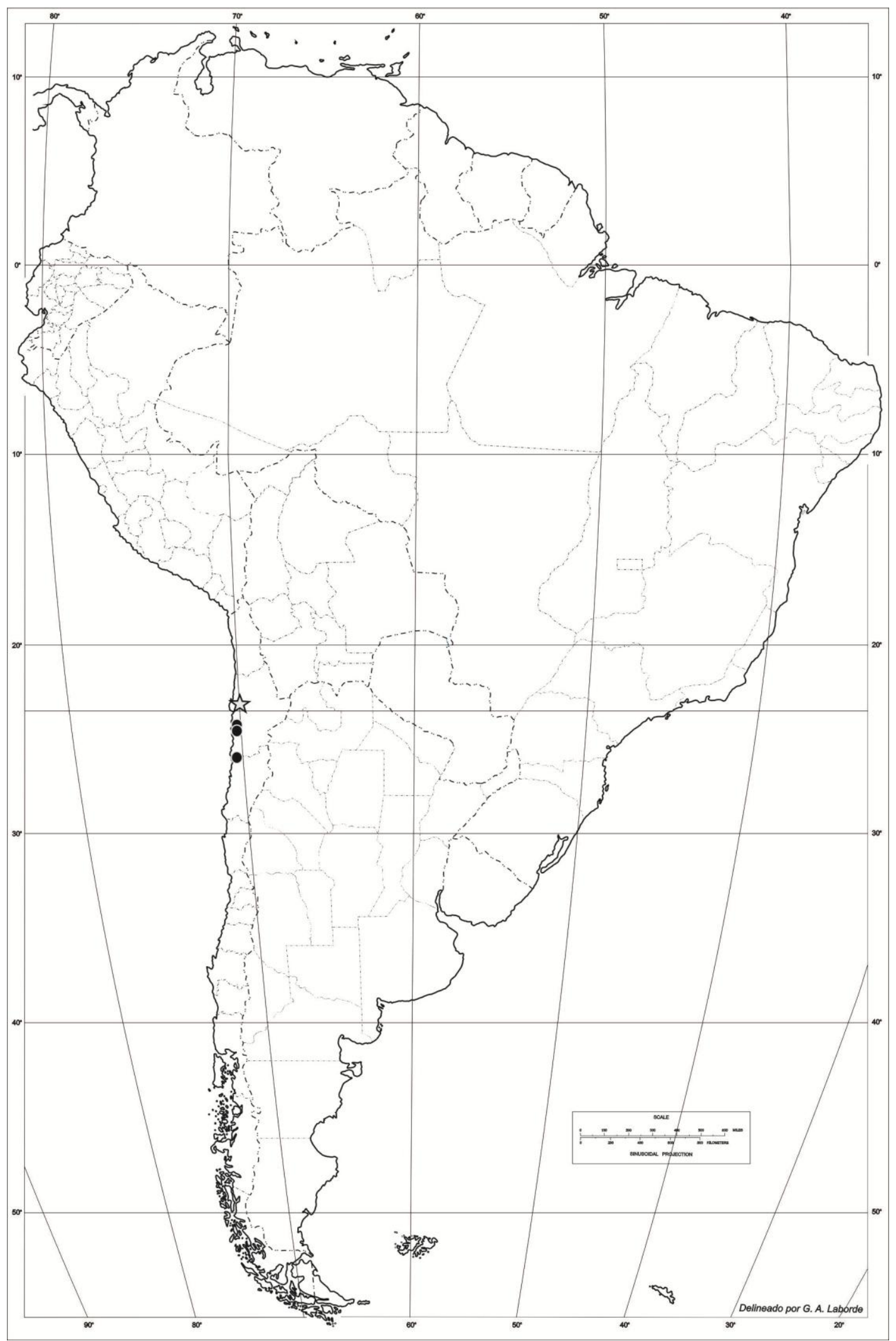

Figura 71. O. johnstonii. Distribución geográfica, la estrella indica la localidad tipo. 


\section{Ophryosporus kuntzei Hieron.}

Botanische Jahrbücher für Systematik, Pflanzengeschichte und Pflanzengeographie 22: 707. 1897.

Tipo: Bolivia: "Süd-Tunari, April Mai 1892 bei $3000 \mathrm{~m}$. $\hbar$ Bl. weisslichen. $\boldsymbol{O}$. Kuntze s.n." Holotipo: B, destruído F foto!, isotipos: NY!, GH foto!. (http://plants.jstor.org/search?searchText=Ophryosporus\%20kuntzei) Fig. 72.

Arbusto erecto. Tallo con entrenudos entre 4,2 y $10,8 \mathrm{~cm}$, ramificaciones secundarias opuestas, ramas glabras, púrpura, con estriaciones. Hojas opuestas, pecioladas, pecíolo 0,6-1 cm, láminas ovadas, $1-2 \times 2,5-7 \mathrm{~cm}$, base cuneada, ápice agudo, margen dentado, plano; consistencia delicadamente herbácea a herbácea, venación acródroma imperfecta suprabasal; pubescente, tricomas eglandulares simples cónicos. Inflorescencia cimoidea, compuesta de corimbos densos; terminal y axilar, con hojas persistentes poco desarrolladas. Capítulos ca. 50-180, pedunculados (0,8-1 mm), $3 \times 5,8 \mathrm{~mm}$. Involucro acampanado, $3 \times 3,2$ $\mathrm{mm}$; filarios 4, eximbricados; en una serie de filarios, ovado-lanceolados, 1,2 × 3,2 $\mathrm{mm}$; ápice fimbriado, margen entero, consistencia herbácea, a veces con porciones esclerificadas en el centro; glanduloso, tricomas glandulares (tipo $\alpha$ ). Flores 4, hermafroditas, corola blanca amarillenta, infundibuliforme, con paso gradual entre tubo y limbo, tubo 1,4 x 0,3 mm, limbo $2 \times 1 \mathrm{~mm}, 5$-dentada, lóbulo 0,3 × 0,5 mm; glandulosa sólo en la base del tubo, tricomas glandulares (tipo $\alpha$ ). Estambres 5, anteras $1 \times 0,3 \mathrm{~mm}$, collar anteral cilíndrico, base de la teca obtusa; apéndice conectival rudimentario, entero. Estilo $5,2 \mathrm{~mm}$, largamente exerto, ramas del estilo fuertemente clavadas en el ápice, ápices más oscuros que el resto de las ramas, las ramas $3,2 \mathrm{~mm}$. Cipsela negra no estipitada, piriforme, $3,5 \mathrm{~mm}$, marcadamente 5-costada; serícea, pelos gemelos en costillas; carpopodio anular, excéntrico. Papus formado por 30 cerdas amarillentas, connadas en la base, 4,2-5 mm. Fig. 73.

Fenología: Florece de agosto a abril. 
Distribución: Bolivia (departamentos de Chuquisaca, Cochabamba y La Paz) a 2000-3300 msnm, habita en yungas y selvas semi-nubladas. Vegetación remanente en las cercas al margen de terrenos cultivados y algunas quebradas. Fig. 74.

\section{Notas:}

1. Esta especie, junto con O. macrodon Griseb., han sido erróneamente sinonimizadas y esto ha conducido a errores en su nomenclatura. Se debe posiblemente a que, el basónimo de O. macrodon es Eupatorium kuntzei Hieron, sin reparar en que el basónimo de esta especie es Ophryosporus kuntzei Hieron.

Etimología: Dedicado al colector del material tipo, el botánico alemán Otto Kuntze (1843-1907).

Estado de Conservación: la localidad tipo (Monte Tunari) está dentro de los terrenos del Parque Nacional Tunari (Bolivia), fue creado en 1978. Ocupa la región de valles secos mesotérmicos y la Cordillera del Tunari, comprendiendo un ecosistema con diversidad de zonas de vida. La región presenta las características propias de zonas cordilleranas y valles interandinos, con un sistema de cuencas que abastecen de agua a las tierras agrícolas y a la ciudad de Cochabamba Muchas poblaciones se encuentran en terrenos dedicados al cultivo, donde quedan relegadas en sus bordes.

Especímenes adicionales estudiados: BOLIVIA. Noryungas: 1900, Buchtien s.n. (NY). La Paz: Inquisivi, Loma El Abra, 22/06/1988, Lewis 88886 (NY). Santa Cruz: Vallegrande, Huasacañada, 05/08/1991, Vargas \& Vargas 1078 (NY) 


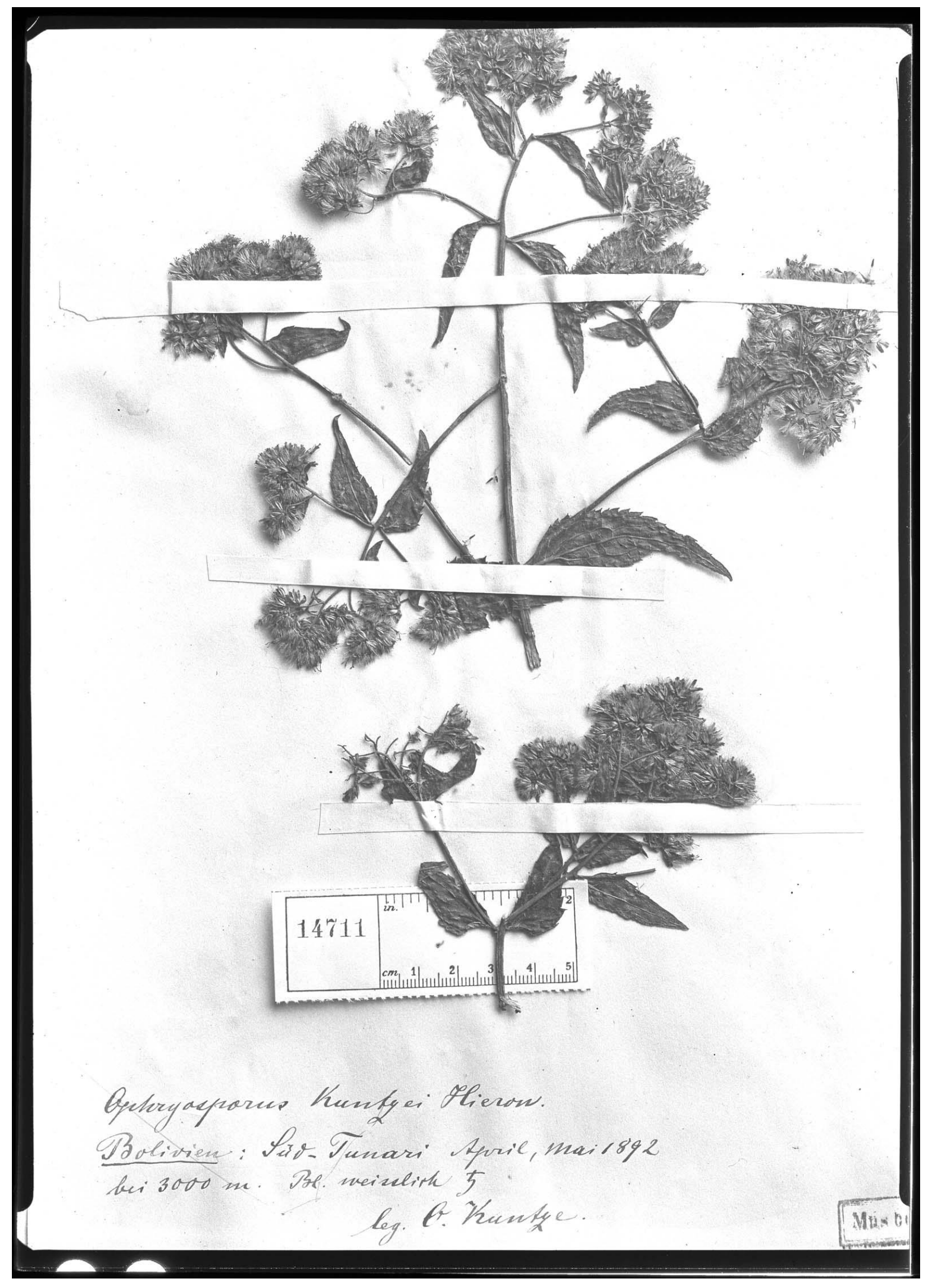

Figura 72. O. kuntzei, holotipo. O. Kuntze s.n. (B en F). 


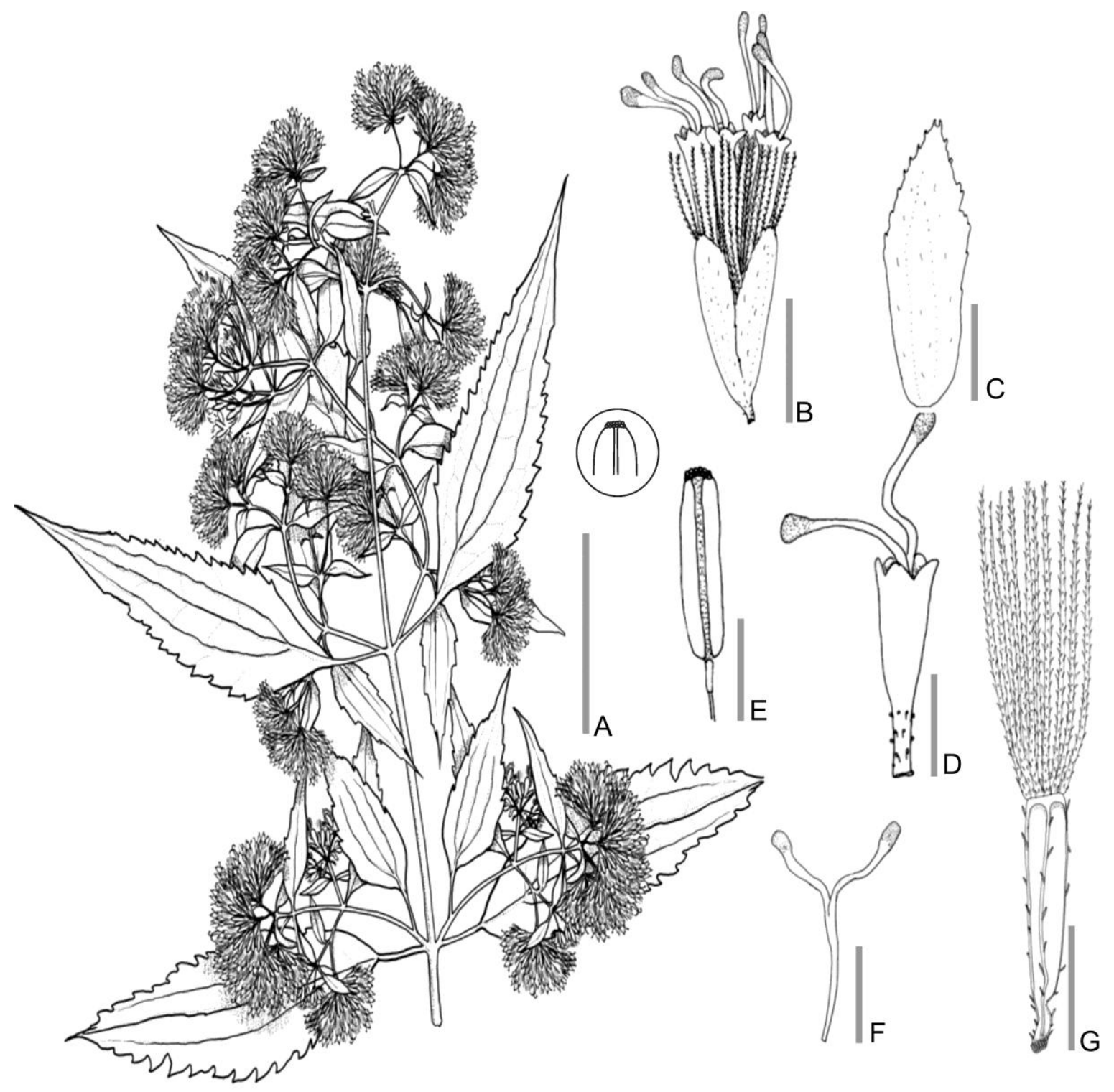

Figura 73. O. kuntzei. A. Rama florífera. B. Capítulo. C. Flor sin papus ni cipsela. D. Filario. E. Antera. F. Estigma. G. Cipsela. Escalas: A: $5 \mathrm{~cm}$; B: $2 \mathrm{~mm}$; C-D: 1 mm; E-F: 250 m; G: $300 \mu \mathrm{m}$. (A-G basados en M. Lewis 88886, NY). 


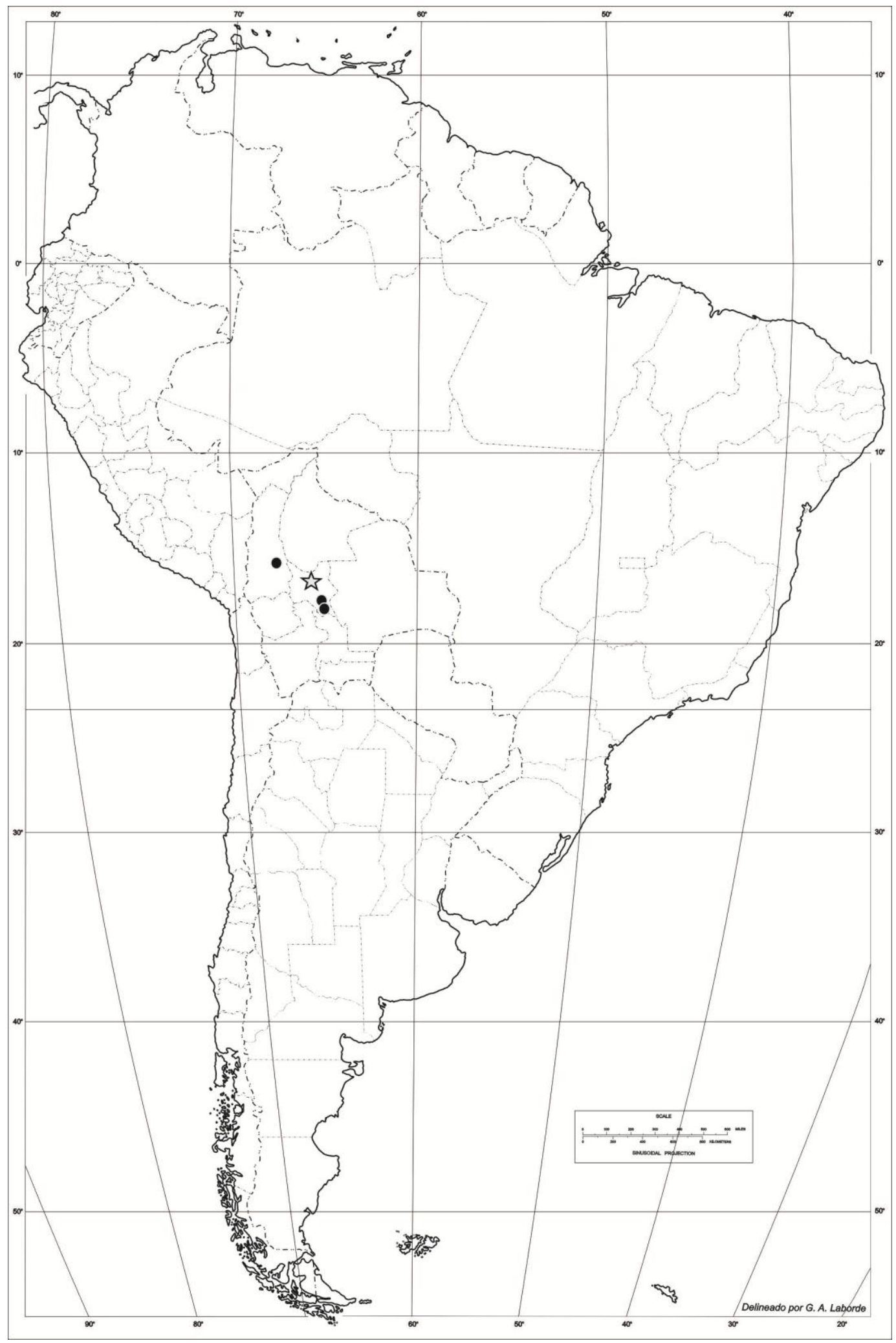

Figura 74. O. kuntzei. Distribución geográfica, la estrella indica la localidad tipo. 


\section{Ophryosporus laxiflorus Baker}

Flora Brasiliensis 6(2): 189. 1876

Tipo: Brasil "Minas Gerais in campis ad Caldas" Regnell III.709. Holotipo: US! Fig. 75.

Arbusto erecto $(2 \mathrm{~m})$. Tallo con entrenudos entre 5 y $7,5 \mathrm{~cm}$, ramificaciones secundarias opuestas, ramas tomentosas, marrón claro. Hojas opuestas, pecioladas, pecíolo 0,1-0,5 cm, láminas oblonga-ovadas, 0,9-1,9 × 3-7 cm, base cuneada, ápice obtuso, margen aserrado, plano; consistencia herbácea, venación acródroma imperfecta suprabasal; pubescente, tricomas eglandulares cónicos simples. Inflorescencia cimoidea, compuesta de corimbos laxos; terminal y axilar, con hojas persistentes poco desarrolladas. Capítulos ca. 180-300, pedunculados (0,8-1,6 mm), 3,5 x 4,5 mm. Involucro acampanado, $3 \times 3 \mathrm{~mm}$; filarios 5-6, eximbricados; en una serie de filarios, ovados, $1 \times 2,25 \mathrm{~mm}$; margen entero, consistencia herbácea, a veces con porciones esclerificadas en el centro; glabros. Flores 5-6, hermafroditas, corola blanca, infundibuliforme, con paso gradual entre tubo y limbo, tubo $1 \times 0,25 \mathrm{~mm}$, limbo $1,3 \times 0,5 \mathrm{~mm}$, 5-dentada, lóbulo 0,25 × 0,3 $\mathrm{mm}$; glandulosa sólo en la base del tubo, tricomas glandulares (tipo $\beta$ ). Estambres 5, anteras $1 \times 0,3 \mathrm{~mm}$, collar anteral cilíndrico, base de la teca auriculada; apéndice conectival nulo. Estilo $3,5 \mathrm{~mm}$, largamente exerto, ramas del estilo fuertemente clavadas en el ápice, ápices más en oscuros que el resto de las ramas, las ramas $1,8 \mathrm{~mm}$. Cipsela negra estipitada, piriforme, 2,7 mm, marcadamente 5-costada; serícea, pelos gemelos dispersos en toda la cipsela; carpopodio anular, excéntrico. Papus formado por 15-20 cerdas blanquecinas, connadas en la base, 2,5-2,7 mm. Fig. 76 .

Fenología: Florece en abril.

Distribución: Brasil (estados de Minas Gerais y Paraná), habita en mata atlántica. Fig. 77. 
Etimología: Del latín laxus, laxo y florus, flores, inflorescencia hace referencia a la disposición laxa de las inflorescencias (Stern 1983, Gledhill 2008).

Especímenes adicionales estudiados: BRASIL. Paraná: Jaguariaiva, Paredão da Santa, Capoeira dos Grotões, 24/04/1988, G. Hatschbach \& J. M. Silva 51977 (MO, US). 


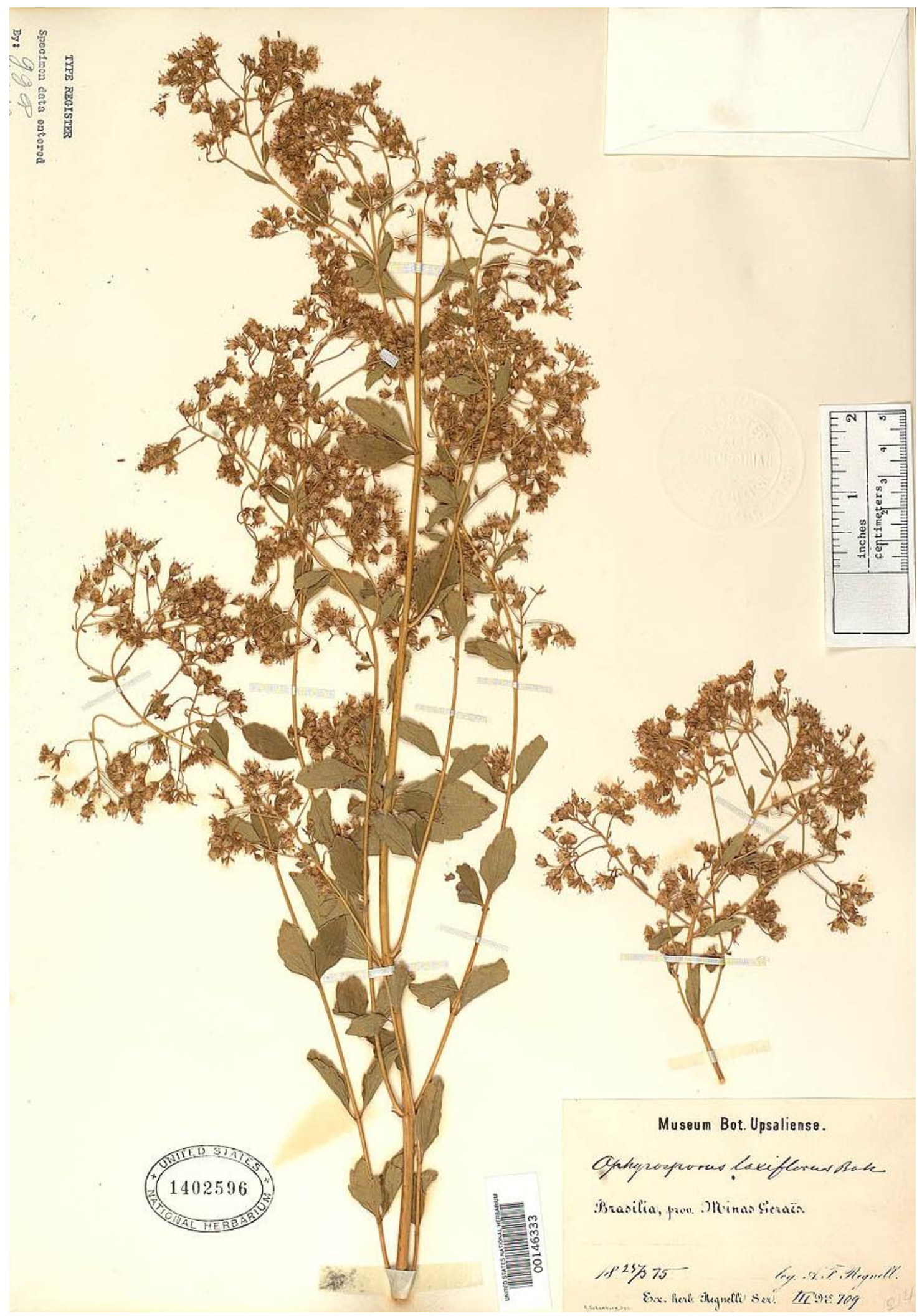

Figura 75. O. laxiflorus, holotipo. Regnell III.709 (US). 


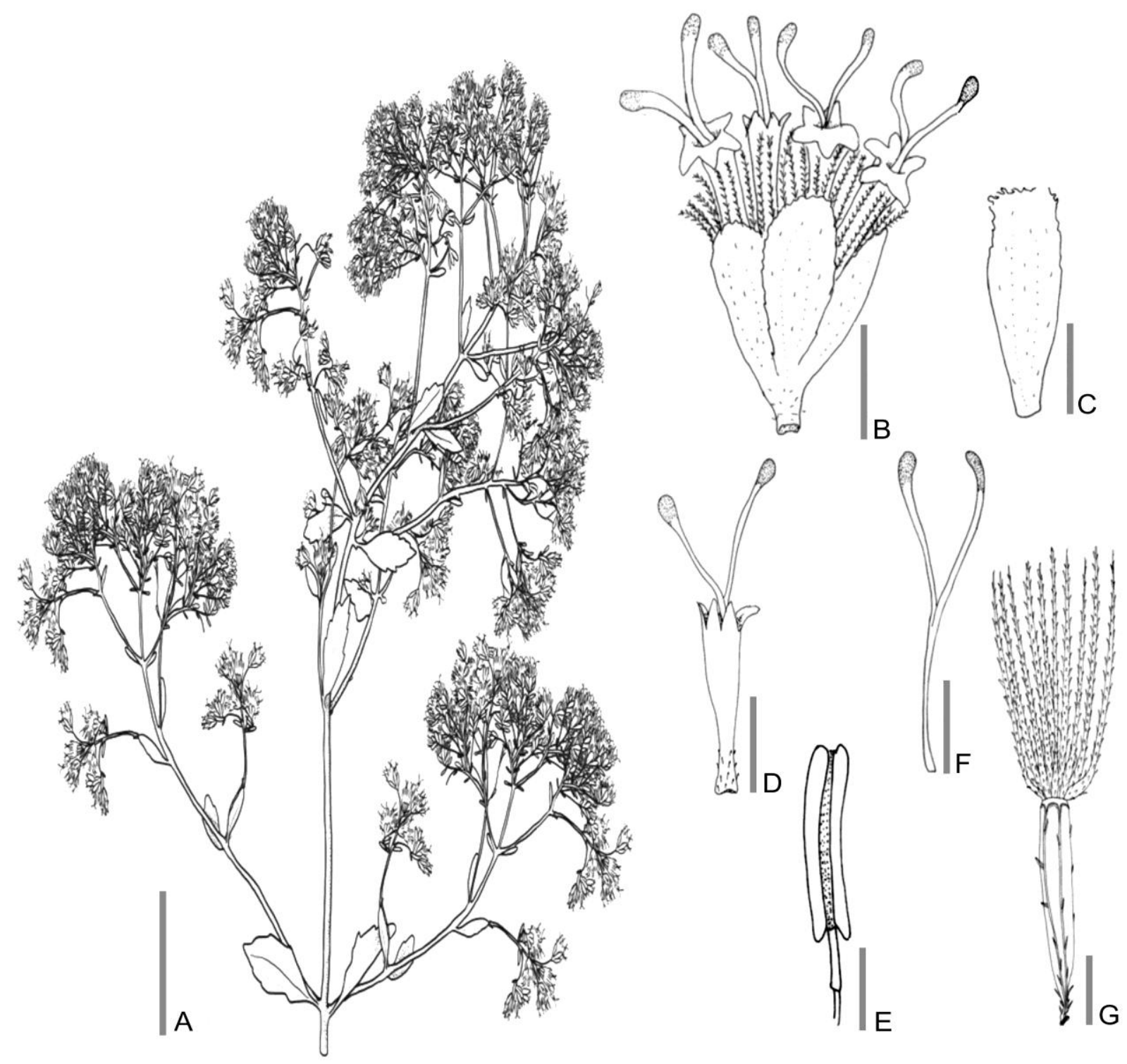

Figura 76. O. laxiflorus. A. Rama florífera. B. Capítulo. C. Flor sin papus ni cipsela. D. Filarios. E. Antera. F. Estigma. G. Cipsela. Escalas: A: $5 \mathrm{~cm}$; B: 2 mm; C-D: 1

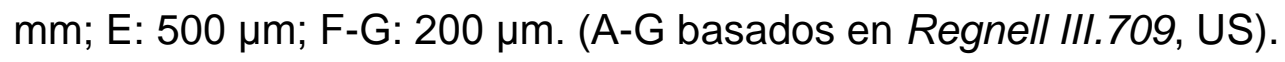




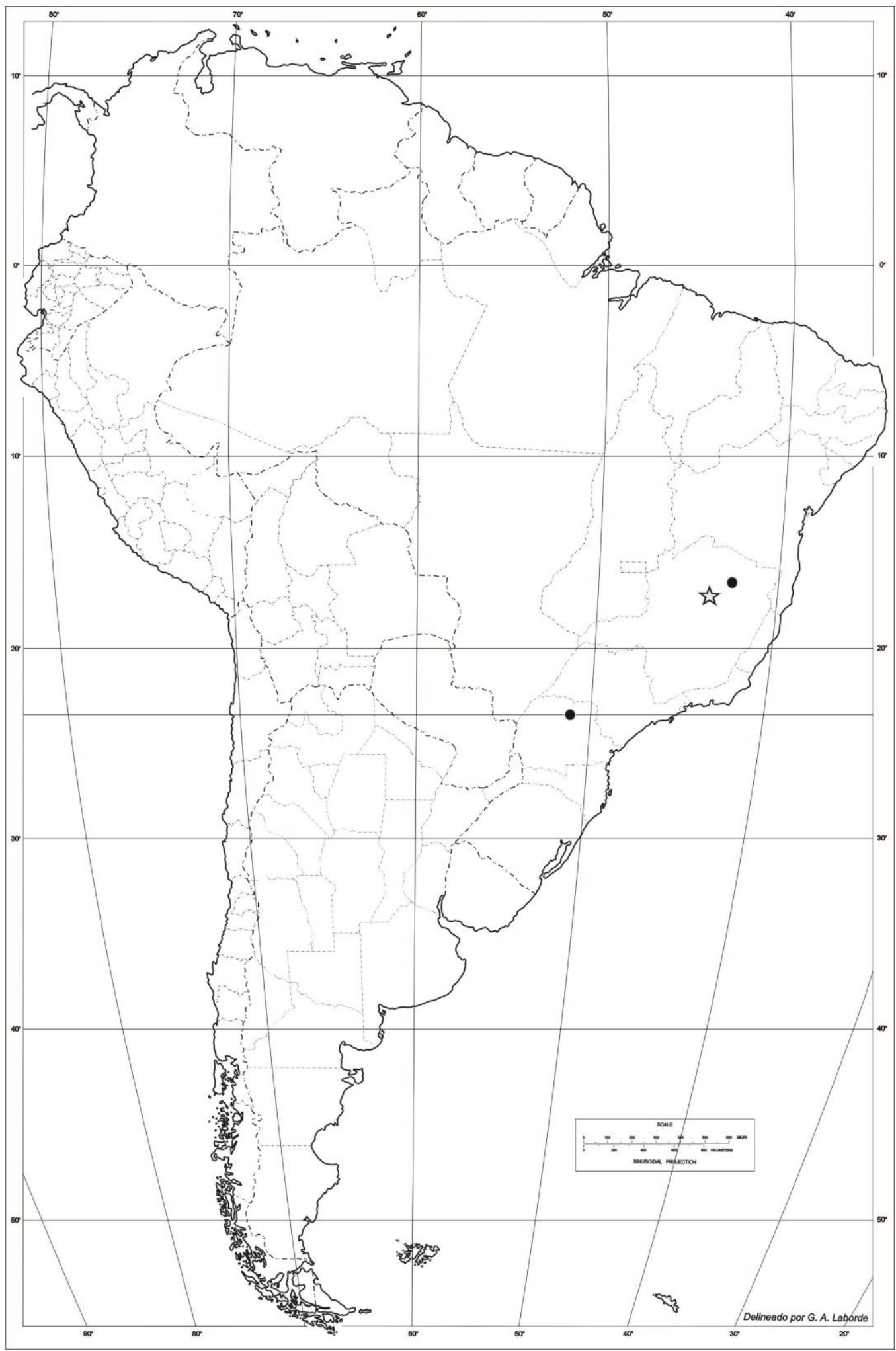

Figura 77. O. laxiflorus. Distribución geográfica, la estrella indica la localidad tipo. 


\section{Ophryosporus lorentzii Hieron.}

Botanische Jahrbürcher für Systematik, Pflanzengeschichte und Pflanzengeographie 22: 706-707. 1897.

Lectotipo: Argentina, "Prov. de Salta, Cuesta entre Yacone (por Yacones) y Los Potreros. 17/03/1873", P. G. Lorentz \& G. Hieronymus 340 CORD 00004712!. (Plos \& Sancho, 2012) Fig. 78.

= Eupatorium laeve Griseb. non DC. Prodromus Systematis Naturalis Regni Vegetabilis 5: 169. 1836. Lectotipo: Lhotsky s.n. (1832). Brazil: Rio de Janeiro. GDC! (King \& Robinson, 1972)

Arbusto erecto $(2 \mathrm{~m})$. Tallo con entrenudos entre 1 y 4,8 cm, ramificaciones secundarias opuestas, ramas glabras, rojizo. Hojas opuestas, pecioladas, pecíolo 0,2-0,4 cm, láminas ovadas a ovado-lanceoladas, $0,8-1 \times 3-4,5 \mathrm{~cm}$, base redondeada, ápice agudo, margen entero, plano; consistencia herbácea, venación acródroma imperfecta suprabasal; glandulosa, tricomas glandulares (tipo a). Inflorescencia cimoidea, compuesta de corimbos densos; terminal y axilar, con hojas persistentes poco desarrolladas. Capítulos ca. 280-340, pedunculados (1-3 $\mathrm{mm}$ ), 3 x 6,5 mm. Involucro acampanado, $3 \times 4 \mathrm{~mm}$; filarios 4, eximbricados; en una serie de filarios, ovados, 0,8 × 3,8 mm; margen entero, consistencia herbácea; glanduloso, tricomas glandulares (tipo a). Flores 4, hermafroditas, corola blanca, infundibuliforme, con paso gradual entre tubo y limbo, tubo $1,2 \times 0,2 \mathrm{~mm}$, limbo 2,3 x 0,6 mm, 5-dentada, lóbulo 0,15 x 0,2 mm; glandulosa sólo en la base del tubo, escasos tricomas glandulares (tipo $\alpha$ ). Estambres 5, anteras $1,3 \times 0,4 \mathrm{~mm}$, collar anteral cilíndrico, base de la teca auriculada; apéndice conectival muy rudimentario, con surco medial. Estilo $6 \mathrm{~mm}$, largamente exerto, ramas del estilo fuertemente clavadas en el ápice, ápices más oscuros que el resto de las ramas, las ramas $3,5 \mathrm{~mm}$. Cipsela negra levemente estipitada, piriforme a levemente falcada, 2,3 mm, marcadamente 5-costada; serícea, pelos gemelos escasos en el tercio superior e inferior de la cipsela; carpopodio anular, excéntrico. Papus 
formado por 20-23 cerdas blanquecinas, connadas en la base, $3,5-4 \mathrm{~mm}$. $n=9$ (Turner et al., 1979) Fig. 79.

Fenología: Florece de enero a agosto.

Distribución: Argentina (provincias de Jujuy, Salta y Tucumán), a 1500-3200 msnm, habita en bosques de alisos en la provincia fitogeográfica de yungas. Fig. 80.

\section{Notas:}

1. Especie de aspecto muy parecido a O. axilliflorus, del cual se diferencia por los involucros de mayor tamaño y glabros (Cabrera, 1978).

2. Según Turner, el dato cromosómico está basado en un material colectado en Catamarca.

3. En la descripción original, Hieronymus (1897), cita además de Lorentz \& Hieronymus 340 otros dos materiales, "Prov. de Salta, Cuesta entre Yacone y Los Potreros. 17/02/1873", Lorentz \& Hieronymus 333 y "Prov. de Salta, Los Potreros, al pié del Nevado del Castillo. 24/03/1873", Lorentz \& Hieronymus s.n., foto B. Se han encontrado ejemplares de Lorentz \& Hieronymus 333 en CORD (00004713!) y en K (000486669 foto!). Debido a que el material de B fue probablemente destruido, se designó como lectotipo del material de Lorentz \& Hieronymus 340 de Córdoba, herbario en el que Hieronymus depositó duplicados de gran parte de sus colecciones y desarrolló sus investigaciones. Dicho ejemplar, debido a su excelente estado de conservación e integridad permite la correcta identificación de la especie.

4. Si bien en la descripción original Hieronymus (1897) cita como fecha de colección 24 de marzo de 1873 para el material de Lorentz \& Hieronymus 340, el labelo del ejemplar de CORD indica 17 de marzo de 1873.

Etimología: Hace referencia al colector del tipo, el botánico alemán Paul Günther Lorentz (1835-1881). 
Estado de Conservación: De acuerdo a Delucchi \& Plos (2011), le corresponde la categoría EN de la UICN, de en peligro. En cuanto a la clasificación de PlanEAr (2012), se le otorgó la categoría 4, plantas restringidas a una sola provincia política, o con áreas reducidas compartidas por dos o más provincias políticas contiguas.

Compuestos químicos de interés: Sigstad et al. (1996) y Herz (2004) citan la presencia de benzofuranos, dihidrobenzofuranos, cumarinas, cromenos, mono y sesquiterpenos (nerolidol).

Especímenes adicionales estudiados: ARGENTINA. Catamarca: Andalgalá, Esquina Grande, 01/05/1916, P. Jörgensen 1505 (LIL, MO). Jujuy: Dr. Manuel Belgrano, camino a Tiraxi, $15 \mathrm{NE}$ de Lozano, 12/05/1998, A. Krapovickas, A. Schinini \& G. Seijo 47341 (NY); Cerro Loza, 10/04/1998, A. Carranza 498 (JUA); ib. 27/05/1998, A. Carranza 499 (JUA); Yala, Laguna El Rodeo, 10/05/1998, A. Carranza 425 (JUA). Ledesma, Calilegua, Parque Nacional Calilegua, 26/08/1988, O. Ahumada \& J. C. Vasquez 6100 (JUA). Tumbaya, Volcán, Laguna de Volcán, 14/04/1989, L. J. Novara 7917 (MCNS). Valle Grande, pasando ca. 2 km de Abra de Cañas, camino a Valle Grande, 14/09/1971, P. R. Lognamo \& A. R. Cuezzo 8602 (LIL, LP). Salta: Guachipas, Pampa Grande, 01/1897, C. Spegazzini 13666 (LP); ib. C. Spegazzini 13667 (LP). Iruya, San Isidro, 08/02/1983, E. M. Zardini et al. 1941 (MO). Orán, 21/10/1945, S. A. Pieroth 1330 (LIL). Santa Victoria, Pueblo Baritú, 22 28' 19"S 64 45' 26”' W, 15/08/1999, L. J. Novara et al. 11329 (MCNS). Tucumán: Chicligasta, Cuesta del Clavillo, 04/1939, Schreiter s.n. (LIL); Estancia Las Pavas, 09/03/1924, S. Venturi 2991 (LIL, LP); Laguna del Tesoro, 12/04/1963, Krapovickas \& Cristóbal 11077 (LIL); Puesto Santa Rosa, 16/04/1949, T. Meyer 15130 (LIL), ib. 15/06/1949, T. Meyer 15157 (LIL). Saladillo, 18/05/1948, T. Meyer 14017 (LIL). Tafí del Valle, camino a Tafí del Valle, Apeadero Muñoz, 15/06/1994, E. Sigstad et al. 1 (LIL). Trancas, 2 Cuestas, 21/04/1926, S. Venturi 4115 (LIL, LP). Monteros, El Huasancho, 22/03/1914, D. Rodríguez 1459 (LP). 


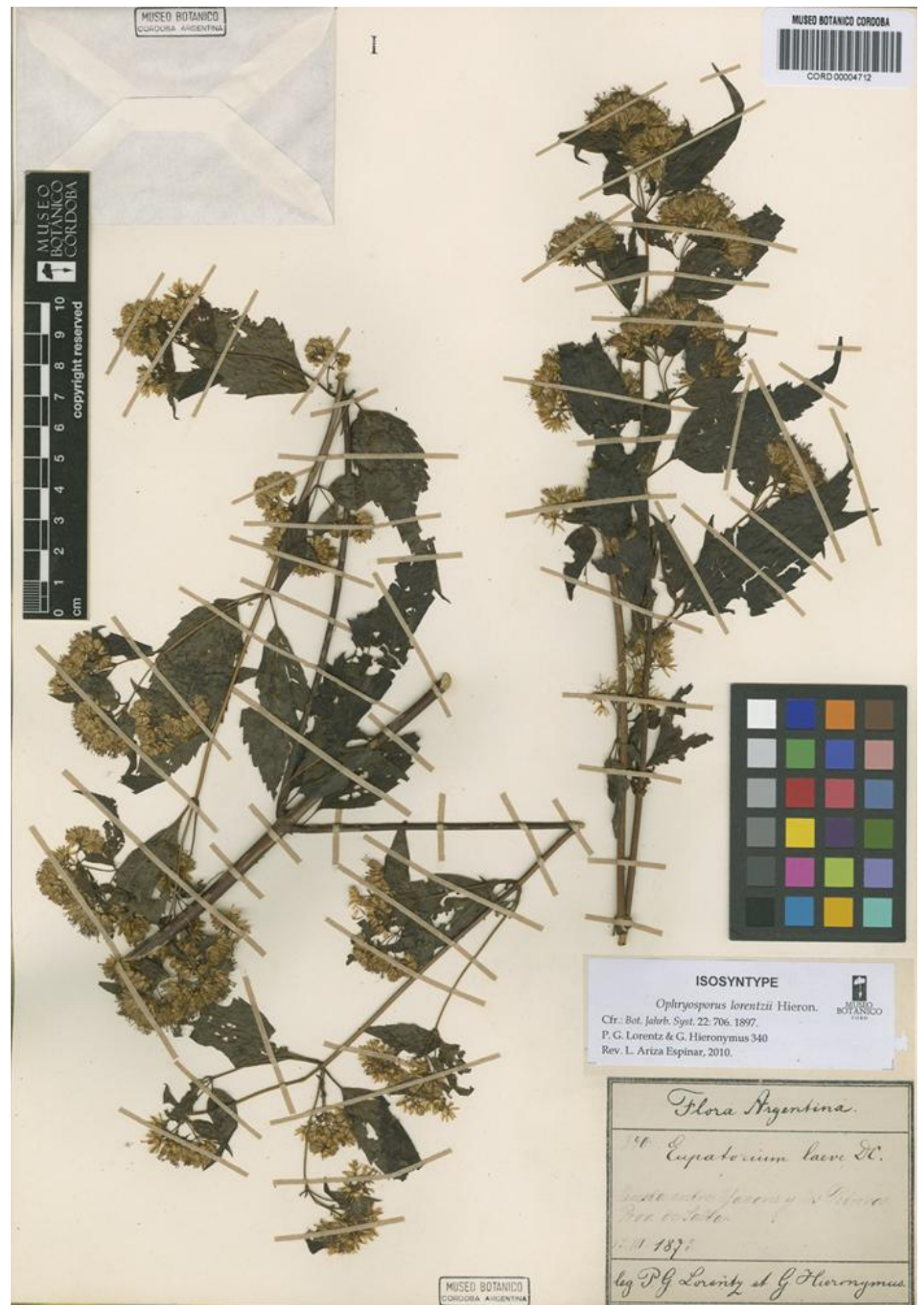

Figura 78. O. Iorentzii, holotipo. P. G. Lorentz \& G. Hieronymus (CORD). 


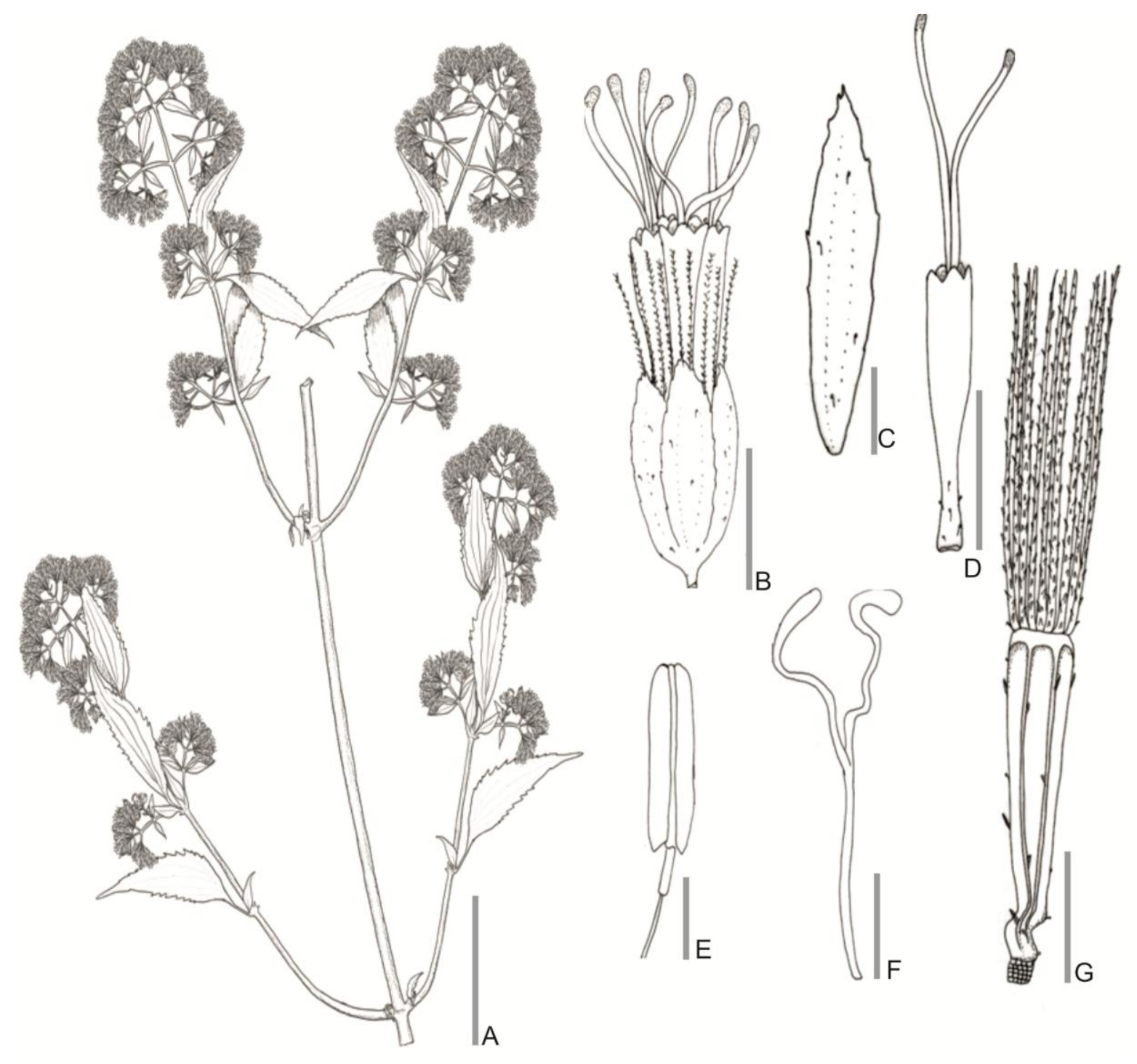

Figura 79. O. lorentzii. A. Rama florífera. B. Capítulo. C. Flor sin papus ni cipsela. D. Filario. E. Antera. F. Estigma. G. Cipsela. Escalas: A: $5 \mathrm{~cm}$; B-E: 2 mm; F-G: 1 mm. (A-G basados en J. C. Solomon 5983, NY). 


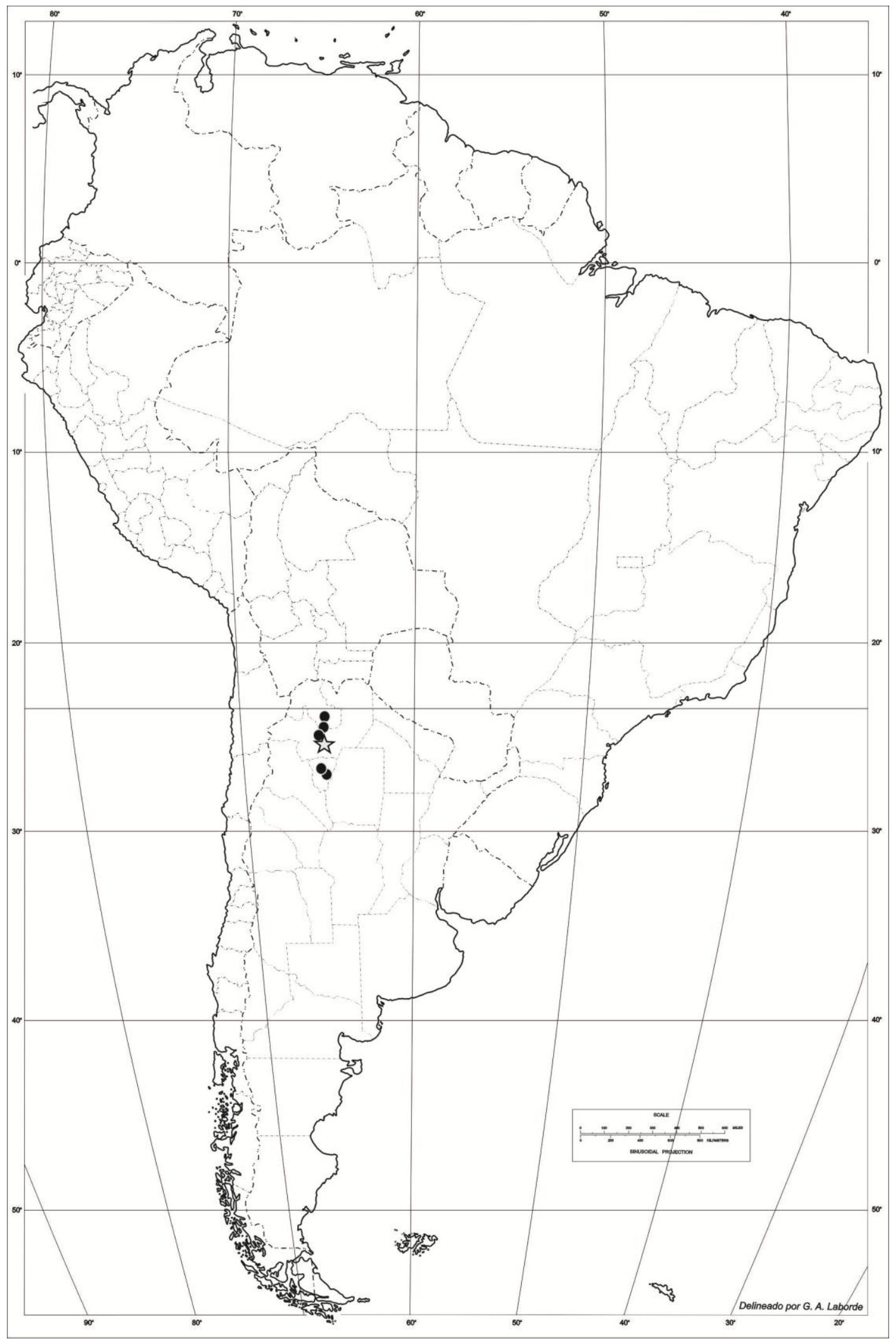

Figura 80. O. lorentzii. Distribución geográfica, la estrella indica la localidad tipo. 
Ophryosporus macbridei B. L. Rob.

Contributions from the Gray Herbarium of Harvard University. New Series 73: 4. 1924.

Tipo: "Peru, Junín: Yanano (por Yanana), slender, $5 \mathrm{ft}$. shrub of sunny ticketedges, about 6000 ft., May 13-1923". Holotipo: J. Francis Macbride 3717 F!, isotipos: GH!, K foto!, US! Fig. 81.

Arbusto erecto $(1,5 \mathrm{~m})$. Tallo con entrenudos entre 1,2 y $9 \mathrm{~cm}$, ramificaciones secundarias opuestas, ramas glabras, marrón claro a rojizo. Hojas opuestas, pecioladas, pecíolo 0,1-0,2 cm, láminas ovadas, $1-1,2 \times 2,7-4,1 \mathrm{~cm}$, base redondeada, ápice agudo, margen entero, plano; consistencia herbácea, venación acródroma imperfecta suprabasal; pubescente, tricomas eglandulares simples cónicos. Inflorescencia cimoidea, compuesta de corimbos laxos; terminal y axilar, con hojas persistentes poco desarrolladas. Capítulos ca. 40-60, pedunculados (0,5-1 mm), 2,5 × 3,5 mm. Involucro acampanado, $2,5 \times 2 \mathrm{~mm}$; filarios 6 , eximbricados; en una serie de filarios, ovados, 0,8 x 1,3 mm; margen entero, consistencia herbácea, a veces con porciones esclerificadas en el centro; pubescente, tricomas eglandulares simples cónicos. Flores 5-7, hermafroditas, corola blanquecina, infundibuliforme, con paso gradual entre tubo y limbo, tubo $1 \mathrm{x}$ 0,4 mm, limbo 1,5 x 0,8 mm, 5-dentada, lóbulo 0,5 × 0,25 mm; glandulosa sólo en la base del tubo, tricomas glandulares (tipo $\alpha$ ). Estambres 5, anteras 1,5 $\times 0,25$ $\mathrm{mm}$, collar anteral cilíndrico, levemente ensanchado hacia la base, base de la antera auriculada; apéndice conectival rudimentario, con surco medial. Estilo 4,5 $\mathrm{mm}$, largamente exerto, ramas del estilo fuertemente clavadas en el ápice, ápices más oscuros que el resto de las ramas, las ramas $2,5 \mathrm{~mm}$. Cipsela negra levemente estipitada, piriforme a levemente falcada, $2,5 \mathrm{~mm}$, marcadamente 5costada; serícea, pelos gemelos escasos, en el tercio inferior de la cipsela; carpopodio anular, central. Papus formado por 20-25 cerdas amarillas, connadas en la base, 2,5 mm. Fig. 82.

Fenología: Florece de abril a agosto. 
Distribución: Perú (departamentos de Amazonas, Huánuco, Junín y Cuzco) a 1800-2600 msnm aproximadamente, hábitat mesoandino, incluye las vertientes occidentales, las laderas de los valles interandinos y el altiplano. (León et al. 2006 [2007]). Selva nublada primaria, húmeda. Fig. 83.

\section{Notas:}

3. De acuerdo con Robinson (1924), esta especie se encuentra dentro de un grupo que incluye a O. cumingii (Sch.-Bip.) Benth y a O. kuntzei Hieron. De dichas especies se diferencia por la inflorescencia más larga y abierta y por la textura más firme de las hojas sub-enteras.

4. Flores pegajosas (Woytkowski et al. 229 F).

5. Flores con olor dulce y picante (Smith \& Vasquez $4937 \mathrm{MO}$ ).

6. Prefiere zonas soleadas (Macbride $3717 \mathrm{G}$ )

Etimología: Hace referencia al colector del tipo, el botánico norteamericano J. Francis Macbride (1892-1976).

Estado de Conservación: De acuerdo con Beltrán et al. (2006) su categoría en la UICN es CR B1 ab (iii), en peligro crítico. Si bien el autor sólo cita la localidad del tipo, se ha comprobado su presencia en otras localidades, mediante material herborizado.

Especímenes adicionales estudiados: PERU. Amazonas: Bongará, Shillac, north by trail from Pedro Ruiz, $05^{\circ} 49^{\prime} \mathrm{S} 78^{\circ} 01^{\prime} \mathrm{W}, 31 / 08$ al 02/09/1983, D. N. Smith \& S. Vasquez S. 4937 (MO). Huánuco: Acomayo, 14/04/1946, F. Woytkowski et al. 229 (F). Cuzco: Anta, Apurimac, Limatambo, 07/06/1954, colector ilegible 1531 (NY). 


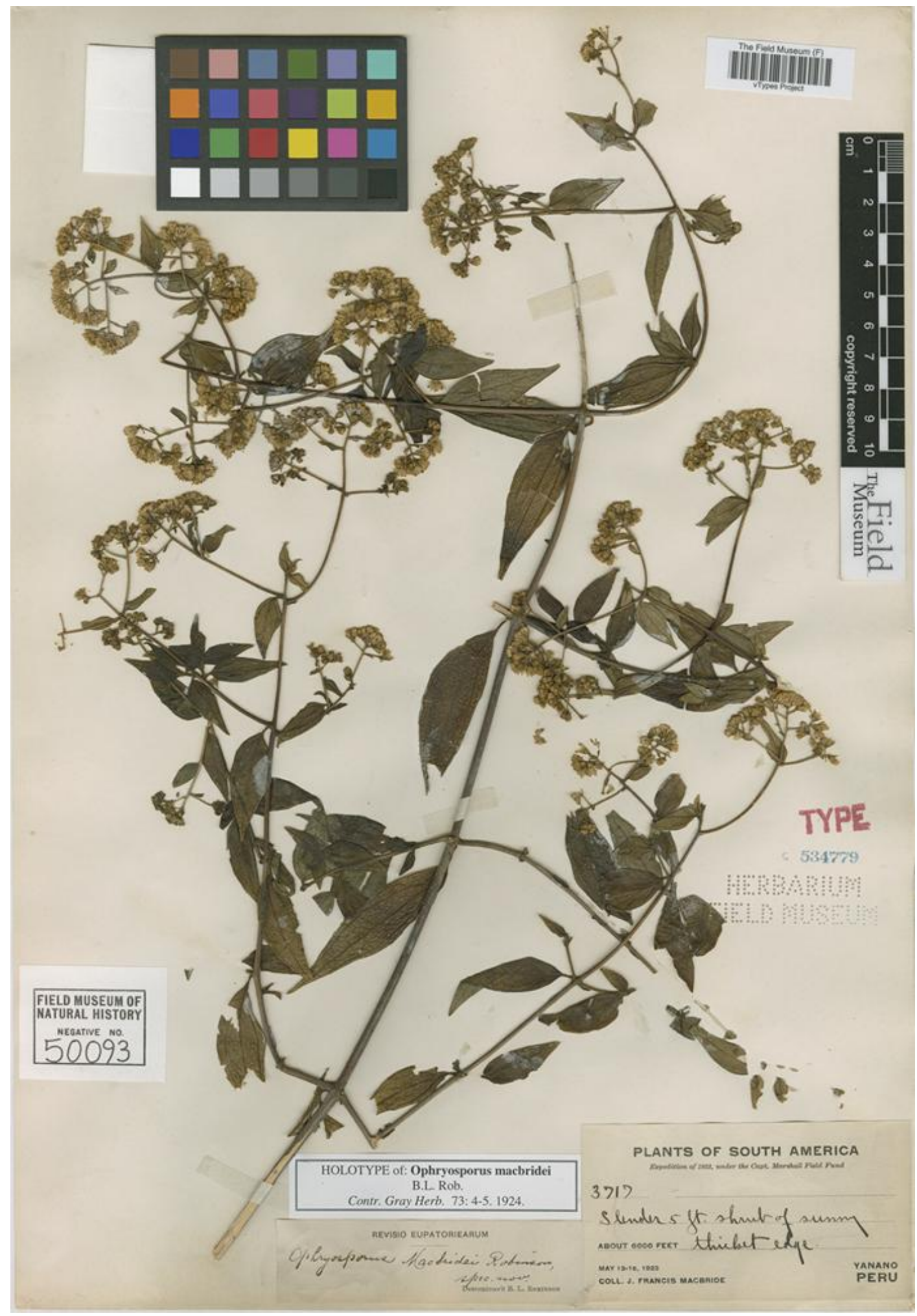

Figura 81. O. macbridei, holotipo. J. Francis Macbride 3717 (F). 


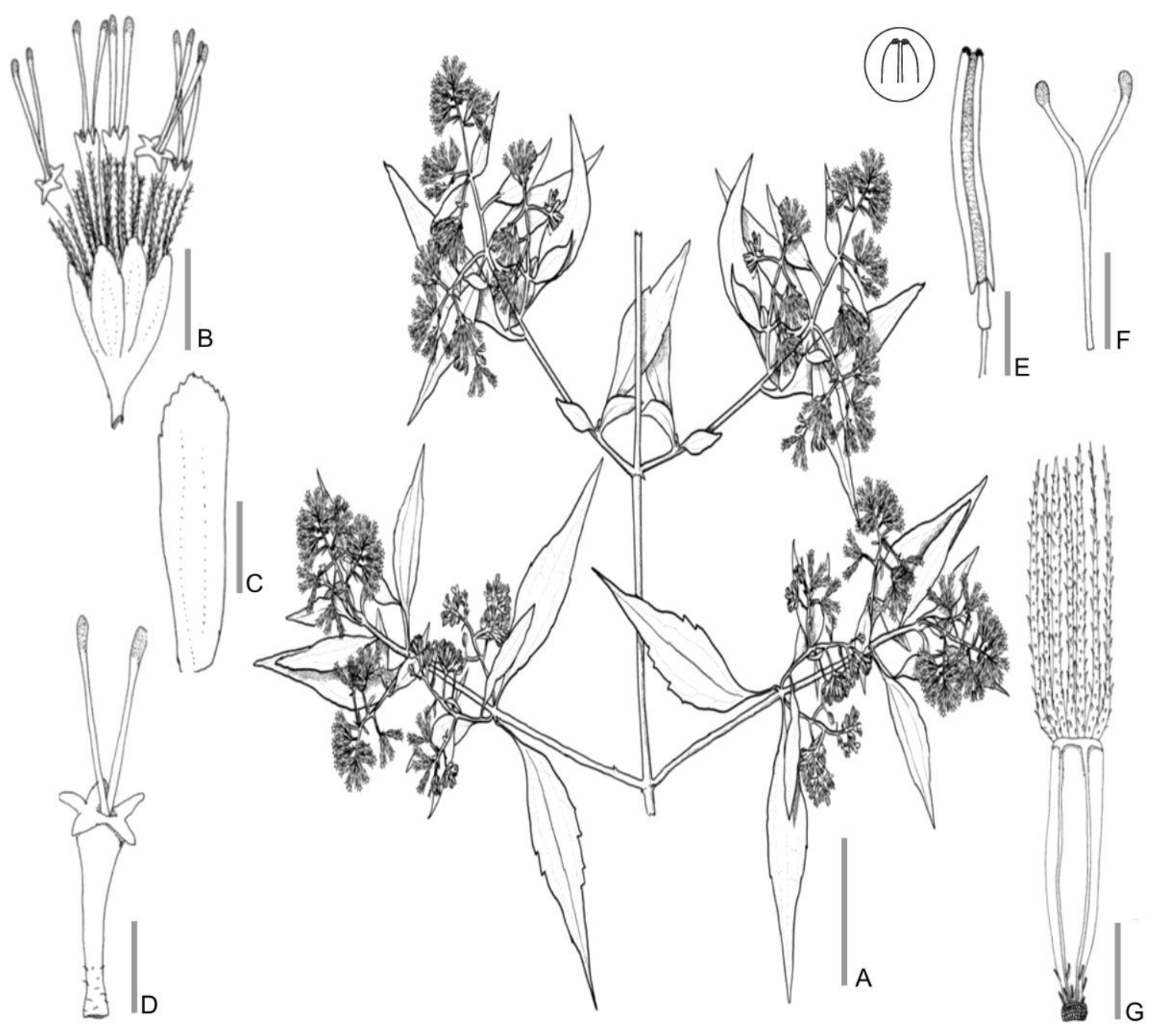

Figura 82. O. macbridei A. Rama florífera. B. Capítulo. C. Flor sin papus ni cipsela. D. Filario. E. Antera. F. Estigma. G. Cipsela. Escalas: A: $5 \mathrm{~cm}$; B: $2 \mathrm{~mm}$; C: $1 \mathrm{~cm}$; D-E: $500 \mu \mathrm{m}$; F-G: $200 \mu \mathrm{m}$. (A-G basados en D. N. Smith \& S. Vasquez $S$. 4937, MO). 


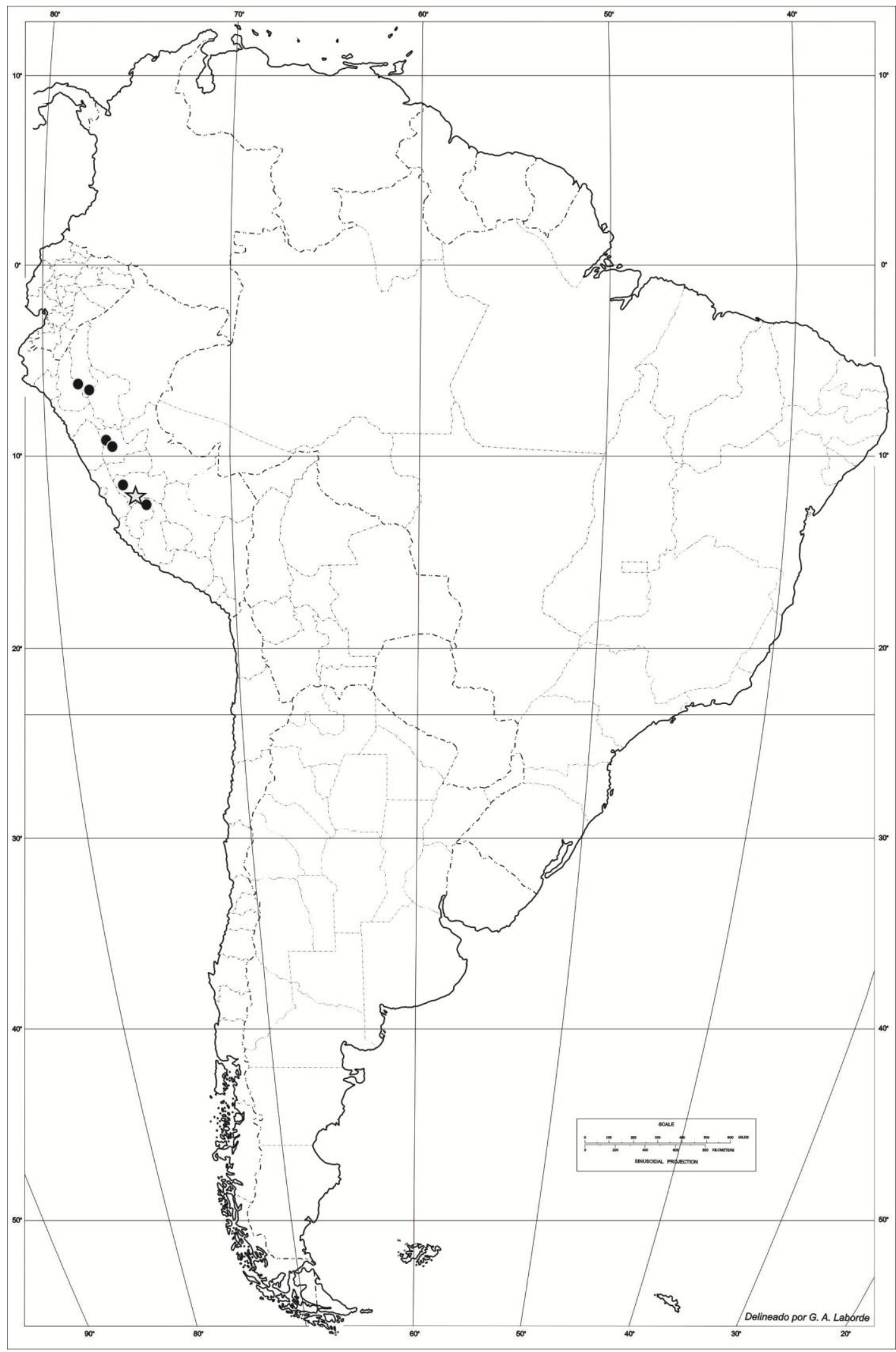

Figura 83. O. macbridei. Distribución geográfica, la estrella indica la localidad tipo. 


\section{Ophryosporus macrodon Griseb.}

Symbolae ad Floram Argentinam: 173. 1879.

Tipo: Argentina: "Los Potreros, al pié del Nevado del Castillo; Salta, 24.III.1873, leg. G. Hieronymus et P. G. Lorentz 156". Holotipo GOET 001859 foto!; isotipos GOET 001858 foto!, B en $F$ foto! (destruido), CORD!, GH foto!, (http://plants.jstor.org/search?searchText=Ophryosporus\%20macrodon), S no visto (Anderberg et al., 1996) Fig. 84.

$=$ Eupatorium kuntzei Hieron. Botanische Jahrbücher für Systematik Pflanzengeschichte und Pflanzengeographie 22: 766. 1897. Tipo: "Bolivien 3000 m, Cochabamba, 26 maerz 1892, Otto Kuntze, s.n." Holotipo B en F foto! (destruido), NY 00169054!, US 00147662 foto! (http://plants.jstor.org/search?searchText=eupatorium\%20kuntzei).

Arbusto erecto (2-3 m). Tallo con entrenudos entre 5 y $12 \mathrm{~cm}$, ramificaciones secundarias opuestas, ramas tomentulosas, marrón claro a rojizo. Hojas opuestas, pecioladas, pecíolo $0,5-1,5 \mathrm{~cm}$, láminas ovadas, $5-8 \times 10-18 \mathrm{~cm}$, base redondeada, a veces asimétrica, ápice agudo, margen entero, plano; consistencia herbácea, venación acródroma imperfecta suprabasal; pubescente, tricomas eglandulares simples cónicos. Inflorescencia cimoidea, compuesta de corimbos densos; terminal y axilar, con hojas persistentes poco desarrolladas. Capítulos ca. 250-300, pedunculados (1-3 mm), 2,5 x 4,5 mm. Involucro acampanado, 2,5 × 3,5 $\mathrm{mm}$; filarios 6, eximbricados; en dos series de filarios, la externa ovadolanceolados, 1,5 × 3,2 mm, la interna ovados 1 × $3 \mathrm{~mm}$; margen entero, consistencia herbácea, a veces con porciones esclerificadas en el centro; glandulosos, tricomas glandulares (tipo $\beta$ ). Flores (5)-8-(10), hermafroditas, corola blanquecina, infundibuliforme, sin paso gradual entre tubo y limbo, tubo $1 \times 0,25$ $\mathrm{mm}$, limbo 2,1 x 0,8 mm, 5-dentada, lóbulo 0,5 × 0,6 mm; glandulosa sólo en la base del tubo, tricomas glandulares (tipo $\alpha$ ). Estambres 5 , anteras $1,1 \times 0,25 \mathrm{~mm}$, collar anteral cilíndrico, base de la teca obtusa; apéndice conectival nulo. Estilo 5,5 $\mathrm{mm}$, largamente exerto, ramas del estilo fuertemente clavadas en el ápice, ápices 
más oscuros que el resto de las ramas, las ramas 2,5 mm. Cipsela negra levemente estipitada, piriforme, 1,5 mm, marcadamente 5-costada; serícea, pelos gemelos en las costillas; carpopodio cilíndrico, excéntrico. Papus formado por 2025 cerdas blanquecinas, connadas en la base, 2-2,3 mm. $n=10$ II (Wullf et al., 1996) Fig. 85.

Fenología: Florece desde febrero hasta mayo.

Distribución: Argentina (provincias de Jujuy, Salta y Tucumán). Bolivia (departamentos de Cochabamba, La Paz, Santa Cruz y Tarija), a entre los 2000 y $3900 \mathrm{msnm}$, habita en bosque tucumano-boliviano, vegeta en los bosques de alisos (Alnus acuminata Kunth) y en los matorrales serranos. Fig. 86.

Nombres comunes: "Racimo de novia" ( $A$. Carranza 392 JUA).

\section{Notas:}

1. Esta especie, junto con $O$. kuntzei Hieron., han sido erróneamente sinonimizadas y esto ha conducido a errores en su nomenclatura. Se debe, posiblemente, a que el basónimo de O. macrodon es Eupatorium kuntzei Hieron.

2. De acuerdo a Grisebach, es afín a O. laxiflorus Baker.

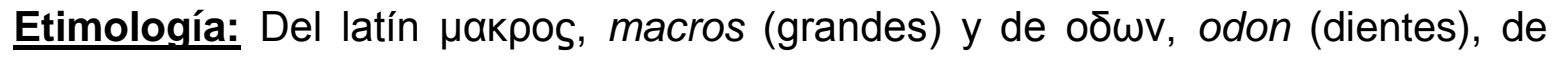
grandes dientes (Gledhill 2008).

Estado de conservación: es una especie de amplia distribución y muy abundante cuando presente. De acuerdo a Delucchi \& Plos (2011), le corresponde la categoría LC de la UICN, de interés menor, debido a su amplia distribución geográfica. Común en zonas disturbadas bien iluminadas (bordes de caminos, cercos, bordes de cultivos). En Argentina se encuentra presente en áreas protegidas de las provincias de Jujuy (Parque Provincial Lagunas de Yala), Salta (Reserva de Biósfera de Yungas) y Tucumán (Quebrada de Los Sosa, Parque 
Sierra San Javier) (Sistema Federal de Áreas Protegidas www.medioambiente.gov.ar).

Compuestos químicos de interés: Se ha detectado la presencia de derivados de p-hidroxiacetofenonas (Sigstad et al 1993). Herz (2004) indica la presencia de benzofuranos, dihidrobenzofuranos, cumarinas, cromenos y glicósidos (flavonas, flavonoles, flavononas).

Especímenes adicionales examinados: ARGENTINA. Jujuy: Capital, camino a Laguna de Yala, 08/05/1962, Cabrera et al. 14398 (LP). Dr. Manuel Belgrano, Lagunas de Yala, 12-14/02/1971, A. L. Cabrera et al. 21284 (LP), ib. 14/03/1969, Lognamo et al. 6098 (LIL, LP); Quebrada de Yala, 26/04/1974, A. L. Cabrera \& R. Kiesling 25220 (LP); Yala, Cerro Loza, 11/04/1998, A. Carranza 392 (JUA); Laguna El Comedero, 16/02/2000, A. Carranza 638 (JUA), ib. 24/02/2000, A. Carranza 649 (JUA); ib. A. Carranza 660 (JUA), ib. 21/03/2000, A. Carranza 677 (JUA); Laguna de los Noques, 20/03/2000, A. Carranza 673 (JUA); Laguna El Rodeo, 31/03/1998, A. Carranza 281 (JUA), ib. 09/05/1998, A. Carranza 403 (JUA); subida a las Lagunas de Yala, 10/05/1989, A. Castellón 100 (JUA). Tumbaya, Volcán, Chilcayo, 4-6/03/1965, Cabrera et al. 16818 (GH, LP). Tucumán: Alpachiri, El Bolsón a la Cascada, 26/03/1953, Meyer 17704 (LIL, LP); Camino a Tafí del Valle, El Indio, 09/02/2010, Plos, Plunkett \& Nicolas 39 (LP), ib. 09/02/2010, Plos, Plunkett \& Nicolas 40 (LP), ib. 09/02/2010, Plos, Plunkett \& Nicolas 41 (LP), ib. 09/02/2010, Plos, Plunkett \& Nicolas 42 (LP), ib. 09/02/2010, Plos, Plunkett \& Nicolas 43 (LP); Cumbres Calchaquíes, Cuesta del Huasancho, 28/03/1914, Rodríguez 1462 (LP); Guachipas, Estancia Pampa Grande, 20/03/1966, Hawkes et al. 3946 (LP); La Quebrada Pajonal, 26/03/1972, T. Meyer \& A. A. Vaca 23665 (LIL); Monteros, Puesto La Laguna, 25/04/1949, F. Vervoorst 547 (LIL); Road to Amaicha del Valle, 04/05/1985, Solomon 13558 (MO); Tafí del Valle, camino a El Mollar, pasando Estancia Las Carreras, 22/02/2011, Plos \& Simon 105 (LP); Tafí del Valle, 17/03/1972, 1908, C. Bruch s.n. (LP), ib. Maruñak et al. 357 (LP), ib. El Mollar, 09/03/1987, E. Sigstad \& C. Catalán 575 (LIL); Tafí del Valle, La Quebradita, 07/02/1959, De la Sota 2063 (LP), ib. 28/02/1960, 
Hunziker 7144 (LP), ib. 25/02/1965, T. Meyer 22897 (LIL); Trancas, Dos Cuestas, 21/04/1926, Venturi 4116 (LIL, LP). Salta: Caldera, Potrero del Castillo, 12/03/1952, Sleumer et al. 2783 (LP); Guachipas, Estancia Pampa Grande, path to Cerro Cristal, 20/03/1966, J.G. Hawkes, J. P. Hjerting \& K. Rahn 3946 (LP); Iruya, Calanzulí, 07/02/1985, Zardini et al. 1920 (MO), Rodeo Colorado, sin fecha, Figueroa 44 (LP); Orán, Cerro Tablada, 04/04/1945, S. A. Pierotti 1172 (LIL), Santa Cruz, 21/10/1945, S. A. Pierotti 1315 (LIL); RN9, Camino de Cornisa, 05/02/2010, Plos et al. 11 (LP); La Caldera, 07/02/2010, Plos, Plunkett \& Nicolas 36 (LP), ib. 07/02/2010, Plos, Plunkett \& Nicolas 37 (LP), ib. 07/02/2010, Plos, Plunkett \& Nicolas 38 (LP); Santa Cruz, 26/04/1971, Okada 5930 (LP); ib. 1971, Hoffmann 2047 (LP); Santa Victoria: Los Toldos, Cuesta Cerro Bravo, 23/04/1968, Fabris et al. 7383 (LP); Valle de Lerma, El Alisal, 07/02/2010, Plos, Plunkett \& Nicolas 33 (LP), ib. 07/02/2010, Plos, Plunkett \& Nicolas 34 (LP). BOLIVIA. Tarija, 21/03/1904, K. Fiebrig 3150 (NY). 


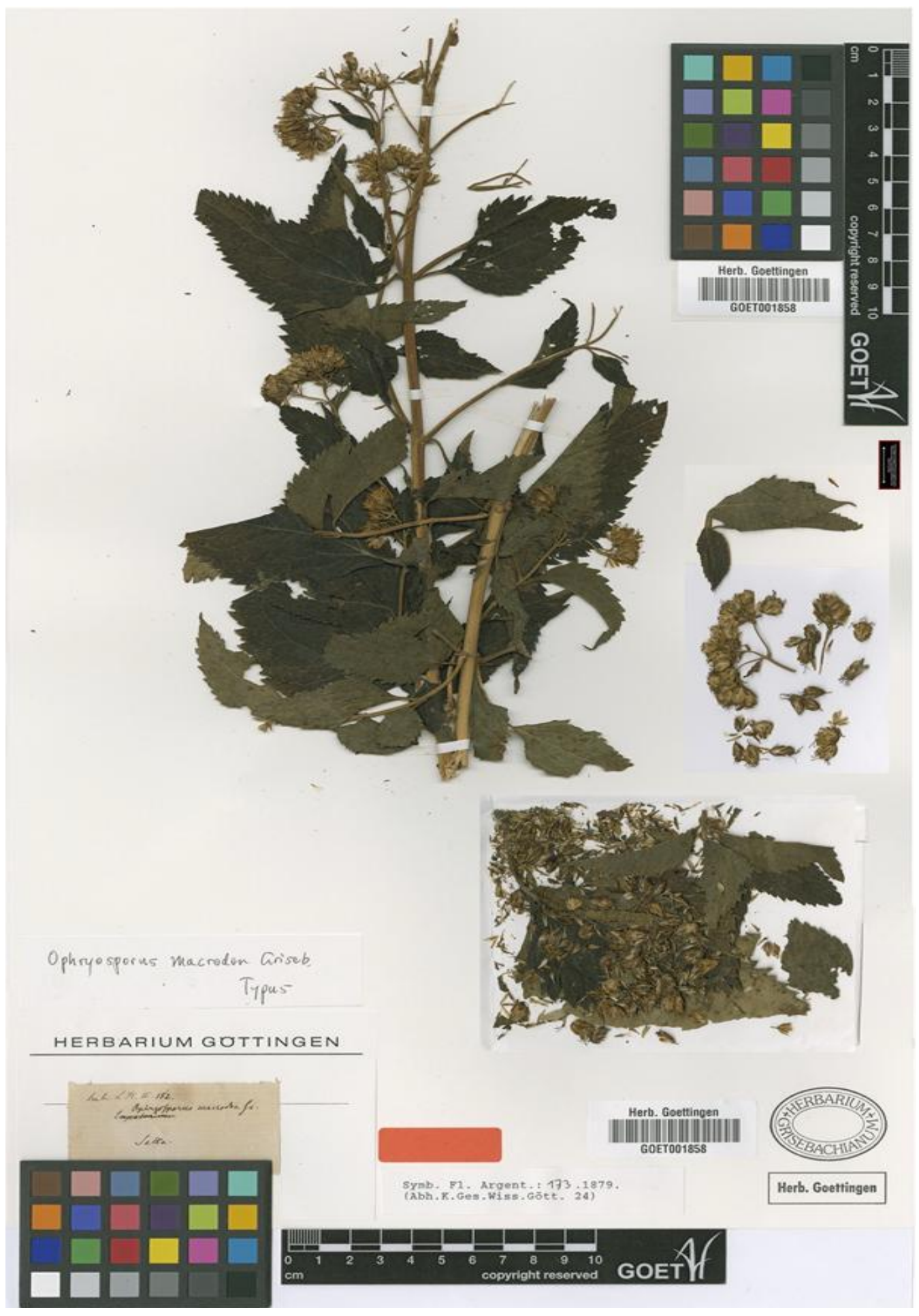

Figura 84. O. macrodon, holotipo. G. Hieronymus \& P. G. Lorentz 156 (GOET). 


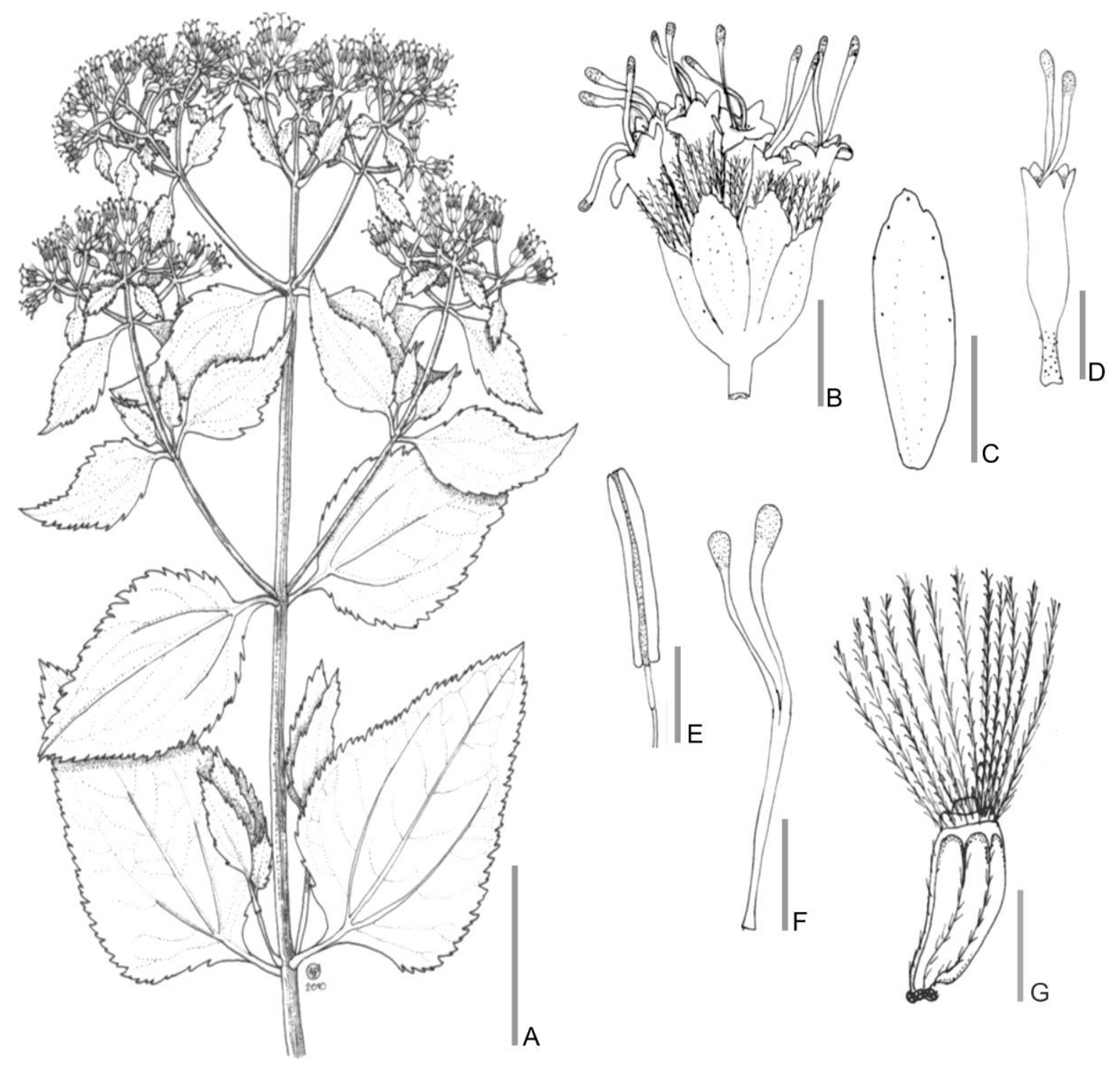

Figura 85. O. macrodon. A. Rama florífera. B. Capítulo. C. Flor sin papus ni cipsela. D. Filario. E. Antera. F. Estigma. G. Cipsela. Escalas: A: $5 \mathrm{~cm}$; B: $2 \mathrm{~mm}$; C-D: 1 cm; E-F: 1 mm; G: 1mm. (A-G basados en A. L. Cabrera et al. 14398, LP). 


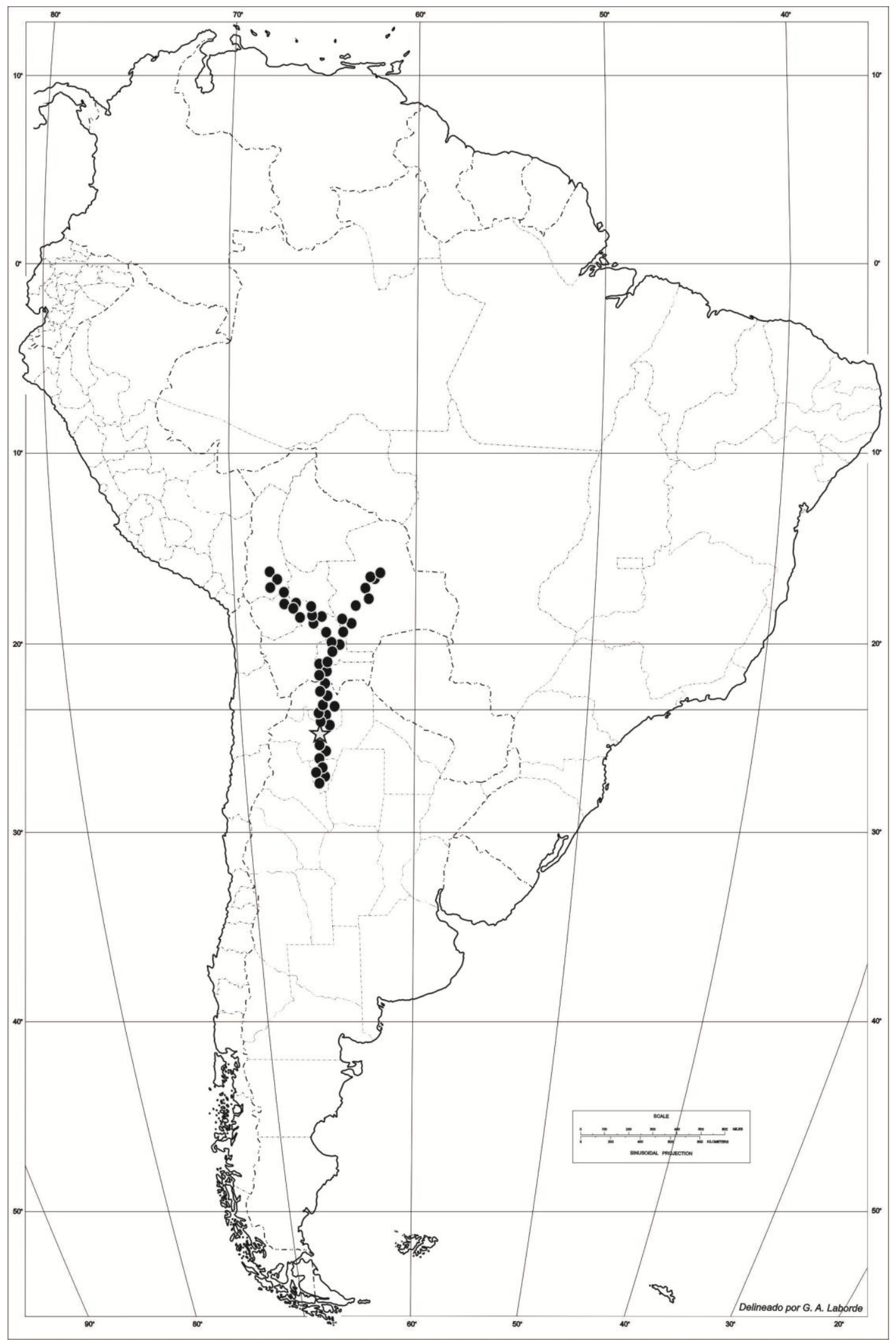

Figura 86. O. macrodon. Distribución geográfica, la estrella indica la localidad tipo. 


\section{Ophryosporus marchii Sagást. \& E. Rodr.}

Revista Peruana de Biología 15(1): 21-23. 2008

Tipo: Perú. "Dpto. Cajamarca, Provincia Contumazá, alrededores del Distrito Guzmango, 2500 m, 25 Julio 2006”, A. Sagástegui A. 17611. Holotipo: HUT no visto; isotipos: F no visto, HUT no visto, MO no visto, US no visto, USM no visto. Fig. 87.

Arbusto erecto $(1,5 \mathrm{~m})$. Tallo con entrenudos entre 3 y $6 \mathrm{~cm}$, ramificaciones secundarias opuestas, ramas glabras, marrón claro. Hojas opuestas, pecioladas, pecíolo 1,5-5 cm, láminas ovadas a ovado-lanceoladas, 3-6 x 7-12 cm, base cuneada, ápice acuminado, margen entero, plano; consistencia herbácea, venación acródroma imperfecta suprabasal. Inflorescencia cimoidea, compuesta de corimbos laxos; terminal, con hojas persistentes poco desarrolladas. Capítulos numerosos, pedunculados (2-3 mm), 1,-1,5 x 6-7 mm. Involucro cilíndrico, 1,5 x 5,3 mm; filarios 4-(5), subimbricados; en una serie de filarios, ovado-lanceolados, $1,2 \times 5,3 \mathrm{~mm}$; margen entero. Flores 4, hermafroditas, corola blanca, infundibuliforme, sin paso gradual entre tubo y limbo, tubo 1-1,5 x 0,3 mm, limbo 1$1,5 \times 1 \mathrm{~mm}$, 5-dentada, lóbulo $0,5 \times 0,4 \mathrm{~mm}$; pubescente sólo en el tubo. Estambres 5, anteras $1 \mathrm{~mm}$. Estilo 4-5 mm, largamente exerto, ramas del estilo fuertemente clavadas en el ápice, ápices más oscuros que el resto de las ramas, las ramas 2,8 mm. Cipsela negra, piriforme, 2-2,5 mm, marcadamente 5-costada; glabras; carpopodio anular. Papus nulo. Fig. 87.

Observación: como únicamente se dispuso de la ilustración correspondiente al holotipo, la descripción se completó con datos de la descripción original y dicha ilustración.

Fenología: florece en julio.

Distribución: Perú (departamento de Cajamarca) a 2200-2500 msnm, vegeta generalmente a lo largo de los cercos de chacras y bosques secundarios asociada 
con Baccharis L. sp., Boerhavia L. sp. y Paracalia jungianoides (Hook. \& Arn.) Cuatrecasas (Sagástegui \& Rodríguez Rodríguez 2008) Fig. 88.

Notas: Afín a $O$. sagasteguii $\mathrm{H}$. Rob., se diferencia de ésta por la presencia de tallos compactos (vs. fistulosos), por la forma y tamaño de las hojas y capítulos, 4 flores por capítulo (vs. 5 flores) y por carecer de papus (Sagástegui \& Rodríguez Rodríguez 2008).

Etimología: Dedicado a Juan March Ordinas (Sagástegui \& Rodríguez Rodríguez 2008).

Estado de conservación: de acuerdo a los criterios de la UICN (UICN 2000), esta especie endémica debería ser incluida en la categoría VU, vulnerable, debido a que el área de presencia y ocupación es pequeña y sin protección. Así mismo, sus poblaciones son pequeñas y reducidas en número y se encuentran afectadas por la expansión de la frontera agrícola (Sagástegui \& Rodríguez Rodríguez 2008). 


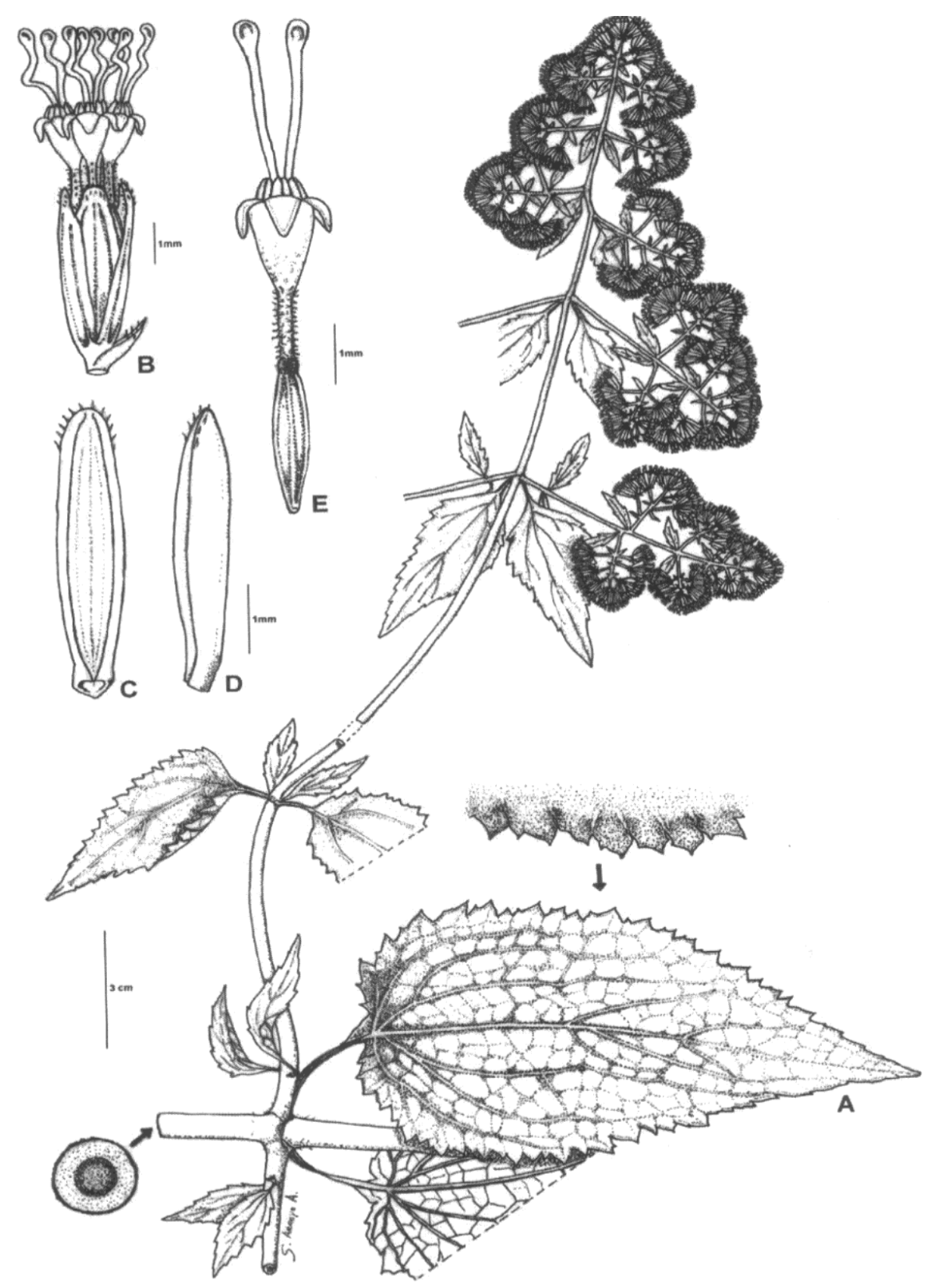

Figura 87. O. marchii, holotipo. A. Sagásteguii A. 17611 (HUT). A. Rama florífera. B. Capítulo. C. Filario, vista ventral. D. Filario, vista dorsal. E. Flor con cipsela. Escalas: A: $3 \mathrm{~cm}$; B-E: $1 \mathrm{~mm}$. (A-E basados en A. Sagásteguii A. 17611, HUT). Ilustración tomada de Sagástegui \& Rodríguez (2008). 


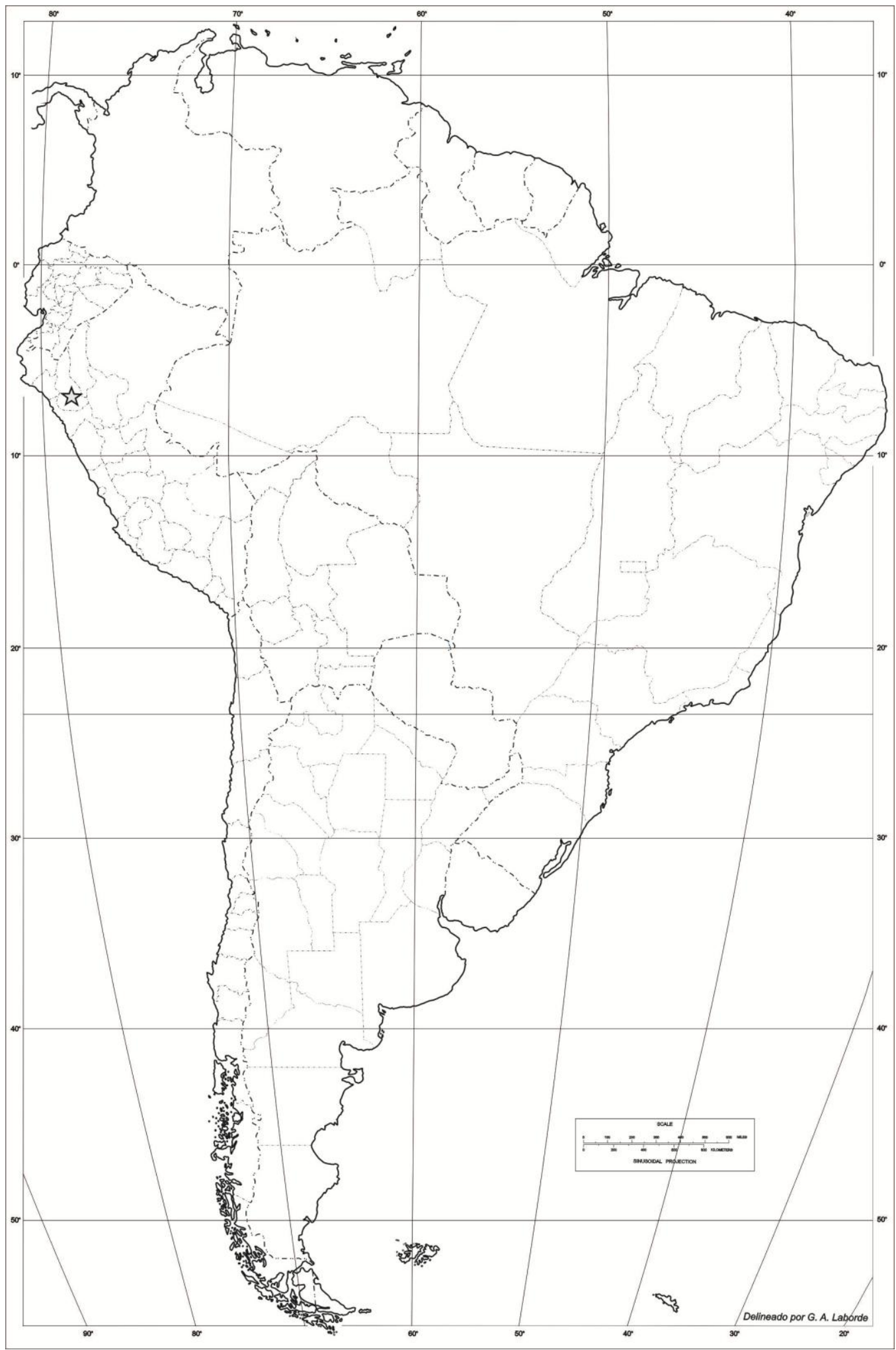

Figura 88. O. marchii. Distribución geográfica, la estrella indica la localidad tipo. 
Ophryosporus mathewsii (B. L. Rob.) R. M. King \& H. Rob.

Phytologia 25(2): 66. 1972.

ミ Piqueria mathewsii B. L. Rob.

Proceedings of the American Academy of Arts and Sciences 42: 12.1906

Lectotipo (designado aquí): "Peru: Purruchuca (por Purruchuco)", Mathews $1015 \mathrm{~K}$ foto! 000486677 . Isolectotipos: $\mathrm{K}$ foto! 000486676 , GH foto! 00010784 . Fig. 89.

Arbusto erecto. Tallo con entrenudos entre 3 y $6 \mathrm{~cm}$, ramificaciones secundarias opuestas, ramas glabras, marrón claro. Hojas opuestas, pecioladas, pecíolo 0,7-1 cm, láminas ovadas, 2-3x 4-6 cm, base cuneada, ápice agudo, margen aserrado; consistencia herbácea, venación acródroma imperfecta suprabasal. Inflorescencia cimoidea, compuesta de corimbos laxos; terminal, con hojas persistentes poco desarrolladas. Capítulos pedunculados Involucro cilíndrico; filarios 4-5, eximbricados; margen entero. Flores 4-5, hermafroditas, corola blanquecina, infundibuliforme, 5-dentada. Estambres 5. Estilo largamente exerto, ramas del estilo fuertemente clavadas en el ápice, ápices más oscuros que el resto de las ramas. Cipsela negra, marcadamente 5-costada. Papus nulo. Fig. 90 .

Observación: como únicamente se dispuso de imágenes en alta definicón del holotipo, la descripción se completó con datos de la descripción original y dicha imagen.

Fenología: Florece en julio.

Distribución: Perú (departamento de Cajamarca) a 2200-2500 msnm, vegeta generalmente a lo largo de los cercos de chacras y bosques secundarios asociada con Baccharis L. sp., Boerhavia L. sp. y Paracalia jungianoides (Hook. \& Arn.) Cuatrecasas (Sagástegui \& Rodríguez Rodríguez 2008) Fig. 91. 


\section{Notas:}

1. En la descripción original, Robinson (1906) hace referencia a materiales pertenecientes a Mathews 1015 depositados en K. Luego de una revisión de los materiales tipos asignados a esta especie, se halló un duplicado en GH. Si bien, el Código de Viena (2006) indica que para lectotipificar se deben priorizar los materiales depositados en los herbarios donde el investigador desarrolló sus actividades, en este caso, como el material depositado en $\mathrm{GH}$ es un fragmento acompañado de una foto correspondiente a un material depositado en $\mathrm{K}$, se procede a designar al espécimen depositado en $\mathrm{K}$ como lectotipo. Dicho material se encuentra en excelente condiciones de conservación y permite la correcta identificación.

Etimología: Dedicado al colector del material tipo, Mathews.

Estado de conservación: De acuerdo con Brako \& Zarucchi (1993) es considerado un endemismo. 


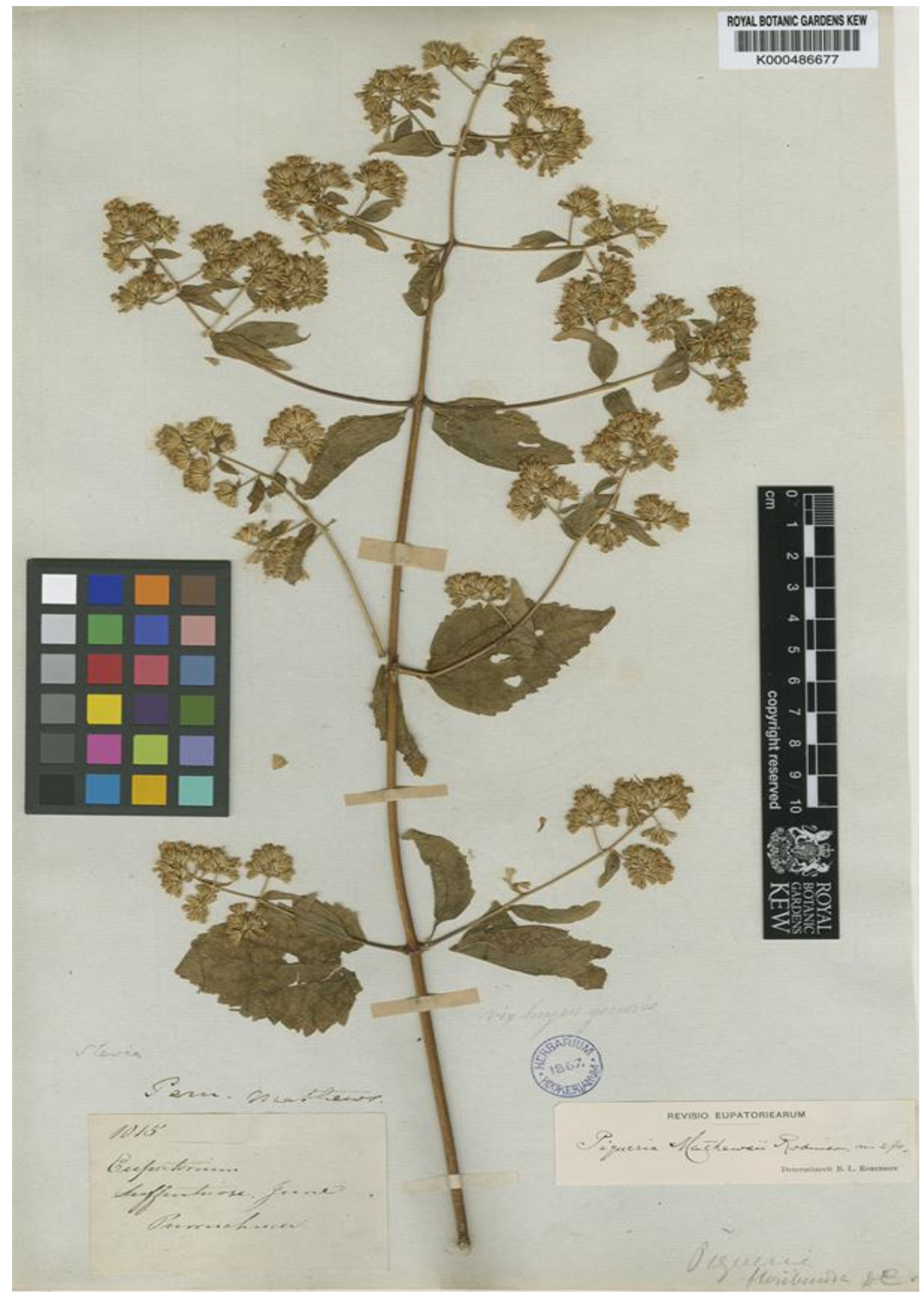

Figura 89. O. mathewsii, lectotipo. Mathews $1015(\mathrm{~K})$. 


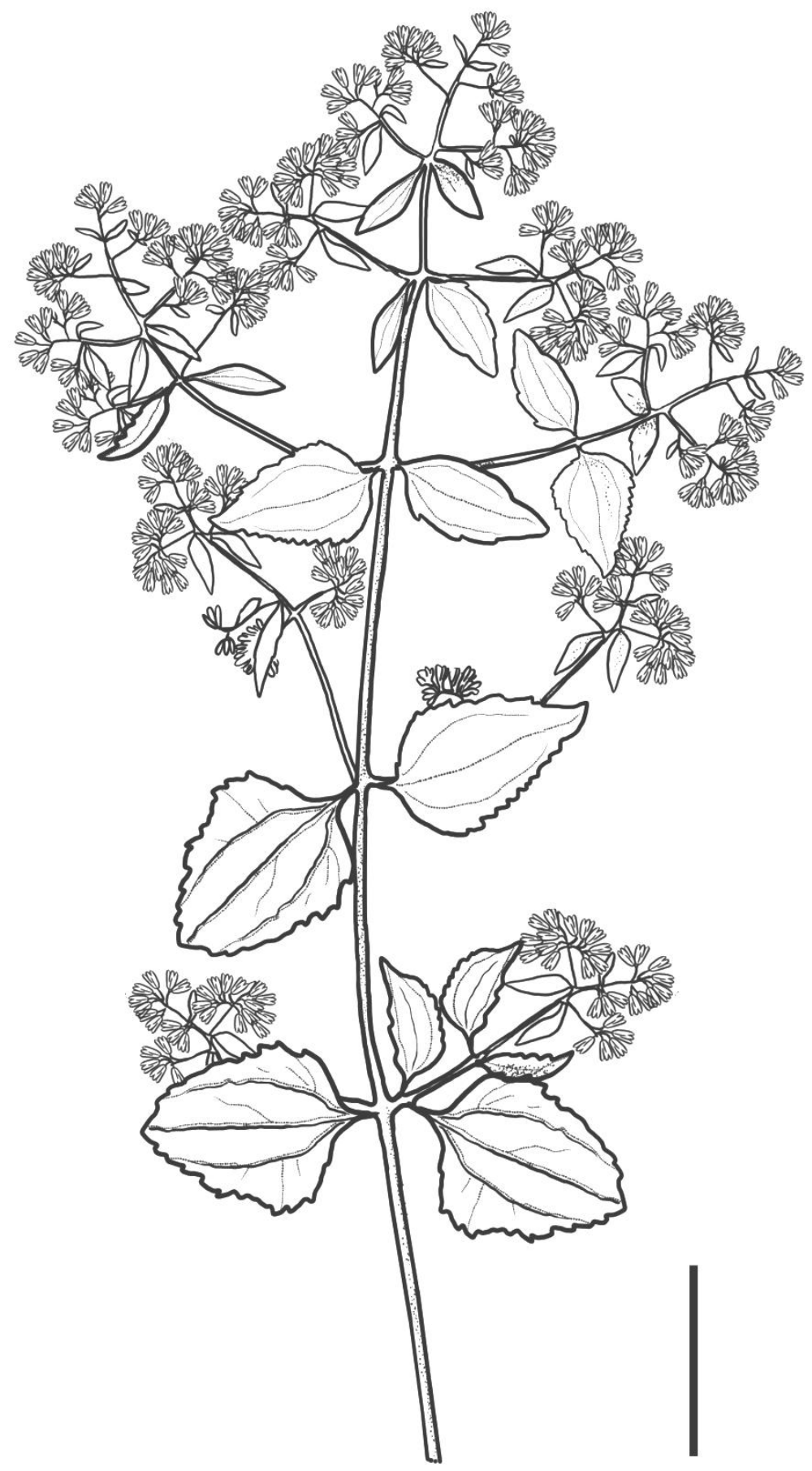

Figura 90. O. mathewsii. Rama florífera. Escala: $5 \mathrm{~cm}$ (basado en una foto de Mathews 1015, K). 


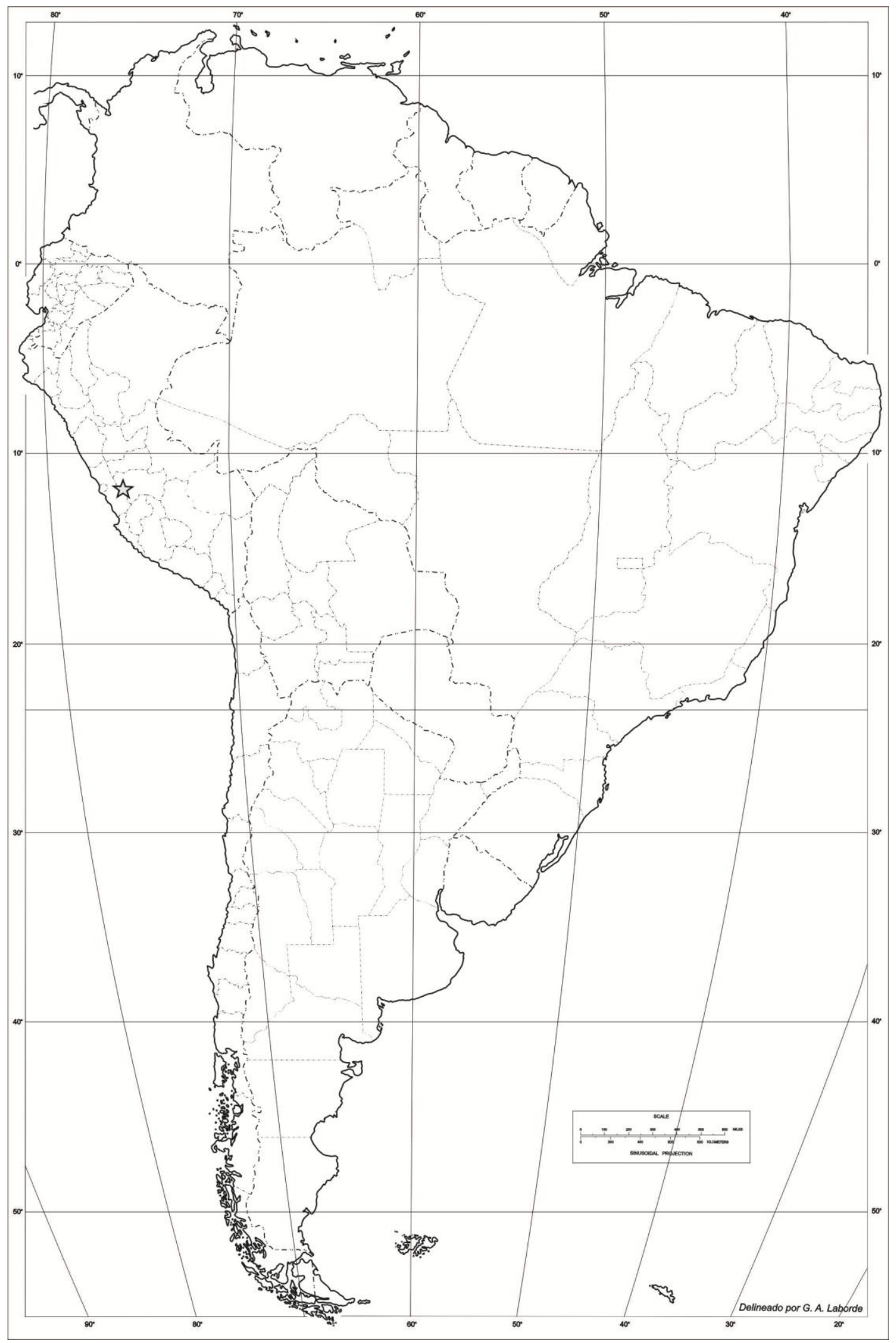

Figura 91. O. mathewsii. Distribución geográfica, la estrella indica la localidad tipo. 


\section{Ophryosporus organensis Cabrera.}

Arquivos do Jardim Botânico do Rio de Janeiro 15: 74. 1957.

Tipo: Brasil "Estado de Río de Janeiro, Serra dos Órgãos, silva ca. 1600 msnm, arbusto apoyante", 12/07/1956. A. L. Cabrera 12269. Holotipo: LP!, isotipo: GH foto!, $\mathrm{K}$ foto!, RB no visto (no se encuentra en ese herbario copia del tipo) Fig. 92.

Arbusto apoyante. Tallo con entrenudos entre 3 y $10 \mathrm{~cm}$, ramificaciones secundarias opuestas, ramas glabras, rojizo. Hojas opuestas, pecioladas, pecíolo 0,5-1 cm, láminas ovadas a ovado-lanceoladas, $1,2-2 \times 3,5-6 \mathrm{~cm}$, base redondeada, ápice agudo, margen aserrado, plano; consistencia herbácea, venación acródroma imperfecta suprabasal; pubescente, tricomas eglandulares simples cónicos. Inflorescencia cimoidea, compuesta por corimbos densos; terminal y axilar, con hojas persistentes poco desarrolladas. Capítulos ca. 120150, pedunculados (1-2 mm), 1,2 x 3,5 mm. Involucro cilíndrico, 3,8 x 3,2 mm; filarios 5, eximbricados; en una serie de filarios, ovado-lanceolados, 1,4 x 3,8 mm; margen entero, consistencia herbácea; glanduloso, tricomas glandulares (tipo $\alpha$ ). Flores 4-5, hermafroditas, corola blanquecina, infundibuliforme, sin paso gradual entre tubo y limbo, tubo $1 \times 0,25 \mathrm{~mm}$, limbo $1,7 \times 0,75 \mathrm{~mm}$, 5-dentada, lóbulo 0,3 $\mathrm{x}$ 0,4 mm; glandulosa sólo en la base del tubo, tricomas glandulares (tipo $\alpha$ ). Estambres 5, anteras $1 \times 0,2 \mathrm{~mm}$, collar anteral cilíndrico, base de la teca auriculada; apéndice conectival nulo. Estilo $3,75 \mathrm{~mm}$, cortamente exerto, ramas del estilo fuertemente clavadas en el ápice, ápices más oscuros que el resto de las ramas, las ramas $2,5 \mathrm{~mm}$. Cipsela negra no estipitada, piriforme a levemente falcadas, 2,2 $\mathrm{mm}$, marcadamente 5-costada; glabras; carpopodio cilíndrico, excéntrico. Papus formado por 20-25 cerdas blanquecinas, connadas en la base, 2,3-2,5 mm. Fig. 93.

Fenología: Florece de julio.

Distribución: Brasil (Río de Janeiro) a 400 msnm. Fig. 94. 
Etimología: Hace referencia a la localidad de colección del material tipo, Sierra dos Orgãos.

Especímenes adicionales estudiados: BRASIL. Rio de Janeiro: Parque Nac. Sierra dos Orgãos, km 10, 05/07/1947, G. Occhioni 1029 (LP). 


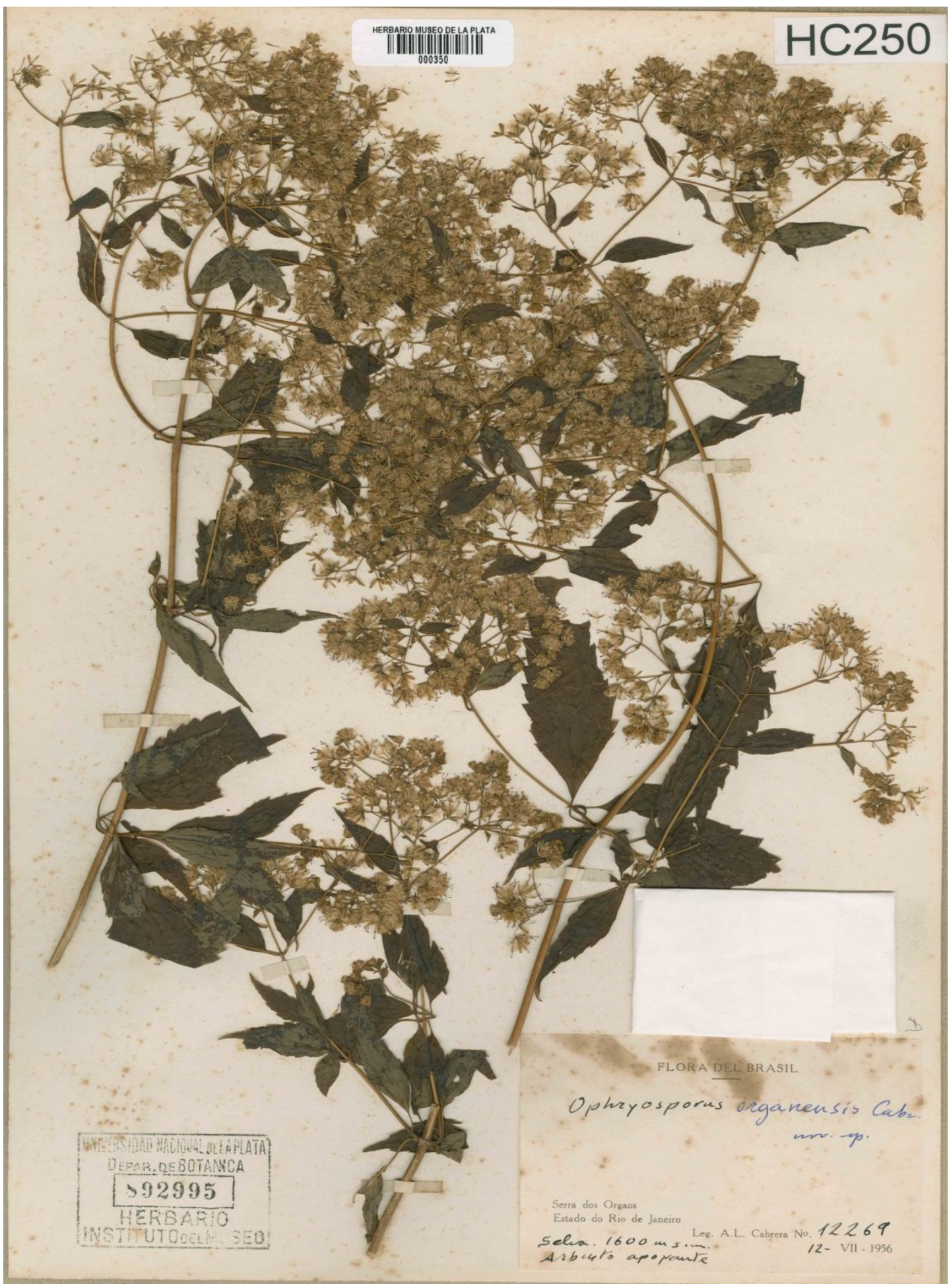

Figura 92. O. organensis, holotipo. A. L. Cabrera 12269 (LP). 


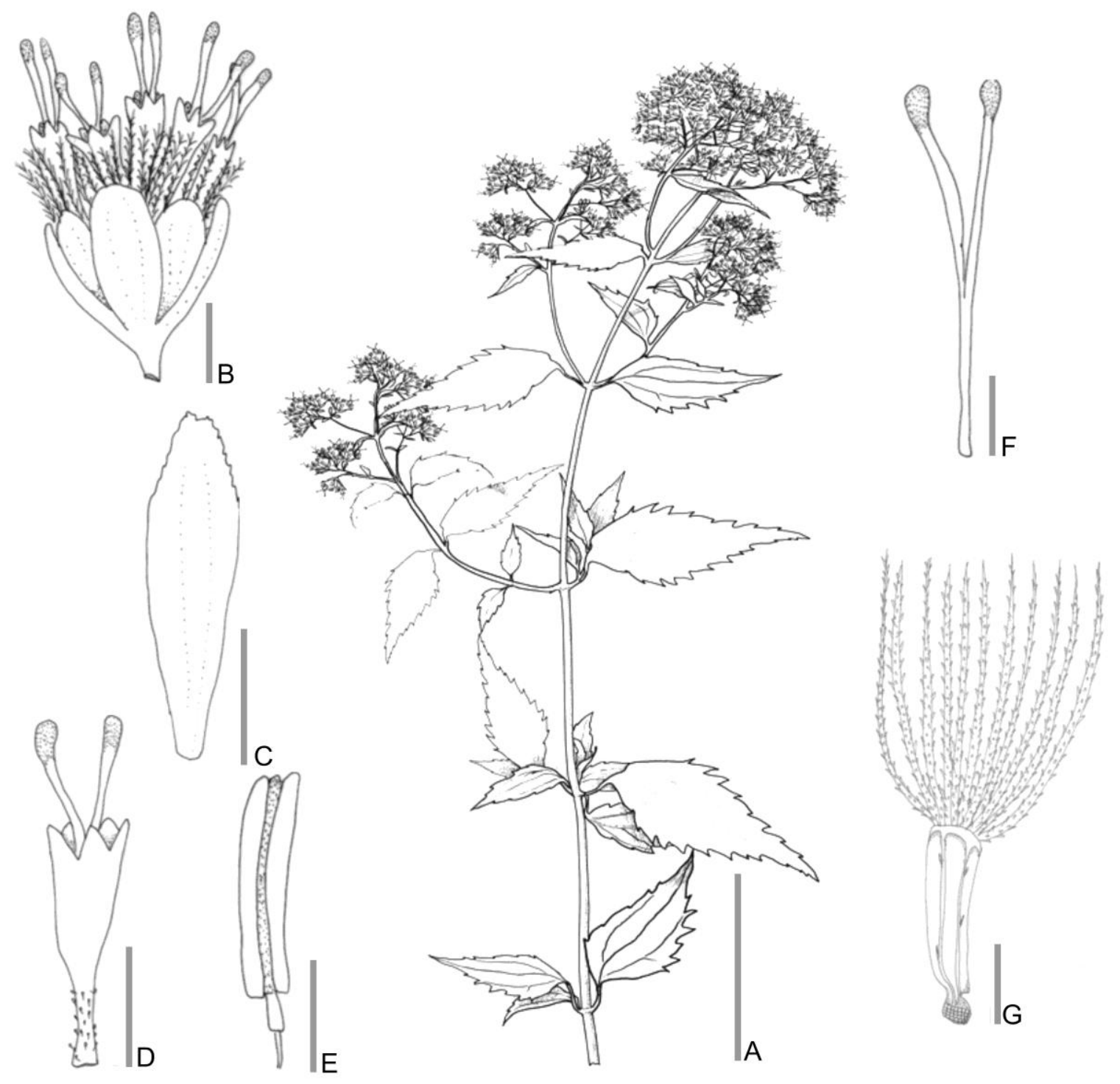

Figura 93. O. organensis A. Rama florífera. B. Capítulo. C. Flor sin papus ni cipsela. D. Filarios. E. Antera. F. Estigma. G. Cipsela. Escalas: A: $5 \mathrm{~cm}$; B-C: 2 mm; D-E: 0,5 cm; F-G: 200 m. (A-G basados en G. Occhioni 1029, LP) 


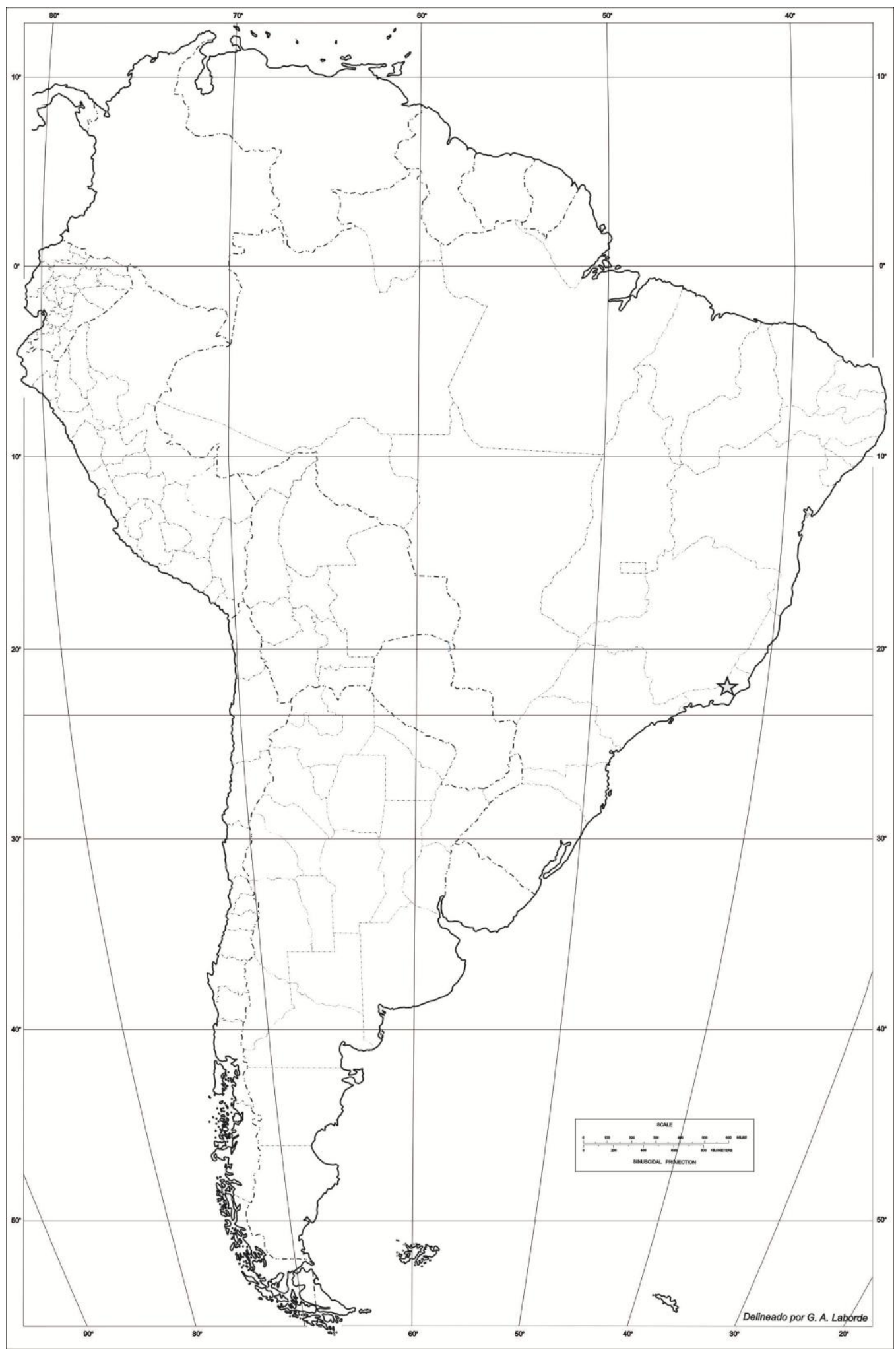

Figura 94. O. organensis. Distribución geográfica, la estrella indica la localidad tipo. 


\section{Ophryosporus ovatus B. L. Rob.}

Proceedings of the American Academy of Arts and Sciences 55: 5-6. 1919.

Tipo: Perú."Chachapoyas" A. Mathews 1370. Holotipo K 000486675 foto!, isotipos GH foto!, K 000486674 foto! Fig. 95.

Arbusto erecto $(1,2 \mathrm{~m})$. Tallo con entrenudos entre 0,3 y $2 \mathrm{~cm}$, ramificaciones secundarias opuestas, ramas glabras, marrón claro. Hojas opuestas, pecioladas, pecíolo 0,7-1,5 cm, láminas ovadas, 1-1,5 x 2-3 cm, base redondeada, ápice agudo, margen aserrado, plano; consistencia herbácea, venación acródroma imperfecta suprabasal; pubescente y glandulosa, tricomas eglandulares simples cónicos y glandulares (tipo a). Inflorescencia cimoidea, compuesta de corimbos densos; terminal, con hojas persistentes poco desarrolladas. Capítulos ca. 60-80, pedunculados $(0,8-1,2 \mathrm{~mm}), 2,5 \times 4 \mathrm{~mm}$. Involucro acampanado, 2,5 x $3 \mathrm{~mm}$; filarios 5-6, eximbricados; en una serie de filarios, lanceolados, $0,8 \times 2,5 \mathrm{~mm}$; margen entero, consistencia herbácea; pubescente y glanduloso, tricomas eglandulares simples cónicos y glandulares (tipo a). Flores 5-7, hermafroditas, corola blanquecina, infundibuliforme, con paso gradual entre tubo y limbo, tubo 1,7 x 0,3 mm, limbo $5 \times 1,8 \mathrm{~mm}$, 5-dentada, lóbulo 0,4 × 0,3 mm; glandulosa en la base del tubo, tricomas glandulares (tipo $\alpha$ ). Estambres 5 , anteras $2 \times 0,3 \mathrm{~mm}$, collar anteral cilíndrico, base de la teca auriculada; apéndice conectival rudimentario, con surco medial. Estilo $3,5 \mathrm{~mm}$, cortamente exerto, ramas del estilo fuertemente clavadas en el ápice, ápices más oscuros que el resto de las ramas, las ramas 1,4 mm. Cipsela negra no estipitada, piriforme a levemente falcada, 1,8 $\mathrm{mm}$, marcadamente 5-costada; serícea, pelos gemelos en las costillas; carpopodio anular, central. Papus formado por 25-30 cerdas amarillentas, connadas en la base, 1,3-1,8 mm. Fig. 96.

Fenología: Florece de marzo a agosto.

Distribución: Perú (departamentos de Arequipa, Cajamarca, Junín y Lambayeque) a 700-3200 msnm. Habita en laderas, monte bajo. Fig. 97. 
Etimología: Hace referencia a la forma ovoide de las láminas de las hojas (Gledhill 2008).

Estado de Conservación: De acuerdo con Brako \& Zarucchi (1993) es considerado un endemismo.

Especímenes adicionales estudiados: PERU. Lambayeque. Ferreñafe, Incahuasi, 22/06/1986, S. Llatos Quiroz 1909 (SI). 


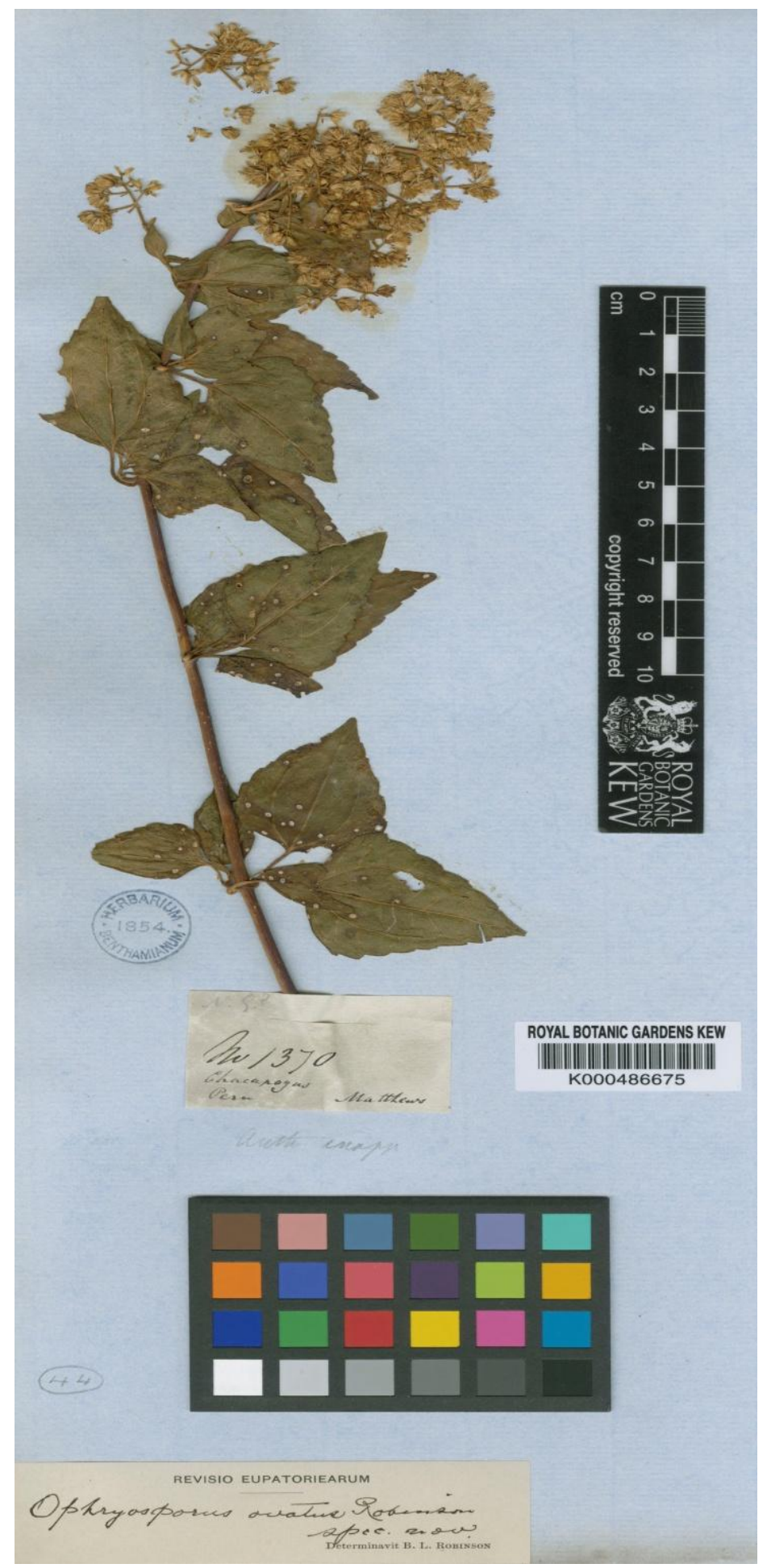

Figura 95. O. ovatus, holotipo. A. Mathews $1370(\mathrm{~K})$. 


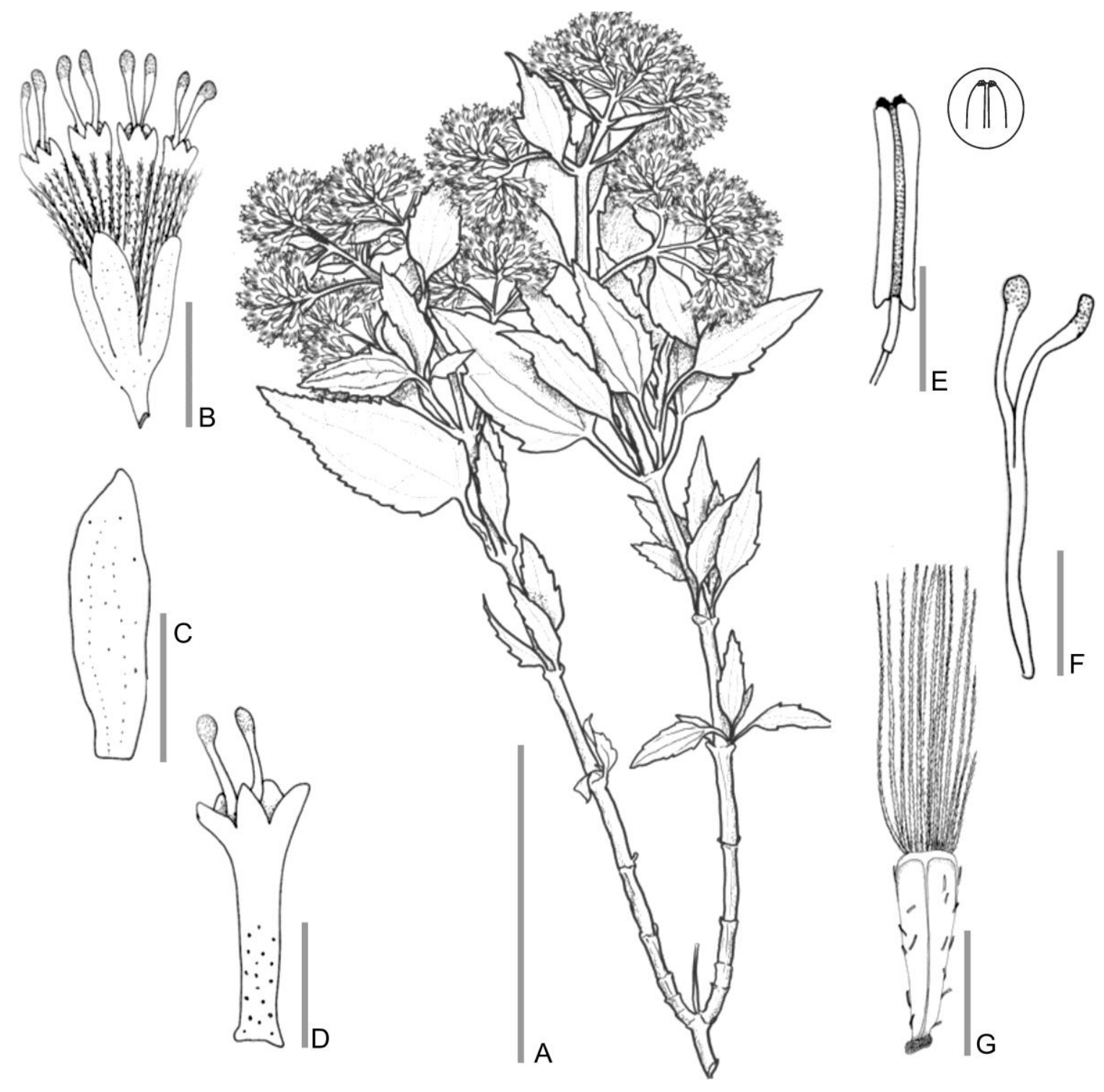

Figura 96. O. ovatus. A. Rama florífera. B. Capítulo. C. Flor sin papus ni cipsela. D. Filarios. E. Antera. F. Estigma. G. Cipsela. Escalas: A: 2,5 cm; B-C: 2 mm; D-E: 0,7 cm; F-G: 200 um. (A-G basados en S. Llatos Quiroz 1909, SI) 


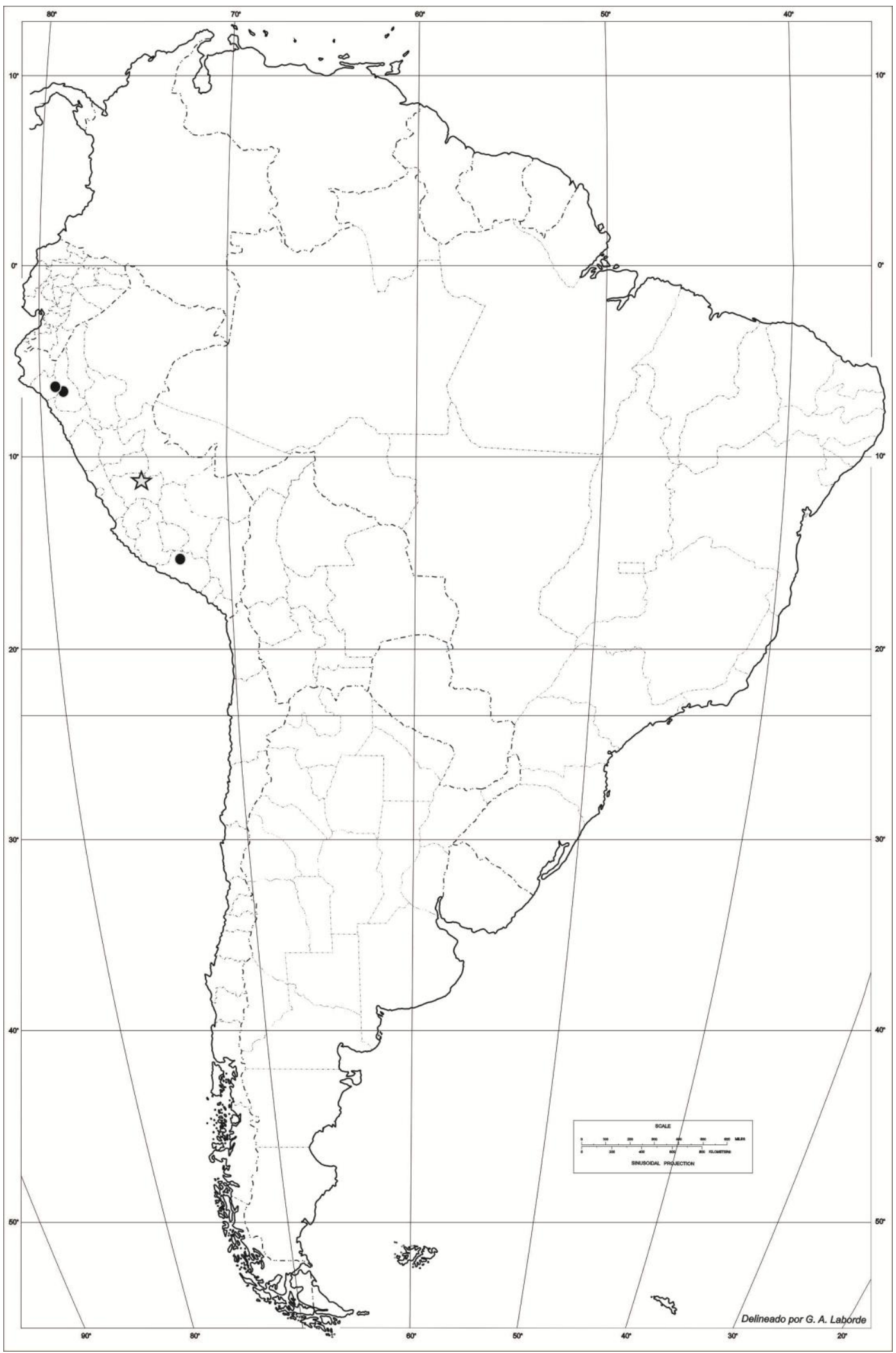

Figura 97. O. ovatus. Distribución geográfica, la estrella indica la localidad tipo. 
Ophryosporus paradoxus (Hook. \& Arn.) Benth. \& Arn. ex Hook. f. \& Jackson.

Index Kewensis 2: 354. 1895.

\section{E Eupatorium paradoxum Hook. \& Arn.}

Companion to the Botanical Magazine 1(8): 240. 1835. [1836].

Lectotipo: Chile, "Valparaíso", Bridges 52 (E 00249901 foto!, montado junto con Cuming 337 E 00249902). Isolectotipos: K 000486667 foto! (montado junto con Cuming 337 K 000486668), W 0018468 foto! (Plos \& Sancho, 2012) Fig. 98.

$=$ Ophryosporus triangularis Reiche. Fl. de Chil. iii. 259. 1902. no Meyen

= Stevia polyphylla DC. Prodromus Systematis Naturalis Regni Vegetabilis 5: 123.1836.

$=$ Nothites baccharoides DC. Prodromus Systematis Naturalis Regni Vegetabilis 5: 187. 1836.

= Stevia baccharidea (DC.) Meigen (como Stevia baccharoides). Bot. Jahrb. Syst 17: 283. 1893.

Arbusto erecto $(1 \mathrm{~m})$. Tallo con entrenudos entre 0,8 y $2 \mathrm{~cm}$, ramificaciones secundarias opuestas, ramas glabras, marrón claro. Hojas alternas, en fascículos, pecioladas, pecíolo $0,1-0,2 \mathrm{~cm}$, láminas lanceoladas, $0,1-0,3 \times 2-3,5 \mathrm{~cm}$, base cuneada, ápice agudo, margen aserrado, plano; consistencia herbácea, venación acródroma imperfecta suprabasal; pubescente, tricomas eglandulares simples cónicos. Inflorescencia tirsoidea laxa, compuesta de corimbos; terminal, con hojas persistentes bien desarrolladas. Capítulos ca. 120, pedunculados (1-2,5 $\mathrm{mm}$ ), $2 \times 4 \mathrm{~mm}$. Involucro cilíndrico, $2 \times 2,5 \mathrm{~mm}$; filarios 4, eximbricados; en una serie de filarios, lanceolados, $0,8 \times 2 \mathrm{~mm}$; ápice fimbriado, margen entero, consistencia herbácea, a veces con porciones esclerificadas en el centro; glanduloso, tricomas glandulares (tipo $\alpha$ ). Flores 4-5, hermafroditas, corola blanca, infundibuliforme, con paso gradual entre tubo y limbo, tubo $1 \times 0,8 \mathrm{~mm}$, limbo $1 \mathrm{x}$ 1,2 mm, 5-dentada, lóbulo 0,5 x 0,5 mm; glandulosa en la base del tubo, tricomas 
glandulares (tipo a). Estambres 5, anteras $1 \times 0,2 \mathrm{~mm}$, collar anteral cilíndrico, base de la teca auriculada; apéndice conectival muy rudimentario, entero. Estilo 4,2 mm, largamente exerto, ramas del estilo fuertemente clavadas en el ápice, ápices más oscuros que el resto de las ramas, las ramas 2,2 $\mathrm{mm}$. Cipsela negra no estipitada, piriforme, $2,5 \mathrm{~mm}$, marcadamente 5-costada; glabra; carpopodio cilíndrico, central. Papus formado por 24-26 cerdas blanquecinas, connadas en la base, 2,5-2,8 mm. Fig. 99.

Fenología: Florece de septiembre a enero.

Distribución: Chile (regiones de Antofagasta, Atacama, Coquimbo, Metropolitana de Santiago y Valparaíso) a 0-1800 msnm, habita cerca de la costa. Fig. 100.

Nombres comunes: "Rabo de zorro" (O. Boelcke 3858 LP).

\section{Notas:}

1. Hojas algo suculentas, gruesas (Teillier 916 NY).

2. Hooker \& Arnott (1835) citan tres ejemplares de referencia para Eupatorium paradoxum: "Valparíso", Bridges 52, Cuming 337 y Gillies s.n. Se han encontrado materiales de Cuming 337 en E (00249900 foto! y 00249900 foto! montado junto a Bridges 5200249901 foto!) y K (000486668 foto!, montado junto a Bridges 52, 00249901 foto!). Se designó como lectotipo al material Bridges 52 depositado en E, por encontrarse en excelente estado de conservación y por ser uno de los materiales en los que seguramente W. J. Hooker describió la especie, ya que cumplía funciones como profesor en Glasgow durante este período. Posiblemente los materiales de Bridges s.n. depositados en K (000486665 foto! y 000486666 foto!) correspondan a Bridges 52, ya que coinciden las características y la localidad de colecta.

3. Si bien B. L. Robinson (1906) cita la existencia de un fragmento de Gillies s.n. (proveniente del material depositado en $\mathrm{K}$ ) en $\mathrm{GH}$ (no visto), según $\mathrm{B}$. Franzone (comunicación personal) no se encuentra en GH. Los materiales de Gillies s.n., que sin duda se encuentran en K, no han podido ser hallados. De acuerdo a N. Hind (comunicación personal) la dificultad de 
poder encontrar dicho espécimen podría deberse a que Gillies s.n. haya sido montado con otros ejemplares incluso de otro género, situación muy común en $\mathrm{K}$ en la época de W. J. Hooker

Etimología: del griego paradoxus, тараס̄o६os, contrario a lo esperado, extraño, inusual (Stern 1983, Gledhill 2008).

Especímenes adicionales estudiados: CHILE. Antofagasta (II Región): Antofagasta, Quebrada La Chimba, $23^{\circ} 32^{\prime}$ S $70^{\circ} 25^{\prime}$ W, 30/09/1987, S. Teillier 471 (MO, NY). Atacama (III Región): Valle de Tosquera, 12/01/1970, O. Zöllner 4097 (LP). Coquimbo (IV Región): Choapa, Illapel, 20/01/1942, E. Barros 2339 (LP); Los Vilos, Cerro Santa Inés, frente a Pichidangui, 06/01/1979, J. V. Crisci 360 (LP); Elqui, near of Los Vilos, 30/10/1976, O. Zöllner 9346 (LP, MO); Paihuano, 01/01/1945, E. Barros 3854 (LP); La Serena, 27/12/1944, E. Barros 3851 (LP); Vicuña, Cerro de la Virgen, 01/1942, E. Barros 2345 (LP); ib. 06/01/1942, E. Barros 2342 (LP); La Totorita, 07/01/1942, E. Barros 2334 (LP); Limarí, Ovalle, Carén, 18/09/1927, E. Barros 1733 (LP); ib. E. Barros 1848 (LP); ib. E. Barros 2491 (LP); 18/09/1927, sin colector 112 (LP); Fray Jorge, 15/10/1947, B. Sparre 3060 (SGO). Metropolitana de Santiago: Santiago, Cordillera de La Costa, en la Cuesta Barriga, 11/1963, O. Zöllner 1717 (LP); Las Condes, 12/01/1956, A. L. Cabrera 3488 (LP). Valparaíso (V Región): Quillota, La Calera, El Cobre, 01/09/1973, M. Mahu 9542 (LP); San Felipe de Aconcagua, Zapalear, camino a la Quebrada del Tigre, 03/01/1959, O. Boelcke 3858 (LP); Valparaíso, 1851, $R$. Philippi 406 (NY); ib. 12/1882, R. Philippi s.n. (LP). Región no especificada: Chile, sin fecha, Gays.n. (NY), 1828-1834, Gay 384 (NY). 


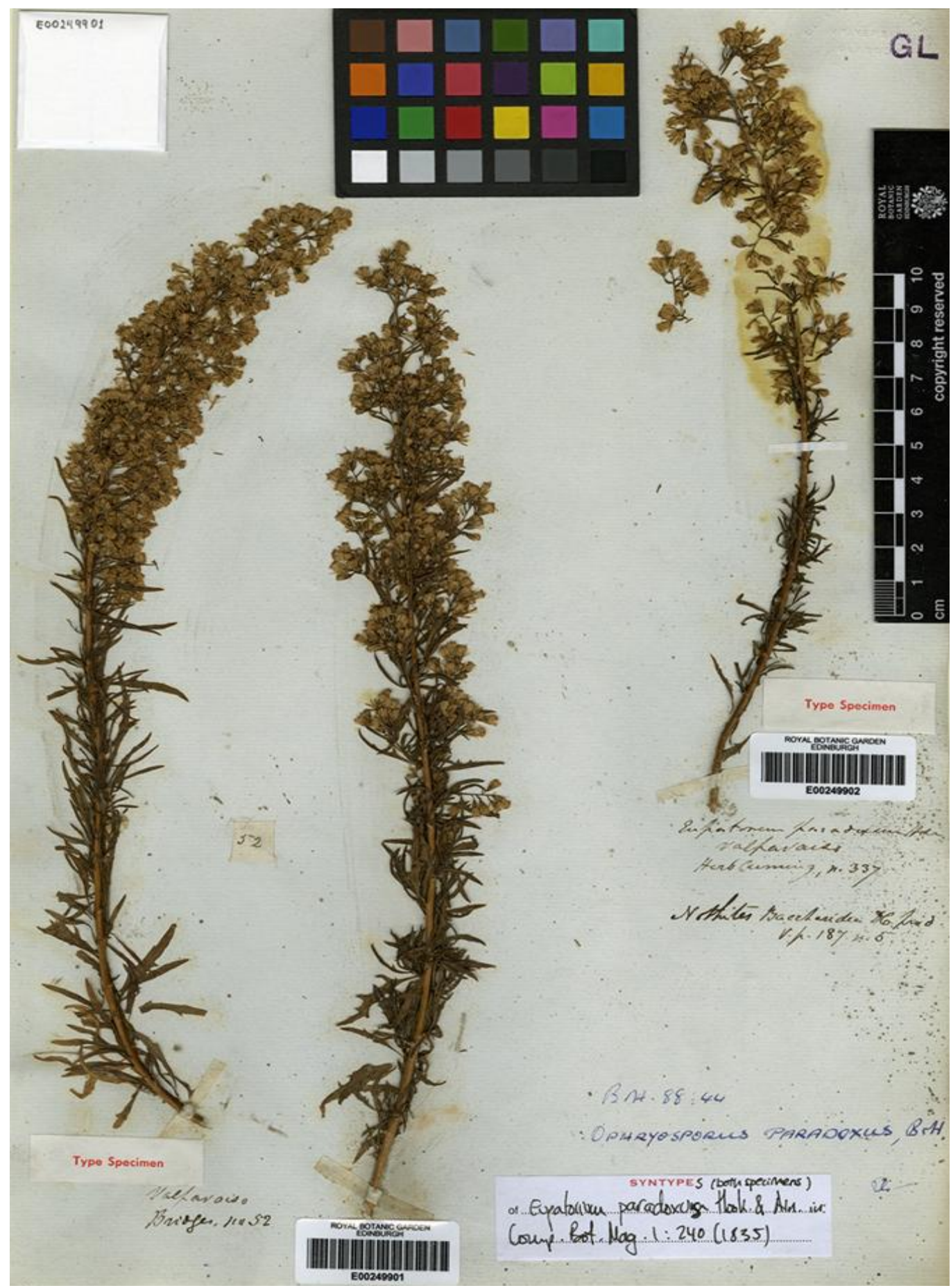

Figura 98. O. paradoxus, lectotipo. Bridges $52(\mathrm{E})$. 

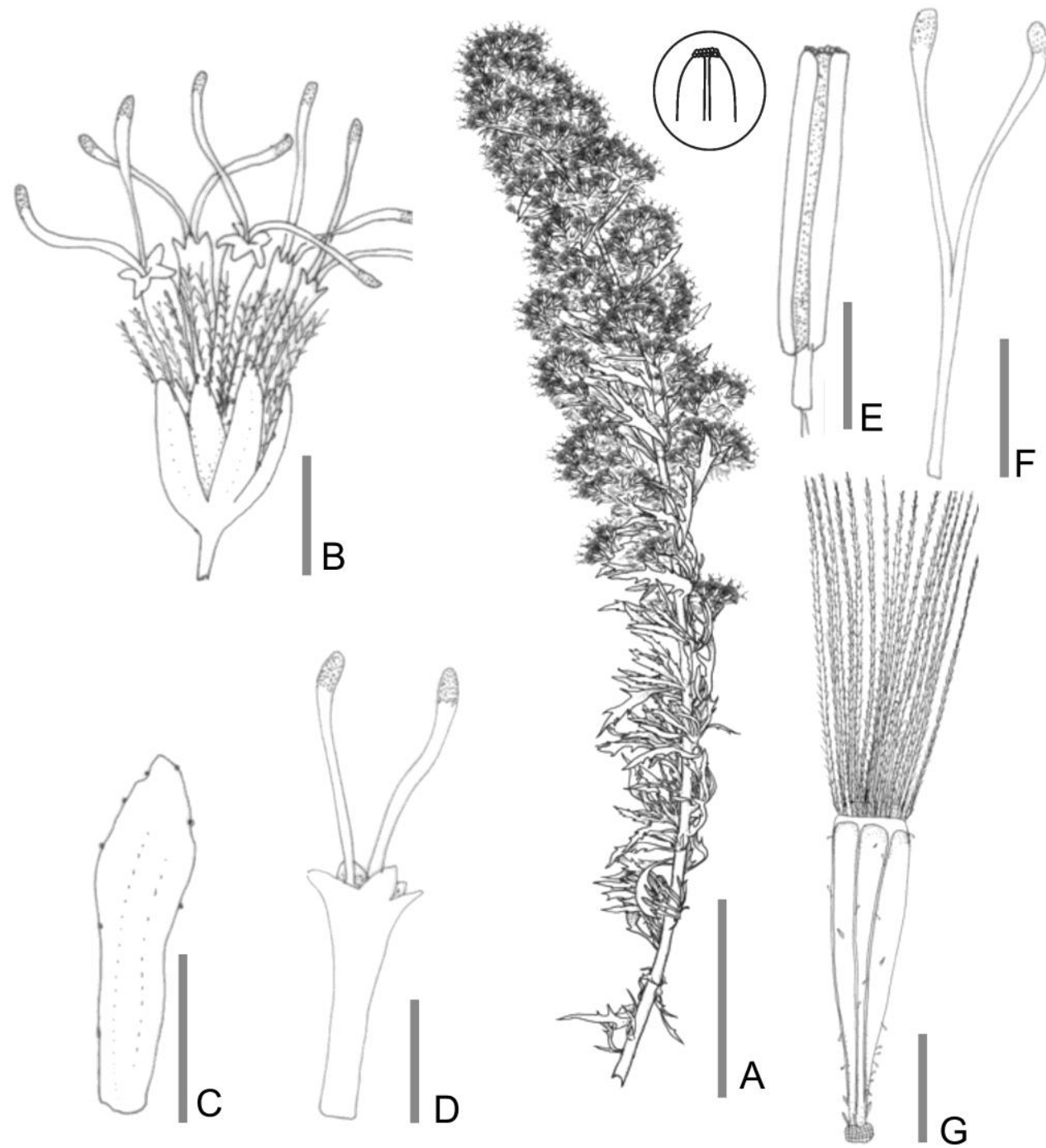

Figura 99. O. paradoxus. A. Rama florífera. B. Capítulo. C. Flor sin papus ni cipsela. D. Filarios. E. Antera. F. Estigma. G. Cipsela. Escalas: A: 2,5 cm; B-C: 2 mm; D-E: 0,7 cm; F-G: 200 m. (A-G basados en O. Boelcke 3858, LP). 


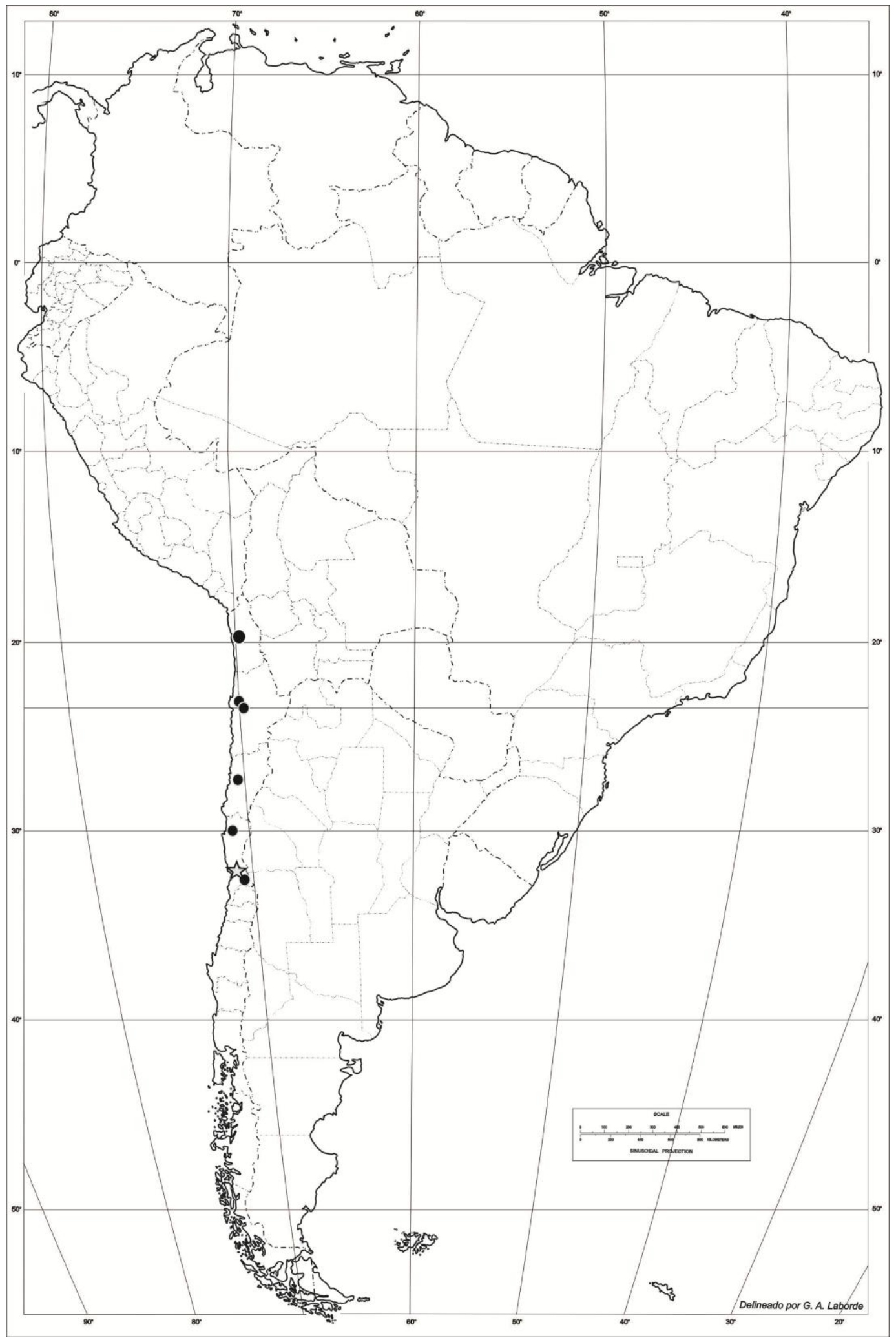

Figura 100. O. paradoxus. Distribución geográfica, la estrella indica la localidad tipo. 
Ophryosporus peruvianus (J. F. Gmel.) R. M. King \& H. Rob.

Phytologia 25: 66. 1972.

三 Flaveria peruviana J. F. Gmel.

Systema vegetabilum 2(2): 1269. 1791.

Tipo: Perú “An Peruvia” Dombey s.n. Holotipo LINN foto!. Fig. 101.

= Flaveria sp. Peruviana a Dombeyo data Juss. Genera Plantarum : 187. 1789.

= Flaveria spicata J. E. Sm. In Ress, The Cyclopædia; or Universal Dictionary of Arts, Sciences, and Literature. XV. 1810.

= Piqueria artemisioides Kunth. Nova Genera et Species Plantarum IV: 153-154. 1820.

= Piqueria peruviana (J. F. Gmel.) B. L. Rob. Contributions from the Gray Herbarium of Harvard University. New Series 32. Proceedings of the American Academy of Arts and Sciences 42: 13. 1906

Arbusto erecto (1-2 m). Tallo con entrenudos entre 2 y $4 \mathrm{~cm}$, ramificaciones secundarias opuestas, ramas glabras, marrón claro. Hojas alternas, en fascículos, pecioladas, pecíolo $0,5-1,5 \mathrm{~cm}$, láminas lineares, 0,2-0,3 × 2-4 cm, base cuneada, ápice obtuso, margen denticulado, plano; consistencia herbácea, venación acródroma imperfecta suprabasal; pubescente, tricomas eglandulares simples cónicos. Inflorescencia tirsoidea densa, compuesta de corimbos; terminal y axilar, con hojas persistentes bien desarrolladas. Capítulos ca. 350-400, pedunculados (1-1,5 mm), 1,2 x $3 \mathrm{~mm}$. Involucro cilíndrico, 1,2 × 2,2 mm; filarios 4, subimbricados; en una serie de filarios, ovados, 1,2 $\times 0,7 \mathrm{~mm}$; ápice fimbriado, margen entero, consistencia herbácea, a veces con porciones esclerificadas en el centro; pubescente, tricomas eglandulares simples cónicos. Flores 4, hermafroditas, corola blanquecina, infundibuliforme, sin paso gradual entre tubo y limbo, tubo 0,5 x 0,3 mm, limbo $1 \times 0,8 \mathrm{~mm}, 5$-dentada, lóbulo 0,3 x 0,5 mm; glandulosa en la base del tubo, tricomas glandulares (tipo $\alpha$ ). Estambres 5 , anteras 
$2 \times 0,3 \mathrm{~mm}$, collar anteral cilíndrico, base de la teca auriculada; apéndice conectival rudimentario, entero. Estilo $4,2 \mathrm{~mm}$, largamente exerto, ramas del estilo fuertemente clavadas en el ápice, ápices más oscuros que el resto de las ramas, las ramas 2,2 $\mathrm{mm}$. Cipsela negra no estipitada, piriforme, 1,8 mm, marcadamente 5-costada; glabra; carpopodio cilíndrico, central. Papus nulo. Fig. 102.

Fenología: Florece de enero a agosto.

Distribución: Ecuador (provincias de Chimborazo, Esmeraldas, Guayas y Loja) y Perú (departamentos de Ancash, Apurimac, Cajamarca, Cuzco, Ica/Ayacucho, La Libertad, Lima y Piura), a 0-3500 msnm, hábitat costero, pedregoso y bosque altoandino conformado por Escallonia L. f., Gynoxys Cass., Citharexylum L.y Polylepis Ruiz \& Pav. Fig. 103.

Nombres comunes: "Chichís" (Ferreyra 6197 MO), "chincha-chincha" (Mori 194 MO), "shacashaca" (Beltrán, 1994), "sheklla" (Rojas et al. 2003), "té inca" (Montenegro Lozada, 2001).

\section{Notas:}

1. Frecuentemente descripta con flores amarillas, pero dicha coloración pertenece al papus y a las ramas del estilo.

Etimología: Hace referencia a Perú (Gledhill 2008), donde fuera colectado el material tipo por Dombey.

Estado de Conservación: Suele habitar zonas disturbadas por el hombre, cerca de las chacras.

Compuestos químicos de interés: Herz (2004) cita la presencia de cumarinas y cromenos. Bohlmann et al. (1984) hacen referencia a p-hidroxiacetofenonas en las partes aéreas.

Usos: Rojas et al. (2003), hacen referencia al uso de hojas y tallos como antiséptico y desinflamatorio. También indican la actividad antibacterial y 
antimicótica de los extractos crudos de etanol. A su vez, en ciertas páginas de internet (www.mamaherb.com) se citan el uso de raíces pulverizadas para paliar llos efectos de otitis, resfriados y conjuntivitis.

Especímenes adicionales estudiados: ECUADOR. Chimborazo: along road between Alausí \& Huigra, SW of Alausí, $3.7 \mathrm{~km}$ SW of Sibambe, $18.5 \mathrm{~km}$ NE of Huigra, 02 $13^{\prime} \mathrm{S} 78^{\circ} 49^{\prime} \mathrm{W}, 18 / 07 / 1986$, T. B. Croat 6556 (NY); Carretero Guasuntos Chunchi, 01/08/1987, A. Freire F. et al. 676 (NY); just N of Chunchi, 12/08/1978, J. D. Boeke \& J. Jaramillo A. 2653 (NY). Esmeraldas: about 1 km S of the city of Esmeralda, 11/09/1974, J. Hudson 717 (MO). Guayas: Guayaquil, 30/10/1933, H. F. J. Schimpff 360 (MO). Loja: road to La Toma-Loja, 79 19' W 03 59' S, 13/08/1988, J. E. Madsen 75039 (NY). PERU. Ancash: Bolognesi, Chiquián, 04/08/1949, R. Ferreyra 6197 (MO). Carhuaz, along Peru highway \# 3 , ca. 6 km N of Carhuaz, 10/01/1982, R. M. King \& J. L. Collins 9029 (MO). Muaraz, Los Pinos, 14/12/1986, E. Cadillo Moreno 18 (MO). Apurimac: Aymaraes, arriba de Chalhuanca, 09/08/1954, R. Ferreyra 9957 (MO); dry slopes overlooking río Chalhuanca, 15 km NW of Chalhuanca, bellow villaje of Pakayca, 24/06/1978, A. Gentry et al. 23321 (MO). Cajamarca: Contumazá, arriba de Cascas, ruta a Contumazá, 24/06/1982, A. López M. et al. 9002 (MO), ib. arriba de Trinidad, 06/07/1977, A. Sagástegui A., E. Alvitez \& J. Mostacero 8954 (MO). Cuzco: Anta, Limatambo, 13 33' 55' S 72 34' 27'W, 20/12/2002, W. Galiano et al. 4584 (MO). Calca, Pisac-Calca, 10/06/1981, L. v. d. Hoogte \& C. Roersch 381 (NY). Huayllbamba entre quebrada Huayoccari, Lagunas de Yanacocha y Kellococha, Urubamba, 20/08/1988, A. Tupayacachi H. 677 (MO). Paruro, Arabito, 07/1937, C. Vargas C. 449 (MO). Ica/Ayacucho: $43 \mathrm{~km}$ of Nazca on road to Puquio, 22/06/1978, A. Gentry et al. 23258 (MO). La Libertad: Otuzco, Otuzco, ribera del río Pollo, 25/09/1997, E. Rodríguez R. F. Luján \& D. Mercado 1860 (MO). Trujillo, Cerro Pesqueda, about $1 \mathrm{~km} \mathrm{~N}$ of Trujillo, 30/11/1974, J. Hudson 1061 (MO); Cerro Chiputur, 11/11/1983, A. Sagástegui A. \& J. Mostacero L. 11052 (NY). Lima: Amancaes, cerca de Lima, 28/01/1954, R. Ferreyra 9622 (MO). Cajatambo, 05/08/1950, R. Ferreyra 8012 (MO). Chancay, Huayopampa, Huaral, 20/03/1947, R. Ferreyra 1986 (MO). Huarochiri, arriba de Infiernillo, entre San Mateo - 
Casapalaca, 08/08/1949, R. Ferreyra 6241 (MOL); ca. 3 km W of San Mateo, ca. $107 \mathrm{~km}$ E of Lima on road to La Oroya, 07/07/1981, M. Dillon 2500 (MO); along Peru highway \#20, ca. 17 km generally SW of San Mateo, 03/01/1982, R. M. King \& J. L. Collins 9001 (MO); cerros de Surco, km 74 carretera Lima-Oroya, 07/08/1960, E. Cerrate 3416 (MO). Rúcuma, camino Canta-Obrajillo, 09/07/1963, I. Mori R. 194 (MO). Oyón, Bosque de Los Nogales, Churín, 05/08/1950, R. Ferreyra 8012 (MOL). Piura: Huancabamba, alrededores de Huancabamba, 21/07/1975, A. Sagástegui A., J. Cabanillas S. \& O. Dios C. 8167 (MO); valley of río Huancabamba, along road just below Huancabamba, $05^{\circ} 15^{\prime} S 79^{\circ} 27^{\prime} \mathrm{W}$, 07/07/1947, F. R. Fosberg 27691 (NY). 


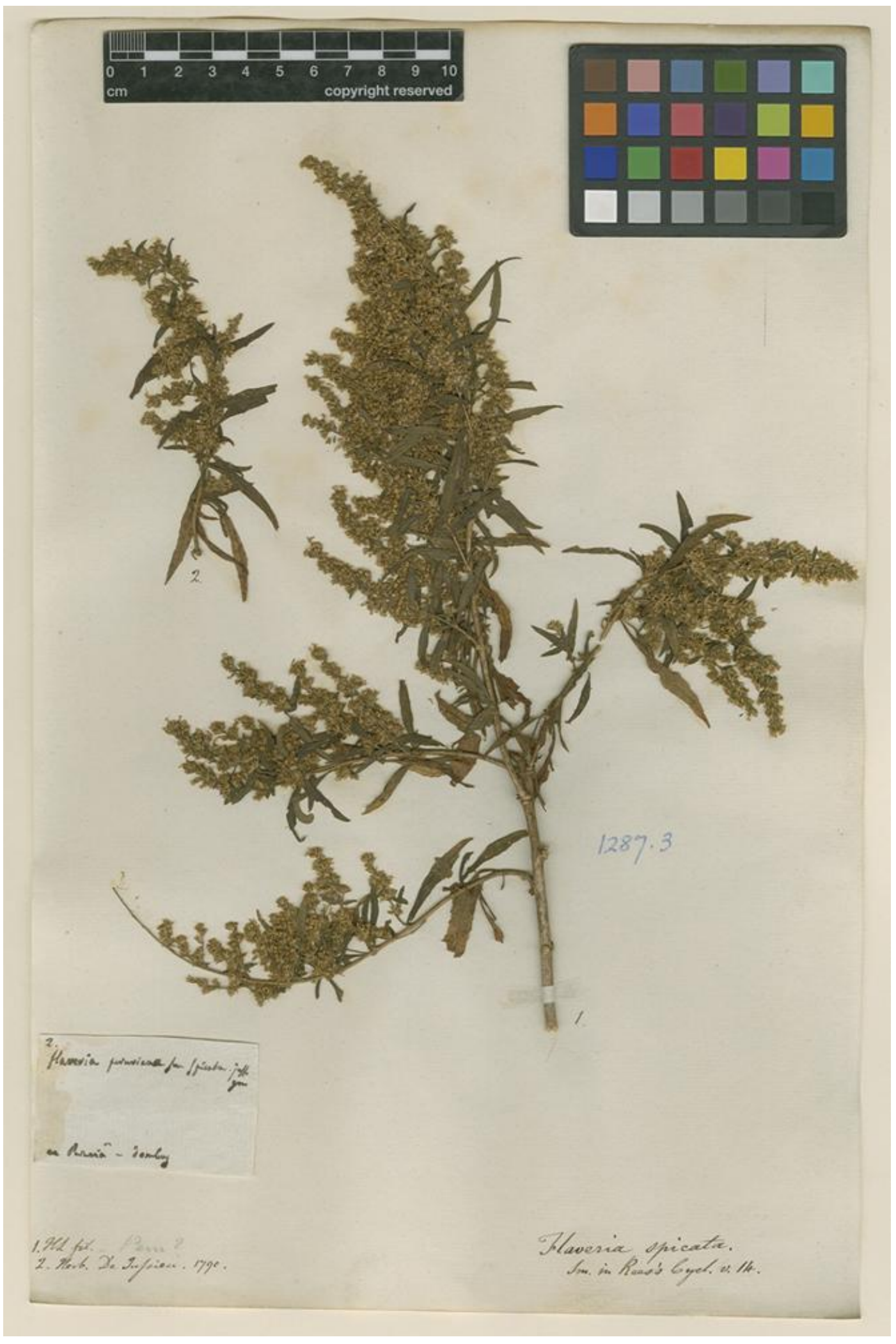

Figura 101. O. peruvianus, holotipo. Dombey s.n. (LINN). 


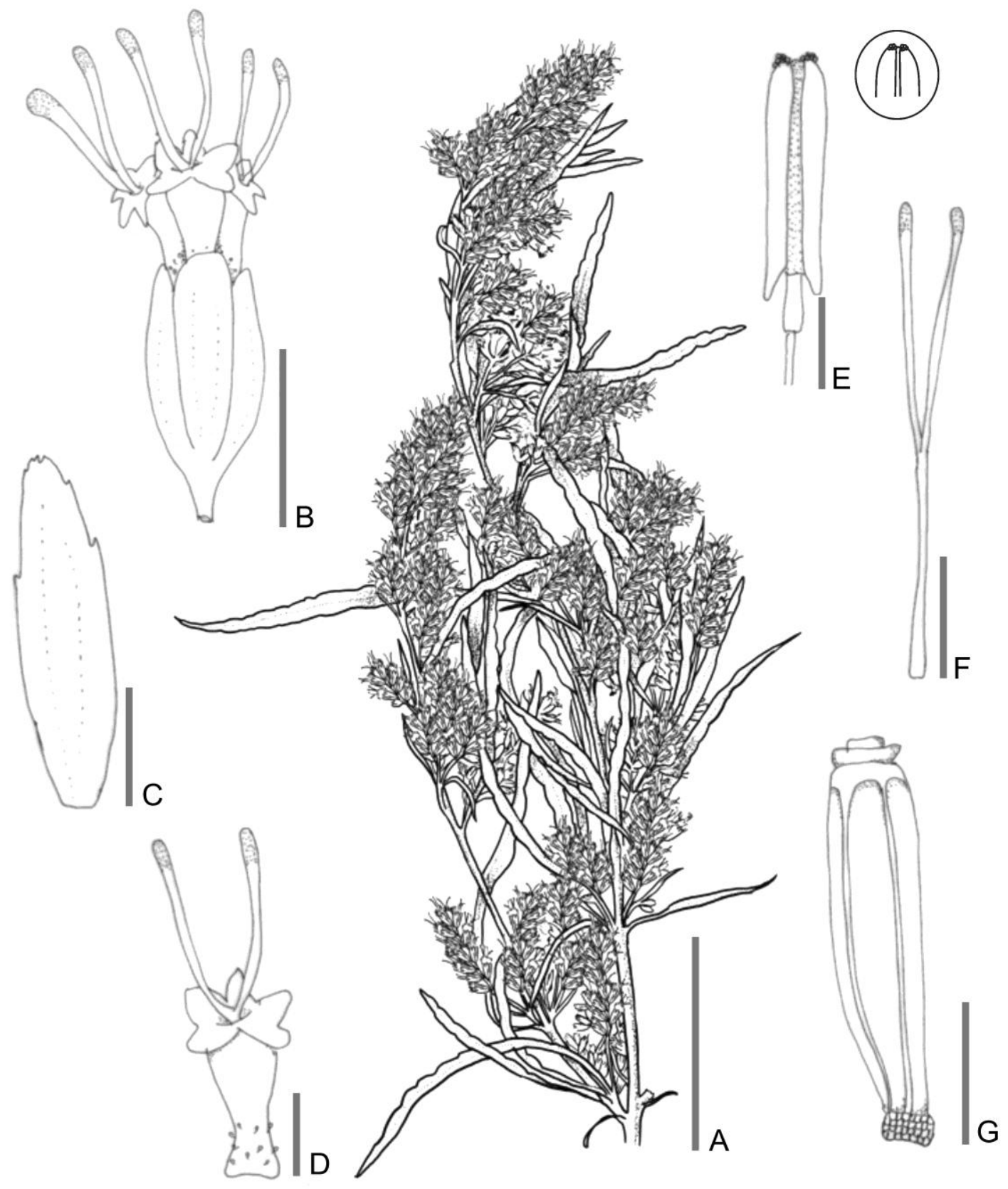

Figura 102. O. peruvianus. A. Rama florífera. B. Capítulo. C. Flor sin papus ni cipsela. D. Filarios. E. Antera. F. Estigma. G. Cipsela. Escalas: A: 2,5 cm; B-C: 2 mm; D-E: 0,5 cm; F-G: 300 um. (A-G basados en J. E. Madsen 75039, NY) 


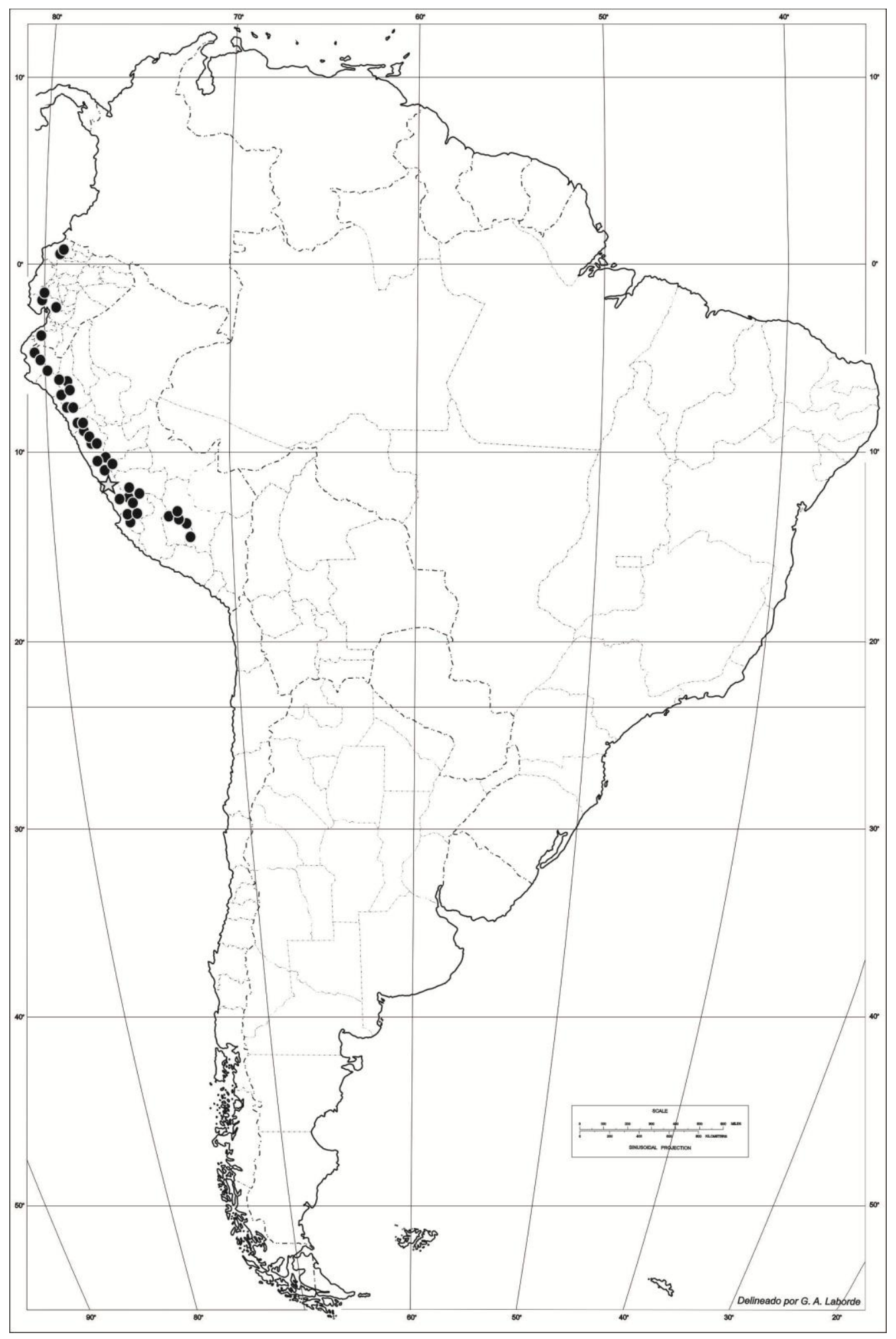

Figura 103. O. peruvianus. Distribución geográfica, la estrella indica la localidad tipo. 


\section{Ophryosporus pinifolius (Phil.) R. M. King \& H. Rob.}

Phytologia 25: 66. 1972.

\section{三 Stevia pinifolia Phil.}

Anales del Museo Nacional de Chile. Segunda Sección. Botánica. : 37. 1891.

= Piqueria pinifolia (Phil.) Hieron. ex B. L. Rob. Proced. Amer. Acad. Arts 42(1): 11.1906.

Lectotipo: Chile "Prov. Tarapacá, Usmagama. 15/03/1885", Philippi s.n. SGO 044738 foto!. Isolectotipos: B 14867 (probablemente destruido) foto!, K 000486664 foto!, SGO 066334 no visto, SGO 072220! (Plos \& Sancho, 2012). Fig. 104.

Arbusto erecto. Tallo con entrenudos entre 1 y $2 \mathrm{~cm}$, ramificaciones secundarias opuestas, ramas glabras, marrón claro. Hojas alternas, en fascículos, pecioladas, pecíolo $0,1-0,3 \mathrm{~cm}$, láminas lineares, $0,1-0,2 \times 1,5-3,5 \mathrm{~cm}$, base cuneada, ápice agudo, margen entero, plano; consistencia herbácea, venación acródroma imperfecta suprabasal; glandulosa, tricomas glandulares (tipo a). Inflorescencia tirsoidea densa, compuesta de corimbos; terminal y axilar, con hojas persistentes bien desarrolladas. Capítulos ca. 50-80, pedunculados (1-3 $\mathrm{mm}$ ), 2 × 6,5 mm. Involucro cilíndrico, 2 × 5,2 mm; filarios 7, eximbricados; en una serie de filarios, lanceolados, 1,4 × 5,5 mm; margen entero, consistencia herbácea a cartácea, a veces con porciones esclerificadas en el centro; glandulosa, tricomas glandulares (tipo $\alpha$ ). Flores 4-5, hermafroditas, corola banquecina, tubulosa 2,8 $\times$ 0,8 m, 5-dentada, lóbulo 0,5 x 0,4 mm; glandulosa sólo en la base, tricomas glandulares (tipo á). Estambres 5, anteras $2 \times 0,3 \mathrm{~mm}$, collar anteral cilíndrico, base de la teca auriculada; apéndice conectival rudimentario, con surco medial. Estilo 5,2 mm, largamente exerto, ramas del estilo fuertemente clavadas en el ápice, ápices más oscuros que el resto de las ramas, las ramas 2,2 mm. Cipsela negra estipitada, piriforme, 3,5 mm, marcadamente 5-costada; glabras; carpopodio cilíndrico, excéntrico. Papus formada por 5-6 escamas pardas, connadas en la base, 2,5-5 mm. Fig. 105. 
Fenología: Florece de diciembre a julio.

Distribución: Chile (regiones de Arica y Tarapacá), a 2710-3500 msnm. Hábitat laderas rocosas. Fig. 106.

\section{Notas:}

1. Las etiquetas de los ejemplares SGO 044738 y SGO 072220 , indican "C. Rahmer", el cual podría ser considerado como colector. Sin embargo, tal como aclara R. A. Philippi (1831) al comienzo de su trabajo, la comisión que colectó en "la gran meseta, que se extiende desde Copiapó hasta el límite con Perú", tenía por jefe a Federico Philippi y a Carlos Rahmer como preparador y subdirector del Museo Nacional. Muñoz Pizarro (1960) asigna a F. Philippi como colector de los tres materiales depositados en SGO.

2. Cabe indicar, que tanto el material depositado en $\mathrm{K}$ como en $\mathrm{B}$, indican como localidad Atacama y no Usmagama en sus etiquetas. De acuerdo a Mélica Muñoz (comunicación personal) antiguamente, durante las colectas de R. A. y F. Philippi, en los labelos de los ejemplares no se indicaba la localidad exacta, sino muchas veces una referencia geográfica más amplia.

Etimología: del griego pitys, mıTv pino y del latín folius, hojas; de hojas similares a las de pino. (Stern 1983, Gledhill 2008).

Estado de Conservación: Se la indica como escasa (Sudzuki 347 SGO). La localidad del tipo, Usmagama, se encuentra en una zona de alta actividad sísmica. Dicho pueblo, fue afectado por un terremoto en 2005 el cual lo destruyo completamente.

Especímenes adicionales estudiados: CHILE. Arica (XV Región): Laraneaqua, 09/12/1946, P. G. Huschel s.n. (SGO). Tarapacá (I Región): Champaja, 18/02/1948, F. Sudzuki 347 (SGO); camino Chapiquiña a Belén, 20/07/1991, C. Fernández \& H. Nienmeyer 77 (SGO); Quebrada de Guatacondo, 20/11/1980, S. Lailhacar 20 (SGO), lquique, Huara 1940'53,7' S 69¹1'11,0" W, 18/02/2003, M. F. Gardner \& S. G. Knees 6512 (SGO). 


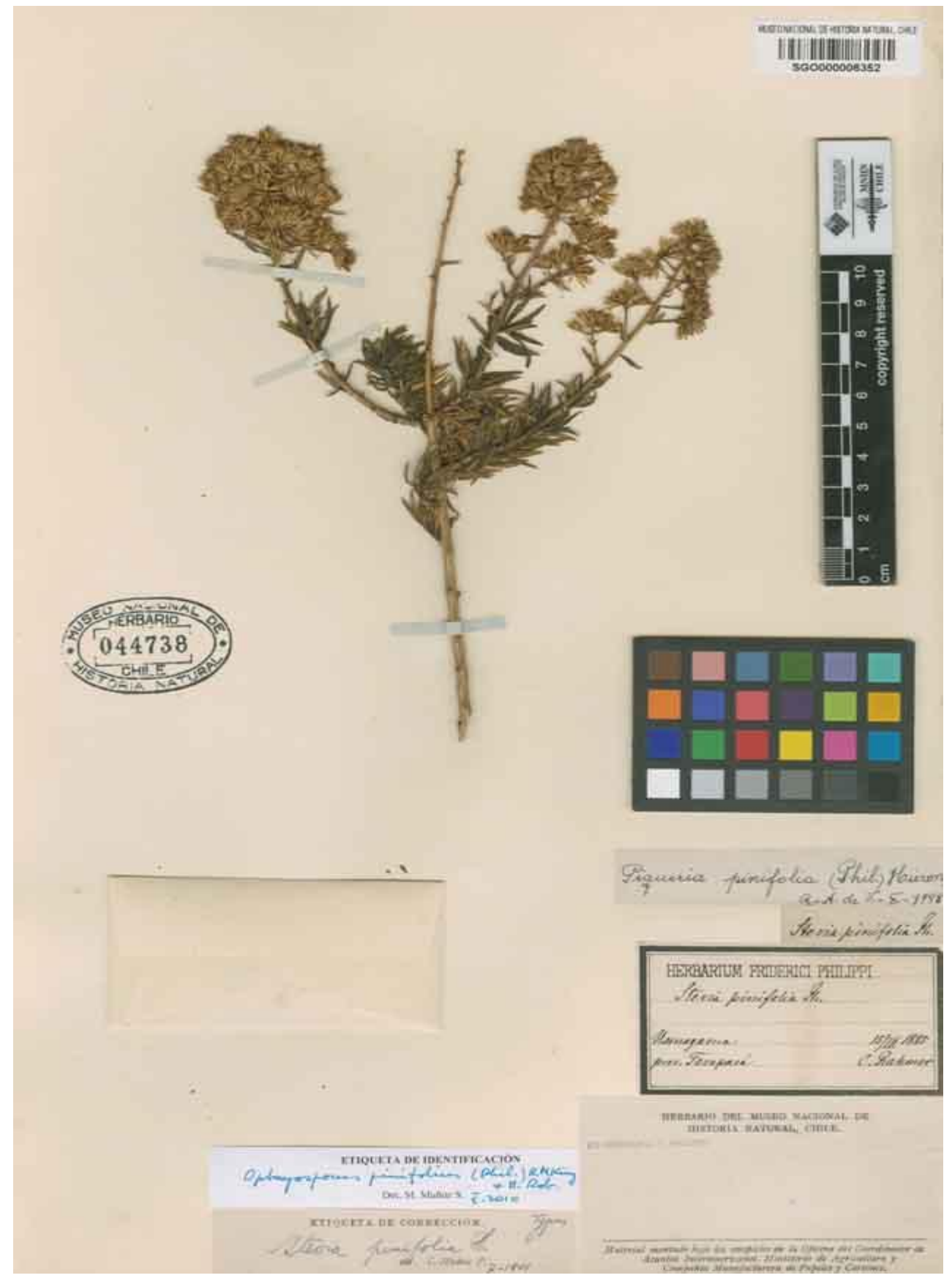

Figura 104. O. pinifolius, lectotipo. Philippi s.n. (SGO). 


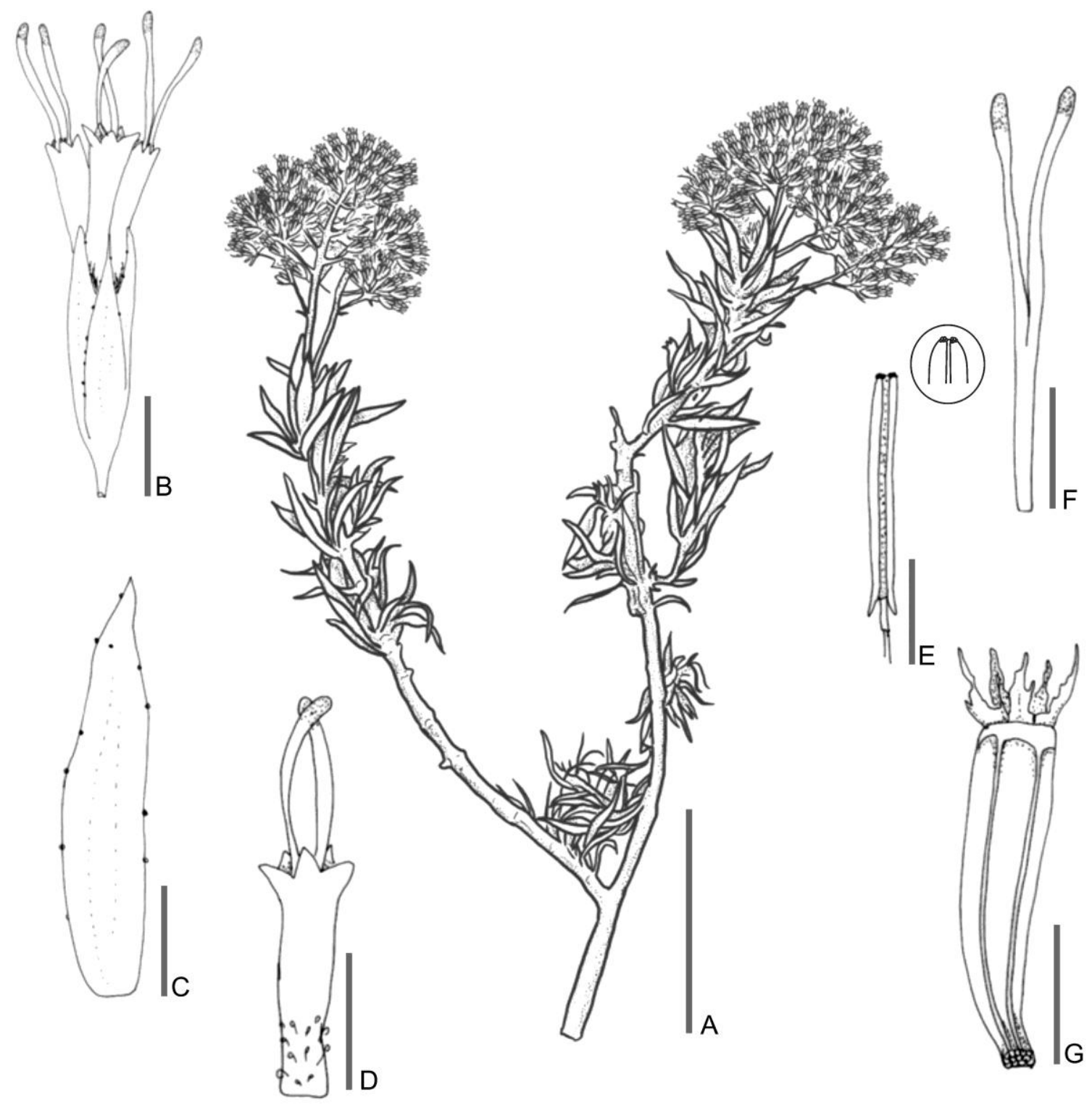

Figura 105. O. pinifolius. A. Rama florífera. B. Capítulo. C. Flor sin papus ni cipsela. D. Filarios. E. Antera. F. Estigma. G. Cipsela. Escalas: A: 2,5 cm; B-C: 2 mm; D-E: 0,7 cm; F-G: 300 m. (A-G basados en Philippi s.n., SGO). 


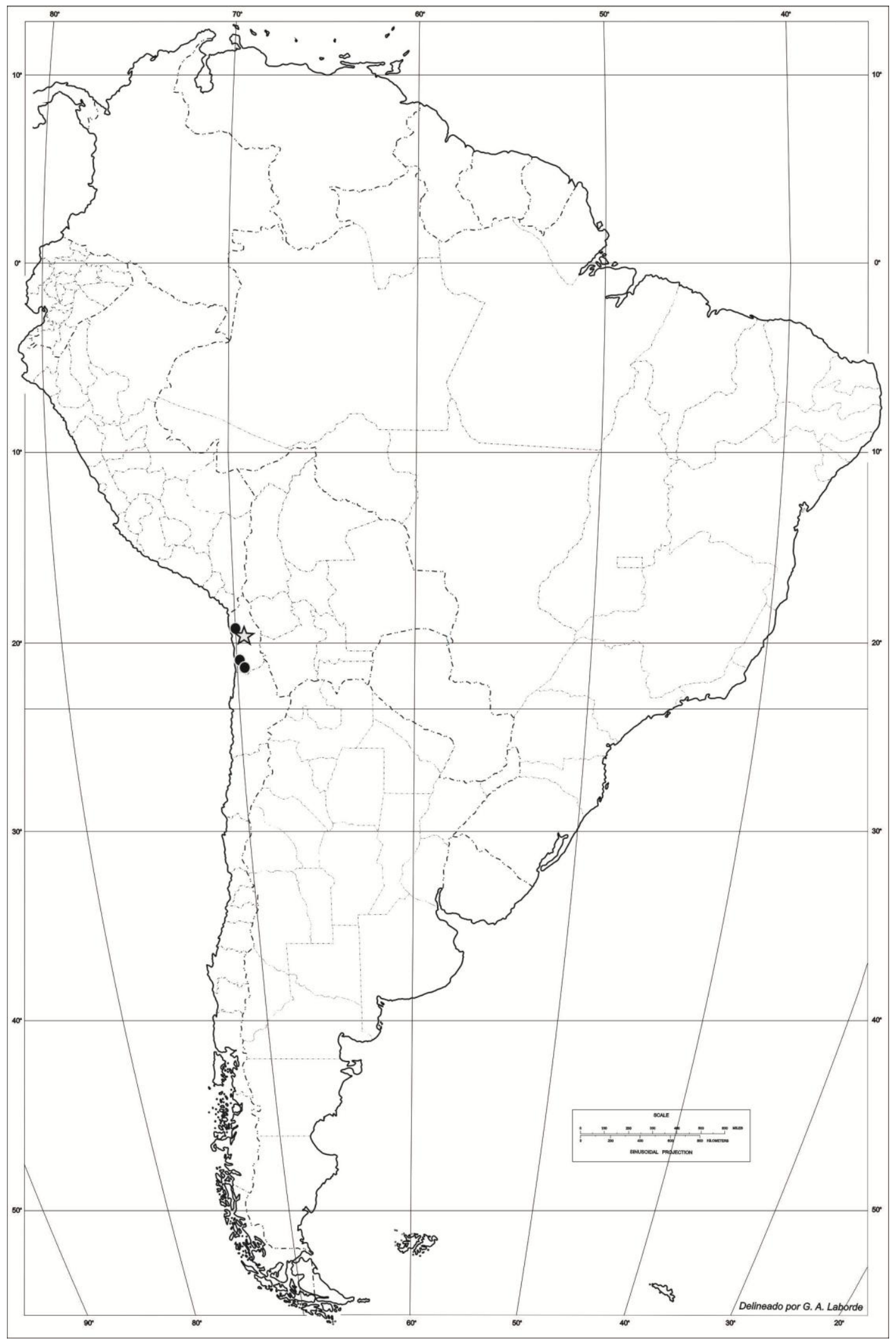

Figura 106. O. pinifolius. Distribución geográfica, la estrella indica la localidad tipo. 


\section{Ophryosporus piquerioides (DC.) Benth. ex Baker}

FI. Bras. 6(2): 188. 1876.

\section{三 Eupatorium piquerioides DC.}

Prodr. 5: 175.

Tipo: Peru "in peruviae montibus Guanoccensibus legit. cl . Haenke." Holotipo: PR no visto, isotipo G-DC foto!. Fig. 107.

= Mikania mandonii Sch. Bip. Bull. Soc. Bot. France 12: 82. 1865. Linnaea 34(5): 536. 1866. Tipo: Bolivia. Mandon 268. Holotipo: P?, isotipo: K

= Eupatorium clavulatum Griseb. Abh. Knigl. Ges. Wiss. Göttingen 19(1): 168. 1874. PI. Lorentz: 120. 1874. Tipo: Argentina, Tucumán, in m. Cuesta de Periquilla. Lorentz 178. Holotipo: GOET.

= Eupatorium clavulatum (Griseb.) Griseb. Abh. Knigl. Ges. Wiss. Göttingen 24(1): 173. 1879. Symb. Fl. Argent.: 173. 1879.

Ophryosporus mandonii (Sch. Bip.) B. D. Jacks. Index Kewensis 2: 354. 1895. Comb. illegit.

= Ophryosporus saltensis Hieron., Bot. Jahrb. Syst. 22(45): 705. 1897.

Tipo: Argentina. Salta: bei Yacone am Wege von Salta nach dem Nevado del Castillo. Lorentz u. Hieronymus 536. 27/28. Mrz. 1873. Holotipo: B?

Arbusto erecto. Tallo con entrenudos entre 6 y $11 \mathrm{~cm}$, ramificaciones secundarias opuestas, ramas tomentulosas, rojizo-púrpura. Hojas opuestas, pecioladas, pecíolo $0,1-0,4 \mathrm{~cm}$, láminas ovada a lanceolar-ovada, 1-2 x 4-8 cm, base redondeada, ápice agudo, margen aserrado, plano; consistencia herbácea, venación acródroma imperfecta suprabasal; pubescente, tricomas eglandulares simples cónicos. Inflorescencia cimoidea, compuesta de corimbos densos, terminal y axilar, con hojas persistentes poco desarrolladas. Capítulos ca. 80-120, pedunculados (1-2 mm), 2 x $5 \mathrm{~mm}$. Involucro acampanado, 2 × $3 \mathrm{~mm}$; filarios 4- 
(5), eximbricados; en una serie de filarios, ovados, $2 \times 0,9 \mathrm{~mm}$; ápice fimbriado, margen entero, consistencia herbácea, a veces con porciones esclerificadas en el centro; pubescente, tricomas eglandulares simples cónicos. Flores 4-6-(7), hermafroditas, corola blanquecina, infundibuliforme, con paso gradual entre tubo y limbo, tubo $1 \times 0,6 \mathrm{~mm}$, limbo 1,7 x 0,7 mm, 5-dentada, lóbulo 0,4 x 0,2 mm; glandulosa en toda la corola, más denso en la base del tubo, tricomas glandulares (tipo a). Estambres 5, anteras $1 \times 0,2 \mathrm{~mm}$, collar anteral cilíndrico, base de la teca obtusa; apéndice conectival muy rudimentario, con surco medial. Estilo 5,3 mm, largamente exerto, ramas del estilo fuertemente clavadas en el ápice, ápices más oscuros que el resto de las ramas, las ramas $2,3 \mathrm{~mm}$. Cipsela negra no estipitada, piriforme, 1,5 mm, marcadamente 5-costada; seríceas, pelos gemelos en costillas; carpopodio anular, excéntrico. Papus formado por 30 cerdas amarillentas, connadas en la base, 1,2-1,5 mm. Fig. 108.

Fenología: Florece de diciembre a marzo.

Distribución: Argentina (provincias de Jujuy, Salta y Tucumán). Bolivia (departamentos de Cochabamba, Chuquisaca, La Paz, Pando, Santa Cruz y Tarija). Ecuador (provincia de Azuay). Perú (departamentos de Amazonas, Apurimac, Arequipa, Ayacucho, Cajamarca, Cuzco, Huánuco, Junín, Pasco y Puno), a 1000-3000 msnm. Habita en yungas, selvas montanas con Podocarpus rusbyi J. Buchholz \& N.E. Gray, Blepharocalyx salicifolius (Kunth) O. Berg., Weinmannia L., Oreopanax Decne. \& Planch., Prumnopitys exigua de Laub. ex Silba, Dicksonia L'Hér. Bosques secos dominados por Schinopsis haenkeana Engl. Fig. 109.

\section{Notas:}

1. De acuerdo a Cabrera (1978), esta especie es muy característica por sus hojas lanceoladas y sus capítulos diminutos numerosísimos.

2. Olor pungente y agradable (Mexia $8125 \mathrm{G}$ ). Otros, en cambio, lo consideran desagradable, a orina (Nee $35615 \mathrm{G}$ ) o a carne podrida (Calatayud et al. $1354 \mathrm{MO})$ 
3. Una vez seca, el material puede quedar en un color verde claro o tornarse amarronado.

4. Prefiere zonas húmedas y suelos con mucho humus (Jardim \& Abbott 2034 $\mathrm{MO})$.

5. Citado como Willoughbya pallida Rusby, nombre aparentemente nunca publicado (Bang 2342 NY) según labelo de J. Prusky (1984).

Etimología: Recuerda al género Piqueria.

Estado de Conservación: De acuerdo a Delucchi \& Plos (2011), le corresponde la categoría EN de la UICN, en peligro.

Compuestos químicos de interés: Herz (2004) cita la presencia de benzofuranos y dihidrobenzofuranos. Sigstad et al. (1992) incluye a las lactonas sesquiterpénicas. Rojas de Arias et al. (1994) indica la actividad in vitro y mutagenicidad de los extractos obtenidos de partes aéreas, contra los tripomastigotas de Trypanosoma cruzi.

Especímenes adicionales estudiados: ARGENTINA. Jujuy: Capital, camino al Cucho, 12/05/1962, A. L. Cabrera et al. 14474 (LP); camino a Tilquiza, 17/04/1975, A. L. Cabrera et al. 25990 (LP, MCNS). Humahuaca, La Capilla, 19/04/1969, A. L. Cabrera \& H. A. Fabris 19993 (LP). Santa Bárbara, de Santa Clara a Abra de los Morteros, 20/06/1973, A. L. Cabrera \& E. M. Zardini 23852 (LP). Valle Grande, Valle Grande de río Jordán, 16/05/1972, A. L. Cabrera \& H. A. Fabris 22694 (LP); ib. San Francisco, 14/05/1972, A. L. Cabrera \& H. A. Fabris 22661 (LP). Salta: Capital, alrededores de Salta, 1967-68, R. J. Lavaque s.n. (NY); Cerro 20 de Febrero, 100 m alrededor de la cima, 30/04/1989, L. Novara \& S. Bruno 8862 (G, MCNS); ib. 30/05/1986, F. Varela 1470 (MCNS), Quebrada de San Lorenzo, 19/06/1989, L. J. Novara \& S. B. Bruno 8978 (MCNS); Finca La Troja-Vipos, 17/04/1975, Falco-Colina s.n. (MCNS). Cachi, La Paya 5 km al oeste del Río Calchaquí, 18/11/1977, L. Novara 459 (JUA). Chicoana, Cuesta del Obispo, 30/10/1991, A. Charpin 23067 (G). La Caldera, Los Yacones, 22/09/1980, E. M. Zardini 1193 (MO, LP); Ruta 9, km 1236, 4 km al N del dique Campo Alegre, antes 
de Alto La Viña, 30/05/2005, L. J. Novara 12275 (MCNS). Orán, Santa Cruz, cerro La Cueva, 21/04/1945, S. A. Pierotti 1317 (LIL; LP); ib. S. A. Pierotti 1330 (LP). Rosario de Lerma, Quebrada del Toro, ruta $51 \mathrm{~km}$ 28, unos $3 \mathrm{~km}$ al W de Campo Quijano, 26/04/1987, L. J. Novara 6567 (G). San Martín, Tartagal, río Tartagal, 18/08/1944, S. Varela 5242 (NY). Tucumán: Burruyacú, La Ramada, 17/07/1948, R. Rocha 405 (LIL); Sierra de Medina, 18/05/1989, C. Catalán 101 (LIL). Siambón, Raco, Los Rastrojos, 12/09/1985, C. Catalán et al. 161 (LIL). Tafí, camino a La Ovejería, 28/05/1924, S. Venturi 3403 (LIL); San Javier, 09/05/1949, R. Rocha 816 (LIL). Duraznillo, 16/03/1950, R. Rocha 2486 (LIL, LP). Trancas, Pié de la Cuesta, 19/04/1926, S. Venturi 4175 (LP); ib. S. Venturi 4184 (LIL, LP), San Pedro de Colalao, verano de 1916, L. Castillón s.n. (LIL). Yerba Buena, cumbre Cerro San Javier, 03/03/1945, D. Olea s.n. (NY). BOLIVIA. Cochabamba: Incachaca, 13/08/1950, W. M. A. Brooke 6677 (NY). Los Molinos, valle de Cochabamba, 30/05/1972, sin colector s.n. (NY). Chuquisaca: H. Siles, roadside before the large waterfall, río Los Pinos, municipally protected area, Monteagudo, $19^{\circ} 48^{\prime} \mathrm{S} 63^{\circ} 57^{\prime}$ W, 28/08/2000, K. Wendelberger 84 (MO). La Paz: Cañamina, 07/07/1921, H. H. Rusby 105 (NY); ib. 28/07/1921, White 424 (NY). Inquisivi, Inquisivi-Miguillas road, at the bridge over the río Khara, ca. $2 \mathrm{~km}$ NW of Licoma Pampa, $16^{\circ} 48^{\prime} \mathrm{S} 67^{\circ} 13^{\prime}$ W, 15/06/1988, M. Lewis 88830 (MO, NY); along río Khatu at the mouth of the río Irupaya, ca. $3 \mathrm{~km} \mathrm{NE}$ of Quime, $16^{\circ} 57^{\prime} \mathrm{S} 67^{\circ} 12^{\prime} \mathrm{W}, 14 / 08 / 1988$, M. Lewis 881070

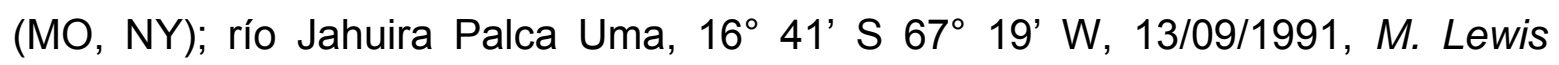
40235 (MO). Larecaja, Sorata, 09/1858 a 1863, G. Mandon 255 (G); ib. 0607/1859 a 1863, G. Mandon 268 (G, MO, NY). Manco Kapac, Copacabana, Challapampa, 14/07/1894, M. Bang 2342 (G, NY). Murillo, valle del río Zongo, 32 km al norte de la cumbre, río Jachcha Cruz, $16^{\circ} 07^{\prime} \mathrm{S} 68^{\circ} 04^{\prime} \mathrm{W}, 30 / 07 / 1988$, J. C. Solomon 18732 (G, NY). NorYungas, 12/1917, O. Buchtien 4408 (LP). SudYungas, Chulumani, 07/1933, M. Cárdenas 902 (G). Pando: Illimani, 12/1911, O. Buchtien 3283 (G, LP, NY). Santa Cruz: Florida, 5.4 km (by road) W of Todos Santos $9 \mathrm{~km}$ (by road) W of Mairana, along dirt road from Mairana to Alto de Mairana, 18 08' S 64 01' W, 08/05/1998, M. Nee 49239 (NY); 10 km (by road) W of río Bermejo, on road from Santa Cruz to Samaipata, $18^{\circ} 09^{\prime} \mathrm{S} 63^{\circ} 42^{\prime} \mathrm{W}$, 
06/08/1987, M. Nee \& G. Coimbra S. 35534 (NY); along road from Santa Cruz to Samaipata, gorge of rio Laja, $1 \mathrm{~km} \mathrm{~W}$ of bridge over rio Colorado in Bermejo, $18^{\circ}$ 08' S 63³ 39'W, 09/08/1987, M. Nee 35615 (G, LP, NY, MO); quebrada Yungas, 5

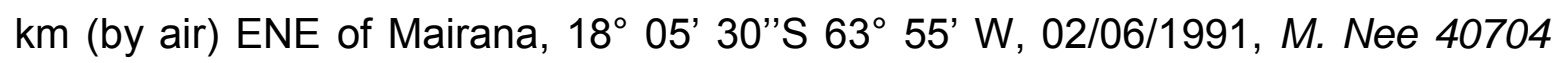
(G, NY, MO). Manuel. M. Caballero, Comarapa, 04/1911, T. Herzog 1926 (LP); P. N. Amboró Cerro Bravo, cerca de Comarapa, 20/06/1995, A. Jardim \& R. Abbott 2034 (MO). Obispo Santiesteban, Laguna Volcán, camino a la laguna, 07/2001, J. C. Catari et al. 78 (MO). Región no especificada: Santa Cruz, 05/1892, O. Kuntze s.n. (NY). Tarija: Arce, comunidad Guayavillas, $23.8 \mathrm{~km} \mathrm{~S}$ of Padcaya on road to Bermejo, W side of Serranias de Cerrillos $21^{\circ} 59^{\prime} \mathrm{S} 64^{\circ} 40^{\prime} \mathrm{W}, 27 / 04 / 1983$, J. C. Solomon 10191 (MO); ib. 05/05/1983, J. C. Solomon 10484 (MO); $5 \mathrm{~km} \mathrm{~S} \mathrm{of}$ Guayavillas, $28.3 \mathrm{~km} S$ of Padcaya, on road Bermejo, 22 $01^{\circ} \mathrm{S} 64^{\circ} 39^{\prime} \mathrm{W}$, 05/05/1983, J. C. Solomon 10505 (MO); Cercado, $10 \mathrm{~km} \mathrm{NW}$ of Tomatas, $5 \mathrm{~km} \mathrm{~N}$ of Tarija, on road through Erquis, Angosturas de Erquis, $21^{\circ} 28.5^{\prime} \mathrm{S} 64^{\circ} 50^{\prime} \mathrm{W}$, 09/05/1983, J. C. Solomon 10602 (MO, NY); ruta Tarija-Villa Montes, Entre Ríos, 21/05/1971, A. Krapovickas, L. A. Mroginski \& A. Fernández 19074 (LP). ECUADOR. Azuay: Hcda Tarqui, km 22 via Patacocha que esta en el km 27, 20/08/1987, J. Jaramillo 9987 (NY). PERU. Amazonas: Chachapoyas, valley of río Sonche, near Sonche, 31/07/1962, J. J. Wurdack 1545 (LP, NY); on the road to Caclic, 9 km west and below Chachapoyas, km 501, 01/06/1964, P. C. Hutchinson \& J. K. Wright 5462 (NY). Rodríguez de Mendoza, Mariscal Benavídez, Izcuchaca, 06 19' 40" S 77 31' 05" W, 29/08/1998, R. Vásquez \& J. Campos 25293 (NY). Apurimac: Grau, 23/04/1946, C. Vargas C. 6013 (LP). Arequipa: Calapampa, 14/07/1894, M. Bang 2342 (LIL). Ayacucho: Carrapa, between Huanta and río Apurimac, 05-06-17/05/1929, E. P. Killip \& A. C. Smith 22303 (NY). Cajamarca: Cajamarca, arriba de Santa Apolonia, 04/05/1985, A. Sagástegui A. \& C. Tellez A. 12666 (MO). Cuzco: Anta, Limatambo, 25/04/1987, L. v. d. Hoogte \& C. Roersch. 2995 (NY). Calca, between Kuyo Chico and Pisaq along path by river, 05/07/1997, E. Emshwiller 932 (NY). La Convención, 43 km from Quillabamba, 26/07/1978, J. Aronson \& P. Berry 561 (MO), Huayopata, Huyro, 130 00' S 72 33' W, 10/06/2003, G. Calatayud et al. 1354 (MO); alrededores de Amaibamba, 28/07/1943, C. Vargas 
C. 3450 (LP); hacienda Amaibamba, 18-19/07/1948, R. Scolnik 796 (LP). Urubamba, laderas pedregosas, 28/03/1962, H. Zamalloa 2010 (LP), Machu Picchu, on the slopes of Altillero, $2.5 \mathrm{~km}$ from $\mathrm{km} 99$ of the Urubamba railroad, 16/06/1982, B. Peyton \& S. Tiney Peyton 623 (MO); Machu Picchu, sin fecha, Novatti s.n. (LP); Ollanta, desde Pachar a Ollanta, a $61 \mathrm{~km}$ de Cuzco, $13^{\circ} 16^{\prime} \mathrm{S}$ 72 16’ W, 09/07/1988, P. Núñez V. 9295 (MO); Ollantaytambo, Huaytampo, 13 12' 00" S $72^{\circ} 21^{\prime} 40^{\prime \prime}$ W, 10/09/2002, J. Farfán et al. 369 (MO); ribera del río Urubamba, 07/08/1952, N. Angulo 1757 (LP). Paucartambo, quebrada Llulluchayoa, 04/06/1944, C. Vargas C. 4336 (LP). Huánuco: Churubamba, Hacienda San Carlos, waterfall rio Ysabel, 04/09/1936, Y. Mexia 8125 (G, LIL, NY); Huánuco, between Chinchao and Puente Durand, 06/07/1940, E. Asplund 12033 (G). Junín: Carpapata, above Huacapistana, 07/06/1929, E. P. Killip \& A. C. Smith 24388 (NY). Tarma, carretera Central between 1-3 km E of Palca, 06/07/1966, G. Edwin \& J. Schunke V. 3932 (NY); east of Huasahuasi, 11/08/1957, P. C. Hutchinson 1107 (NY). Pasco: Oxapampa, hilly roadside $2 \mathrm{~km}$ south of Oxapampa, near junction of Oxapampa-La Merced road and Quebrada Llamaquizú, 10 36' 55" S 75²2' 22"' W, 05/09/2008, J. Pruski et al. 4418 (MO). Puno: Carabaya, carr. a San Gaban, 19/10/1984, L. v. d. Hoogte \& C. Roersch 2208 (NY); Ollachea, $1 \mathrm{~km}$ south of village, 13/08/1980, J. D. Boeke \& S. Boeke 2967 (NY); Ollachea to San Gabon, 17-24/07/1978, M. Dillon et al. 1123 (MO, NY); ib. M. Dillon et al. 1142 (MO); ib. Chacaneque, along Chamayo river, 19/08/1980, J. D. Boeke \& S. Boeke 3134 (NY). Región no especificada: Peruvia, 1862, Mathews s.n. (NY). Yungas, 1850, A. D'Orbigny $421(\mathrm{G})$. 


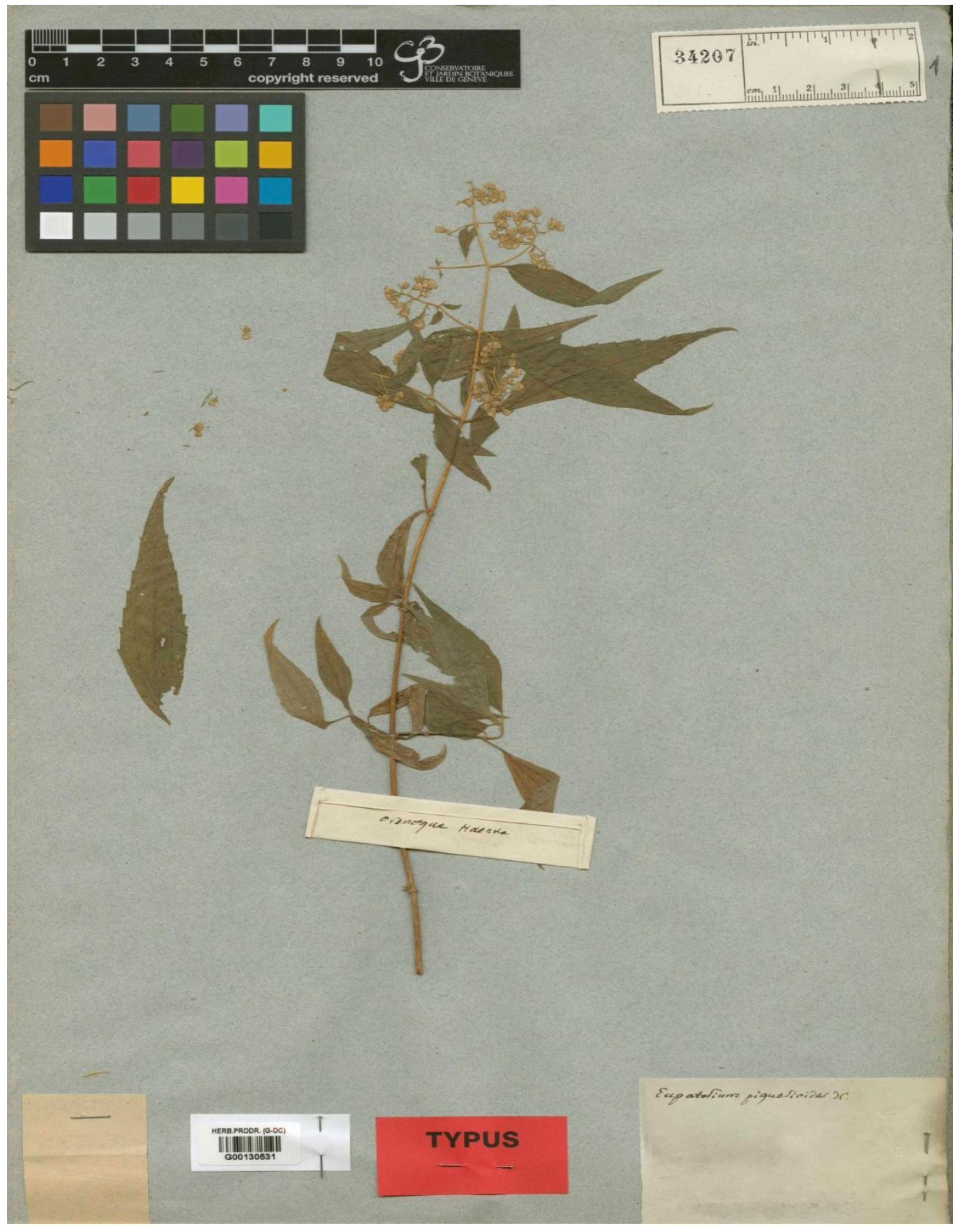

Figura 107. O. piqueiroides, isotipo. Haenke s.n. (G-DC). 

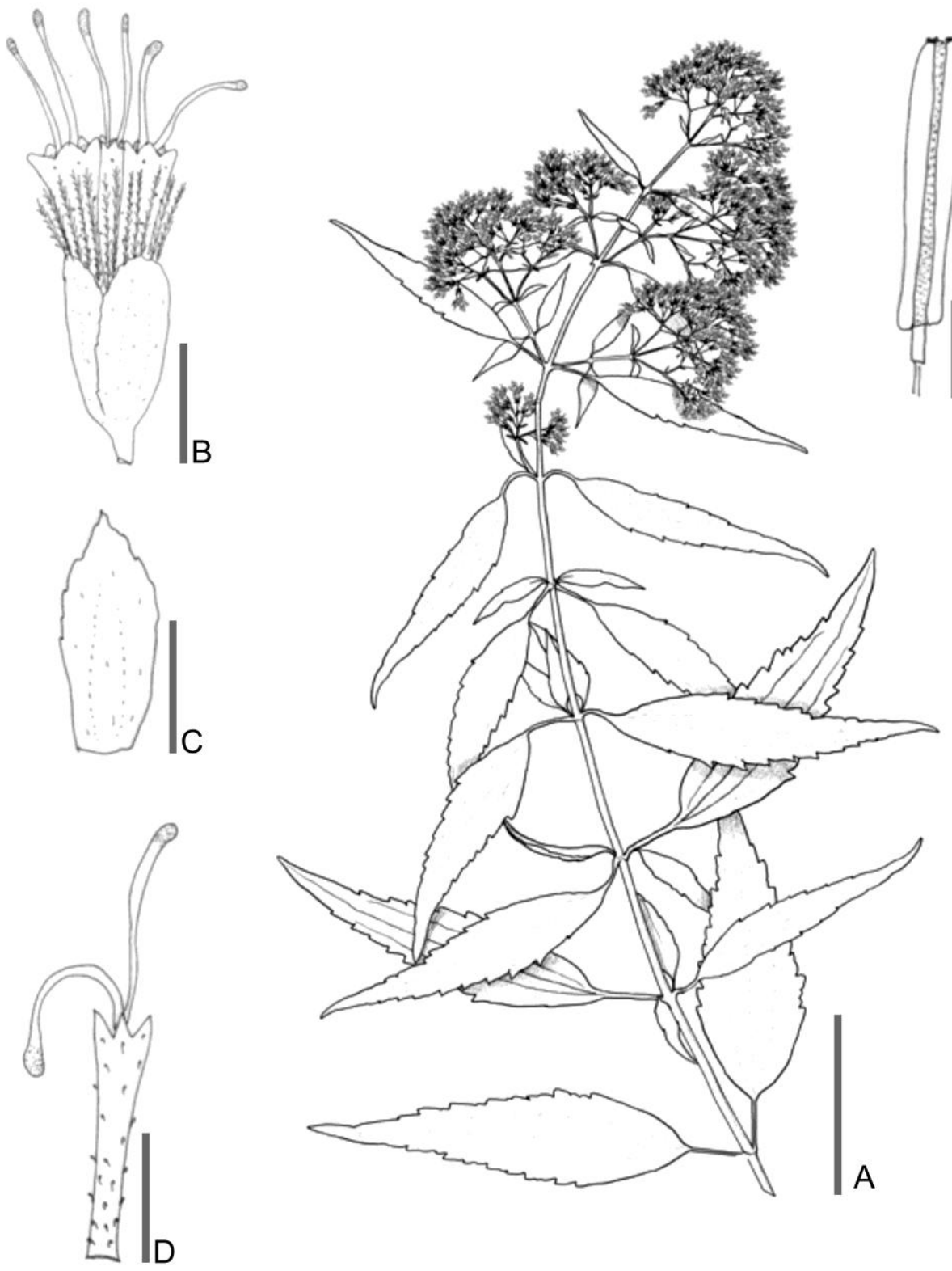

(iil)
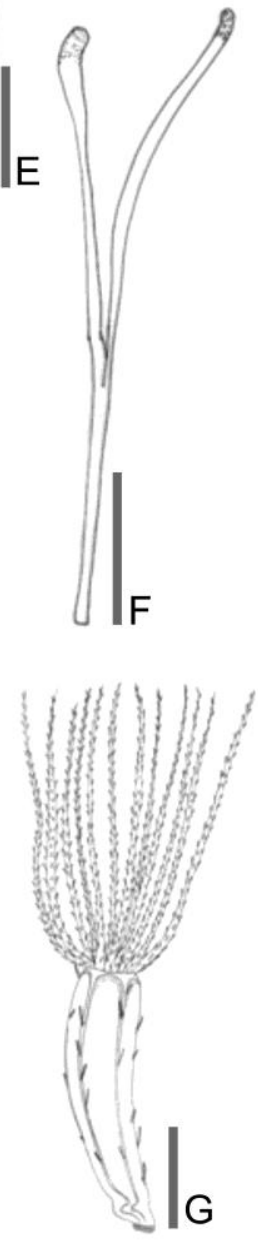

Figura 108. O. piquerioides. A. Rama florífera. B. Capítulo. C. Flor sin papus ni cipsela. D. Filarios. E. Antera. F. Estigma. G. Cipsela. Escalas: A: 2,5 cm; B-C: 2 mm; D-E: 1 cm; F-G: 300 m. (A-G basados en L. Novara \& S. bruno 8862, G). 


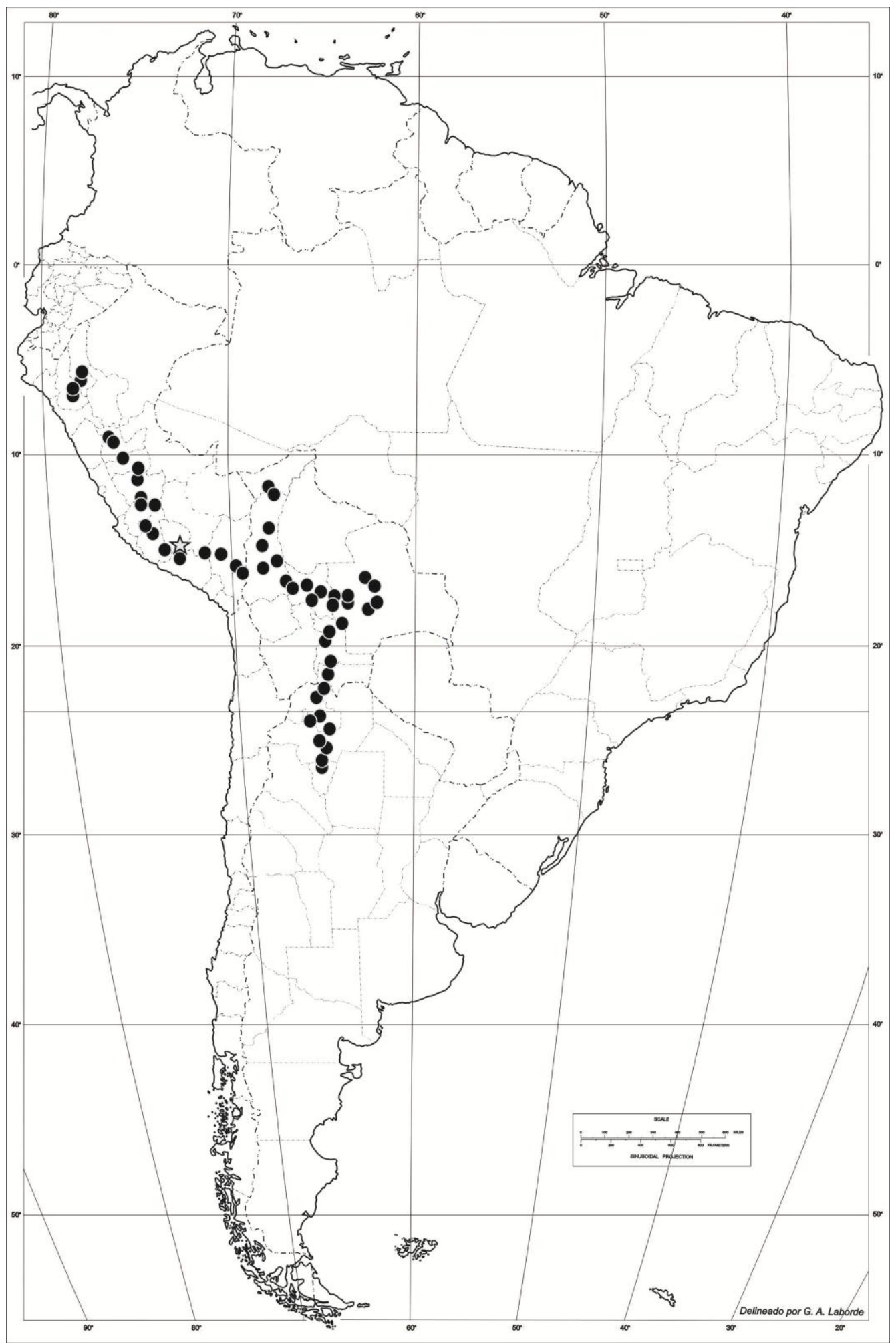

Figura 109. O. piquerioides. Distribución geográfica, la estrella indica la localidad tipo. 


\section{Ophryosporus pubescens (Sm.) R. M. King \& H. Rob.}

FI. Bras. 6(2): 188. 1876.

\section{三 Piqueria pubescens Sm.}

Prodr. 5: 175.

Tipo: Perú “Hab. Peru?”Anónimo s.n. Holotipo: LINN foto! Fig. 110.

Arbusto erecto $(1 \mathrm{~m})$. Tallo con entrenudos entre 2 y $6 \mathrm{~cm}$, ramificaciones secundarias opuestas, ramas glabras, marrón claro. Hojas opuestas, pecioladas, pecíolo 0,3-0,5 cm, láminas ovadas, 1,1-2 x 3-4 cm, base cuneada, ápice agudo, margen lobulado-crenado, plano; consistencia herbácea, venación acródroma imperfecta suprabasal; pubescente, tricomas eglandulares simples cónicos. Inflorescencia cimoidea, compuesta de corimbos densos; terminal, con hojas persistentes poco desarrolladas. Capítulos ca. 50-70, pedunculados (0,8-1,2 mm), 2,4 x $5 \mathrm{~mm}$. Involucro acampanado, 2,4 x $4 \mathrm{~mm}$; filarios 4-(5), eximbricados; en una serie de filarios, lanceolados, 2,4 × $1 \mathrm{~mm}$; ápice fimbriado, margen entero, consistencia herbácea; pubescente y glanduloso, tricomas eglandulares simples cónicos y glandulares (tipo a). Flores 4-5, hermafroditas, corola blanca, infundibuliforme, con paso gradual entre tubo y limbo, tubo 2,1 x 0,7 mm, limbo 3,1 x $1 \mathrm{~mm}, 5$-dentada, lóbulo 0,5 x $1 \mathrm{~mm}$; glandulosa en el tubo, tricomas glandulares (tipo a). Estambres 5, anteras $2 \times 0,3 \mathrm{~mm}$, collar anteral cilíndrico, levemente ensanchado hacia la base, base de la teca auriculada; apéndice conectival rudimentario, entero. Estilo $8 \mathrm{~mm}$, cortamente exerto, ramas del estilo fuertemente clavadas en el ápice, ápices más oscuros que el resto de las ramas, las ramas 3,8 $\mathrm{mm}$. Cipsela negra no estipitada, piriforme a levemente falcada, $1,5 \mathrm{~mm}$, marcadamente 5-costada; serícea, pelos gemelos en el tercio superior; carpopodio cilíndrico, central. Papus nulo. Fig. 111.

Fenología: Florece de marzo a diciembre.

Distribución: Perú (departamento de Arequipa y Lima) a 120-2500 msnm. Hábitat desierto semicálido tropical (a lo largo de la franja costera al sur del valle del 
Chicama) y matorral desértico (en las laderas de la vertiente del Pacífico) (León et al., 2006 [2007]). Fig. 112.

Notas: Arbusto conocido de la costa y vertiente occidental, de por lo menos cinco poblaciones naturalmente fragmentadas. Una de las poblaciones proviene de la cuenca del río Rimac (Beltrán et al., 2006)

Etimología: Hace referencia a la abundante pubescencia presente en la planta (Gledhill 2008).

Estado de Conservación: De acuerdo con Beltrán et al. (2006) su categoría en la UICN es EN, B1ab (iii), en peligro.

Especímenes adicionales estudiados: PERU. Arequipa: south Chala, $5 \mathrm{~km}$ from the ocean, steep quebrada to the left (N.W.) of the main canyon, 22/09/1938, C. R. Worth \& J. L. Morrison $15702(\mathrm{~F})$. 


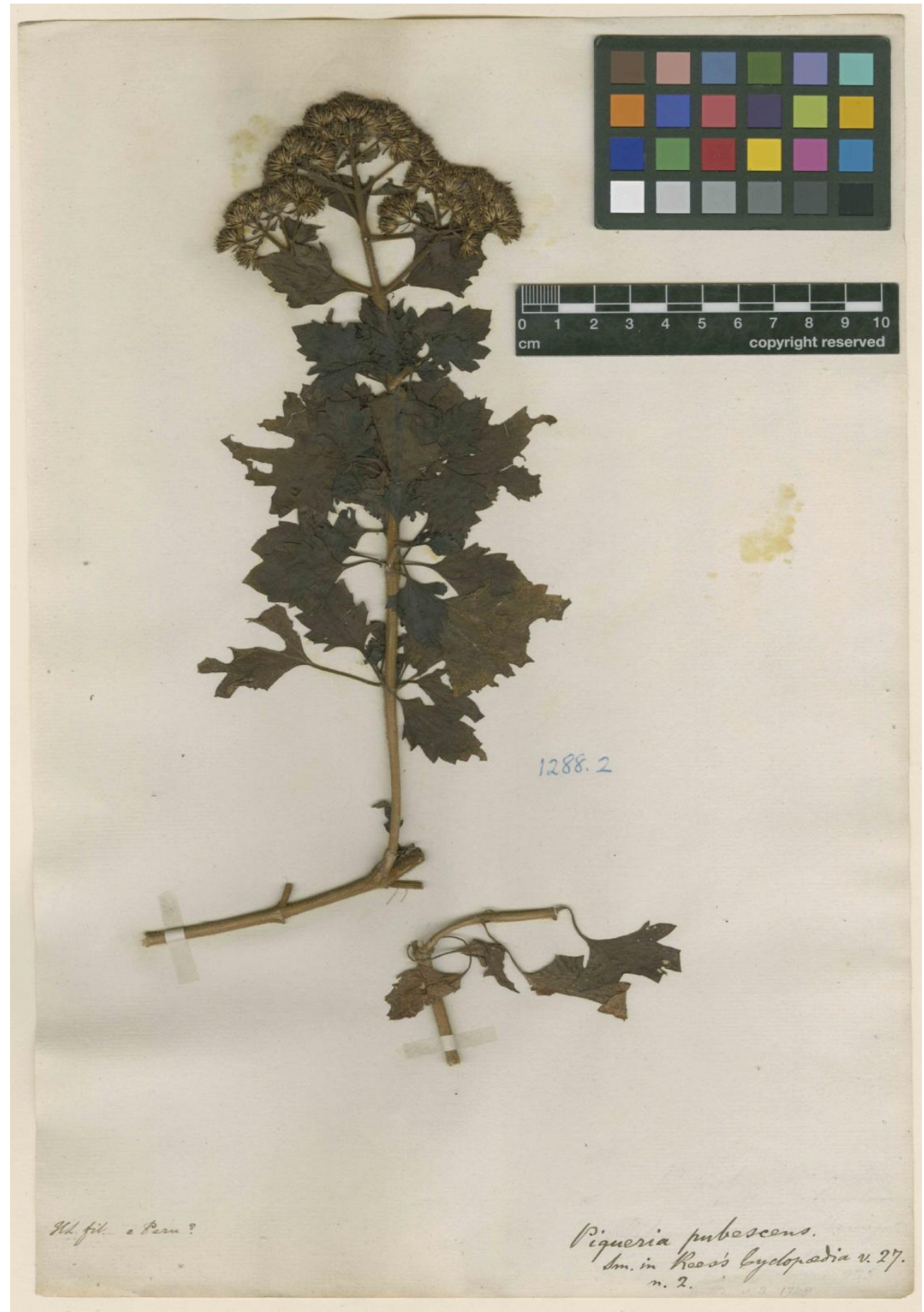

Figura 110. O. pubescens, holotipo. Anónimo s.n. (LINN). 


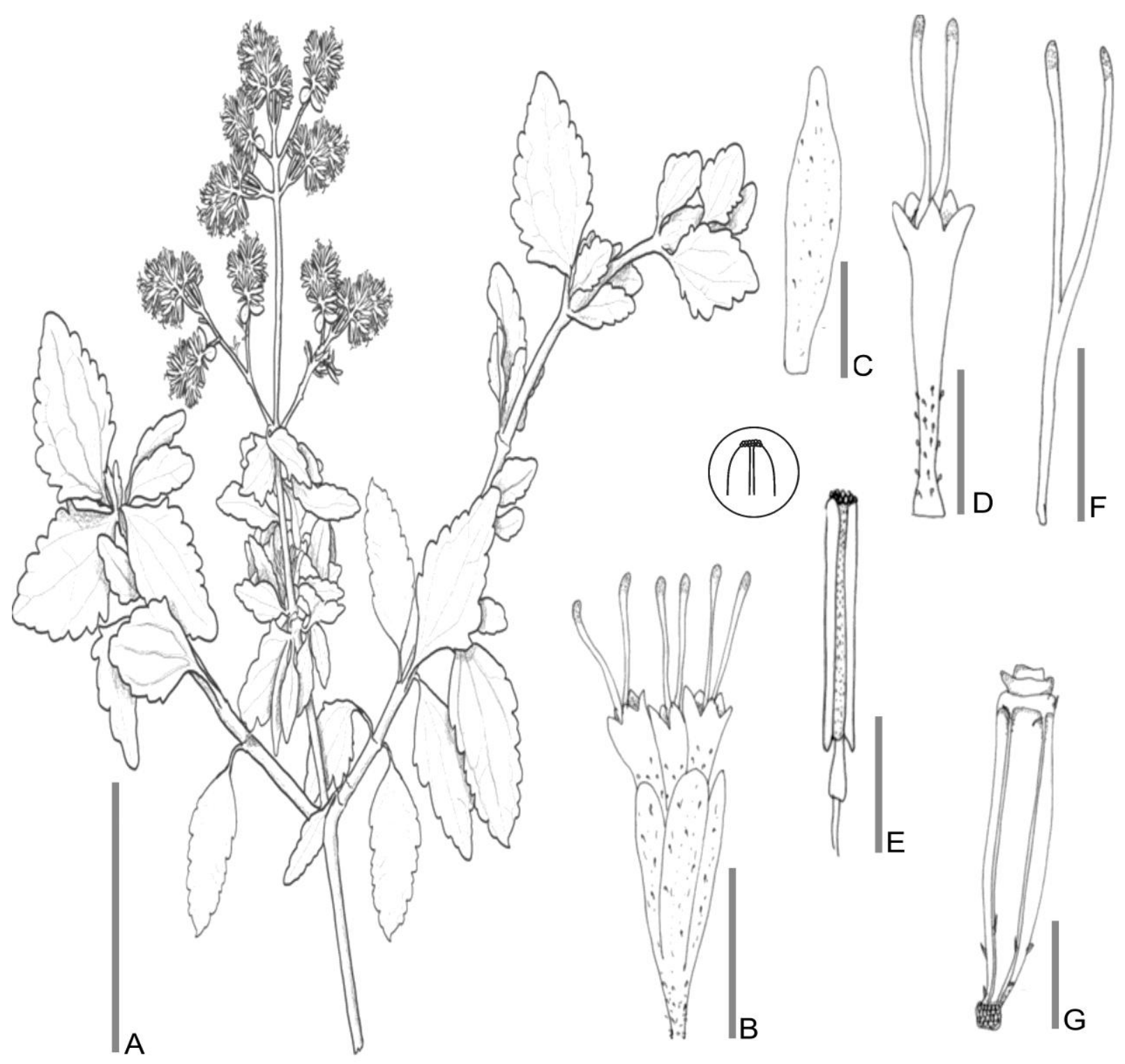

Figura 111. O. pubescens. A. Rama florífera. B. Capítulo. C. Flor sin papus ni cipsela. D. Filarios. E. Antera. F. Estigma. G. Cipsela. Escalas: A: 2,5 cm; B-C: 3 mm; D-E: $1 \mathrm{~cm}$; F-G: $300 \mu \mathrm{m}$. (A-G basados en C. R. Worth \& J. L. Morrison $15702, \mathrm{~F})$. 


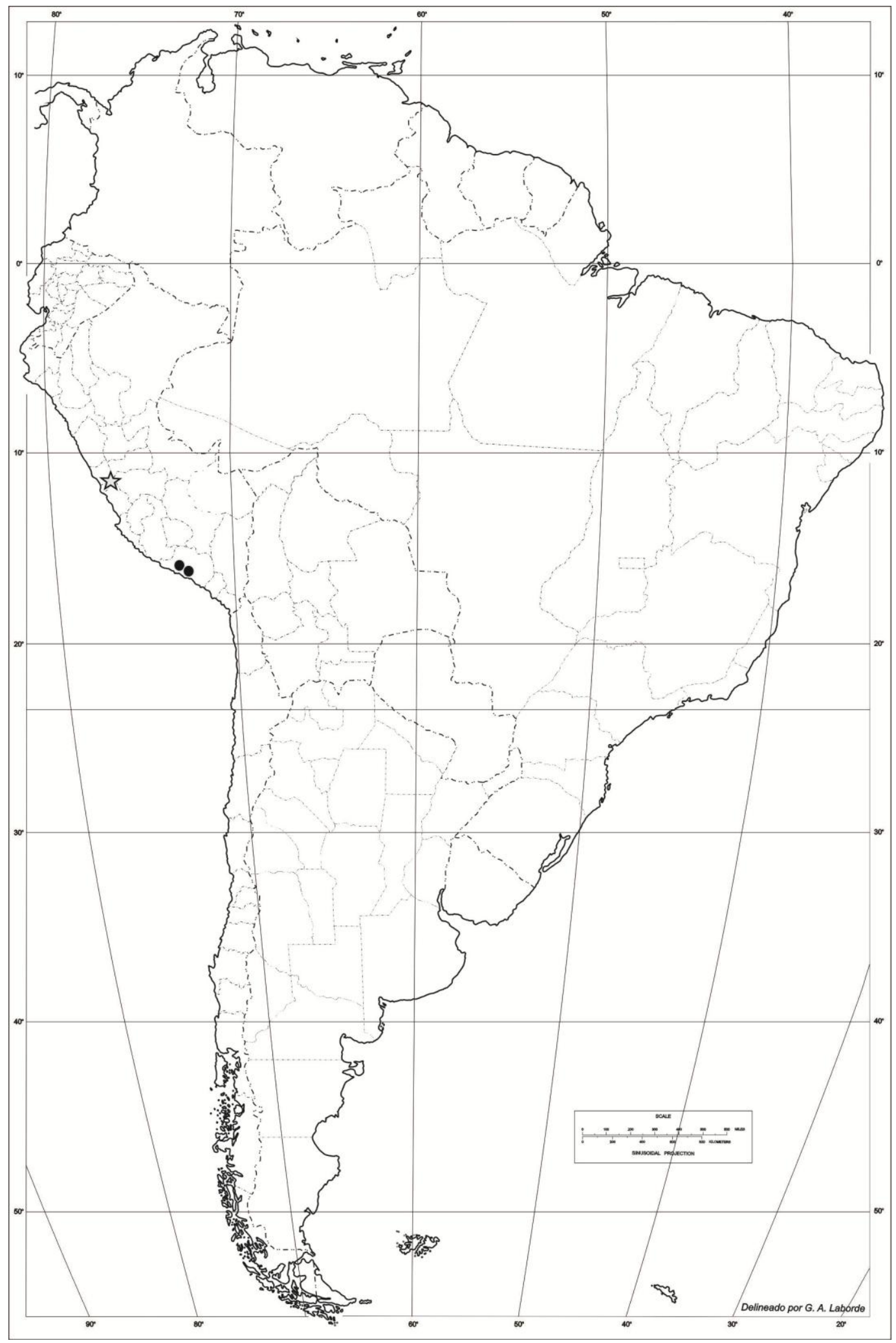

Figura 112. O. pubescens. Distribución geográfica, la estrella indica la localidad tipo. 


\section{Ophryosporus regnelli Baker}

Flora Brasiliensis 6(2): 188. 1876.

Tipo: Brasil, Prov. Minas Geraes, Caldas. Regnell I 237, 08/1862. Holotipo US!, isotipo BR foto!, S foto! Fig. 113.

Arbusto apoyante, profusamente ramificado. Tallo con entrenudos entre 5 y $11 \mathrm{~cm}$, ramificaciones secundarias opuestas, ramas tomentulosas, rojizo, con estriaciones. Hojas opuestas, pecioladas, pecíolo 1-2,2 cm, láminas ovadas, 2,5-4 X 8-11 cm, base cuneada, ápice agudo, margen aserrado, plano; consistencia delicadamente herbácea, venación acródroma imperfecta suprabasal; pubescente, tricomas eglandulares simples cónicos. Inflorescencia cimoidea, compuesta de corimbos densos, terminal y axilar, con hojas persistentes poco desarrolladas. Capítulos ca. 120-150, pedunculados (0,5-1 mm). Involucro acampanado, 3 × 2 $\mathrm{mm}$, filarios 6 , eximbricados, en una serie de filarios, ovados, $3 \times 1 \mathrm{~mm}$, ápice fimbriado, margen entero, consistencia herbácea; pubescentes, tricomas eglandulares simples cónicos. Flores 5-6, hermafroditas, corola blanca, infundibuliforme, sin paso gradual entre tubo y limbo, tubo $1 \times 0,4 \mathrm{~mm}$, limbo $1,7 \mathrm{x}$ 0,7 mm, 5-dentada, lóbulo 0,5 x 0,3 mm, glandulares en el tubo, tricomas glandulares (tipo $\alpha$ ). Estambres 5, anteras $1 \times 0,25 \mathrm{~mm}$, collar anteral cilíndrico, levemente ensanchado hacia la base, base de la teca obtusa, apéndice conectival nulo. Estilo 4,8 mm, largamente exerto, ramas del estilo fuertemente clavadas en el ápice, ápices más oscuros que el resto de las ramas, las ramas 2,2 mm. Cipsela negra no estipitada, piriforme, $2,5 \mathrm{~mm}$, marcadamente 5 -costada, serícea y glandulosa, pelos gemelos y glandulares (tipo $\alpha$ ) en toda la cipsela; carpopodio anular, excéntrico. Papus formado por 22-26 cerdas blanquecinas, connadas en la base, 2-2,5 mm. Fig. 114.

Fenología: Florece de agosto a abril.

Distribución: Brasil (estados de Minas Gerais, Espírito Santo, Paraná, Santa Catarina, São Pablo y Rio de Janeiro) a 500-1200 msnm, habita en mata atlántica (Campostrini Forzza, 2010). Fig. 115. 


\section{Notas:}

1. Flores con olor a absenta (Tessmann 80 RB). Para otros, fétido (Vidal 202 LP).

Etimología: Hace referencia al colector del material tipo, físico y botánico sueco Anders Fredrik Regnell (1807-1884).

Especímenes adicionales estudiados: BRASIL. Rio de Janeiro: Itatiaia, Parque Nac. Itatiaia, Maramba, 12/08/1953, E. Pereira, Egler \& Graziela 57 (RB); na estrada de terra que accesa o Parque Nacional, partindo do municipio de Itamonte (Minas Gerais); 24/06/2005, R. L. Estevez 2154 (RB); ib. R. L. Estevez 2156 (RB); ib. R. L. Estevez 2157 (RB). Nova Friburgo, 07/1946, J. E. Leite 4097 (RB). Minas Gerais: Minas Gerais, Belo Horizonte, Engenho Nogueira, 23/07/1942, M. Magalhães 3314 (LP); Poços de Caldas, 01/07/1942, J. E. de Oliveira 942 (LP); St. Luzia, Sanat. Hugo Werneck, 20/07/1955, L. Roth 1417 (RB); Viçosa, saindo do prédio principal pela estrada de ferro, rumo a Coimbra, 19/05/1984, W. N. Vidal 202 (LP). Paraná: Bocaiuva do Sul, Estr. p /S Paulo, Serra da Ribeira, 22/04/1957, G. Hatschbach 3883 (RB, LP). Cerro Azul, rodovia Cerro Azul para Tunas do Paraná, Boi Perdido, 20/04/2006, E. Barbosa \& E. F. Costa 1266 (RB). Curitiba, vale do Iguaçu, $15 \mathrm{~km}$ da cidade, 13/06/1950, G. Tessmann 80 (RB).Santa Catarina: Joachim Murtinho, 21/03/1916, P. Dusén 17989 (NY, SI, US). Región no especificada: Brasilia, 1833-35, L. Riedel \& Lund 2360 (NY). 


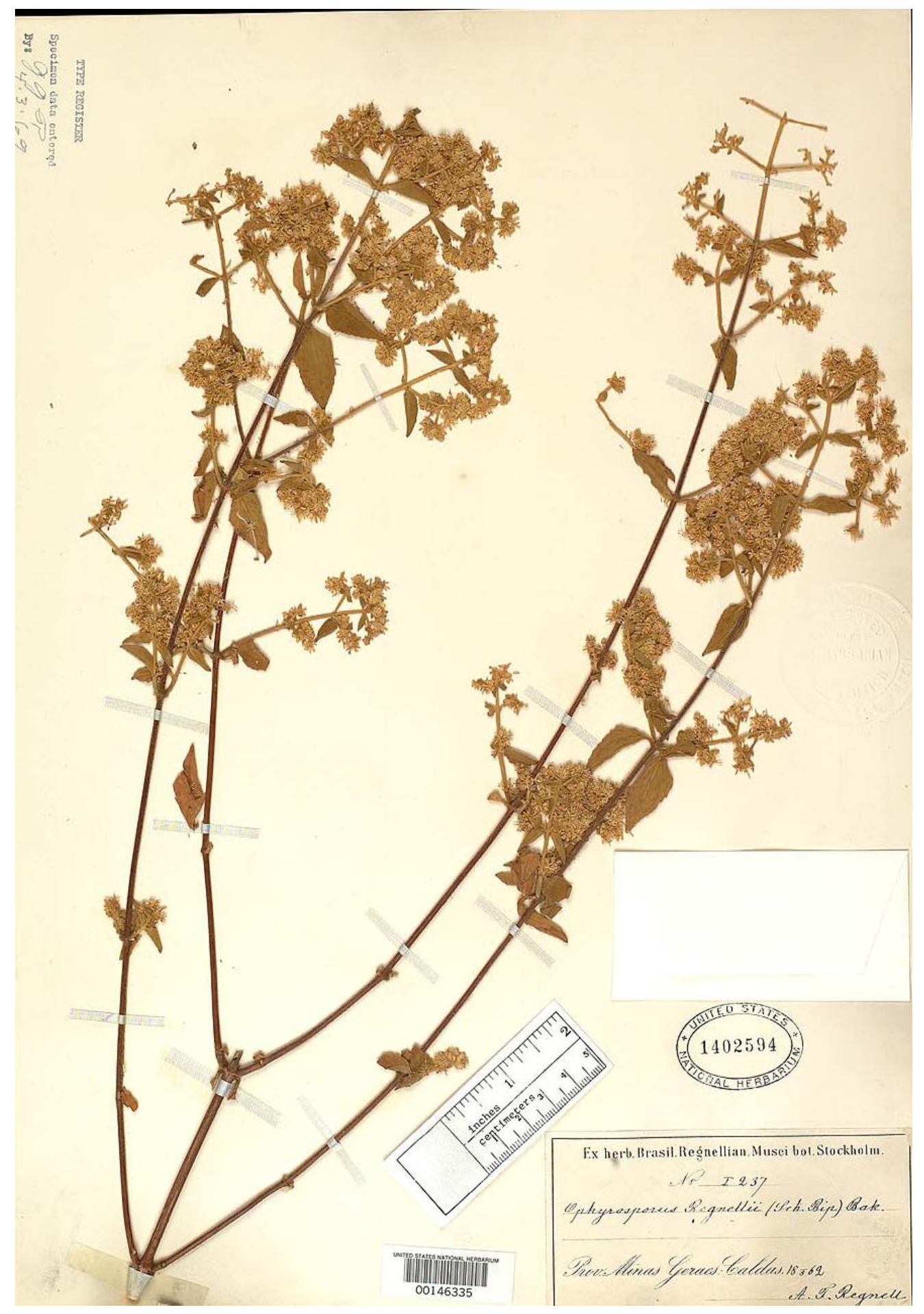

Figura 113. O. regnellii, holotipo. Regnell I 237 (US). 

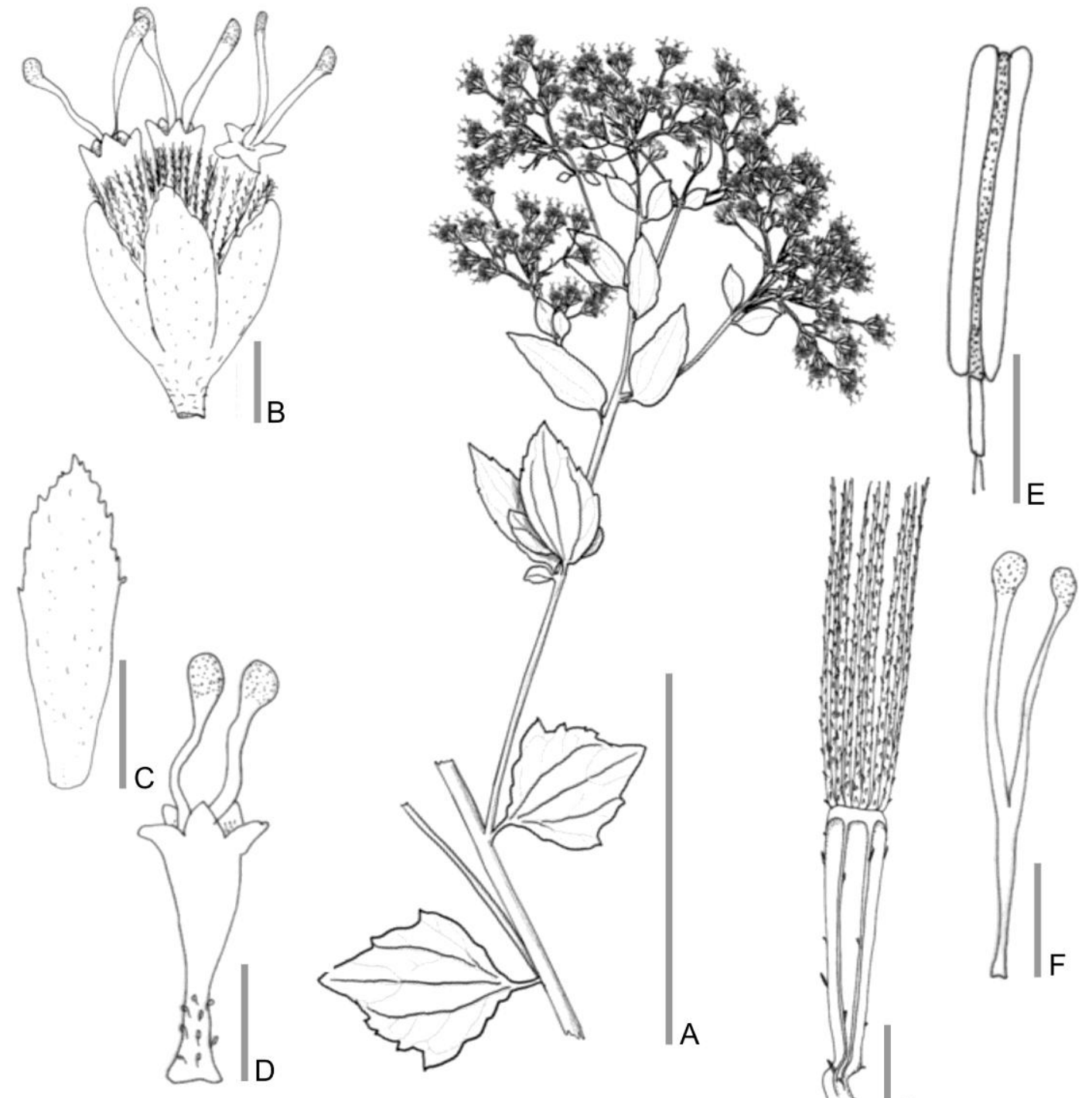

Figura 114. O. regnellii. A. Rama florífera. B. Capítulo. C. Flor sin papus ni cipsela. D. Filarios. E. Antera. F. Estigma. G. Cipsela. Escalas: A: $5 \mathrm{~cm}$; B-C: $2 \mathrm{~mm}$; D-E: 1 cm; F-G: 250 um. (A-G basados en E. Barbosa \& E. F. Costa 1266, RB). 


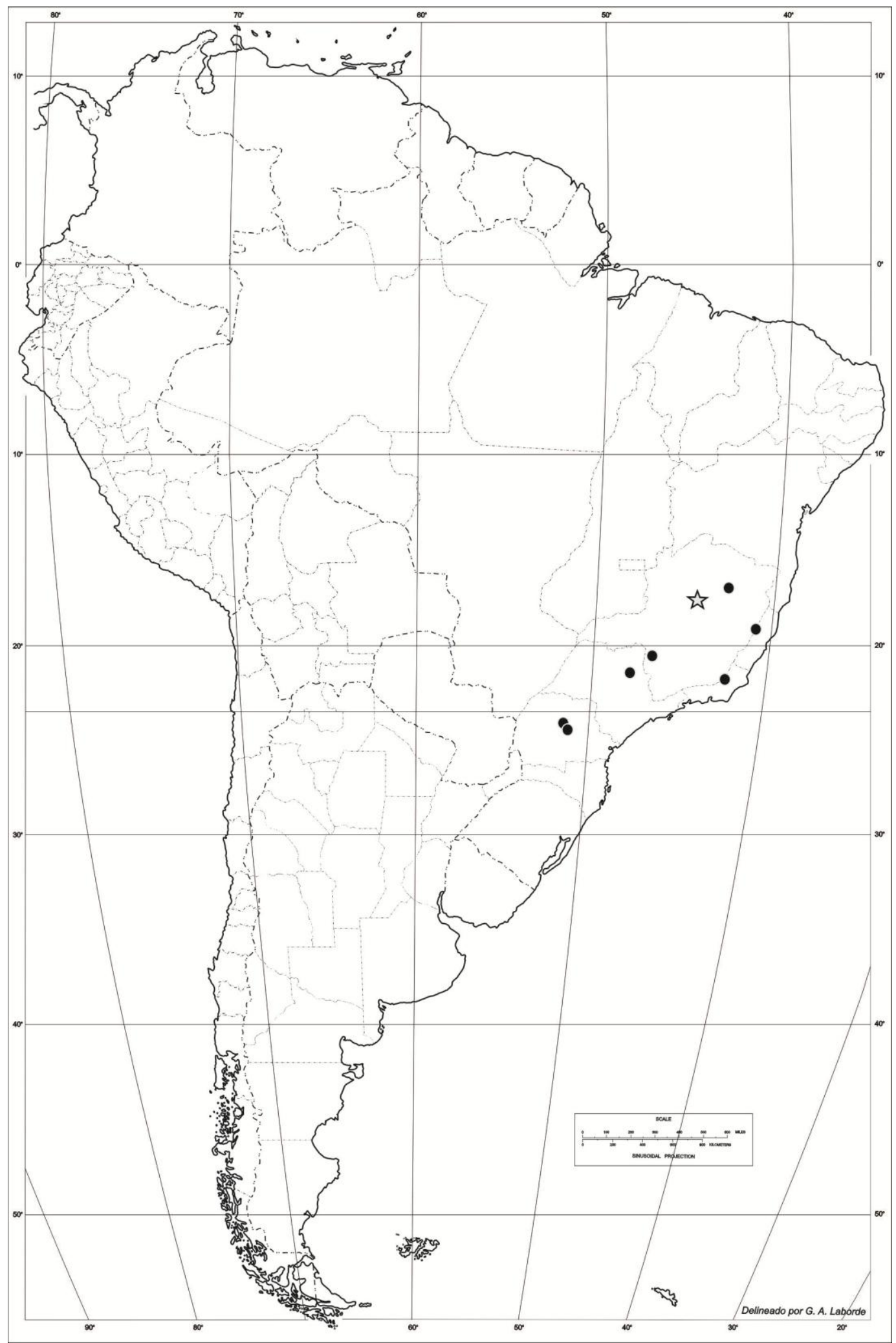

Figura 115. O. regnellii. Distribución geográfica, la estrella indica la localidad tipo. 


\section{Ophryosporus sagasteguii H. Rob.}

Phytologia 84(5): 352. 1998.

Tipo: Perú. "Cajamarca. Contumazá, Contumazá-Cascabamba. Subfrútice con capítulos blancos. Hábitat laderas, 2700 msnm." 12/06/1981, A. Sagástegui A., E. García, S. López \& J. Mostacero 9975. Holotipo US!, isotipo HAO no visto. Fig. 116.

Arbusto erecto (1-2 m). Tallo con entrenudos entre 5 y $8 \mathrm{~cm}$, ramificaciones secundarias opuestas, ramas glabras, rojizo, con estriaciones. Hojas opuestas, pecioladas, pecíolo 0,8-1 cm, láminas ovadas, 1,5-3 X 4-6 cm, base redondeada, ápice agudo, margen aserrado, plano; consistencia delicadamente herbácea, venación acródroma imperfecta suprabasal; pubescente y glandular, tricomas eglandulares simples cónicos y glandulares (tipo a). Inflorescencia cimoidea, compuesta de corimbos laxos, terminal y axilar, con hojas persistentes poco desarrolladas. Capítulos ca. 100-120, pedunculados (0,8-1 mm). Involucro acampanado, 1,5 ×4 mm, filarios 5, eximbricados, en una serie de filarios, ovados, 1,5 x 0,5 mm, ápice fimbriado, margen entero, consistencia herbácea; pubescente y glanduloso, tricomas eglandulares simples cónicos y glandulares (tipo $\alpha$ ). Flores 5, hermafroditas, corola blanca, a veces con tintes rojizos cuando cerrada, infundibuliforme, sin paso gradual entre tubo y limbo, tubo $0,8 \times 0,5 \mathrm{~mm}$, limbo $2 \times$ 0,8 mm, 5-dentada, lóbulo 0,4 × 0,3 mm, glandulosa en toda la corola, más denso en el tubo, tricomas glandulares (tipo $\alpha$ ). Estambres 5, anteras $1 \times 0,2 \mathrm{~mm}$, collar anteral cilíndrico, levemente ensanchado hacia la base, base de la teca auriculada, apéndice conectival rudimentario, con surco medial. Estilo 4,1 mm, cortamente exerto, ramas del estilo fuertemente clavadas en el ápice, ápices más oscuros que el resto de las ramas, las ramas $1,8 \mathrm{~mm}$. Cipsela negra no estipitada, piriforme, 2,5 mm, marcadamente 5-costada, serícea y glandulosa, pelos gemelos y glandulares (tipo $\alpha$ ) en las costillas; carpopodio cilíndrico, central. Papus formado por 4-14 cerdas amarillentas, a veces ausente, connadas en la base, 22,5 mm. Fig. 117. 
Fenología: Florece en junio.

Distribución: Perú (departamento de Cajamarca) a 2700 msnm. Fig. 118.

Etimología: hace referencia al botánico peruano Abundio Sagástegui Alva (19252012). 


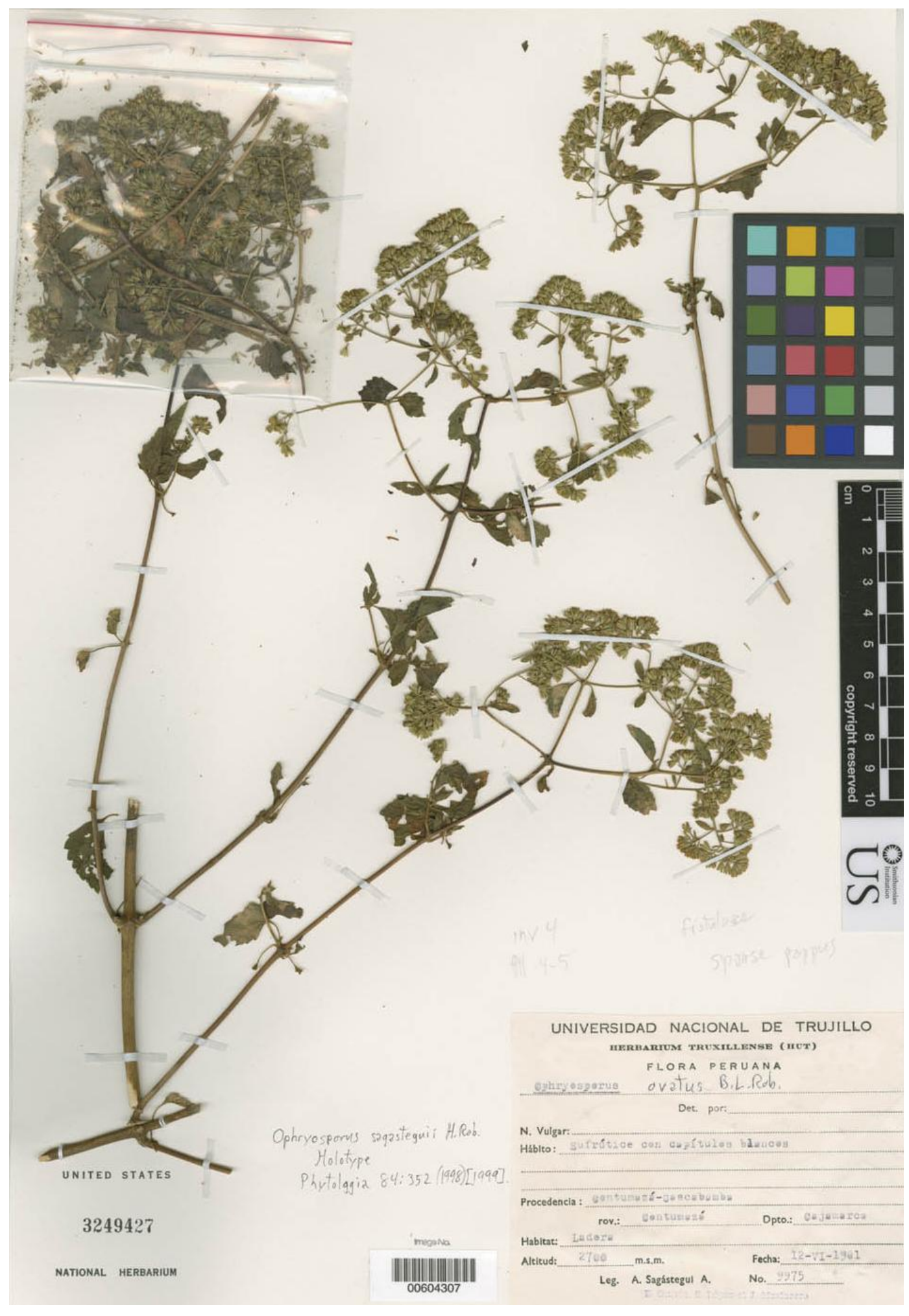

Figura 116. O. sagasteguii, holotipo. Sagástegui et al. 9975, US). 


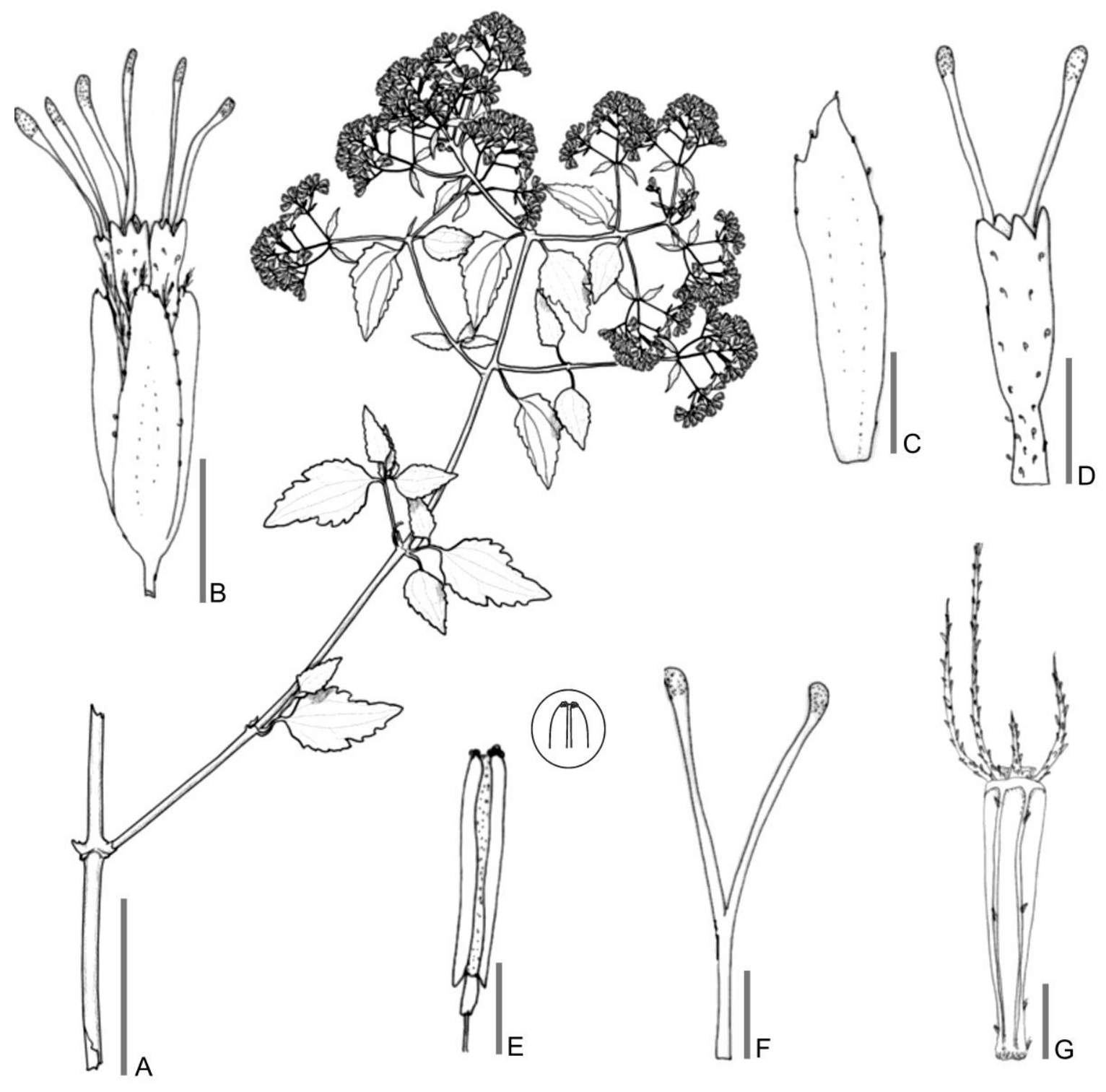

Figura 117. O. sagasteguii. A. Rama florífera. B. Capítulo. C. Flor sin papus ni cipsela. D. Filarios. E. Antera. F. Estigma. G. Cipsela. Escalas: A: 2,5 cm; B-C: 2 mm; D-E: 1 cm; F-G: 200 m. (A-G basados en Sagástegui et al. 9975, US). 


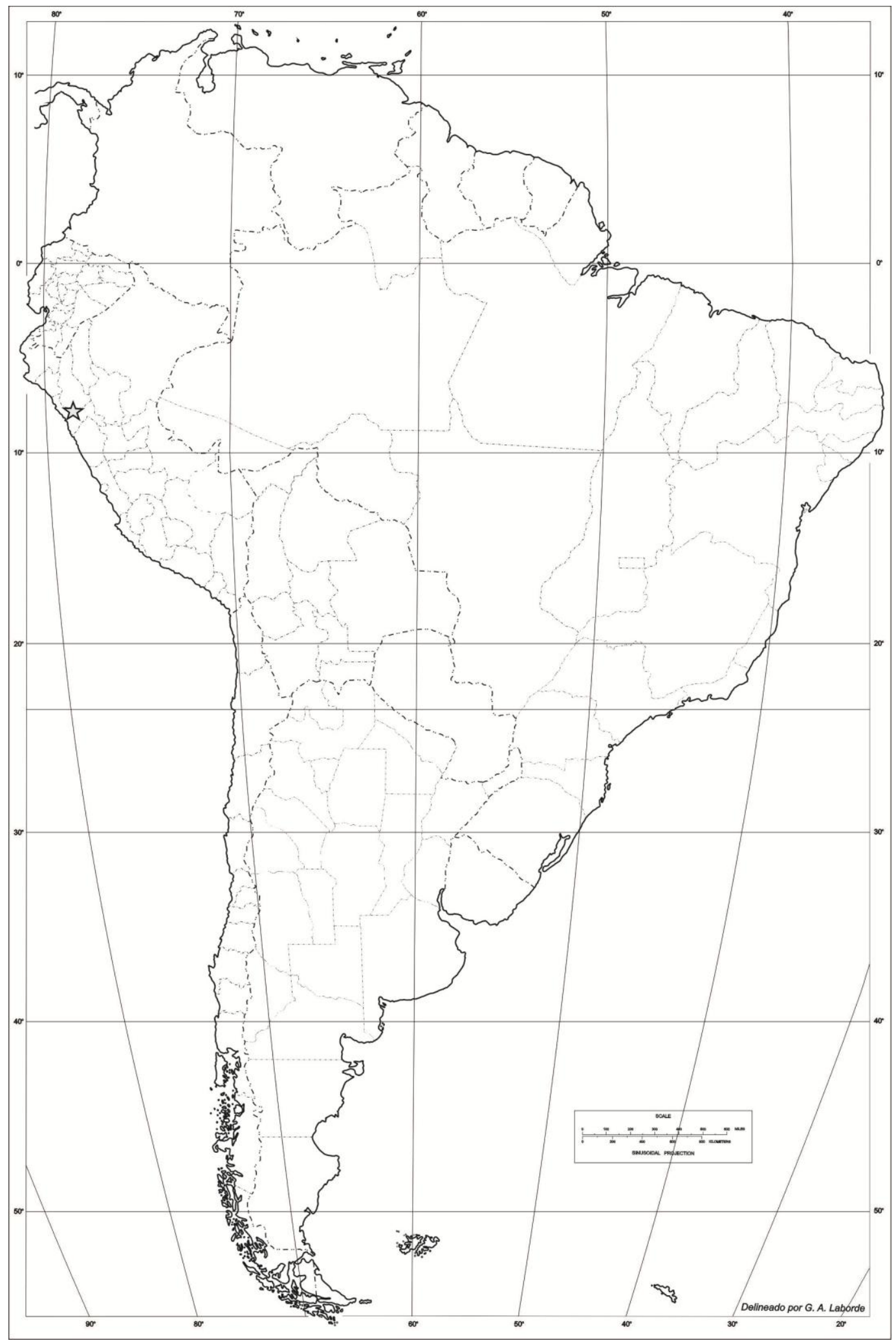

Figura 118. O. sagasteguii. Distribución geográfica, la estrella indica la localidad tipo. 
Ophryosporus serratifolius (Kunth) B. L. Rob.

Contributions from the Gray Herbarium of Harvard University. 90: 3. 1930.

\section{ミMikania serratifolia Kunth}

Nova Genera et Species Plantarum (folio ed.) 4: 108. 1820 (1818).

Tipo: Ecuador "Crescit in Nova Granata" Humboldt \& Bonpland s.n. Holotipo: P 00742654 foto!. Isotipo: P 00742651 foto! Fig. 119.

= Eupatorium serratifolium (Kunth) DC. Prodromus Systematis Naturalis Regni Vegetabilis 5: 181. 1836

Arbusto erecto. Tallo con entrenudos entre 3 y $8 \mathrm{~cm}$, ramificaciones secundarias opuestas, ramas glabras, marrón claro, con estriaciones. Hojas opuestas, pecioladas, pecíolo 0,8-1,1 cm, láminas ovadas, 1-3 X 3-6 cm, base cuneada, ápice agudo, margen denticulado-aserrado, plano; consistencia delicadamente herbácea, venación acródroma imperfecta suprabasal; pubescente, tricomas eglandulares simples cónicos. Inflorescencia cimoidea, compuesta de corimbos densos, terminal, con hojas persistentes poco desarrolladas. Capítulos ca. 90-120, pedunculados (0,8-1,2 mm). Involucro acampanado, $3 \times 4 \mathrm{~mm}$, filarios 5, eximbricados, en una serie de filarios, ovados, 1,2 $23 \mathrm{~mm}$, ápice fimbriado, margen entero, consistencia herbácea; pubescente, tricomas eglandulares simples cónicos. Flores 5 , hermafroditas, corola blanca, infundibuliforme, sin paso gradual entre tubo y limbo, tubo $1 \times 0,5 \mathrm{~mm}$, limbo $2 \times 1 \mathrm{~mm}$, 5-dentada, lóbulo 0,8 $\times$ 0,4 $\mathrm{mm}$, glandulosa en el tubo, tricomas glandulares (tipo $\alpha$ ). Estambres 5, anteras $2 \mathrm{x}$ $0,3 \mathrm{~mm}$, collar anteral cilíndrico, base de la teca auriculada, apéndice conectival nulo. Estilo $4 \mathrm{~mm}$, largamente exerto, ramas del estilo fuertemente clavadas en el ápice, ápices más oscuros que el resto de las ramas, las ramas 1,8 mm. Cipsela negra ligeramente estipitada, piriforme, $2,5 \mathrm{~mm}$, marcadamente 5-costada, serícea y glandulosa, pelos gemelos y glandulares (tipo $\alpha$ ) en las costillas; carpopodio cilíndrico, central. Papus formado por 30 cerdas blanquecinas, connadas en la base, 1,8-2,5 mm. Fig. 120. 
Fenología: Florece de marzo a agosto.

Distribución: Ecuador (provincia de Cañar) a 2500-3000 msnm. Hábitat: valle intermontano seco, con escasos cactus y arbustos espinosos. Si bien el material tipo ha sido adjudicado a Colombia, en su momento de colecta ésta pertenecía, junto con parte de Ecuador, al reino de Nueva Granada, de ahí el error. Fig. 121.

Etimología: Hace referencia a la forma aserrada del borde de las hojas (Gledhill 2008).

Especímenes adicionales estudiados: ECUADOR. Cañar: Ingapirica, $78^{\circ} 52^{\prime} \mathrm{W}$ $02^{\circ} 32^{\prime}$ S, 27/12/1979, L. Holm-Nielsen 20878 A (AAU). 


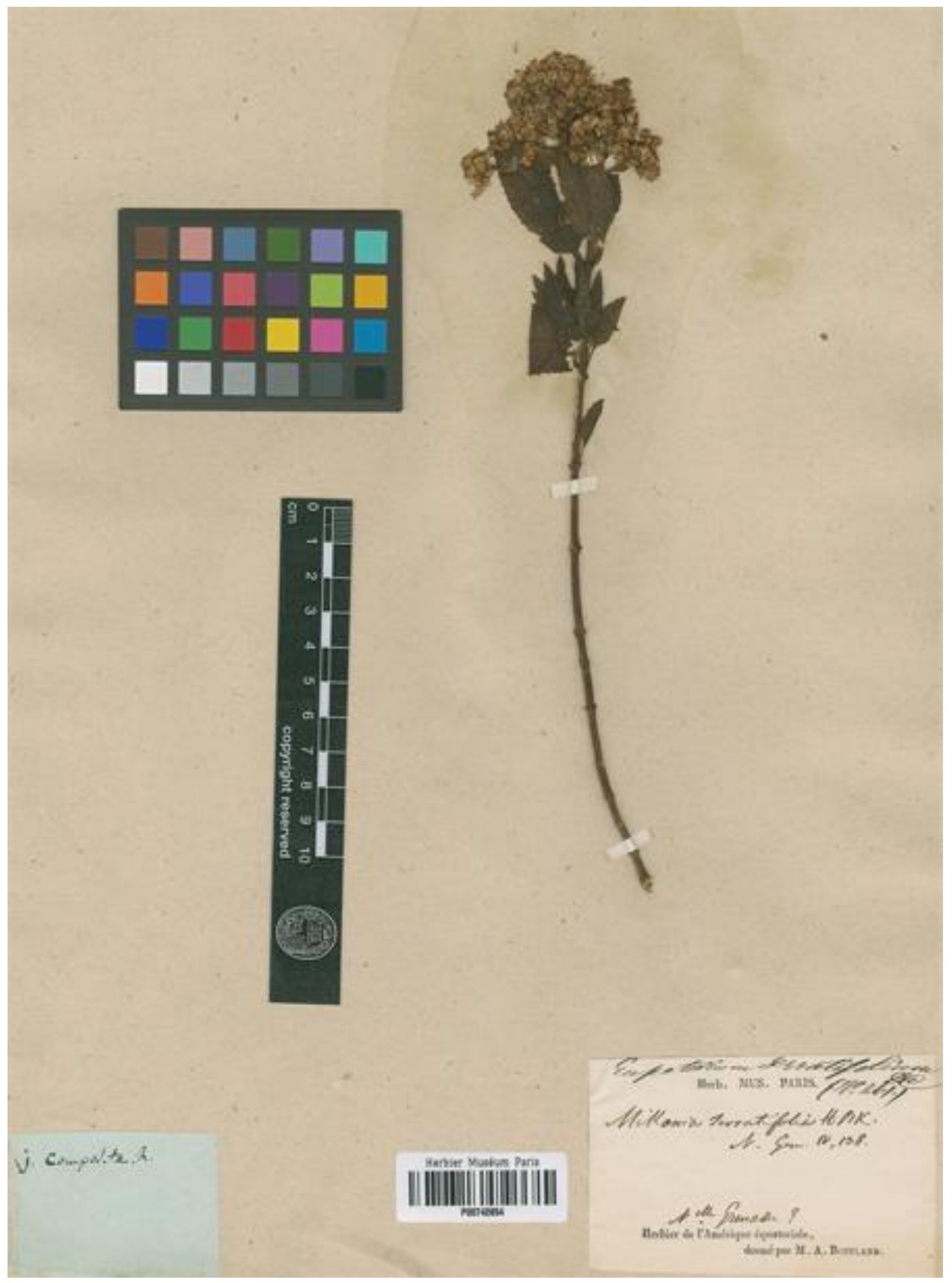

Figura 119. O. serratifolius, holotipo. Humboldt \& Bonpland s.n. (P). 


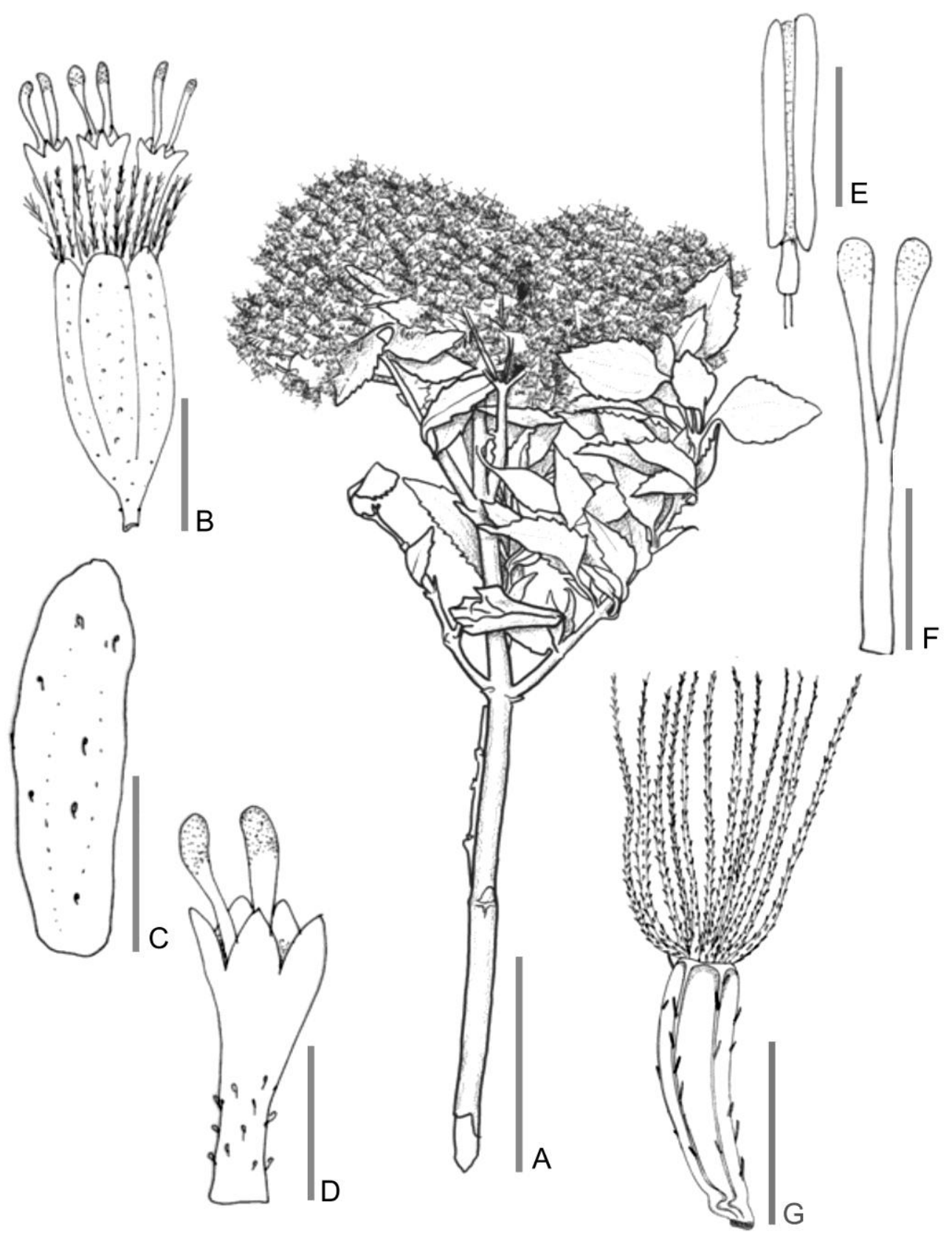

Figura 120. O. serratifolius. A. Rama florífera. B. Capítulo. C. Flor sin papus ni cipsela. D. Filarios. E. Antera. F. Estigma. G. Cipsela. Escalas: A: 2,5 cm; B-C: 2

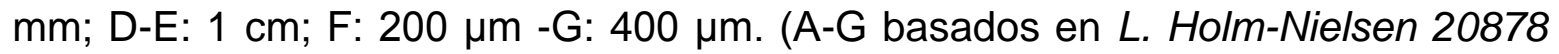
$A, \mathrm{AAU})$. 


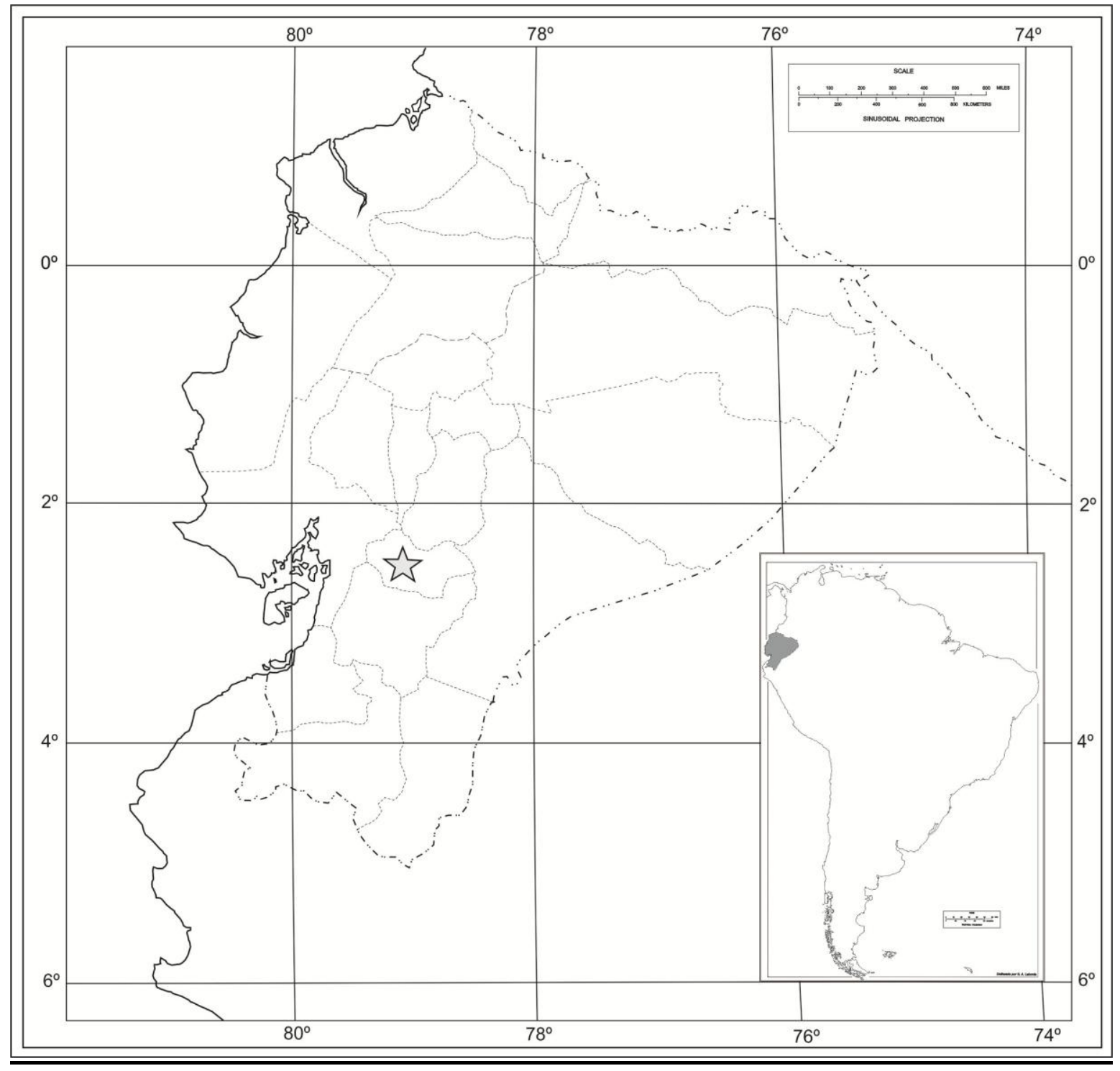

Figura 121. O. serratifolius. Distribución geográfica, la estrella indica la localidad tipo. 


\section{Ophryosporus sodiroi Hieron.}

Bonische Jahrbücher für Systematik, Pflanzengeschichte und Pflanzengeographie 29: 3. 1900.

Tipo: Ecuador. Sodiro 6/18. Holotipo: B posiblemente destruído, foto en F!. Isotipo GH foto! Fig. 122.

Arbusto apoyante. Tallo con entrenudos entre 6 y $10 \mathrm{~cm}$, ramificaciones secundarias opuestas, ramas glabras, rojizo, con estriaciones. Hojas opuestas, pecioladas, pecíolo 0,4-0,6 cm, láminas ovadas, 1,2-1,5 X 3-4,5 cm, base cuneada, ápice agudo, margen denticulado-aserrado, plano; consistencia delicadamente herbácea, venación acródroma imperfecta suprabasal; pubescente, tricomas eglandulares simples cónicos. Inflorescencia cimoidea, compuesta de corimbos densos, terminal y axilar, con hojas persistentes poco desarrolladas. Capítulos ca. 30-50, pedunculados (0,5-0,9 mm). Involucro acampanado, 2,5 x 5 $\mathrm{mm}$, filarios 6-(7), eximbricados, en una serie de filarios, ovados, $2,5 \times 1 \mathrm{~mm}$, ápice fimbriado, margen entero, consistencia herbácea; pubescente, tricomas eglandulares simples cónicos. Flores (5)-6-(7), hermafroditas, corola blanca, a veces con tintes violáceos cuando cerrada, infundibuliforme, con paso gradual entre tubo y limbo, tubo $1 \times 0,4 \mathrm{~mm}$, limbo $2 \times 0,8 \mathrm{~mm}$, 5-dentada, lóbulo 0,5 × 0,8 $\mathrm{mm}$, glandulosa en toda la corola, más denso en el tubo, tricomas glandulares (tipo a). Estambres 5, anteras $2 \times 0,3 \mathrm{~mm}$, collar anteral cilíndrico, levemente ensanchado hacia la base, base de la antera auriculada, apéndice conectival muy rudimentario, entero. Estilo $5 \mathrm{~mm}$, largamente exerto, ramas del estilo fuertemente clavadas en el ápice, ápices más oscuros que el resto de las ramas, las ramas 2,8 $\mathrm{mm}$. Cipsela negra ligeramente estipitada, piriforme a levemente falcada, $2,5 \mathrm{~mm}$, marcadamente 5-costada, serícea y glandulosa, pelos gemelos y glandulares (tipo a) en el tercio inferior y superior; carpopodio anular, central. Papus formado por 25 cerdas amarillentas, connadas en la base, 2-2,5 mm. Fig. 123.

Fenología: Florece de julio a agosto.

Nombres comunes: "Llenguer" (L. Ellemann 66604, AAU) 
Distribución: Ecuador (provincias de Azuay, Bolívar, Chimborazo, Loja y Pichincha) a 2500-3500 msnm, hábitat andino, bosques secundarios dominados por Weinmannia fagaroides Kunth, Escallonia myrtilloides L. f., Myrcianthes O. Berg.y algunas Lauraceae. Fig. 124.

\section{Nota:}

1. Existe un material en $P$ (P00742223), el cual puede llegar a pertenecer a la serie tipo, aunque carece de número. Su localidad es correspondiente con la del tipo, Ecuador.

Etimología: Hace referencia al colector del material tipo, el botánico italiano Luiggi Sodiro (1836-1909).

Usos: se utiliza como medicina para la picazón entre la etnia Saraguro. Se rompen las plantas en alcohol y se coloca sobre la piel (L. Ellemann 66604, AAU).

Especímenes adicionales estudiados: ECUADOR. Azuay: Rio Mazan, E slopes of Las Cajas, 79 10' W 02 45' S, 17/08/1987, P. M. Jørgensen 61866 (AAU, NY). Pichincha: Alluriquin, Quito road, km 50, 78 $44^{\prime} \mathrm{W} 00^{\circ} 28^{\prime} \mathrm{N}, 22 / 07 / 1985$, A. S. Barfod \& F. Skov 60090 (AAU, NY). Loja: 2 km south of Saraguro, 79 14' W 03 38' S, 08/10/1988, L. Ellemann 66604 (AAU). 


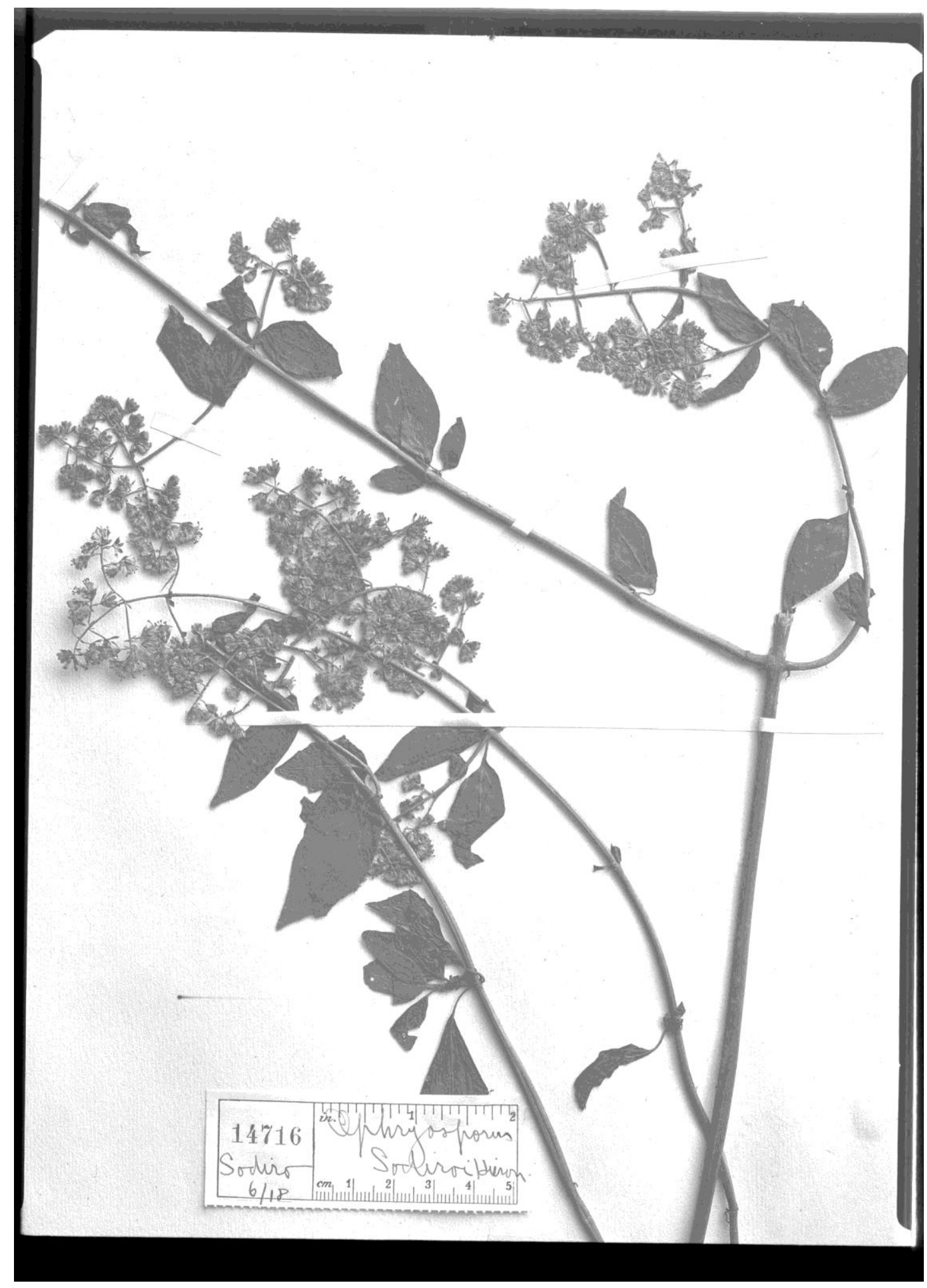

Figura 122. O. sodiroi, holotipo. Sodiro 6/18 (B en F). 

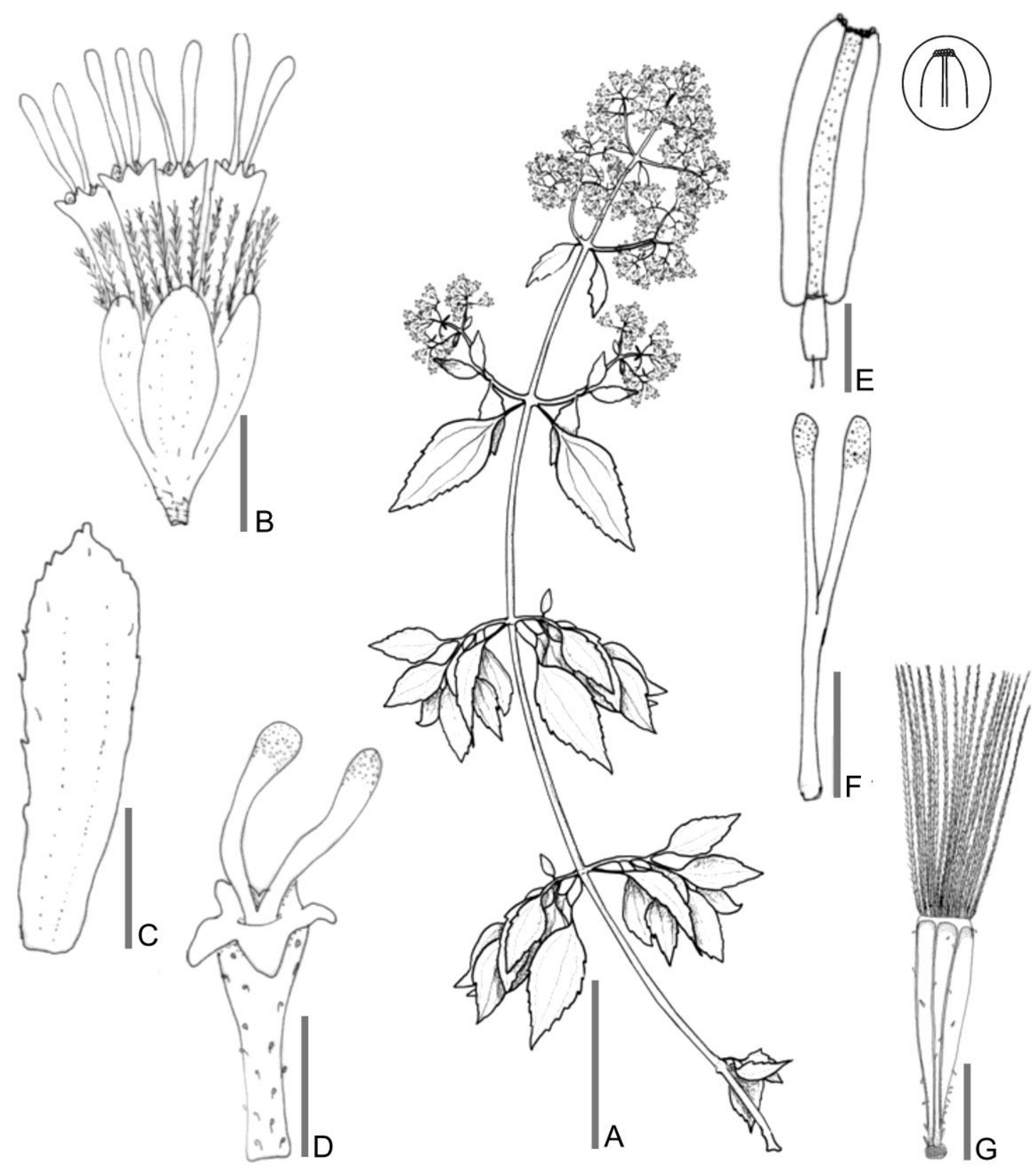

Figura 123. O. sodiroi. A. Rama florífera. B. Capítulo. C. Flor sin papus ni cipsela. D. Filarios. E. Antera. F. Estigma. G. Cipsela. Escalas: A: 2,5 cm; B-C: 2 mm; D-E: $1 \mathrm{~cm}$; F-G: 250 m. (A-G basados en A. S. Barfod \& F. Skov 60090, AAU). 


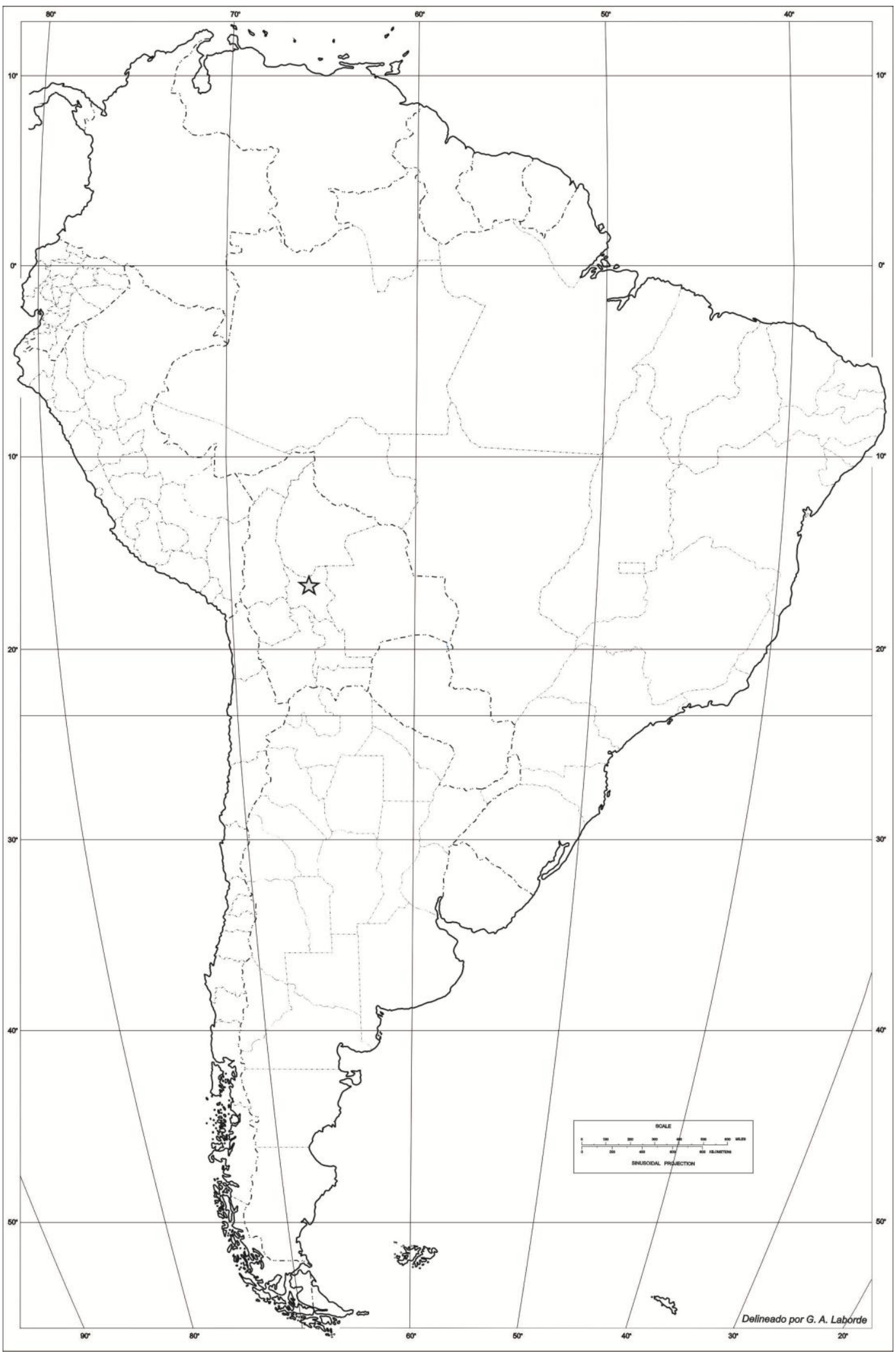

Figura 124. O. sodiroi. Distribución geográfica, la estrella indica la localidad tipo. 
Ophryosporus steinbachii B. L. Rob.

Contributions from the Gray Herbarium of Harvard University. 77: 5. 1926.

Tipo: Bolivia "common in a low thicket, Incachaca, Prov. Sacaba, Dept. Cochabamba, atl. 2500 m., Aug. 30. 1921. José Steinbach 5726”. Holotipo: F!, isotipos: GH foto! (fragmento), MO foto!, SI SI000922!, SI SI000923! Fig. 125.

Arbusto erecto. Tallo con entrenudos entre 2,5 y $8 \mathrm{~cm}$, ramificaciones secundarias opuestas, ramas glabras, rojizo, con estriaciones. Hojas opuestas, pecioladas, pecíolo $0,3-10 \mathrm{~cm}$, láminas ovadas, 1,2-1,8 X 2,8-4,2 $\mathrm{cm}$, base cuneada, ápice agudo, margen aserrado, plano consistencia delicadamente herbácea, venación acródroma imperfecta suprabasal; pubescente y glandulosa, tricomas eglandulares simples cónicos y glandulares (tipo a). Inflorescencia cimoidea, compuesta de corimbos densos, terminal y axilar, con hojas persistentes poco desarrolladas. Capítulos ca. 50-80, pedunculados (1-2 mm). Involucro acampanado, $5 \times 4 \mathrm{~mm}$, filarios 5-(6), eximbricados, en una serie de filarios, ovados, $1 \times 4 \mathrm{~mm}$, ápice fimbriado, margen entero, consistencia herbácea; pubescente y glanduloso, tricomas eglandulares simples cónicos y glandulares (tipo a). Flores 6, hermafroditas, corola blanca, infundibuliforme, con paso gradual entre tubo y limbo, tubo $1 \times 0,4 \mathrm{~mm}$, limbo $1,8 \times 0,8 \mathrm{~mm}$, 5-dentada, lóbulo 0,4 $\mathrm{x}$ $0,5 \mathrm{~mm}$, glandulosa en toda la corola, más denso en el tubo, tricomas glandulares (tipo a). Estambres 5, anteras $2 \times 0,3 \mathrm{~mm}$, collar anteral cilíndrico, base de la teca auriculada, apéndice conectival nulo. Estilo $4 \mathrm{~mm}$, largamente exerto, ramas del estilo fuertemente clavadas en el ápice, ápices más oscuros que el resto de las ramas, las ramas $2,5 \mathrm{~mm}$. Cipsela negra ligeramente estipitada, piriforme a levemente falcada, $2,5 \mathrm{~mm}$, marcadamente 5-costada, glandulosa, tricomas glandulares (tipo $\alpha$ ) en el tercio inferior y superior; carpopodio cilíndrico, central. Papus formado por 24 cerdas blanquecino-amarillentas, connadas en la base, 2,8$3,5 \mathrm{~mm}$. Fig. 126.

Fenología: Florece de julio a agosto.

Distribución: Bolivia (Cochabamba) a 2500 msnm. Fig. 127. 
Etimología: Dedicado al colector del material tipo, el botánico alemán José L. Steinbach (1875-1930). 


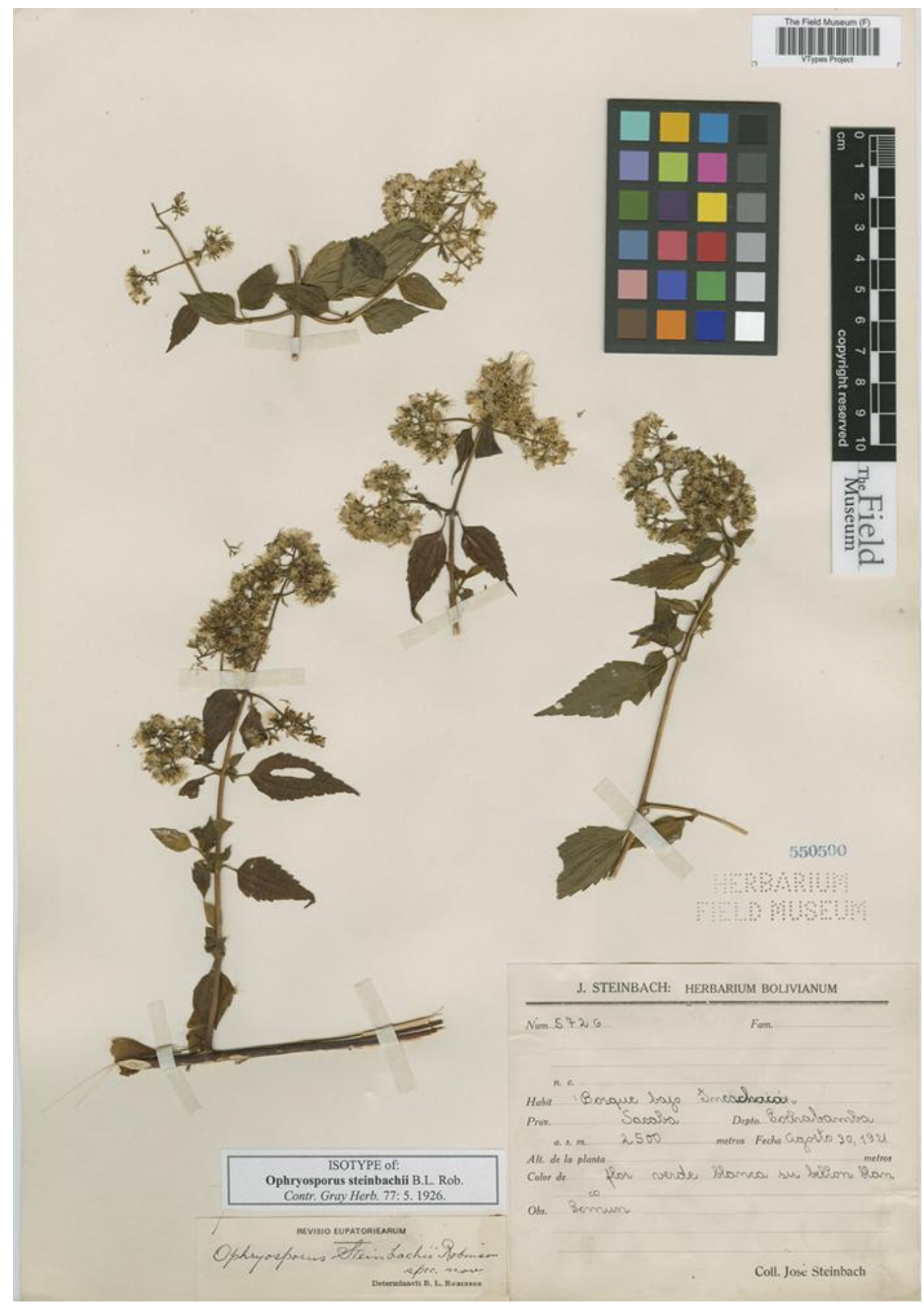

Figura 125. O. steinbachii, isotipo. J. Steinbach $5726(\mathrm{~F})$. 

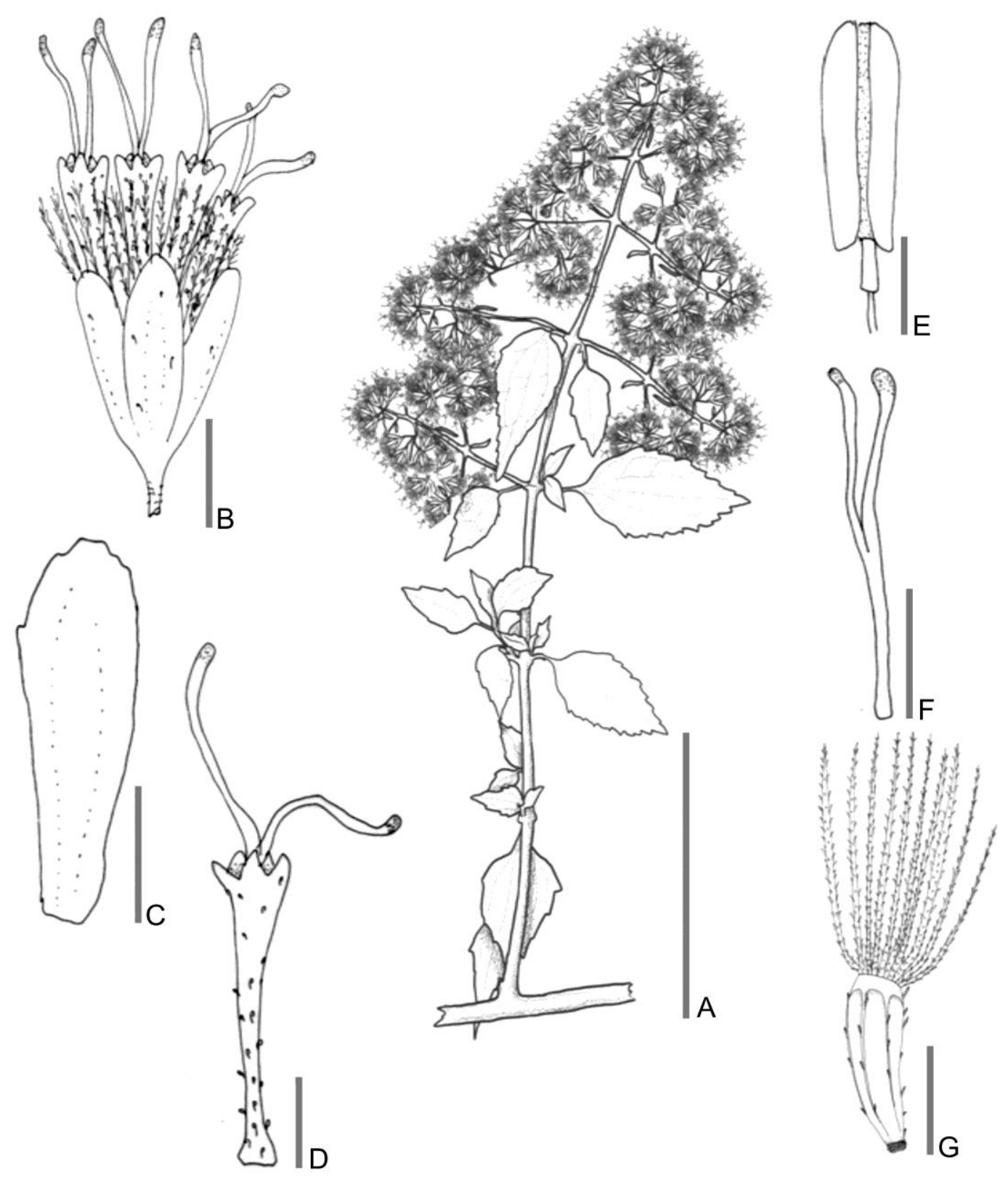

Figura 126. O. steinbachii. A. Rama florífera. B. Capítulo. C. Flor sin papus ni cipsela. D. Filarios. E. Antera. F. Estigma. G. Cipsela. Escalas: A: 2,5 cm; B-C: 2 mm; D-E: 0,7 cm; F-G: 300 m. (A-G basados en J. Steinbach 5726, F). 


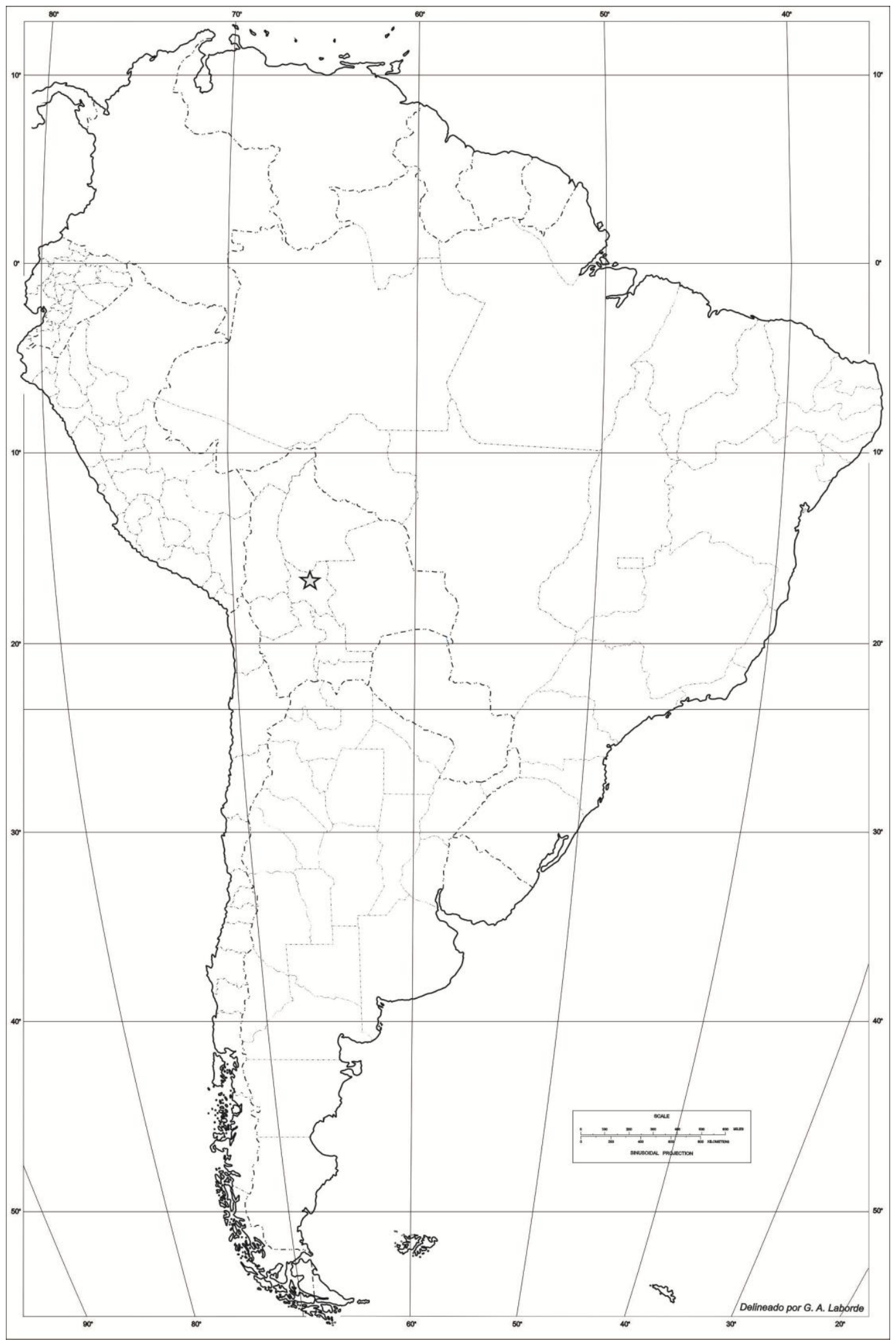

Figura 127. O. steinbachii. Distribución geográfica, la estrella indica la localidad tipo. 


\section{Ophryosporus triangularis Meyen.}

Reise um die Erde 1: 402.1834.

= Eupatorium decipiens Hook. \& Arn. in Hook. Companion Botanical Magazine i: 240. 1835.

= Eupatorium foliolosum DC. Prodromus 5: 174. 1836.

= Kuhnia multiramea Turcz. Bull. Soc. Imp. Naturalistes Moscou 24: 168. 1851.

= Eupatorium volckmanii Phil. Anal. Univ. Chile 18: 51. 1861.

= Ophryosporus foliolosus Reiche. FI. de Chile 3: 259. 1902.

Tipo: Chile, “Copiapó. Meyen s.n.". Holotipo B, posiblemente destruído foto!. Fig. 128.

Arbusto erecto, profusamente ramificado. Tallo con entrenudos entre 0,3 y 2 $\mathrm{cm}$, ramificaciones secundarias opuestas, ramas glabras, marrón claro, con estriaciones. Hojas alternas, en fascículos, pecioladas, pecíolo 0,1-0,2 cm, láminas ovadas, 0,1-0,35 X 0,3-0,6 cm, base cuneada, ápice agudo, margen aserrado-lobulado, revoluto; consistencia carnosa, venación acródroma imperfecta suprabasal; pubescente, tricomas eglandulares simples cónicos. Inflorescencia tirsoidea densa, compuesta de corimbos, terminal y axilar, con hojas persistentes bien desarrolladas. Capítulos ca. 50-80, pedunculados (0,5-0,8 mm). Involucro acampanado, $4 \times 4 \mathrm{~mm}$, filarios 7, eximbricados, en una serie de filarios, ovadolanceolados, 4 × 0,8 mm, ápice fimbriado, margen entero, consistencia herbácea; pubescente, tricomas eglandulares simples cónicos. Flores (6-7)-8, hermafroditas, corola blanca, con tintes violáceos cuando cerrada, tubular, $3 \times 0,5 \mathrm{~mm}$, 5dentada, lóbulo 0,4 × 0,5 mm, glandulosa en toda la corola, tricomas glandulares (tipo a). Estambres 5, anteras $2 \times 0,3 \mathrm{~mm}$, collar anteral cilíndrico, base de las tecas obtusa, apéndice conectival nulo. Estilo $5 \mathrm{~mm}$, largamente exerto, ramas del estilo fuertemente clavadas en el ápice, ápices más oscuros que el resto de las ramas, las ramas $2,7 \mathrm{~mm}$. Cipsela negra ligeramente estipitada, piriforme a 
levemente falcada, 2,5 mm, marcadamente 5-costada, serícea y glandulosa, pelos gemelos y tricomas glandulares (tipo $\alpha$ ) en las costillas; carpopodio anular, central. Papus formado por 24 cerdas blanquecino-pardas, connadas en la base, 2,5-3 mm. Fig. 129.

Fenología: Florece de enero a diciembre.

Distribución: Chile (regiones de Atacama, Antofagasta, Coquimbo y Tarapacá) a 0-3000 msnm. Fig. 139.

Nombres comunes: "Rabo de zorra" (Robinson 1906).

Etimología: Deriva del latín triangularis, con tres ángulos (Gledhill 2008).

Estado de Conservación: De acuerdo con Beltrán et al. (2006) su categoría en la UICN es CR B1 ab (iii), en peligro crítico.

Compuestos químicos de interés: Herz (2004) cita la presencia de glicósidos (flavonas, flavonoles, flavononas).

Especímenes adicionales estudiados: CHILE. Atacama (III Región): Chañaral, Desierto de Atacama, 08-09/1890, T. Morong 1149 (NY); ib. T. Morong 1296 (NY). Copiapó, Tierra Amarilla, 1924, E. Wedermann 456 (LIL; MO, NY). Chañaral, Parc National Pan de Azúcar, 26 10'S 7045’W, 26/10/1991, F. Billier \& B. Jadin 5396 (MO); Pan de Azúcar, entrada a Quinchihue, 26 04' S 70³2' W, 05/12/1987, M. Rosas 1115 (NY). Huasco, Carrizal Bajo, 02/09/1982, O. Zöllner 11348 (MO). Freirina, camino de Chañaral de Aceituna a Bahía Carrizal, 23/10/1971, Manticorena, Rodriguez, Weldt 1845 (LP); Isla Guacolda, 26/10/1938, C. R. Worth \& J. L. Morrison 16226 (MO); Quebrada del Pretil, 14/11/1956, M. Ricardi 3969 (LP); Vallenar, 08/12/1971, G. L. Badilla 10345 (LP). Antofagasta (II Región): Antofagasta, Antofagasta, 03/04/1925, F. W. Pennell 13018 (NY); Antofagasta alrededores, 12/01/1967, O. Zöllner 1566 (LP); Quebrada de la Chimba, 18/09/1958, Ricardi \& Manticorena 4643 (LP); ib. 27/09/1953, A. L. Cabrera 11332 (LP). Taltal, 26/09/1940, E. Barros 1780 (LP); Cifuncho road ca. $45 \mathrm{~km}$ south of Taltal (by road) ca. $5 \mathrm{~km}$ from the ocean, near the junction of the road and 
Quebrada Cifuncho, 15/09/1938, C. R. Worth \& J. L. Morrison 16131 (MO). Tocopilla, Cobija, 19/01/1971, O. Zöllner 5313 (LP). Coquimbo (IV Región): Coquimbo, 03/10/1953, A. L. Cabrera 11416 (LP); 03/1842, Bridges 1412 (NY); 1720/09/1933, G. Looser 9818 (MO, NY); 1908, O. Kuntze s.n. (NY); sin fecha, $R$. Philippi s.n. (LP); sin fecha, sin colector 13046 (LP). Elqui, La Herradura, 09/08/1917, C. Skottskerg 704 (LP), El Tofo, 10/09/1926, E. Barros 1457 (LP); ib. 10/09/1926, E. Barros 1777 (LP); La Serena, 13/09/1927, E. Barros 1778 (LP); ib. 27/12/1944, E. Barros 3852 (LP); ib. 11/01/1989, Roig 12673 (MERL); Cerro Grande, 11/01/1942, E. Barros 2337 (LP); Punta Teatinos, 03/12/1987, S. S. Landrum \& L. R. Landrum 5636 (MO, NY); ib. 07/12/1953, Kausel 3766 (LP); vicinity of La Serena, 11/10/1914, J. N. Rose 19315 (NY); ca. 14 km ESE of La Serena \& $4 \mathrm{~km} E$ of Islón, along N side of Río Elqui, $29^{\circ} 57^{\prime} \mathrm{S} 71^{\circ} 07^{\prime} \mathrm{W}$, 01/12/1987, M. O. Dillon \& J. T. S. Teillier 4994 (MO). Limari, Parc National Fray Jorge, estuaire du rio Limari, $30^{\circ} 40^{\prime} \mathrm{S} 71^{\circ} 40^{\prime} \mathrm{W}, 22 / 10 / 1991$, F. Billier \& B. Jadin 5269 (MO); Ovalle, Bahía Tongay, 19/08/1951, C. Jiles P. 1996 (LP); Fray Jorge, 11/1925, E. Wedermann 892 (LIL, NY); Parque Talinay, 12/10/1967, O. Zöllner 5318 (LP). Región no especificada: Chile, 1828-1834, Gay 182 (NY); sin fecha, C. Gays.n. (NY). 


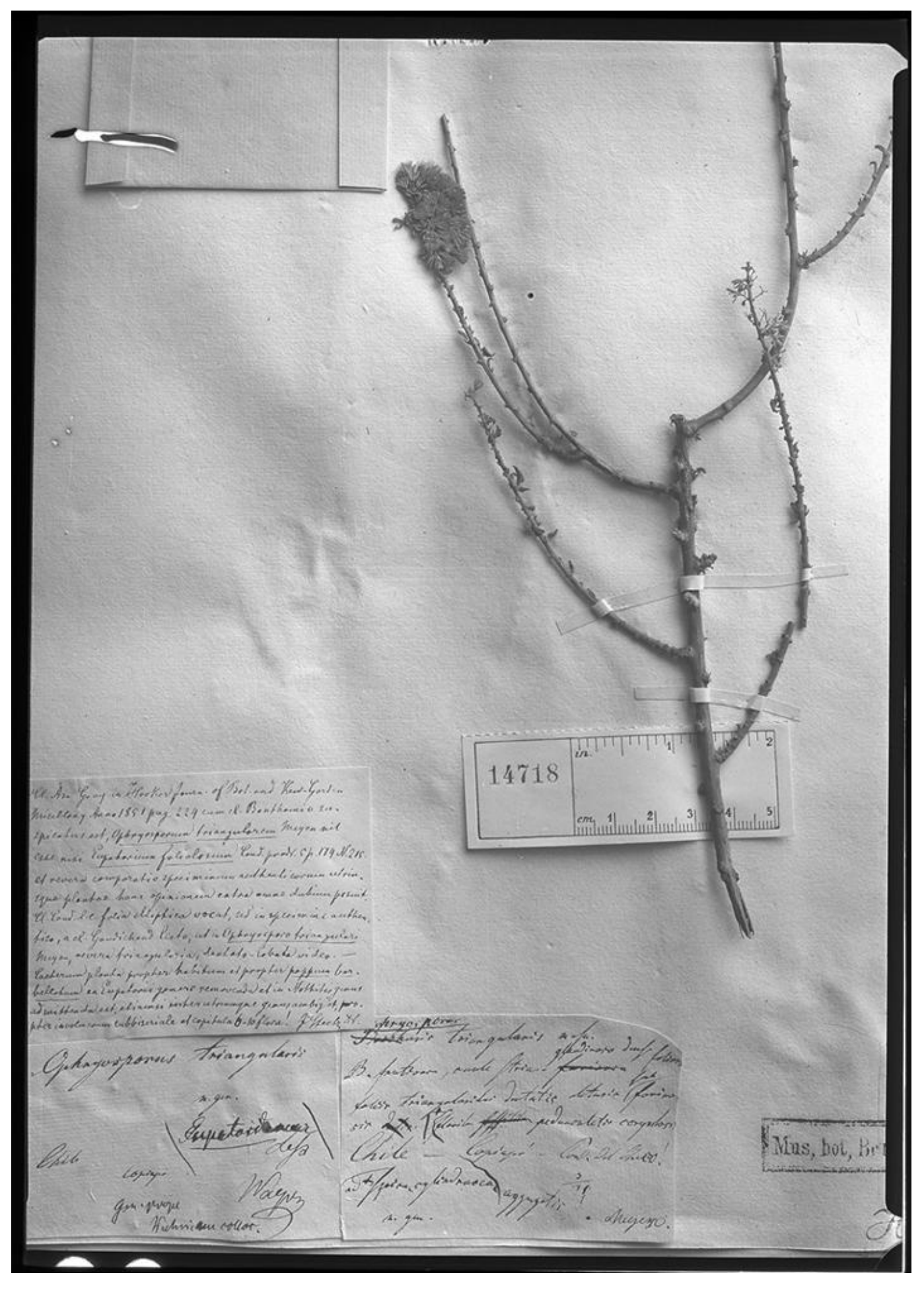

Figura 128. O. triangularis, holotipo. Meyen s.n. (B en F). 

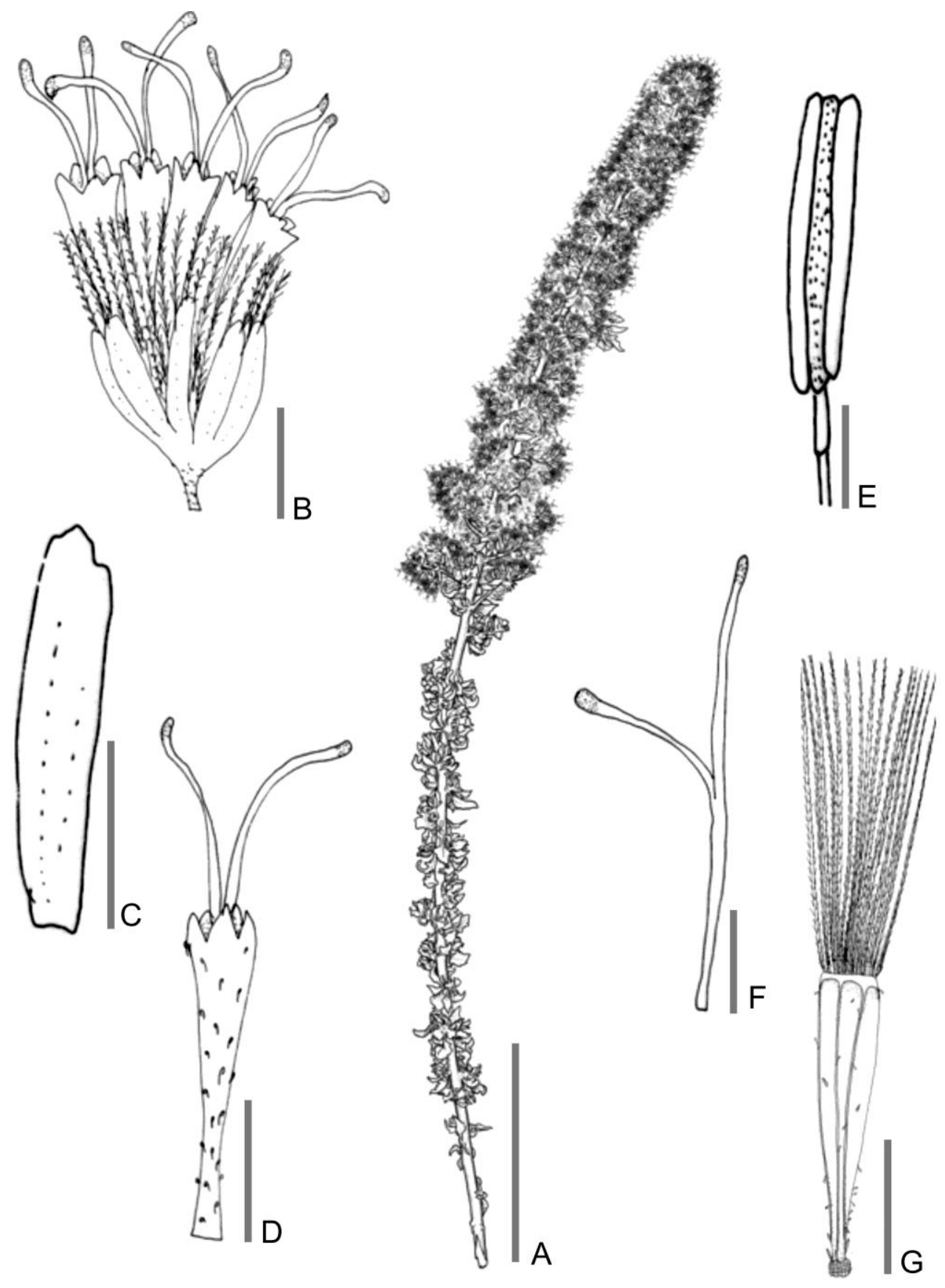

Figura 129. O. triangularis. A. Rama florífera. B. Capítulo. C. Flor sin papus ni cipsela. D. Filarios. E. Antera. F. Estigma. G. Cipsela. Escalas: A: 2,5 cm; B-C: 2 mm; D-E: 0,7 cm; F-G: 250 m. (A-G basados en F. Billiel \& B. Jadim 5396, MO). 


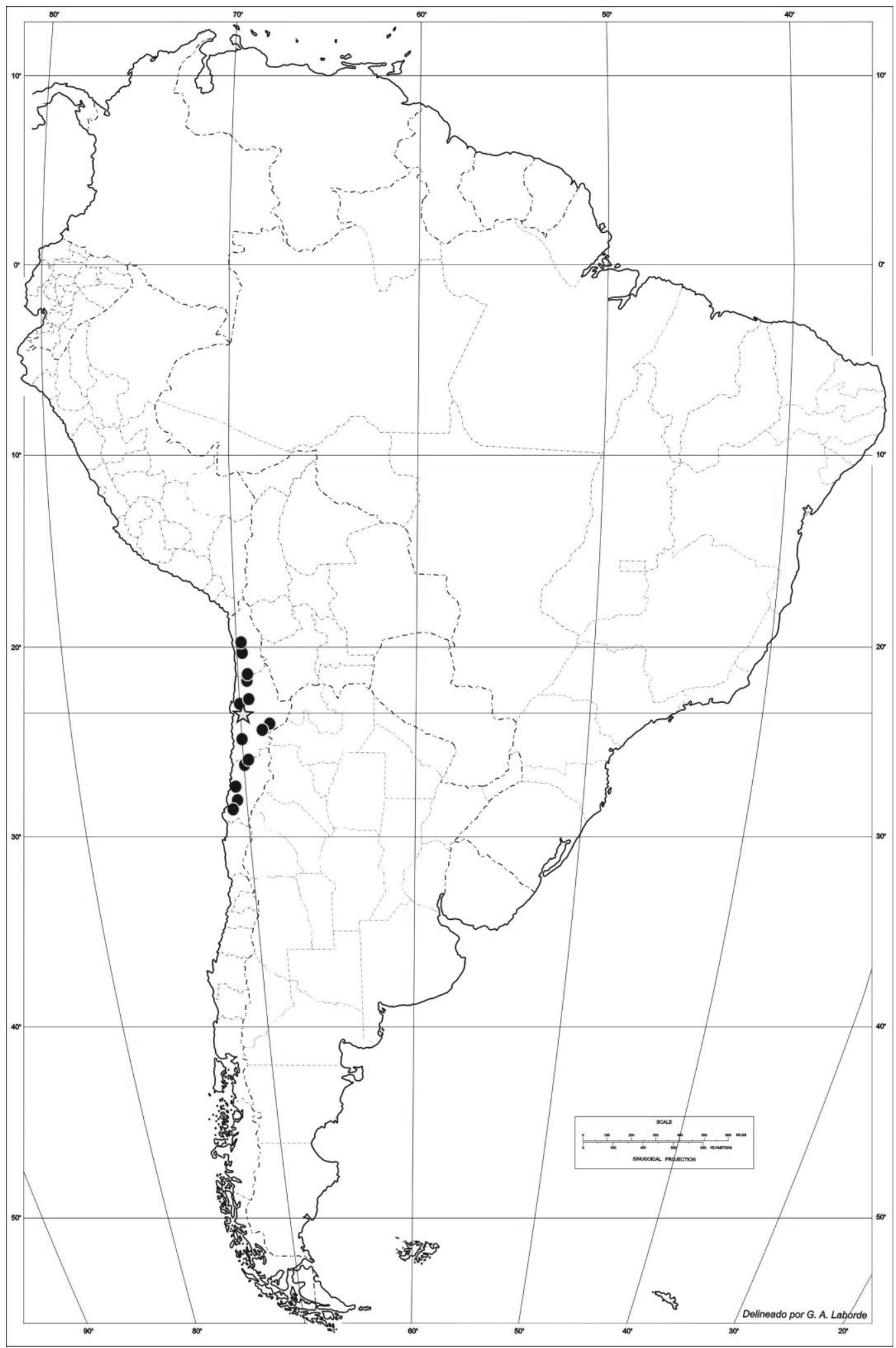

Figura 130. O. triangularis. Distribución geográfica, la estrella indica la localidad tipo. 


\section{Ophryosporus venosissimus (Rusby) B. L. Rob.}

Proceedings of the American Academy of Arts and Sciences 41:271. 1905

玉 Eupatorium venosissimum Rusby. Memoirs of the Torrey Botanical Club 6(1): 57. 1896.

Lectotipo: "Bolivia, Vic. Cochabamba, 1981", M. Bang 1113 (NY 00169259!). Duplicados: GH 00010791 foto!, K 000486673 foto!, M 0029504 foto!, MO 104733 foto!, NY 00169260!, US 00145772!, Z 000003380 foto! (Plos \& Sancho, 2012) Fig. 131.

Arbusto erecto $(1,8 \mathrm{~m})$. Tallo con entrenudos entre 4 y $10 \mathrm{~cm}$, ramificaciones secundarias opuetas, ramas glabras, púrpura, con estriaciones. Hojas opuestas, pecioladas, pecíolo 0,9-1,5 cm, láminas ovadas, 0,1-0,35 X 0,3-0,6 cm, base cuneada, ápice agudo, margen aserrado, plano; consistencia herbácea, venación acródroma imperfecta suprabasal; pubescente y glandulosa, tricomas eglandulares simples cónicos y glandulares (tipo $\beta$ ). Inflorescencia cimoidea, compuesta de corimbos densos, terminal y axilar, con hojas persistentes poco desarrolladas. Capítulos ca. 90-120, pedunculados (1-1,2 mm), 2 × $6 \mathrm{~mm}$. Involucro acampanado, $2 \times 4 \mathrm{~mm}$, filarios 4, eximbricados; en una serie de filarios, ovados, $2 \times 1,2 \mathrm{~mm}$, ápice fimbriado, margen entero, consistencia herbácea, pubescente, tricomas eglandulares simples cónicos. Flores 4, hermafroditas, corola blanca, tubular, $4 \times 1 \mathrm{~mm}$, 5-dentada, lóbulo 0,3 x 0,3 mm; glandulosa en la base de la corola, tricomas glandulares (tipo a). Estambres 5, anteras $2 \times 0,3 \mathrm{~mm}$, collar anteral cilíndrico, base de las tecas auriculada; apéndice conectival rudimentario, entero. Estilo 1,2 x 0,2 mm, largamente exerto, ramas del estilo fuertemente clavadas en el ápice, las ramas $2 \mathrm{~mm}$. Cipsela negra no estipitada, piriforme a levemente falcada, $3,5 \mathrm{~mm}$, marcadamente 5-costada; serícea y glandulosa, pelos gemelos y glandulares (tipo $\alpha$ ) en el tercio inferior; carpopodio anular, excéntrico. Papus formado por 24-26 cerdas blanquecinas, connadas en la base, 3-3,5 mm. Fig. 132.

Fenología: Florece de agosto a abril. 
Distribución: Bolivia (departamentos de La Paz y Cochabamba) a 2500 - 3500 msnm. Habita en bosques de Alnus Mill.-Hesperomeles Lindl., en acantilados y pendientes empinadas. Fig. 133.

\section{Notas:}

2. La descripción original del basónimo es válida a pesar de estar escrita en inglés, ya que fue realizada con fecha anterior al $1^{\circ}$ de enero de 1935 (CNB, artículo 36).

3. De acuerdo a Rusby "near to E. laeve DC." Probablemente a esta similitud se deba a que el espécimen tipo fuera determinado originalmente como $E$. laeve.

Etimología: Adjetivo superlativo del latín venosus, de venas notablemente ramificadas (Stearn 1980, Anónimo 1996- 2005).

Estado de Conservación: La localidad tipo (Monte Tunari) está dentro de los terrenos del Parque Nacional Tunari (Bolivia), fue creado en 1978. Ocupa la región de valles secos mesotérmicos y la Cordillera del Tunari, comprendiendo un ecosistema con diversidad de zonas de vida. La región presenta las características propias de zonas cordilleranas y valles interandinos, con un sistema de cuencas que abastecen de agua a las tierras agrícolas y a la ciudad de Cochabamba.

Especímenes adicionales estudiados: BOLIVIA. Cochabamba: Cercado, Chirimarca, 09/04/1955, Jimenez 46 (LP). La Paz: Murillo, 20/08/1979, Beck 2125 (NY); Inquisivi, 29/05/1990, Lewis 37316 (LPB, MO). 


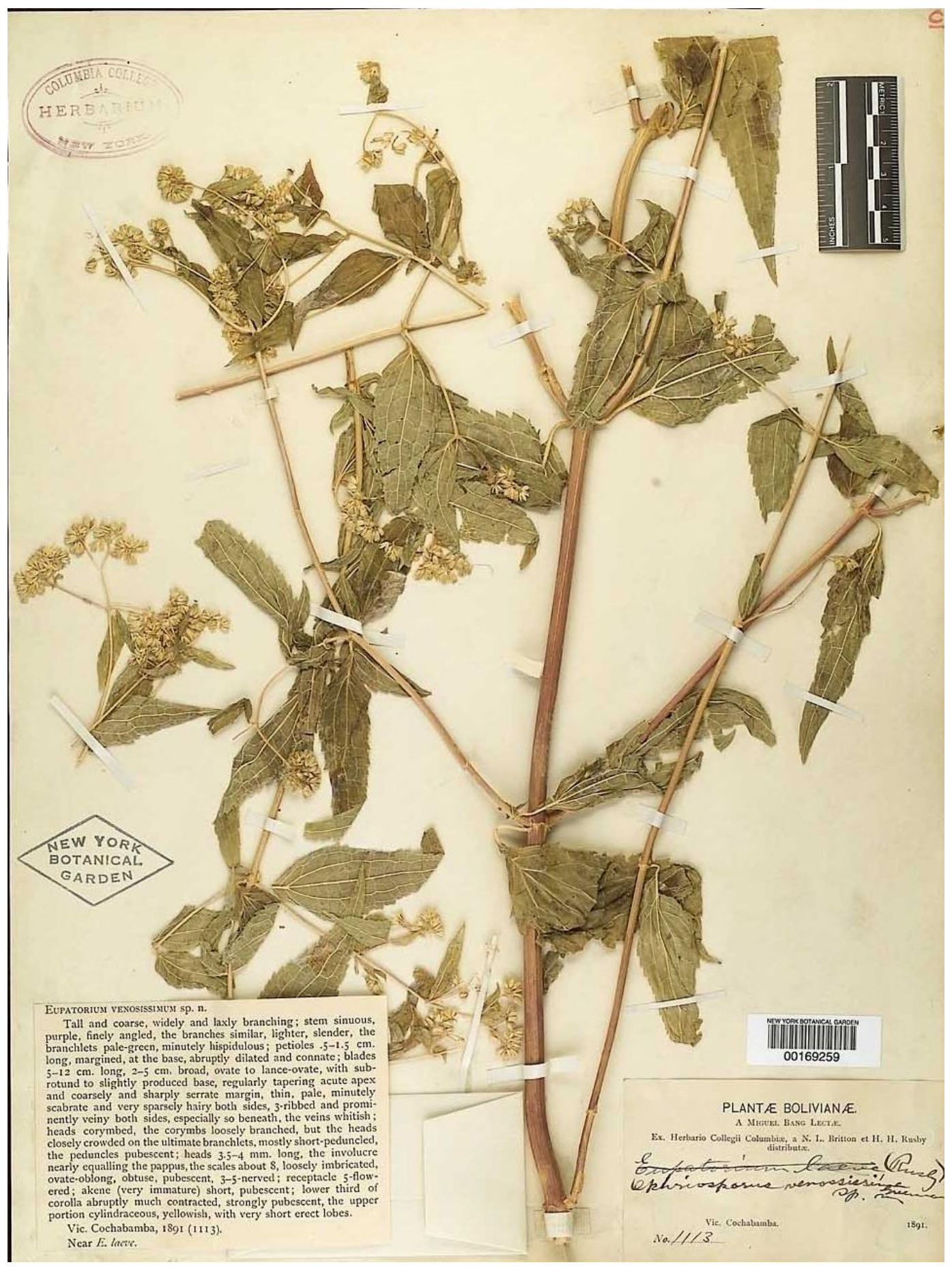

Figura 131. O. venosissimus, lectotipo. M. Bang 1113 (NY). 


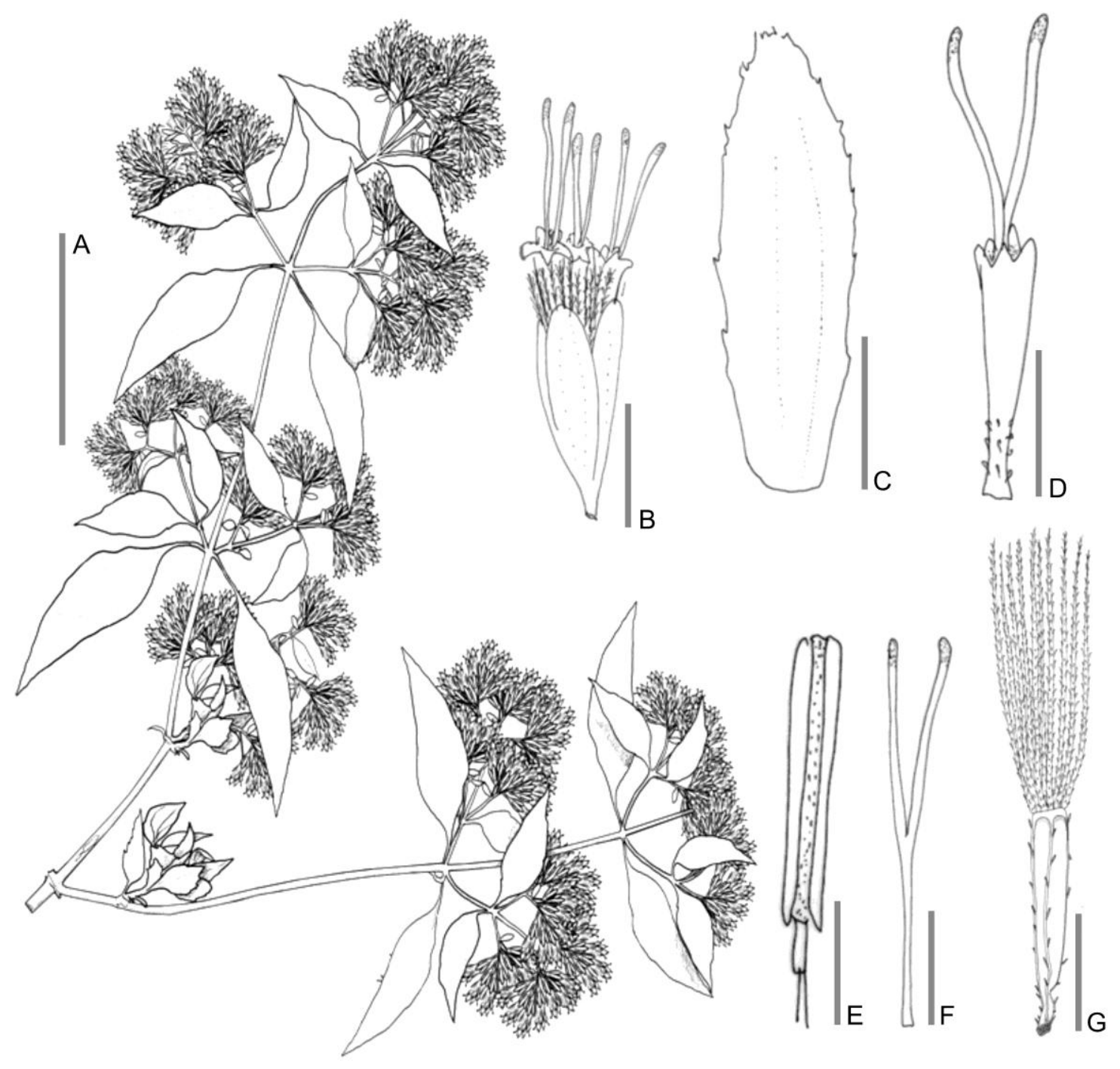

Figura 132. O. venosissimus. A. Rama florífera. B. Capítulo. C. Flor sin papus ni cipsela. D. Filarios. E. Antera. F. Estigma. G. Cipsela. Escalas: A: 2,5 cm; B-C: 2 mm; D-E: 0,7 cm; F-G: 230 нm. (A-G basados en Beck 2125, NY). 


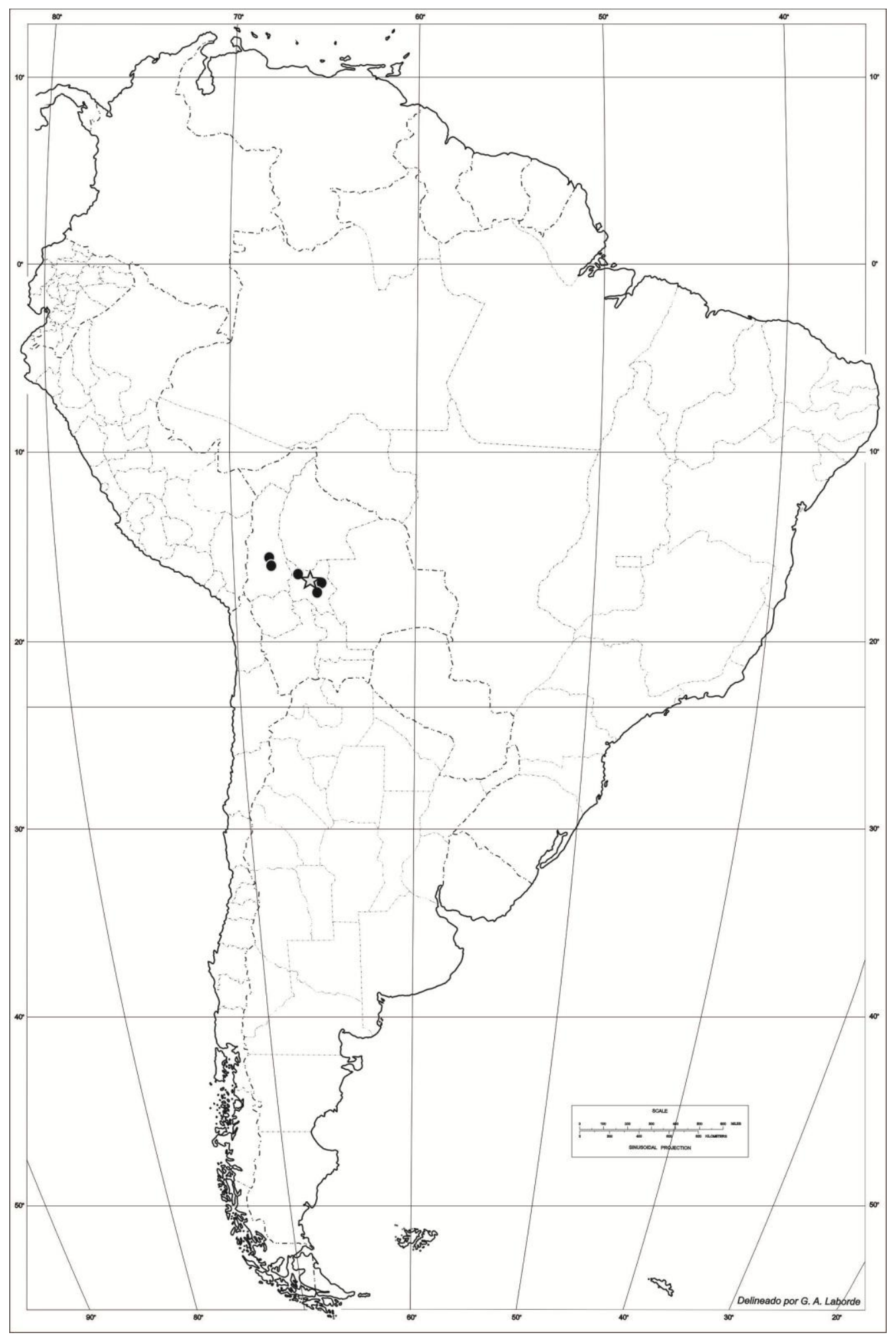

Figura 133. O. venosissimus. Distribución geográfica, la estrella indica la localidad tipo. 


\section{4 - Especies y variedades excluídas}

Ophryosporus burchellii Baker. Flora Brasiliensis 6(2): 187. 1876. Burchell 5180= Koanophyllum tetranthum (Griseb.) R. M. King \& H. Rob. Phytologia 32(3): 264.

三 Eupatorium tetranthum Griseb. FI. Brit. W. Ind. 360. 1861. Burchell 5180.

Nota: Presenta apéndice conectival totalmente desarrollado, por lo tanto no se incluye en el concepto genérico de Ophryosporus.

Ophryosporus ovatifolius (DC.) Benth. \& Hook. f. ex. Hemsl. Biologia CentraliAmericana, Botany 2(7): 79. 1881. = Decachaeta ovatifolia (DC.) R. M. King \& H. Rob. Brittonia 21: 282. 1969.

ミ Nothites ovatifolia DC. Prodr. 5: 187. 1836. Haenke s.n.(G-DC, GH, US). $=$ Eupatorium polybotrium DC. Prodr. 5: 174. 1836. Haenke s.n. (G-DC, US)

Nota: Presenta apéndice conectival totalmente desarrollado, por lo tanto no se incluye en el concepto genérico de Ophryosporus.

Ophryosporus pachychaeta Baker. Flora Brasiliensis 6(2): 187. 1876. Claussen s.n. (G), Lund s.n. (C) = Mikania pachychaeta (Baker) G.M. Barroso. Arquivos do Jardim Botânico do Rio de Janeiro 16: 272. 1958.

= Pachychaeta eupatorioides Sch. Bip. Flora Brasiliensis 6(2): 187. 1876. Nomen nudum.

Nota: Barroso (1958) no comprende la razón por la cual Baker, coloca a este taxón bajo Ophryosporus, ya que el mismo presenta anteras apendiculadas. Este criterio, fue también compartido con Robinson, el cual incluye a Mikania pachychaeta como O. pachychaeta en su revisión de 1906.

Ophryosporus petraeus (B. L. Rob.) B. L. Rob. Contributions from the Gray Herbarium of Harvard University 75: 4. 1925. = Decachaeta ovatifolia (DC.) R. M. King \& H. Rob. Brittonia 21: 282. 1969.

三 Eupatorium petraeum B. L. Rob. Proceedings of the American Academy of Arts and Sciences 41: 275. 1905. Langlasse $565(\mathrm{GH})$. 
Nota: Robinson (1905) considera a E. petraeum como una transición hacia el género Ophryosporus debido a la forma de sus anteras. Pero la modificación de la parte superior del conectivo en un tejido esponjoso genera una estructura que se considera un apéndice anteral.

Ophryosporus scabrellus (B. L. Rob.) B. L. Rob. Contributions from the Gray Herbarium of Harvard University 74: 4. 1929 = Decachaeta scabrella (B.L. Rob.) R.M. King \& H. Rob. Brittonia 21: 283. 1969.

E Eupatorium scabrellum B. L. Rob. Proceedings of the American Academy of Arts and Sciences 35(16): 339-340. 1900. Goldman 197 (US, GH)

Nota: Presenta apéndice conectival totalmente desarrollado, por lo tanto no cumple con el concepto genérico de Ophryosporus.

Ophryosporus solidaginoides (Kunth) Hieron. Botanische Jahrbücher für Systematik, Pflanzengeschichte und Pflanzengeographie 29: 4. 1901. = Koanophyllon solidaginoides (Kunth) R.M. King \& H. Rob. Phytologia 22(3): 151. 1971.

三 Eupatorium solidaginoides Kunth. Nova Genera et Species Plantarum (folio ed.) 4: 99.1820 [1818]. Humboldt \& Bonpland s.n. (P).

Nota: Presenta apéndice conectival totalmente desarrollado, por lo tanto no cumple con el concepto genérico de Ophryosporus.

Ophryosporus solidaginoides var. bonplandiana Hieron. Botanische Jahrbücher für Systematik, Pflanzengeschichte und Pflanzengeographie 29: 4. 1901.

ミEupatorium bonplandianum Schultz-Bip.

Nota: Presenta apéndice conectival totalmente desarrollado, por lo tanto no cumple con el concepto genérico de Ophryosporus. 


\section{X- ANÁLISIS CLADÍSTICO}

\section{1 - Antecedentes.}

Como indicado anteriormente, el género Ophryosporus se encuentra incluido en la subtribu Critoniinae, tribu Eupatorieae (King \& Robinson, 1987). Según se observa en diferentes estudios previos (King \& Robinson, 1987; Bremer, 1994; Hind \& Robinson, 2007; Robinson et al., 2009) las relaciones filogenéticas dentro de la tribu Eupatorieae no están resueltas y la información aportada por diferentes fuentes de caracteres resulta muchas veces contradictoria. Dado que la tribu Eupatorieae comprende alrededor de 2500 géneros, resulta sumamente complejo realizar un muestreo adecuado de la misma, y por esta razón, las relaciones entre los géneros varían de acuerdo al muestreo y al set de caracteres utilizado (Bremer, 1994).

King \& Robinson (1987) en su monografía de la tribu Eupatorieae re-analizan los géneros y sus límites y describen 18 subtribus basándose en el criterio morfológico clásico (fundamentalmente sobre el uso de microcaracteres anatómicos y morfológicos en común) sin realizar análisis filogenéticos para el establecimiento de los grupos. Sin embargo, actualmente la sistemática filogenética (Henning 1950, 1965, 1966) es la metodología más aceptada para la inferencia de relaciones entre taxa y que basa los agrupamientos en caracteres homólogos derivados compartidos, restringidos a dicho grupo (sinapomorfías).

Bremer (1994) realizó un estudio filogenético en Eupatorieae en base a datos morfológicos que muestran a la subtribu Critoniinae como estrechamente relacionada con la subtribu Hebecliniinae, Neomirandeinae y Alomiinae. Esta relación estuvo sustentada por la presencia de ramas del estilo lisas a mamilosas (prorrulosas). Más recientemente, Ito et al. (2000) y Robinson et al. (2009) muestran en un estudio filogenético (basado en nITS) que la subtribu Critoniinae es hermana de Fleischmaniinae y Ageratinae, aunque el número de géneros incluidos en el análisis es escaso (uno por cada subtribu). 
Dos géneros de Critoniinae, Koanophyllon y Cronquistianthus han sido señalados como posiblemente cercanos a Ophryosporus, por compartir caracteres de anteras, estilo y cipsela (ver Sección III: Relaciones Intergenéricas). Hasta el momento, no se han realizado estudios filogenéticos que incluyan a Koanophyllon y Cronquistianthus que permitan confirmar las relaciones de Ophryosporus con los mismos.

El análisis cladístico desarrollado en esta tesis, presenta los siguientes objetivos:

1. Testear, de forma preliminar, las relaciones filogenéticas de Ophryosporus, Koanophyllon y Cronquistianthus.

2. Comprobar la monofilia del género Ophryosporus.

3. Establecer las relaciones filogenéticas entre las especies de dicho género.

\section{2 - Metodología.}

a. Elección del grupo externo: Sobre la base de los estudios filogenéticos previos (Bremer et al. 1994; Schmidt \& Schilling, 2000; Robinson, et al., 2009), los criterios de agrupamientos en subtribus de King \& Robinson (1987) y observaciones personales, se eligieron especies pertenecientes a los géneros Critonia, Cronquistianthus, Koanophyllon, (los tres pertenecientes a la subtribu Critoniinae) y Fleischmannia Sch. Bip. (subtribu Fleischmanniinae) para conformar el outgroup o grupo externo (Nixon \& Carpenter, 1993). En la elección de especies del grupo externo se procuró incluir la especie tipo y aquellas que, en conjunto, representen el rango más amplio de distribución para el género.

El género Critonia está conformado por 40 especies, las cuales presentan una distribución amplia, desde México hasta Argentina. Para el análisis cladístico se incluyeron tres especies $C$. daleoides DC. (México hasta Panamá), C. megaphylla (Baker) R. M. King \& H. Rob. (Argentina, Brasil y Paraguay) y C. morifolia (Miller) R. M. King \& H. Rob. (México, Guatemala, Bélice, El Salvador, Honduras, 
Nicaragua, Costa Rica, Panamá, Colombia, Venezuela, Ecuador, Perú, Bolivia y Brasil).

El género Cronquistianthus está conformado por 25 especies, con una distribución restringida a Colombia, Ecuador y Perú. Para el análisis cladístico se incluyó una especie, C. callacatensis (Hieron.) R. M. King \& H. Rob., la cual habita en Perú.

El género Koanophyllon presenta 114 especies, con una distribución que abarca México, América Central y Sudamérica. Para el análisis cladístico se incluyeron tres especies K. simillimum (B. L. Rob.) R. M. King \& H. Rob (Argentina, Paraguay), K. solidaginoides (H. B. K.) R. M. King \& H. Rob. (México, América Central, Colombia, Ecuador, Venezuela, Ecuador, Perú, Brasil y Argentina) y $K$. stipuliferum (Rusby) R. M. King \& H. Rob. (Argentina, Bolivia).

El género Fleischmannia se compone de 79 especies, con una distribución amplia, desde el sur de Estados Unidos hasta Argentina. Para el análisis cladístico se incluyó una especie, F. arguta (H. B. K.) B. L. Rob. (México, Guatemala, Honduras, Nicaragua, Costa Rica). Este género fue considerado como grupo hermano de las restantes taxa analizados (Ito et al., 2000; Robinson et al., 2009).

Los especímenes de herbario utilizados para el análisis de caracteres en el grupo externo, se listan en el Anexo II.

\section{b. Grupo interno:}

Las 41 especies de Ophryosporus conformaron el grupo interno en el análisis.

Los especímenes de herbario utilizados para el análisis de caracteres en el grupo interno Ophryosporus, corresponden a los del análisis morfológico (Sección IV).

El total de taxones tanto del grupo interno como externo, incluidos en el análisis cladístico fue de 49 especies.

\section{c. Codificación y análisis:}


Para la realización del análisis cladístico, se consideraron 61 caracteres cualitativos. De ellos, 24 caracteres fueron vegetativos y 37 reproductivos. En la tabla 2 se detallan los caracteres y los estados utilizados en el análisis. De los 61 caracteres, 59 fueron binarios. Los caracteres multiestado (23 y 27) fueron considerados como no aditivos (desordenados). La elección de los caracteres cualitativos utilizados en el análisis cladístico se realizó sobre la base de trabajos de B. L. Robinson (1905, 1906a, 1906b, 1919, 1920, 1924, 1925, 1926, 1928 у 1930), Bremer et al. (1994), King \& Robinson (1987), Hind \& Robinson (2007) y Robinson et al. (2009) como así también, observaciones personales de las especies.

La matriz de datos fue confeccionada en base a los caracteres de la tabla 2 y fue analizada bajo el criterio de parsimonia con el programa TNT versión 1.1 (Goloboff et al., 2008). Se realizó una búsqueda heurística, comenzando con árboles de Wagner como punto de partida, con 1000 réplicas de RAS (random addition sequence) más TBR (tree bisection-reconection) como criterio de reorganización de las ramas y se salvaron 100 árboles en cada réplica. Se generaron árboles de consenso estricto y mayoría. Luego, para comparación de resultados, se analizó la matriz con los mismos parámetros de búsqueda anteriores, pero aplicando pesos implicados. Los pesos de los caracteres no fueron dados a priori, sino que fueron asignados durante la búsqueda de árboles, resolviendo el conflicto en favor de caracteres menos homoplásicos. La depreciación de los caracteres homoplásicos fue calculada de acuerdo a la función de la concavidad de la homoplasia (Farris, 1969; Goloboff, 1993). El grado de intensidad de esta función es determinado por la constante $k$. En el presente análisis se usó una concavidad de k:3. Además se testearon otras concavidades ( $k: 5, k: 9, k: 12$ ), las cuales se descartaron, ya que la concavidad $k: 3$ fue la que generó mayor resolución en los cladogramas.

Se calcularon los índices de consistencia $(\mathrm{Ci})$ y de retención (Ri) de los árboles más cortos obtenidos en las búsquedas. 
Para evaluar el soporte de las ramas, se aplicaron los análisis Jacknife (JN) (Farris et al., 1996) y Bootstrap (BS) (Felsensten, 1985), generados a partir de 1000 réplicas en el programa TNT; se estableció un límite inferior de 50 en ambos análisis.

En la matriz de datos, los datos faltantes se codificaron con '-' y los no aplicables con '?', aunque el programa TNT los trata de igual manera al calcular los árboles.

\section{4 - Resultados.}

Mediante la búsqueda heurística, se obtuvieron 120 árboles más cortos a partir de la matriz de datos, con una longitud de 250 pasos. Los valores de los índices obtenidos fueron $\mathrm{Ci}: 0,266-0,268$ y $\mathrm{Ri}: 0,582-0,587$. La figura 134 muestra el cladograma de consenso estricto obtenido, con los valores de soporte de Bootstrap (por encima de la rama) y Jacknife mayores a 50 (por debajo de la rama). El consenso de mayoría mostró un árbol semejante al de consenso estricto, salvo por la resolución de $O$. pubescens y $O$. floribundus, en un clado hermano del grupo que contiene a $O$. hoppii.

Del análisis generado a partir de la búsqueda heurística utilizando pesos implicados, se obtuvieron 21 árboles, con una longitud entre 263 y 265 pasos. Los valores de los índices obtenidos fueron Ci: 0,253-0,255 y Ri: 0,553-0,558. La figura 135 muestra al cladograma de consenso estricto obtenido bajo pesos implicados y en detalle, el clado $\mathrm{B}$ como fue obtenido en el consenso de mayoría, que resuelve parte de las especies obtenidas en politomías en el árbol de consenso estricto (B').

Al comparar los análisis generados en las búsquedas heurísticas bajo pesos iguales (figura 134) y con pesos implicados (figura 135), podemos observar en ambos casos a Cronquistianthus callacatensis como hermano del resto de la subtribu Critoniinae. El clado conformado por los grupos monofiléticos Koanophyllon + Critonia por un lado y Ophryosporus por otro, registró valores de soporte de Bootstrap (BS) y Jacknife (JN) únicamente para la búsqueda heurística sin los pesos implicados, siendo los valores BS: 52 y JN: 59 (figura 134). 
El grupo monofilético que agrupa a Critonia, se encuentra soportado, en ambas búsquedas, con altos valores tanto para Bootstrap como para Jacknife: en la búsqueda heurística sin pesos implicados (figura 134) BS: 97 y JN: 99 y para la búsqueda con pesos implicados (figura 135) BT: 95 y JN: 99.

Ophryosporus se presenta como monofilético en ambas búsquedas y su topología es muy similar tanto para la búsqueda sin (figura 134) y con pesos implicados (figura 135) mostrando dos clados principales (A y B) y dos terminales (O. ovatus y $O$. serratifolius). El clado que incluye a todas las especies de Ophryosporus, registró valores tanto de Bootstrap como Jacknife superiores a $50 \%$ en ambas búsquedas: para la búsqueda heurística (figura 134) BS: 65 y JN: 61 y para la búsqueda con pesos implicados (figura 135) fueron mayores en ambos casos BS: 84 y JN: 95. Además, en la búsqueda con pesos implicados, sólo se registró soporte de Jacknife mayor al $50 \%$, para un grupo de especies dentro del clado A, específicamente el clado hermano de $O$. galioides, con un valor de JN: 51.

Uno de los 21 árboles más cortos, obtenidos por búsqueda heurística bajo pesos implicados (figura 136), muestra al grupo que contiene a Koanophyllon, Critonia y Ophryosporus sustentado por la presencia de estriaciones en el tallo (6:1), corolas blancas, verdosas a amarillentas (39:1) y por cipselas pirifomes (52:1). Dicho clado incluye otros dos clados: el primero que contiene a Koanophyllon + Critonia y está caracterizado por ser plantas de una altura superior a 2 m (2:1) y tener la corola pubescente (42:1); y el segundo clado contiene a Ophryosporus. Las especies de Koanophyllon incluidas en este estudio forman un grupo monofilético, sustentado por la presencia de un nectario en el estilopodio desarrollado (51:1) y dentro de dicho clado $K$. stipulliferum y $K$. solidaginoides forman otro grupo monofilético, definido por la presencia de ramas del estilo clavadas (48:1). El clado que incluye a las especies de Critonia, se encuentra definido por tallos hexagonales en corte transversal (7:1), venación pinnada de las láminas foliares (11:1), áreas de la lámina foliar superiores a $4500 \mathrm{~mm}^{2}$ (12:2), consistencia cartácea de la lámina foliar (18:2), ausencia de tricomas glandulares en la lámina foliar (22:1), involucros cilíndricos (30:1), disposición imbricada de los 
filarios (32:1), caducidad de alguna de las series del involucro (34:1) y por la presencia de filarios graduados (35:1). Este clado, finalmente, muestra a $C$. morifolia y $C$. megaphylla como hermanas en un clado soportado por corolas de color rosado o púrpura (39:0).

Todas las especies de Ophryosporus conformaron un grupo monofilético definido por la presencia de involucros de hasta 8 filarios (31:1), el involucro conformado por 1 o 2 series de filarios (33:1), hasta 8 flores por capítulo (38:1), apéndices conectivales de las anteras nulos o muy rudimentarios (44:1), ramas del estilo clavadas (48:1) y por células del carpopodio heteromorfas (60:1).

Dicho clado muestra una politomía, constituida por dos terminales (O. ovatus y O. serratifolius) y dos clados, indicados como A y B en la figura 136 . El clado A se encuentra definido por la presencia de involucros cilíndricos (30:1), pubescencia en las cipselas (56:1) y la ausencia de papus (61:2) ( $O$. anomalus, $O$. bipinnatifidus, O. densiflorus, O. floribundus, O. galioides, O. hartwegii, O. hoppii, O. johnstonii, O. marchii, O. mathewsii, O.pubescens, O. peruvianus, O. pinifolius, $O$. paradoxus y $O$. triangularis). El clado $\mathrm{B}$, se encuentra definido por la presencia de tallos color púrpura o rojizos (5:1) (O. angustifolius, $O$. apricus, $O$. axilliflorus, $O$. burkartii, 0 . carchiensis, 0 . charua, $O$. chilca, $O$. cumingii, $O$. eleutherantherus, $O$. ferreyrii, O. freyreisii, O. heptanthus, O. kuntzei, O. laxiflorus, O. lorentzii, O. macbridei, 0 . macrodon, $O$. organensis, 0 . piquerioides, 0 . regnellii, $O$. sagasteguii, $O$. sodiroi, $O$. steinbachii y 0 . venosissimus).

El clado A muestra una politomía conformada por O. marchii, O. mathewsii y el clado definido por presentar entrenudos rudimentarios (3:1), que incluye a $O$. densiflorus y su grupo hermano; este último está definido por la presencia de resinas en el exterior de la planta (8:1) y está conformado, a su vez, por otros dos grupos monofiléticos: uno que contiene a $O$. pubescens y $O$. floribundus, soportado por la presencia de cipselas glabras (56:0) y el segundo (O. anomalus, O. bipinnatifidus, O. galioides, O. hartwegii, O. hoppii, O. johnstonii, O. paradoxus, $O$. peruvianus, $O$. pinifolius y $O$. triangularis) definido por hojas alternas, en fascículos (9:1), pecíolos rudimentarios (10:1) y por poseer inflorescencias 
foliosas, con hojas semejantes a las presentes en el eje principal (29:1). En cuanto al grupo hermano de $O$. galioides se encuentra caracterizado por la ausencia de hidatodos en los dientes del margen foliar (15:1) y la presencia de inflorescencias tirsoideas (24:1). Este clado, se resuelve en dos grupos, uno que incluye a $O$. peruvianus y $O$. hartwegii, definido por inflorescencias conformadas por más de 100 capítulos (28:1) y flores infundibuliformes abruptamente diferenciadas entre tubo y limbo (41:2); y un segundo grupo, caracterizado por la presencia de cipselas pubescentes (56:0), que contiene al grupo monofilético de O. pinifolius y su grupo hermano. Dentro de dicho clado, se encuentran las especies que poseen hojas con áreas foliares pequeñas, inferiores a $25 \mathrm{~mm}^{2}$ hasta $225 \mathrm{~mm}^{2}$ (12:1). Este clado que contiene al grupo hermano de $O$. anomalus, se encuentra soportado por cipselas sin papus (61:2) e incluye a $O$. bipinnatifidus, $O$. hoppii, $O$. johnstonii, $O$. paradoxus y $O$. triangularis. Por la presencia de pecíolos rudimentarios (10:1) y margen foliar revoluto (17:1), se define el grupo monofilético que contiene a $O$. hoppii, esta especie a su vez como especie hermana del clado que incluye a $O$. bipinnatifidus, O.johnstonii y $O$. triangularis, caracterizado por la presencia de láminas lobuladas (13:1). O. johnstonii se muestra como especie hermana del clado que agrupa a $O$. bipinnatifidus y $O$. triangularis, el cual está sustentado por la presencia de hojas con margen lobulado (14:2) y pubescencia densa en la lámina foliar (21:1).

El clado B, muestra dos grupos monofiléticos: uno que agrupa a $O$. macbridei y O. steinbachii sustentado por la presencia de hidatodos en la lámina foliar (15:1) y por tener cipselas con pubescencia sectorizada (57:1); y el segundo clado definido por cipselas con su base distorsionada (55:1). Este segundo clado presenta dos grupos monofiléticos, uno que contiene a $O$. heptanthus y su grupo hermano y otro conformado por una politomía e incluye a $O$. lorentzii y tres grupos monofiléticos. El clado que contiene a $O$. heptanthus se caracteriza por la presencia de cipselas falcadas (53:1) y con tricomas glandulares (58:1); el clado que contiene a $O$. ferreyrii y $O$. sodiroi, se caracteriza por el hábito apoyante (1:1), las corolas sin pelos glandulares (43:0) y por tener anteras auriculadas (47:1). La politomía que contiene a $O$. lorentzii y tres grupos monofiléticos, se define por inflorescencias 
formadas por más de 100 capítulos (28:1); el clado que contiene a 0 . chilca y $O$. angustifolius, se caracteriza por poseer inflorescencias foliosas, con hojas no reducidas (29:1); el siguiente grupo, que contiene a $O$. burkartii, $O$. piquerioides y O. kuntzei, se caracteriza por carecer de tricomas glandulares en hojas (22:1) y cipselas no estipitadas (54:0), donde $O$. burkatii aparece como grupo hermano del clado que reúne a las especies con ausencia de tricomas glandulares en filarios (37:1) y células del carpopodio isomorfas (60:0) (O. piquerioides y O. kuntzei). El tercer grupo monofilético que conforma la politomía (que incluye a $O$. apricus, $O$. axilliflorus, $O$. carchiensis, $O$. charua, 0 . cumingii, $O$. eleutherantherus, $O$. freyreisii, O. laxiflorus, O. macrodon, O. organensis, O. regnellii, O. sagasteguii y O. venosissimus), se caracteriza por corolas con un paso abrupto entre el tubo y el limbo (41:2). El grupo hermano de $O$. macrodon, se caracteriza por tener cipselas no estipitadas (54:1) y contiene dos grupos: el primero, definido por la presencia de tricomas glandulares en la cipsela (58:0) y que contiene a $O$. eleutherantherus y O. sagasteguii; y el segundo, que se caracteriza por la presencia de tricomas glandulares sin cabeza diferenciada (23:1) y por filarios pubescentes (36:1). E clado que contiene a las especies hermanas de $O$. venosissimus, presenta especies con hábito apoyante (1:1) y láminas foliares sin tricomas glandulares (22:1). Dicho clado está compuesto por dos grupos monofiléticos: el grupo que contiene a $O$. charua está definido por inflorescencias parciales glomerulares (25:2), y el otro grupo que contiene a $O$. organensis está caracterizado por células del carpopodio isomorfas (60:0). El clado conformado por las especies hermanas de $O$. charua $(O$. axilliflorus y $O$. cumingii) se caracteriza por presentar cipselas con base distorsionada (55:0). En tanto que el clado que incluye a las especies hermanas de $O$. organensis está soportado por la presencia de tricomas glandulares en la cipsela (58:1). El grupo monofilético que incluye a $O$. freyreisii aparece sustentado por la presencia de inflorescencias densas (26:0) y corolas con paso gradual entre tubo y limbo (41:1). El grupo monofilético que contiene a O. apricus está definido por tener tallos color marrón (5:0) y cipselas estipitadas (54:1). A su vez, O. apricus aparece como especie hermana del clado formado por 
O. carchiensis y $O$. laxiflorus, que se encuentra soportado por la presencia de tallos tomentosos (4:1) y cipselas sin tricomas glandulares (58:0). 


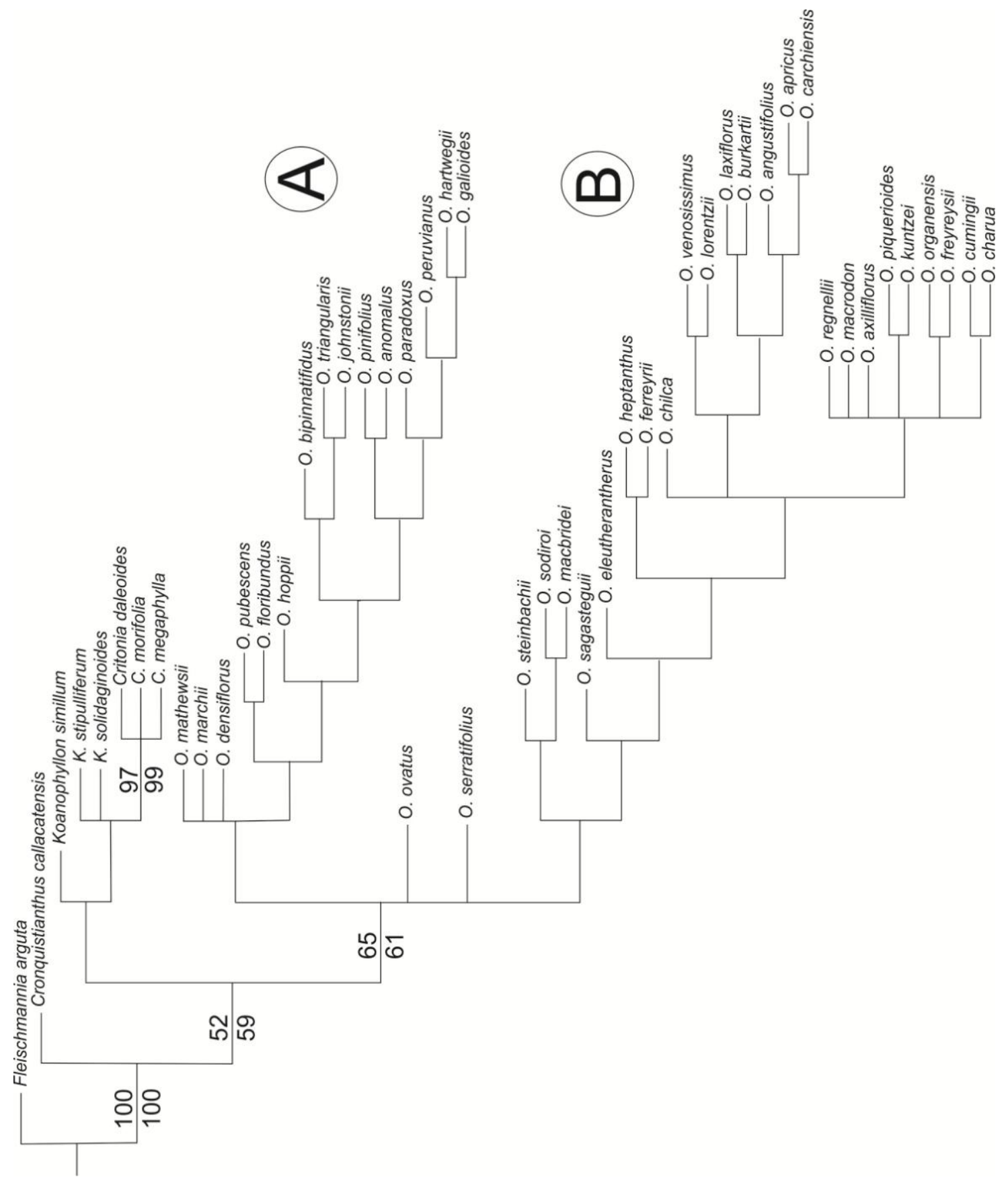

Figura 134. Cladograma de consenso estricto obtenido, con los valores de soporte de Bootstrap (por encima de la rama) y Jacknife mayores a 50 (por debajo de la rama). Los valores de los índices obtenidos fueron $\mathrm{Ci}$ : 0,266-0,268 y Ri: 0,5820,587 . 


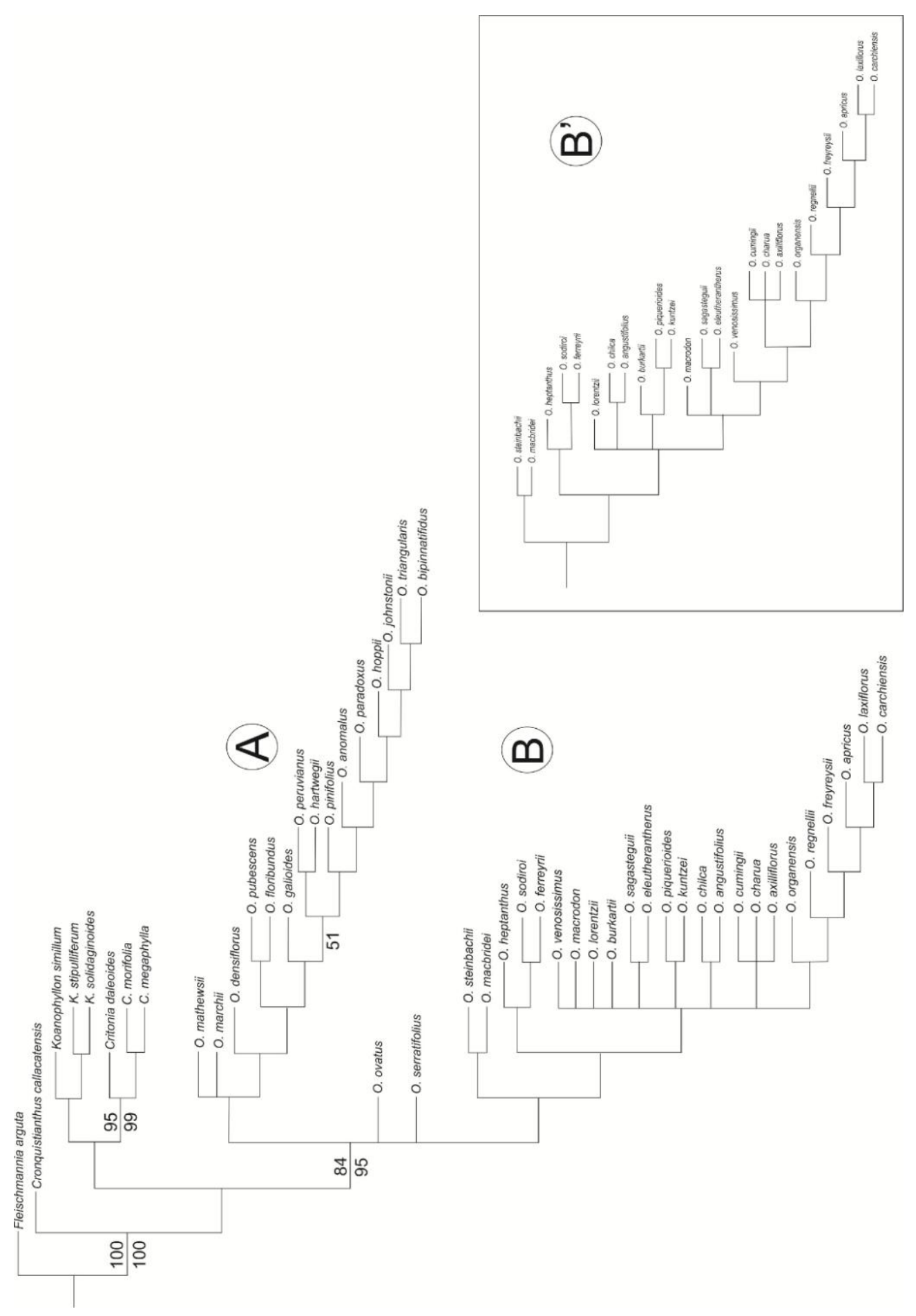

Figura 135. Cladograma de consenso estricto obtenido con pesos implicados y en detalle, el clado $\mathrm{B}$ como fue obtenido en el consenso de mayoría, que resuelve parte de las especies obtenidas en politomías en el árbol de consenso estricto (B'). Se muestran los valores de soporte de Bootstrap (por encima de la rama) y Jacknife mayores a 50 (por debajo de la rama). Los valores de los índices obtenidos fueron Ci: 0,253-0,255 y Ri: 0,553-0,558. 


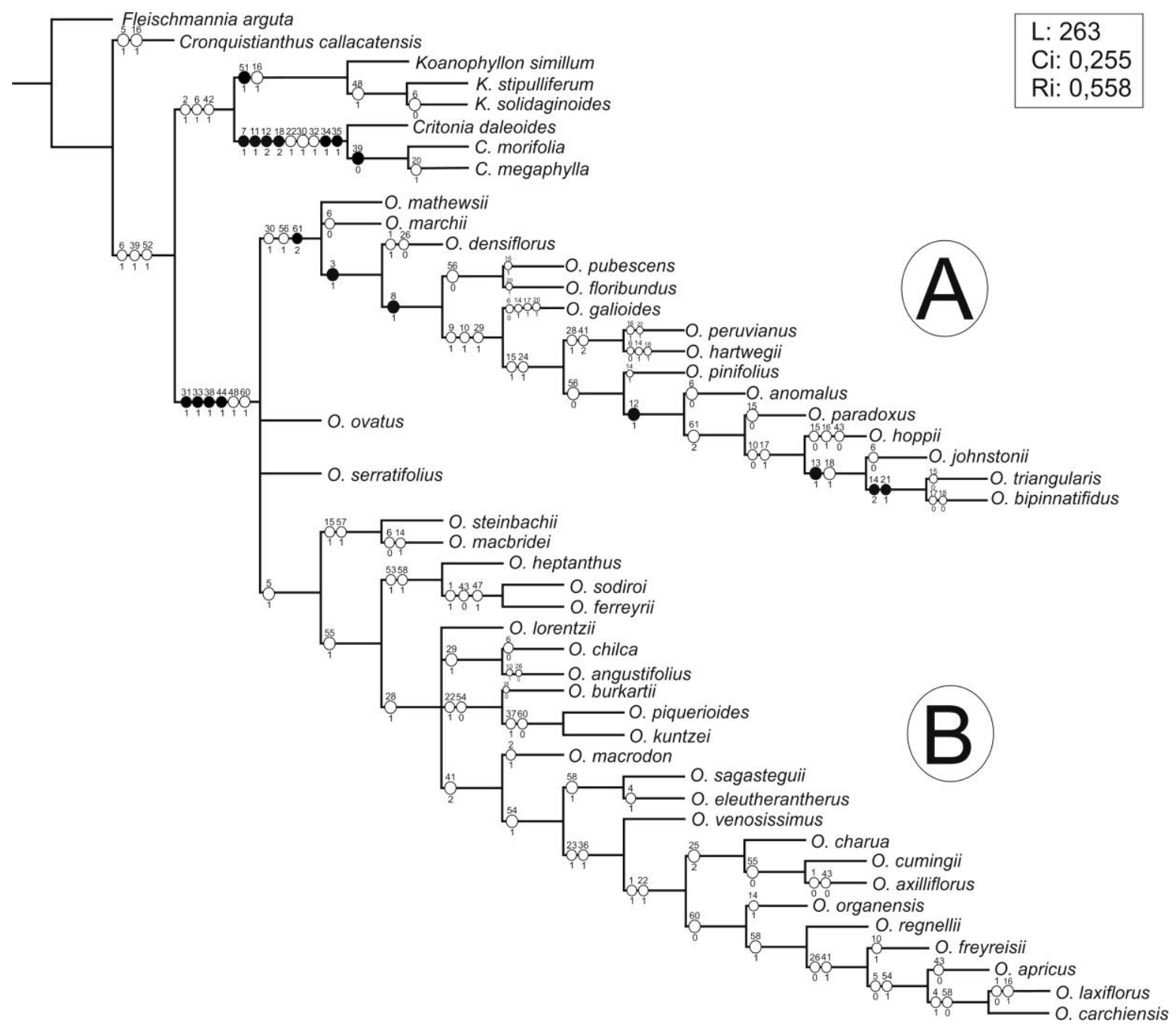

Figura 136. Uno de los 21 árboles más cortos, obtenidos por búsqueda heurística bajo pesos implicados. Las sinapomorfías que sustentan las ramas se muestran como círculos negros, los círculos blancos indican caracteres homoplásicos (paralelismos y reversiones). 


\section{Matriz de datos utilizados.}

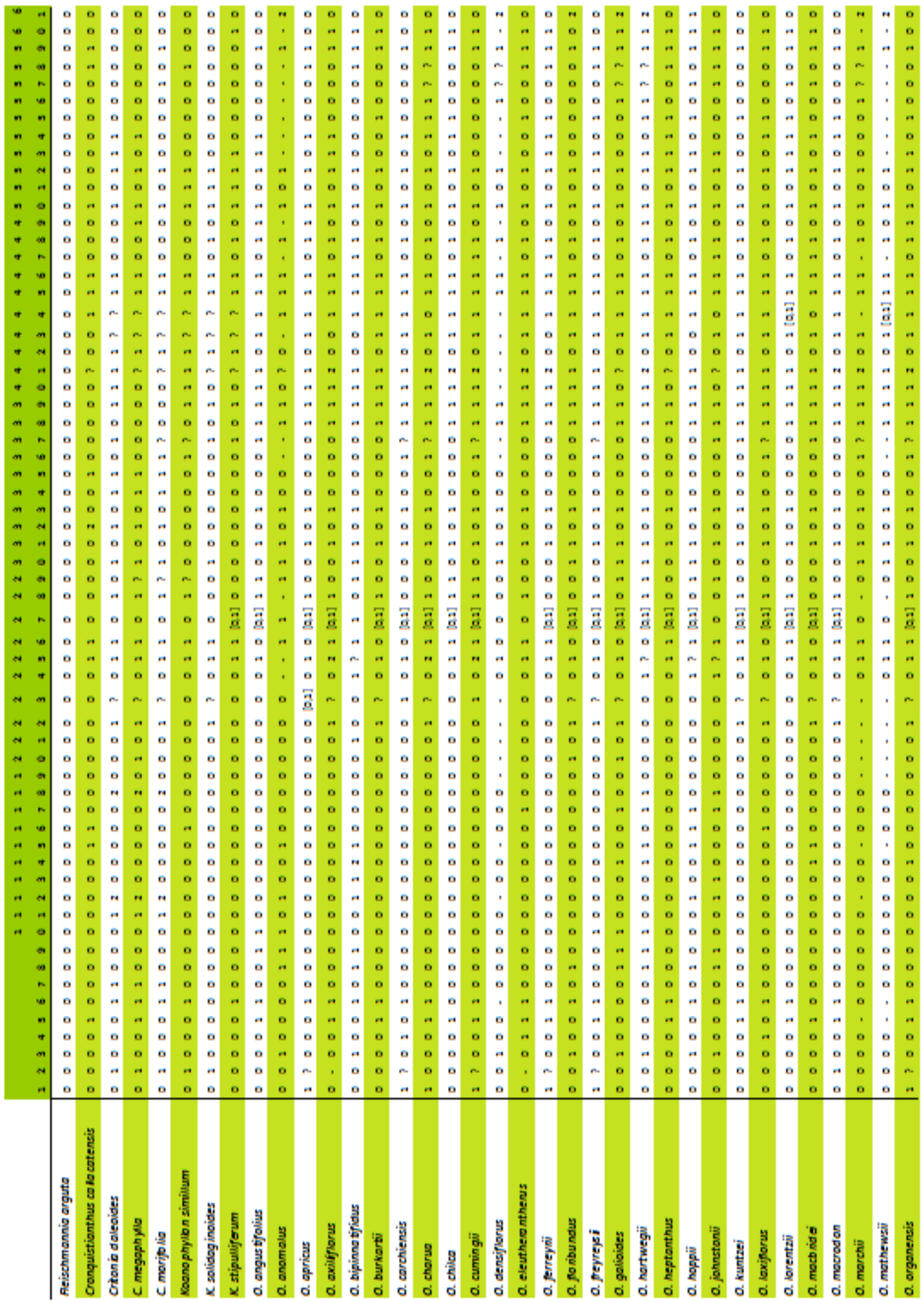


Cont. Matriz.
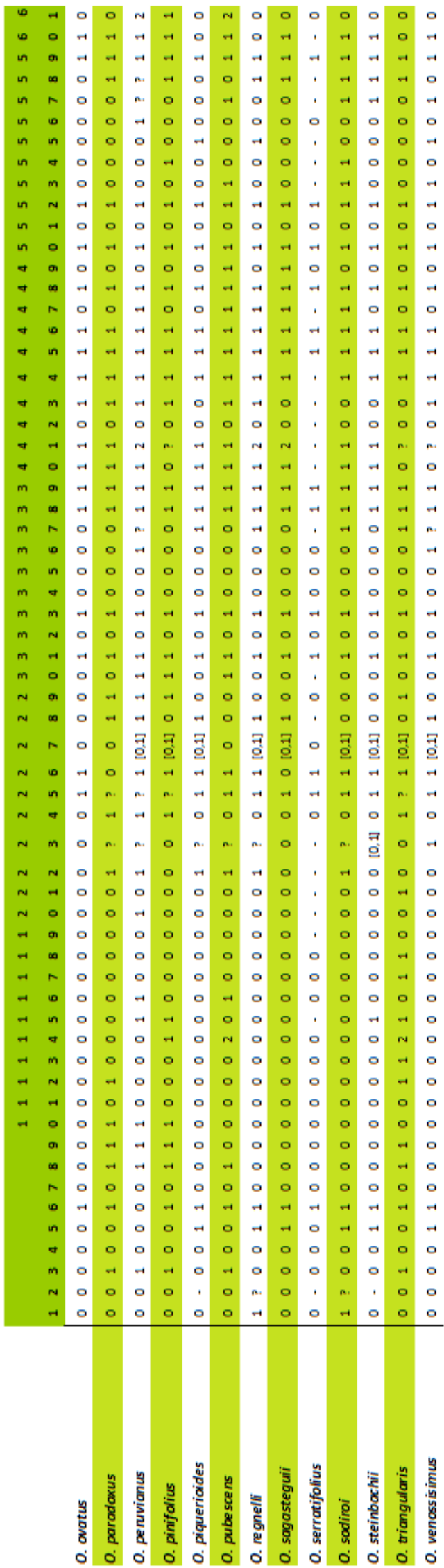


\section{5 - Discusión.}

\section{a- Relaciones intergenéricas de Ophryosporus.}

Como se puntualizó anteriormente, dos géneros, Koanophyllon y Cronquistianthus han sido señalados como cercanos a Ophryosporus (King \& Robinson, 1987). Si bien especies pertenecientes a Koanophyllon presentan apéndices conectivales rudimentarios, ramas estigmáticas largas, y en algunos casos presentan involucros eximbricados, igual que en Ophryosporus, en la mayoría de sus especies tienen una extrema reducción de los apéndices conectivales (aunque no en todas) siendo este último caracter lo que lo diferencia de Koanophyllon. Los resultados obtenidos a partir del análisis cladístico, muestran a las especies de Koanophyllon y Critonia, incluidas en este estudio, como grupos hermanos de Ophryosporus, confirmando cierta cercanía de Koanophyllon con este último género, indicada por otros autores. La presencia de carpopodio excéntrico en la cipsela acercan a Cronquistianthus y Ophryosporus, aunque Cronquistianthus difiere de Ophryosporus por sus apéndices conectivales bien desarrollados e involucros fuertemente imbricados. A pesar de las similitudes con Cronquistianthus, el presente análisis muestra que este género no se encuentra tan estrechamente relacionado con Ophryosporus. La ocurrencia de los caracteres similares en ambos géneros se debería a fenómenos de paralelismo y no a la presencia de un ancestro cercano en común.

\section{b- Monofilia y taxonomía infragenérica de Ophryosporus.}

Tanto los resultados del análisis bajo pesos iguales como el de pesos implicados confirman la monofilia del género Ophryosporus, la cual se encuentra sustentada por la presencia de involucros de hasta 8 filarios, dispuestos en con 1 o 2 series, hasta 8 flores por capítulo, apéndices conectivales de las anteras nulos o muy rudimentarios, ramas del estilo clavadas y por células del carpopodio heteromorfas.

B. L. Robinson (1906) caracterizó al género Ophryosporus por sus involucros sub-simples (con 1 o 2 series de filarios), apéndices conectivales nulos o muy rudimentarios, ramas del estilo clavadas y papus formado por cerdas. Estos 
caracteres son consistentes con los que sustentan la monofilia de Ophryosporus en la presente tesis, a excepción de las células heteremorfas del carpopodio y del papus formado por cerdas. Esto se debe a que, por un lado B. L. Robinson no utilizaba microcaracteres (tal como las forma de las células del carpopodio) para definir especies en Eupatorieae y por otro a que el concepto actual de Ophryosporus (King \& Robinson, 1972) es mucho más amplio que el usado por B. L. Robinson e incluye especies con elementos del papus variable y hasta papus nulo. El presente estudio filogenético confirma la monofilia de Ophryosporus en su sentido amplio actual y corrobora la inclusión de las especies de Piqueria sección Artemisioides (O. anomalus, $\mathrm{O}$. densiflorus, $\mathrm{O}$. floribundus, $\mathrm{O}$. galioides, $\mathrm{O}$. hartwegii, O. mathewsii, O. peruvianus, $O$. pinifolius y 0 . pubescens), con papus nulo o escamoso y de Trychinolepis hoppii (O. hoppii) con papus escamoso en este género, tal como lo propusieron King \& Robinson (1972). Es interesante destacar que O. sagasteguii, especie recientemente descripta (Robinson, 1998) presenta dos estados en relación al papus, el cual puede ser estar compuesto por escasas cerdas o bien estar ausente. Esta especie fortalece aún más la ampliación del concepto genérico de Ophryosporus al relativizar el valor del tipo de papus como carácter diagnóstico usado por B. L. Robinson.

El presente análisis muestra una politomía conformada por dos clados principales (clado A, soportado por la presencia de involucros cilíndricos, pubescencia en las cipselas y la ausencia de papus y clado B, soportado por la presencia de tallos color púrpura o rojizos) y dos taxones terminales ( $O$. ovatus y O. serratifolius) dentro de Ophryosporus. El único tratamiento infragenérico de Ophryosporus fue propuesto por, B. L. Robinson (1906) quien dividió el género en dos secciones en base al tipo de inflorescencia y la disposición de las hojas: sect. Euophryochaeta con inflorescencias tirsoideas y hojas alternas y sect. Ophryochaeta, con inflorescencias cimoideas y hojas opuestas. Con la inclusión de Piqueria sect. Artemisioides y Trychinolepis (King \& Robinson, 1972) las secciones infragenéricas (Euophryosporus y Ophryochaeta) propuestas por B. L. Robinson caen en desuso, ya que se tornaron inaplicables para el nuevo concepto 
genérico debido a que algunas de las nuevas especies incorporadas presentan inflorescencias tirsoideas con hojas opuestas.

Los dos clados obtenidos en la presente tesis, confirman la inaplicabilidad de las secciones definidas por B. L. Robinson (1906), debido a los caracteres de inflorescencias cimoideas y hojas opuestas aparecen paralelamente tanto en el clado A como el B. Sin embargo, se puede observar que las especies, anteriormente pertenecientes a Piqueria y a Trychinolepis aparecen en el árbol más relacionados con las especies de la antigua sección Euophryosporus $(O$. bipinnatifidus, O. johnstonii, O. paradoxus y O. triangularis, clado A, figura 136), aunque difieren por la forma escamosa o ausente del papus o por la presencia de hojas alternas e inflorescencias cimoideas (vs. el papus formado por cerdas, la presencia de hojas opuestas e inflorescencias tirsoideas presentes en la sección Euophryosporus).

En cuanto a los dos taxones terminales de la politomía, Ophryosporus ovatus y $O$. serratifolius, presentan por la disposición opuesta de sus hojas, inflorescencias cimoideas y papus formado por cerdas, lo que indicaría mayor afinidad con el clado $B$. En el presente análisis no han quedado incluidos dentro de dicho clado por la ausencia de tallos púrpuras o rojizos; sin embargo, debido a la escasez de material al momento de relevar los caracteres (sólo se pudo estudiar un espécimen para cada especie) y a que generalmente, la parte de la planta colectada para los especímenes de herbario, muchas veces no es representativa, no se puede demostrar fehacientemente la ausencia de tallos púrpuras. En cualquier caso, la presencia de los otros caracteres sustentaría la relación de estas especies con las del clado B.

De acuerdo al presente análisis filogenético resulta evidente que la antigua clasificación infragenérica propuesta por B. L. Robinson debería ser replanteada con el objetivo de conformar grupos monofiléticos.

Sin embargo, si bien se han obtenido dos clados claramente definidos, los mismos no están debidamente soportados. Este hecho, sumado a que muchos de 
los caracteres parecen surgir en paralelo en ambos clados, imposibilita la creación de nuevas secciones en Ophryosporus.

\section{c- Análisis de la evolución de los caracteres.}

El hábito preponderante en Ophryosporus, Koanophyllon y Critonia es el arbustivo erecto, y se presenta en la mayoría de las especies. El presente análisis muestra al estado apoyante como derivado y aparece tanto en clado A como en el clado B de Ophryosporus, aunque en forma paralela en diferentes especies $(O$. densiflorus, O. carchiensis, O. apricus, O. sodiroi, entre otras). Como ha sido referido por varios autores (Stern et al., 2003; Begon et al., 2005; Alcaraz, 2012) el hábito apoyante favorece la captación de luz en ambientes donde la misma, bajo el canopeo, es escasa. Concordantemente, las especies de Ophryosporus que habitan ambientes selváticos donde la luz es un recurso escaso, presentan hábito arbustivo apoyante. En cambio, otras especies selváticas, pero con preferencia de zonas más abiertas y con mayor intensidad lumínica, muestran un hábito arbustivo erecto. De acuerdo a la presente hipótesis, el hábito apoyante habría surgido como una adaptación alternativa a lugares selváticos con menor luminosidad.

El apéndice conectival de las anteras rudimentario o ausente ha sido, desde el momento de la primera descripción de Ophryosporus en 1834, el carácter que identifica al mismo de manera inequívoca. En cuanto a la funcionalidad del apéndice conectival, se ha determinado su participación en la liberación fraccionada del polen cuando éste, luego de ser liberado en el tubo de la corola, es elevado por el crecimiento de las ramas del estilo (Small, 1919; Ladd, 1994; Erbar \& Leins). En el caso de los apéndices rudimentarios de Ophryosporus, esta función se llevaría a cabo con las escasas células papilosas presentes (Small, 1919). Tanto Small (1919), Bremer (1994), King \& Robinson (1987) y Denda et al. (1999) consideran la reducción del apéndice conectival como un estado derivado. La tendencia a la reducción del apéndice conectival también ha sido observada en otras Eupatorieae como Mexianthus B. L. Rob., Decachaeta DC. (King \& Robinson, 1987) y en otras Astereae como Brachycome Cass., (Denda et al., 
1999). En el caso de Ophryosporus se ha comprobado la visita de polinizadores y la presencia de polen en mieles de especies que habitan las Yungas, aunque se requieren estudios más profundos de biología floral para determinar la presencia o ausencia de fenómenos de endogamia y, de existir, su potencial relación con el ambiente donde habitan las especies. En algunos géneros como Brachyome, se han observado procesos de endogamia en especies con apéndices conectivales ausentes.

El papus es muy variable dentro del género Ophryosporus. De acuerdo al presente análisis, el estado basal, presente tanto en el grupo externo como en muchas especies del grupo interno, es un papus de cerdas y el papus de escamas (O. hoppii y $O$. pinifolius) o ausente ( $O$. anomalus, $O$. galioides, entre otras) es derivado. Coincidentemente, en otros estudios de Eupatorieae, se ha considerado como derivado al papus escamoso de Ageratum (Schmidt \& Schilling, 2000). Las especies con papus de escamas o nulos han quedados incluidas exclusivamente en el clado $A$, aunque la mayor parte de las especies más derivadas de este clado (O. bipinnatifidus, $O$. johnstonii, $O$. paradoxus y $O$. triangularis), presentan papus formado por cerdas. Considerando el tipo de papus en general, de acuerdo a la hipótesis obtenida en el análisis cladístico, esta estructura no podría ser considerada como diagnóstica para delimitar grupos y las variaciones en la mismo habrían surgido de forma paralela en diferentes especies sin un ancestro más reciente, para luego revertir en el grupo de especies más derivadas $(O$. bipinnatifidus, 0 . johnstonii, O. paradoxus y 0 . triangularis).

La mayoría de las especies de Ophryosporus presenta disposición de hojas opuesta y áreas foliares medianas (mayores a $225 \mathrm{~mm}^{2}$ pero inferiores a 4500 $\mathrm{mm}^{2}$ ), aunque el grupo monofilético de especies que incluye a $O$. galioides ( $\mathrm{O}$. anomalus, $O$. bipinnatifidus, $O$. hartwegii, $O$. hoppii, O. johnstonii, O. paradoxus, $O$. peruvianus, $O$. pinifolius y $O$. triangularis, clado $A$ ) son alternas, fasciculadas y con áreas foliares pequeñas (inferiores a $225 \mathrm{~mm}^{2}$ ). De acuerdo a Housman et al., (2002), la disposición foliar alterna se encuentra correlacionada con ambientes xéricos, ya que reducen el área foliar expuesta reduciendo así la evapotranspiración. Además, el área foliar se correlaciona de manera directa con 
la cantidad de lluvia caída en el área, siendo una estrategia frecuente la reducción del tamaño de las hojas en ambientes xéricos (Stace, 1965; Wiemann et al., 1998; Lambrecht \& Dawson, 2007; Espindola Jr. et. al., 2009). La inflorescencia presente en Ophryosporus, Koanophyllon y Critonia es cimoidea amplia y está presente en la mayoría de las especie. Por otro lado, las inflorescencias tirsoideas se muestran en el presente análisis como un estado derivado, encontradas exclusivamente en el clado de $O$. galioides (O. anomalus, $O$. bipinnatifidus, $O$. hartwegii, $O$. hoppii, $O$. johnstonii, 0 . paradoxus, 0 . peruvianus, $O$. pinifolius y $O$. triangularis). Las inflorescencias tirsoideas han sido consideradas en Liatris, otra eupatorea, como derivada (Schmidt \& Schilling, 2000). De acuerdo a Lambrecht \& Dawson (2007) las inflorescencias tirsoideas representarían una adaptación en ambientes con baja humedad relativa. Este hecho condice con que las especies que presentan inflorescencias tirsoideas habitan en ambientes con alta insolación y baja precipitación como es el área de la Formación de Las Lomas y Atacama (Chile y Perú). De esta manera, las especies de Ophryosporus que vegetan en ambientes con mayores precipitaciones, tienden a presentar hojas opuestas, con áreas foliares mayores e inflorescencias cimoideas amplias que aquellas especies que lo hacen en ambientes xéricos, las cuales tienden a reducir la superficie foliar expuesta, mediante una filotaxis más apretada (hojas alternas y fasciculadas), láminas de menor tamaño e inflorescencias tirsoideas concentradas. De acuerdo a la presente hipótesis filogenética, las adaptaciones a ambientes xeromórficos se muestran como derivadas. En este sentido Ophryosporus podría haberse diversificado a partir de ancestros que habitaban zonas selváticas o semiselváticas para colonizar ambientes más secos, como los de la Formación de Las Lomas y Atacama, donde el grupo con adaptaciones xeromórficas habita.

Si bien el presente análisis confirma la monofilia de Ophryosporus, no se han podido obtener clados internos bien soportados que definan absolutamente grupos y subgrupos dentro de Ophryosporus. Además, el grado de homoplasia de los caracteres es alto. Esto último es de alguna manera consistente con la utilización de caracteres morfológicos en sí mismos (vs. datos moleculares) y con el hecho de que no existe un carácter sino un conjunto de caracteres, que tienden a definir 
agrupaciones infragenéricas. Es decir que gran cantidad de los estados de los caracteres y sus respectivas combinaciones, se presentan en distintos taxones, apareciendo de manera parelela y en distintas asociaciones a lo largo del cladograma (figura 136). Este hecho, se repite en muchos estudios de Eupatorieae (Bremer, 1994; King \& Robinson, 1987) y en algunos casos, ha sido adjudicado a la alta tasa de hibridaciones presentes en esta tribu (King \& Robinson, 1987; Schmidt \& Schilling, 2000).

La presencia de patrones reticulados de caracteres, generados en muchos casos por hibridaciones, dificulta los análisis filogenéticos los cuales, por el contrario, asumen la independencia de linajes (Doolittle, 1999; Xu, 2000; Linder et al., 2004). Las especies híbridas pueden tener un número cromosómico idéntico al de sus parentales (hibridización diploide) o tener la suma del total de los cromosomas parentales (hibridización poliploide) (Linder et al., 2004). Para Ophryosporus, si se considerara la hibridación como causa de una posible evolución reticulada, el escenario más probable, sería el de una hibridación diploide ( $n=10$, como en O. macrodon) o poliploide ( $n=20$, como en O. heptanthus, Robinson et al., 1989). Sin embargo, la comprobación de que el alto número cromosómico en Ophryosporus se deba a hibridaciones o a fenómenos de poliploidía, deberán ser comprobados con estudios específicos.

Para detectar la evolución reticulada, existen métodos para determinar la recombinación, la transferencia horizontal de genes y la especiación híbrida, aunque muchos de ellos pueden generar falsos positivos (Linder et al., 2004). En ciertas Asteraceae, donde las tasas de hibridación son altas, se ha llegado a dilucidar su historia evolutiva mediante el estudio de caracteres moleculares, como es el caso de Helianthus L., donde el estudio mediante caracteres morfológicos no había resuelto la filogenia (Timme et al., 2007). En cuanto a la tribu Eupatorieae, Schilling et al. (1999) e lto et al. (2000b), han obtenido filogenias moleculares más resueltas para el género Eupatorium y Siripun \& Schilling (2006) han comprobado el origen híbrido para Eupatorium godfreyanum Cronquist, mediante estudios moleculares. De esta manera, considero que estudios posteriores a nivel 
molecular podrían ayudar a un mayor esclarecimiento de la filogenia de Ophryosporus como ha ocurrido en otros grupos. 
1. Hábito: 0 (hierbas 0 arbustos) / 1 (hierbas 0 arbustos apoyantes)

2. Altura de la planta: 0 (hasta $1,20 \mathrm{~m}$ ) / 1 (+ de $2 \mathrm{~m}$ )

3. Entrenudos: 0 (bien desarrollados) / 1 (rudimentarios)

4. Pilosidad del tallo: 0 (glabro o subglabro) / 1 (tomentoso)

5. Color permanente del tallo: 0 (marrón) / 1 (rojizo, púrpura)

6. Estriaciones del tallo: 0 (ausente) / 1 (presente)

7. Forma del tallo en corte transversal: 0 (circular) / 1 (marcadamente cuadrangular, hexagonal)

8. Presencia de resinas en el exterior de la planta (tallos, hojas, inflorescencias): 0 (ausente) / 1 (presente)

9. Disposición de las hojas: 0 (opuestas) / 1 (alternas)

10. Pecíolo: 0 (bien desarrollado) / 1 (poco desarrollado)

11. Venación de la lámina foliar: 0 (trinervadas) / 1 (pinnada)

12. Área de la lámina foliar: $\mathbf{0}$ (microfilo, notofilo) / $\mathbf{1}$ (leptofilo, nanofilo) / $\mathbf{2}$ (mesofilo)

13. Grado de división primaria de la lámina foliar: 0 (entera) / 1 (lobulada)

14. Margen de la lámina foliar, división secundaria: $\mathbf{0}$ (denticulado, aserrado) / $\mathbf{1}$ (entero) / 2 (lobulado)

15. Presencia de hidatodos en los dientes de la lámina foliar: $\mathbf{0}$ (presente) / 1 (ausente)

16. Forma del ápice foliar: 0 (agudo, acuminado) / 1 (obtuso, redondeado)

17. Margen revoluto de la lámina foliar: $\mathbf{0}$ (ausente) / $\mathbf{1}$ (presente)

18. Consistencia de la lámina foliar: $\mathbf{0}$ (delicadamente herbácea, herbácea) / 1 (carnosa) / 2 (otra)

19. Pubescencia de la lámina foliar: $\mathbf{0}$ (presente) / 1 (ausente)

20. Posición de la pubescencia en la lámina foliar: 0 (ambas caras) / 1 (solo una cara)

21. Grado de pubescencia de la lámina foliar: 0 (laxo) / 1 (denso)

22. Tricomas glandulares en la lámina foliar: 0 (presentes) / 1 (ausentes)

23. Tipo de tricomas glandulares en la lámina: $\mathbf{0}$ (con cabeza diferenciada, tipo $\alpha$ ) / $\mathbf{1}$ (con cabeza no diferenciada, tipo B)

24. Tipo de inflorescencia: 0 (cimoidea) / 1 (tirsoidea)

25. Tipo de cimoidea: $\mathbf{0}$ (de capítulos solitarios) / 1 (de corimbos) / 2 (de glomérulos)

26. Densidad de la inflorescencia: 0 (laxa) / 1 (densa)

27. Posición de la inflorescencia, respecto del eje principal: 0 (terminal) / 1 (lateral)

28. Cantidad de capítulos por inflorescencia: 0 (hasta 80 capítulos) / 1 (+ de 100 capítulos)

29. Hojas en la inflorescencia: $\mathbf{0}$ ( $\neq$ a las hojas del eje) / 1 (= a las hojas del eje)

30. Forma del involucro: 0 (acampanado) / 1 (cilíndrico)

31. Cantidad de filarios: 0 (+ de 10 filarios) / 1 ( hasta 8 filarios)

32. Disposición de los filarios: 0 (eximbricados) / 1 (subimbricados) / 2 (imbricados)

33. Cantidad de series del involucro: 0 (+ de 3 series) / 1 ( hasta 2 series)

34. Caducidad de alguna serie del involucro: 0 (ausente) / 1 (presente)

35. Filarios graduados: $\mathbf{0}$ (ausente) / $\mathbf{1}$ (presente)

36. Pubescencia en los filarios: 0 (presente) / 1 (ausente)

37. Tricomas glandulares en los filarios: 0 (presentes) / 1 (ausentes)

38. Cantidad de flores por capítulo: 0 (+ 15 flores) / 1 (entre 4 y 10 flores)

39. Color de la corola: $\mathbf{0}$ (rosada, púrpura) / 1 (blanca, verdosa, amarillenta)

40. Forma de la corola: 0 (tubular) / 1 (infundibuliforme)

41. Paso entre tubo y limbo en la corola: 1 (gradual) / 2 (abrupto)

42. Pubescencia en la corola: 0 (presente) / 1 (ausente)

43. Tipo de tricomas en la corola: $\mathbf{0}$ (no glandular) / 1 (glandular)

44. Apéndice conectival de las anteras: 0 (presente, bien desarrollado) / 1 (ausente o rudimentario)

45. Células del collar anteral de las anteras: 0 (con paredes engrosadas) / 1 (sin paredes engrosadas)

46. Forma del collar anteral de las anteras: 0 (cilíndrico regular) / 1 (cilíndrico, ensanchado hacia la base)

47. Forma de la base de las anteras: 0 (redondeada, obtusa) / 1 (auriculada)

48. Forma de las ramas del estilo: 0 (lineares) / 1 (clavadas, fuertemente clavadas)

49. Largo de las ramas del estilo: 0 (largamente exertas) / 1 (cortamente exertas)

50. Base del estilo: 0 (ensanchada) / 1 (recta)

51. Nectario presente en el estilopodio: 0 (poco desarrollado) / 1 (marcadamente desarrollado)

52. Forma de la cipsela: 0 (linear) / 1 (piriforme)

53. Cipsela falcada: 0 (ausente) / 1 (presente)

54. Cipsela estipitada: 0 (ausente) / 1 (presente)

55. Base distorsionada de la cipsela (twist): 0 (ausente) / 1 (presente)

56. Pubescencia en la cipsela: 0 (presente) / 1 (ausente)

57. Posición de la pubescencia en la cipsela: 0 (en toda la cipsela) / 1 (sectorizada)

58. Tricomas glandulares en la cipsela: $\mathbf{0}$ (ausente) / 1 (presente)

59. Engrosamiento en las células del carpopodio: 0 (marcadamente engrosadas) / 1 (no engrosadas)

60. Forma de las células del carpopodio: 0 (isomorfas) / 1 (heteromorfas)

61. Papus: 0 (presente, de cerdas) / 1 (presente, de escamas) / 2 (ausente)

Tabla 2. Caracteres utilizados para generar la matriz de datos. 


\section{XI- ANÁLISIS BIOGEOGRÁFICO}

\section{1 - Introducción.}

Como indicado en la Sección VIII, el género Ophryosporus se encuentra restringido a Sudamérica, con seis especies en Argentina, cinco en Brasil, 9 en Bolivia, 8 en Chile, siete en Ecuador y 19 en Perú (12 exclusivas). La mayoría de las especies presentan una distribución andina, creciendo en ambientes selváticos húmedos o bien relativamente xéricos. También se desarrollan en ambientes costeros del océano Pacífico (tanto en zonas de clima extremadamente seco como húmedo) y en selvas lindantes con el océano Atlántico (Mata Atlántica).

Hasta el momento no existe información acerca de los eventos históricos que influyeron en la distribución actual de las especies de Ophryosporus, tampoco de la subtribu Critoniinae a la que pertenece, y son escasos aquellos estudios que analizan la historia biogeográfica de las Eupatorieae en general. De acuerdo a los últimos análisis filogenéticos en Asteraceae, la tribu Eupatorieae es uno de los linajes más derivados y de más reciente aparición dentro de la familia. Sin embargo, no existen registros fósiles de la tribu que permitan realizar inferencias precisas acerca de la edad cronológica de la misma, aunque sí existen algunos registros de polen fósil de otras tribus cercanas (Heliantheae-Helenieae) que datan de aproximadamente 15 millones de años (Mioceno medio) (Demarcq et al., 1976; Nagy, 1969; Gray, 1964). Por otro lado, mediante el análisis de las tasas evolutivas de ciertos algunos genes (ej., gen ndhF), Schmidt \& Schilling (2000) estimaron que el tiempo de divergencia entre la tribu Eupatorieae y la tribu Heliantheae fue hace 14,8 millones de años (Mioceno medio) en América del Norte, coincidiendo con el registro polínico fósil. De acuerdo a los mismos autores, el género Eupatorium s.s. (subtribu Eupatoriinae) se habría originado hace unos 7,4 millones de años (Mioceno tardío), posiblemente también en América del Norte, donde hipotéticamente se encuentran los ancestros de la tribu Eupatorieae.

Hipótesis biogeográficas basadas en filogenias moleculares (nITS y cpDNA) también postulan a América del Norte como el inicio de la diversificación del grupo Helianthoideo (que incluye la tribu Eupatorieae) en el Nuevo Mundo (Baldwin et 
al., 2002; Panero \& Funk, 2002). Posteriores dispersiones hacia América Central y América del Sur ocurrieron en una amplia variedad de linajes y fueron seguidas por una gran radiación de las Heliantheae, Millerieae y Eupatorieae (Baldwin, 2009).

Debido a la ausencia de estudios específicos, se llevó a cabo un análisis de biogeografía histórica del género Ophryosporus con el fin de hallar los eventos que podrían haber generado la distribución actual de sus especies.

\section{2 - Metodología}

\section{Análisis de dispersión y vicarianza (DIVA)}

En los últimos años, los métodos basados en eventos han ganado reconocimiento en la biogeografía histórica (Miranda-Esquivel, 1999; Zink et al., 2000; Sanmartín et al., 2001; Vinnersten \& Bremer, 2001; Donato et al., 2003). A diferencia de la mayoría de los otros métodos biogeográficos históricos, los métodos basados en eventos postulan modelos explícitos de los procesos que afectan la distribución geográfica de los seres vivos. Los diferentes tipos de procesos (dispersión, extinción, duplicación y vicarianza) son identificados y se les asignan valores de costo-beneficio bajo un modelo explícito de funcionamiento de la naturaleza. De esta manera, la historia de la distribución de un taxón es inferida sobre la base de la información filogenética y aplicando el criterio de máximo beneficio y mínimo costo con respecto a todos o sólo a algunos de estos procesos (Crisci et al., 2000, 2003).

El análisis de dispersión y vicarianza (DIVA) es uno de los métodos basados en eventos más utilizado. Este método fue desarrollado por Ronquist $(1996,1997)$ a partir de sus propias ideas aplicadas originalmente a asociaciones entre especies (Ronquist \& Nylin, 1990).

Para la reconstrucción de las distribuciones ancestrales de Ophryosporus, se utilizó DIVA 1.1 (Ronquist, 1996), aplicando una búsqueda exacta de acuerdo a la optimización de dispersión-vicarianza propuesta por Ronquist (1997). DIVA opera a través de la optimización de una matriz tridimensional de costos, construida sobre la base de datos de distribución y cladísticos de uno o más grupos de 
organismos que habiten un grupo de áreas en común. Las premisas para la construcción de estas matrices son las siguientes: si la especiación se debe a vicarianza, separando una distribución amplia en dos grupos de áreas mutuamente excluyentes, el costo asignado es 0; la especiación dentro de un área única (simpatría o duplicación) tiene un costo de 0; los eventos de dispersión entre áreas tienen un costo de 1 por cada área agregada a la distribución original; y los eventos de extinción tienen asimismo un costo de 1 por cada área eliminada de la distribución.

La historia biogeográfica de Ophryosporus fue analizada sobre la base de la filogenia obtenida en la presente tesis. El cladrograma generado mostró una serie de politomías, las cuales fueron resueltas por afinidades morfológicas evidentes (ver sección X, Análisis Cladístico) en el caso de O. marchii y O. mathewsii, en el clado A, y de O. ovatus y O. steinbachii, en el clado B (Fig 137), ya que el programa DIVA 1.1 sólo acepta cladogramas totalmente resueltos. En el caso de la resolución de la politomía del clado $\mathrm{B}$, conformado por los clados que contienen a $O$. burkartii, O. lorentzii y $O$. sagasteguii (Fig 137), se analizaron las tres hipótesis posibles. Nueve áreas de endemismos fueron consideradas para el análisis biogeográfico. Dichas áreas fueron definidas en esquemas biogeográficos previos (Cabrera \& Willink, 1973; Josse et al., 2003; Veblen et al., 2007). Las áreas utilizadas para este estudio se listan a continuación (Fig 138) y la presencia de cada especie en dichas áreas se indica en la tabla 3:

1. Chaco (Área A): se encuentra delimitado al oeste por los Andes húmedos y Patagonia, al norte por el Cerrado, al este por la Mata Atlántica y Pampas. Al sur está delimitado por Patagonia. Llanuras con ligeras depresiones o con cauces de ríos. En su porción centro-oeste hay serranías de poca elevación. Las precipitaciones son variables: escasas precipitaciones estivales en la porción occidental y lluvias abundantes en la oriental.

2. Andes secos, centrales y sur (Área B): se ubican en la cordillera de los Andes, desde sur de Perú hasta Argentina, con su máximo desarrollo en Bolivia. Se encuentra flanqueado hacia el norte por los Andes húmedos, al oeste por el 
Desierto peruano-chileno y Chile mediterráneo, al este limita con los Andes húmedos y Patagonia. Incluye a las altas montañas de la cordillera de los Andes y se encuentra por encima de los $2500 \mathrm{msnm}$. Las precipitaciones son sólo estivales y decrecen a medida que aumenta la altitud.

3. Chile mediterráneo (Área C): ocupa una banda angosta a lo largo del margen oeste de Sudamérica, desde los 30 a $36^{\circ} \mathrm{S}$ en Chile central. Representa una zona de transición entre el Desierto peruano-chileno y los Bosques Templados (deciduos y perennes) al sur del paralelo 36ㅇ․ La precipitación anual es escasa variando entre 200 a $700 \mathrm{~mm}$ al año

4. Desierto peruano-chileno (Área D): forma un cinturón continuo a lo largo de la costa oeste de Sudamérica, extendiéndose $3500 \mathrm{~km}$ desde el norte de Perú (5ำ S) hasta el norte-centro de Chile, cercano a La Serena ( $29^{\circ} 55^{\prime} \mathrm{S}$ ). La zona desértica puede llegar a extenderse desde 20 a $100 \mathrm{~km}$ hacia el continente. Las precipitaciones son muy escasas a lo largo de la costa, el principal aporte de humedad es mediante las neblinas provenientes del océano Pacífico. En la costa se encuentran desarrollados parches de vegetación denominados "Iomas".

5. Andes húmedos, centrales y norte (Área E): se ubican en la cordillera de los Andes, desde Venezuela hasta Argentina, donde se denominan comúnmente "yungas". Se extiende desde los 500 a 3500 msnm. Las precipitaciones son abundantes y son acrecentadas por las neblinas que cubren casi continuamente las montañas.

6. Mata atlántica (Área F): incluye las montañas costeras que recorren 4.000 $\mathrm{km}$ a lo largo del margen este de Brasil, desde $5^{\circ} \mathrm{S}$ en Cabo San Roque hasta los $30^{\circ}$ en el río Taquari. Su centro se encuentra en la Sierra de Mar y Sierra de Mantiqueira en los estados de São Paulo, Minas Gerais, Río de Janeiro y Espírito Santo. Es un terreno montañoso, con alturas que varían entre los 1000 y 3000 msnm. Las precipitaciones varían entre 1500 a $2000 \mathrm{~mm}$ anuales, con una estación seca en invierno y abundantes lluvias estivales.

7. Pacífico ecuatorial húmedo (Área G): corresponde a las laderas occidentales bajas de los Andes ecuatorianos y colombianos, incluyendo a los 
valles interandinos (selvas de Chocó). Se trata de una de las regiones más húmedas del planeta, con puntos donde la precipitación anual llega a los 10.000 $\mathrm{mm}$ anuales.

8. Pacífico ecuatorial seco (Área H): abarca el extremo costero norte de Perú y el extremo sur costero de Ecuador. Está delimitado por la región Mesoamérica Húmeda hacia el norte, los Andes Húmedos hacia el este y el océano Pacífico hacia el oeste y al sur por el Desierto peruano-chileno. Al igual que en el Desierto peruano-chileno, las precipitaciones son escasas y básicamente están representadas por neblinas.

9. Mesoamérica húmeda (Área I): abarca las regiones húmedas Mesoamérica, tanto en las costas del Pacífico como del Atlántico. Incluye tanto montañas como tierras bajas, donde la precipitación es muy abundante, alrededor de $10.000 \mathrm{~mm}$ anuales.

Para facilitar la lectura e interpretación de las áreas, se generó una tabla removible (de la contratapa de la tesis) para poder acompañar la lectura.

\section{3 - Resultados.}

Del análisis de los tres posibles cladogramas, se obtuvieron tres reconstrucciones óptimas de las distribuciones ancestrales en los nodos, que implicaron 27 eventos de dispersión y 8 eventos vicariantes. Los resultados obtenidos para las tres resoluciones de las politomías del clado $B$ fueron idénticos.

Como se mencionó anteriormente, América del Norte ha sido sugerida como el lugar de origen de la tribu Eupatorieae. El presente análisis biogeográfico muestra que el área ancestral reconstruida por DIVA para el nodo que incluye a Ophyosporus y a todas las especies de Critoniinae utilizadas como grupos externos en el análisis cladístico, corresponde al área de los Andes Húmedos Centrales-Norte (E).

Debido a las dimensiones de los géneros de los grupos hermanos, no se incluyeron la totalidad de las especies: para Koanophyllon se utilizaron 3 especies de un total de 114 y para Critonia 3 especies de un total de 40 . De esta manera, 
los nodos hacia la base del cladograma deben ser considerados con cuidado. Para generar una resolución de los nodos basales menos ambigua, sería necesario incluir a todas y cada una de las especies de los grupos hermanos de Ophryosporus, cuyo estudio excede ampliamente el objetivo de presente análisis biogeográfico.

En el nodo 1 (Fig 137) se produce un primer evento vicariante entre la región Mesoamericana Húmeda (I) y los Andes Húmedos Centrales-Norte (E), en el clado donde se separan Fleischmannia arguta del resto de las especies pertenecientes a Critoniinae.

De acuerdo a lo observado en el nodo 2, el área ancestral de las Critoniinae corresponde a los Andes Húmedos Centrales-Norte (E). En el clado que contiene a Critonia y Koanophyllon se observan posteriores dispersiones desde los Andes Húmedos Centrales-Norte (E) hacia Mesoamérica Húmeda (I) y hacia la Mata Atlántica $(F)$.

Tanto el nodo 3 como 4, ubican al ancestro hipotético de Critoniinae en los Andes Húmedos Centrales-Norte (E). El nodo 3 muestra la división de un linaje que contiene a los actuales grupos hermanos de Ophryosporus (Critonia + Koanophyllon), los cuales posteriormente se dispersan hacia Mata Atlántica (E) y Mesoamérica Húmeda (I) y el linaje que contiene al ancestro de Ophryosporus.

Coincidentemente, el área ancestral reconstruida por DIVA para el nodo correspondiente al ancestro hipotético de Ophryosporus, corresponde a los Andes Húmedos Centrales-Norte $(E)$. En el nodo 4 se produce la separación de dos linajes, uno indicado como clado A (nodo 5) y otro indicado como clado B (nodo 7) en la figura 137. El segundo evento vicariante (clado A, nodo 5) se produce en el área ancestral Andes Húmedos Centrales-Norte $(E)$ y el Desierto peruano-chileno (D). Una rama de este linaje, que permanece en los Andes Húmedos CentralesNorte $(\mathrm{E})$, deriva en $O$. marchii y $O$. mathewsii. El resto del linaje parece tener un origen en áreas más secas, pertenecientes al Desierto peruano-chileno (D).

En el nodo 6 (clado A), se observa el tercer evento vicariante que habría permitido la diversificación de dos linajes, uno se desarrolla hacia el área Pacífica 
Ecuatorial Seca $(H)$ y el otro continúa su dispersión hacia áreas secas lindantes: Chaco (A), Andes Secos Centrales-Sur (B) y Chile Meridional (C).

En nodo 7 ubica a parte del linaje ancestral de Ophryosporus en los Andes Húmedos Centrales-Norte $(E)$, el cual comienza a dispersarse hacia áreas más secas, pertenecientes a los Andes Secos Centrales-Sur (B), como es el caso de $O$ heptanthus. Hacia el nodo 8 y 9 , se encuentran dos linajes paralelos en los cuales se observan el cuarto y quinto evento vicariante. En ambos linajes se producen dos eventos vicariantes, aparentemente simultáneos, hacia los Andes Secos Centrales-Sur (B). Posteriormente, en el linaje que contiene a O. macrodon, se produce una dispersión hacia áreas secas contiguas (Chaco, área A) y húmedas (Andes Húmedos Centrales-Norte, área E).

Ya hacia el nodo 10, donde el linaje ancestral se presenta en el área de Andes Secos Centrales-Sur (B), se produce el sexto evento vicariante con el área de Mata Atlántica (F).

Hacia el nodo 11, ocurre el anteúltimo evento vicariante entre el linaje presente en la Mata Atlántica (F) y el de los Andes Secos Centrales-Sur (B) y los Andes Húmedos Centrales-Norte (E).

Finalmente, hacia el nodo 12, se observa el último evento vicariante, entre el linaje que habita la Mata Atlántica $(F)$ y el de los Andes Húmedos Centrales-Norte $(E)$, con una posterior dispersión desde los Andes Húmedos Centrales-Norte $(E)$ al área Pacífico Ecuatorial Húmeda (G).

\section{4 - Discusión.}

El período potencial del origen de Ophryosporus (14,8-7,4 Ma) se situaría en el Mioceno medio (15 Ma.) período a partir del cual habría ocurrido su diversificación. Hacia el Mioceno medio, los hielos se retrajeron y se generó un óptimo climático, con aumento en la temperatura y la humedad. A su vez, se produjeron tres transgresiones marinas desde el océano Atlántico hacia el continente sudamericano ya que debido al calentamiento durante este período interglacial, el nivel del mar alcanzó un máximo de 150 metros sobre el nivel actual (hacia los 12 
Ma). Hacia los 10 Ma. la temperatura volvió a descender y comenzó a formarse el hielo Antártico (Benedetto, 2010).

En el Plioceno (5,3-1,8 Ma) aún continuó formándose el hielo Antártico y se sucedieron al menos ocho glaciaciones, las cuales intercalaron períodos cálidos y húmedos con períodos fríos y secos a lo largo de todo el planeta. Si bien en Sudamérica la influencia de estos períodos glaciales fue menor que en otras zonas del globo, su mayor incidencia fue la región patagónica, donde se generaron los hielos continentales. Esta zona afectó el clima del resto del continente, ya que, conjuntamente con los efectos del período glacial, los vientos generados en los hielos continentales produjeron un corrimiento del clima frío y seco hacia el centro y norte de Sudamérica (Benedetto, 2010).

Ya en el Pleistoceno (1,8-0,0117 Ma) la inestabilidad climática se tornó más marcada. Se sucedieron rápidamente períodos glaciales con períodos interglaciales de clima templado y grandes deshielos. Se estima que en los últimos 1,5 Ma han ocurrido más de 50 ciclos glacial/interglacial de diferente magnitud. Finalmente, el Holoceno (8 Ka-presente) se produjeron una serie de oscilaciones climáticas: el clima era frío en su comienzo y posteriormente fue tornándose más y cálido (Benedetto, 2010).

En este contexto de fluctuaciones climáticas se produjeron expansiones y retracciones tanto de bosques húmedos como de vegetación semiárida (Prado \& Gibbs, 1993). Estas pulsaciones de vegetación parecen haber alcanzado su mayor desarrollo en el Pleistoceno. Los eventos de descenso de flora de los Andes durante los períodos glaciales habrían permitido la expansión de los elementos florísticos de zonas más altas de montaña (Simpson Vuilleumier, 1971, 1975). El efecto combinado de la reducción de hábitats no favorables entre áreas montañosas y la interposición de nuevos parches de bosque montano, habrían actuado como trampolín, permitiendo a las plantas andinas dispersarse más fácilmente hacia el este. Períodos similares con incremento en las oportunidades de dispersión en épocas glaciales, son considerados la causa de las distribuciones disyuntas de organismos en los Andes y en el planalto del sudeste de Brasil 
(Simpson Vuilleumier, 1971). Esto explicaría los diferentes eventos vicariantes y de dispersión observados en el presente análisis entre los Andes Húmedos Centrales Norte y otras áreas, como los Andes Secos Centrales Sur, Chaco y Mata Atlántica.

Las laderas oeste de los Andes Centrales (desde Colombia a Bolivia) sufrieron una serie de cambios vegetacionales durante el Pleistoceno (Simpson Vuilleumier, 1975). Las áreas áridas actuales de la ladera media oeste de los Andes fueron húmedas durante las glaciaciones, mientras que las áreas costeras (hoy Desierto peruano-chileno) eran más áridas de lo que son actualmente. Esta humedad habría permitido la expansión hacia las laderas más bajas de la vegetación siempreverde de grandes altitudes.

Tal vez ese haya sido el caso de las especies ancestrales de Ophryosporus, que pudieron colonizar desde mayores altitudes las laderas más bajas del oeste de los Andes. Posteriormente, quizás por eventos de retracción de vegetación, dichas especies quedaron aisladas y se diversificaron en la zona de la costa del Pacífico, desde la cual se dispersaron hacia otras áreas.

Las especies de Ophryosporus que habitan el Desierto peruano-chileno costero habitan en áreas específicas denominadas "lomas". Veblen et al. (2007) indica que el origen florístico de las lomas muestra fuertes conexiones subtropicales y que la flora de las lomas del norte de Perú exhibe una particular influencia de especies menos xerófilas, con orígenes andinos a mayor altura. Esto soportaría la hipótesis de que especies ancestrales de Ophryosporus de zonas húmedas andinas altas habrían descendido en tiempos donde las laderas medias eran más húmedas. 


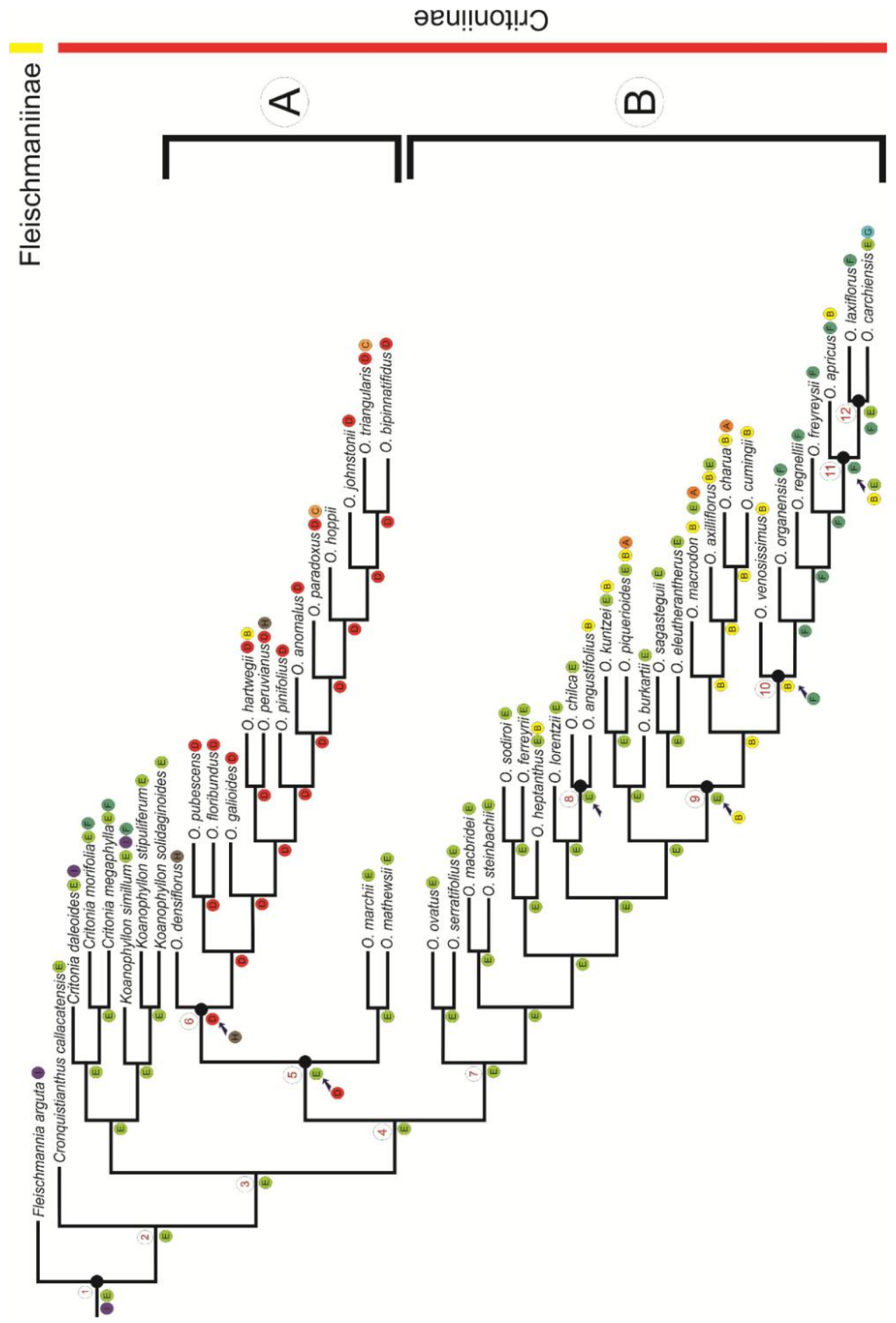

Figura 137. Cladograma de áreas obtenido mediante DIVA. 


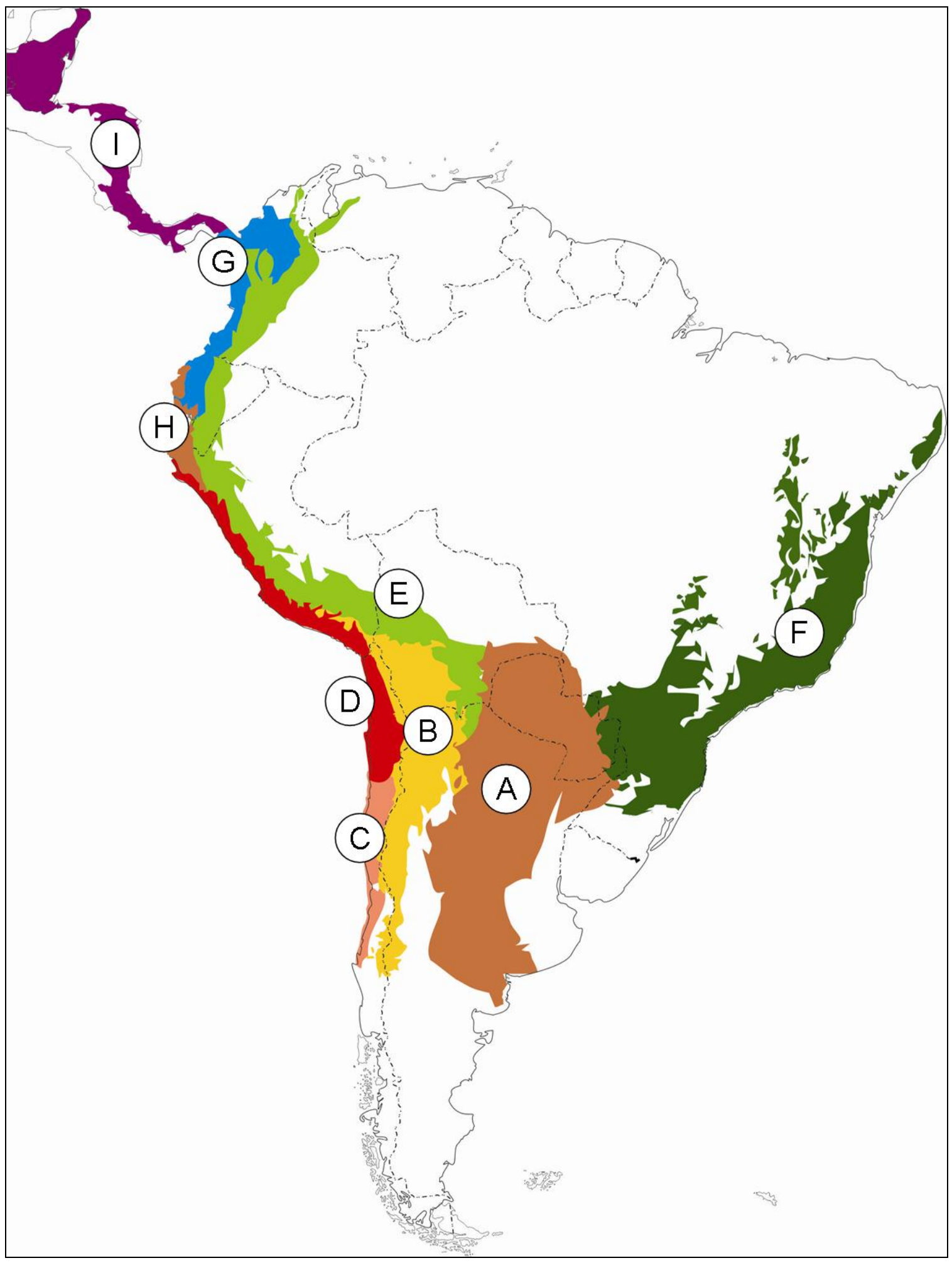

Figura 138. Mapa donde se indican las áreas de endemismo (modificado de Josse et al., 2003) 


\begin{tabular}{|c|c|c|c|c|c|c|c|c|c|}
\hline & A & B & C & D & E & $\mathrm{F}$ & G & $\mathrm{H}$ & I \\
\hline \multicolumn{10}{|l|}{ O. angustifolius } \\
\hline \multicolumn{10}{|l|}{ O. anomalus } \\
\hline \multicolumn{10}{|l|}{ O. apricus } \\
\hline \multicolumn{10}{|l|}{ O. axilliflorus } \\
\hline \multicolumn{10}{|l|}{ O. bipinnatifidus } \\
\hline \multicolumn{10}{|l|}{ O. burkartii } \\
\hline \multicolumn{10}{|l|}{ O. carchiensis } \\
\hline \multicolumn{10}{|l|}{ O. charua } \\
\hline \multicolumn{10}{|l|}{ O. chilca } \\
\hline \multicolumn{10}{|l|}{ O. cumingii } \\
\hline \multicolumn{10}{|l|}{ O. densiflorus } \\
\hline \multicolumn{10}{|c|}{ O. eleutherantherus } \\
\hline \multicolumn{10}{|l|}{ O. ferreyrii } \\
\hline \multicolumn{10}{|l|}{ O. floribundus } \\
\hline \multicolumn{10}{|l|}{ O. freyreisii } \\
\hline \multicolumn{10}{|l|}{ O. galioides } \\
\hline \multicolumn{10}{|l|}{ O. hartwegii } \\
\hline \multicolumn{10}{|l|}{ O. heptanthus } \\
\hline \multicolumn{10}{|l|}{ O. hoppii } \\
\hline O. johnstonii & & & & & & & & & \\
\hline O. kuntzei & & & & & & & & & \\
\hline O. laxiflorus & & & & & & & & & \\
\hline O. Iorentzii & & & & & & & & & \\
\hline O. macbridei & & & & & & & & & \\
\hline O. macrodon & & & & & & & & & \\
\hline O. marchii & & & & & & & & & \\
\hline O. mathewsii & & & & & & & & & \\
\hline O. organensis & & & & & & & & & \\
\hline O. ovatus & & & & & & & & & \\
\hline O. paradoxus & & & & & & & & & \\
\hline O. peruvianus & & & & & & & & & \\
\hline O. pinifolius & & & & & & & & & \\
\hline O. piquerioides & & & & & & & & & \\
\hline O. pubescens & & & & & & & & & \\
\hline O. regnellii & & & & & & & & & \\
\hline O. sagasteguii & & & & & & & & & \\
\hline O. serratifolius & & & & & & & & & \\
\hline O. sodiroi & & & & & & & & & \\
\hline O. steinbachii & & & & & & & & & \\
\hline O. triangularis & & & & & & & & & \\
\hline O. venosissimu & & & & & & & & & \\
\hline Fleisch.arguta & & & & & & & & & \\
\hline Cronq.callacate & & & & & & & & & \\
\hline Koano.simillum & & & & & & & & & \\
\hline K. stipuliferum & & & & & & & & & \\
\hline K. solidaginoide & & & & & & & & & \\
\hline Critonia daleoid & & & & & & & & & \\
\hline C. morifolia & & & & & & & & & \\
\hline C. megaphylla & & & & & & & & & \\
\hline
\end{tabular}

\begin{tabular}{|l|}
\hline Chaco $(A)$ \\
\hline Andes Secos Centrales norte $(B)$ \\
\hline Chile Mediterráneo $(C)$ \\
\hline Desierto peruano chileno $(D)$ \\
\hline Andes Húmedos Centrales Norte $(E)$ \\
\hline Mata Atlántica $(F)$ \\
\hline Pacífico Ecuatorial Húmedo $(\mathrm{G})$ \\
\hline Pacífico Ecuatorial Seco $(H)$ \\
\hline Mesoamérica Húmeda $(\mathrm{I})$ \\
\hline
\end{tabular}

Tabla 3 y referencias de las áreas de endemismo. 


\section{XII- CONCLUSIONES}

1. El género Ophryosporus queda conformado por 41 especies, reconocidas en esta revisión: 0 . angustifolius, $O$. anomalus, 0 . apricus, 0 . axilliflorus, $O$. bipinnatifidus, $O$. burkartii, $O$. carchiensis, $O$. charua, $O$. chilca, O. cumingii, $O$. densiflorus, $O$. eleutherantherus, O. ferreyrii, O. floribundus, O. freyreisii, $O$. galioides, O. hartwegii, O. heptanthus, O. hoppii, O. johnstonii, O. kuntzei, O. laxiflorus, O. lorentzii, O. macbridei, O. macrodon, O. marchii, O. mathewsii, O. organensis, 0 . ovatus, 0 . paradoxus, 0 . peruvianus, 0 . pinifolius, 0. piquerioides, $O$. pubescens, $O$. regnellii, $O$. sagasteguii, $O$. serratifolius, $O$. sodiroi, $O$. steinbachii, $O$. triangularis y $O$. venosissimus.

2. Se excluyeron los siguientes nombres: $O$. burchellii, $O$. ovatifolius, $O$. pachychaeta, $O$. petraeus, $O$. scabrellus, $O$. solidaginoides y $O$. solidaginoides var. bonplandiana.

3. Se resolvieron los status de 102 los nombres asociados al género Ophryosporus y se lectotipificaron 12 nombres.

4. Se reasignó la autoría de Eupatorium heptanthum Sch. Bip. $=O$. heptanthum (Sch. Bip.) R. M. King \& H. Rob. .

5. Se analizaron en profundidad las estructuras secretoras presentes en hojas (cavidades y tricomas glandulares) por primera vez en Ophryosporus, y se asociaron los compuestos químicos, con aplicaciones medicinales.

6. Se generó por primera vez, en base al estudio morfológico profundo, una clave dicotómica y descripciones detalladas para todas las especies del género Ophryosporus.

7. Se ilustraron todas las especies, tanto en su aspecto general, como los detalles que incluyen microcaracteres diagnósticos. Además se generaron mapas de distribución para cada una de ellas.

8. Se confirmó, mediante un análisis filogenético la monofilia del género Ophryosporus. Además los resultados obtenidos, muestran a las especies de Koanophyllon y Critonia, incluidas en este estudio, como grupos hermanos de Ophryosporus. 
9. Dentro de Ophryosporus se obtuvieron dos clados definidos. Estos clados no coinciden con las secciones previas propuestas por B. L. Robinson. A su vez, por el bajo soporte, no pueden definirse nuevas secciones.

10. De acuerdo al registro fósil de tribus cercanas a Eupatorieae podría sugerirse que el origen de Ophryosporus habría tenido lugar entre los 7,4 y 14,8 Ma.

11. Del análisis generado por DIVA, se postula el origen del género Ophryosporus en los Andes Húmedos Centrales-Norte de Sudamérica. Posteriormente, numerosas dispersiones se habrían producido hacia las áreas Andes Secos Centrales-Sur y Chaco. Los eventos vicariantes principales se habrían producido en el área ancestral Desierto peruano-chileno-Pacífico Ecuatorial Seco y en el área ancestral Andes Húmedos Centrales-Norte-Andes Secos Centro-Sur

12. Las laderas oeste de los Andes Centrales (desde Colombia a Bolivia) sufrieron una serie de cambios vegetacionales durante el Pleistoceno (Simpson Vuilleumier, 1975). Las áreas áridas actuales de la ladera media oeste de los Andes fueron húmedas durante las glaciaciones, mientras que las áreas costeras (hoy Desierto peruano-chileno) eran más áridas de lo que son actualmente. Esta humedad habría permitido la expansión hacia las laderas más bajas de la vegetación siempreverde de grandes altitudes.Tal vez ese haya sido el caso de las especies ancestrales de Ophryosporus, que pudieron colonizar desde mayores altitudes las laderas más bajas del oeste de los Andes. Posteriormente, quizás por eventos de retracción de vegetación, dichas especies quedaron aisladas y se diversificaron en la zona de la costa del Pacífico, desde la cual se dispersaron hacia otras áreas.

13. En base a los resultados obtenidos, las dispersiones de los ancestros de Ophryosporus hacia el Desierto Costero Peruano Chileno habrían tenido lugar más tempranamente que aquellas producidas hacia el este (ej., Chaco, Andes Secos Centrales-Sur), lo cual estaría sustentado no sólo por el análisis biogeográfico sino por la amplia diferenciación morfológica observada en las especies del desierto con respecto a las de los Andes Húmedos Centro-Norte. 


\section{XIII - LITERATURA CITADA}

Abreu, V. H. R., Esteves, R. L., Mendoça, C. B. F. \& V. Gonçalves-Esteves. 2009. Estudo polínico de espécies do gênero Ophryosporus Meyen (EupatorieaeAsteraceae). $60^{\circ}$ Congresso Nacional de Botânica. Bahía. Brasil.

Alcaraz, Francisco. 2012. Selvas ecuatoriales y tropicales. Universidad de Murcia. España.

Anderberg, A. A., M. E. Salter \& B. Norderstam. 1996. Type material of the Asteraceae in the Swedish Museum of Natural History (S). Compositae Newsletter 28: 1-172.

Anónimo. 2012. www.iucnredlist.org. (Último acceso, Junio 2012).

Anónimo. 2012. www.mamaherb.com. (Último acceso, Junio 2012).

Ariza Espinar, L. 1994. Pródromo de la Flora Fanerogámica de Argentina Central. Familia Asteraceae, II. Tribu Eupatorieae: Ophryosporus. 1: 18-21.

Ariza Espinar, L. 2006. Asteraceae. pp. 291-493. En: Flora Medicinal de la Provincia de Córdoba (Argentina), eds. G. E. Barboza, J. J. Cantero, C. O. Nuñez y L. Ariza Espinar. Museo Botánico de Córdoba, Córdoba.

Arteta Beltrán, M. C. 2008. Etnobotánica de plantas vasculares en el centro poblado Llanchón, Distrito Capachica, Departamento de Puno, 2007-2008. Tesis de grado. Arequipa. Perú.

Baker, J. G. 1876. Compositae II. Eupatoriaceae. pp. 181-374. En Flora Brasiliensis 6(2), ed. C. F. P. Martius. München: Wien, Liepzig, Lipsiae Apud Frid. Fleischer in Comm.

Baldwin, B. G. \& B. L. Wessa. 2000. Origin and relationships of the tarweedsilversword lineage (Compositae-Madiinae). American Journal of Botany 87: 18901908.

Baldwin, B. G. 2009. Heliantheae alliance. En: Funk, V.A.; Susanna, A; Stuessy, T. F \& Bayer, R. J. (eds.), Systematic, Evolution and Biogeography of Compositae, Pp.689-711. International Association for Plant Taxonomy, Vienna, Austria.

Baldwin, B.G., Wessa, B. L. \& J. L. Panero 2002. Nuclear rDNA evidence for major lineages of helenioid Heliantheae (Compositae). Systematic Botany 27: 161:198. 
Barbieri Ferreira Mendonça, C. \& Gonçalves-Esteves, V. 2000. Palinología de espécies da tribo Eupatorieae (Compositae Giseke) ocorrentes na Restinga de Carapebus, Rio de Janeiro. Revta. Brasil. Bot. 23: 195-205.

Barboza, G. E., Cantero, J. J., Núñez, C. O. \& L. A. Espinar. 2006. Flora medicinal de la provincia de Córdoba (Argentina). Pteridófitas y antófitas silvestres o naturalizadas. Museo Botánico. Córdoba. Gráficamente Ediciones. 1250 p.

Barrero, A. F., Mar Herrador, M., Arteaga, P., Rosas-Romero, A. \& J. F. Arteaga. 2006. Antioxidant activity of diterpenes and polyphenols from Ophryosporus heptanthus. J. Agric. Food Chem. 54: 2537-2542.

Bascope, M. \& O. Sterner. 2007. Phytochemical research of plants used by the association of traditional medicine at Apillapampa. Rev. Bol. Quim. 24: 14-25.

Begon, M; Townsend, C. R. \& J. L. Harper. 2005. Ecology: from individuals to ecosystems. 4th edition. Blackwell Publising. Victoria. Australia.

Beltrán, H, Granda, A., León, B., Sagástegui, A., Sánchez, I. \& M. Zapata. 2006. Asteraceae endémicas del Perú. Rev. peru. biol. Número especial 13(2): 64 $-164$.

Beltrán, H. 1994. Las Asteráceas del Distrito de Laraos Yauyos. Tesis Biólogo. Facultad de Ciencias Biológicas. Universidad Nacional Mayor de San Marcos.

Benedetto, J. L. 2010. El continente de Gondwana a través del tiempo. Una introducción a la Geología Histórica. Academia Nacional de Ciencias. Córdoba. Argentina.

Bentham, G. \& J. D. Hooker. 1873. Genera plantarum ad exemplaria imprimis in herbariis kewensibus servata definite. Volumen 2, parte I: 239. Lovell Reeve and Co., London.

Bentham, G. 1873. Notes on the clasiffication, history, and grographical distribution of the Compositae. Journal of the Linnean Society, Botany 13: 335-577. BohIman, F. \& C. Zdero. 1979. Nue anol-derivate aus Ophryosporus angustifolius. Phytochemistry 18: 145-147.

Bohlman, F., Wallmeyer, M., King, R. M. \& H. Robinson. 1984. 2-Oxo-labda8(17), 13-dien-15-OL from Ophryosporus chilca. Phytochemistry 23:1513-1514.

Bremer, K. 1994. Asteraceae: Cladistic and Classification. Timber Press, Portland, 
Oregon. $752 \mathrm{p}$.

Cabrera, A. L. \& A. Willink. 1973. Biogeografía de América Latina. Programa Regional de Desarrollo Científico y Tecnológico. Departamento de Asuntos Científicos. Secretaría General de la Organización de los Estados Americanos. Washington, DC. USA.

Cabrera, A. L. \& S. E. Freire. 1997. PROFLORA. Flora Fanerogámica Argentina. 280. Asteraceae, parte 8. Tribu II. Eupatorieae. 27: 76-79.

Cabrera, A. L. 1957. Compositae brasilienses novae. Arquivos do Jardim Botânico 15: 71-76.

Cabrera, A. L. 1961. Anatomy of some xerophilous plants of Patagonia. UNESCO, Arid Lands Research. Proceedings of the Madrid Symposium. 233-239.

Cabrera, A. L. 1973. Notas sobre los tipos de Compuestas sudamericanas en herbarios europeos IV. Boletín de la Sociedad Argentina de Botánica 15: 113-125.

Cabrera, A. L. 1978. Flora de la Provincia de Jujuy. Parte X: Compositae. Colección Científica del INTA. Buenos Aires, Argentina.

Campostrini Forzza, R. (ed.). 2010. Catálogo de Plantas e Fungos do Brasil. vol. 1. Jardim Botânico do Rio de Janeiro y Estudio Andrea Jakobsson. Brasil.

Crisci, J. V., Katinas, L. \& P. Posadas. 2000. Introducción a la teoría y práctica de la biogeografía histórica. Soc. Argent. Bot., Buenos Aires.

Crisci, J. V., Katinas, L. \& P. Posadas. 2003. Historical biogeography: An introduction. Harvard University Press, Cambridge, Massachusetts.

Curtis, J. D. \& N. R. Lersten. 1986. Development of bicellular foliar secretory cavities in white snakeroot, Eupatorium rugosum (Asteraceae). Amer. J. Bot. 73: 79-86.

De Candolle, A. P. 1836. Compositae. Eupatorium. Prodromus Systematis Naturalis Regni Vegetabilis 5:174.

De Candolle, A. P. 1836. Compositae. Nothites. Prodromus Systematis Naturalis Regni Vegetabilis 5:187.

De Candolle, A. P. 1836. Compositae. Piqueria. Prodromus Systematis Naturalis Regni Vegetabilis 5:105. 
De Candolle, A. P. 1838. Compositae. Ophryosporus. Prodromus Systematis Naturalis Regni Vegetabilis 7:270.

De Lampasona, M. E. P., Catalán, C. A. N., Gedris, T. E. \& W. Herz. 1997. Benzofurans, benzofuran dimers and other constituents from Ophryosporus charua. Phytochemistry 46: 1077-1080.

Delucchi, G. \& A. Plos. 2011. Asteraceae amenazadas de la Argentina: criterios para categorizar su grado de amenaza. XXXIII Jornadas Argentinas de Botánica. Posadas. Misiones. Argentina.

Demarcq, G., Méon-Vilain, H., Miquet, R. \& H. Kujaswski. 1976. Un basin paralique Néogène: celui de Skanes-Manastir (Tunisie orientale). Notes Serv. Géol. Tunisie 42: 97-147.

Erbar, C. \& P. Leins. 1995. Portioned pollen release and the syndromes of secondary pollen presentation in the Campanulales-Asterales-complex. Flora 190: 323-338.

Espindola, A. Jr., Torres Boeger, M. R., Maccari Jr., A., Reissmann, C. B. \& F. Lessa Rickli. 2009. Variação na estrutura foliar de Mikania glomerata Spreng. (Asteraceae) sob diferentes condiçסes de luminosidade. Revista Brasil. Bot. 32(4): 749-758.

Fahn, A. 1988. Secretory tissues in vascular plants. New Phytol. 108: 229-257.

Farris, J. S. 1969. A successive approximations approach to character weighting. Syst. Zool. 18: 374-385.

Favier, L. S., Nieto, M., Giordano, O. S. \& C. Tonn. 1997. Diterpenoids and flavonoids from Ophryosporus charrua. Phytochemistry 45: 1469-1474.

Favier, L., Tonn, C., Guerreiro, E., Rotelli, A.\& L. Pelzer. 1998. Anti-inflamatory activity of acetophenones from Ophryosporus axilliflorus. PI. Med. 64: 657-659.

Fernández Casas, J. \& J. Fernández Piqueras. 1981. Estudio cariológico de algunas plantas bolivianas. Anales del Jardín Botánico de Madrid 38: 149-152.

Ferracini, V. L., Roewer, I., Gao, F. \& T. J. Mabry. 1989. Ent-labdane diterpenoids, tremetone and chromene derivatives and flavonoids from Ophryosporus heptanthus. Phytochemistry 28: 1463-1465.

Font Quer, P. 1993. Diccionario de Botánica. 1 ed. 11 reimpresión. Editorial Labor. 
Barcelona. España.

Fournet, A., Barrios, A. A. \& V. Muñoz. 1994. Leishmanicidal and trypanocidal activities of Bolivian medicinal plants. J. Ethno-pharmacol. 41: 19-37.

Freire, S. E. \& L. Katinas. 1995. Morphology and ontogeny of the cypsela hairs of Nassauviinae (Asteraceae, Mutisieae). En: Hind, D. J. N., Jeffrey, C. \& G. V. Pope (Eds.). Advances in Compositae Systematics 107-143. Royal Botanical Gardens, Kew. U. K.

Funk, V. A, Bayer, R. J., Keeley, S., Chan R., Watson, L., Gemeinholzer, B., Schilling, E., Panero, J. L., Baldwin, B. G., Garcia-Jacas, N., Susanna, A. \& R. K. Jansen. 2005. Everywhere but Antarctica: Using a supertree to understand the diversity and distribution of the Compositae. Biologiske skrifter kongelige danske videnskabernes selskab 55:343-374

Gledhill, D. 2008. The names of Plants. Fourth edition. Cambridge University Press. Cambridge. U. K.

Goloboff, P. A. 1993. Estimating character weights during tree search. Cladistics 9: 433-436.

Goloboff, P. A., Carpenter, J. M., Salvador Arias, J. \& D. R. Miranda Esquivel. 2008b. Weighting against homoplasy improves phylogenetic analysis of morphological data sets. Cladisitics 24: 1-16.

Goloboff, P. A., Farris, J. S. \& K. C. Nixon. 2008a. TNT (Tree analysis using new technology) (BETA) Versión 1.1. Publicado por sus autores. Tucumán.

Goloboff, P. A., Farris, J. S., Källersjö, M., Oxelmann, B., Ramirez, M. \& C. Szumik. 2003. Improvements to resampling measures if group support. Cladistics 19: 324-332.

Gray, J. 1964. Northwest American Tertiary palynology: the emerging picture. En L.M. Cranwell (ed.). Ancient Pacific floras, Pp. 21-30. Univ. Hawaii Press, Honolulu.

Grisebach, A. 1874. Plantae Lorentzianae. Bearbeitung der ersten und zweiten Sammlung argentinischer Pflanzen des Professor Lorentz zu Cordoba. Dieterich, Göttingen. 
Grisebach, A. 1879. Symbolae ad Floram argentinam. Zweite Bearbeitung argentinischer Pflanzen, nach den durch die Regierung zu Buenos Ayres veranstalteten Sammlungen der Professor Lorentz und Hieronymus, so wie den im Museum zu Göttingen aufbewahrten Herbarien anderer Naturfoscher. Dieterich, Göttingen.

Hanson, J. R. 1999. Diterpenoids. Nat. Prod. Rep. 16: 209-219.

Hemsley, W. B. 1881-1882. Biologia Centrali-Americana; or, Contributions to the knowledge of the fauna and flora of Mexico and Central America. Botany. Vol.II: 79. London.

Hennig, W. 1950. Grundzüge einer Theorie der phylogentischen Systematik. Deutscer Zentralverlag. Berlin.

Hennig, W. 1965. Phylogenetic Systematics. Ann. Rev. Ent. 10: 97-116.

Hennig, W. 1966. Phylogenetics Systematics. Univ. Illinois Press.

Herz, W. 2004. Chemistry of Critoniinae. Biochem. Syst. Ecol. 32: 1159-1185.

Hess, H. 1938. Vergleichende Untersuchungen über die Zwillingshaare der Kompositen. Bot. Jahrb. 68: 435-496.

Heusser, C. J. 1971. Pollen and Spores of Chile. University of Arizona Press, Tucson.

Hickey, L. J. 1973. Classification of the architecture of dicotyledoneous leaves. American Journal of Botany 60 (1): 17-33.

Hieronymus, G. 1897. Erster Beitrag zur Kenntris der Siphonogamenflora der Argentina und der angrensen den Länder, besonder von Uruguay, Paraguay, Brasilien und Bolivien. Botanische Jahrbücher für Systematik, Pflanzengeschichte und Pflanzengeographie. Leipzig. 22: 672-798.

Hieronymus, G. 1901. Plantae Ecuadorenses II. Botanische Jahrbücher für Systematik, Pflanzengeschichte und Pflanzengeographie. Leipzig. 29: 1-85.

Hieronymus, J. 1882. Plantas diafóricas. Flora Argentina. Editorial Atlántida. Buenos Aires. Argentina.

Hind, D. J. N. \& H. Robinson. 2007. Eupatorieae, pp. 510-574. In: K. Kubitzki, series ed. The Families and Genera of Vascular Plants, Vol. 8. J. W. Kadereit and 
C. Jeffrey, eds. Flowering plants-eudicots-Asterales. Berlín, Heidelberg, New York: Springer-Verlag.

Hind, D. J. N. 2011. An annotated preliminary checklist of the Compositae of Bolivia.

(Version

2).

www.kew.org/science/tropamerica/boliviacompositae/checklist.pdf

Hoffman, O. 1890. Compositae. En: Die Natürlichen Pflanzanfamilien, vol. 4, no.

5. Eds. A. Engler \& K. Prantl. Leipzig: Verlag von Wilhelm Engelmann. 87-391.

Holmgren, P. K., Holmgren, N. H. \& L. C. Barnett. 1990. Index Herbariorum. Part I: The Herbaria of the World. Eighth edition. International Association for Plant Taxonomy and the New York Botanical Garden. New York. USA. 639 p.

Hooker, J. D. f. \& B. D. Jackson. 1895. Index Kewensis. An enumeration of the genera and species of flowering plants from the time of Linnaeus to the year 1885 inclusive together with their author's names, the works in which they were first published, their native countries and their synonyms. Volume II: 354. Clarendon Press. Oxford.

Housman, D. C., Price, M. V. \& R. A. Redak. 2002. Architecture of coastal and desert Encelia farinosa (Asteraceae): consequences of plastic and heritable variation in leaf characters. American Journal of Botany 89: 1303-1310.

Humphries, C. J., Williams, P. H. \& R. I. Vane Right. 1995. Measuring biodiversity value for conservation. Annu. Rev. Ecol. Syst. 26: 93-111.

Ito, M, Yahara, T., King, R. M., Watanabe, K., Oshita, S., Yokoyama, J. \& D. J.Crawford. 2000a. Molecular phylogeny of Eupatorieae (Asteraceae) estimated from cPDNA RFLP and its implications for the polyploidy origin hypothesis of the tribe. Journal of Plant Research 113: 91-96.

Ito, M., Watanabe, K., Kitai, Y., Kawahara, T., Crawford, D. J. \& T. Yahara. 2000b. Phylogeny and phytogeography of Eupatorium (Eupatorieae, Asteraceae): insights from sequence data of the nrDNA ITS regions and cpDNA RFLP. Journal of Plant Research 113: 79-89.

Jeffrey, C. 2007 [2006]. Introduction with key to tribes, pp. 61-87. In: K. Kubitzki, series ed. The Families and Genera of Vascular Plants, Vol. 8. J. W. Kadereit and 
C. Jeffrey, eds. Flowering plants-eudicots-Asterales. Berlín, Heidelberg, New York: Springer-Verlag.

Johansen, D. A. 1940. Plant microtechnique. MacGraw-Hill. New York. London. $523 \mathrm{p}$.

JØrgensen, P. M. \& S. León -Yánez (eds.). 1999. Catalogue of the vascular plants of Ecuador. Monograf. Syst. Bot. Missouri Bot. Gard. 75: 301.

Josse, C., Navarro, G., Comer, P., Evans, R., Faber-Langendoen, D., Fellows, M., Kittel, G., Menard, S., Pyne, M., Reid, M., Schulz, K., Snow, K. \& J. Teague. 2003. Ecological Systems of Latin America and the Caribbean: A Working Classification of Terrestrial Systems. NatureServe, Arlington, Virginia. USA.

Kim, Y. W., Choi, H. D., Seo, P. J. \& B. W. Son. 2001. Synthesis of 2arylbenzofuran derivatives using $\omega$-(methylsulfinyl) acetophenones. J. Kor. Chem. Soc. 45: 391-394.

King, R. M. \& H. Robinson. 1969. Studies in the Eupatorieae (Asteraceae). XVI. A monograph of the genus Decachaeta DC. Britonnia 21: 275-284.

King, R. M. \& H. Robinson. 1971. Studies in the Eupatorieae (Asteraceae) XLVIII. The genus, Critonia. Phytologia 22: 46-51

King, R. M. \& H. Robinson. 1972. Studies in the Eupatorieae (Asteraceae). LXXIII. The genus Ophryosporus. Phytologia 23: 397-400.

King, R. M. \& H. Robinson. 1987. The genera of the Eupatorieae (Asteraceae). Monographs in Systematic Botany From the Missouri Botanical Garden 22: 1-581.

King, R. M., Robinson, H. \& G. M. Barroso. 1979. Studies in Eupatorieae (Asteraceae) CLXXXVII. A new genus, Morithamnus. Phytologia 44: 451-454.

King, R.M., Kyhos, W., Powell, A.M., Raven, P.H. \& Robinson, H. 1976. Chromosome numbers in Compositae, XIII. Eupatorieae. Annals of the Misssouri Botanical Garden 63 (4): 862-888.

King; R. M. \& H. Robinson 1980. Studies in the Eupatorieae (Asteraceae). CXCII. Validation of subtribes. Phytologia 46: 446-450.

King; R. M. 1967. Studies in the Eupatorieae (Compositae), VII. Key to genera of subtribe Piquerinae. Sida 3: 163-164. 
Ladd, P. G. 1994. Pollen presenters in the flowering plants-form and function. Botanical Journal of the Linnean Society 115: 165-195.

Lambrecht, S. C. \& T. E. Dawson. 2007. Correlated variation of floral and leaf traits along moisture availability gradient. Oecologia 151: 574-583.

Langenheim, J. H. 1994. Higher plants terpenoids: a phytocentric overview of their ecological roles. J. Chem. Ecol. 20: 1223-1279.

Leaf Architecture Working Group. 1999. Manual of Leaf Architecture morphological description and categorization of dicotyledonous and net-veined monocotyledonous angiosperms. Smithsonian Institution. Washington DC. USA.

León, B, Pitman, N. \& J. Roque. 2006 [2007]. El Libro Rojo de las Plantas Endémicas del Perú. Revista Peruana Biol. 13(núm. 2 especial): 1s-971s.

Lersten, N. R. \& J. D. Curtis. 1986. Tubular cavities in white snakeroot, Eupatorium rugosum (Asteraceae). Amer. J. Bot 73: 1016-1021.

Lessing, C. F. 1832. Synopsis Generum Compositarum. Berlin. Duncker \& Humblot.

Linder, R. L., Moret, B. M. E., Nakhleh, L. \& T. Warnow. 2004. Network (reticulate) evolution: biology, models and algorithms. The Ninth Pacific Symposium on Biocomputing.

Lopez Arze, J. B., Collin, G., Garneau, F. X., Jean, F. I. \& H. Gagnon. 2004. Essential oils from Bolivia II. Asteraceae: Ophryosporus heptanthus (Wedd.) H. Rob. \& King. J. Essent. Oil Res. 16: 554-557.

Luebert, F., García, N. \& N. Schultz. 2007. Observaciones sobre la flora y la vegetación de los alrededores de Tocopilla $\left(22^{\circ} \mathrm{S}\right.$, Chile). Boletín del Museo de Historia Natural, Chile 56: 27-52.

Mcneill, J., Barrie, F.R., Burdet, H.M., Demoulin, V., Hawksworth, D.L., Marhold, K., Nicolson, D.H., Prado, J., Silva, P.C., Skog, J. E., Wiersema, J. H. \& N. J. Turland. (Eds. \& Compilers). 2006. International Code of Botanical Nomenclature (Vienna Code) adopted by the Seventeenth International Botanical Congress Vienna, Austria, July 2005. Gantner, Ruggell (Regnum Vegetabile 146).

Mears, J. A. 1977. Types of Asteraceae at the Philadelphia Academy of Natural Sciences (PH). Compositae Newsletter 4: 13-15. 
Mendoça, C. B. F \& V. Gonçalves-Estevez. 2000. Palinologia de species da tribo Eupatorieae (Compositae Giseke) ocorrentes na Restinga de Carapebus, Carapebus, Río de Janeiro. Rvta Brasil. Bot., São Paulo 23 (2): 195-205.

Meo, A. A. 2005. Palynological studies of selected genera of the tribes of Asteraceae from Pakistan. Tesis doctoral. Department of Biological Sciences. Quaid-i-Azam University. Islamabad. Pakistan

Metcalfe, C. R. \& L. Chalk. 1950. Anatomy of the Dicotyledons. Vol. II. Oxford. Clarendon Press. 775 p.

Meyen, F. J. F. 1834. Reise um die Erde ausgeführt auf dem Königlich preussischen Seehandlungs-Schiffe Prinzess Louise, commandirt von Capitain W. Wendt, in den Jahren 1830, 1831 und 1832. Berlin.

Milan, P., Hissae Hayashi, A. \& B. Appezzato-da-Glória. 2006. Comparative leaf morphology and anatomy of three Asteraceae species. Braz. arch. biol. technol. 49: 135-144.

Miranda-Esquivel, D. R. 1999. Análisis filogenético de la tribu Simuliini (sensu Crosskey, 1987) para las regiones zoogeográficas Neotropical, Etiópica y Australiana. PhD Thesis, Universidad Nacional de La Plata, Argentina.

Montenegro Lozada, C. A. 2001. Estudio químico del aceite esencial del té inca (Ophryosporus peruvianus). Tesis. Lima. Perú.

Montúfar, R \& N. Pitman. 2003. Ophryosporus densiflorus. En: IUCN 2011. IUCN Red List of Threatened Species. Version 2011.1. www.iucnredlist.org

Nagy, E. 1969. Palynological elaborations of the Miocene layers of the Bakony Mountains (Valpalota) of Hungary. Acta Botanica 8: 153-163.

Nuñez, C. \& J. Cantero. 2000. Las plantas medicinales del sur de la provincia de Córdoba. Fundación Universidad Nacional de Río Cuarto, Córdoba, Argentina.

Oliva, M. M., Demo, M. S., López, M. L., Zunino, M. O., Lucini, E. I., Faillace, S. M. \& J. A. Zygadlo. 2002. Flora aromática del centro de Argentina. Composición y actividad antimicrobiana de los aceites esenciales. I Congreso Latinoamericano de Fitoquímica. IV Reunión de la Sociedad Latinoamericana de Fitoquímica. Buenos Aires. Argentina.

Olivera Gonzáles, P., Angeles, C. T., Castillo Picón, F. \& M. Choy Wong. 2011, 
Características de suelo y usos tradicionales de especies vegetales en la Provincia de Huaraz, Ancash, Perú. ECIPerú 8(1): 44-47.

Panero, J. L \& V. A. Funk. 2002. Toward a phylogenetic subfamilial classification of the Compositae (Asteraceae). Proccedings of the Biological Society of Washington 115: 909-922.

Panero, J. L. 2007. Tribe Helenieae (pp. 400-406), Tribe Bahieae (pp. 433-438), Tribe Polymnieae (pp.439-440), Tribe Heliantheae (pp.440-476), Tribe Millerieae (477-491), Tribe Perityleae (pp.507-509). En: Kadereit, J.W. \& Jeffrey, C. (eds.), The Families and Genera of Vascular Plants, vol. 8, Flowering Plants. Eudicots. Asterales. Springer, Berlin.

Payne, W. W. 1969. A quick method for clearing leaves. Ward's Bulletin new series 61: 4-5.

Pla Dalmau, J. M. 1961. Polen. Estructura y características de los granos de polen. Precisiones morfológicas sobre el polen de especies recolectadas en el N.E. de España. Talleres Gráficos D. C. P. Gerona.

PlanEAr. Plantas Endémicas de Argentina. 2012. http://www.lista-planear.org/

Plos, A. \& G. Sancho. 2012. Lectotipificaciones en Ophryosporus (Asteraceae, Eupatorieae, Critoniinae). En prensa.

Prado, D. E. \& P. E. Gibbs. 1993. Patterns of species distributions in the dry seasonal forest of South America. Ann. Missouri Bot. Gard. 80: 902-927.

Ragonese, A. M. 1988. Canales secretores en los órganos vegetativos de Eupatorium inulaefolium H.B.K. (Compositae). Lat. Am. J. Pharm. 7: 161-168.

Ramayya, N. 1962. Studies on the trichomes of some Compositae I. General structure. Bull. Bot. Surv. India 4: 177-188.

Raunkier, C. 1934. The use of leaf size in biological plant geography. En: The life forms of plants and statistical plant geography. Oxford Clarendon Press. UK.

Reiche, K. F. 1901. Estudios críticos sobre la flora de Chile (continuación). Anales de la Universidad de Chile 109: 9.

Robinson, B. L. 1905. Diagnoses and notes relating to american Eupatorieae. Proceedings of the American Academy of Arts and Sciences 41: 271-278 (Contributions from the Gray Herbarium of Harvard University n.s. 31) 
Robinson, B. L. 1906a. Revision of the Genus Piqueria. Contributions from the Gray Herbarium of Harvard University. New Series 32. Proceedings of the American Academy of Arts and Sciences 42 (1): 3 - 16.

Robinson, B. L. 1906b. Studies in the Eupatorieae. Revision of the genus Ophryosporus. Proceedings of the American Academy of Arts and Sciences 42(1): 17-27 (Contributions from the Gray Herbarium of Harvard University n.s. 32)

Robinson, B. L. 1913. A generic key to the Compositae-Eupatorieae. Proceedings of the American Academy of Arts and Sciences 49 (8): 429-437 (Contributions from the Gray Herbarium of Harvard University n.s. 42)

Robinson, B. L. 1919. On tropical American Compositae, chiefly Eupatorieae. Proceedings of the American Academy of Arts and Sciences 55(1): 3-41 (Contributions from the Gray Herbarium of Harvard University n.s. 60)

Robinson, B. L. 1920. Further diagnoses and notes on tropical American Eupatorieae. Contributions from the Gray Herbarium of Harvard University n.s. 61: 3-30

Robinson, B. L. 1924. Records preliminary to a general treatment of the Eupatorieae - IV. Contributions from the Gray Herbarium of Harvard University 73:3-30.

Robinson, B. L. 1925. Records preliminary to a general treatment of the Eupatorieae - V. Contributions from the Gray Herbarium of Harvard University 75:3-15.

Robinson, B. L. 1926. Eupatorium, Ophryosporus. In: Standley, O. C. Trees and Shrubs of Mexico. Contr. U. S. Nat. Herb. 23: 1432-1470.

Robinson, B. L. 1926. Records preliminary to a general treatment of the Eupatorieae - VI. Contributions from the Gray Herbarium of Harvard University 77: 3-62.

Robinson, B. L. 1928. Records preliminary to a general treatment of the Eupatorieae VII. Contributions from the Gray Herbarium of Harvard University 80: 3 
Robinson, B. L. 1930. Records preliminary to a general treatment of the Eupatorieae - VIII. Contributions from the Gray Herbarium of Harvard University 90:3-35.

Robinson, H. 1998. New species and new combinations of Neotropical Eupatorieae (Asteraceae). Phytologia 84 (5): 347-353.

Robinson, H., Powell, A. M., Carr, G. D., King, R. M. \& Weedin, J. F. 1989. Chromosome numbers in Compositae, XVI: Eupatorieae II. Ann. Missouri Bot. Gard. 76: 1004-1011.

Robinson, H., Powell, A.M., King, R.M. \& Weedin, J.F. 1981. Chromosome numbers in Compositae, XII: Heliantheae. Smithsonian Contributions to Botany 52: 1-28.

Robinson, H., Schilling, E. \& Panero, J. L. 2009. Tribe Eupatorieae. p.731-744, en: Funk, V.A.; Susanna, A; Stuessy, T. F \& Bayer, R. J. (eds.), Systematic, Evolution and Biogeography of Compositae. International Association for Plant Taxonomy, Vienna, Austria.

Rodriguez Cancelli, R., Pacheco Evaldt, A. C. \& Girardi Bauermann, S. 2007. Contribuição à morfología polínica da familia Asteraceae Martinov. no Rio Grande do Sul - Parte I. Pesquisas, Botânica 58: 347-374.

Rojas de Arias, A., A. Inchausti, M. Ascurrat, N. Fleitas, E. Rodríguez \& A. Fournet. 1994. In vitro activity and mutagenicity of bisbenzylisoquinolines and quinones against Trypanozoma cruzi trypomastigotes. Phytother. Res. 8: 141-144.

Rojas, R., B. Bustamante, J. Bauer, I. Fernandez, J. Albán \& O. Lock. 2003. Antimicrobial activity of selected Peruvian medicinal plants. J. Ethno-pharmacol. 88: 199-204.

Ronquist, F. \& S. Nylim. 1990. Process and pattern in the evolution of species association. Systematic Zoology 39: 323-344.

Ronquist, F. 1996. DIVA versión 1.1. Computer program and manual available by anonymous FTP from Uppsala University.

Ronquist, F. 1997. Dispersal-Vicariance analysis: a new approach to the quantification of historical biogeography. Systematic Biology.46: 195-203.

Rosas-Romero, A \& G. Saavedra. 2005. Screening bolivian plants for antioxidant 
activity. Pharmaceutical Biology 43(1): 79-86.

Rua, G. H. 1999. Inflorescencias: bases teóricas para su análisis. Sociedad Argentina de Botánica. Buenos Aires.

Rusby, H. H. 1983. An enumeration of the plants collected in Bolivia by Miguel Bang, with descriptions of new genera and species. Memoirs of the Torrey Botanical Club 3 (3): 53.

Sagástegui Alva, A. \& E. F. Rodríguez Rodríguez. 2008. Una nueva especie de Ophryosporus (Eupatorieae: Asteraceae) para el Perú. Revista peruana de Biología 15(1): 21-23.

Sancho, G. \& L. Katinas. 2002. Are the trichomes in corollas of Mutisieae (Asteraceae) really twin hairs?. Botanical Journal of the Linnean Society 140: 427433.

Sanmartín I, Enghoff H \& F. Ronquist. 2001. Patterns of animal dispersal, vicariance and diversification in the Holarctic. Biological Journal of the Linnean Society 73: 345-390.

Sayas Rivera, R. \& L. Huamán Mesía. 2009. Determinación de la flora polinífera del valle de Oxapampa (Pasco-Perú) en base a estudios palinológicos. Ecología Aplicada 8: 53-59.

Schilling, E. E., Panero, J. L. \& P. B. Cox. 1999. Chloroplast DNA restriction site data support a narrowed interpretation of Eupatorium (Asteraceae). Plant Systematics and Evolution 219: 209-223.

Schmidt, G. J. \& E. E. Schillin. 2000. Phylogeny and biogeography of Eupatorium based on nuclear ITS sequence data. American Journal of Botany 87(5): 716- 726.

Schultz Bipontinus, C. H. 1856. Lechler's neueste Sammlungen aus Peru und Chile. Bonplandia 4: 50-55.

Schultz, N., Aceituno, P. \& M. Richter. 2011. Phytogeographic divisions, climate change and plant dieback along the coastal desert of northern Chile. Erkunde 65 (2): 169-187.

Sigstad, E, Catalán, C. A. N., Díaz, J. G. \& W. Herz. 1993. Diprenylated derivatives of p-hidroxyacetophenone from Ophryosporus macrodon. Phytochemistry 33 (1): $165-169$ 
Sigstad, E. E., C. A. N. Catalán, J. G. Díaz \& W. Herz. 1996. Chromanones, benzofurans and other constituents from Ophryosporus lorentzii. Phytochemistry 42: 1443-1445.

Sigstad, E. E., Catalán, C. A. N., Díaz, J. G. \& W. Herz. 1992. Sesquiterpene lactones, chromans, and other constituents of Ophryosporus piquerioides. J. Nat. Prod. (Lloydia) 55: 1155-1156.

Simon, P. M., Katinas, L. \& A. M. Arambarri. 2002. Secretory structures in Tagetes minuta (Asteraceae, Helenieae). Bol. Soc. Argent. Bot. 37: 181-191.

Simpson Vuilleumier, B. 1971. Pleistocene changes in the fauna and flora of South America. Science 173: 771-780.

Simpson, B. B. 1975. Pleistocene changes in the flora of the high tropical Andes. Paleobiology 1: 273-294.

Siripun, K. C. \& E. E. Schilling. 2006. Molecular confirmation of the hybrid origin of Eupatorium godfreyanum (Asteraceae). American Journal of Botany 93: 319325.

Skvarla, J. J., Turner, B. L, Patel, V. C. \& A. S. Tomb. 1977. Pollen morphology in the Compositae and in morphologically related families. En Heywood, V.H., Harbone, J.B., Turner, B.L. (Eds.). Pollen Morphology in the Biology and Chemistry of the Compositae. Academic Press, London, pp. 141-248.

Small, J. 1919. The Origin and Development of the Compositae. New Phytologist Reprint, No. 11.

Stace, C. A. 1965. Cuticular studies as an aid to plant taxonomy. British Museum (Natural History). London, U. K.

Stafleu, F. A. \& E. R. Mennega. 1992-2000. Taxonomic literature. Supl. 1-6. Greuter, W. (ed.). International Association of Plant Taxonomy, Königstein.

Stafleu, F.A. \& R. S.Cowan.1976-1988. Taxonomic literature. Vol. 1-7. Stafleu, F.A. (ed.). International Association of Plant Taxonomy, Utrecht.

Stearn, K., Bidlack, J. \& S. Jansky. 2003. Introductory to Plant Biology. 9th. Edition. McGraw-Hill.

Stearn, W. T. 1983. Botanical Latin. History, Grammar, Syntax, Terminology and Vocabulary. Third impression. Davied \& Charles. Newton Abbot. London. 
Stix, E. 1960. Pollenmorphologische untersuchungen an Compositen. Grana Palynologica 2: 2-104.

Taleb-Contini, S. H., Schorr, K., Batista Da Costa, F. \& D. C. Rodríguez de Oliveira. 2007. Detection of flavonoids in glandular trichomes of Chromolaena species (Eupatorieae, Asteraceae) by reversed-phase high-perfomance liquid chromatography. Braz. J. Pharm. Sci. 43: 315-321.

Taugourdeau, 0. 2006. Atlas de quelques grains de pollen du Pérou, en particulier de la región du Nevado Coropona. Tesis. Universite des Sciences et Techeniques du Languedoc.

Timme, R. E., Simpson, B. B. \& R. Linder. 2007. High-resolution phylogeny for Helianthus (Asteraceae) using the 18S-26S ribosomal DNA external transcribed spacer. American Journal of Botany 94: 1837-1852.

Turner, B. L., Bacon, J., Urbatsch, L. \& Simpson, B. 1979. Chromosome numbers in South American Compositae. Amer. J. Bot. 66: 173-178.

UICN. 2000. Categorías y criterios de la Lista Roja de la UICN. Versión 3.1. Preparado por la Comisión de Supervivencia de Especies de la UICN. UICN, Gland, Suiza y Cambrige, Reino Unido. ii + 33 pp.

Veblen, T. T., Young, K. R. \& A. R. Orme (eds.) 2007. The physical geography of south America. Oxford University Press. USA.

Vinnersten, A. \& K. Bremer. 2001. Age and biogrography of major clades in Liliales. American Journal of Botany 88: 1695-1703.

Watanabe, K., King, R. M., Yahara, T., Ito, M., Yokoyama, J., Suzuki, T. \& D. J.Crawford. 1995. Chromosomal cytology and evolution in Eupatorieae (Asteraceae). Annals of the Missouri Botanical Garden 2 (1): 581-592.

Watson, L. E., Jansen, K. J, \& J. R. Esteves. 1991. Tribal placement of Marshallia (Ateraceae) using chloroplast DNA restriction site mapping. American Journal of Botany 78: 1028-1035.

Webb, L. J. 1959. A physiognomic classification of australian rain forest. Journal of Ecology 47 (3): 551-570.

Weddell, H. A. 1855 [1857]. Essai d'une flore de la región alpine des cordilléres de L'Amérique du Sud. Chloris Andina 1: 1-231 
Wiemann, M. C., Manchester, S. R., Dilcher, D. L., Hinojosa, L. F. \& E. A. Wheeler. 1998. Estimation of temperature and precipitation from morphological characters of dicotyledonous leaves. American Journal of Botany 85 (12): 17961802.

Wulff, A. F., Hunziker, J. H. \& A. Escobar. 1996. Estudios cariológicos en Compositae VII. Darwiniana 34: 213-233.

Xu, S. 2000. Phylogenetic analysis under reticulate evolution. Mol. Biol. Evol. 17 (6): 897-907.

Zardini, E. M. 1984. Etnobotánica de Compuestas argentinas con especial referencia a su uso farmacológico (Primera Parte). Lat. Am. J. Pharm. 3:77-99.

Zdero, C., BohImann, F.\& H. M. Niemeyer. 1990. Seco-labdanes and other constituents from Ophryosporus floribundus. Phytochemistry 29: 3247-3253.

Zink R. M., Blackwell-Rago, R. C. \& F. Ronquist 2000. The shifting roles of dispersal and vicariance in biogeography. Proceedings of the Royal Society of London 267: 497-503

Zuloaga, F. O., Morrone, O. \& M. J. Belgrano (eds.). 2008. Catálogo de las Plantas Vasculares del Cono Sur (Argentina, Sur de Brasil, Chile, Paraguay y Uruguay). Missouri Botanical Garden Press. USA. 


\section{ANEXO I}

Ophryosporus angustifolius B. L. Rob. (ANG)

Ophryosporus anomalus R. M. King \& H. Rob. (ANO)

Ophryosporus apricus B. L. Rob. (APR)

Ophryosporus axilliflorus (Griseb.) Hieron. (AXI)

Ophryosporus bipinnatifidus B. L. Rob. (BIP)

Ophryosporus burkartii Cabrera. (BUR)

Ophryosporus carchiensis H. Rob. (CAR)

Ophryosporus charua (Griseb.) Hieron. (CHA)

Ophryosporus chilca (Kunth) Hieron. (CHI)

Ophryosporus cumingii Benth. ex Baker (CUM)

Ophryosporus densiflorus (Benth.) R. M. King \& H. Rob. (DEN)

Ophryosporus eleutherantherus (Rusby) B. L. Robinson (ELE)

Ophryosporus ferreyrii $\mathrm{H}$. Rob. (FER)

Ophryosporus floribundus (DC.) R. M. King \& H. Rob. (FLO)

Ophryosporus freyreissii (Thunb.) Baker (FRE)

Ophryosporus galiodes (DC.) R. M. King \& H. Rob. (GAL)

Ophryosporus hartwegii (B. L. Rob.) R. M. King \& H. Rob. (HAR)

Ophryosporus heptanthus (Sch. Bip.) R. M. King \& H. Rob. (HEP)

Ophryosporus hoppii (B. L. Rob.) R. M. King \& H. Rob. (HOP)

Ophryosporus johnstonii B. L. Rob. (JOH)

Ophryosporus kuntzei Hieron. (KUN)

Ophryosporus laxiflorus Baker (LAX)

Ophryosporus lorentzii Hieron. (LOR)

Ophryosporus macbridei B. L. Rob. (MACB)

Ophryosporus macrodon Griseb. (MACR)

Ophryosporus marchii Sagást. \& E. Rodr. 
Ophryosporus mathewsii (B. L. Rob.) R. M. King \& H. Rob.

Ophryosporus organensis Cabrera (ORG)

Ophryosporus ovatus B. L. Rob. (OVA)

Ophryosporus paradoxus (Hook. \& Arn.) Benth. \& Arn. ex Hook. f. \& Jackson. (PAR)

Ophryosporus peruvianus (J. F. Gmel.) R. M. King \& H. Rob. (PER)

Ophryosporus pinifolius (Phil.) R. M. King \& H. Rob. (PIN)

Ophryosporus piquerioides (DC.) Benth. ex Baker (PIQ)

Ophryosporus pubescens (Sm.) R. M. King \& H. Rob. (PUB)

Ophryosporus regnelli Baker (REG)

Ophryosporus sagasteguii $\mathrm{H}$. Rob.

Ophryosporus serratifolius (Kunth) B. L. Rob. (SER)

Ophryosporus sodiroi Hieron. (SOD)

Ophryosporus steinbachii B. L. Rob.

Ophryosporus triangularis Meyen (TRI)

Ophryosporus venosissimus (Rusby) B. L. Rob. (VEN) 
ANEXO II.

Critonia daleoides: MEXICO. Veracruz. Coatzacoalcos, isthmus of Tehauntepec, 03/1895, C. L. Smith 588 (LP). PANAMÁ. Coclé. Hill south of El Valle de Anton, 02/12/1941, P. H. Allen 2851 (LP). Critonia megaphylla: ARGENTINA. Salta. San Martín. Laguna La Yuntada, 20 km al NW de Tartagal, 13/09/1983, L. Novara 3678 (LP). PARAGUAY. Tebicuary, Azucarera, 05/08/1947, T. Rojas 13994 (LP). Critonia morifolia: ARGENTINA. Jujuy. Ledesma. Camino a Valle Grande, 28/08/1970, A. L. Cabrera 20800 (LP). BRASIL. Paraná. S. Izabel de Ivai. S. Izabel de Ivai, 29/08/1967, G. Hatschbach 17085 (LP). BOLIVIA. NorYungas. Millanguayarin, 12/1917, O. Buchtien 4400 (LP). Cronquistianthus callacatensis: PERU. Huancavelica. Huancavelica. Debajo de Sachahuaccta, a $8 \mathrm{~km}$ SO de Conaica, 04/04/1952, O. Tovar 954 y 956 (LP). Cuzco. Convención. Quellamayo a Lucumayo, 26/07/1944, C. Vargas C. 4544 (LP). Koanophyllon simillimum: BOLIVIA. Santa Cruz, Andrés Ibáñez, $12 \mathrm{~km} E$ of center of Santa Cruz, on road to

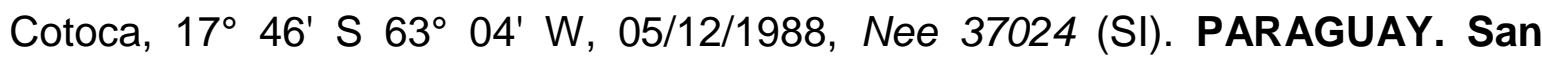
Pedro. Primavera, 27/04/1958, Woolston 961 (SI). Rosario. Cñía Mobocayá a 3 km de Villa del Rosario, 24 27' S 57 03' W, 07/01/1983, L. Pérez 107 (SI). Koanophyllon solidaginoides: ARGENTINA. Jujuy. Valle Grande, San Francisco, 14/05/1972, A. L. Cabrera 22657 (LP). ECUADOR. Chimborazo. Cañon of the río Chanchan near Huigra, 7-14/05/1945, Camp 3149 (LP). GUATEMALA. Santa Rosa. Cienaguilla, 11/1892, Heyde \& Lux s.n. (LP). HONDURAS. Yoro. Yoro, 19/01/1934, Edwards 739 (LP). Koanophyllon stipuliferum: BOLIVIA. Tarija. Arce. $29.2 \mathrm{~km} \mathrm{~S}$ of Emboroza-Sidras road on road to Bermejo (12.7 S of Naranjo Agrio), $22^{\circ} 22^{\prime} \mathrm{S} 64^{\circ} 29^{\prime} \mathrm{W}, 21-23 / 04 / 1983$, Solomon 10003 (SI). Fleischmannia arguta: MEXICO. Cuernavaca. Morelos, 23/03/1945, N. L. H. Krauss 51 (LP). 


\section{APÉNDICE I. Índice de colectores}

Colectores de materiales adicionales únicamente. Los acrónimos se listan en el Anexo I.

A. Sagástegui, A, E. Alvitez \& J. Mostacero 10840 (ANG)

A. Sagástegui, A, J. Cabanillas S. \& O. Dios C. 8039 (ANG)

A. Sagástegui, A, M. Diestra \& S. Leiva 11651(ANG)

A. Sagástegui, A. \& J. Mostacero 9058 (APR)

Abbiatti, D.et al. 3225 (CHA)

Acevedo-Rdgz, P. \& A. Siaca 6719 (CUM)

Adolfo M., H. 04 c/ (CUM)

Ahumada, O. \& J. C. Vasquez 6100 (LOR)

Angulo, N. 1757 (PIQ) 902 (APR)

Argarañaz, R. \& M. Azarevich 1957 (CHA)

Aronson, J. \& P. Berry 561 (PIQ)

Asplund, E. 11072 (FLO) 11201 (GAL) 12033 (PIQ)

Badilla, G. L. 10345 (TRI)

Bang, M. 27, 193 (ELE) 2342 (PIQ)

Barbosa, E. \& E. F. Costa 1266 (REG)

Barfod, A. S. \& F. Skov 60090 (SOR)

Barros, E. 1733, 1848, 2334, 2339, 2342, 2345, 2491, 3851, 3854 (PAR) 1457, 1777, 1778, 1780, 2337, 3852 (TRI)

Beck 2125 (VEN)

Billier, F. \& B. Jadin 5269, 5396 (TRI)

Boeke, J. D. \& J. Jaramillo A. 2653 (PER)

Boeke, J. D. \& S. Boeke 2967, 3134 (PIQ)

Boeke, J. D. 1565 (HEP) 
Boelcke, O. 3858 (PAR)

Bridges 1412 (TRI)

Brooke, W. M. A. 6677 (PIQ)

Buchtien, O. 541 (ELE) 3022, 3023 (HEP) 3283, 4408 (PIQ) s.n. (KUN)

Burkart, A. 7520, 13290 (CHA)

Cabrera et al. 14398 (MACR)

Cabrera et al. 16818 (MACR)

Cabrera, A. L. \& E. M. Zardini 23905 (AXI) 23852 (PIQ)

Cabrera, A. L. \& H. A. Fabris 13536 (HEP) 19993, 22661, 22694 (PIQ)

Cabrera, A. L. \& R. Kiesling 25129 (AXI) 25220 (MACR)

Cabrera, A. L. 3027, 6399, 12167 (AXI) 3804 (CHA) 3488 (PAR) 11332, 11416 (TRI)

Cabrera, A. L. et al. 14335, 17018 (AXI) 14474, 25990 (PIQ) 21284 (MACR)

Cadillo Moreno, E. 18 (PER)

Calatayud, G. et al. 1354 (PIQ)

Cañigueral S. J., J. 485 (HEP)

Carauta, J. P. P. et al. 1119 (FRE)

Cárdenas, M. 902 (PIQ)

Carranza, A. 679, 705, 735 (AXI) 425, 498, 499 (LOR) 281, 392,403, 649, 660, 673, 677 (MACR)

Castellanos 29/480 (CHA)

Castellón, A. 100 (MACR)

Castillón, L. 1438 (AXI) s.n (PIQ)

Castillón, L. 1884 (AXI)

Catalán, C. 101 (PIQ)

Catalán, C. et al. 161 (PIQ) 
Catari, J. C. et al. 78 (PIQ)

Cerrate, E. 3416 (PER)

Charpin, A.23067 (PIQ)

colector ilegible 384 (HEP) 1531 (MACB)

Crisci, J. V. 360 (PAR)

Croat, T. B. 6556 (PER)

D’Orbigny, A. 421 (PIQ)

Dawson, G. 3486 (CHA)

De la Sota 365 (CHA) 2063 (MACR)

de Oliveira, J. E. 942 (REG)

Del Castillo, A. s.n., 71 (CHA)

Díaz, R. s.n (CHA)

Dillon, M. 2500 (PER)

Dillon, M. et al. 1123, 1142 (PIQ)

Dillon, M. O. \& J. T. S. Teillier 4994 (TRI)

Dusén, P. 17989 (REG)

Edwin, G. \& J. Schunke V. 3796 (FER) 3932 (PIQ)

Ellemann, L. 66604 (SOR)

Emshwiller, E.932 (PIQ)

ERTS 315 (ANG)

Estevez, R. L. 2154, 2156, 2157 (REG)

Evangelista, M. s.n (CHI)

Fabris et al. 7383 (MACR)

Fabris, H. A. \& J. V. Crisci 6914 (BUR)

Fabris, H. A. 4473 (AXI) 6571 (CHA) 
Falco-Colina s.n. (PIQ)

Farfán, J. et al. 369 (PIQ)

Fernández, C. \& H. Nienmeyer 77 (PIN)

Ferreyra, Ramón. 6247 (FER) 3554 (GAL) 1986, 6241, 8012, 9622, 9957 (PER)

Fiebrig, K. 3150 (MACR)

Figueroa 44 (MACR)

Filipovich Urquiza, R. 125 (CHA)

FLSP 1539 (BIP)

Fosberg, F. R. 28607 (ANG) 27691 (PER)

Freire F., A. et al. 676 (PER)

Galander, C. s.n. (AXI)

Galiano, W. et al. 4584 (PER)

Gardner, M. F. \& S. G. Knees 6512 (PIN)

Gautier, E. D. 8567 (AXI)

Gays.n., 384 (CHA) s.n (PAR) s.n. (TRI)

Gentry, A. et al. 23258 (PER)

Giardelli \& Nicora 1120 (CHA)

Giardelli, M. L 584 (AXI)

Granda P., A. 597 (FER)

Halway, E. R. D. s.n. (HEP)

Harley, R. M. et al. 25330 (FRE)

Hatschbach, G. \& J. M. Silva 51977 (LAX)

Hatschbach, G. 3883 (REG)

Hawkes et al. 3946 (MACR)

Hawkes, J. G., J. P. Hjerting \& K. Rahn 3946 (MACR) 
Herzog, T. 1926 (PIQ) 2219 (CUM)

Hoffmann 2047 (MACR)

Holm-Nielsen, L. 20878 A (SER)

Hudson, J. 717, 1061 (PER)

Hunziker, A. T. \& A. E. Cocucci $17630(\mathrm{CHA})$

Hunziker, A. T. 1258, 1711, 6807, 7428, 7617, 8348 (AXI) 6807, 6837, 6993 (CHA) 7144 (MACR)

Hunziker, A. T., R. Subils \& A. J. Toledo 23727 (CHA)

Huschel, P. G. s.n. (PIN)

Hutchinson, P. C. \& J. K. Wright 5462 (PIQ)

Hutchinson, P. C. 1107 (PIQ)

Jaffuel, F. 1026 (ANO)

Jaramillo, J. 9987 (PIQ)

Jardim, A. \& R. Abbott 2034 (PIQ)

Jiles P., C. 1996 (TRI)

Jimenez 46 (VEN)

Johnston, Ivan M. 5259, 5297, $5310(\mathrm{JOH})$

Jörgensen, P. 1505 (LOR)

Jørgensen, P. M. 61866 (SOR)

Juarez, F. \& A. Del Castillo 215 (CHA)

Kausel 3766 (TRI)

Keil, David et al. 199962 (GAL)

Kiesling, R. et al. 455 (BUR) 705 (AXI)

Killip, E. P. \& A. C. Smith 21820, 21829, 21861, 23319 (HEP) 22303, 24388 (PIQ)

King, D. $0.310(\mathrm{CHA})$ 
King, R. M. \& J. L. Collins 9001, 9029 (PER)

King, R. M. \& L. E. Bishop 7593 (HEP) 7638 (ANG)

Krapovickas \& Cristóbal 11077 (LOR)

Krapovickas, A, .L. A. Mroginski \& A. Fernández 18883 (AXI) 19074 (PIQ)

Krapovickas, A., A. Schinini \& G. Seijo 47341 (LOR)

Kuntze, O. s.n. (AXI) s.n. (CHA) s.n (HEP) s.n. (PIQ) s.n. (TRI)

Landrum, L. R. 4637 (HEP)

Landrum, S. S. \& L. R. Landrum 5636 (TRI)

Larraín, H. 98200 (HOP)

Lavaque, R. J. s.n (PIQ)

Leite, J. E. 4097 (REG)

Lewis, M. 37778 (ANG) 88638 (AXI) 9132, 38964, 39135, 39958 (CUM) 871214, 88372 (HEP) 88886 (KUN) 40235, 881070,88830 (PIQ) 37316 (VEN)

Lillo 7137 (CHA)

Llatos Quiroz, S.1909 (OVA)

Lloveras \& López s.n. (AXI)

Lognamo \& Cuezzo 4149 (CHA)

Lognamo et al. 6098 (MACR)

Lognamo, P. R. \& A. R. Cuezzo 8602 (LOR)

Looser, G. 9818 (TRI)

López M., A. \& Sagástegui A., A. $8220(\mathrm{CHI})$

López M., A. et al. 9002 (PER)

Macbride \& Featherstone 767 (FLO)

Madsen, J. E. 63858, 63902 (DEN) 75039 (PER)

Magalhães, M. 3314 (REG) 
Mahu, M. 9542 (PAR)

Mandon, G. 264 (CUM) 260 (HEP) 255, 268 (PIQ)

Manticorena, Rodriguez, Weldt 1845 (TRI)

Maruñak et al. 357(MACR)

Mathews s.n (PIQ)

Mendes Magalhães 406 (FRE)

Mexia, Y. 8125 (PIQ)

Meyer, T. \& A. A. Vaca 23665 (MACR)

Meyer, T. 12486 (AXI) 14017, 15130, 15157 (LOR) 17704, 22897 (MACR)

Meza R, I. 212 (APR)

Monheim 17, 64 (HEP)

Morello, J. \& A. R. Cuezzo 1116 (AXI)

Morello, J. 5064, 5232, 5337 (CHA)

Mori R., I. 194 (PER)

Morong, T. 1149, 1296 (TRI)

Mostacero L., J. \& L. Ramírez V. 672 (GAL)

Mostacero L., J. et al. $1376(\mathrm{CHI})$

Nee, M. \& D. Atha 49979 (HEP)

Nee, M. \& G. Coimbra S. 35534 (PIQ)

Nee, M. \& M. Mendoza 52529 (AXI) 52527 (CUM)

Nee, M. 38918 (ANG) 35615, 40704, 49239 (PIQ)

Nicora, E. G. 1933 (AXI)

Novara L. J. 469, 1310, 10020 (AXI) 1270, 1273, 1310, 4300, 5475 (CHA) 459, 6567, 12275 (PIQ) 7917 (LOR)

Novara, L. J. \& G. Hoy 1413 (CHA) 
Novara, L. J. \& S. B. Bruno 8978 (PIQ)

Novara, L. J. \& S. Bruno 11348 (CHA) 8862 (PIQ)

Novara, L. J. et al. 11329 (LOR)

Novatti s.n. (PIQ)

Núñez V. P. 9295 (PIQ)

Núñez, O. V 3100 (HAR)

Occhioni, G.1029 (ORG)

Okada 5930 (MACR)

Olea, D. s.n. (PIQ)

Pennell, F. W. 14308, 14475 (GAL) 13538, 13711, 14277 (HEP)

Pereira, E., Egler \& Graziela 57 (REG)

Peyton, B. \& S. Tiney Peyton 623 (PIQ)

Philippi, R. s.n., 406 (PAR) s.n (TRI)

Pieroth, S. A. 1330 (LOR)

Pierotti, S. A 1172, 1315 (MACR) 1317, 1330 (PIQ)

Pinto, R. s.n (FLO)

Plos \& Simon 105 (MACR)

Plos et al. 11 (MACR)

Plos, Plunkett \& Nicolas 33, 34, 36, 37, 38, 39, 40, 41, 42, 43 (MACR)

Pruski, J. et al. 4418 (PIQ)

Renvoize, S. A., M. Wilmot-Dear \& R. Kiesling 3395 (CHA)

Ricardi \& Manticorena 4643 (TRI)

Ricardi, M. \& O. Parra 31 (FLO)

Ricardi, M. 3849 (JOH) 3969 (TRI)

Ricardi, Manticorena \& Matthei 1067 (HOP) 
Ricardi, Wedlt \& Quezada 150 (HOP)

Riedel, L. \& Lund 2360 (REG)

Riedel, L. 356 (FRE)

Riocio, F. \& F. La Rosa 554 (FER)

Rocha, R. 405, 816, 2486 (PIQ)

Rodrigo, A. P. 2035 (CHA) 3571 (AXI)

Rodríguez 1462 (MACR)

Rodríguez R., E. et al. 405 (CHI)

Rodríguez, D. 1326 (CHA) 1459 (LOR)

Rodríguez, E., R. F. Luján \& D. Mercado 1860 (PER)

Roig 12673 (TRI)

Rose, J. N. 19315 (TRI)

Roth, L. 1417 (REG)

Ruiz Leal \& F. Roig 18885 (CHA)

Ruiz Leal 12462, 12542 (AXI) 12158, 12303, 19704, 19797, 20128 (CHA)

Rusby, H. H. 105 (PIQ)

Sagástegui A., A, S. López \& J. Mostacero 9840 (CHI)

Sagástegui A., A. \& C. Tellez A. 12666 (PIQ)

Sagástegui A., A. \& J. Mostacero L. 11334 (GAL) 11052 (PER)

Sagástegui A., A. 7770 (CHI) 10940 (GAL)

Sagástegui A., A. et al. 9790, 12457 (GAL)

Sagástegui A., A., E. Alvitez \& J. Mostacero 8954 (PER)

Sagástegui A., A., J. Cabanillas S. \& O. Dios C. 8039 (CHI) 8167 (PER)

Sagástegui A., A., J. Mostacero \& S. Leiva 12002 (CHI)

Sagástegui A., A., J. Mostacero L. \& E. Alvitez I. 10840 (CHI) 
Sagástegui A., A., J. Mostacero L. \& M. Diestra Q. 11719 (CHI)

Sagástegui A., A., M. Diestra \& S. Leyva 11651 (CHI)

Sánchez V., I. 3412 (GAL)

Sánchez V., l. et al. 3025 (GAL)

Santos Llatas Q. 478 (GAL)

Schimpff, H. F. J. 360 (PER)

Schreiter s.n (LOR)

Schultz, C. H. 138 (FRE)

Scolnik, R. 796 (PIQ)

Serrano, M., J. Villalobos \& A. Lliully 6146 (CUM)

Shepard, R. S. 247 (HEP)

Sigstad, E. \& C. Catalán 575 (MACR)

Sigstad, E. et al. 1 (LOR)

sin colector 112 (PAR) s.n (PIQ) 13046 (TRI)

Skottskerg, C. 704 (TRI)

Sleumer et al. 2783 (MACR)

Sleumer, H. 749 (CHA)

Smith, D. N. \& I. Sánchez V. $4242(\mathrm{CHI})$

Smith, D. N. \& S. Vasquez S. 4937 (MACB)

Smith, D. N. 7370, 10574, 11415, $11547(\mathrm{CHI})$

Smith, D. N., M. Buddensiek \& R. Valencia $11690(\mathrm{CHI})$

Solomon, J. C. 10237, 10056 (AXI) 18707 (CUM) 7453, 15271, 16325 (HEP) 13558 (MACR) 10191, 10484, 10505, 10602 (PIQ)

Sotelo, J. B. (AXI)

Sparre, B. 3060 (PAR) 
Spegazzini, C. 13677, 13680 (AXI) 13605, 13673 (CHA) 13666, 13667 (LOR)

Steinbach, J. 9767, 9811 (CUM)

Steinbach, R. F. 207 (CUM)

Suárez, C. 45, $1383(\mathrm{CHA})$

Sudzuki, F. 347 (PIN)

Sullivan, G., D. Soejarto \& J. K. Sullivan 899 (HEP)

Teillier, S. 471 (PAR)

Tessmann, G. 80 (REG)

Tovar, O. 348 (APR) 753, 1384 (HEP)

Tupayacachi H., A. 677 (PER)

Tutin, T. G. 1090 (HEP)

v. d. Hoogte, L. \& C. Roersch 381 (PER) 2208, 2995 (PIQ)

Varela, Colina \& Hoy $45(\mathrm{CHA})$

Varela, F. 1470 (PIQ)

Varela, S. 5242 (PIQ)

Vargas \& Vargas 1078 (KUN)

Vargas C., C. 12630 (BIP) 449 (PER) 450, 4336, 6013 (PIQ)

Vargas C., I. G. 5001(CUM)

Vásquez, R. \& J. Campos 25293 (PIQ)

Venturi 4116 (MACR)

Venturi, S. 964, 2602, 3490 (CHA) 2991, 4115 (LOR) 3403, 4175, 4184 (PIQ)

Vervoorst, F. 7266 (CHA) 547 (MACR)

Vidal, W. N. 202 (REG)

Wall, E. s.n. (CHA)

Weberbauer, A.5379 (GAL) 
Wedermann, E. 456, 892 (TRI)

Wendelberger, K. 84 (PIQ)

White 424 (PIQ)

White, O. E.153 (CUM)

Worth, C. R. \& J. L. Morrison 15702 (PUB) 16131, 16226 (TRI)

Woytkowski, F. et al. 229 (MACB)

Wurdack, J. J. 1545 (PIQ)

Young, K. \& M. Eisenberg $901(\mathrm{CHI})$

Zamalloa, H. 2010 (PIQ)

Zardini et al. 1920 (MACR)

Zardini, E. M. 1193 (PIQ)

Zardini, E. M. et al. 1941 (LOR)

Zöllner, O. 2997 (HEP) 2997 (HOP) 1717, 4097, 9346 (PAR) 5313, 5318, 11348 (TRI) 


\section{APÉNDICE II. Índice de nombre científicos}

\section{Los nombres en cursiva corresponden a sinónimos}

Ageratina

sterbergiana 175

Cacalia

cordifolia 138

Decachaeta

ovatifolia 315

scabrella 316

Eupatorium

affine 120-121

axilliflorum 23, 84

bonplandianum 316

chilca 120-121

clavulatum 23, 263

decipiens 303

eleutherantherum 138-139

foliolosum 23-24, 303

freyreissi 157-158

freyreysi 157-158

heptanthum 175-177, 353

kuntzei 194, 216-217

laeve 157, 204, 311

officinale 138

origanoides 175 
paradoxum 243-244

petraeum 315-316

piquerioides 23, 263

polybotrium 315

riedelianum 157-159

scabrellum 316

serratifolium 287

solidaginoides 316

tetranthum 315

venosissimum 24,310

volckmanii 303

Flaveria

peruviana 249

spicata 249

Koanophyllon

solidaginoides 316

tetranthum 315

Kuhnia

multiramea 303

Mikania

charua 23, 110

clavellata 157

cordifolia 138

cumingii 73,127

mandonii 263 
officinalis 138

pachychaeta 315,353

serratifolia 287

\section{Nothites}

baccharoides 243

ovatifolia 23,315

Ophryosporus

angustifolius 28, 31, 33-37, 54, 57, 62, 67

anomalus 58, 63, 73-75

apricus 28, 30, 32-34, 37, 62, 79

axilliflorus 24, 33, 35-36, 47, 58, 64, 84, 205

bipinnatifidus 30, 33-36, 64, 94

burchellii 315, 353

burkartii 25, 30, 34, 36, 65, 99

carchiensis $25,28,58,62,104$

charua $24,30,35-36,58,62,110$

chilca 33, 54, 120-121

clavulatus 23-24

cumingii 73,127

cumingii 24, 28, 31, 36, 62, 127

densiflorus 58, 62, 133

eleutherantherus 65,138

ferreyrii 25, 63, 146 
floribundus 42, 65, 81, 179

foliolosus 65,351

freyreissii 30-31, 37-39, 64-65, 72, 80, 185

galiodes $35,37,41,44,65,81,195$

hartwegii 37, 40-41, 81, 201

heptanthus 37-38, 41-44, 65, 71, 74, 84, 207

hoppii 35, 37, 43-44, 74, 82, 215

johnstonii 44, 65, 82, 221

kuntzei 31, 84, 227

laxiflorus 30-31, 39, 64-65, 72, 75, 83, 233

lorentzii 31, 42, 65, 71, 84, 239

macbridei 83, 247

macrodon 31, 35, 37, 39-42, 65, 71, 74, 83, 253

mandonii 305

marchii 32, 81, 261

mathewsii 81, 265

organensis $31,37,64-65,72,81,271$

origanoides 31,207

var. microcephala 31, 207

ovatifolius 365

ovatus 83,277

pachychaeta 30-31, 365 
paradoxus $31,65,82,283$

peruvianus $37-41,65,72-73,81,291$

petraeus 365

pinifolius 38, 42, 65, 82, 299

piquerioides $30-31,39,65,84,305$

pubescens 81,315

regnelli 30-31, 39, 42, 62, 64-65, 72, 81, 321

sagasteguii 32, 44, 65, 82, 327

saltensis 305

scabrellus 366

serratifolius 83,333

sodiroi $31,65,81,339$

solidaginoides 366

var. bonplandiana 31,366

steinbachii 40, 64-65, 83, 345

triangularis 19, 29-31, 36-37, 39-41, 44, 65, 74-75, 79, 82, 351

triangularis 283

venosissimus $31,64-65,84,359$

Pachychaeta

eupatorioides 365

\section{Piqueria}

artemisioides 79, 201, 291

cumingii 93 
densiflora 159

floribunda 30, 179

galioides 30, 195

hartwegi 201

mathewsii 265

peruviana 291

pinifolia 299

pubescens 315

Stevia

baccharidea 283

pinifolia 299

polyphylla 283

Trychinolepis

hoppii 79, 215

Willoughbya

charua 133

cordifolia 165

officinalis 165 